\title{
RENATO CONTESSOTTO
}

Classificação de domínios mineralógicos e caracterização de minérios de níquel da mina de Santa Rita - BA, em apoio à geometalurgia 


\section{RENATO CONTESSOTTO}

Classificação de domínios mineralógicos e caracterização de minérios de níquel da mina de Santa Rita - BA, em apoio à geometalurgia

Dissertação apresentada à Escola

Politécnica da Universidade de São Paulo para obtenção do título de Mestre em Ciências 


\section{RENATO CONTESSOTTO}

Classificação de domínios mineralógicos e caracterização de minérios de níquel da mina de Santa Rita - BA, em apoio à geometalurgia

Dissertação apresentada à Escola Politécnica da Universidade de São Paulo para obtenção do título de Mestre em Ciências

Área de Concentração:

Engenharia Mineral.

Orientador:

Prof. Dr. Henrique Kahn 
Este exemplar foi revisado e corrigido em relação à versão original, sob responsabilidade única do autor e com a anuência de seu orientador.

São Paulo, de de

Assinatura do autor:

Assinatura do orientador:

Catalogação-na-publicação

\section{Contessotto, Renato}

Classificação de domínios mineralógicos e caracterização de minérios de níquel da mina de Santa Rita - BA, em apoio à geometalurgia / R. Contessotto versão corr. -- São Paulo, 2017.

$213 \mathrm{p}$.

Dissertação (Mestrado) - Escola Politécnica da Universidade de São Paulo. Departamento de Engenharia de Minas e Petróleo.

1.Caracterização Tecnológica de Minérios 2.Difração por Raios $X$ 3.Estatística aplicada 4.MINERAÇÃO DE MINERAIS METALICOS I.Universidade de São Paulo. Escola Politécnica. Departamento de Engenharia de Minas e Petróleo II.t. 


\section{AGRADECIMENTOS}

Agradeço, primeiramente, ao meu orientador Prof $^{\circ}$ Dr. Henrique Kahn, por todos esses anos de ensinamentos e amizade, e a empresa Mineração Mirabela por permitir a realização deste estudo.

Em especial a M.Sc. Juliana Livi Antoniassi pela ajuda nas análises de difração de raios $X$ ao M.Sc. Daniel Uliana pelos ensinamentos na análise automatizada de imagens por microscopia eletrônica de varredura, a Prof ${ }^{a}$ Dra. Carina Ulsen pelos ensinamentos sobre a estruturação de um texto acadêmico na qualificação desta dissertação e ao Sr. Gabriel Pato pelas discussões e ensinamentos de estatística multivariada. Aos alunos da UNIFAL-MG, Rafael Cunha e Ronaldo Fulgêncio, pela ajuda no processamento dos dados de MLA.

A toda equipe técnica da Mineração Mirabela e do Laboratório de Caracterização Tecnológica - POLI/USP pela ajuda na amostragem e preparação de amostras.

Aos meus familiares, amigos e a Bárbara Viera Neto pelo companheirismo, amor e amizade.

E a todos que de alguma forma contribuíram para realização deste estudo, meus sinceros agradecimentos. 
Nosso conhecimento só pode ser finito, enquanto nossa ignorância deve necessariamente ser infinita.

(Karl Popper) 


\section{RESUMO}

A Mina de Santa Rita, situada no complexo máfico-ultramáfico Fazenda Mirabela, é uma intrusão máfica-ultramáfica, mineralizada a sulfetos de níquel e cobre, situada no sudeste do Estado da Bahia, município de Itagibá. Esse depósito é composto por rochas de idade Paleoproterozóica, metamorfizadas em fácies granulito. Os sulfetos de níquel e cobre ocorrem disseminados e, preferencialmente, associados a harzburgitos, olivina ortopiroxenitos e ortopiroxenitos. O minério é composto por uma grande variedade de $\mathrm{Mg}$-silicatos, sendo que o níquel ocorre essencialmente como pentlandita nos peridotitos, além de se apresentar como elemento menor em silicatos e espinélios em rochas mais máficas. Informações de processo demonstram a impossibilidade de se estabelecer uma correlação robusta entre a composição química do minério e seu comportamento na etapa de beneficiamento mineral. Desta forma, o conhecimento da variabilidade mineralógica no depósito é de fundamental importância para o planejamento de lavra e processamento mineral. Mais de 300 amostras do plano de mineração de curto prazo (2013-2017) relativas a intervalos de furos de sondagem considerados no estudo de viabilidade econômica (período de 1985-2004) foram agrupadas em domínios mineralógicos, utilizando a análise estatística multivariada de dados de difração de raios X (DRX-AEM). Dezessete domínios mineralógicos inicialmente definidos são essencialmente diferenciados com base na presença e conteúdos relativos dos principais minerais de ganga: serpentina, olivina e piroxênio. Amostras representativas dos principais domínios mineralógicos, pré-definidos por DRX-AEM, foram submetidas a estudos de caracterização mineralógica de detalhe por análise de imagens (MEV-MLA). Os resultados indicam que os grupos com composições mais peridotíticas e/ou carbonáticas, com maiores conteúdos de serpentina, apresentam menor tempo de moagem para atingir $\mathrm{P}_{95}$ igual a 0,15 mm; maior alteração dos grãos de pentlandita; maior parcela de total de níquel associado a silicatos; menor grau de liberação dos sulfetos; e maior quantidade de sulfetos abaixo de $10 \mu \mathrm{m}$, em relação aos grupos de composição mais piroxenítica.

Palavras chaves: domínios mineralógicos, difratometria de raios $X$, estatística multivariada, caracterização de minérios, minério de níquel, geometalurgia, mina Santa Rita. 


\section{ABSTRACT}

The Santa Rita mine, located in the mafic-ultramafic complex Fazenda Mirabela, is a mafic-ultramafic intrusion mineralized to nickel and copper sulphides located in the southeast of Bahia state, Itagibá municipality. The nickel sulphide deposit comprises a portion of a mafic-ultramafic layered complex under granulite metamorphism facies. Disseminated $\mathrm{Ni}$ and $\mathrm{Cu}$ sulphides form a stratiform body parallel to the lithostratigraphic contacts extending upwards essentially from the harzburgite unit and through the olivine orthopyroxenite unit. The nickel content is mainly associated to pentlandite in peridotitic rocks but also enriched in silicates and spinels in mafic rocks (dunites). Industrial plant benchmark data have shown the unfeasibility of establishing a strong relation between the ore chemical composition and its behavior in the mineral beneficiation process. Therefore, the knowledge of the mineralogical variability in the deposit is crucial for mine planning and mineral/metallurgical processing. More than 300 samples from drill core samples from the feasibility studies (period of 1985-2004) included in the short-term mining plan (2013-2017) were clustered into geological domains applying multivariate statistical analysis (MSA) of X-ray diffraction data (XRD). Results discriminated seventeen initial mineralogical domains considering the content of major gangue minerals: serpentine, olivine and pyroxene. Representative samples of the main mineralogical domains pre-defined by XRD-MSA ore-types were later subject to sieve size analysis followed by detailed mineralogical studies by automated SEM image analysis (MLA). The results indicate that groups with more peridotite and / or carbonatic compositions, with higher content of serpentine, have less time of grinding to reach $P_{95}$ equal to $0,15 \mathrm{~mm}$; high level of pentlandite alteration; greater portion of nickel associated into silicates; lower sulphides liberation degree; and a higher amount of sulphides below $10 \mu \mathrm{m}$; in relation to the most pyroxenic composition groups.

Key words: mineralogical domains, $X$-ray diffraction, multivariate statistical analysis, process mineralogy, nickel ore, geometallurgy, Santa Rita mine. 


\section{SUMÁRIO}

1 INTRODUÇÃO ..................................................................................1

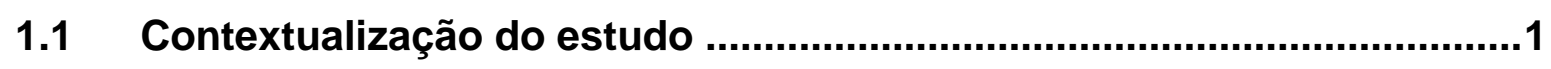

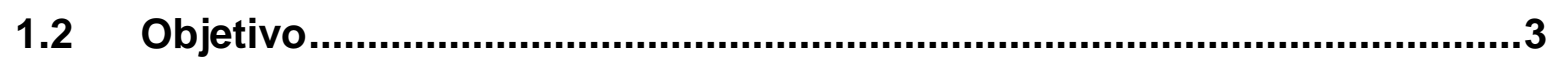

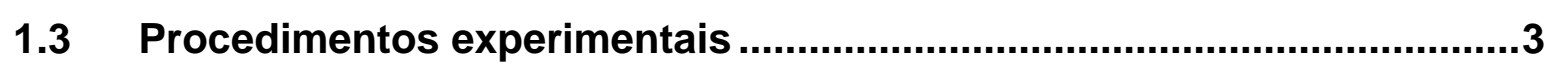

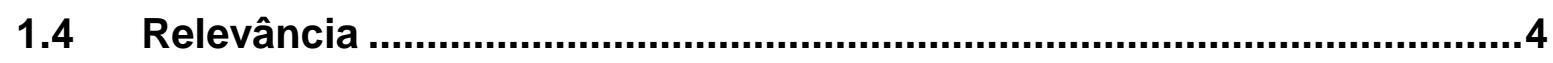

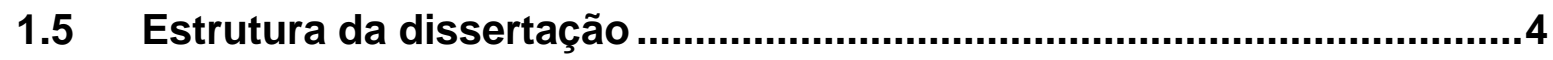

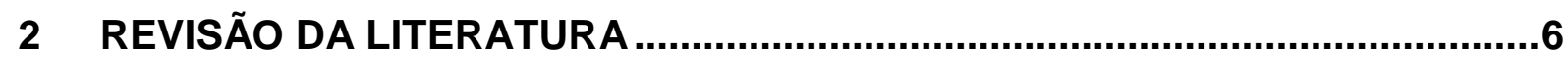

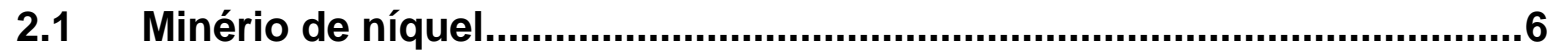

2.2 Intrusão Fazenda Mirabela e mina de Santa Rita ......................................

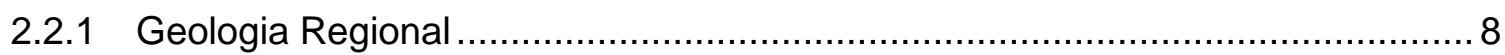

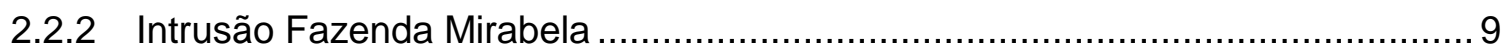

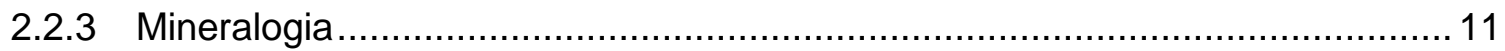

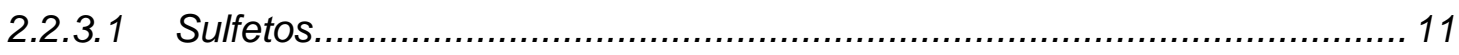

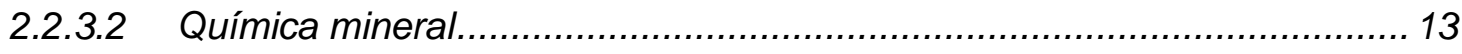

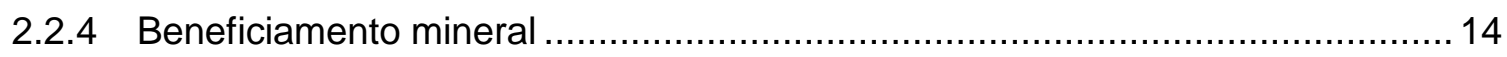

2.2.5 Tipos de minério / domínios geometalúrgicos .............................................. 15

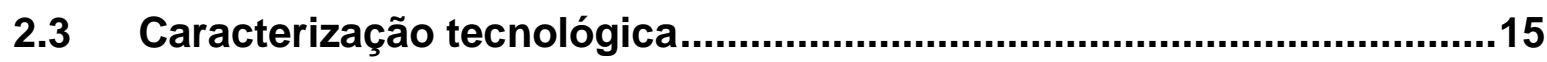

2.3.1 Técnicas analíticas empregadas em estudos de caracterização ...................... 16

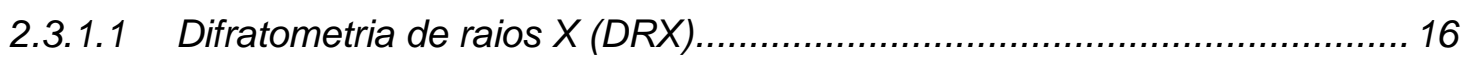

2.3.1.2 Mineralogia quantitativa automatizada .............................................. 18

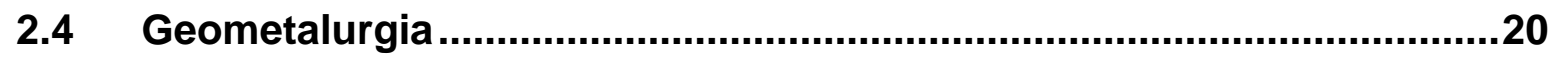

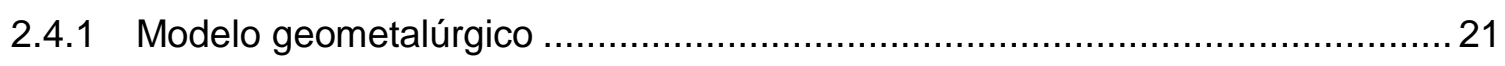

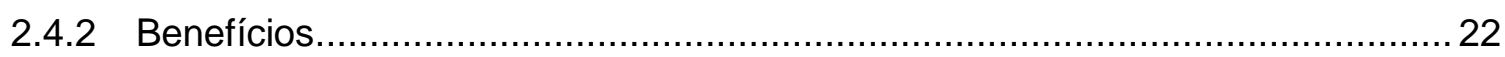

2.4.3 Amostragem e estimativa de variáveis geometalúrgicas..................................2

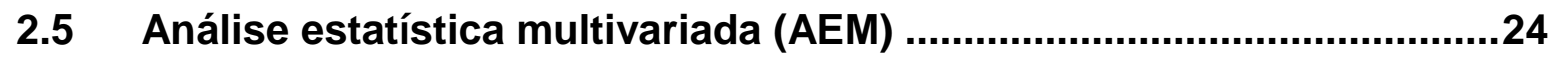

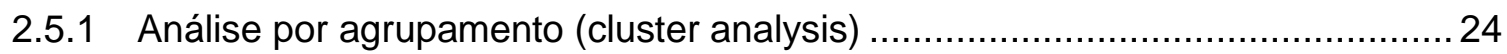

2.5.2 Análise de componentes principais (PCA) ................................................... 28

2.5.3 Software X'Pert Highscore Plus na análise por agrupamento e PCA ................31

3 DEFINIÇÃO DOS DOMÍNIOS MINERALÓGICOS (1 a ETAPA) ........................34

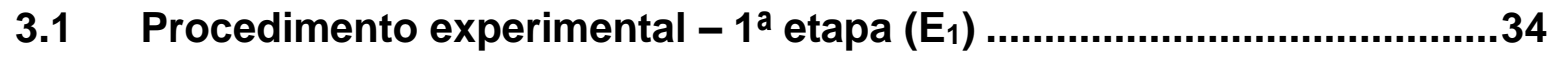

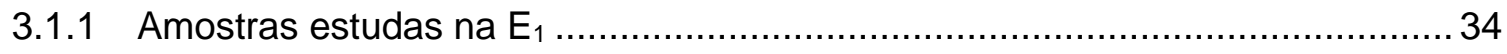

3.1.2 Procedimentos da análise por DRX + AEM da 1를 Etapa ………......................37

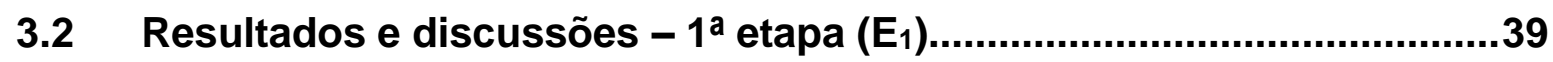




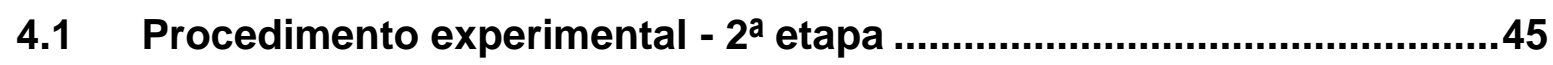

4.1.1 Amostras estudas e procedimentos da análise DRX+AEM na $E_{2} \ldots \ldots \ldots \ldots \ldots \ldots . . . .45$

4.1.2 Procedimentos para caracterização mineralógica de detalhe …………….......51

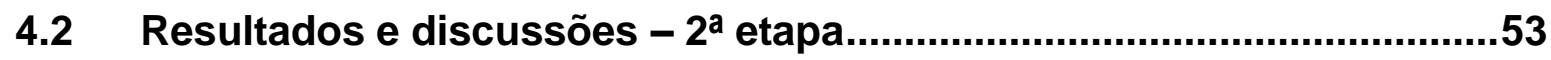

4.2.1 Análise estatística multivariada (AEM) dos difratogramas de raios $\mathrm{X} \ldots \ldots \ldots \ldots \ldots . . . .53$

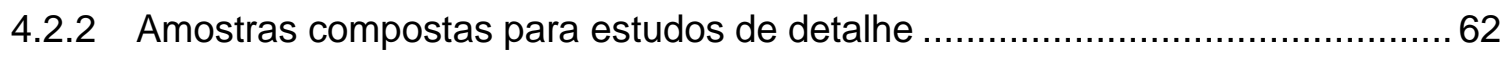

4.2.2.1 Tempo de moagem e análise granuloquímica....................................... 63

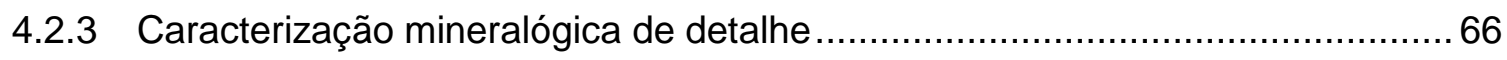

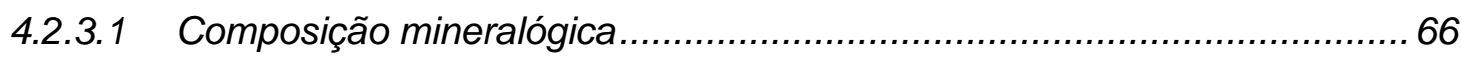

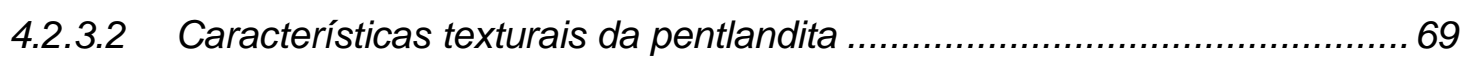

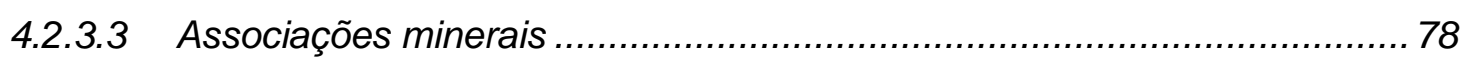

4.2.3.4 Distribuição granulométrica dos minerais de interesse .............................. 83

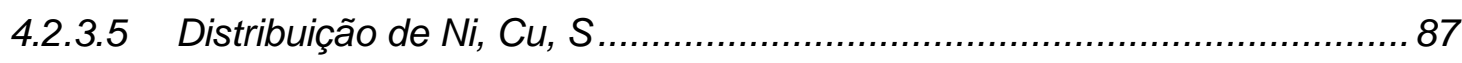

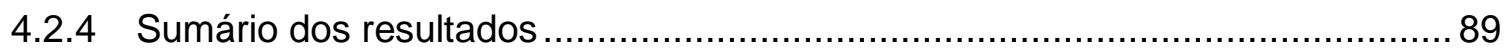

5 DISCUSSÃO INTEGRADA DOS RESULTADOS ...........................................

5.1 Em relação aos resultados obtidos nesse estudo .................................91

5.2 Em relação aos métodos empregados nesse estudo.............................96

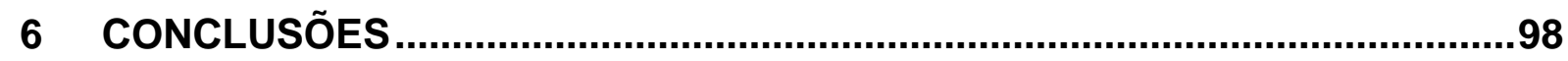

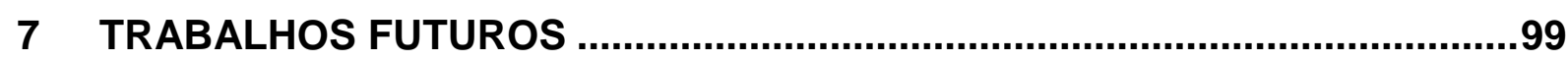

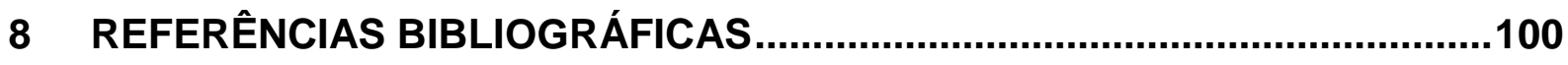

APÊNDICE 1 - Comparativo entre os difratogramas dispostos em cada grupo APÊNDICE 2 - Relação de amostras por grupo e parâmetros PC APÊNDICE 3 - Difratogramas médios dos domínios mineralógicos

APÊNDICE 4 - Análises químicas semi-quantitativas das amostras de contraparte dos pós de perfuratriz

APÊNDICE 5 - Composição químicas dos minerais (base para banco de dados $\mathrm{MLA})$

APÊNDICE 6 - Resultados MLA

APÊNDICE 7 - Composição química calculada por fração a partir do MLA (\% em massa)

APÊNDICE 8 - Imagens das fases discriminadas ao MLA com destaque para pentlandita 


\section{INTRODUÇÃO}

\subsection{Contextualização do estudo}

A mineração é um termo que abrange todas atividades econômicas que extraem substâncias portadoras de elementos de interesse, ou algum material (e.g brita, argilas), em sua grande maioria na forma de minerais, objetivando concentrá-los e modifica-los para as demandas da humanidade. Portanto, pode-se considerar três perguntas inerentes a esta atividade: onde estão estes materiais/elementos, de que forma concentrá-los e como modificá-los?

Ao longo da história, estas perguntas foram investigadas, gerando áreas de conhecimento, atualmente denominadas de prospecção/exploração (onde e como é o minério?), extração/explotação (de que forma concentrá-lo?) e a atividade industrial (como modificá-lo). Dentro dessas grandes áreas, existem inúmeras outras menores dedicando-se a responder as mais variadas questões.

Considerando a grande área da prospecção/exploração, a caracterização tecnológica de matérias-primas minerais é a área do conhecimento que estuda minérios e recursos minerais, através da determinação de caraterísticas físicas e/ou químicas que influencia sua recuperação nas etapas de beneficiamento (SANT'AGOSTINO; KAHN, 1997; KAHN et al., 2008; NEUMANN et al., 2004).

A caracterização é uma área de interface, pois ela abastece de informações a próxima grande área do conhecimento da extração/explotação. Por exemplo, a caracterização informa se o elemento de interesse está em um mineral com propriedades magnéticas, para então o processamento mineral escolher, dimensionar e otimizar a operação unitária de concentração: que máquina utilizar, qual tamanho, qual a capacidade de produção, qual o custo de implementação e os custos operacionais.

Em regras gerais, uma mina comumente apresenta milhões de toneladas de material a ser explotado; esta explotação ocorrerá ao longo de muitas décadas a depender da sua economicidade. Assim, as pessoas envolvidas em um empreendimento mineiro lidam com o seguinte problema: como estudar as variações nas características de milhões de toneladas de um material, afim de prever seu comportamento nas etapas de concentração, maximizando recuperações e minimizando os riscos do negócio. 
Uma das abordagens atuais para solução deste problema é a determinação de tipos de minério/domínios geometalúrgicos: segmenta-se o depósito em materiais espacialmente correlacionáveis com características geológicas semelhantes, que reflitam no comportamento do processamento mineral (LAMBERG, 2011). Assim, é preciso definir os critérios/parâmetros para serem considerados na classificação do material.

Comumente, estes critérios/parâmetros são definidos com base nos dados de descrição geológica de testemunhos de sondagens da etapa de exploração, e suas respectivas análises químicas. Porém, qualquer tentativa de discretização de eventos naturais, no caso processos geológicos relacionados à gênese de depósitos, mostrase uma tarefa complexa. Prever as possíveis variações geológicas locais com base nas análises de teores e na descrição visual do geólogo, apresentam-se muitas vezes como um método sem a sensibilidade necessária para discriminar as heterogeneidades do material.

Considerando o acima exposto, este estudo utilizou a difratometria de raios $X$ (DRX) associada à análise estatística multivariada dos dados (AEM - análise por agrupamento e análise de componentes principais), como uma ferramenta auxiliar ao modelo geometalúrgico, definindo os grupos de semelhança mineralógica do minério da mina de Santa Rita (aqui denominados de domínios mineralógicos), considerando uma porção do depósito planejada para lavra entre 2013 e 2017.

A difratometria de raios $X$ é uma das principais técnicas de caracterização mineralógica, com destacada importância no setor mineral. Conjugada com análises químicas quantitativas, pode ser rotineiramente utilizada em auxílio à exploração, ao planejamento de lavra (blendagens) e ao controle de processos do beneficiamento (KÖNIG; GOBBO, 2009; ANTONIASSI et al., 2011; SHIMIZU et al., 2012).

O recurso estatístico da análise multivariada dos dados, aplicada a difratogramas de raios $X$, corresponde a uma ferramenta de classificação de materiais geológicos através da associação de diferentes amostras em grupos de similaridade mineralógica (MACCHIAROLA et al., 2007).

Uma vez definidos os domínios mineralógicos, suas características de associações mineralógicas, liberação mineral e partição de elementos de interesse podem ser avaliadas com elevada robustez através das técnicas de análise de imagens automatizadas de microscopia eletrônica, conjugada a microanálise por EDS (FANDRICH et al., 2007; KAHN et al., 2002; PETRUK, 1989; SUTHERLAND; 
GOTTLIEB, 1991). Essas informações podem ser utilizadas nas interpretações do comportamento potencial desses domínios frente às etapas de concentração mineral, e, portanto, ser uma fonte de dados geometalúrgicos.

Em uma mina, o que se processa, concentra e descarta são minerais. A hematita será cominuída e não o teor de ferro; a calcopirita será flotada e não o teor de cobre. Portanto, é essencial analisar um depósito com dados de natureza mineralógica.

A Mina de Santa Rita, situada no complexo máfico-ultramáfico Fazenda Mirabela, é uma intrusão magmática acamadada de idade Paleoproterozóica mineralizada a sulfetos de níquel e cobre, situada no sudeste do Estado da Bahia, município de Itagibá. Seus tipos de minério/domínios geometalúrgicos foram definidos em seu estudo de viabilidade econômica (feasibility studies) e são, atualmente, nominados de dunito/serpentinito $(S)$, harzburgitos $(H)$, olivina-ortopiroxenito $(O)$ e ortopiroxenito (P) (MIRABELA, 2007). Estudos recentes de caracterização tecnológica, realizados no Laboratório de Caracterização Tecnológica POLI/USP (não publicados) têm demonstrado que, particularmente no caso da mina Santa Rita, não é possível estabelecer uma correlação adequada entre os atuais tipos de minério e o comportamento desses na etapa de beneficiamento.

\subsection{Objetivo}

O presente estudo tem como objetivo classificar os domínios mineralógicos da mina de Santa Rita, na região do depósito planejada para lavra de 2013 a 2017, seguido de estudos mineralógicos de detalhe dos principais domínios.

\subsection{Procedimentos experimentais}

Para atingir os objetivos propostos, o presente estudo foi dividido em duas etapas $(E)$ :

- $\mathrm{E}_{1} \rightarrow$ Definição dos domínios mineralógicos (grupos) por análise estatística multivariada de difratogramas de raios $\mathrm{X}$

- $E_{2} \rightarrow$ Estudos de caracterização mineralógica detalhada dos principais domínios por análise automatizada de imagens (MEV-MLA) 
Optou-se por detalhar os procedimentos experimentais por capítulo referente aos resultados de cada etapa, ao invés de condensá-los em um capítulo único. Parte dos procedimentos definidos na segunda etapa dependiam dos resultados da primeira etapa. Assim, expor os procedimentos da segunda etapa, antes dos resultados da primeira, inverteria a lógica dos acontecimentos.

\subsection{Relevância}

Na literatura, são escassos os estudos publicados envolvendo DRX associada à análise estatística multivariada. Destacam-se os trabalhos König e Gobbo (2009) para controle de processo de minério de ferro, Antoniassi et al. (2011) na explotação de minérios de bauxita e Shimizu et al. (2012) para a definição de tipos de minérios em uma mina de cobre. Portanto, este trabalho é pioneiro na aplicação deste método a um depósito de níquel e cobre sulfetado associados a uma intrusão máficaultramáfica acamadada.

Do ponto de vista prático, o presente estudo, iniciado em 2012, contribuirá para o plano de aproveitamento econômico da mina de Santa Rita, através do aprimoramento do conhecimento das características do minério e de sua variabilidade mineralógica no depósito, relevantes para fins de processo e eventuais comportamentos diferenciados na etapa de concentração.

\subsection{Estrutura da dissertação}

Esta dissertação está segmentada por capítulos como segue:

1) INTRODUÇÃO: buscou-se contextualizar o leitor para o tema abordado; os objetivos e os métodos aplicados para alcançá-los; a relevância do estudo; e como esse documento foi estruturado.

2) REVISÃO DA LITERATURA: buscou-se dar uma base teórica ao leitor dos principais tópicos desse estudo, para o entendimento dos resultados e discussões apresentados a seguir.

3) DEFINIÇÃO DOS DOMÍNIOS MINERALÓGICOS (1 $1^{\text {a }}$ ETAPA): exposição dos procedimentos experimentais, resultados e discussões na definição dos domínios mineralógicos. 
4) CARACTERIZAÇÃO MINERALÓGICA DE DETALHE (2 $2^{\mathrm{a}}$ ETAPA): exposição dos procedimentos experimentais, resultados e discussões das amostras de minério representativa dos principais domínios mineralógicos.

5) DISCUSSÃO INTEGRADA DOS RESULTADOS: os resultados das duas etapas anteriores foram integrados em uma discussão, visando atingir os objetivos do estudo.

6) CONCLUSÕES: quais as conclusões desse estudo.

7) TRABALHOS FUTUROS: sugestão de estudos podem ser realizados no futuro, considerando o que foi exposto nesse trabalho. 


\section{REVISÃO DA LITERATURA}

\subsection{Minério de níquel}

Níquel (Ni) é um elemento de transição que possui características de propriedades metálicas tanto de elementos ferrosos como não-ferrosos. Ele é encontrado na natureza na forma de um elemento siderófilo (associado com ferro) e como um elemento calcófilo (associado com enxofre). As mais expressivas minas de níquel estão alocadas em dois tipos de depósitos, descrito a seguir, sendo o primeiro tipo o mais expressivo quanto à produção mundial (CORNWALL, 1966):

- lateríticos, onde os principais minerais de minério são uma limonita niquelífera $[(\mathrm{Fe}, \mathrm{Ni}) \mathrm{O}(\mathrm{OH})]$ e a garnerita (um silicato hidratado de níquel);

- magmáticos, onde há mineralização por sulfetos de níquel, predominantemente na forma de pentlandita $\left[(\mathrm{Ni}, \mathrm{Fe})_{9} \mathrm{~S}_{8}\right]$.

O raio iônico do níquel bivalente é similar ao do ferro e magnésio, permitindo assim a substituição entre estes três elementos na estrutura cristalina de alguns óxidos e silicatos (CORNWALL, op. cit.). Assim, depósitos de níquel sulfetado são comumente associados com rochas ricas em minerais ferro-magnesianos, denominadas de rochas ultramáfica. Estas rochas podem ser encontradas tanto na forma plutônica como vulcânica. Muitos depósitos de níquel sulfetado ocorrem em grandes profundidades, enquanto os de origem laterítica são formadas na superfície pela alteração das rochas ultramáfica $(\mathrm{ROBB}, 2005)$

Segundo a USGS (2016), cerca de $65 \%$ do níquel consumido no mundo ocidental é usado para fabricar aço inoxidável austenítico. Outros $12 \%$ vão para superligas (por exemplo, Inconel 600) ou ligas não ferrosas. Ambas as famílias de ligas são amplamente utilizadas devido à sua resistência à corrosão. A indústria aeroespacial é um dos principais consumidores de superligas à base de níquel. As lâminas de turbina, os discos e outras peças críticas dos motores a jato são fabricados a partir dessas superligas. Os restantes (23\%) do consumo são divididos entre baterias recarregáveis, catalisadores e outros produtos químicos, de fundição e revestimento. Os principais produtos químicos comerciais são o carbonato $\left(\mathrm{NiCO}_{3}\right)$, cloreto $\left(\mathrm{NiCl}_{2}\right)$, óxido divalente $(\mathrm{NiO})$ e sulfato $\left(\mathrm{NiSO}_{4}\right)$ de níquel. 
O processo para tratamento e extração do minério de níquel sulfetado pode ser dividido em três etapas, segundo Goonan (2009): concentração, refino e fundição. A etapa de concentração ocorre através da flotação de sulfetos com coletores a base de xantatos. Já para o minério laterítico, a via de processamento pode ser hidro e/ou pirometalúrgica, a depender do tipo de minério pela relação magnésio/ferro (minério garnerítico ou limonítico). Minérios limoníticos são tratados por hidrometalurgia (os métodos mais comuns são o "pressure acid leach process" e "ammonia leach process"), enquanto os garneríticos com pirometalurgia, preferencialmente.

A Figura 1 mostra a variação do preço do minério de níquel nos últimos nove anos. Nota-se que em 2008 houve uma acentuada queda do preço do minério de níquel atingindo valores de aproximadamente US\$ 9.000/tonelada, com sua recuperação em 2009, até atingir cerca de US\$30.000/tonelada em 2010. Porém, a partir de 2010 o preço da tonelada voltou a cair substancialmente atingindo seu valor mais baixo em 2016, sendo comercializado abaixo de 8.000/tonelada.

Figura 1 - Variação do preço do minério de níquel nos últimos nove anos para contratos tipo "cash buyer"

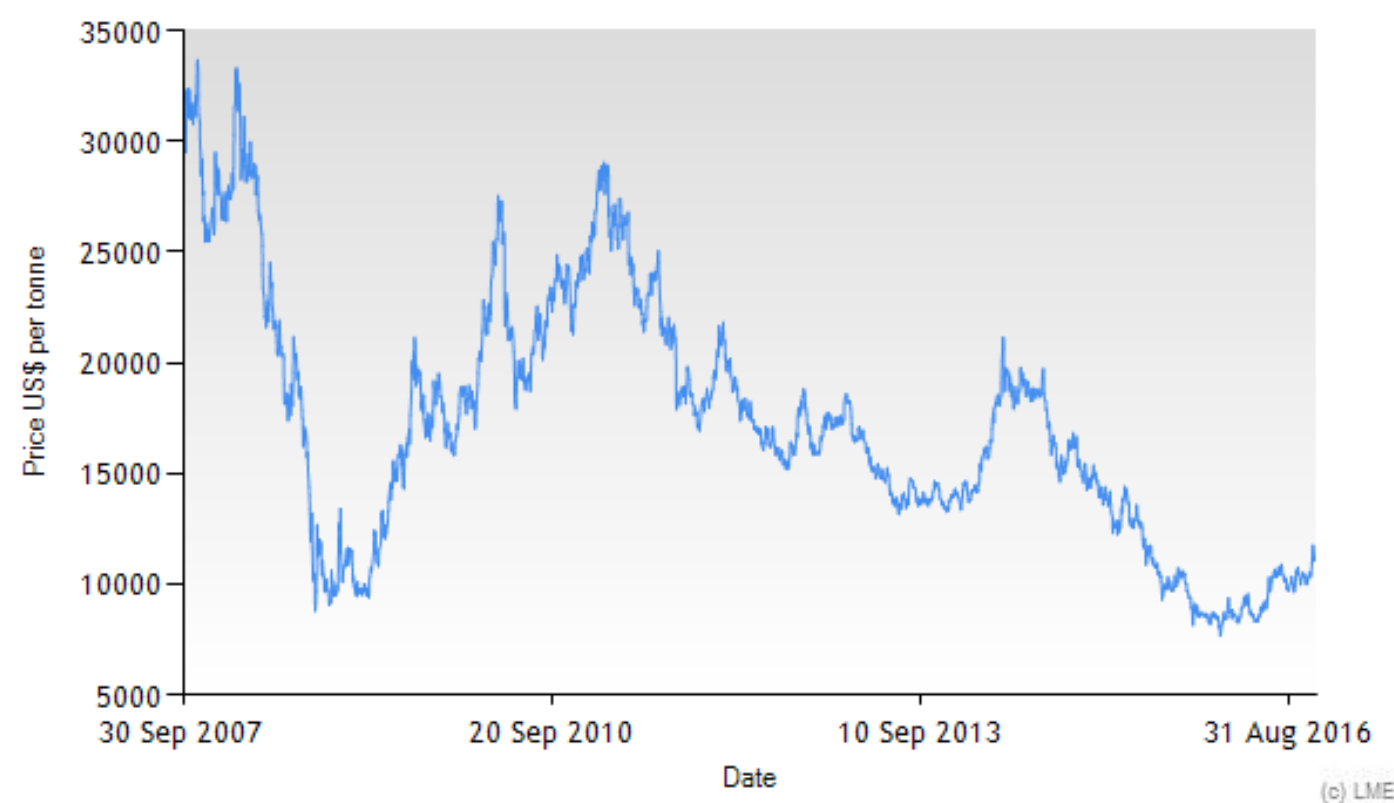

Fonte: London Metal Exchange (LME) 


\subsection{Intrusão Fazenda Mirabela e mina de Santa Rita}

\subsubsection{Geologia Regional}

A intrusão máfica-ultramáfica Fazenda Mirabela encontra-se na região sulsudeste do Cráton do São Francisco (CSF). Barbosa e Sabaté (2004) definem a segmentação desta região em bloco Gavião, bloco Jequié, bloco Serrinha e o cinturão orogenético Itabuna-Salvador-Curaçá - Figura 2.

Figura 2 - Mapa geológico da porção sul-sudeste do Cráton São Francisco com destaque para os terrenos geotectônicos definidos por Barbosa e Sabaté (2004) e a intrusão fazenda Mirabela

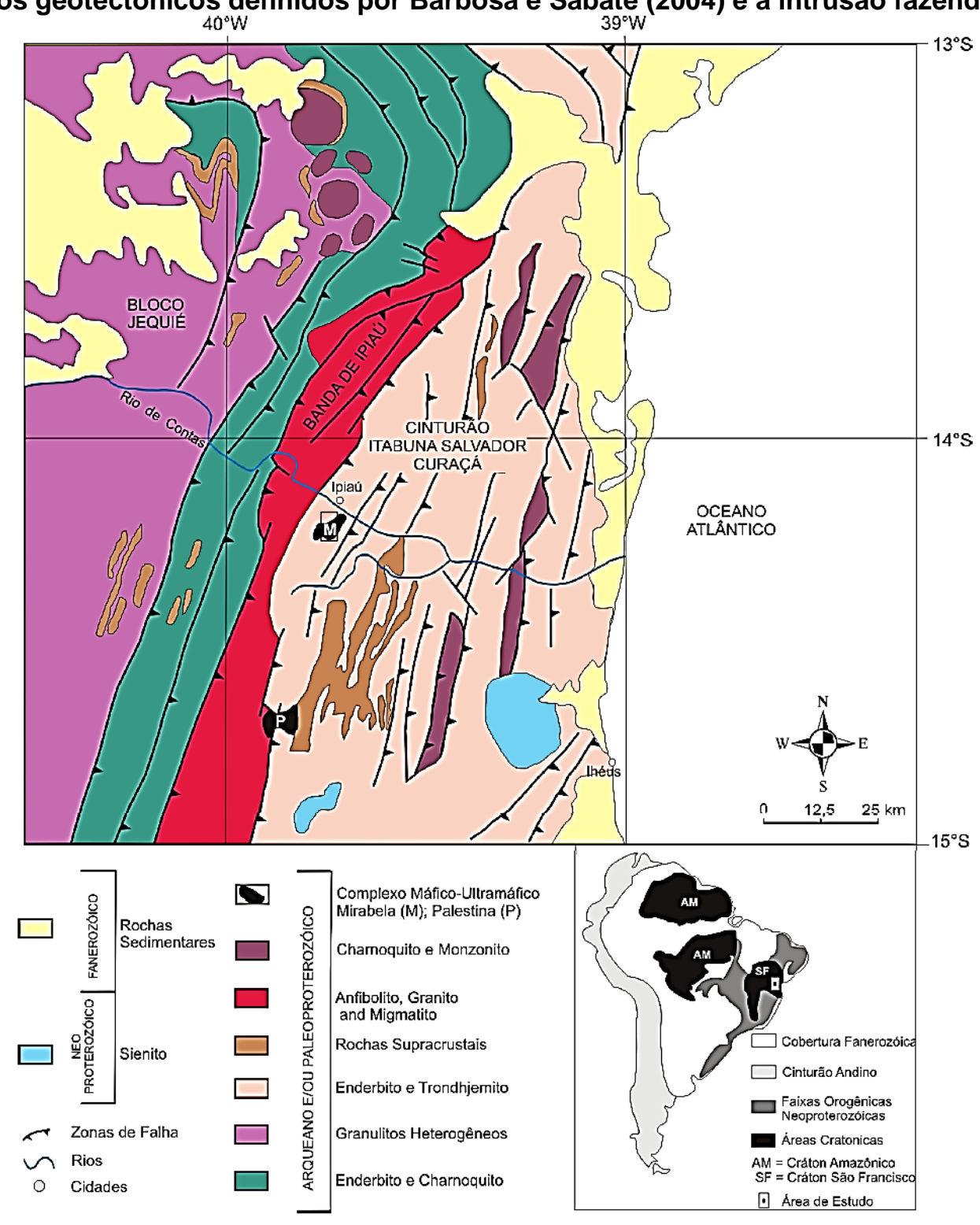

Fonte: Lazarin (2011) modificado de Barbosa et al. (2003)

O bloco Gavião possui porções graníticas, granodioríticas e migmatíticas de crosta continental, associadas com remanescentes de tonalitos-trondhjemitosgranodioritos (TTGs) de 3,4 G.a e greenstonebelts Arqueanos. Já o bloco Jequié é 
formado por granulitos e migmatitos supracrustais, intrudidos por plútons charnockíticos, enquanto o bloco Serrinha apresenta ortognaisses e migmatitos embasando greenstonebelts Paleoproterozóicos. Por fim, o cinturão orogenético Itabuna-Salvador-Curaçá originou-se da colisão dos blocos Serrinha e Gavião (2,15 2,05 G.a) e é composto de uma suíte plutônica cálcio-alcalina de baixo teor de potássio, intercalada com basaltos e gabros de fundo oceânico e/ou bacias de retroarco, bem como metassedimentos (BARBOSA et al., 2003; BARBOSA; SABATÉ, 2004).

Dentro deste contexto geotectônico, a intrusão máfica-ultramáfica Fazenda Mirabela ocorreu nos núcleos de estruturas antiformais da margem oeste do cinturão Itabuna-Salvador-Curaçá. Esta intrusão foi então metamorfizada em fáceis granulito durante a transpressão final da parte sul do cinturão orogenético entre 2,08 - 2,06 G.a. (BARBOSA; SABATÉ, 2004).

\subsubsection{Intrusão Fazenda Mirabela}

A intrusão Fazenda Mirabela é um corpo com 4,2 Km de comprimento por 2,5km de largura, composto de rochas ígneas cumuláticas máficas-ultramáficas, em uma área de aproximadamente $7 \mathrm{~km}^{2}$. Sua forma assemelha-se a uma canoa (do inglês: boat-shaped layered intrusion). Apesar de suas rochas encaixantes apresentarem alto grau de deformação, a intrusão não mostra evidências deformacionais: as texturas ígneas estão perfeitamente preservadas (BARNES et al., 2011).

Litoestratigraficamente apresenta uma sequência fracionada, reconhecendo-se duas zonas: a) zona ultramáfica inferior (a oeste da intrusão), composta de dunitos, harzburgitos e piroxênitos (olivina-ortopiroxênitos e ortopiroxênitos); e b) zona máfica superior (porção leste), composta de gabronoritos, variando composicionalmente até augita noritos.

A porção mineralizada com sulfetos disseminados foi denominada de Santa Rita e ocorre em toda extensão da intrusão dentro da camada de harzburgitos, olivina ortopiroxênitos e ortopiroxênitos - Figura 3, Figura 4 e Figura 5. 
Figura 3 - Mapa geológico do corpo intrusivo Fazenda Mirabela

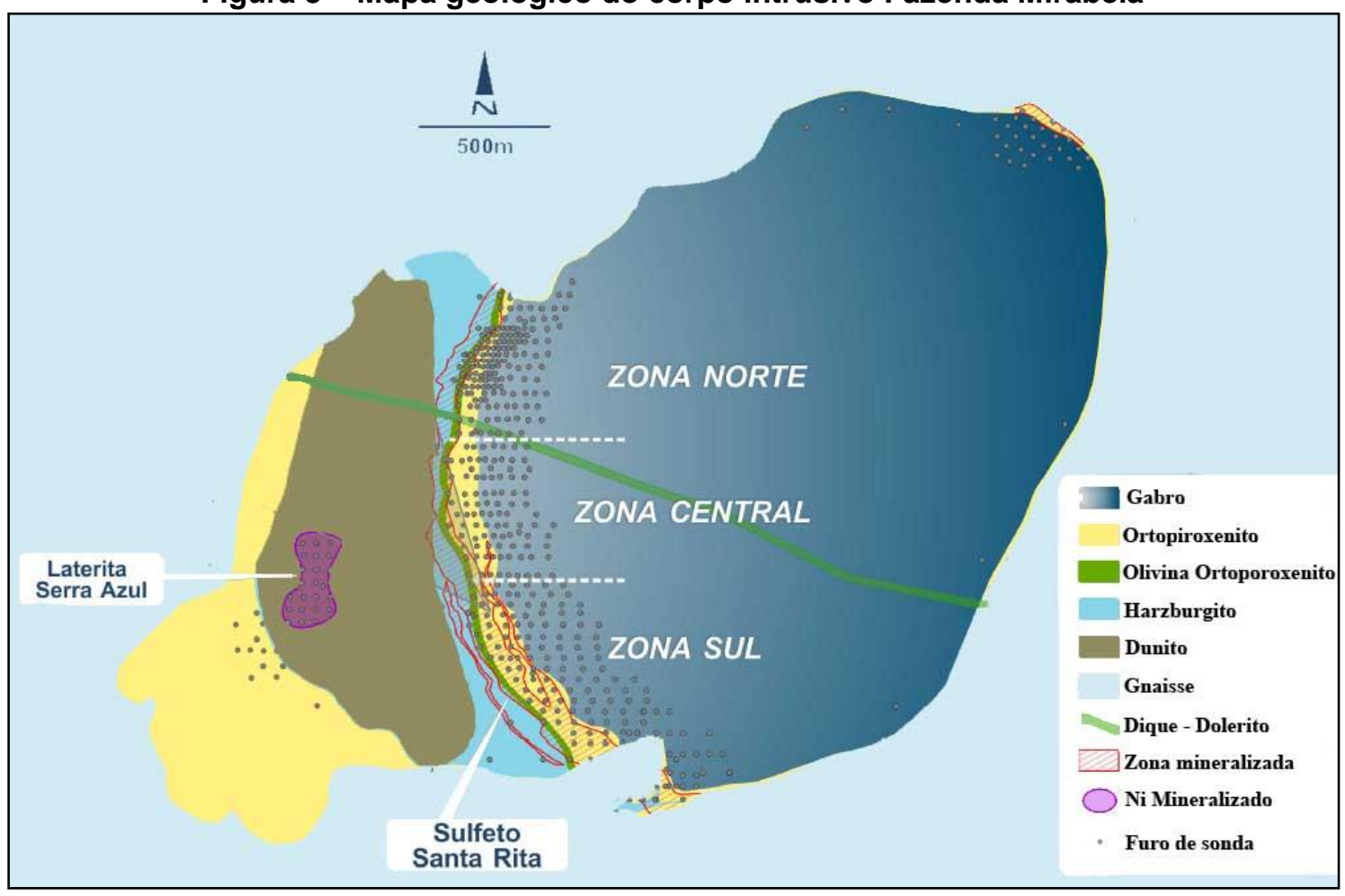

Fonte: Cunha e Ferreira (1992)

Figura 4 - Seção vertical na área da mina de Santa Rita, corpo Fazenda Mirabela.

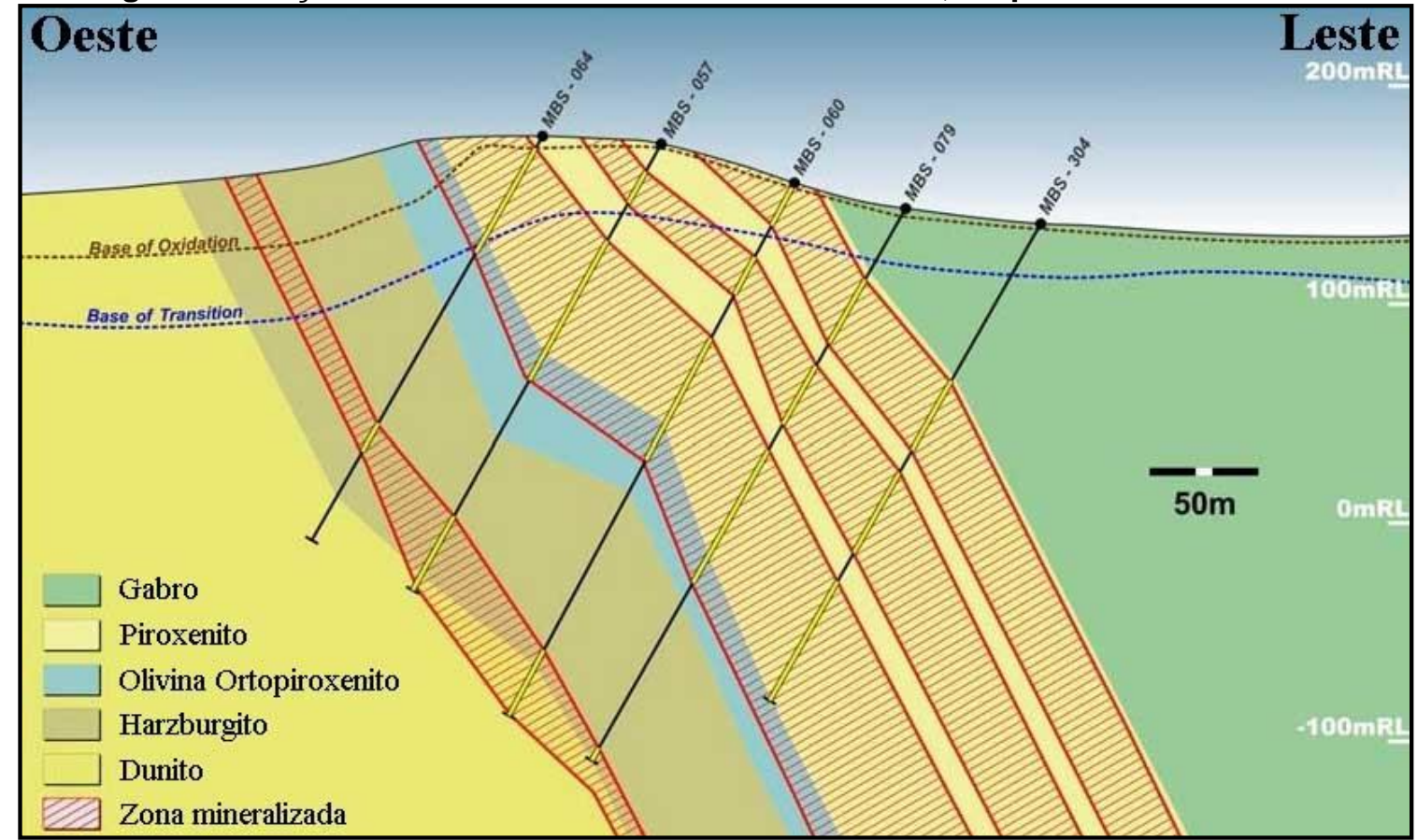

Fonte: Cunha e Ferreira (1992) 
Figura 5 - Testemunhos de sondagem exemplificando a variação litológica do depósito com destaque em vermelho para o intervalo mineralizado em sulfetos

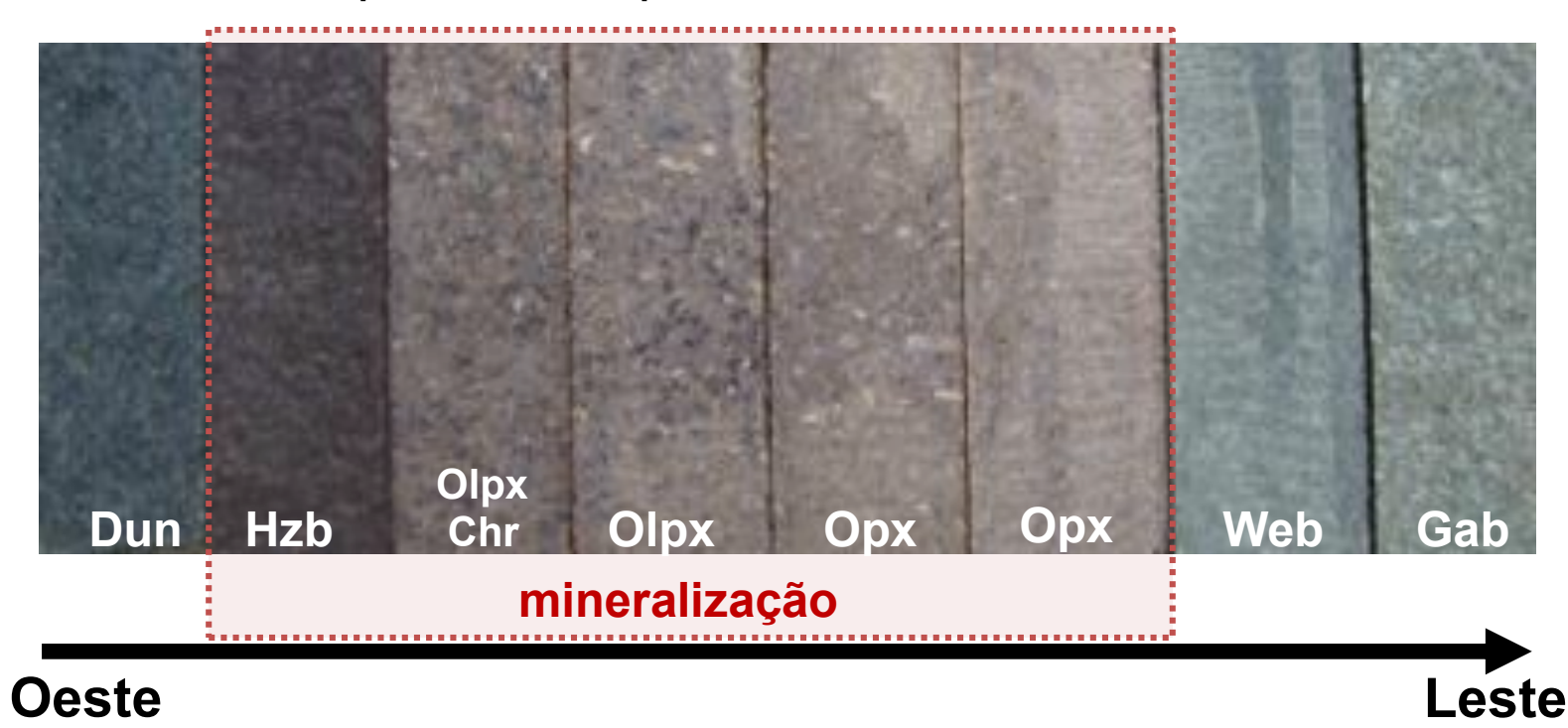

Dun = dunito; $\mathrm{Hzb}=$ harzburgito; Olopx-Chr = olivina ortopiroxenito com cromita; Olpx = olivina ortopiroxenito; Web = websterito; Gab = gabronoritos

Fonte: modificado de Cunha e Ferreira (1992)

\subsubsection{Mineralogia}

A ordem de fracionamento mineral no depósito foi definida como: olivina $\rightarrow(\mathrm{Cr}-$ espinélio) $\rightarrow$ ortopiroxênio $\rightarrow$ clinopiroxênio $\rightarrow$ plagioclásio $\rightarrow$ (magnetita /ilmenita), refletindo a litoestratigrafia estabelecida (BARNES et al., 2011). Segundo Mirabela (2007), a mineralização de sulfetos apresenta forte controle litoestratigráfico, concentrada nos peridotitos e piroxenitos. Tem uma natureza primária disseminada, resultante da acumulação de líquido sulfetados na fase cumulática dos silicatos. Os principais sulfetos são a pentlandita, calcopirita, pirita e pirrotita.

\subsubsection{1 $\underline{\text { Sulfetos }}$}

Os sulfetos mais abundantes normalmente possuem granulação fina, ocorrendo também como agregados de tamanho não superior a $0,5 \mathrm{~mm}$ ou $1 \mathrm{~mm}$. Os grãos compostos de sulfuretos ricos em $\mathrm{Ni}$ são comumente alongados e com dimensões de até 1-2 mm. Os sulfetos menos abundantes incluem mackinawita, milerita, pirita, cubanita, bornita e calcossita.

Uma descrição detalhada da morfologia dos sulfetos de acordo com as litologias presentes no depósito é apresentada a seguir de acordo com Mirabela (op. cit.): 
- Serpentinito/Dunito: os sulfetos ocorrem na granulação de 50-300 $\mu \mathrm{m}$, intensamente associados com magnetita e serpentina; também ocorrem como inclusões $(<1-15 \mu \mathrm{m})$ na serpentina. O principal mineral de níquel é a pentlandita $\left[(\mathrm{Fe}, \mathrm{Ni})_{9} \mathrm{~S}_{8}\right]$, contudo vestígios de calcopirita e calcosita $\left(\mathrm{Cu}_{2} \mathrm{~S}\right)$ também ocorrem como inclusões na olivina. Purvis (2006) estudou 49 amostras de dunito e obteve uma média de 0,38\% de Ni (acima de um grau de corte de $0,3 \%$ ), mas apenas $0,12 \%$ de Ni estava presente em sulfetos, o que significa que o dunito em média não constitui minério (predomina Ni em olivina - serpentina).

- Peridotitos (Harzburgito): os sulfetos ocorrem principalmente na forma de pentlandita e calcopirita com granulação de 30-400 $\mu \mathrm{m}$, intercalados com cristais reliquiares de olivina. Também ocorrem como grãos disseminados (5-60 $\mu \mathrm{m})$ na serpentina. Os grãos de pentlandita são comumente intersectados por micro veios de serpentina e magnetita. Além disso, a serpentina forma bordas contínuas (até $10 \mu \mathrm{m}$ de largura) ao longo dos limites dos grãos de pentlandita.

- Olivina ortopiroxenito: os sulfetos ocorrem como agregados com granulação de 100-1.500 $\mu \mathrm{m}$ em associações com silicatos (predominantemente piroxênios). Os sulfetos também mostram associação com Cr-espinélio. O principal mineral de $\mathrm{Ni}$ é a pentlandita [( $\left.\mathrm{Fe}, \mathrm{Ni})_{9} \mathrm{~S}_{8}\right]$, enquanto a violarita $\left(\mathrm{FeNi}_{2} \mathrm{~S}_{4}\right)$ é uma fase rara que ocorre ao longo dos planos de clivagem da pentlandita e de micro fraturas. A pentlandita ocorre como parte dos aglomerados de sulfetos intersticiais aos piroxênios; esses aglomerados são compostos por pentlandita, calcopirita, pirrotita e pirita. Enquanto os contatos entre os sulfetos são tipicamente simples, com limites de grão retos. Outros sulfetos observados como constituintes menores incluem bornita $\left(\mathrm{Cu}_{5} \mathrm{FeS}_{4}\right)$, galena $(\mathrm{PbS})$, mackinawita $\left[(\mathrm{Fe}, \mathrm{Ni})_{1}+\mathrm{xS}\right] \mathrm{e}$ marcasita $\left(\mathrm{FeS}_{2}\right)$.

- Piroxenito: os sulfetos ocorrem como aglomerados de pentlandita, calcopirita e pirita. A pentlandita também é encontrada como grãos não aglomerados $(<100 \mu \mathrm{m})$ inclusa nos piroxênios. A pirita geralmente forma um padrão de intercrescimento complexo com pentlandita. Milerita ocorre 
tipicamente como inclusões na pentlandita e como agregados irregulares de grãos finos (até $120 \mu \mathrm{m}$ ).

\subsubsection{Química mineral}

A química mineral da intrusão Fazenda Mirabela foi estudada por Fróes (1993) e Purvis (2005) e as principais observações desses autores são resumidas a seguir:

- Olivina/Serpentina: a composição de olivina a partir dos cumulatos de olivina para os peridotitos é notavelmente homogénea. A olivina é relativamente rica em ferro $(9,9-11,5 \%$ de Fe, Fo84-86) com 0,3-0,32\% de $\mathrm{Ni}$ (como $\mathrm{Ni}_{2} \mathrm{SiO}_{4}$ ). A composição da serpentina possui $0,25-0,28 \%$ de $\mathrm{Ni}$ (como $\mathrm{Ni}_{3} \mathrm{Si}_{2} \mathrm{O}_{5}(\mathrm{OH})_{4}$ ), com Ni menos abundante em serpentina rica em ferro $(8,6 \% \mathrm{Fe})$ do que em serpentina rica em $\mathrm{Mg}(4-5 \% \mathrm{Fe})$.

- Ortopiroxênio: os ortopiroxênios apresentam uma grande variação na sua composição. Os teores de $\mathrm{MgO}$ variam de $32 \%$ em nas rochas ultramáficas a $27 \%$ em nas rochas leucogabronoríticas. Os conteúdos de $\mathrm{Al}_{2} \mathrm{O}_{3}$ são muito constantes; nas rochas ultramáficas cerca de 2,0\% em massa diminuindo para $1,5 \%$ nos gabronoritos. $\mathrm{O} \mathrm{CaO}$ varia amplamente mesmo para diferentes grãos dentro da mesma amostra, enquanto que o teor de $\mathrm{TiO}_{2}$ apresenta uma faixa estreita entre 1,0-1,6\% em massa.

- Clinopiroxênio: os clinopiroxênios exibem uma ampla faixa composicional. Os teores de $\mathrm{MgO}$ variam de $18 \%$ em massa nos piroxênitos a 14,5\% em massa nos leucogabronoritos. O $\mathrm{CaO}$ aumenta progressivamente nos peridotitos e piroxênitos ( 21,0\% em peso) para os gabronoritos ( 24,0\% em peso). Os valores de $\mathrm{NiO}$ variam desde $0,02 \%$ em massa $(0,016 \%$ de $\mathrm{Ni})$ nos gabbronoritos até um máximo de $0,26 \%$ em massa $(0,20 \%$ de $\mathrm{Ni})$ no bronzitito.

- Cr-espinélios: entre os espinélios tem-se 25-45\% na forma de cromita, 6 $12 \%$ como magnetita e $43-65 \%$ como Cr-espinélio. As relações $\mathrm{Cr} / \mathrm{Fe}$ diminuem de 1,43 nos serpentinitos para 1,12 em peridotitos. A relação $\mathrm{Cr} /(\mathrm{Cr}+\mathrm{Al})$ varia de $0,18-0,60$ nos olivina ortopiroxênitos, para 0,61 nos 
ortopiroxenitos. Estes espinélios possuem 200-900 ppm de Ni (580 \pm 230 ppm), com 200 ppm de Ni na magnetita.

\subsubsection{Beneficiamento mineral}

Segundo Santos Júnior e Delboni Júnior (2016), o processamento do minério da mina Santa Rita (Figura 6) inicia-se com o desmonte da rocha por explosivos. 0 minério é então transportado por caminhões para dois britadores primários, um cônico e um de mandíbulas, em uma taxa média de alimentação de $1300 \mathrm{t} / \mathrm{h}$. O produto da britagem primária é transportado por correia transportadora para uma pilha pulmão com capacidade de $67 \mathrm{kt}$.

Figura 6 - Esquema simplificado do circuito de beneficiamento da Mina Santa Rita

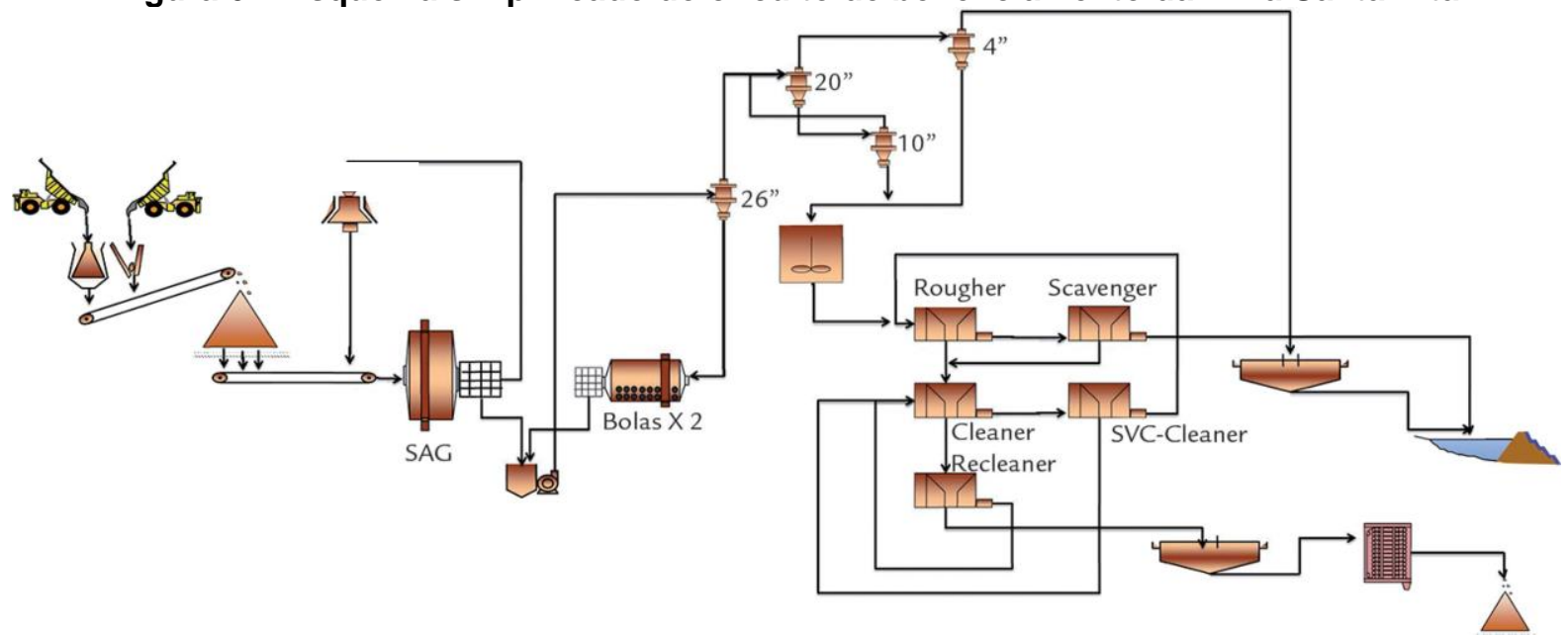

Fonte: Santos Júnior e Delboni Júnior (2016)

O material da pilha é transportado por correias até o circuito de moagem, que é composto de um moinho tipo SAG (Semi-Autogenous Grinding), dois britadores cônicos secundários e dois moinhos de bolas. O produto da moagem é bombeado para um estágio de deslamagem com $\mathrm{P}_{80}$ de $125 \mu \mathrm{m}$, que inclui três hidrociclones projetados para a remoção de material fibroso (serpentinas) concentrados na fração mais fina.

Após a deslamagem, o material é bombeado para o circuito de concentração por flotação direta dos sulfetos de níquel e cobre, com as etapas rougher, scavenger, cleaner e recleaner, utilizando-se de coletores a base de xantatos. A recuperação metalúrgica da planta varia de acordo com as características mineralógicas do minério, principalmente quanto à partição de níquel em silicatos. A recuperação global média de níquel é de $58 \%$ e o concentrado final possui teores de níquel variando entre $13 \%$ a $15 \%$. 
Toda a água do circuito é reutilizada; o rejeito é reportado à barragem e o concentrado é filtrado e despachado via caminhões ao porto de llhéus - BA, onde $100 \%$ da produção é exportada via navios, majoritariamente, para Finlândia (MIRABELA, 2015).

\subsubsection{Tipos de minério / domínios geometalúrgicos}

Os domínios geometalúrgicos da Mina Santa Rita foram definidos nos estudos de viabilidade econômica (MIRABELA, 2007). De acordo com esse documento, os quatro domínios geológicos, dunito/serpentinito $(S)$, harzburgitos $(H)$, olivinaortopiroxenito $(\mathrm{O})$ e ortopiroxenito $(\mathrm{P})$, possuem características similares de processo e, portanto, também são classificados como domínios geometalúrgicos / tipos de minério.

As variáveis avaliadas para justificar esta classificação foram os teores de $\mathrm{Ni}$, $\mathrm{Cu}, \mathrm{Co}, \mathrm{MgO}$; a razão dos teores de S/Ni; RQD (Rock Quality Designation). Uma vez definidos os domínios, estes foram submetidos a ensaios de flotação direta de sulfetos em escala de bancada (MIRABELA, op. cit.).

Os domínios $\mathrm{P}$ e $\mathrm{O}$ possuem os maiores teores de $\mathrm{Ni}$, presente majoritariamente na forma de sulfetos e, portanto, apresentam os maiores valores de recuperação de $\mathrm{Ni}$ em ensaios de flotação. Os domínios $\mathrm{H}$ e S possuem a partição do níquel dividida quase equitativamente entre sulfetos e a ganga silicática e, comparativamente, possuem baixos teores de $\mathrm{Ni}$ e elevados teores de $\mathrm{MgO}$. Consequentemente, apresentam baixa recuperação de Ni nos ensaios de flotação.

\subsection{Caracterização tecnológica}

Segundo Sant'Agostino e Kahn (1997) a caracterização tecnológica é uma expressão aplicada num sentido amplo para o estudo de minérios e recursos minerais para os quais se vislumbra aproveitamento econômico, abordando também, de forma bastante criteriosa, as diversas etapas da caracterização, compreendendo, por exemplo, o processo de descrição e quantificação da composição mineralógica, tamanho e forma dos grãos, associações minerais e grau de liberação de um material.

A determinação destes parâmetros é fundamental para o aproveitamento de um recurso mineral de forma otimizada, pois fornece informações sobre o potencial de recuperação do material, além de predizer a resposta do material frente aos 
processos de beneficiamento (NEUMANN et al., 2004). Estes estudos também podem ser empregados para avaliar problemas no processamento já implantado.

\subsubsection{Técnicas analíticas empregadas em estudos de caracterização}

A seguir, somente as principais técnicas utilizadas nesse estudo serão abordadas em detalhe.

\subsubsection{Difratometria de raios $X(D R X)$}

A difração de raios $X$ teve seu início em 1912 com a descoberta de que cristais difratam raios $X$ refletindo sua estrutura cristalina, por Von Laue (CULLITY, 1978), estando relacionada a um fenômeno de interação entre a radiação incidente e os elétrons que compõem os átomos do material analisado (CULLITY, 1978; FULTZ; HOWE, 2007).

Os raios $\mathrm{X}$ mudam sua trajetória após atingir a amostra, mantendo, porém, seu comprimento de onda - espalhamento elástico. Cada elétron que compõem a amostra se torna uma nova fonte de emissão de raios $X$. Se os átomos da amostra estiverem arranjados de forma sistemática, como em estruturas cristalinas de minerais, as fases das ondas da radiação difratadas ocorrem de forma periódica, gerando assim uma interação construtiva.

Desta forma, o fenômeno de difração de raio $X$ é observado para diferentes ângulos $(\theta)$ do raio incidente, desde que seu comprimento de onda $(\lambda)$ seja da mesma ordem de magnitude que a distância entre os átomos na estrutura cristalina do material analisado (d), seguindo a lei de Bragg descrita pela equação 1 e ilustrada na Figura 7, onde: "n" é um inteiro que assegura interferência construtiva (CULLITY 1978; FULTZ; HOWE 2007).

No caso dos minerais, o parâmetro "d" é a distância interplanar da estrutura cristalina e pode ser representada pelos índices de Miller (hkl) para cada ângulo de medição ( $2 \theta \mathrm{hkl})$. Portanto, os ângulos $\theta$ oriundos da difração de raios $X$ são relacionados com as dimensões das células unitárias e as orientações interatômicas dos planos "hkl" de um material cristalino (REYNOLDS, 1989). 
Figura 7 - llustração do fenômeno de difração de acordo com a lei de Bragg

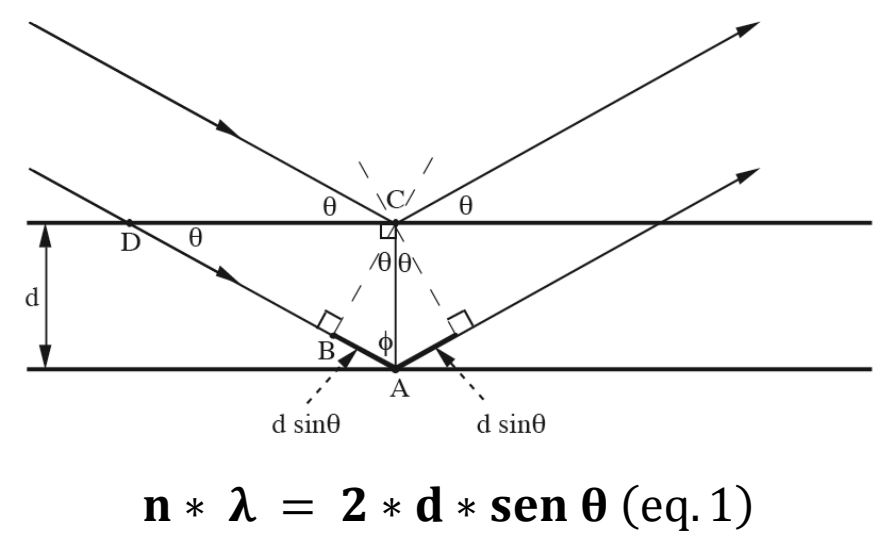

Fonte: extraída e modificada de Fultz e Howe (2007)

Os minerais possuem estrutura cristalina com configuração única quanto à disposição dos planos e a densidade de átomos para cada posição específica dos sítios cristalográficos. Portanto, cada mineral possui um único padrão de difração, permitindo suas identificações pela posição angular e intensidades relativas dos raios X difratados (CULLITY, 1978).

\section{Identificação de fases cristalinas por DRX}

O difratômetro apresenta como resultado o difratograma que é um gráfico de intensidade de raios $X$ que chegam ao detector (contagens por segundo) pelo ângulo

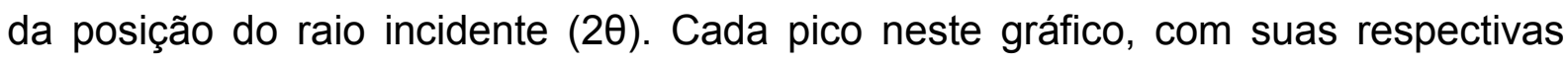
intensidades, representam um plano cristalino, representado pelos índices de Miller hkl - Figura 8.

A identificação de fases cristalinas por DRX é realizada pela comparação entre o difratograma da amostra e padrões de referência, disponíveis em um banco de dados. O centro internacional de dados de difração (ICDD - International Center for Diffraction Data) é a instituição responsável por padronizar e regular um banco de dados que reúne padrões de diversas fases cristalinas. 
Figura 8 - Exemplo de difratograma de uma amostra de sílica sintética policristalina

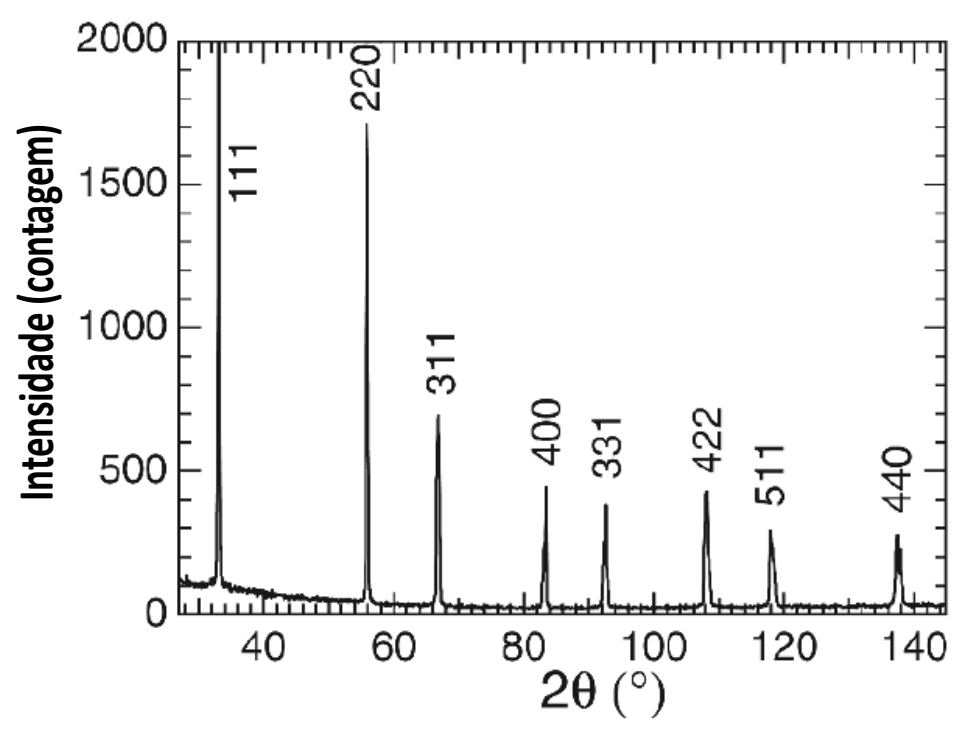

Fonte: extraída e modificada de Fultz e Howe (2007)

Atualmente, existem alguns softwares comerciais disponíveis que realizam a comparação entre os picos mais intensos, de cada possível fase cristalina analisada, com os picos das fases padrões, oriundas do banco de dados da ICDD. Desta forma, cada pico difratado possui um score/penalty, de acordo com a presença/ausência de um plano cristalino (posição dos picos) e a intensidade de uma fase mineral proposta pelo software (ANTONIASSI, 2010). O usuário pode então analisar cada fase proposta de acordo com seu score e aceita-la ou não.

\subsubsection{Mineralogia quantitativa automatizada}

Ferramentas de mineralogia quantitativa automatizada através da conjugação de técnicas de análise de imagens e microscopia eletrônica de varredura e microanálise por EDS evoluíram de forma muito significativa nos últimos vinte anos, possibilitando gerar dados estatísticos substancialmente mais robustos (FANDRICH et al., 2007; KAHN et al., 2002; PETRUK, 1989; SUTHERLAND; GOTTLIEB, 1991).

As imagens mais utilizadas são as de microscopia eletrônica de varredura ou óptica por luz refletida. Nas imagens provenientes de microscopia óptica, o parâmetro utilizado para a discriminação dos minerais é a sua cor - espectro de refletância. No caso do MEV são utilizadas imagens de elétrons retroespalhados (BSE) associadas com microanálises por EDS. Nas imagens de BSE, o tom de cinza de cada pixel é proporcional ao número atômico médio daquele ponto. Em alguns casos essa distinção é suficiente para a discriminação dos minerais presentes; nos casos em que 
minerais possuem número atômicos médios muito semelhantes (calcopirita e esfalerita, por exemplo) e os tons de cinza não são distinguíveis entre si a identificação é baseada, essencialmente, em análises qualitativas pontuais ou em áreas por EDS (FANDRICH et al., op.cit; NEUMANN et al., op. cit.).

Após a identificação dos minerais, o sistema atribui valores numéricos para distintas propriedades das imagens, tais como comprimento, largura, área, perímetro, arredondamento e esfericidade, fornecendo informações como proporção mineralógica, distribuição granulométrica, distribuição de elementos de interesse, forma dos grãos, além de associações entre distintas fases: associações minerais e grau de liberação mineral, dentre outras (FANDRICH et al., op.cit; NEUMANN et al., op. cit.).

Atualmente, há uma série de sistemas de análise de imagens automatizadas comerciais para operação em MEV, dentro os quais se podem destacar: QEMSCAN, MLA (Mineral Liberation Analyser) (ambos da marca FEI), TIMA (marca Tescan), INCAMineral (marca Oxford) e Mineralogic Mining \& Mineralogic Reservoir (marca Zeiss).

O sistema MLA, utilizado nesse estudo, consiste em um software que controla os detectores de espectrômetro de energia dispersiva (EDS) e o microscópio eletrônico de varredura (MEV), adquirindo imagens e espectros de EDS de raios $\mathrm{X}$ de forma automatizada. Tipicamente cerca de 40 a 100 imagens/frames (contendo 4.000 a 10.000 partículas) são adquiridas para cada seção polida/amostra. Posteriormente, um processamento off-line das imagens das partículas e respectivos dados de raios $\mathrm{X}$ geram mapas digitais dos minerais e são calculadas as proporções em massa, associações minerais e grau de liberação, dentre outros parâmetros (GU, 2003).

Quanto ao funcionamento do MLA, este combina a análise de imagens por elétrons retroespalhados (BSE) e espectros de raios $X$ característicos. $O$ uso de imagens por BSE para análise de grãos tem a vantagem de apresentar uma resolução substancialmente superior que a obtida por raios $\mathrm{X}$, cerca de algumas dezenas de nanômetros (a depender do equipamento e magnificação) versus alguns micrômetros, além de ser muito mais rápido (GU, op. cit.).

Fandrich et al. (2007) listou os vários modos de coleta do MLA, que são utilizados em diferentes tipos de matérias a depender do objetivo do estudo e das características das amostras. Os modos de medição mais comumente utilizados são descritos abaixo, sendo o modo XBSE o aplicado neste estudo: 
1. Standart BSE liberation analysis (BSE): é o modo de medição mais básico de análise de liberação do MLA, onde uma série de imagens são coletadas on-line e depois processadas off-line para produzir dados de liberação. Este modo de medição baseia-se unicamente nos diferentes tons de cinza da imagem de BSE.

2. Extended BSE liberation analysis (XBSE): neste modo de medição cada imagem de BSE é coletada e segmentada para delinear contornos de grãos minerais e, em seguida, cada grão mineral é analisado por raios $\mathrm{X}$.

3. Ford analysis or grain-based X-ray mapping (GXMAP): trata-se de um método de mapeamento seletivo. Emprega mapeamento de raios $X$ segundo uma grade de pontos para as fases que não podem ser segmentadas por diferentes tons de cinza da imagem de BSE. O operador seleciona os grãos onde haverá mapeamento por meio de um intervalo no histograma da imagem de BSE ou por um determinado espectro de raios $X$.

4. Sparse phase liberation analysis (SPL): este modo de medição busca as imagens de BSE com partículas contendo a fase de interesse, usando para isto a faixa da escala de tom de cinza da fase de interesse; em seguida executa uma análise XBSE sobre a partícula.

5. X-ray modal analysis (XMOD): este modo de medição só produz dados de mineralogia modal. Neste método, uma grade de pontos é definida pelo operador e para cada ponto da grade (sobre as partículas) é coletado um espectro de raios. O método XMOD também pode ser implementado para o modo linescan, que produz dados a partir do tradicional modo de medição por intercepto linear (espaçamento entre pontos da direção " $x$ " é de 1 pixel). Nesse método a imagem BSE é utilizada somente para diferenciar as partículas do background (resina).

\subsection{Geometalurgia}

A área interdisciplinar conhecida como geometalurgia conecta três áreas da indústria mineral: geologia, lavra e processamento mineral. Ela envolve o entendimento e mensuração das propriedades do minério relevantes para sua lavra e processamento. Segundo Lamberg (2001), a geometalurgia considera informações 
geológicas e metalúrgicas para criar um modelo de previsão tridimensional do depósito no processamento mineral. Coward et al. (2009) vai além e inclui como variáveis geometalúrgicas qualquer propriedade do material que influencie positiva ou negativamente no empreendimento mineiro.

\subsubsection{Modelo geometalúrgico}

Geólogos possuem tradição na criação de modelos tridimensionais do corpo de minério com as variações dos teores e a definição dos contatos litológicos. A ideia do modelo geometalúrgico é somar ao modelo geológico parâmetros quantitativos relevantes para o processamento mineral. Estas novas informações serão utilizadas para a otimização da produção (LUND; LAMBERG, 2014; BATTERHAM et al, 1992).

Uma rápida evolução nos modelos geometalúrgicos tem ocorrido nas últimas duas décadas. Uma das importantes contribuições para esta evolução está relacionada ao desenvolvimento de análises mineralógicas automatizadas (GOTTLIEB et al., 2000), que permitiu um estudo detalhado, rápido e estatisticamente robusto das características mineralógicas do material a ser explotado.

O conhecimento das características mineralógicas é fundamental no processamento mineral (NEUMANN et al., 2004; PETRUK, 2000; SANT'AGOSTINO; $\mathrm{KAHN}$,1997). Por isso, comumente a geometalurgia é confundida como uma caracterização tecnológica de minérios. Porém, estas áreas diferenciam-se no que se refere à espacialidade: geometalurgia necessariamente precisa possuir um estudo relacionado à distribuição tridimensional no depósito das variáveis que influenciaram na lavra e no processo, já a caracterização não se preocupa com essa questão.

Recentemente, houve uma tentativa de aumentar a abrangência do termo geometalurgia, considerando variáveis de natureza sustentável no modelo de blocos geometalúrgico, como a quantidade de emissão de $\mathrm{CO}_{2}$ e consumo de água (LUND; LAMBERG, 2014).

A implementação do modelo geometalúrgico deve ser o mais cedo possível, preferencialmente na etapa de avaliação de recursos e reservas de uma jazida. A caracterização tecnológica do minério deve ser realizada com ferramentas rápidas, de baixo custo e práticas e, acima de tudo, que possam ser aplicadas rotineiramente (LUND; LAMBERG, 2014). Porém, este é o grande desafio: encontrar técnicas e métodos que atendam esses requisitos. 
Alguns programas industriais geometalúrgicos vêm sendo aplicados atualmente. Seus passos podem ser divididos, de acordo com Dobby et al. (2004) e Lamberg (2011) e Lund e Lamberg (2014), como:

1) coleta de dados geológicos através da descrição de testemunhos de sondagem, medindo as propriedades mecânicas das rochas, seus parâmetros petrofísicos e análises químicas;

2) um programa de amostragem do minério para ensaios de processamento mineral, onde os dados geológicos são utilizados na identificação de possíveis tipos de minério;

3) ensaios em escala de laboratório para extrair parâmetros que serão utilizados no modelo do processamento mineral (comumente chamado de teste de variabilidade);

4) validação dos tipos de minério definidos pelos parâmetros geológicos da primeira etapa com base nos dados ensaios de processamento mineral. Assim, definindo os domínios geometalúrgicos/tipos de minério;

5) desenvolvimento de relações matemáticas na estimativa de importantes parâmetros metalúrgicos com os dados geológicos/químicos da primeira etapa;

6) desenvolvimento do modelo blocos geometalúrgicos, utilizando as variáveis que influenciam no processamento mineral, definidas na etapa três.

7) simulação da planta de processamento de cada domínio geometalúrgico;

8) calibração de todos os modelos com base nos dados de operações físicas existentes (planta piloto ou e/ou planta de beneficiamento industrial).

\subsubsection{Benefícios}

Uma vez estabelecido o modelo geometalúrgicos, este pode ser utilizado, de acordo com Coward et al. (2009) e Lund e Lamberg (2014), para o aprimoramento de:

- optimização do processamento mineral, porque é possível sintonizar o processo de acordo com as característica da amostra da alimentação;

- planejamento de lavra a médio e curto prazo com a seleção de blocos para possíveis blendagens; 
- planejamento da lavra e processo a longo prazo, portanto melhor alocação de capital e melhores condições de avaliar mudanças para novas tecnologias;

- redução de riscos, considerando os preços das commodities, pode adequar a produção, considerando diversos cenários econômicos; e portanto

- previsão de receitas e despesas a curto, médio e longo prazo.

\subsubsection{Amostragem e estimativa de variáveis geometalúrgicas}

Os problemas nos modelos geometalúrgicos estão normalmente relacionados com uma amostragem inadequada: informações erradas coletadas dos testemunhos de sondagem e número reduzido de amostras nos testes de variabilidade (problemas de representatividade estatística). Esta questão levanta um dilema: como selecionar amostras representativas de toda variabilidade do material no depósito, em termos de comportamento metalúrgico, se esse comportamento só pode será estudado após o término dos testes para qual essas amostras foram selecionadas (LUND; LAMBERG, 2014).

Segundo Lamberg (2011) há duas formas de seleção de amostras para uma abordagem geometalúrgica: a) com base em ensaios de processamento mineral; e b) com base na mineralogia. A abordagem com base em ensaios de processamento mineral considera testes em escala de laboratório que visam medir diretamente a recuperação metalúrgica do material. Alguns exemplos desses tipos de testes são GeM Comminution Index test, o JK Mineral Separability Indicator test e o teste em tubo Davis (LUND; LAMBERG, 2014; NIIRANEN; BÖHM, 2012; LAMBERG, 2011). Já a abordagem mineralógica, considera somente parâmetros minerais, como mineralogia modal, texturas minerais, associação mineral, tamanhos de grãos minerais e suas relações com a liberação, para construir o modelo geometalúrgico (nessa abordagem consideram-se os parâmetros mineralógicos quantitativos para se prever a resposta no processamento mineral).

Outro problema relacionado ao modelo de blocos geometalúrgico é a estimativa dos valores das variáveis geometalúrgicas em blocos não amostrados. Dunham e Vann (2007), demonstraram que a aplicação de modelos clássicos de estimava linear média (como krigagem) não apresenta bons resultados. Muitas dessas variáveis são 
claramente não aditivas (por exemplo, a alteração de algum mineral) e, portanto, seus modelamentos precisam ser baseados em variáveis aditivas (COWARD et al., 2009).

\subsection{Análise estatística multivariada (AEM)}

A análise multivariada é um ramo da estatística que trata da analises de múltiplas medidas de variáveis de um ou mais indivíduos (COOLEY; LOHNES, 1971). A seguir, serão detalhadas a análise por agrupamento (cluster analysis) e a análise de componentes principais (PCA), ambas utilizadas neste estudo.

\subsubsection{Análise por agrupamento (cluster analysis)}

A técnica de análise por agrupamento (cluster analysis) é um recurso estatístico que facilita a análise de grande quantidade de dados, visando à classificação em grupos por semelhança e dissimilaridades (MOITA NETO; MOITA, 1998). O objetivo desta análise é: dado um número $\boldsymbol{n}$ de amostras, descritas por um conjunto de variáveis $\boldsymbol{p}$, é necessário um esquema de agrupamento, onde todos os indivíduos pertencentes a este grupo sejam similares entre si (MANLY, 1994).

Muitos algoritmos são utilizados na análise por agrupamento, aqui a atenção será dada paras os métodos de agrupamento hierárquicos.

Os métodos hierárquicos começam com o cálculo da matriz de distâncias entre as amostras. A medida das distâncias consiste em considerar os valores de um conjunto de variáveis $\boldsymbol{p}\left(\boldsymbol{X}_{1}, \boldsymbol{X}_{2}, \ldots, \boldsymbol{X}_{p}\right)$ para $\boldsymbol{n}$ amostras e compará-las entre si, transformando cada valor atribuído a variável como uma posição (ponto) no espaço. O número de dimensões do espaço é igual ao número de variáveis $\boldsymbol{p}$ analisadas. $A$ Tabela 1 e a Figura 9 ilustram o descrito acima para três variáveis.

A distância Euclidiana (equação 2) é uma das formas mais simples para cálculo de distância entre pontos no espaço. Existem diversas outras maneiras de efetuar este cálculo que podem ser consultadas nos trabalhos de Cooley e Lohnes (1971), Manly (1994) e Everitt et al., (2010).

Tabela 1 - Pontos utilizados na construção do gráfico Figura 9

\begin{tabular}{c|ccc}
\hline $\begin{array}{c}\text { Amostra } \\
(\mathbf{n = 2})\end{array}$ & $\mathbf{X}_{\mathbf{1}}$ & $\begin{array}{c}\text { Variáveis }(\mathbf{p = 3}) \\
\mathbf{X}_{\mathbf{2}}\end{array}$ & $\mathbf{X}_{\mathbf{3}}$ \\
\hline $1(\mathrm{i}=1)$ & $\mathrm{x}_{\mathrm{i} 1}$ & $\mathrm{x}_{\mathrm{i} 2}$ & $\mathrm{x}_{\mathrm{i}}$ \\
$2(\mathrm{j}=2)$ & $\mathrm{x}_{\mathrm{j} 1}$ & $\mathrm{x}_{\mathrm{j} 2}$ & $\mathrm{x}_{\mathrm{j}}$ \\
\hline
\end{tabular}


Figura 9 - Distância Euclidiana entre objetos i e j, $\operatorname{com} p=3$ variáveis

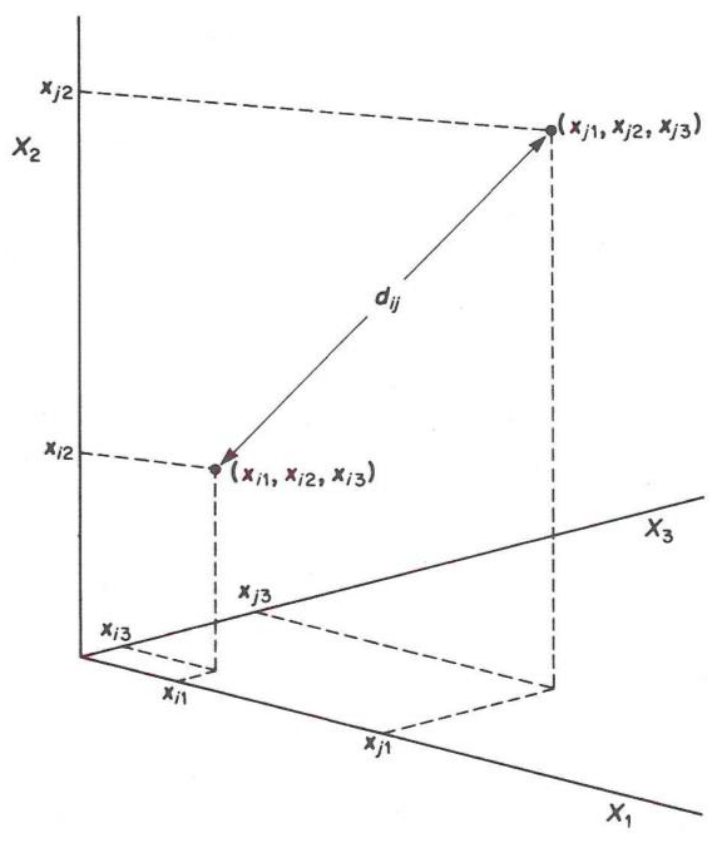

Fonte: Manly (1994)

$$
d i j=\sqrt{\sum_{k=1}^{p}\left(x_{i k}-x_{j k}\right)^{2}} \text { (eq. 2) }
$$

Uma vez definida a matriz de distância, inicia-se o processo de agrupamento. Primeiramente, todas amostras são consideradas como um grupo composto de apenas um indivíduo; grupos considerados "próximos" são então aglomerados, formando um novo grupo. Existem várias formas de definir "próximos" (métodos de agrupamento), as três mais comuns são: vizinho mais próximos (nearest neighbours), vizinho mais distante (furthest neighbour) e média dos grupos (group average) (MANLY, 1994).

A Tabela 2 traz um exemplo de uma matriz de distâncias para cinco amostras, extraída de Manly (op. cit.).

Tabela 2 - Exemplo de matriz de distâncias para cinco amostras

\begin{tabular}{c|ccccc} 
& $\mathbf{1}$ & $\mathbf{2}$ & $\mathbf{3}$ & $\mathbf{4}$ & $\mathbf{5}$ \\
\hline $\mathbf{1}$ & - & & & & \\
$\mathbf{2}$ & 2 & - & & & \\
$\mathbf{3}$ & 6 & 5 & - & & \\
$\mathbf{4}$ & 10 & 9 & 4 & - & \\
$\mathbf{5}$ & 9 & 8 & 5 & 3 & - \\
\hline
\end{tabular}


Se considerado o método de agrupamento pelo vizinho mais próximo (nearest neighbours), os grupos surgirão assim que o valor mais próximo da distância entre qualquer indivíduo pertencente a outro grupo for atingido. No caso dos dados apresentados na Tabela 2, inicialmente tem-se cinco grupos com apenas um indivíduo cada. Assim que atingirmos o valor de distância dois, pode-se considerar as amostras 1 e 2 como pertencentes ao mesmo grupo (1,2); ao atingir o valor de distância três, um novo grupo se formará com as amostras 5 e 4, e assim sucessivamente, como demonstra a Tabela 3.

Tabela 3 - Exemplo de agrupamento pelo método do vizinho mais próximo, destacando em negrito a formação de novos grupos

\begin{tabular}{cc}
\hline Distância & Grupos \\
\hline 0 & $1,2,3,4,5$ \\
2 & $(\mathbf{1}, \mathbf{2}), 3,4,5$ \\
3 & $(\mathbf{1}, \mathbf{2}), 3,(\mathbf{4}, \mathbf{5 )}$ \\
4 & $(\mathbf{1}, \mathbf{2}),(\mathbf{3}, \mathbf{4}, \mathbf{5})$ \\
5 & $(\mathbf{1}, \mathbf{2}, \mathbf{3}, \mathbf{4}, \mathbf{5})$ \\
\hline
\end{tabular}

Fonte: traduzido de Manly (1994)

Analisando os mesmos dados pelo método de agrupamento vizinho mais distante, a ordem de formação dos grupos continuará a mesma, porém em diferentes distâncias - Tabela 7.

Tabela 4 - Exemplo de agrupamento pelo método do vizinho mais distante, destacando em negrito a formação de novos grupos

\begin{tabular}{cc}
\hline Distância & Grupos \\
\hline 0 & $1,2,3,4,5$ \\
2 & $(\mathbf{1}, \mathbf{2}), 3,4,5$ \\
3 & $(\mathbf{1}, \mathbf{2}), 3,(\mathbf{4}, \mathbf{5})$ \\
5 & $(\mathbf{1}, \mathbf{2}),(\mathbf{3}, \mathbf{4}, \mathbf{5})$ \\
10 & $(\mathbf{1}, \mathbf{2}, \mathbf{3}, \mathbf{4}, \mathbf{5})$ \\
\hline
\end{tabular}

Fonte: traduzido de Manly (1994)

A amostra 3 só se agrupará com as amostras 4 e 5, quando o valor de distância de cinco é atingido. Este é o valor mais distante (furthest neighbour) comparando as distâncias entre a amostra 3-4 e 3-5 apresentados na matriz da Tabela 2. 
Utilizando do método de agrupamento pela média dos grupos, os novos grupos se formarão nas distâncias apresentadas pela Tabela 10.

Tabela 5 - Exemplo de agrupamento pelo método da média dos grupos, destacando em negrito a formação de novos grupos

\begin{tabular}{cc}
\hline Distância & Grupos \\
\hline 0 & $1,2,3,4,5$ \\
2 & $(\mathbf{1}, \mathbf{2}), 3,4,5$ \\
3 & $(\mathbf{1}, \mathbf{2}), 3,(\mathbf{4}, \mathbf{5})$ \\
4,5 & $(\mathbf{1}, \mathbf{2}),(\mathbf{3}, \mathbf{4}, \mathbf{5})$ \\
7,8 & $(\mathbf{1}, \mathbf{2}, \mathbf{3}, \mathbf{4}, \mathbf{5})$
\end{tabular}

Fonte: traduzido de Manly (1994)

Neste método, os grupos serão formados se a média das distâncias entre os elementos que compõem os dois grupos (group average) for atingida. Por exemplo, os grupos $(1,2)$ e $(3,4,5)$ se unem a distância de 7,8 , pois a média das distâncias entre as amostras 1 e 2 comparadas com 3, 4 e 5 é igual à 7,8.,

Os métodos de agrupamento hierárquicos são apresentados graficamente através do dendrograma. Neste tipo de gráfico, plota-se as amostras em função dos valores de distâncias, indicando pela união de linhas, quando as amostras compõem um novo grupo a partir daquela distância. Os exemplos apresentados na Tabela 3, Tabela 4 e na Tabela 5 são ilustrados pelos respectivos dendrograma da Figura 10.

Figura 10 - Exemplos de dendrograma baseados nos dados da Tabela 3, Tabela 4 e Tabela 5 pelos métodos de aglomeração a) vizinho mais próximo, b) vizinho mais distante e c) média dos grupos, respectivamente

(a)

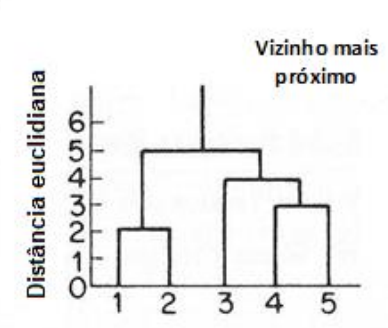

(b)

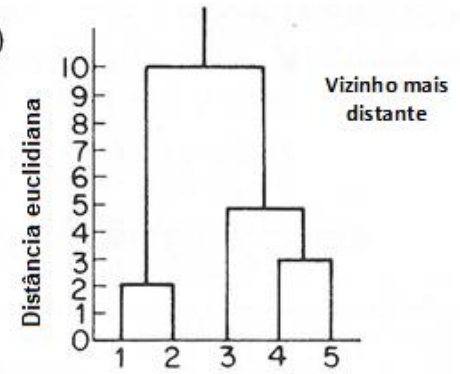

(c)

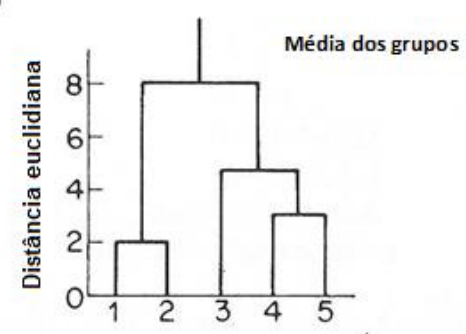

Fonte: traduzido e modificado de Manly (1994)

A leitura do dendrograma permite reconhecer quais amostras possuem maiores semelhanças entre si e quais são mais distintas. As amostras mais próximas terão suas correspondentes linhas unificadas a uma menor distância, ocorrendo o inverso para as amostras mais distintas. No exemplo dos dendrogramas da Figura 10, a 
amostra 1 e 2 são as mais similares entre si quando comparadas com as demais amostras. Já a amostras 3 é mais similar se comparada as amostras 4 e 5 em relação as amostras 1 e 2.

É importante ressaltar que existem diversos algoritmos utilizados na análise por agrupamento, entretanto não há um consenso sobre qual seria o melhor entre as opções disponíveis. Diferentes algoritmos não necessariamente geram resultados idênticos para um mesmo grupo de amostras e, portanto, existe um forte componente subjetivo na sua escolha (MANLY, 1994).

\subsubsection{Análise de componentes principais (PCA)}

A técnica de análise de componentes principais (PCA) foi descrita inicialmente por Karl Pearson (1901). O objetivo desta análise é considerar um conjunto de variáveis $\boldsymbol{p}\left(\boldsymbol{X}_{1}, \boldsymbol{X}_{2}, \ldots, \boldsymbol{X}_{p}\right)$ correlacionáveis e encontrar combinações, entre estas variáveis, que produzam novos índices $\mathbf{Z}_{1}, \mathbf{Z}_{2}, \ldots, \boldsymbol{Z}_{p}$ linearmente descorrelacionáveis, denominados de componentes principais (COOLEY; LOHNES, 1971, MANLY, 1994).

Em termos práticos, a PCA permite que se explique a variância do conjunto de variáveis $\boldsymbol{p}$, por um número reduzido de índices $\boldsymbol{Z}$. Por exemplo, um conjunto de 20 ou 30 variáveis originais podem ter suas variâncias representadas por dois ou três componentes principais (MANLY, 1994).

A descrição dos procedimentos para o cálculo dos PC's foi baseada no trabalho de Manly (1994) e será apresentada de maneira matematicamente simplificada, sem demonstrações e derivações. Maiores detalhes podem ser encontrados no trabalho de Cooley e Lohnes (1971).

O PCA começa pela transformação dos dados das variáveis $\boldsymbol{X}_{1}, \boldsymbol{X}_{2}, \ldots, \boldsymbol{X}_{p}$, de forma que suas médias sejam zero e variâncias unitárias. Posteriormente calcula-se a matriz de covariância $\boldsymbol{C}$ entre os conjuntos de variáveis $\boldsymbol{p}$ - equação 3 , Figura 11 .

$$
\mathrm{c}_{\mathrm{jk}}=\sum_{i=1}^{n}\left(x_{i j}-\bar{x}_{j}\right) *\left(x_{i k}-\bar{x}_{k}\right) /(n-1)(\text { eq. } 3)
$$

Figura 11 - Matriz de covariância C

$$
\boldsymbol{C}=\left(\begin{array}{ccc}
c_{11} & \cdots & c_{1 p} \\
\vdots & \ddots & \vdots \\
c_{p 1} & \cdots & c_{p p}
\end{array}\right)
$$


Após o cálculo da matriz $\boldsymbol{C}$, encontra-se uma combinação linear do conjunto de variáveis $\boldsymbol{p}$, descritas por índices adotados $\boldsymbol{Z}_{i}$ (equação 4).

$$
\begin{aligned}
& Z_{1}=a_{11} X_{1}+a_{12} X_{2}+\cdots+a_{1 p} X_{p} \\
& Z_{2}=a_{21} X_{1}+a_{22} X_{2}+\cdots+a_{2 p} X_{p} \\
& \text { ） } \quad \vdots \quad \vdots \quad \\
& Z_{p}=a_{p 1} X_{1}+a_{p 2} X_{2}+\cdots+a_{p p} X_{p}
\end{aligned}
$$

Para que a variância de $\boldsymbol{Z}_{i}, \operatorname{var}\left(\boldsymbol{Z}_{i}\right)$, seja máxima é preciso que a soma dos quadrados das constantes $\boldsymbol{a}_{i p}$ seja igual a 1 (equação 5).

$$
\begin{aligned}
& a_{11}^{2}+a_{12}^{2}+\cdots+a_{1 p}^{2}=1 \\
& a_{11}^{2}+a_{12}^{2}+\cdots+a_{1 p}^{2}=1 \\
& \vdots \quad \vdots \quad \vdots \quad \vdots \\
& a_{i 1}^{2}+a_{i 2}^{2}+\cdots+a_{i p}^{2}=1
\end{aligned}
$$

Uma importante propriedade da PCA é que a soma das variâncias dos índices $\boldsymbol{Z}_{i}$ é igual à soma dos autovalores (eigenvalues, $\lambda$ ) da matriz de covariância $\boldsymbol{C}$ (equação 6).

$$
\left.\lambda_{1}+\lambda_{2}+\cdots+\lambda_{p}=c_{11}+c_{22}+\cdots+c_{p p} \text { (eq. } 6\right)
$$

Assim, haverá $\boldsymbol{p}$ valores de $\lambda$, que, se ordenados em ordem crescente $\lambda_{1} \geq \lambda_{2} \geq$ $\ldots \geq \lambda_{p} \geq 0$, correspondem ao principal componente $1\left(P C_{1}\right), P C_{2}, P C_{3} \ldots P C_{p}$ (equação 4). Para cada valor de $\lambda_{p}$, existe um autovetor (Eigenvector $-v$ ) correspondente, onde $\boldsymbol{v}_{i}=\boldsymbol{a}_{i p}$ (constantes da equação 5). Portanto, é preciso calcular os autovalores e autovetores da matriz $\boldsymbol{C}$. 
Qualquer matriz pode ser escrita na forma de um sistema de equações. A matriz de correlação $\boldsymbol{C}$ pode então ser escrita como mostra as equações 7 .

$$
\begin{array}{cc}
c_{11} v_{1}+c_{12} v_{2}+\cdots+c_{1 p} v_{p}= & \lambda v_{1} \\
c_{21} v_{1}+c_{22} v_{2}+\cdots+c_{2 p} v_{p}= & \lambda v_{2} \\
\vdots \quad \vdots \quad \vdots & \vdots \\
c_{p 1} v_{1}+c_{p 2} v_{2}+\cdots+c_{p p} v_{p}= & \lambda v_{p}
\end{array}
$$

Estas equações podem ser reescritas na forma matricial - equação 8.

$$
C v=\lambda v(\text { eq. } 8)
$$

Ou, igualando a equação 8 a zero (equação 9).

$$
(C-\lambda I) v=0 \text { (eq. 9) }
$$

Onde, I é uma matriz $p_{x} p$ identidade, 0 é $p_{x} 1$ vetor zero, $\lambda$ é o autovalor de $C$, e $v$ o autovetor de $\boldsymbol{C}$. A equação 9 possui raízes para valores particulares de autovalores $(\lambda)$ da matriz $\boldsymbol{C}$. Para cada autovalor $\lambda_{i}$, haverá um respectivo autovetor $(v)$ composto pelos valores dos $\boldsymbol{v}_{i}$, onde a igualdade da equação 8 é garantida.

Em resumo, $\boldsymbol{c}_{i i}$ é a variância de $\boldsymbol{X}_{i}$ e $\boldsymbol{\lambda}_{i}$ é a variância de $Z_{i}$, isto significa que a soma das variâncias dos componentes principais é a soma das variâncias das variáveis originais. Portanto, alguns principais componentes $\left(P C^{\prime} s\right)$ podem descrevem quase toda a variância dos dados originais (MANLY, 1994).

Os PC's podem ser então calculados para cada amostra e, com os valores do principal componente 1, 2 e 3 , se plota um gráfico tridimensional para visualização dos dados - Figura 12. 
Figura 12 - Exemplo de gráfico 3D com amostras agrupadas segundo as cores

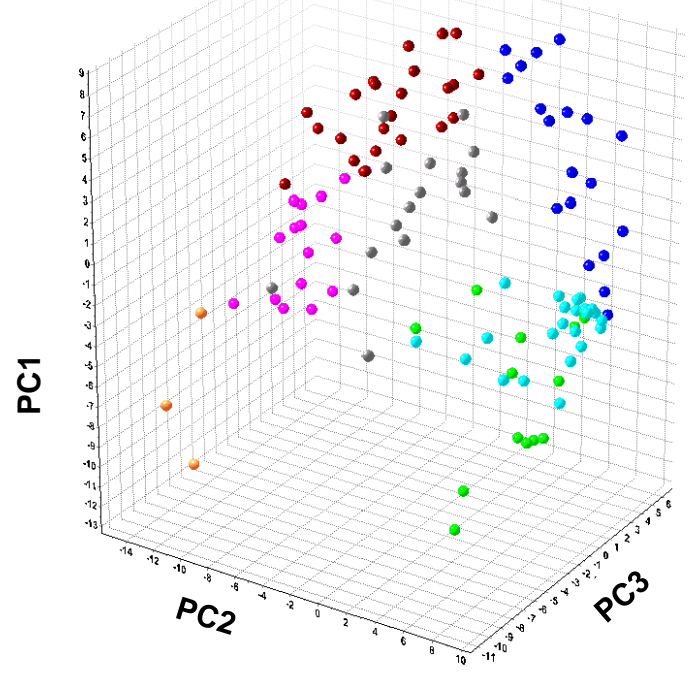

Fonte: próprio autor

\subsubsection{Software X'Pert Highscore Plus na análise por agrupamento e PCA}

O software comercial X'Pert Highscore Plus foi utilizado no presente estudo. Neste subitem serão apresentados os métodos utilizados neste software, para a análise por agrupamento e PCA. As informações são baseadas no manual do programa (PANALYTICAL, 2008).

No caso do referido software, pode-se separar os dados de um difratograma entre a) dados do perfil ou leitura (profile/scan data) e b) dados dos picos (peak data).

Tanto a análise por agrupamento, quanto o PCA, utilizam-se da comparação entre difratogramas. Todos os tipos de dados de um difratograma (dados de pico, dados de perfil ou ambos) são reduzidos em uma curva de distribuição normal $\boldsymbol{u}_{\boldsymbol{i}}(\boldsymbol{x})$. Esta abordagem é diferente de outros softwares comercias análogos, que comparam os dados diretamente após algumas normalizações.

A curva de distribuição normal ou curva de Gauss-Moivre-Laplace é um modelo matemático que descreve vários fenômenos (BITTENCOURT; VIALI, 2006) equação10, onde, $\boldsymbol{\mu}$ é a média da amostra e $\boldsymbol{\sigma}$ o seu desvio padrão

$$
f(x, \mu, \sigma)=\frac{1}{\sigma \sqrt{2 \pi}} \exp \left\{-\frac{1}{2}\left(\frac{x-\mu}{\sigma}\right)^{2}\right\}, \text { para } x \in \mathbb{R} ; \mu \in \mathbb{R} ; \sigma>0 \text { (eq. 10) }
$$


Após esta conversão, as curvas de probabilidade (Gaussianas) $\boldsymbol{u}_{\boldsymbol{i}}(\boldsymbol{x})$ são comparadas através de uma figura de mérito (figure of merit - FOM). No caso do software X'Pert Highscore Plus, a equação 11 é aplicada.

$$
\operatorname{FOM}_{(i, j)}=\frac{\sum 1-\left[u_{i}^{2}(x)+u_{j}^{2}(x)-2 * u_{i}^{2}(x) * u_{j}^{2}(x)\right]}{n}
$$

Se as amostras são semelhantes, o valor da FOM será próximo à 1 (ou 100\%). Quando um difratograma é comparado com ele mesmo o resultado da FOM não é igual a 1, devido a imprecisões computacionais dos cálculos.

\section{Análise por agrupamento}

O software X'Pert Highscore Plus utiliza-se de vários algoritmos para realizar a análise por agrupamento. Inicialmente todas as amostras são comparadas entre si, como descrito acima. Após o cálculo das FOM (equação 13), uma matriz de correlação p é apresentada. Esta matriz sumariza os resultados da comparação individual de um par de difratogramas. Sua diagonal representa a comparação das amostras com elas mesmas e somente metade de seus dados são relevantes, uma vez que a amostra $A$ comparada com a B possui o mesmo resultado da amostra B comparada com a A ( $\boldsymbol{p}$ é uma matriz simétrica).

Para realizar a análise por agrupamento, a matriz $\boldsymbol{p}$ é convertida em uma matriz de distâncias euclidianas $\boldsymbol{d}$, através da equação 2 , com a mesma dimensão: $\boldsymbol{d}=(1-\boldsymbol{p})$. Após esta transformação, o método de agrupamento hierárquico é aplicado. O software permite a escolha do método de agrupamento. Então os resultados são apresentados na forma de um dendrograma. Os principais parâmetros que determinam os critérios de agrupamento são:

- medida da distância: cálculo da distância euclidiana entre as amostras (equação 2);

- método de agrupamento: tipo de algoritmo utilizado para agrupamento das amostras, por exemplo o método dos vizinhos mais próximos.

\section{Análise dos componentes principais}

A análise dos componentes principais é realizada separadamente e independentemente da análise por agrupamento, como um método de visualização e 
julgamento da qualidade do agrupamento. Esta análise depende principalmente dos parâmetros de comparação:

- fonte de dados: dados do perfil (profile/scan data), e dados dos picos (peak data);

- escolha da figura de mérito - FOM;

- $\quad$ limiar (threshold): intensidade relativa da curva de probabilidade $\boldsymbol{u}_{\boldsymbol{i}}(\boldsymbol{x})$, onde apenas valores acima deste limiar serão considerados na comparação das amostras. Valores baixos de limiar (threshold) considerarão picos menos proeminentes do difratograma (próximos ao valor de background) na comparação, sendo o oposto para valores altos. 


\section{DEFINIÇÃO DOS DOMÍNIOS MINERALÓGICOS $\left(1^{\mathrm{a}}\right.$ ETAPA)}

\subsection{Procedimento experimental - $1^{\text {a }}$ etapa $\left(E_{1}\right)$}

\subsubsection{Amostras estudas na $E_{1}$}

Foram amostrados testemunhos de sondagens de campanha de pesquisa geológica disponíveis em arquivos da Mirabela Mineração Ltda. (empresa que atualmente explota o depósito).

Os furos contidos em cada uma das seções foram visualizados tridimensionalmente no software Surpac 6.2, concomitantemente com as superfícies da cava de 2013 e da cava planejada para 2017, além do sólido de mineralização em sulfetos, conforme ilustrado na Figura 13.

Figura 13 - llustração esquemática da definição das seções e seleção de furos para amostragem

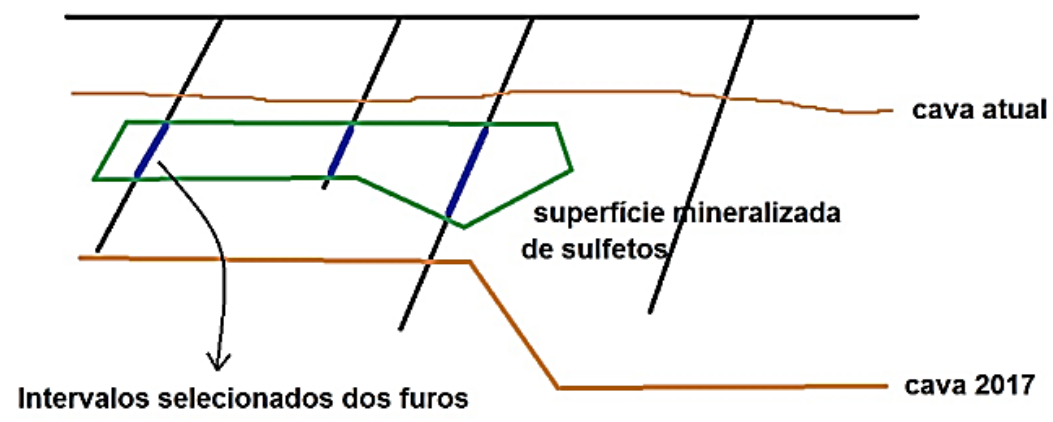

Foram definidas dezessete seções E-W, espaçadas em cerca de $100 \mathrm{~m}$, visando abranger uma ampla distribuição espacial ao longo do depósito, considerando a posição georeferenciada de furos de sondagens disponíveis na superfície do plano de aproveitamento de médio prazo (1 a 5 anos - 2013/2017) da mina de Santa Rita.

A Tabela 6 mostra a relação dos furos amostrados por seção, bem como número de amostras coletadas em cada furo. Uma análise das distribuições dos furos permite observar que a porção sul do depósito está mais bem representada em relação à porção central e norte.

Os litotipos geológicos coletados foram classificados macroscopicamente pelos geólogos na descrição dos testemunhos de sondagem entre harzburgito, dunito, ortopiroxenito, olivina piroxenito, veios e outros (websterita, diques e gabro). O número de amostras coletadas por cada litotipo está exposto na Figura 14. 
Tabela 6 - Relação dos furos de sondagens e das amostras coletadas

\begin{tabular}{|c|c|c|c|c|}
\hline $\begin{array}{l}\text { Porção do } \\
\text { depósito }\end{array}$ & Seção & Furos & $\begin{array}{c}\text { № de amostras coletadas } \\
\text { compostas }(5 \mathrm{em} 5 \mathrm{~m})\end{array}$ & Intervalo amostrado (m) \\
\hline Norte & $\begin{array}{l}1 \\
2 \\
2 \\
2 \\
3 \\
4 \\
\end{array}$ & $\begin{array}{c}\text { MBS-249 (RE) } \\
\text { MBS-278 } \\
\text { MBS-288 (RE) } \\
\text { MBS-318 } \\
\text { MBS-464 (RE) } \\
\text { MBS-501 (RE) }\end{array}$ & \begin{tabular}{|c|}
6 \\
11 \\
6 \\
6 \\
9 \\
6 \\
\end{tabular} & $\begin{array}{l}30 \\
55 \\
30 \\
30 \\
45 \\
30\end{array}$ \\
\hline Central & $\begin{array}{l}5 \\
6 \\
6 \\
7 \\
8 \\
9 \\
9\end{array}$ & $\begin{array}{c}\text { MBS-165 (RE) } \\
\text { MBS-133 } \\
\text { MBS-134 } \\
\text { MBS-155 (RE) } \\
\text { MBS-542 (RE) } \\
\text { MBS-140 } \\
\text { MBS-141 }\end{array}$ & $\begin{array}{c}11 \\
9 \\
14 \\
2 \\
17 \\
7 \\
15\end{array}$ & $\begin{array}{l}54 \\
43 \\
68 \\
11 \\
77 \\
35 \\
78\end{array}$ \\
\hline Sul & $\begin{array}{l}10 \\
10 \\
10 \\
11 \\
11 \\
11 \\
12 \\
12 \\
12 \\
13 \\
13 \\
14 \\
14 \\
14 \\
15 \\
\end{array}$ & $\begin{array}{c}\text { MBS-123 } \\
\text { MBS-196 } \\
\text { MBS-275 (RE) } \\
\text { MBS-280 } \\
\text { MBS-587 (RE) } \\
\text { MBS-593 } \\
\text { MBS-188 } \\
\text { MBS-345 (RE) } \\
\text { MBS-415 } \\
\text { MBS-146 } \\
\text { MBS-147 } \\
\text { MBS-149 } \\
\text { MBS-150 } \\
\text { MBS-199 (RE) } \\
\text { MBS-204 }\end{array}$ & $\begin{array}{c}8 \\
14 \\
12 \\
10 \\
6 \\
8 \\
3 \\
2 \\
10 \\
14 \\
7 \\
7 \\
17 \\
11 \\
16 \\
\end{array}$ & $\begin{array}{l}43 \\
70 \\
59 \\
35 \\
30 \\
42 \\
16 \\
11 \\
46 \\
60 \\
37 \\
35 \\
87 \\
55 \\
85 \\
\end{array}$ \\
\hline & TOTAL & 28 & 264 & 1297 \\
\hline
\end{tabular}

Figura 14 - Classificação geológica dos litotipos amostrados (total de 264 amostras)

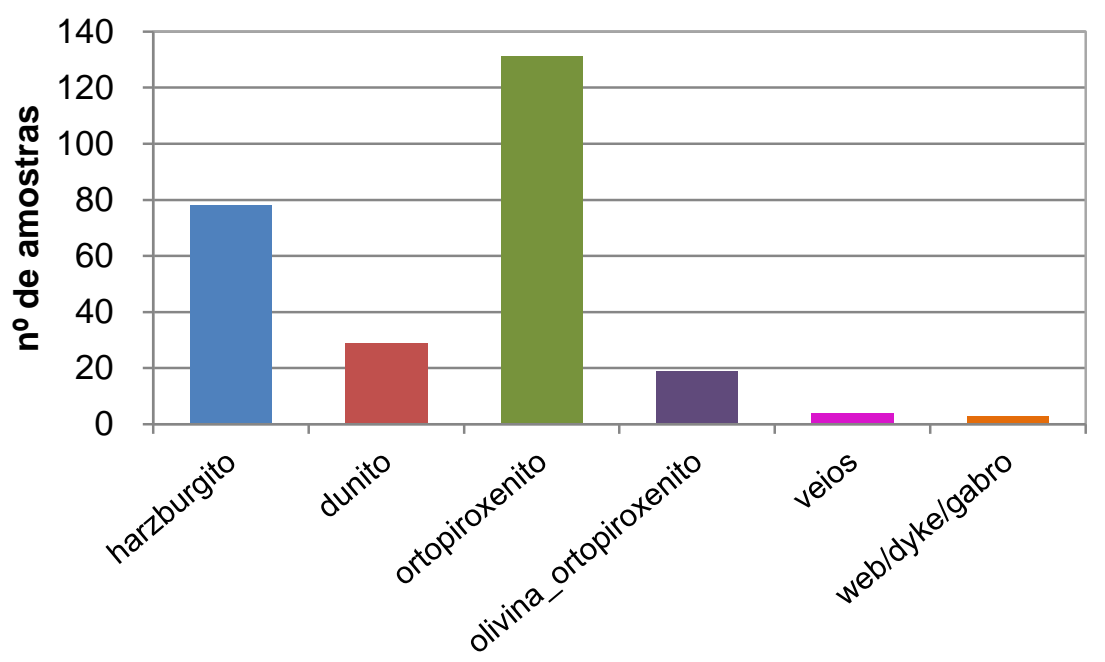

Litotipos amostrados - descrição geológica

A amostragem foi efetuada em intervalos específicos, selecionando-se 2 ou 3 furos por seção, respeitando os contatos litológicos e visando englobar todas as 
litologias presentes no depósito; todos os furos selecionados continham intervalos mineralizados de sulfetos entre os limites da cava.

Pesquisas geológicas de exploração realizadas anteriormente no depósito, amostraram os furos de sondagem, metro a metro, para a realização de análises químicas. Os arquivos dessas amostras, na forma de "polpa" já cominuída (abaixo de $150 \mu \mathrm{m})$, correspondente a cada intervalo, estavam armazenados na litoteca da mina e foram disponibilizados para este estudo.

Desta forma, foi efetuado um planejamento de composição de amostras de testemunhos de sondagens considerando intervalos de 5 em 5 metros, respeitandose eventuais variações litológicas (adequação do intervalo amostrado). Ou seja, os intervalos dos testemunhos, amostrados inicialmente metro a metro, foram compostos gerando uma única amostra a cada intervalo de 5 metros de sondagem, exceto onde verificou-se variações litológicas do minério, onde o intervalo amostral foi reduzido ou aumentado em no máximo 2 metros. Optou-se por essa composição, levando-se em consideração que a mina é explotada em bancadas de 5 em 5 metros.

Após a composição destes intervalos, cada amostra resultante foi devidamente homogeneizada. A Figura 15 ilustra o procedimento inicial adotado para a amostragem dos furos de sondagem da mina de Santa Rita.

A opção por se realizar o estudo com amostras de furos de sondagens levou em consideração os seguintes aspectos:

- ampla distribuição de furos de sondagem no deposito;

- dificuldades de coleta de grande número de amostras nas frentes de lavra;

- análise por DRX + estatística multivariada baseada essencialmente nas proporções de minerais de ganga (o conteúdo dos minerais de interesse sulfetos - situa-se próximo ou abaixo do limite de detecção da técnica de difração de raios $\mathrm{X}$ ). 
Figura 15 - Procedimento de amostragem inicial dos furos de sondagem da mina Santa Rita, utilizados na $\mathrm{E}_{1}$

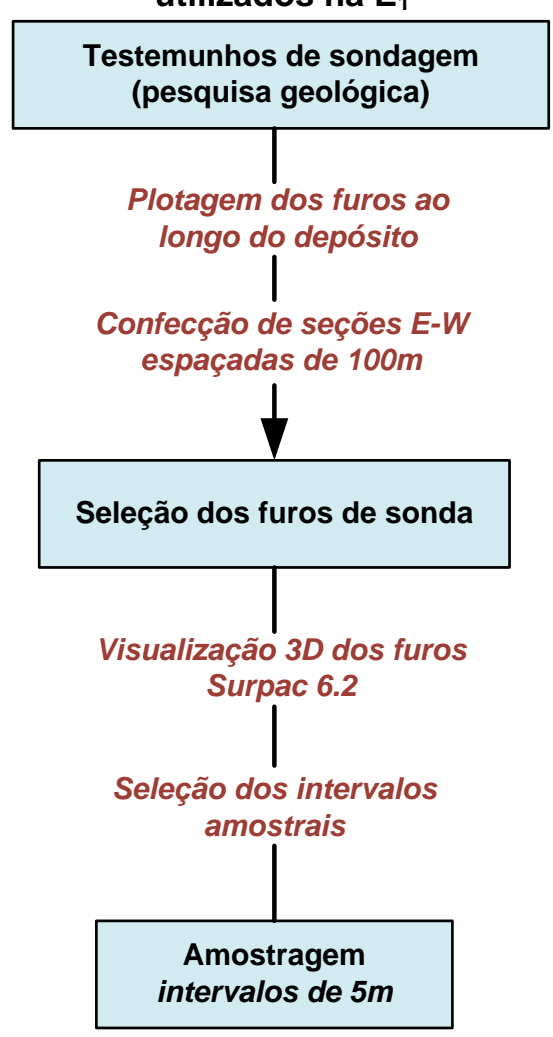

\subsubsection{Procedimentos da análise por $D R X+A E M$ da $1^{a}$ Etapa}

Todas as 264 amostras compostas foram submetidas ao seguinte procedimento e analisadas no LCT - Laboratório de Caracterização Tecnológica da EPUSP:

- homogeneização e retirada de alíquotas representativas de aproximadamente $15 \mathrm{~g}$ para a realização da coleta de difratograma de raios $\mathrm{X}$;

- pulverização das alíquotas em moinho planetário, em condições controladas, seguida de montagem de amostras em suportes adequados para análises por difração de raios $\mathrm{X}$;

- obtenção dos difratogramas de raios $X$ das amostras utilizando difratômetro X'Pert Pro, marca PANalytical com tubo de Cu e detector sensível à posição (PSD - X'Celerator). As condições de coleta adotadas foram: tubo de $\mathrm{Cu}, 45$ kV e $40 \mathrm{~mA}$, monocromador no feixe difratado; fenda automática e máscara 
de $10 \mathrm{~mm}$; faixa de ângulo de coleta de 2,5 a 70, passo de 0,02ㅜ; tempo de $50 \mathrm{~s}$ por passo, totalizando 26 minutos por difratograma.

- análise por agrupamento dos difratogramas através do software X'Pert Highscore Plus considerando posição e intensidade dos picos difratados (conteúdo dos minerais presentes sem a necessidade de identificação de fases); os principais parâmetros empregados são apresentados na Tabela 7. Estes resultados são apresentados graficamente na forma de dendrograma e gráfico da análise de componente principal (PCA).

Tabela 7 - Principais parâmetros da análise por agrupamento (software High Score) para as amostras da $1^{\mathrm{a}}$ etapa

\begin{tabular}{|ll|}
\hline Tratamento & Remoção do background \\
Fonte de dados & Perfil + Picos \\
Figura de mérito & Pos. + Int. dos picos \\
Threshold (Limiar) & $30 \%$ \\
Condições do Agrupamento & \\
$\quad \begin{array}{l}\text { Medida de distância } \\
\text { Método de agrupamento }\end{array}$ & Euclidiana \\
Cut-off para definição de clusters & 119,0 \\
\hline
\end{tabular}

- obtenção do difratograma médio de cada grupo, seguida de interpretação por comparação com o banco de dados PAN-ICSD - PANalytical Inorganic Crystal Structure Database (2007) e análise mineralógica semiquantitativa feita pelo método de RIR - Ratio Intensity Reference utilizando estruturas cristalinas do banco de dados ICSD - Inorganic Crystal Structures Database de 2007. 


\subsection{Resultados e discussões - $1^{\mathrm{a}}$ etapa $\left(E_{1}\right)$}

Com as condições de análise empregadas foram definidos 14 grupos distintos de amostras conforme ilustrado no dendrograma da Figura 16. A seta verde, na Figura 16, indica o valor de cut-off, onde cada cruzamento entre a linha de cut-off (azul tracejada) com as linhas do dendrograma (em vermelho) representa um grupo.

Figura 16 - Dendrograma indicando o agrupamento das amostras em 14 grupos distintos

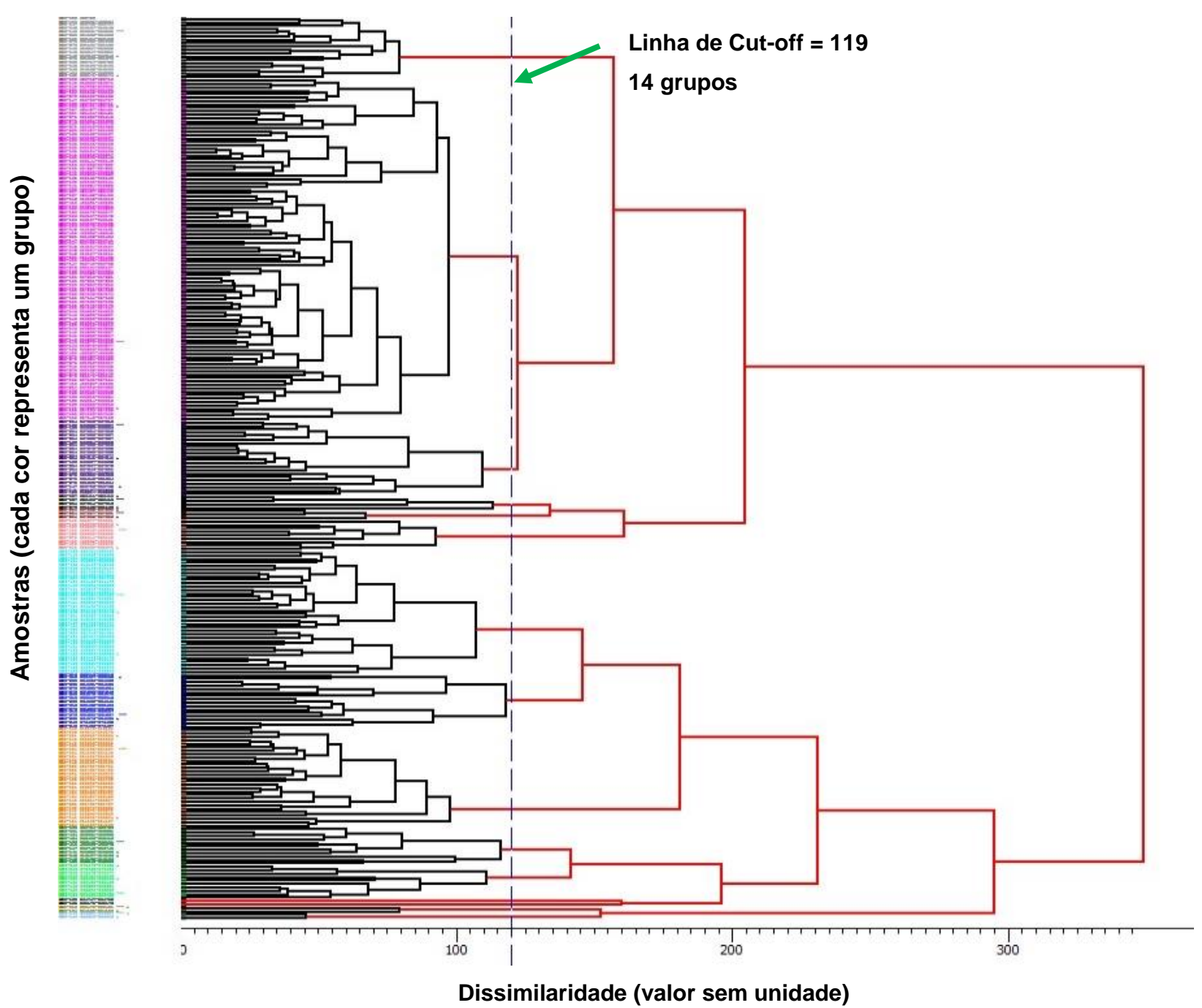

Legenda dos grupos: 1 = azul; 2 = verde escuro; 3 = preto; 4 = verde; 5 = roxo; 6 = ciano; 7 = laranja; 8 = magenta; 9 = rosa claro; 10 = cinza; 11 = bege; 12 = marrom; 13 = azul claro; 14 = vermelho (outliers).

No dendrograma encontram-se indicados os grupos definidos por diferentes cores, bem como as amostras inseridas em cada grupo, apontando semelhanças e dissimilaridades entre as mesmas. A diferenciação entre os grupos se fez, essencialmente, com base na presença e conteúdo relativo dos principais constituintes das amostras: serpentina, olivina e piroxênio. Uma comparação dos difratogramas das diversas amostras contidas em cada grupo está no Apêndice 1. 
A Figura 17 apresenta o gráfico 3D da análise por componente principal (PC) sob diferentes ângulos de visão.

Figura 17 - Distribuição espacial dos agrupamentos de principal (PC1 a PC3), sob diferentes ângulos de visão com as setas indicando o aumento dos teores dos minerais

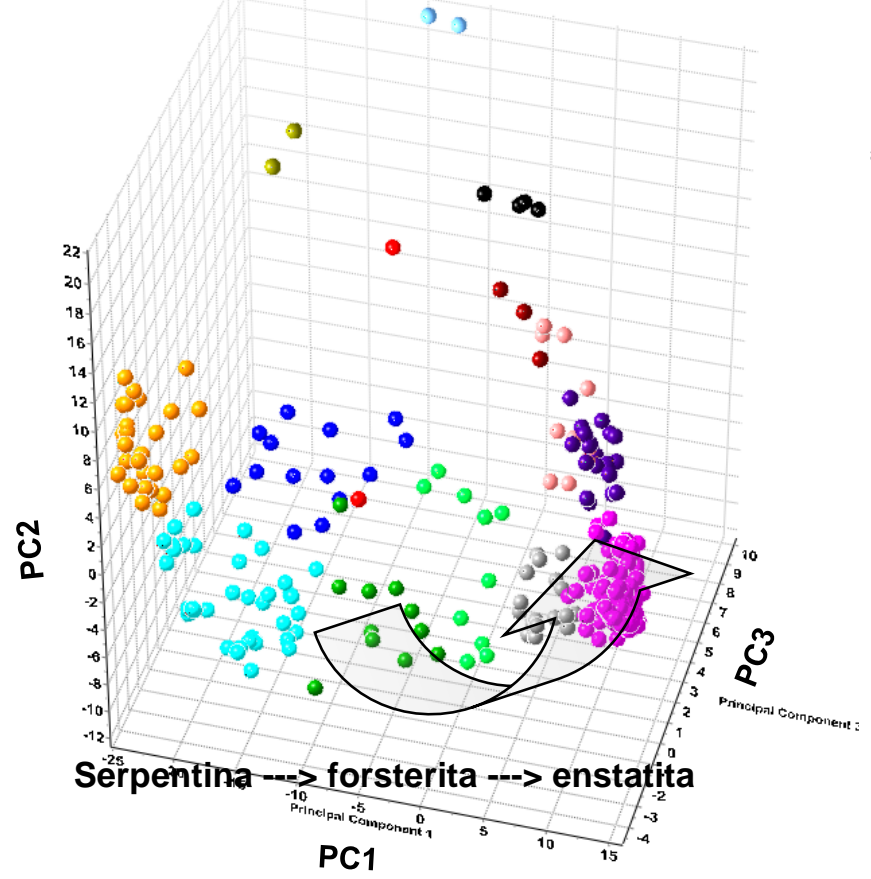

Filossilicatos, feldspato, carbonatos

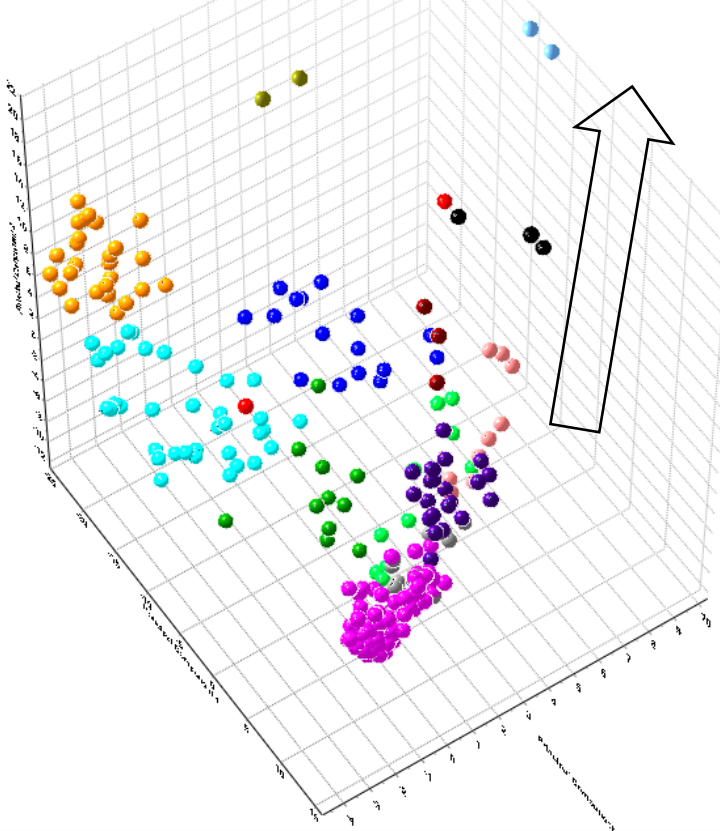

Legenda dos grupos: 1 = azul; 2 = verde escuro; $3=$ preto; 4 = verde $; 5=$ roxo; 6 = ciano; 7 = laranja; $8=$ magenta; 9 = rosa claro; 10 = cinza; 11 = bege; 12 = marrom; 13 = azul claro; 14 = vermelho (outliers)

No Apêndice 2 é apresentada a relação de amostras com seus respectivos agrupamentos e parâmetros da análise do componente principal - valores de PC1 a PC10.

A análise das amostras médias (amostras consideradas mais representativas do grupo) de cada um dos 14 grupos definidos permitiu a identificação da assembleia mineralógica presente, conforme apresentado na Tabela 8.

As amostras são compostas essencialmente por serpentina (essencialmente lizardita), olivina (forsterita), piroxênio (ortopiroxênio - enstatita e, secundariamente, clinopiroxênio - diopsídio), além de estarem presentes anfibólio (tremolita/pargasita e antofilita), feldspato potássico, plagioclásio, filossilicatos (mica, clorita/vermiculita e talco), quartzo e, subordinadamente, magnesita e pentlandita. 
Tabela 8 - Minerais identificados por difração de raios $\mathrm{X}$ nas amostras estudadas

\begin{tabular}{|c|c|}
\hline Mineral & Fórmula química teórica \\
\hline serpentina (lizardita) & $\mathrm{Mg}_{3} \mathrm{Si}_{2} \mathrm{O}_{5}(\mathrm{OH})_{4}$ \\
\hline olivina (forsterita) & $\mathrm{Mg}_{2} \mathrm{SiO}_{4}$ \\
\hline \multicolumn{2}{|l|}{ piroxênio } \\
\hline ortopiroxênio - enstatita & $\mathrm{Mg}_{2} \mathrm{Si}_{2} \mathrm{O}_{6}$ \\
\hline clinopiroxênio - diopsídio & $\mathrm{CaMgSi}_{2} \mathrm{O}_{6}$ \\
\hline \multicolumn{2}{|l|}{ anfibólio } \\
\hline tremolita? & $\mathrm{Ca}_{2} \mathrm{Mg}_{5} \mathrm{Si}_{8} \mathrm{O}_{22}(\mathrm{OH})_{2} / \mathrm{NaCa}_{2}(\mathrm{Mg}, \mathrm{Fe})_{4} \mathrm{AlSi}_{6} \mathrm{Al}_{2} \mathrm{O}_{22}(\mathrm{OH})_{2}$ \\
\hline antofilita & $\mathrm{Mg}_{7} \mathrm{Si}_{8} \mathrm{O}_{22}(\mathrm{OH})_{2}$ \\
\hline \multicolumn{2}{|l|}{ feldspato } \\
\hline K-feldspato & $\mathrm{KAISi}_{3} \mathrm{O}_{8}$ \\
\hline plagioclásio & $(\mathrm{Na}, \mathrm{Ca})(\mathrm{Si}, \mathrm{Al})_{4} \mathrm{O}_{8}$ \\
\hline \multicolumn{2}{|l|}{ outros filossilicatos } \\
\hline mica & $\mathrm{KMg}_{3}\left(\mathrm{Si}_{3}, \mathrm{Al}\right) \mathrm{O}_{10}(\mathrm{~F}, \mathrm{OH})_{2}$ \\
\hline vermiculita & $\left(\mathrm{Mg}, \mathrm{Fe}^{2+}, \mathrm{Al}\right)_{3}(\mathrm{Al}, \mathrm{Si})_{4} \mathrm{O}_{10}(\mathrm{OH})_{2} 4 \mathrm{H}_{2} \mathrm{O}$ \\
\hline clorita & $\left(\mathrm{Mg}, \mathrm{Fe}^{2+}, \mathrm{Al}\right)_{6}(\mathrm{Al}, \mathrm{Si})_{4} \mathrm{O}_{10}(\mathrm{OH})_{8}$ \\
\hline talco & $\mathrm{Mg}_{3} \mathrm{Si}_{4} \mathrm{O}_{10}(\mathrm{OH})_{2}$ \\
\hline quartzo & $\mathrm{SiO}_{2}$ \\
\hline magnesita & $\mathrm{MgCO}_{3}$ \\
\hline pentlandita & $(\mathrm{Fe}, \mathrm{Ni})_{9} \mathrm{~S}_{8}$ \\
\hline
\end{tabular}

A estimativa semi-quantitativa da composição mineralógica média em cada grupo de amostras, obtida pelo método de RIR por difração de raios $X$, é apresentada na Tabela 9.

As amostras inseridas nos denominados grupos 1, 6 e 7 são caracterizadas pelos elevados conteúdos de olivina e diferenciam-se principalmente pelas menores proporções de serpentina e enstatita associadas. Dentre esses grupos, o 7 representa as amostras que apresentam, em média, as maiores quantidades de serpentina.

As amostras inseridas nos grupos 2, 4, 5, 8, 9 e 10 são preferencialmente compostas por enstatita, com variações em relação aos menores constituintes: serpentina, olivina, mica, anfibólio, plagioclásio, entre outros. Destaca-se que o grupo 8 é o mais representativo dentre o universo amostrado, englobando um total da ordem de 100 amostras, e apresenta, em média, as proporções mais elevadas de enstatita dentre as amostras.

O grupo 11 também contempla amostras ricas em serpentina e praticamente isentas de olivina e piroxênio, sendo destacadas as quantidades de outros filossilicatos ( 25\%) e de magnesita ( 10\%) contidas. No grupo 12 são significativos os conteúdos de enstatita e diopsídio ( $35 \%$ cada). 
Tabela 9 - Estimativa mineral média em cada grupo definido (\% RIR; semiquantitativo)

\begin{tabular}{|c|c|c|c|c|c|c|c|c|c|c|c|c|c|c|c|}
\hline \multirow{2}{*}{ Mineral } & \multicolumn{15}{|c|}{$\%$ Estimativa / grupo } \\
\hline & 7 & 1 & 6 & 2 & 4 & 10 & 8 & 5 & 9 & 12 & 3 & 11 & 13 & $14^{*}$ & $14^{\star \star}$ \\
\hline serpentina & 25 & 10 & 20 & 10 & 5 & 5 & & & $<5$ & & & 20 & $<5$ & 20 & 5 \\
\hline olivina & 50 & 55 & 40 & 30 & 25 & 20 & & & & & & & & & 15 \\
\hline piroxênio & 20 & 25 & 30 & 50 & 50 & 65 & 80 & 65 & 55 & 70 & 40 & & 10 & 55 & 25 \\
\hline anfibólio & $<5$ & 10 & 5 & 5 & 10 & 5 & 5 & 10 & 15 & 10 & 15 & 20 & $<5$ & 15 & 5 \\
\hline feldspato & & $<5$ & $<5$ & & 5 & & 10 & 10 & 10 & 10 & 20 & 15 & 50 & & 20 \\
\hline outros filossilic. & $<5$ & $<5$ & $<5$ & $<5$ & $<5$ & $<5$ & $<5$ & 10 & 10 & 10 & 10 & 25 & 5 & 10 & $<5$ \\
\hline quartzo & & & & & & & & $<5$ & 10 & & 15 & 10 & 30 & & 25 \\
\hline magnesita & $<5$ & & $<5$ & $<5$ & $<5$ & $<5$ & & & $<5$ & & & 10 & & & 5 \\
\hline pentlandita & & $<5$ & $<5$ & $<5$ & $<5$ & $<5$ & $<5$ & $<5$ & & & & & & $<5$ & \\
\hline
\end{tabular}

\begin{tabular}{lllllllllllllllll}
\hline $\begin{array}{l}\text { № de amostras } \\
\text { inseridas no grupo }\end{array}$ & 29 & 16 & 36 & 11 & 10 & 18 & 100 & 22 & 9 & 3 & 4 & 2 & 2 & 1 & 1
\end{tabular}

Nota: Grupo 14 é composto por amostras diferentes das demais (outliers) - ${ }^{*}$ = amostra MBS-165 360175-360179; $* *$ amostra MBS-188 364747-364752.

No grupo 13 foram inseridas amostras com elevadas proporções de quartzo e feldspatos e, no grupo 3, estão amostras com quartzo, enstatita, anfibólio e mica.

Por fim, dentre as amostras diferentes das demais (outliers; "grupo 14"), a MBS165 360175-360179 é composta basicamente por serpentina e enstatita, enquanto que a MBS-188 364747-364752 apresenta proporções significativas de enstatita, olivina, plagioclásio e quartzo.

A técnica de difração de raios $X$ permitiu a detecção apenas de pentlandita como mineral típico portador de níquel, e em pequenas proporções nos grupos de amostras definidos ( $<5 \%$ - próximo ao limite de detecção da técnica); calcopirita e outros eventuais sulfetos de cobre não foram passíveis de identificação.

$\mathrm{Na}$ Figura 18 são apresentas comparações entre os difratogramas médios de cada grupo, possibilitando a visualização das principais diferenças mineralógicas detectadas entre os mesmos, preferencialmente em relação as suas proporções relativas.

$O$ valor de cut-off é o valor de dissimilaridade expresso no eixo $x$ do dendrograma. Quanto maior este valor, mais distintos são os grupos entre si. Se, hipoteticamente, no mesmo dendrograma da Figura 16, fosse escolhido um valor maior de cut-off, ter-se-ia um menor número de grupos, porém com amostras mais distintas pertencentes a um mesmo grupo. 
Figura 18 - Comparação dos difratogramas médios de cada grupo

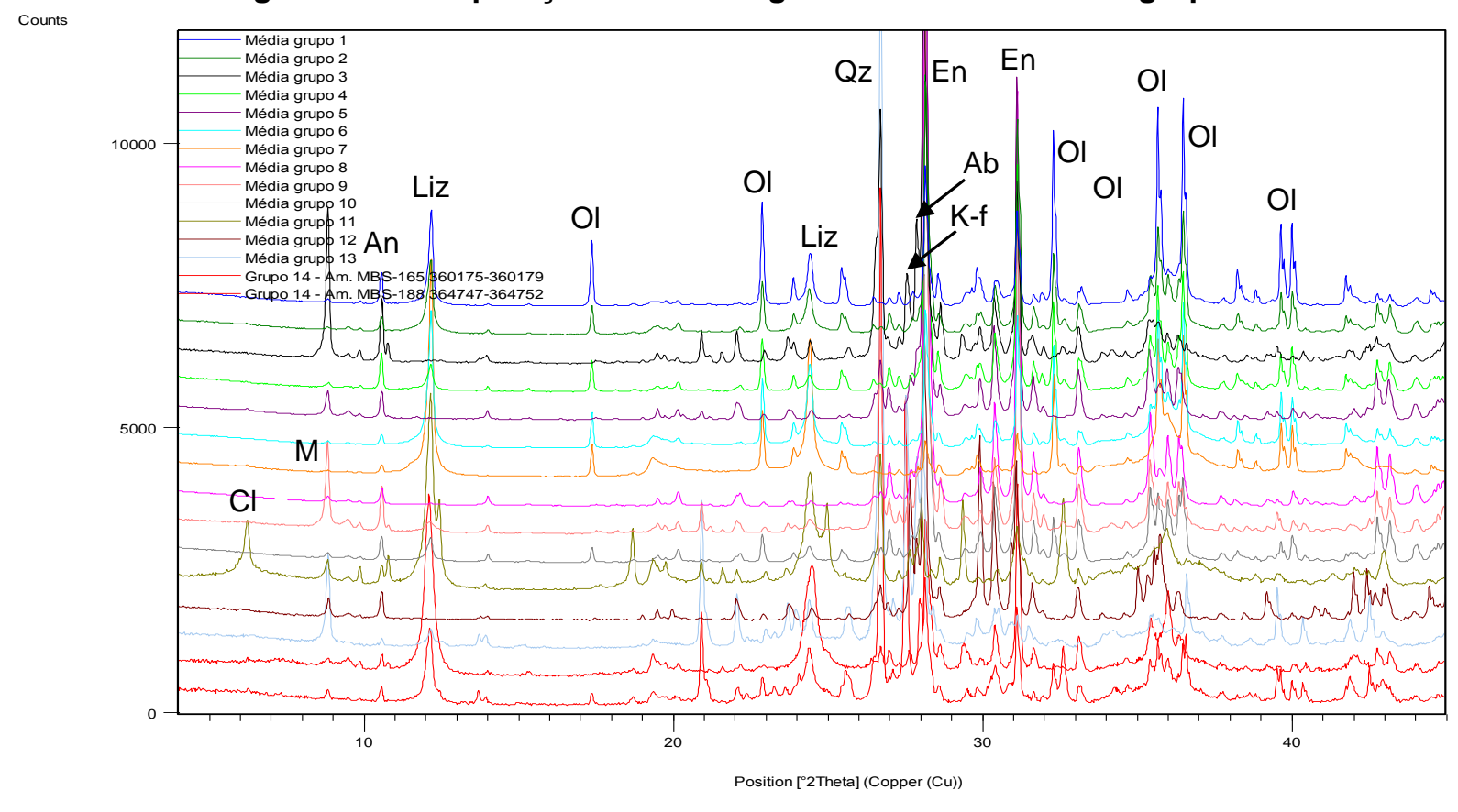

Principais constituintes: $\mathrm{Liz}=$ lizardita; $\mathrm{OI}=$ olivina; $\mathrm{En}=$ enstatita; $\mathrm{An}$ = anfibólio; $\mathrm{Ab}=$ albita; $\mathrm{K}-\mathrm{f}$ = feldspato potássico; $\mathrm{M}=$ mica; $\mathrm{Cl}=$ clorita.

Assim, a escolha do valor de cut-off é uma tarefa complexa. Existem formas estatísticas de cálculo para o valor de cut-off, porém ele precisa ter um significado físico. Para este estudo, optou-se pela adoção de um valor de cut-off definido visualmente, com base na observação do gráfico 3D da análise por componente principal (PCA), justificado pela mineralogia.

Como salientado anteriormente na revisão bibliográfica, o gráfico 3D da PCA é uma forma de visualização do agrupamento (uma forma de visualização da matriz de correlação). Amostras são representadas como pontos no gráfico 3D; aquelas mineralogicamente semelhantes possuirão posições mais próximas e o inverso para as amostras mais distintas.

No gráfico 3D da PCA, a distância entre os pontos (amostras) não sofrerá mudanças com valores diferentes de cut-off, ela se alteraria se houvesse mudanças no método de comparação, (distância euclidiana, o inverso distância, entre outros) ou no valor de threshold (limiar).

Portanto, variando-se o valor de cut-off, somente o número de grupos é que sofrerá alterações: amostras pertencentes a dois grupos, poderão, por exemplo, serem classificadas como de um mesmo grupo.

Como se pode observar na Figura 17, há uma variação gradual na presença de serpentina, forsterita (olivina) e enstatita (piroxênio), representada por uma seta no 
gráfico. A outra possível distinção dos grupos de amostras está relacionada a presença de filossilicatos (micas principalmente), carbonatos e feldspatos.

A distribuição dos pontos no gráfico 3D do PCA e o dendrograma, mostram que não há uma segmentação das amostras em famílias bem distintas: não há uma distinção clara entre os grupos. Se assim houvesse, ter-se-ia famílias de pontos agrupadas, porém separadas espacialmente no gráfico. O que se observa nas amostras desse estudo é que elas possuem uma relação contínua de mudança, exceto na direção do PC3, indicando a presença do filossilicatos (micas principalmente), carbonatos e feldspatos. 


\section{CARACTERIZAÇÃO MINERALÓGICA DE DETALHE $\left(2^{\mathrm{a}}\right.$ ETAPA)}

\subsection{Procedimento experimental - $2^{\mathrm{a}}$ etapa}

\subsubsection{Amostras estudas e procedimentos da análise $D R X+A E M$ na $E_{2}$}

As 264 amostras, coletadas na 1ํㅡㄹ etapa do estudo, possuíam suas posições no depósito conhecidas (georeferenciadas), possibilitando sua correlação espacial (Figura 19) e com o modelo geológico.

Figura 19 - Visualização inferior da mina de Santa Rita com a porção dos furos amostrados; cada cor representa um domínio mineralógico e, em marrom, a superfície da cava em 2011 e os furos de sondagem

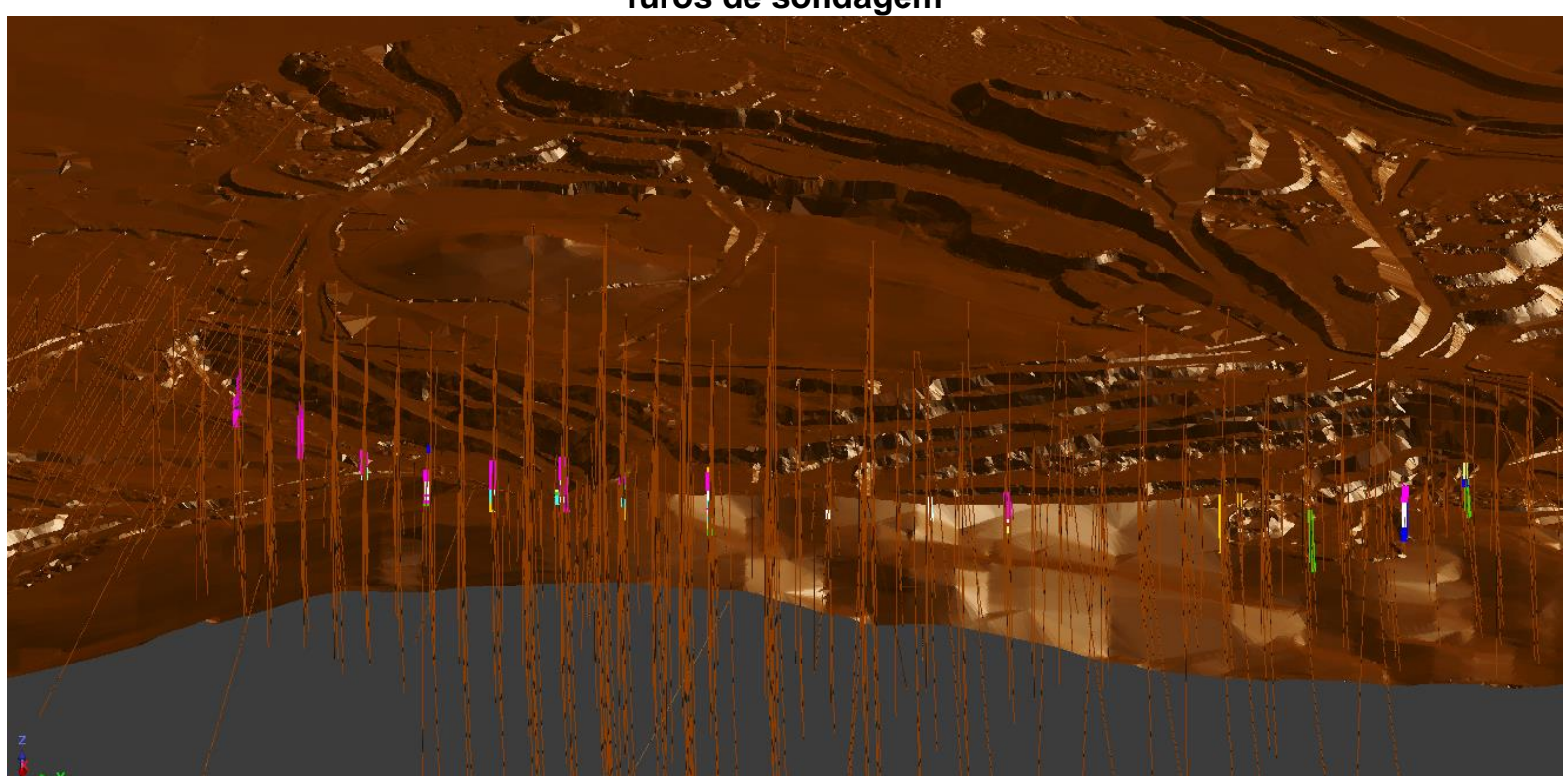

Fonte: próprio autor

Amostras representativas dos principais domínios mineralógicos, definidos na primeira etapa do estudo $\left(E_{1}\right)$, seriam objeto de uma segunda campanha de amostragem, diretamente da mina, para os estudos de caracterização mineralógica detalhada $\left(E_{2}\right)$. Entretanto, devido a problemas de acessibilidade na mina, foram disponibilizadas somente 55 amostras de pó de perfuratriz, gerados na perfuração de furos para detonação, com intervalos de 5 metros, em agosto de 2014.

O pó gerado na perfuração foi quarteado (quarteador Jones) e alíquotas de aproximadamente $300 \mathrm{~g}-400 \mathrm{~g}$, abaixo de $3 \mathrm{~mm}$, foram enviadas para os estudos de caracterização detalhada (2 $2^{-a}$ etapa desse estudo) - Figura 20. 
Figura 20 - A) Sonda em operação; B) Quarteamento do pó gerado na perfuração; C) Alíquotas ensacadas e enviadas para análises de acompanhamento de lavra e estudos de caracterização
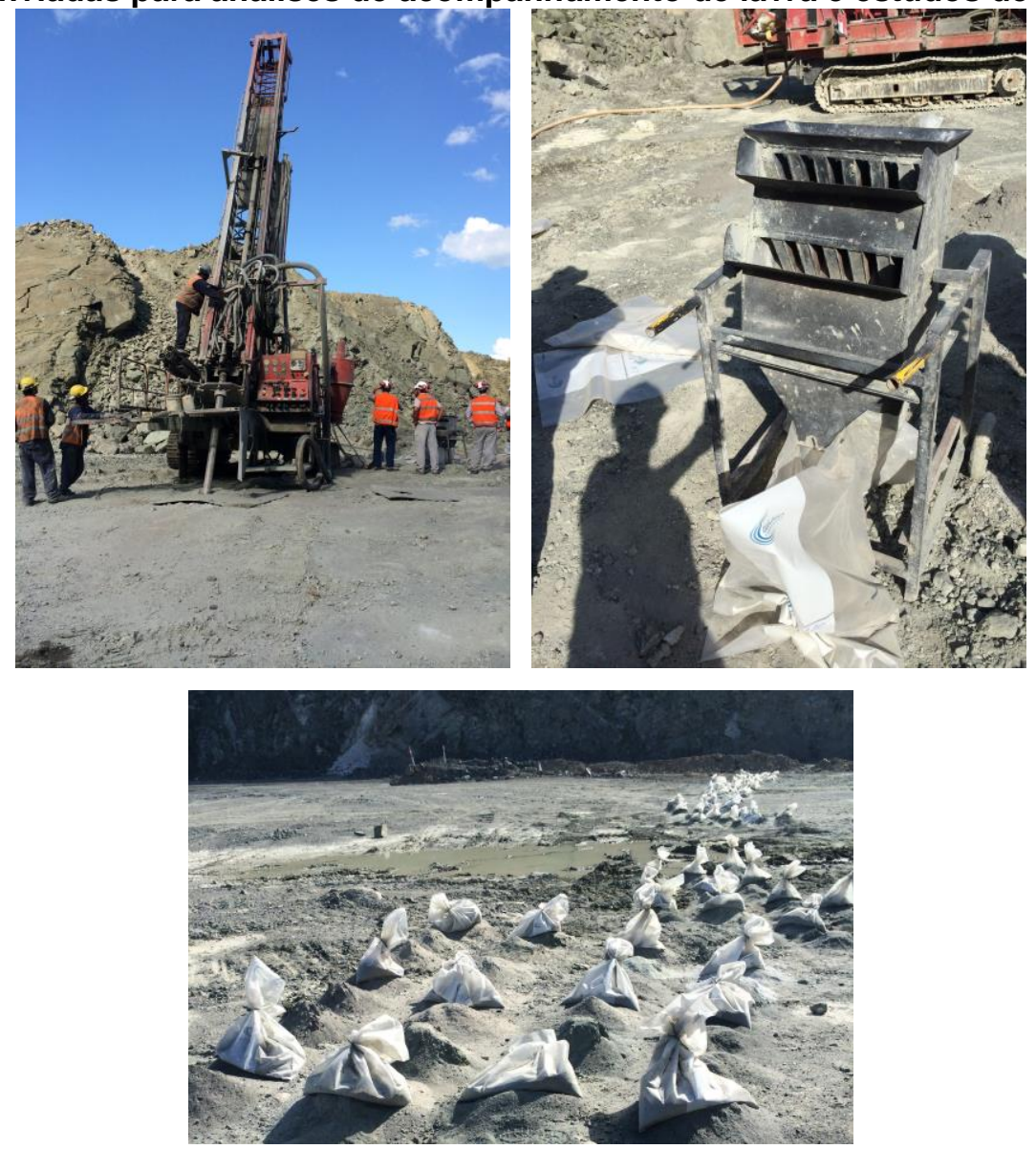

Fonte: próprio autor

É importante ressaltar que as amostras oriundas dos testemunhos de sondagem da $1^{\underline{a}}$ etapa não foram utilizadas na $2^{\underline{a}}$ etapa de estudo, pois poderiam apresentar os sulfetos parcialmente alterados, devido ao armazenamento prolongado em um ambiente oxidante (atmosfera), mascarando suas características naturais.

Todas as 55 amostras de pó de perfuratriz foram submetidas aos mesmos procedimentos descritos para a $1^{\text {a }}$ etapa em termos de preparação e obtenção dos difratogramas.

A análise por agrupamento considerou juntamente os 319 difratogramas (264 amostras dos furos de sondagem da exploração e 55 amostras de pó de perfuratriz da frente de lavra), sendo que os parâmetros de comparação ora empregados na análise são apresentados na Tabela 10. 
Tabela 10 - Principais parâmetros da análise por agrupamento (software High Score) para as amostras da $1^{\underline{a}}$ e $2^{a}$ etapas de amostragem

\begin{tabular}{|ll|}
\hline Tratamento & Remoção do background \\
Fonte de dados & Perfil + Picos \\
Figura de mérito & Pos. + Int. dos picos \\
Threshold (Limiar) & $10 \%$ \\
Condições do Agrupamento & \\
$\quad \begin{array}{l}\text { Medida de distância } \\
\text { Método de agrupamento }\end{array}$ & Euclidiana \\
Cut-off para definição de clusters & 119,0 \\
\hline
\end{tabular}

O conjunto de 319 amostras (264 amostras da exploração e 55 amostras de pó de perfuratriz) foi classificado em termos de semelhança de composição mineralógica, através da análise estatística multivariada de seus difratogramas, retratando num primeiro nível preferencialmente as variações no conteúdo relativo dos maiores constituintes: serpentina, olivina e piroxênio.

A Tabela 11 mostra em que grupos definidos na $1^{\text {a }}$ Etapa as amostras de pó de perfuratriz foram incorporadas. É importante ressaltar que a numeração dos grupos foi modificada por características do software utilizado: assim o grupo referido como 5 na $1^{\text {a }}$ etapa, não é o mesmo da $2^{\underline{a}}$ Etapa.

Tabela 11 - Amostras de pó de perfuratriz agrupadas nos domínios mineralógicos definidos na 1. Etapa do estudo

Grupo/Domínio mineralógico

\begin{tabular}{|c|c|c|c|c|c|c|c|c|c|c|c|c|c|c|c|c|c|}
\hline & 5 & 10 & 2 & 11 & 8 & 14 & 3 & 16 & 6 & 13 & 1 & 15 & 12 & 4 & 9 & 7 & $17^{*}$ \\
\hline $\begin{array}{l}\text { № de amostras } \\
\text { furos de sonda }\end{array}$ & 20 & 10 & 10 & 32 & 40 & 5 & 122 & 11 & 33 & 6 & 8 & 4 & 2 & 2 & 6 & 3 & 5 \\
\hline $\begin{array}{l}\text { № de amostras } \\
\text { pó perfuratriz }\end{array}$ & - & 1 & - & 1 & 7 & 2 & 15 & 7 & 4 & 6 & - & - & 1 & 2 & 6 & - & 3 \\
\hline
\end{tabular}

Nota-se que muitos grupos não possuíam amostras de pó de perfuratriz disponíveis para estudos mineralógicos de detalhe por MEV-MLA. Optou-se, então, por compor as amostras de pó de perfuratriz. Para tal, uma análise DRX/RIR e a posição das amostras no diagrama de PCA (Figura 21) foram consideradas.

A composição proposta é exposta na Tabela 12, assim como o número de amostras candidatas a composição. Como a estimativa dos teores por DRX/RIR possui um uma imprecisão associada a este método ( $\pm 5 \%$ de variação nos teores), 
optou-se por agrupar as amostras por semelhança mineralógica, considerando a imprecisão do método.

Tabela 12 - Composição mineralógica média dos grupos de domínios mineralógicos compostos para estudos de caracterização mineralógica detalhada (\% RIR; semiquantitativo)

\begin{tabular}{|c|c|c|c|c|c|c|c|c|c|c|c|c|c|c|c|c|c|}
\hline \multirow{2}{*}{ Mineral } & \multicolumn{17}{|c|}{ \% Estimativa / grupo } \\
\hline & 5 & 10 & 2 & 11 & 8 & 14 & 3 & 16 & 6 & 13 & 1 & 15 & 12 & 4 & 9 & 7 & $17^{\star}$ \\
\hline serpentina & 25 & 25 & 15 & 20 & 10 & 10 & $<5$ & $<5$ & $<5$ & $<5$ & & & 25 & 10 & $<5$ & $<5$ & \\
\hline olivina & 50 & 45 & 45 & 50 & 35 & 40 & 10 & 5 & 5 & 5 & & & & 10 & & & \\
\hline piroxênio & 20 & 20 & 35 & 25 & 50 & 45 & 75 & 80 & 85 & 85 & 65 & 60 & 5 & 20 & & 10 & \\
\hline anfibólio & 5 & 10 & 5 & $<5$ & $<5$ & 5 & 5 & 5 & 5 & $<5$ & 10 & 10 & 10 & $<5$ & $<5$ & $<5$ & \\
\hline feldspato & & & & 5 & & $<5$ & 5 & 5 & $<5$ & 5 & 15 & 25 & 5 & 15 & 65 & 45 & \\
\hline $\begin{array}{l}\text { outros } \\
\text { filossilic. }\end{array}$ & $<5$ & $<5$ & $<5$ & $<5$ & $<5$ & $<5$ & $<5$ & 5 & $<5$ & 5 & $<5$ & 5 & 30 & 15 & 10 & 10 & \\
\hline quartzo & & & & & & & $<5$ & $<5$ & $<5$ & & 5 & & 10 & 15 & 10 & & \\
\hline carbonatos & $<5$ & $<5$ & & $<5$ & $<5$ & $<5$ & & & & & $<5$ & & 15 & 15 & 15 & 35 & \\
\hline pentlandita & $<5$ & $<5$ & $<5$ & $<5$ & $<5$ & $<5$ & $<5$ & $<5$ & $<5$ & $<5$ & & & & & & & \\
\hline $\begin{array}{l}\text { № de amostras } \\
\text { furos de sonda }\end{array}$ & 20 & 10 & 10 & 32 & 40 & 5 & 122 & 11 & 33 & 6 & 8 & 4 & 2 & 2 & 6 & 3 & 5 \\
\hline $\begin{array}{l}\text { № de amostras } \\
\text { pó perfuratriz }\end{array}$ & - & 1 & - & 1 & 7 & 2 & 15 & 7 & 4 & 6 & - & - & 1 & 2 & 6 & - & 3 \\
\hline $\begin{array}{c}\text { № de amostras } \\
\text { canditadas a } \\
\text { composição }\end{array}$ & & & 2 & & & 9 & 15 & & 17 & & & 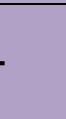 & & & & & \\
\hline
\end{tabular}

Nota: ${ }^{*}=$ amostras diferentes entre si (outliers).
OPS = Olivina/piroxênio/ com serpentina $>10 \%$
POS $=$ Piroxênio/olivina/ com serpentina $=10 \%$
PO = Piroxênio/ com olivina $=10 \%$
P = Piroxênio/ com olivina $=5 \%$
PAF = Piroxênio/anfibólio/feldspato
CS = Minério carbonático com serpentina $>5 \%$
C = Minério carbonático

A nomenclatura adotada considerou a ordem de abundância dos minerais. Por exemplo, o grupo olivina/piroxênio/ com serpentina $>10 \%$ (OPS) possui a olivina como mineral mais abundante, seguida do piroxênio e serpentina. Para facilitar na escrita, os nomes foram condensados em siglas, sendo cada letra representante das iniciais dos minerais $(\mathrm{O}=$ olivina, $\mathrm{P}=$ piroxênio, $\mathrm{S}=$ serpentina, $\mathrm{A}=$ anfibólio e $\mathrm{C}=$ carbonatos).

Para a validação da forma de composição proposta e da representatividade das amostras candidatas à composição, os difratogramas das mesmas foram comparados com os difratogramas médios de cada cluster representativo dos litotipos (Apêndice 3; exceto para o grupo POS, composto apenas por amostras do grupo 3), sendo possível observar a significativa similaridade dos difratogramas. 
Análises químicas sem padrões por fluorescência de raio $X$ também foram realizadas em todas as amostras de pó de perfuratriz, sendo os resultados apresentados no Apêndice 4.

Figura 21 - Distribuição espacial dos agrupamentos segundo a análise de componente principal (PC1 a PC3), sob diferentes ângulos de visão com destaque para as amostras de pó de perfuratriz (esferas maiores)

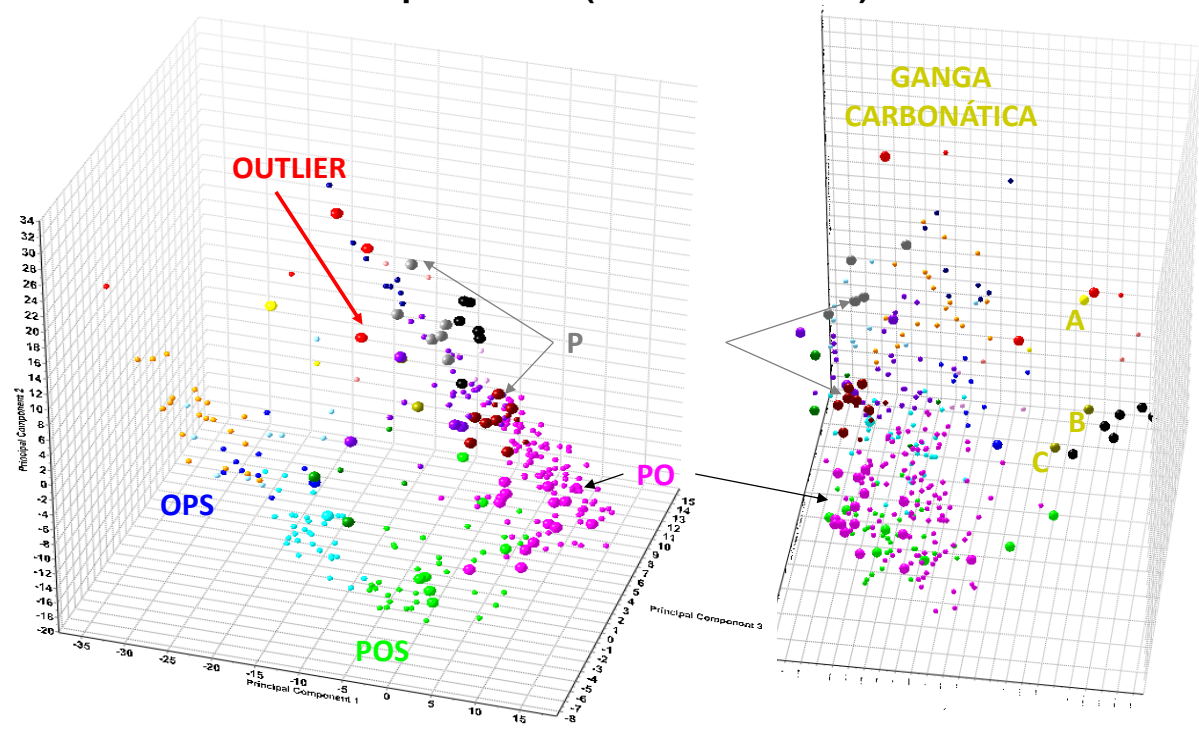

Legenda dos grupos: 1 = azul escuro; $2=$ azul claro; $3=$ magenta; 4 = bege; $5=$ laranja; $6=$ roxo; $7=$ vermelho claro; $8=$ verde; $9=$ preto; $10=$ azul; $11=$ ciano; $12=$ amarelo $; 13=$ cinza; $14=$ verde escuro; $15=$ rosa; $16=$ marrom; 17 = vermelho (outliers).

As amostras representativas dos grupos compostas para estudos possuem composição química relativamente semelhante entre si, preferencialmente em relação aos elementos maiores $\mathrm{Fe}_{2} \mathrm{O}_{3}, \mathrm{SiO}_{2}, \mathrm{MgO}, \mathrm{Al}_{2} \mathrm{O}_{3}$ e $\mathrm{CaO}$. Todavia, aquelas representativas do grupo CS apresentam maiores discrepâncias de composição química, corroborando com as variedades mineralógicas evidenciadas pela comparação dos difratogramas. Estas observações demonstram a necessidade de subdivisão das amostras do grupo CS.

Nesta composição considerou-se também a massa disponível das contrapartes dos pós de perfuratriz e o conteúdo de níquel e enxofre (Apêndice 4). Amostras com teores de níquel inferiores a $0,35 \%$ e/ou enxofre menor que 0,10\% foram desconsideradas para composição por apresentarem baixo teor de sulfetos (teores inferiores ao cut-off da mina).

É importante ressaltar que o grupo PAF não possui nenhuma amostra de pó de perfuratriz das 55 enviadas; as amostras do grupo C não possuíam os critérios químicos para serem amostradas; e o grupo OPS possui somente uma amostra de pó 
de perfuratriz para ser caracterizada pertencente ao grupo 10, considerando as premissas expostas (\%Ni $>0,35$ e/ou \%S $>0,1)$.

A Tabela 13 apresenta as amostras de pó de perfuratriz que efetivamente foram compostas para os estudos de $2^{\mathrm{a}}$ etapa; considerando o exposto, as amostras para estudo da $2^{2}$ etapa são:

- OPS = Olivina/piroxênio/ com serpentina $>10 \%$

- $\mathrm{POS}=$ Piroxênio/olivina/ com serpentina $=10 \%$

- $\mathrm{PO}=$ Piroxênio/ com olivina $=10 \%$

- $P=$ Piroxênio/ com olivina $=5 \%$

- Minério com ganga tipo A - micáceo

- Minério com ganga tipo $B$ - carbonático

- Minério com ganga tipo $\mathrm{C}$ - feldspático/micáceo Minério carbonático com

- Outlier

Tabela 13 - Composição da contraparte das amostras de pós de perfuratriz para os estudos de caracterização tecnológica de detalhe

\begin{tabular}{|c|c|c|}
\hline Amostra & Grupos & $\begin{array}{c}\text { ID amostras } \\
\text { Pó de perfuratriz }\end{array}$ \\
\hline OPS & 10 & SEC 8431120 (RC_130 366) 1013435 \\
\hline \multirow{8}{*}{ POS } & 8 & SEC 8430620 (RC_130 219) 1010691 \\
\hline & 8 & 1012641 \\
\hline & 8 & 1012642 \\
\hline & 8 & 1012643 \\
\hline & 8 & 1013508 \\
\hline & 8 & RC_100_0067 PCT 1016170 \\
\hline & 14 & RC_100_0070 PCT 10160063 \\
\hline & 14 & RC_100_0067 PCT 1016167 \\
\hline \multirow{7}{*}{ PO } & 3 & SEC 8430080 (RC_095 129) 1008649 \\
\hline & 3 & SEC 8430080 (RC_095 129) 1008646 \\
\hline & 3 & SEC 8430080 (RC_095 129) 1008643 \\
\hline & 3 & SEC 8430080 (RC_095 132) 1008756 \\
\hline & 3 & SEC 8430080 (RC_095 132) 1008759 \\
\hline & 3 & 1012640 \\
\hline & 3 & 1012934 \\
\hline \multirow{10}{*}{$\mathbf{P}$} & 16 & SEC 8430080 (RC_095 129) 1008640 \\
\hline & 16 & 1012936 \\
\hline & 16 & RC_100_0073 PCT 1016200 \\
\hline & 16 & RC_100_0073 РCT 1016203 \\
\hline & 6 & SEC̄ 84300080 (RC_095 132) 1008763 \\
\hline & 6 & SEC 8430080 (RC_095 132) 1008766 \\
\hline & 13 & RC_100_0067 PCT 1016169 \\
\hline & 13 & RC_100_0070 PCT 10160064 \\
\hline & 13 & RC_100_0070 PCT 10160065 \\
\hline & 13 & RC_100_0073 PCT 1016202 \\
\hline \multirow{3}{*}{ CS } & 12 & SEC 8430620 (RC_130 219) 1010692 - A \\
\hline & 4 & SEC 8431120 (RC_130 366) 1013434 - B \\
\hline & 4 & SEC 8430620 (RC_130 219) 1010688 - C \\
\hline Out & 17 & RC_100_0073 PCT 1016204 \\
\hline
\end{tabular}

Obs: $\mathbf{O P S}=$ Olivina/piroxênio/ com serpentina $>10 \% ; \overline{\mathbf{P O S}}=$ Piroxênio/olivina/ com serpentina $=10 \% ; \boldsymbol{P O}=$ Piroxênio/ com olivina $=10 \% ; \boldsymbol{P}=$ Piroxênio/ com olivina $=5 \% ; \boldsymbol{C S}=$ Minério carbonático com serpentina $>5 \%$ (separado em Ganga A, B e C); Out = Outlier. 


\subsubsection{Procedimentos para caracterização mineralógica de detalhe}

As amostras compostas foram submetidas ao seguinte procedimento e analisadas no LCT - Laboratório de Caracterização Tecnológica da EPUSP:

- retirada de 1/32 da massa da amostra tal qual para análises químicas quantitativas, por fluorescência de raios $\mathrm{X}$, em pastilhas fundidas com determinações de $\mathrm{Ni}, \mathrm{Cu}, \mathrm{S}, \mathrm{CaO}, \mathrm{SiO}_{2}, \mathrm{Al}_{2} \mathrm{O}_{3}, \mathrm{Fe}_{2} \mathrm{O}_{3}$ e $\mathrm{MgO}$.

- retirada de 1/32 da massa da amostra tal qual para análise mineralógica por difração de raios $X(D R X)$ e posterior análise por agrupamento, com as mesmas condições descritas na Tabela 10;

- peneiramento a úmido do restante da massa na abertura de 0,15 mm;

- o material retido em 0,15 mm foi moído em moinho planetário por quatro minutos seguido de peneiramento em $0,15 \mathrm{~mm}$ e remoagem do retido em tempo suplementar de 4 minutos, repetindo as etapas de moagem e moagem até assegurar $\mathrm{P}_{95}=0,15 \mathrm{~mm}$ (equivalente a granulometria de moagem industrial);

- o passante em 0,15 mm e o material moído foram homogeneizados e submetidos a peneiramento à úmido em peneiras com abertura de 0,105 $\mathrm{mm}, 0,053 \mathrm{~mm}$ e $0,020 \mathrm{~mm}$, seguindo-se amostragem para análises químicas efetuadas pelo LCT e preparação de seções polidas transversais para análise ao MEV-MLA e microscopia óptica de luz refletida também no LCT.

O estudo mineralógico das frações granulométricas acima de $0,020 \mathrm{~mm}$ foi efetuado de forma automatizada, em seções polidas, utilizando o software MLA Mineral Liberation Analyser (MLA - FEI) versão 3.1 acoplado ao microscópio eletrônico de varredura Quanta 650 FEG (FEI), e sistema de microanálise por EDS Esprit (Bruker).

As análises mineralógicas realizadas consideraram tanto o contraste de número atômico (imagens de elétrons retroespalhados) como a composição química de cada fase (espectros de raios $X$ característicos por EDS; modo XBSE). Após a coleta das imagens e espectros de raios $X$, as fases foram classificadas, seguidas de desaglomeração manual de partículas e agrupamento das fases minerais. A 
composição química das fases individualizadas e consideradas no banco de dados do MLA é apresentada no Apêndice 5.

Especificamente em relação à pentlandita foram observadas feições de alteração constituídas por mais de uma fase mineral que se apresentava como um espectro misto entra a pentlandita e a fase alterada, não possibilitando uma classificação adequada pelo sistema MLA na resolução adotada. Assim, optou-se por um tratamento adicional de imagem pelo histograma de tons de cinza (backscattering overlay - uma função de tratamento das imagens do software MLA) para a discriminação conjunta das fases de alteração associadas à pentlandita (violarita e óxido de ferro) que foram agrupadas como pentlandita oxidada.

É importante ressaltar que essas limitações foram impostas pela configuração da coleta ao MEV-MLA e não pela capacidade do equipamento utilizado. Se a resolução requerida pela textura da alteração da pentlandita fosse adotada, cada seção polida (fração de uma das amostras) levaria cerca de seis horas para ser coletada considerando um número mínimo de cinco mil partículas analisadas por seção - representatividade estatística.

As imagens digitais obtidas (MLA/XBSE + overlay) foram então processadas obtendo-se as seguintes informações: composição mineralógica; composição química calculada; distribuição de Ni e Cu nas fases presentes; distribuição granulométrica de pentlandita + pentlandita oxidada, calcopirita e sulfetos; associações e liberação da pentlandita + pentlandita oxidada, calcopirita e sulfetos.

A composição química de elementos/óxidos é calculada considerando a massa específica e composição de cada um dos minerais presentes na amostra; já as respectivas distribuições são obtidas a partir da contribuição de cada mineral na somatória dos teores destes elementos/óxidos.

Adicionalmente, para observação e documentação das texturas dos minerais de minério seções polidas do material acima de 0,20 mm foram observadas em microscópio óptico de luz refletida Leica DMR e ao microscópio eletrônico de varredura Quanta 650 FEG (FEI), com sistema de microanálise por EDS Esprit (Bruker) acoplado. 


\subsection{Resultados e discussões $-2^{\mathrm{a}}$ etapa}

\subsubsection{Análise estatística multivariada (AEM) dos difratogramas de raios $X$}

Com as condições analíticas empregadas foram definidos 17 grupos distintos de amostras conforme ilustrado no dendrograma da Figura 22.

Figura 22 - Dendrograma indicando o agrupamento das amostras em 17 grupos de cluster

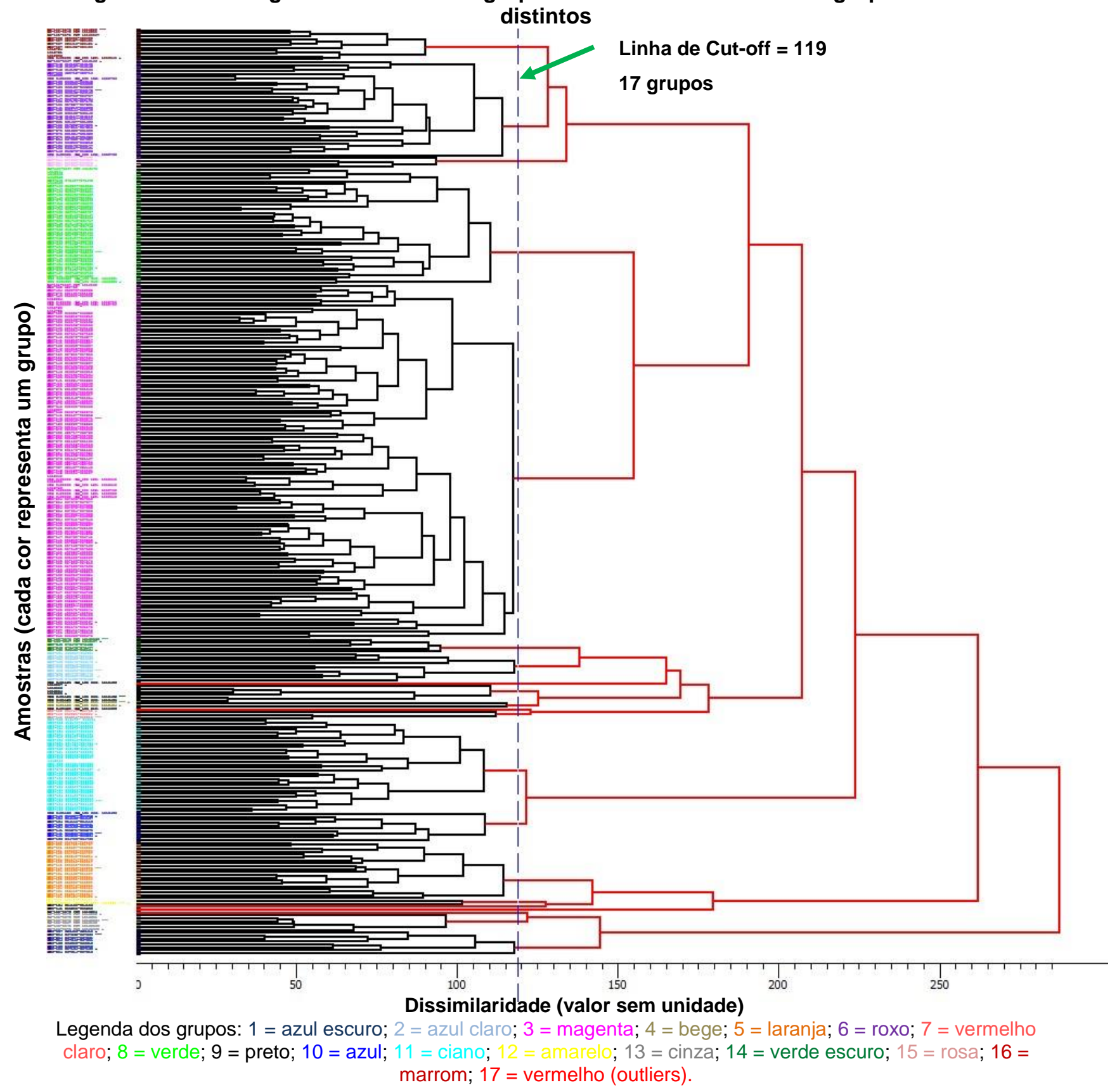

A Figura 23 apresenta o gráfico 3D da análise por componente principal (PCA) sob diferentes ângulos de visão. 
Figura 23 - Distribuição espacial dos agrupamentos segundo a análise de componente principal (PC1 a PC3), sob diferentes ângulos de visão com as setas indicando o aumento dos teores dos minerais
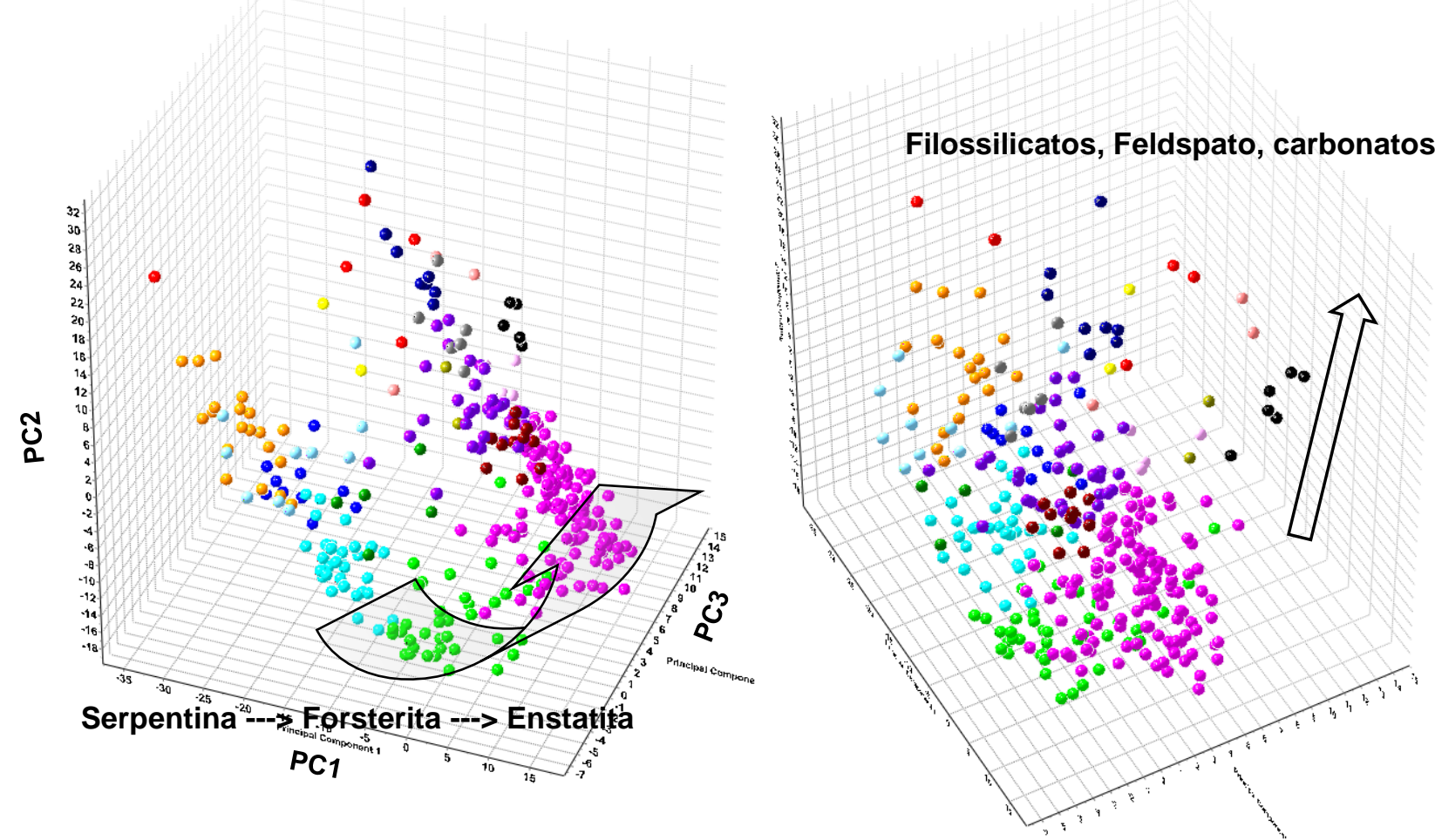

Legenda dos grupos: 1 = azul escuro; 2 = azul claro; 3 = magenta; 4 = bege; 5 = laranja; 6 = roxo; 7 = vermelho claro; 8 = verde; 9 = preto; 10 = azul; $11=$ ciano; $12=$ amarelo $; 13=$ cinza; $14=$ verde escuro; $15=$ rosa; $16=$ marrom; 17 = vermelho (outliers).

No Apêndice 2 é apresentada a relação de amostras com seus respectivos agrupamentos e parâmetros da análise do componente principal (valores de PC1 a PC10).

A análise das amostras médias de cada um dos 17 grupos de cluster definidos permitiu a identificação da assembleia mineralógica presente, conforme apresentado na Tabela 14.

As amostras são compostas essencialmente por serpentina (essencialmente lizardita), olivina (forsterita), piroxênio (ortopiroxênio - enstatita e, secundariamente, clinopiroxênio - diopsídio), além de estarem presentes anfibólio (tremolita/pargasita e antofilita), feldspato potássico, plagioclásio, filossilicatos (mica, clorita/vermiculita e talco), quartzo e, subordinadamente, carbonatos (magnesita e dolomita) e pentlandita. 
Tabela 14 - Minerais identificados por difração de raios $\mathrm{X}$ nas amostras estudadas

\begin{tabular}{|c|c|}
\hline Mineral & Fórmula química teórica \\
\hline serpentina (lizardita) & $\mathrm{Mg}_{3} \mathrm{Si}_{2} \mathrm{O}_{5}(\mathrm{OH})_{4}$ \\
\hline olivina (forsterita) & $\mathrm{Mg}_{2} \mathrm{SiO}_{4}$ \\
\hline \multicolumn{2}{|l|}{ piroxênio } \\
\hline ortopiroxênio - enstatita & $\mathrm{Mg}_{2} \mathrm{Si}_{2} \mathrm{O}_{6}$ \\
\hline clinopiroxênio - diopsídio & $\mathrm{CaMgSi}_{2} \mathrm{O}_{6}$ \\
\hline \multicolumn{2}{|l|}{ anfibólio } \\
\hline tremolita? & $\mathrm{Ca}_{2} \mathrm{Mg}_{5} \mathrm{Si}_{8} \mathrm{O}_{22}(\mathrm{OH})_{2} / \mathrm{NaCa}_{2}(\mathrm{Mg}, \mathrm{Fe})_{4} \mathrm{AlSi}_{6} \mathrm{Al}_{2} \mathrm{O}_{22}(\mathrm{OH})_{2}$ \\
\hline antofilita & $\mathrm{Mg}_{7} \mathrm{Si}_{8} \mathrm{O}_{22}(\mathrm{OH})_{2}$ \\
\hline \multicolumn{2}{|l|}{ feldspato } \\
\hline K-feldspato & $\mathrm{KAISi}_{3} \mathrm{O}_{8}$ \\
\hline plagioclásio & $(\mathrm{Na}, \mathrm{Ca})(\mathrm{Si}, \mathrm{Al})_{4} \mathrm{O}_{8}$ \\
\hline \multicolumn{2}{|l|}{ outros filossilicatos } \\
\hline mica & $\mathrm{KMg}_{3}\left(\mathrm{Si}_{3}, \mathrm{Al}\right) \mathrm{O}_{10}(\mathrm{~F}, \mathrm{OH})_{2}$ \\
\hline vermiculita & $\left(\mathrm{Mg}, \mathrm{Fe}^{2+}, \mathrm{Al}\right)_{3}(\mathrm{Al}, \mathrm{Si})_{4} \mathrm{O}_{10}(\mathrm{OH})_{2} 4 \mathrm{H}_{2} \mathrm{O}$ \\
\hline clorita & $\left(\mathrm{Mg}, \mathrm{Fe}^{2+}, \mathrm{Al}\right)_{6}(\mathrm{Al}, \mathrm{Si})_{4} \mathrm{O}_{10}(\mathrm{OH})_{8}$ \\
\hline talco & $\mathrm{Mg}_{3} \mathrm{Si}_{4} \mathrm{O}_{10}(\mathrm{OH})_{2}$ \\
\hline quartzo & $\mathrm{SiO}_{2}$ \\
\hline \multicolumn{2}{|l|}{ carbonato } \\
\hline magnesita & $\mathrm{MgCO}_{3}$ \\
\hline dolomita & $\mathrm{CaMg}\left(\mathrm{CO}_{3}\right)_{2}$ \\
\hline pentlandita & $(\mathrm{Fe}, \mathrm{Ni})_{9} \mathrm{~S}_{8}$ \\
\hline
\end{tabular}

A estimativa semi-quantitativa da composição mineralógica média em cada grupo de amostras, obtida pelo método de RIR por difração de raios $X$, é apresentada na Tabela 15. Esses resultados serão posteriormente discutidos considerando a tendência de similaridade dos grupos observada na análise do componente principal - PCA (Figura 23).

As amostras inseridas nos denominados grupos 2, 5 e 10 são caracterizadas pelos elevados conteúdos de olivina e diferenciam-se principalmente pelas proporções de serpentina e enstatita associadas; a amostra MBS-141 355255355259, inserida no grupo 17 (outliers), apresenta composição relativamente semelhante. Os grupos 8, 11 e 14 também apresentam elevadas proporções de olivina, porém com quantidades de enstatita preferencialmente superiores as de serpentina. 
Tabela 15 - Estimativa mineral média em cada grupo definido na DRX-AEM (\% RIR; semiquantitativo)

Outliers (Grupo 17, composto por 5 amostras diferentes das demais):

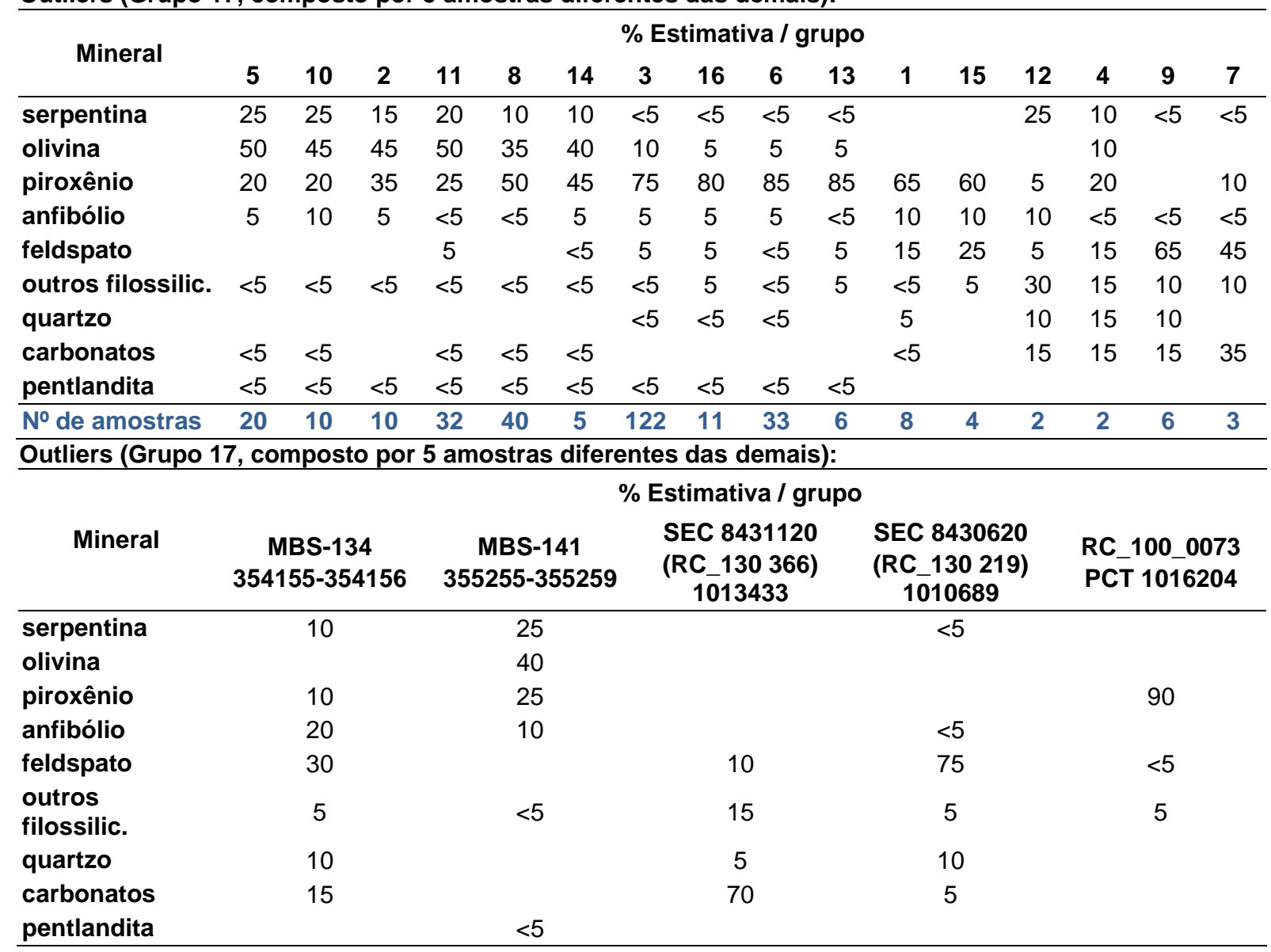

As amostras inseridas nos grupos 3, 6, 13 e 16 são basicamente compostas por enstatita, com variações em relação aos menores constituintes: olivina, anfibólio, plagioclásio, mica, entre outros. Destaca-se que o grupo 3 é o mais representativo dentre o universo amostrado, englobando um total da ordem de 122 amostras, e apresenta, em média, $\sim 75 \%$ de enstatita e $\sim 10 \%$ de olivina.

Nos grupos 1 e 15 são significativos os conteúdos de enstatita e diopsídio (respectivamente $40-45 \%$ e $20 \%$ na média de cada grupo). O grupo 12 também contempla amostras ricas em serpentina e praticamente isentas de olivina e piroxênio, sendo destacadas as quantidades de outros filossilicatos ( $\sim 30 \%$; preferencialmente clorita e, secundariamente, mica e talco) e de magnesita ( 15\%) contidas.

Nas amostras inseridas nos grupos 4, 7 e 9 destacam-se os conteúdos de carbonatos presentes, com predominância de dolomita. O primeiro é ainda composto por proporções intermediárias de enstatita, serpentina, olivina, plagioclásio, quartzo, mica e talco, enquanto que nos grupos 7 e 9 são elevadas as proporções de feldspatos (plagioclásio e/ou K-feldspato). 
No grupo 17 foram inseridas as amostras diferentes das demais (outliers), sendo que a MBS-134 354155-354156 mostra elevado conteúdo de plagioclásio (30\%) e de anfibólio (20\%), a amostra SEC 8431120 (RC_130 366) 1013433 é composta principalmente por carbonatos ( $40 \%$ dolomita e $30 \%$ magnesita), a SEC 8430620 (RC_130 219) 1010689 é tipicamente composta por feldspatos (60\% plagioclásio e 15\% K-feldspato) e a amostra RC_100_0073 PCT 1016204 por enstatita.

A técnica de difração de raios $\mathrm{X}$ permitiu a detecção apenas de pentlandita em pequenas proporções como mineral típico portador de níquel ( $<5 \%$ - próximo ao limite de detecção da técnica); calcopirita e outros eventuais sulfetos de cobre não foram passíveis de identificação por DRX.

Na Figura 24 e Figura 25 são apresentas comparações entre os difratogramas médios de cada grupo, possibilitando a visualização das principais diferenças mineralógicas detectadas entre os mesmos, preferencialmente em relação as suas proporções relativas.

Figura 24 - Comparação dos difratogramas inseridos no grupo 17 (amostras diferentes das demais)

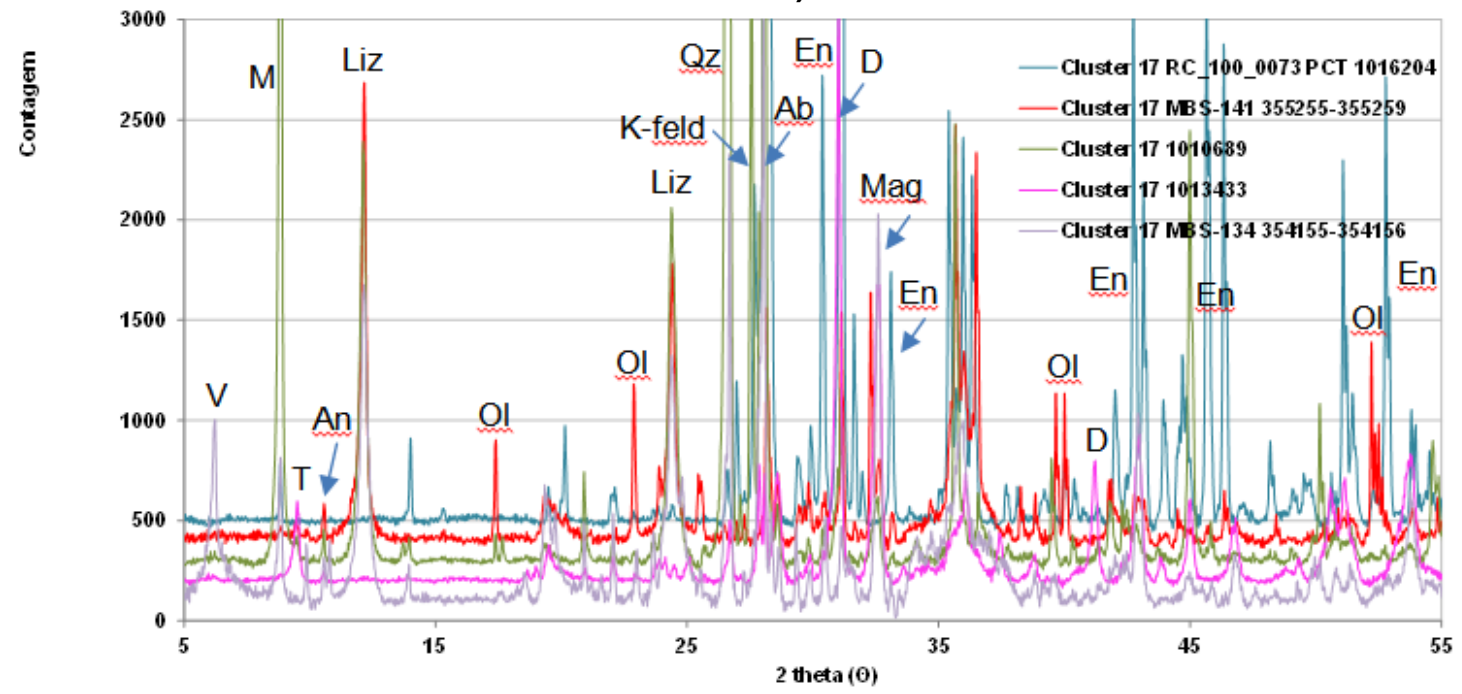

Principais constituintes: $\mathrm{Liz}=$ lizardita; $\mathrm{Ol}=$ olivina; $\mathrm{En}=$ enstatita; $\mathrm{An}=$ anfibólio; $\mathrm{Qz}=$ quartzo; $\mathrm{T}=$ talco; $\mathrm{M}=$ mica; $\mathrm{K}$-feld = feldspato potássico; $\mathrm{Ab}=$ plagioclasio;albita?; $\mathrm{D}=$ dolomita; $\mathrm{Mag}=$ Magnesita; $\mathrm{V}=$ vermiculita; $\mathrm{Cl}=$ clorita . 
Figura 25 - Comparação dos difratogramas médios de cada grupo determinado (grupo 1 ao 16)
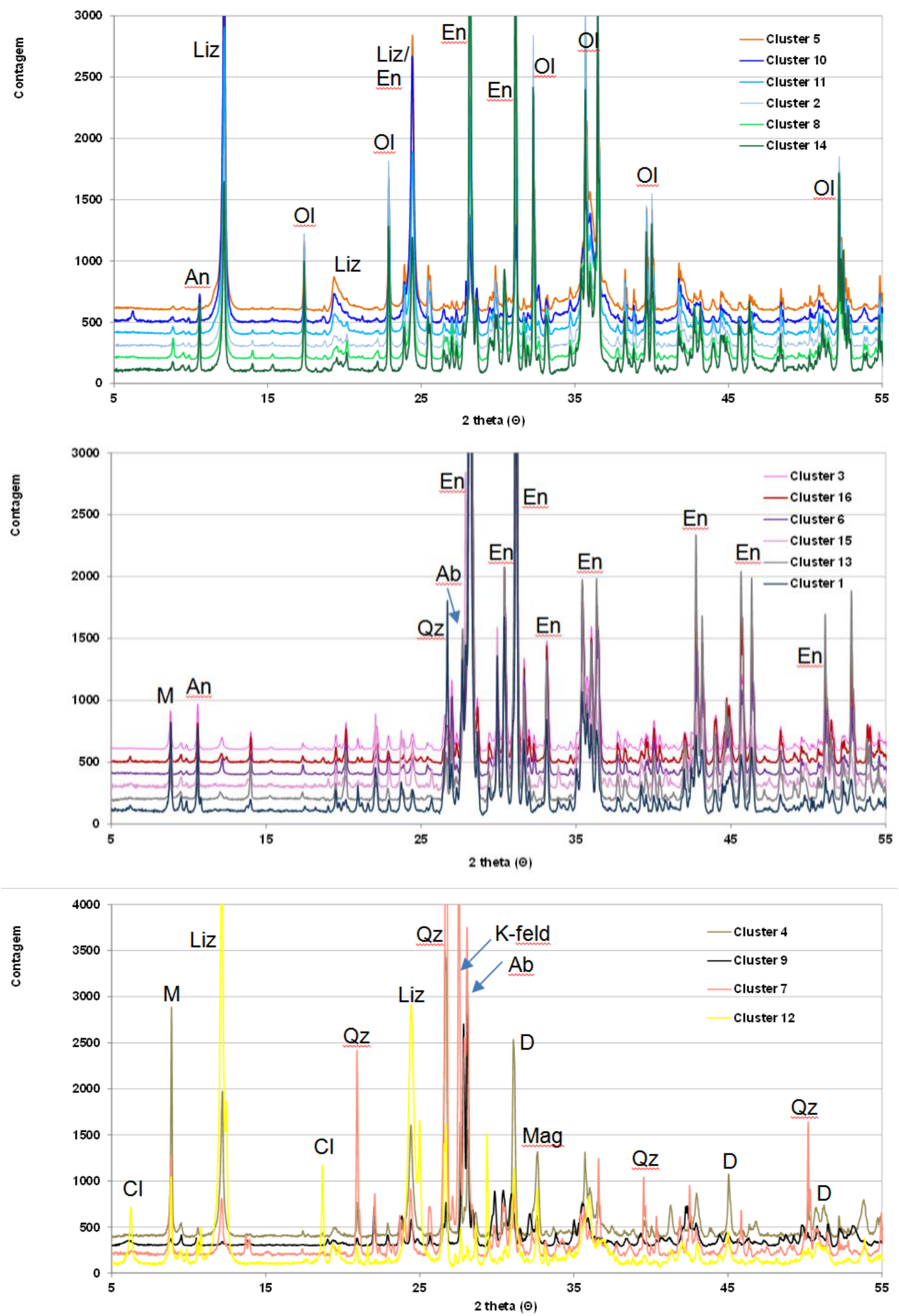

Principais constituintes: $\mathrm{Liz}=$ lizardita; $\mathrm{Ol}=$ olivina; $\mathrm{En}=$ enstatita; $\mathrm{An}=$ anfibólio; $\mathrm{Qz}=$ quartzo; $\mathrm{T}=$ talco; $\mathrm{M}=$ mica; $\mathrm{K}$-feld = feldspato potássico; $\mathrm{Ab}=$ plagioclasio;albita?; $\mathrm{D}=$ dolomita; $\mathrm{Mag}=$ Magnesita; $\mathrm{V}=$ vermiculita; $\mathrm{Cl}=$ clorita . 
A distribuição especificamente das 55 amostras de pó de perfuratriz incorporadas aos agrupamentos é apresentada na Tabela 16.

Tabela 16 - Composição mineralógica média dos grupos de domínios mineralógicos, segundo o agrupamento definido (\% RIR; semiquantitativo), relacionando as amostras de pó de perfuratriz por grupo

\begin{tabular}{|c|c|c|c|c|c|c|c|c|c|c|c|c|c|c|c|c|c|}
\hline \multirow{2}{*}{ Mineral } & \multicolumn{17}{|c|}{$\%$ Estimativa / grupo } \\
\hline & 5 & 10 & 2 & 11 & 8 & 14 & 3 & 16 & 6 & 13 & 1 & 15 & 12 & 4 & 9 & 7 & $17^{*}$ \\
\hline serpentina & 25 & 25 & 15 & 20 & 10 & 10 & $<5$ & $<5$ & $<5$ & $<5$ & & & 25 & 10 & $<5$ & $<5$ & \\
\hline olivina & 50 & 45 & 45 & 50 & 35 & 40 & 10 & 5 & 5 & 5 & & & & 10 & & & \\
\hline piroxênio & 20 & 20 & 35 & 25 & 50 & 45 & 75 & 80 & 85 & 85 & 65 & 60 & 5 & 20 & & 10 & \\
\hline anfibólio & 5 & 10 & 5 & $<5$ & $<5$ & 5 & 5 & 5 & 5 & $<5$ & 10 & 10 & 10 & $<5$ & $<5$ & $<5$ & \\
\hline feldspato & & & & 5 & & $<5$ & 5 & 5 & $<5$ & 5 & 15 & 25 & 5 & 15 & 65 & 45 & \\
\hline $\begin{array}{l}\text { outros } \\
\text { filossilic. }\end{array}$ & $<5$ & $<5$ & $<5$ & $<5$ & $<5$ & $<5$ & $<5$ & 5 & $<5$ & 5 & $<5$ & 5 & 30 & 15 & 10 & 10 & \\
\hline quartzo & & & & & & & $<5$ & $<5$ & $<5$ & & 5 & & 10 & 15 & 10 & & \\
\hline carbonatos & $<5$ & $<5$ & & $<5$ & $<5$ & $<5$ & & & & & $<5$ & & 15 & 15 & 15 & 35 & \\
\hline pentlandita & $<5$ & $<5$ & $<5$ & $<5$ & $<5$ & $<5$ & $<5$ & $<5$ & $<5$ & $<5$ & & & & & & & \\
\hline $\begin{array}{l}\text { № de amostras } \\
\text { furos de sonda }\end{array}$ & 20 & 10 & 10 & 32 & 40 & 5 & 122 & 11 & 33 & 6 & 8 & 4 & 2 & 2 & 6 & 3 & 5 \\
\hline $\begin{array}{l}\text { № de amostras } \\
\text { pó perfuratriz }\end{array}$ & - & 1 & - & 1 & 7 & 2 & 15 & 7 & 4 & 6 & - & - & 1 & 2 & 6 & - & 3 \\
\hline
\end{tabular}

A maior parte delas (32 amostras; $~ 60 \%$ do total) está relacionada aos grupos caracterizados por elevados conteúdos de enstatita: grupos 3, 6, 13 e 16, contendo respectivamente, 15, 4, 6 e 7 de amostras de pó de perfuratriz.

Outras 11 amostras ( $20 \%$ do total) são relacionadas aos grupos tipicamente compostos por elevadas proporções de olivina, enstatita e serpentina (grupos 8, 10, 11 e 14). Os agrupamentos 4, 9 e 12, caracterizados pelas elevadas proporções de carbonatos presentes, são representados preferencialmente por amostras de pó de perfuratriz. Por fim, 3 amostras foram definidas como outliers (diferentes das demais), sendo a SEC 8431120 (RC_130 366) 1013433 composta principalmente por carbonatos, a SEC 8430620 (RC_130 219) 1010689 por feldspatos e a amostra RC_100_0073 PCT 1016204 por enstatita. Não foram observadas amostras de pó de perfuratriz com composição tipicamente similar aos agrupamentos 1, 2, 5, 7 e 15.

A Figura 26 destaca a distribuição das amostras de pó de perfuratriz no gráfico 3D da análise por componente principal (PCA), enquanto que a descrição/ identificação das mesmas, associada aos respectivos agrupamentos, é apresentada no Apêndice 2. 
Figura 26 - Distribuição espacial dos agrupamentos segundo a análise de componente principal, com destaque para as amostras de pó de perfuratriz

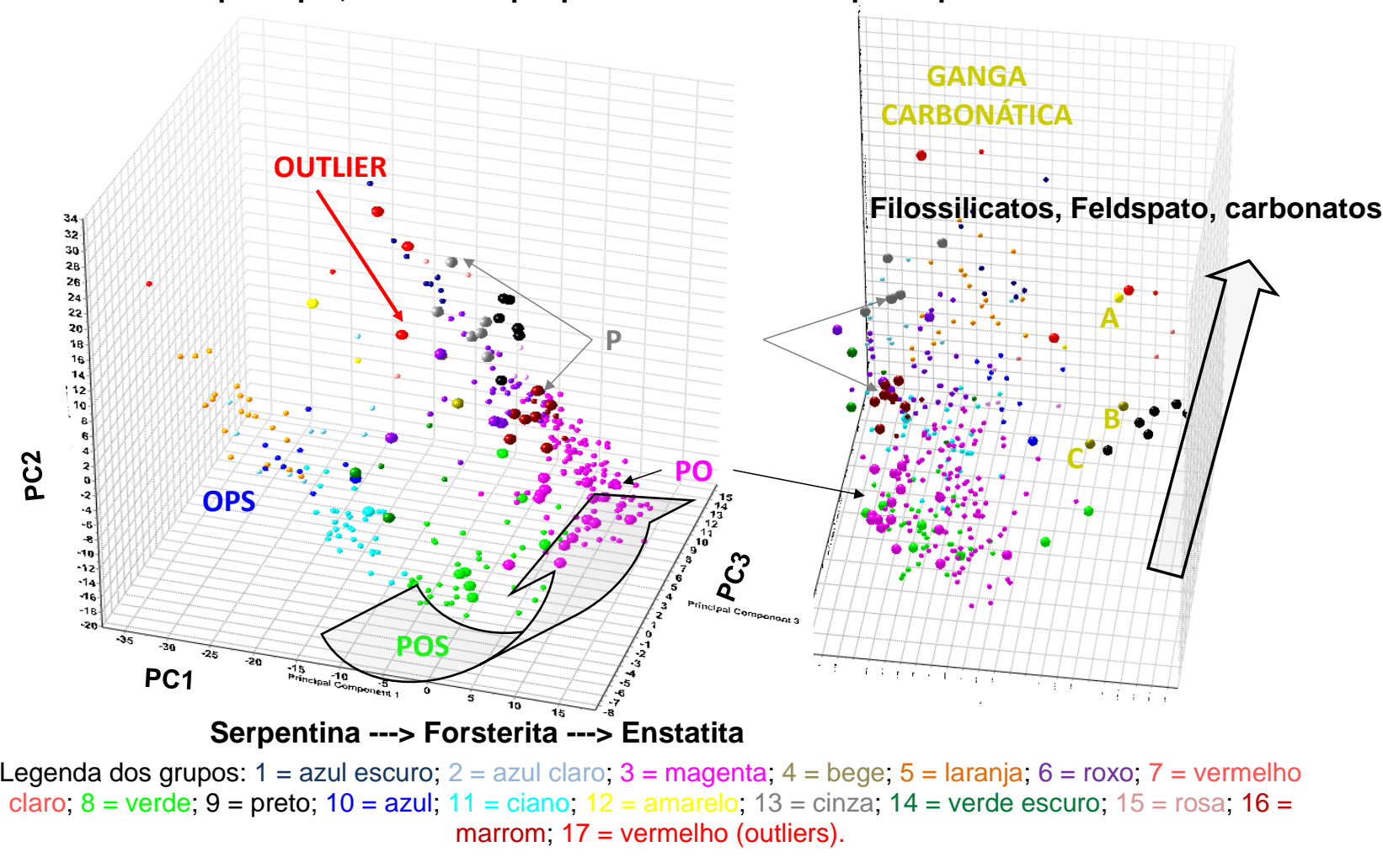

A análise do gráfico 3D do PCA para as amostras de testemunho de sondagens mais as 55 amostras de pó de perfuratriz possibilita o mesmo tipo de interpretação que os resultados da $1^{\circ}$ etapa: há uma variação gradual na presença de serpentina, forsterita (olivina) e enstatita (piroxênio) e a uma clara distinção dos grupos de amostras que possuem conteúdo expressivo de filossilicatos, carbonatos e feldspatos.

$\mathrm{Na}$ análise deste agrupamento houve uma mudança no valor de threshold (limiar) para $10 \%$. Na $1^{\text {a }}$ etapa do estudo o valor de threshold utilizado foi de $30 \%$. A Figura 27 compara os gráficos 3D de PCA com os diferentes thresholds.

Com base na observação dos gráficos, nota-se uma clara mudança na distribuição dos pontos (amostras). O gráfico com threshold de 30\% possuía uma maior aglutinação entre as amostras do mesmo grupo (mesma cor dos pontos) e uma maior diferença entre as distâncias intergrupos. Já quando utilizamos o threshold de $10 \%$ a dispersão dos pontos aumentou e houve uma maior sobreposição nas interfaces entre os grupos. 
Figura 27 - Comparação entre os gráficos 3D de PCA com diferentes valores de threshold

Amostras de testemunho de sondagem

$\left(E_{1}\right)$

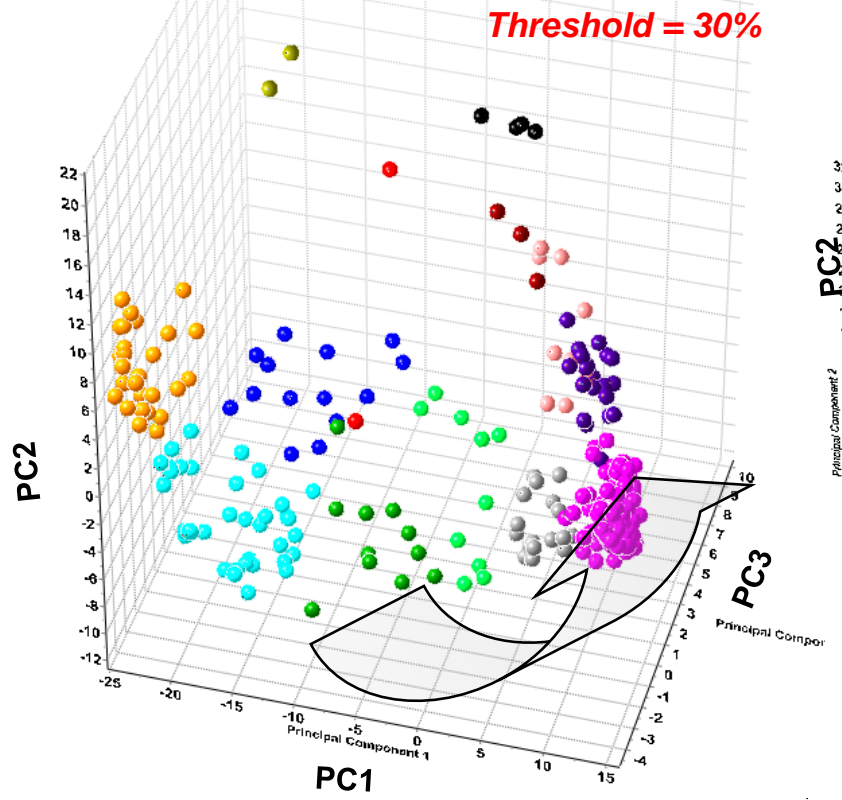

Serpentina ---> Forsterita ---> Enstatita
Amostras de testemunho de sondagem

+ 55 amostras de pó de perfuratriz $\left(E_{2}\right)$

Threshold $=10 \%$

Legenda dos grupos: 1 = azul; 2 = verde escuro; $3=$ preto; 4 = verde; $5=$ roxo; $6=$ ciano; 7 = laranja; $8=$

magenta; 9 = rosa claro; 10 = cinza; 11 = bege; 12 = marrom; 13 = azul claro; $14=$ vermelho (outliers).

Assim como o valor de cut-off, o valor de threshold é selecionado por critérios visuais do dendrograma e do gráfico 3D do PCA. Não há cálculo estatístico para seleção deste valor. Mais uma vez, encontra-se a dificuldade de selecionar um valor que reflita um significado físico. Assim, optou-se por variar este valor na análise das amostras de testemunho de sondagem somadas as 55 amostras de pó de perfurtariz, para um valor menor, onde pequenas variações seriam consideradas.

Usando o mesmo valor de cut-off $(119,0)$ o número de grupos aumentou de 14 para 17. A comparação entre as amostras agrupadas nas condições da $1^{\mathfrak{a}}$ etapa com a da $2^{\text {a }}$ etapa, mostrou que há uma pequena variação, mas, de forma geral, as amostras permaneceram nos mesmos grupos.

Poder-se-ia assumir um valor maior de threshold ou de cut-off, para o agrupamento das amostras, tanto na $1^{\underline{a}}$ quanto na $2^{\underline{a}}$ etapa, resultando em um número menor de grupos: somente os principais picos seriam considerados na comparação dos difratogramas. Porém, como se trata de um depósito onde a mineralogia é relativamente simples e com variações nas proporções minerais de olivina, serpentina, clino e orto-piroxênios, o agrupamento poderia tender a uma simplificação 
exacerbada, talvez se igualando a sensibilidade de uma classificação visual na descrição das amostras de testemunhos de sondagens aplicada na operação da mina.

Prezou-se por elevar o nível de discretização da análise multivariada dos difratogramas de raios $X$ ao máximo. Acredita-se que, mesmo sem a presença dos picos das fases menores (concentração abaixo de 5\%), devido ao limite de detecção por DRX, estes influenciam no perfil do difratograma (pequenas variações nas linhas próximas ao valor de background e a largura a meia altura dos picos). Assim, os grupos definidos por DRX-AEM na $1^{\underline{a}}$ e $2^{\underline{a}}$ Etapa foram mantidos como tal para respeitar o critério de máxima discretização.

\subsubsection{Amostras compostas para estudos de detalhe}

As amostras de pó de perfuratriz consideradas nas composições de amostras para os estudos caracterização de detalhe são apresentados no Apêndice 4. A seguir, na Tabela 17, são apresentadas amostras compostas e seus respectivos teores.

Tabela 17 - Teores dosados dos principais elementos das amostras tal qual das amostras estudadas

\begin{tabular}{|c|c|c|c|c|c|c|c|}
\hline \multirow[b]{2}{*}{ Amostra } & \multicolumn{7}{|c|}{ Teores (\% massa) } \\
\hline & $\mathrm{Ni}$ & $\mathrm{Cu}$ & Co & $\mathrm{Fe}$ & $\mathbf{S}$ & $\mathrm{SiO}_{2}$ & $\mathrm{MgO}$ \\
\hline OPS & 0,88 & 0,19 & 0,04 & 9,86 & 1,20 & 34,6 & 34,0 \\
\hline POS & 0,57 & 0,11 & 0,03 & 9,18 & 0,93 & 43,8 & 29,3 \\
\hline PO & 0,47 & 0,11 & 0,03 & 9,25 & 0,86 & 47,6 & 27,2 \\
\hline $\mathrm{P}$ & 0,44 & 0,09 & 0,03 & 9,37 & 0,67 & 49,1 & 27,2 \\
\hline Ganga A & 0,42 & 0,06 & 0,03 & 7,21 & 0,52 & 38,5 & 28,5 \\
\hline Ganga B & 0,51 & 0,10 & 0,03 & 7,22 & 0,67 & 31,2 & 27,9 \\
\hline Ganga C & 0,35 & 0,04 & 0,06 & 8,17 & 0,38 & 46,8 & 22,9 \\
\hline Out & 0,49 & 0,12 & 0,01 & 8,25 & 1,06 & 51,3 & 26,4 \\
\hline
\end{tabular}

Obs: OPS = Olivina/piroxênio/ com serpentina $>10 \% ;$ POS = Piroxênio/olivina/ com serpentina $=10 \% ; P O=$ Piroxênio/ com olivina = 10\%; $\boldsymbol{P}=$ Piroxênio/ com olivina $=5 \%$; $\boldsymbol{C S}=$ Minério carbonático com serpentina $>5 \%$ (separado em Ganga A, B e C); Out = Outlier.

A amostra OPS possui os maiores teores de $\mathrm{Ni}, \mathrm{Cu}, \mathrm{S}, \mathrm{Fe}$ e $\mathrm{MgO}$. Os teores de $\mathrm{Ni}$ estão na faixa de $0,4-0,5 \%$ nas amostras, exceto para o OPS com $0,88 \%$ e na Ganga C, com 0,35\%. O maior teor de $\mathrm{SiO}_{2}$ está na amostra Out (51,3\%) e o menor na amostra Ganga B (31,2\%). De maneira geral, pode-se separar as amostras em dois grupos mais a amostra Out: 1) OPS, POS, PO e P, com os teores de Ni, Cu, S, $\mathrm{MgO}$ decrescendo do OPS para o $\mathrm{P}$ com o aumento do teor de $\mathrm{SiO}_{2}$ no sentido inverso - do P para OPS; 2) Ganga A, B e C não possuem nenhuma tendência de aumento ou diminuição de teores entre si, mas quando comparadas ao primeiro grupo, pode- 
se dizer que elas possuem teores menores de Fe e S; a amostra Out possui teores similares ao primeiro grupo acima citado com maior conteúdo de $\mathrm{SiO}_{2}$.

\subsubsection{1 $\quad \underline{\text { Tempo de moagem e análise granuloquímica }}$}

As amostras compostas foram peneiradas a úmido na peneira de abertura de $0,15 \mathrm{~mm}$. O material retido em $0,15 \mathrm{~mm}$ foi moído em moinho planetário por quatro minutos seguido de peneiramento em $0,15 \mathrm{~mm}$ e remoagem do retido em tempo suplementar de 4 minutos, repetindo as etapas de moagem e peneiramento até assegurar $\mathrm{P}_{95}=0,15 \mathrm{~mm}$ (equivalente a granulometria de moagem industrial). $\mathrm{A}$ Tabela 18 apresenta o tempo de moagem em moinho planetário por amostras composta, assegurando $\mathrm{P}_{95}=0,15 \mathrm{~mm}$.

Tabela 18 -Tempo de moagem em moinho planetário para $P_{95}=0,15 \mathrm{~mm}$

\begin{tabular}{c|cccccccc}
\hline & \multicolumn{1}{c}{ Amostras } \\
& OPS & POS & PO & P & Ganga A & Ganga B & Ganga C & Out \\
\hline № de ciclos (4 mim) & 1 & 3 & 3 & 4 & 1 & 1 & 2 & 4 \\
Tempo total (mim) & 4 & 12 & 12 & 16 & 4 & 4 & 8 & 16 \\
\hline
\end{tabular}

Obs: OPS = Olivina/piroxênio/ com serpentina $>10 \% ; P O S=$ Piroxênio/olivina/ com serpentina $=10 \% ; P O=$ Piroxênio/ com olivina $=10 \% ; \boldsymbol{P}=$ Piroxênio/ com olivina $=5 \% ; \boldsymbol{C S}=$ Minério carbonático com serpentina $>5 \%$ (separado em Ganga A, B e C); Out = Outlier.

As amostras OPS, Ganga A e B necessitam apenas de um ciclo de 4 minutos, no moinho planetário, para atingir $\mathrm{P}_{95}=0,15 \mathrm{~mm}$; a Ganga $\mathrm{C}$ necessita de 2 ciclos em um total de 8 minutos; já as amostras POS e PO necessitam de três ciclos cada, totalizando 12 minutos; e as amostras Out e $\mathrm{P}$ possuem a maior resistência a moagem, necessitando de 16 minutos (4 ciclos), para atingir a especificação de tamanho desejada.

A distribuição em massa, de níquel, cobre e enxofre está exposta na Tabela 19 e as respectivas curvas de curva de distribuição granulométrica acumulada abaixo são apresentadas na Figura 28.

No que se refere a distribuição em massa, pode-se agrupar as amostras em:
a) maior conteúdo de finos - Ganga A e Ganga B, com cerca de 40\% da distribuição em massa menor que $0,020 \mathrm{~mm}$;
b) intermediárias - OPS, POS, PO, e Ganga C, com o OPS levemente mais fino; e
c) menor conteúdos de finos - P e Out, com curvas muito semelhantes. 
Aproximadamente de $40 \%-50 \%$ do níquel contido nas amostras está no intervalo $-0,105+0,020 \mathrm{~mm}$. A distribuição do níquel entre as amostras varia no intervalo acima de 0,105 mm e abaixo de 0,020 mm. As amostras PO e OPS possuem $23 \%$ e $19 \%$ no níquel acima de 0,105 mm, respectivamente, enquanto as Gangas $\mathrm{A}$ e B concentram $46 \%$ e $41 \%$ do níquel abaixo de $0,020 \mathrm{~mm}$.

Destaca-se que a amostra Out possui as curvas de distribuição mais distintas das demais, com uma concentração de níquel, cobre e enxofre nas frações mais finas. Entre as gangas, a Ganga C concentra esses elementos nas frações mais grossas.

Massa

Tabela 19 - Distribuição em massa, de Ni, Cu e S das amostras estudadas

\begin{tabular}{c|cccccccc}
\hline & & \multicolumn{7}{c}{$\%$ massa } \\
Fração $(\mathbf{m m})$ & OPS & POS & PO & P & Ganga A & Ganga B & Ganga C & Out \\
\hline$+0,105$ & 20,0 & 20,1 & 21,6 & 25,6 & 13,8 & 16,0 & 16,2 & 26,8 \\
$-0,105+0,053$ & 29,3 & 31,9 & 32,3 & 33,3 & 24,1 & 23,0 & 33,2 & 31,9 \\
$-0,053+0,020$ & 21,6 & 24,8 & 22,0 & 23,4 & 21,9 & 22,0 & 25,4 & 23,7 \\
$-0,020$ & 29,1 & 23,2 & 24,1 & 17,7 & 40,2 & 39,0 & 25,2 & 17,6 \\
\hline
\end{tabular}

Níquel

\begin{tabular}{c|cccccccc}
\hline & \multicolumn{10}{c}{ Distribuição de Ni (\%) } \\
Fração (mm) & OPS & POS & PO & P & Ganga A & Ganga B & Ganga C & Out \\
\hline$+0,105$ & 19 & 16 & 23 & 14 & 13 & 15 & 13 & 14 \\
$-0,105+0,053$ & 27 & 24 & 21 & 24 & 20 & 23 & 27 & 16 \\
$-0,053+0,020$ & 23 & 27 & 21 & 29 & 22 & 20 & 23 & 28 \\
$-0,020$ & 31 & 33 & 36 & 33 & 46 & 41 & 36 & 42 \\
\hline
\end{tabular}

Cobre

\begin{tabular}{c|cccccccc}
\hline & \multicolumn{1}{|c}{ Distribuição de Cu (\%) } & & \\
Fração $(\mathbf{m m})$ & OPS & POS & PO & P & Ganga A & Ganga B & Ganga C & Out \\
\hline$+0,105$ & 14 & 13 & 19 & 8 & 13 & 15 & 14 & 8 \\
$-0,105+0,053$ & 22 & 19 & 14 & 18 & 20 & 23 & 29 & 10 \\
$-0,053+0,020$ & 22 & 25 & 19 & 25 & 26 & 21 & 27 & 25 \\
$-0,020$ & 42 & 44 & 47 & 49 & 41 & 41 & 30 & 57 \\
\hline
\end{tabular}

\section{Enxofre}

\begin{tabular}{c|cccccccc}
\hline & \multicolumn{1}{|c}{ Distribuição de S (\%) } & & \\
Fração $(\mathbf{m m})$ & OPS & POS & PO & P & Ganga A & Ganga B & Ganga C & Out \\
\hline$+0,105$ & 21 & 18 & 22 & 12 & 13 & 19 & 15 & 9 \\
$-0,105+0,053$ & 29 & 24 & 17 & 24 & 24 & 23 & 28 & 15 \\
$-0,053+0,020$ & 23 & 28 & 23 & 33 & 21 & 23 & 25 & 29 \\
$-0,020$ & 27 & 30 & 37 & 32 & 42 & 35 & 31 & 47 \\
\hline
\end{tabular}

Obs: OPS = Olivina/piroxênio/ com serpentina $>10 \% ;$ POS = Piroxênio/olivina/ com serpentina $=10 \% ; \mathbf{P O}=$ Piroxênio/ com olivina $=10 \% ; \boldsymbol{P}=$ Piroxênio/ com olivina $=5 \%$; $\boldsymbol{C S}=$ Minério carbonático com serpentina $>5 \%$ (separado em Ganga A, B e C); Out = Outlier. 
Figura 28 - Curvas de distribuição granulométrica acumulada abaixo (massa Ni, Cu e S)

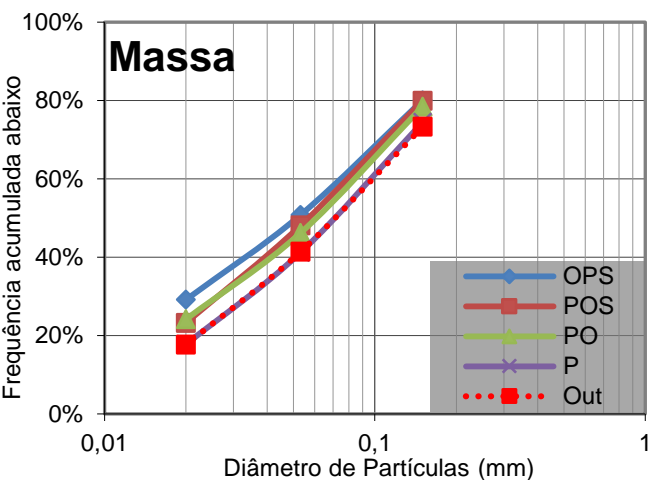

Amostras OPS, POS, PO e P
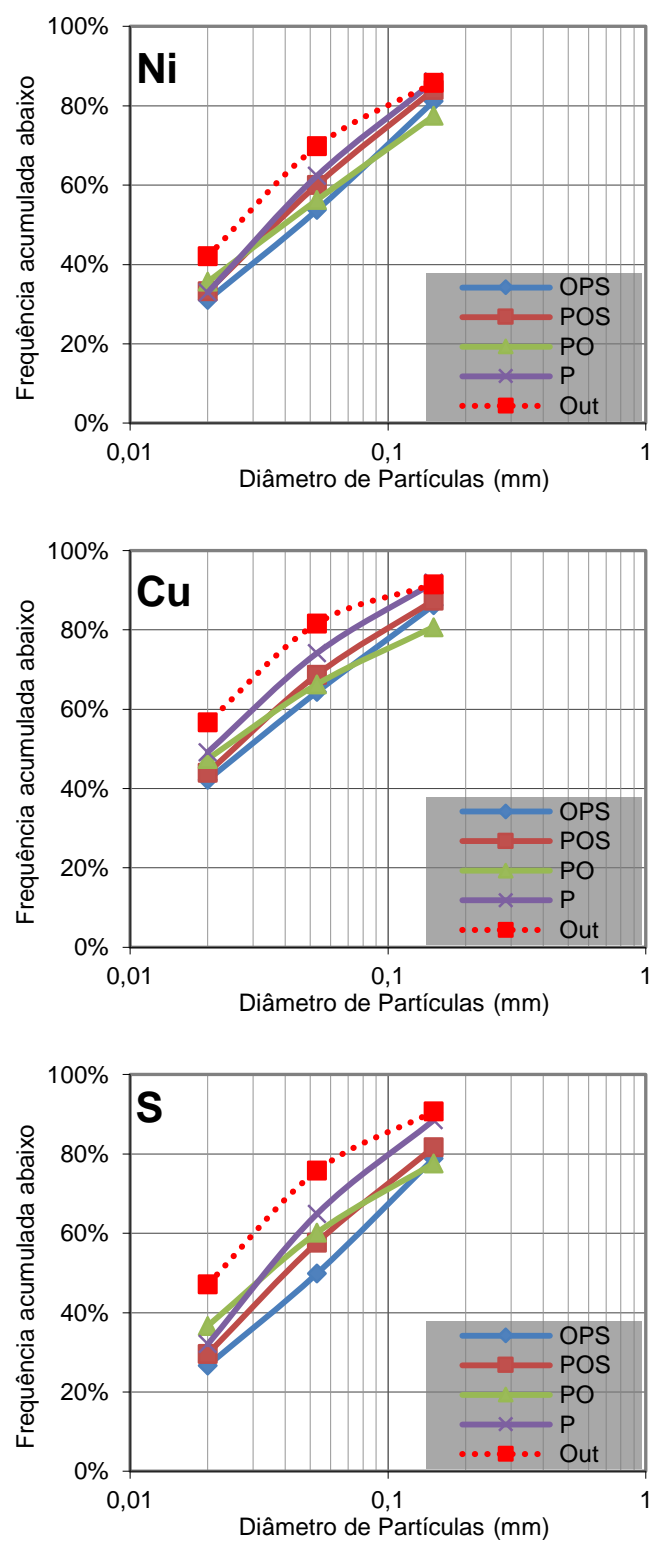

Amostras OPS, POS, PO e P

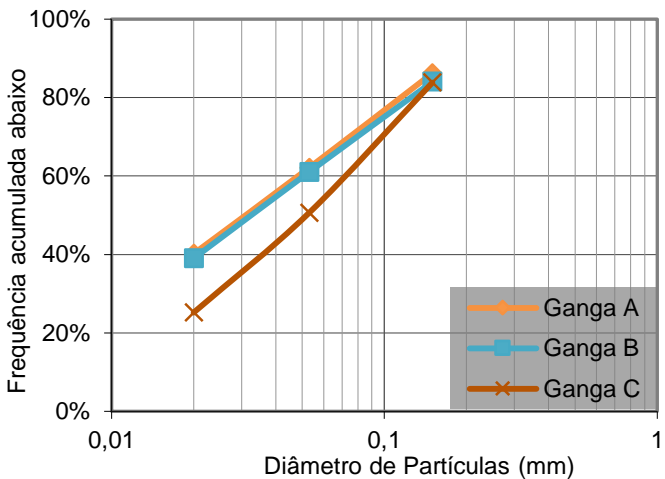

Amostras de Ganga A, B e C
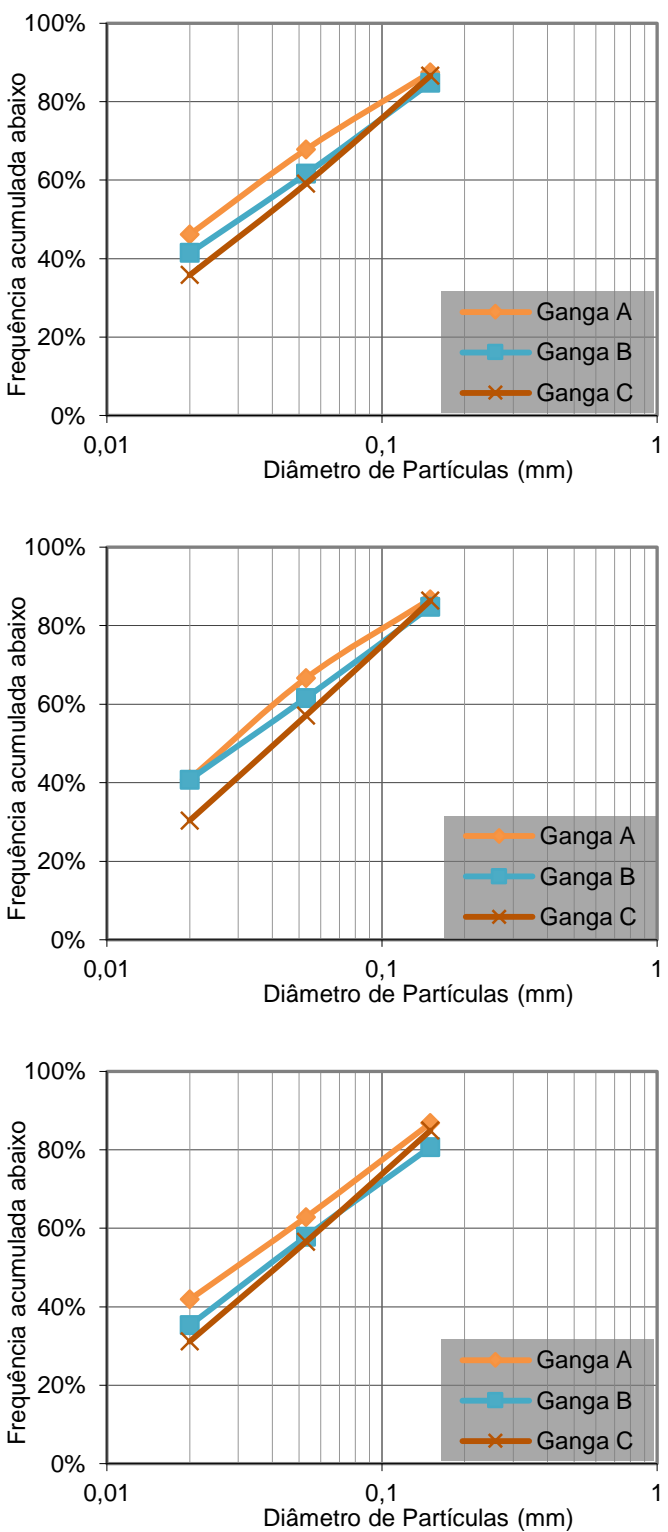

Amostras de Ganga A, B e C

Obs: OPS = Olivina/piroxênio/ com serpentina $>10 \% ;$ POS = Piroxênio/olivina/ com serpentina $=10 \% ; P O=$ Piroxênio/ com olivina $=10 \% ; \boldsymbol{P}=$ Piroxênio/ com olivina $=5 \% ; \boldsymbol{C S}=$ Minério carbonático com serpentina $>5 \%$ (separado em Ganga $A, B$ e $C$ ); Out = Outlier. 


\subsubsection{Caracterização mineralógica de detalhe}

Neste subitem serão apresentados e discutidos de forma condensada e comparativa os resultados das amostras objeto de estudos mineralógicos de detalhe por MEV-MLA. O Apêndice 6 traz em detalhe e, separado por frações, os resultados condensados a seguir. $O$ Apêndice 7 traz a química calculada a partir da mineralogia quantificada por MLA.

\subsubsection{Composição mineralógica}

A Tabela 20 e a Tabela 21, respectivamente, mostram a composição mineralógica das amostras OPS, POS, PO, P, Ganga A, Ganga B, Ganga C e Out, bem como o total de sulfetos e a proporção entre eles por amostras. A Figura 29 e a Figura 30 ilustram os conteúdos da Tabela 20 e Tabela 21.

Tabela 20 - Composição mineralógica das amostras estudadas (total - \% em massa)

\begin{tabular}{|c|c|c|c|c|c|c|c|c|}
\hline Minerais & OPS & POS & PO & $\mathbf{P}$ & Ganga A & Ganga B & Ganga C & Out \\
\hline olivina & 37,8 & 18,5 & 9,99 & 8,78 & 2,58 & 3,11 & 11,8 & 0,14 \\
\hline serpentina & 37,8 & 16,1 & 3,88 & 5,03 & 36,8 & 42,2 & 24,2 & 0,30 \\
\hline ortopiroxênio & 6,49 & 49,5 & 72,6 & 69,7 & 38,7 & 13,2 & 27,2 & 85,7 \\
\hline clinopiroxênio & 1,77 & 3,86 & 6,11 & 5,45 & 0,67 & 1,00 & 1,06 & 7,18 \\
\hline anfibólio & 2,00 & 2,42 & 1,79 & 4,50 & 1,81 & 1,64 & 2,92 & 0,64 \\
\hline outros silicatos & 0,78 & 1,78 & 2,20 & 1,76 & 3,44 & 8,16 & 19,8 & 2,56 \\
\hline espinelio-Cr & 3,38 & 1,47 & 0,78 & 1,34 & 1,30 & 3,92 & 1,09 & 0,27 \\
\hline oxido-Fe & 2,14 & 0,39 & 0,34 & 0,47 & 0,24 & 1,45 & 0,71 & 0,56 \\
\hline mica & 0,25 & 1,24 & 0,30 & 0,35 & 6,88 & 0,11 & 8,33 & 0,23 \\
\hline carbonatos & 3,11 & 1,72 & 0,37 & 0,54 & 4,87 & 22,2 & 1,55 & 0,08 \\
\hline outros & 0,29 & 0,24 & 0,12 & 0,14 & 0,84 & 0,29 & 0,13 & 0,04 \\
\hline \multicolumn{9}{|l|}{ Sulfetos } \\
\hline pentlandita & 1,67 & 1,37 & 0,80 & 0,90 & 0,68 & 0,69 & 0,48 & 1,18 \\
\hline pentl_oxid & 1,71 & 0,31 & 0,10 & 0,20 & 0,30 & 0,64 & 0,26 & 0,18 \\
\hline calcopirita & 0,25 & 0,35 & 0,19 & 0,23 & 0,19 & 0,24 & 0,11 & 0,29 \\
\hline pirita & 0,48 & 0,58 & 0,34 & 0,29 & 0,61 & 1,04 & 0,28 & 0,53 \\
\hline pirrotita & 0,04 & 0,15 & 0,11 & 0,26 & 0,01 & 0,01 & 0,02 & 0,13 \\
\hline arsenopirita & $<0,01$ & $<0,01$ & 0,01 & $<0,01$ & 0,01 & $<0,01$ & $<0,01$ & $<0,01$ \\
\hline sulfetos_FeCoNi & 0,09 & 0,02 & $<0,01$ & 0,01 & 0,02 & 0,12 & 0,02 & 0,01 \\
\hline Pentl+Pentl oxid. & 3,38 & 1,67 & 0,90 & 1,10 & 0,97 & 1,33 & 0,74 & 1,36 \\
\hline
\end{tabular}

Obs: OPS = Olivina/piroxênio/ com serpentina >10\%; POS = Piroxênio/olivina/ com serpentina $=10 \% ; \boldsymbol{P O}=$ Piroxênio/ com olivina = 10\%; $\boldsymbol{P}=$ Piroxênio/ com olivina $=5 \% ; \boldsymbol{C S}=$ Minério carbonático com serpentina $>5 \%$ (separado em Ganga $A, B$ e C); Out = Outlier; outros silicatos = quartzo, feldspato potássico e plagioclásio; carbonatos = calcita, dolomita, magnesita e anquerita; outros = clorita, espinélio-Cr, óxido-Fe, ilmenita, apatita, coríndon. 
Tabela 21 - Composição mineralógica das amostras estudadas mineralógicos (total - \% em massa): total de sulfetos e a porcentagem relativa entre eles

\begin{tabular}{l|cccccccc}
\hline \multicolumn{1}{c|}{ Minerais } & OPS & POS & PO & P & Ganga A & Ganga B & Ganga C & Out \\
\hline \% sulfetos & $\mathbf{4 , 2}$ & $\mathbf{2 , 8}$ & $\mathbf{1 , 5}$ & $\mathbf{1 , 9}$ & $\mathbf{1 , 8}$ & $\mathbf{2 , 7}$ & $\mathbf{1 , 2}$ & \multirow{2}{*}{$\mathbf{2 , 3}$} \\
\hline & \multicolumn{7}{c}{ \% relativa entre os sulfetos (normalizado a 100\%) } \\
\hline pentlandita & 39,3 & 49,2 & 51,6 & 47,2 & 37,4 & 25,1 & 40,8 & 50,9 \\
pentl_Oxid & 40,5 & 11,1 & 6,40 & 10,7 & 16,3 & 23,6 & 22,6 & 7,55 \\
calcopirita & 5,78 & 12,6 & 12,0 & 12,3 & 10,5 & 8,66 & 9,22 & 12,6 \\
pirita & 11,4 & 21,0 & 22,0 & 15,5 & 33,4 & 38,0 & 23,9 & 23,0 \\
pirrotita & 0,99 & 5,28 & 7,03 & 13,8 & 0,39 & 0,28 & 1,47 & 5,49 \\
arsenopirita & 0,00 & 0,07 & 0,56 & 0,13 & 0,76 & 0,10 & 0,00 & 0,13 \\
sulfetos_FeCoNi & 2,07 & 0,74 & 0,23 & 0,33 & 1,30 & 4,28 & 1,72 & 0,22 \\
\hline
\end{tabular}

Obs: $\mathbf{O P S}=$ Olivina/piroxênio/ com serpentina $>10 \% ; \boldsymbol{P O S}=$ Piroxênio/olivina/ com serpentina $=10 \% ; \mathbf{P O}=$ Piroxênio/ com olivina = 10\%; $\boldsymbol{P}=$ Piroxênio/ com olivina $=5 \% ; \boldsymbol{C S}=$ Minério carbonático com serpentina $>5 \%$ (separado em Ganga A, B e C); Out = Outlier;

A amostra OPS possui o maior conteúdo de pentlandita, pentlandita oxidada e sulfetos, corroborando com seus maiores teores de $\mathrm{Ni}$, Cu e $\mathrm{S}$, quando comparada com as demais amostras.

Considerando as amostras OPS, POS, PO e P, há uma diminuição nos teores de olivina, serpentina e sulfetos das amostras OPS e POS para PO e P e, nesta mesma ordem, um aumento nos teores de piroxênio. A amostra Ganga B destaca-se pelo alto conteúdo de carbonatos (22\%), enquanto a amostra Ganga $A$ e B pela alta nos teores de mica e outros silicatos (predominantemente feldspatos). A amostra Out possui a maior concentração de piroxênios, aliada à quase ausência de olivina e serpentina.

Estas observações corroboram as interpretações propostas para distribuição dos pontos (amostras) nos gráficos 3D do PCA gerados: as amostras se diferenciam basicamente pelo conteúdo de olivina, serpentina, piroxênios, carbonatos e outros silicatos (predominantemente feldspatos). Sendo as amostras OPS, POS, PO e P diferenciadas pelos conteúdos de olivina, serpentina e piroxênios; e as amostras Ganga A, B e C por apresentarem maiores concentrações de carbonatos e/ou micas e/ou outros silicatos/feldspatos.

O termo pentlandita oxidada refere-se às formas de alteração da superfície da pentlandita (textura de alteração). Não existem partículas de pentlandita oxidada livres e elas estão quase em sua totalidade associadas à pentlandita. Esta relação será discutida e explicada posteriormente no item 4.2.3.2. 
Figura 29 - Composição mineralógica das amostras OPS, POS, PO e P (\% em massa)

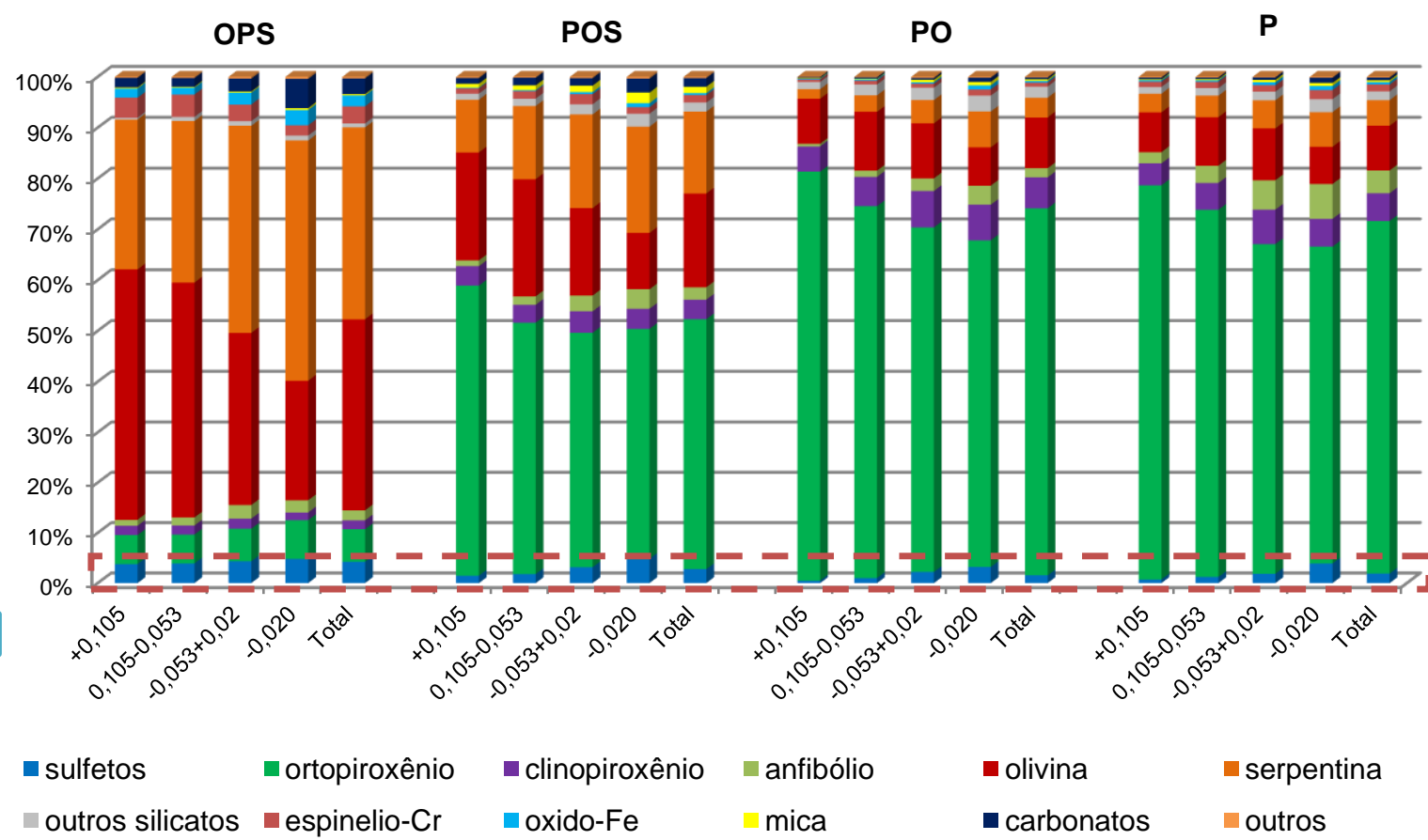

Obs: outros silicatos = quartzo, feldspato potássico e plagioclásio; carbonatos = calcita, dolomita, magnesita e anquerita; outros = clorita, espinélio-Cr, óxido-Fe, ilmenita, apatita, coríndon.

$\%$ relativa entre os sulfetos

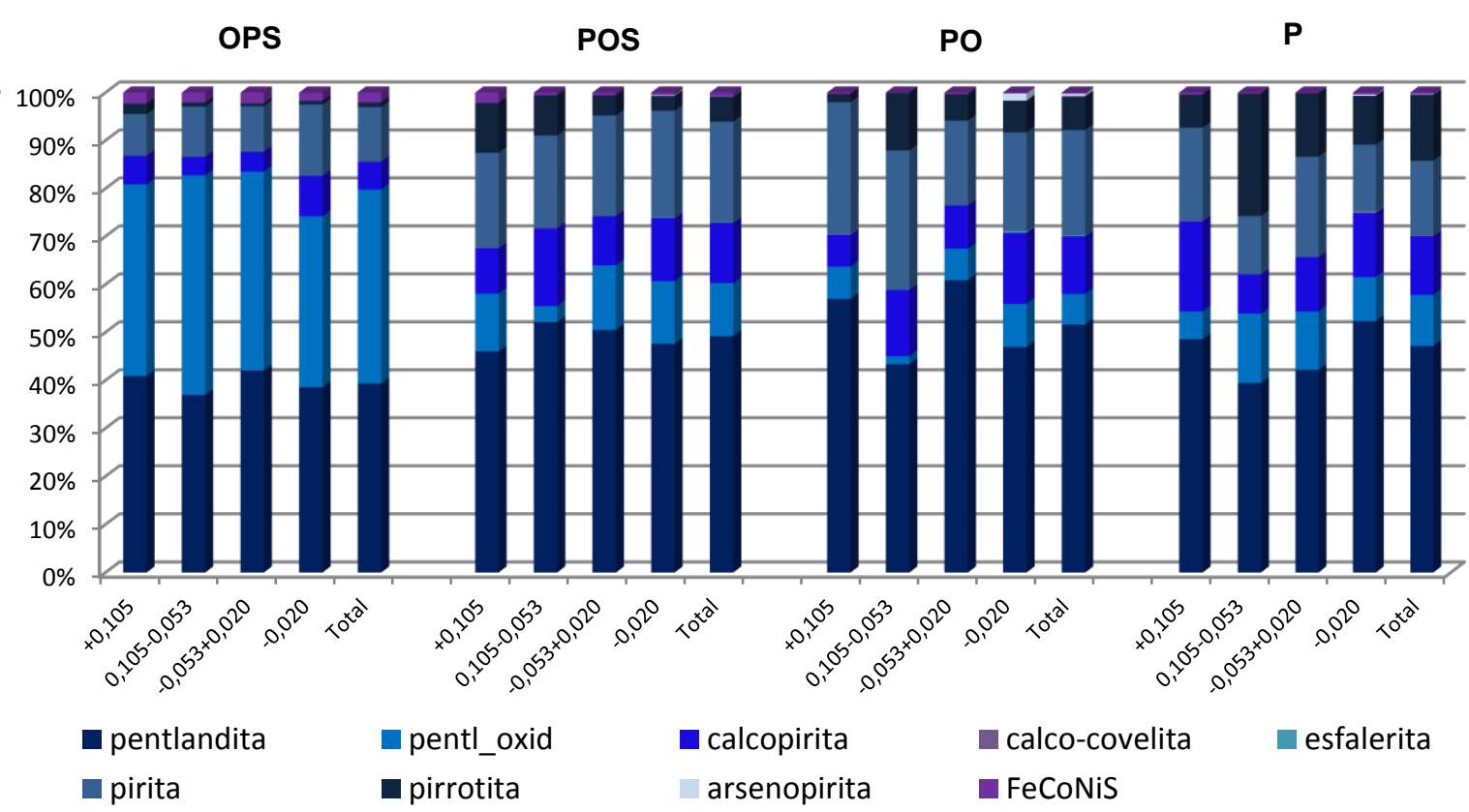

Obs: OPS = Olivina/piroxênio/ com serpentina $>10 \% ;$ POS = Piroxênio/olivina/ com serpentina $=10 \% ; P O=$ Piroxênio/ com olivina $=10 \% ; \boldsymbol{P}=$ Piroxênio/ com olivina $=5 \%$ 
Figura 30 - Composição mineralógica das amostras de Ganga A, B, C e Outlier (\% em massa)

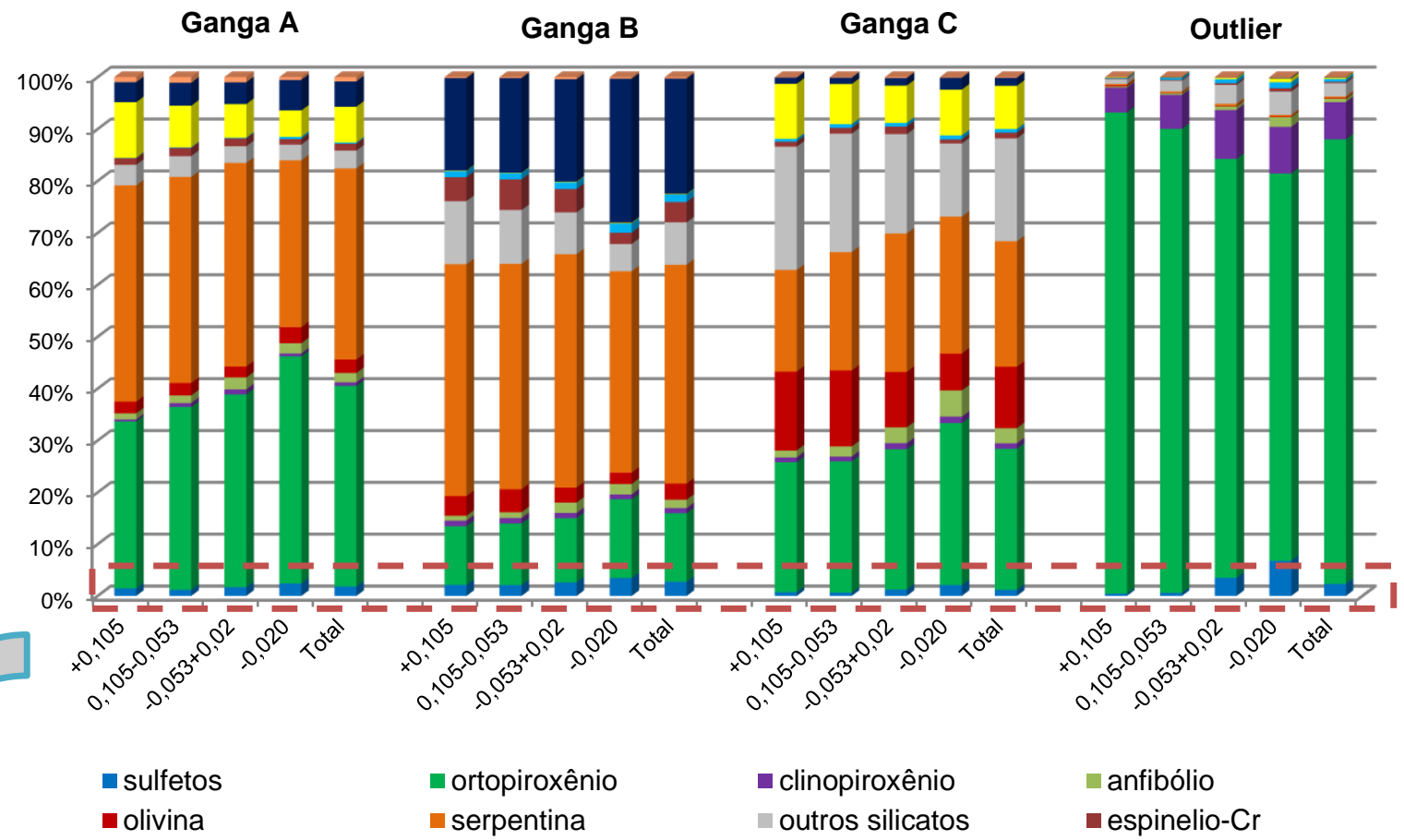

Obs: outros silicatos = quartzo, feldspato potássico e plagioclásio; carbonatos = calcita, dolomita, magnesita e anquerita; outros = clorita, espinélio-Cr, óxido-Fe, ilmenita, apatita, coríndon.

\section{$\%$ relativa entre os sulfetos}

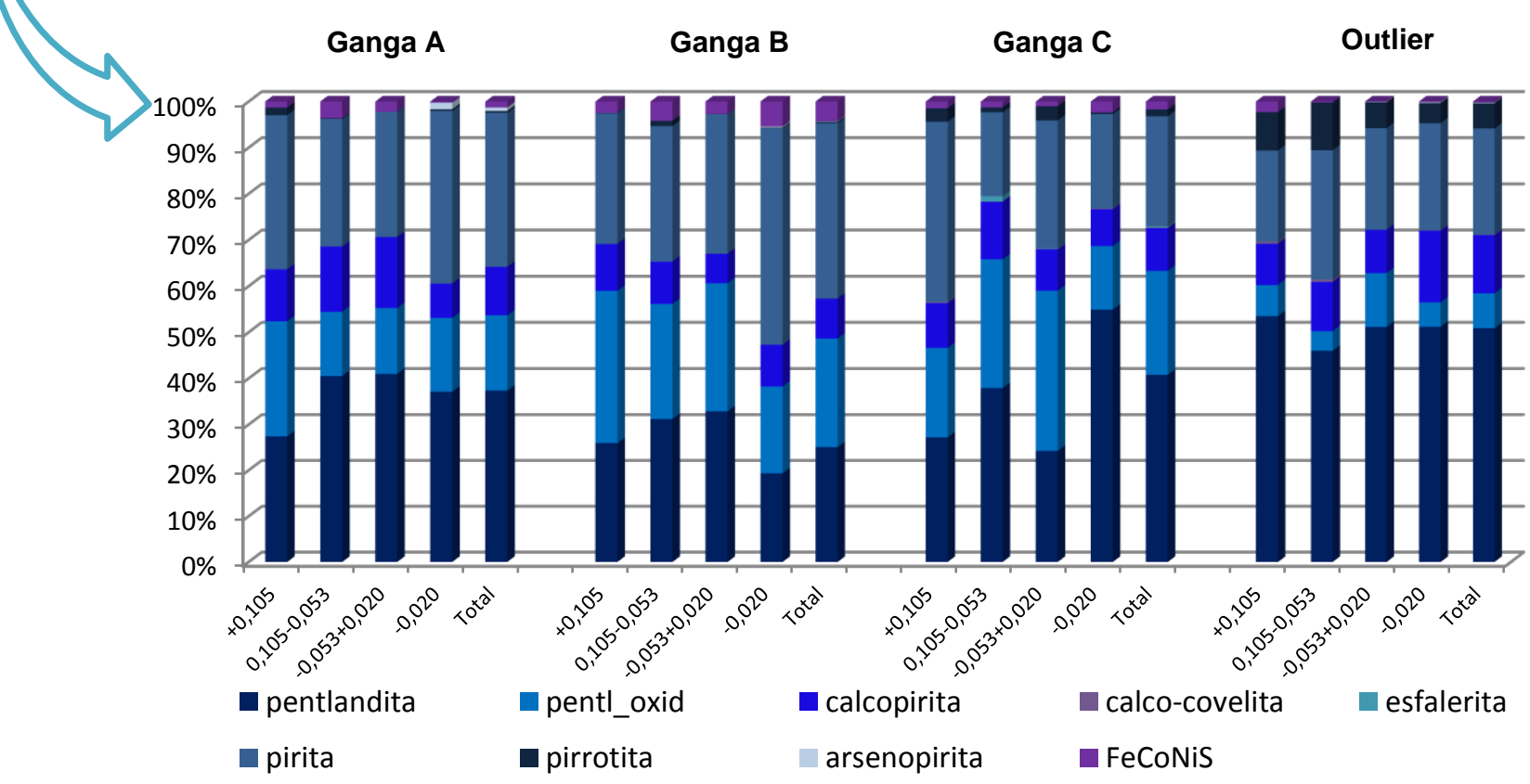

\subsubsection{Características texturais da pentlandita}

Uma investigação da textura da pentlandita foi realizada nas oito amostras estudadas ao microscópio eletrônico de varredura (MEV), com auxílio de um sistema de microanálise de EDS (Energy-dispersive X-ray spectroscopy), assim como ao 
microscópio óptico. Observou-se que as amostras OPS e as Gangas A, B e C, possuem partículas com grãos de pentlandita alterados, como ilustra a Figura 31.

Figura 31 - Imagem de MEV-BSE da pentlandita mostrando sua textura de alteração

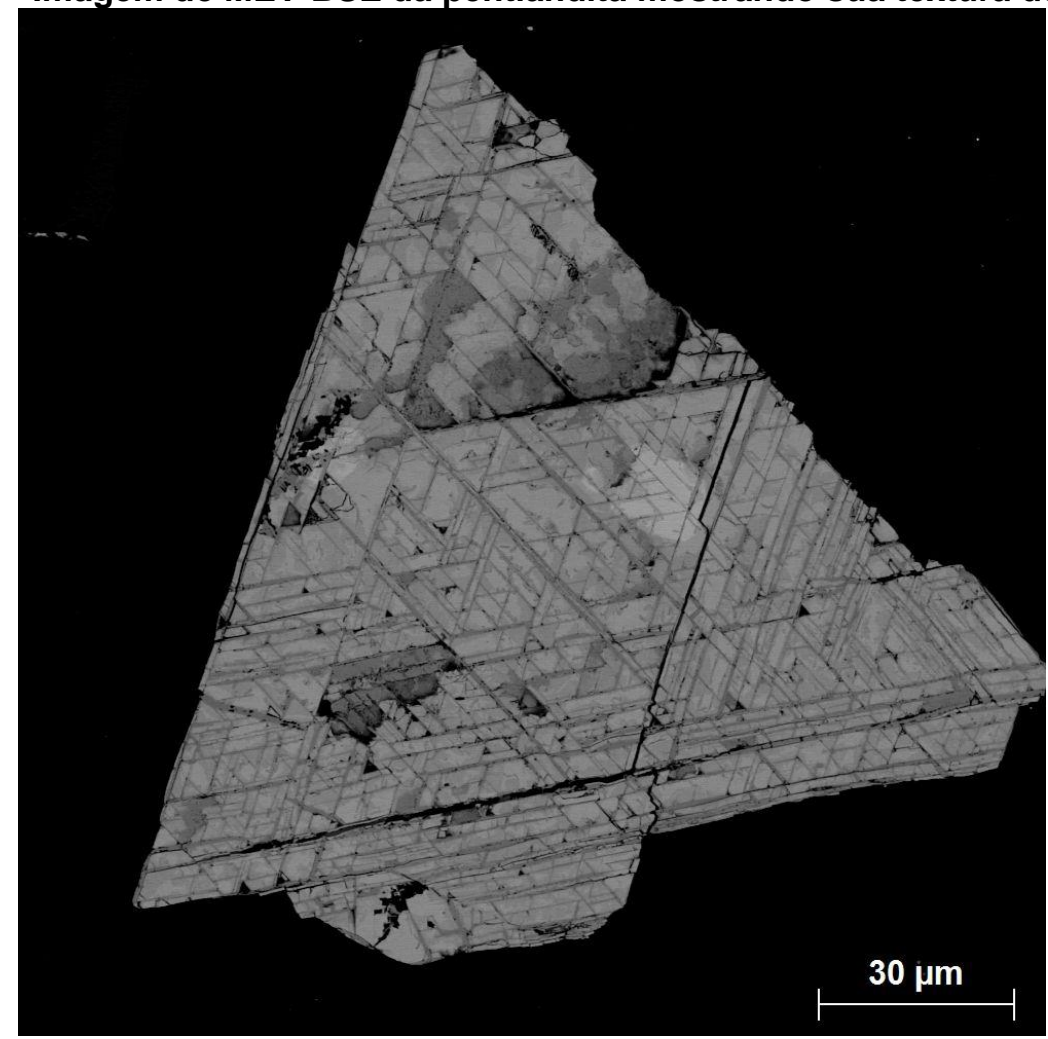

Fonte: amostra OPS

A partícula da Figura 31 apresenta regiões com diferentes tons de cinza. Como o detector utilizado na captura dessa imagem foi o de elétrons retroespalhados (backscattered electrons - BSE), que detecta variações composicionais: as regiões onde há tons de cinza mais escuros possuem átomos de elementos mais leves em sua composição em relação as regiões em tons de cinza mais claros.

A Figura 32 traz um mapeamento elementar por EDS da mesma partícula acima. O mapeamento por EDS mostra em falsa cor a concentração de cada elemento presente na partícula. Nota-se que as regiões com tons de cinza mais escuros são aquelas onde há uma concentração de ferro e oxigênio e a ausência de níquel e enxofre. 
Figura 32 - Mapeamento elementar por MEV-EDS da textura de alteração da pentlandita
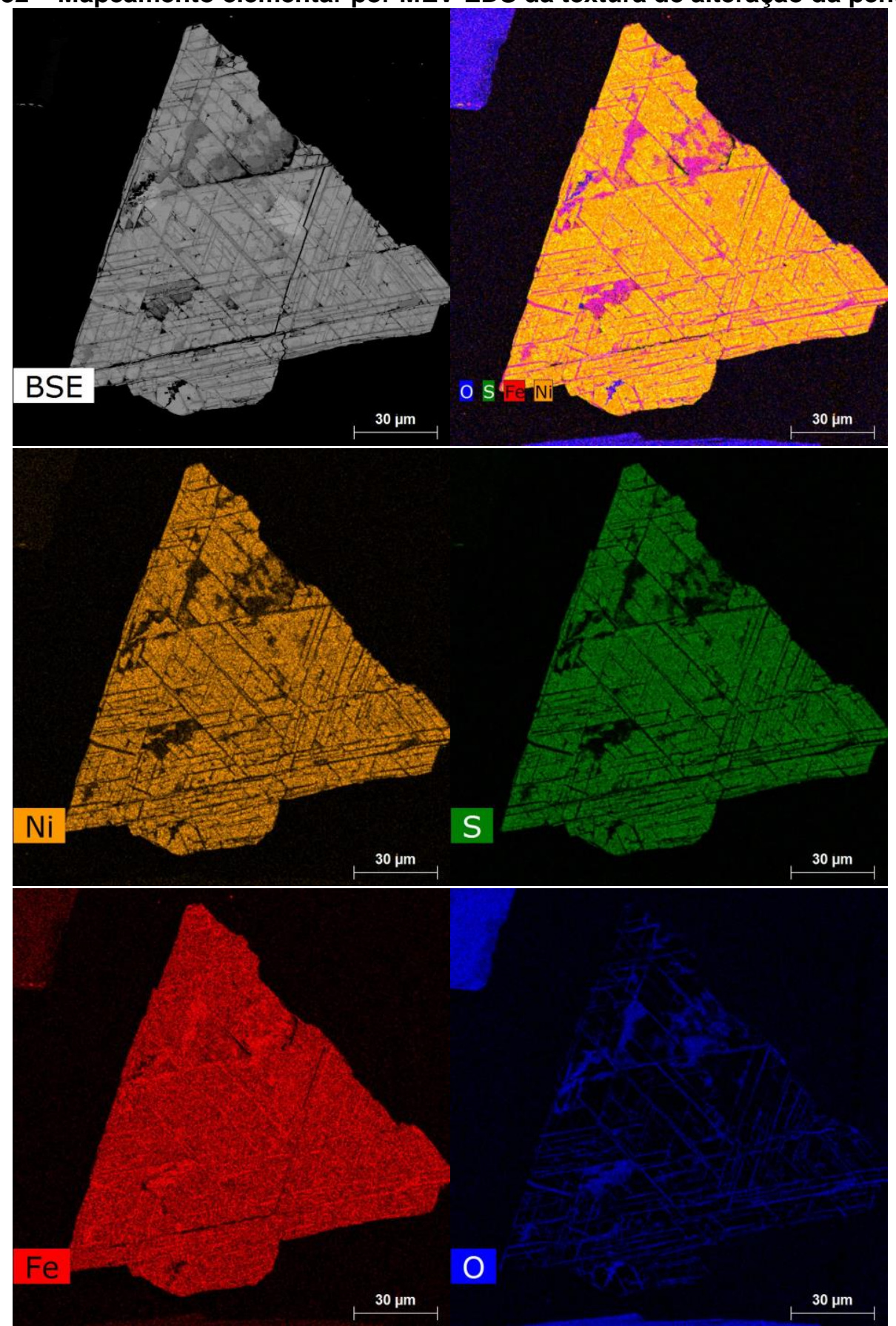

Fonte: amostra OPS

A Figura 33 mostra análise pontual por EDS de uma região da partícula de pentlandita descrita acima, para quantificar a composição das áreas com diferentes tons de cinza. 
Figura 33 - Imagem de BSE da pentlandita com um zoom em uma região para quantificar por EDS a composição das áreas com diferentes tons de cinza (áreas/pontos verdes)
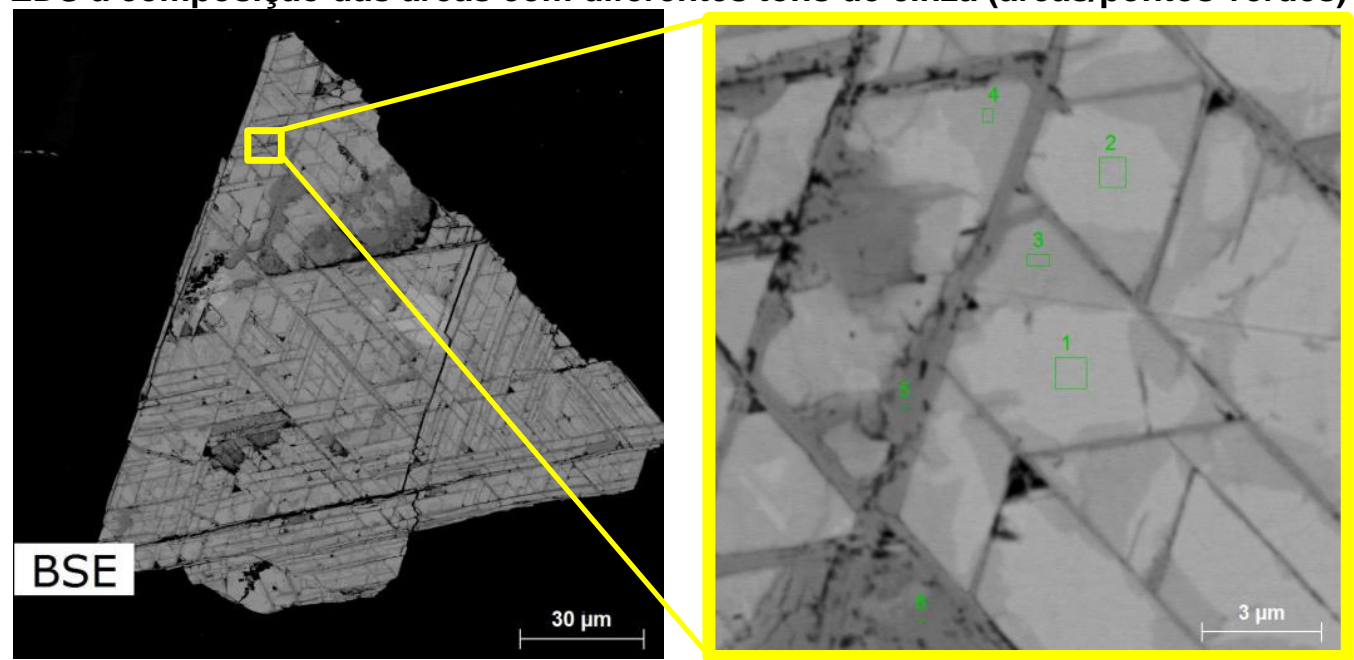

Fonte: amostra OPS

\begin{tabular}{c|cccc}
\hline $\begin{array}{c}\text { Ponto/ } \\
\text { Área }\end{array}$ & $\mathbf{N i}$ & $\mathbf{S}$ & $\mathbf{F e}$ & $\mathbf{0}$ \\
\hline 1 & 40,7 & 33,9 & 25,4 & \\
2 & 40,9 & 33,8 & 25,4 & \\
3 & 37,3 & 43,0 & 19,7 & \\
4 & 40,9 & 42,5 & 16,6 & 35,2 \\
5 & & & 64,8 & 35,9 \\
6 & & & 64,1 & \\
\hline
\end{tabular}

Considerando os resultados apresentados na Figura 31, Figura 32 e Figura 33, pode-se sugerir a pentlandita sofreu uma alteração parcial, transformando-a inicialmente e, posteriormente, em um óxido de ferro (magnetita?), sendo esta alteração condicionada pela direção de partição (111) da pentlandita. Desta forma, o tom de cinza mais claro corresponde a pentlandita, o tom de cinza intermediário a violarita e o mais escuro ao óxido de ferro.

Também foram observados grãos de pentlandita sem alteração, como mostra a Figura 34 - imagem de BSE com uma análise pontual de EDS. Nota-se também que sua composição não apresenta variações expressivas. 
Figura 34 - Imagem de pentlandita não alterada com a quantificação de sua composição, nas áreas verdes assinaladas, por análise pontual de EDS

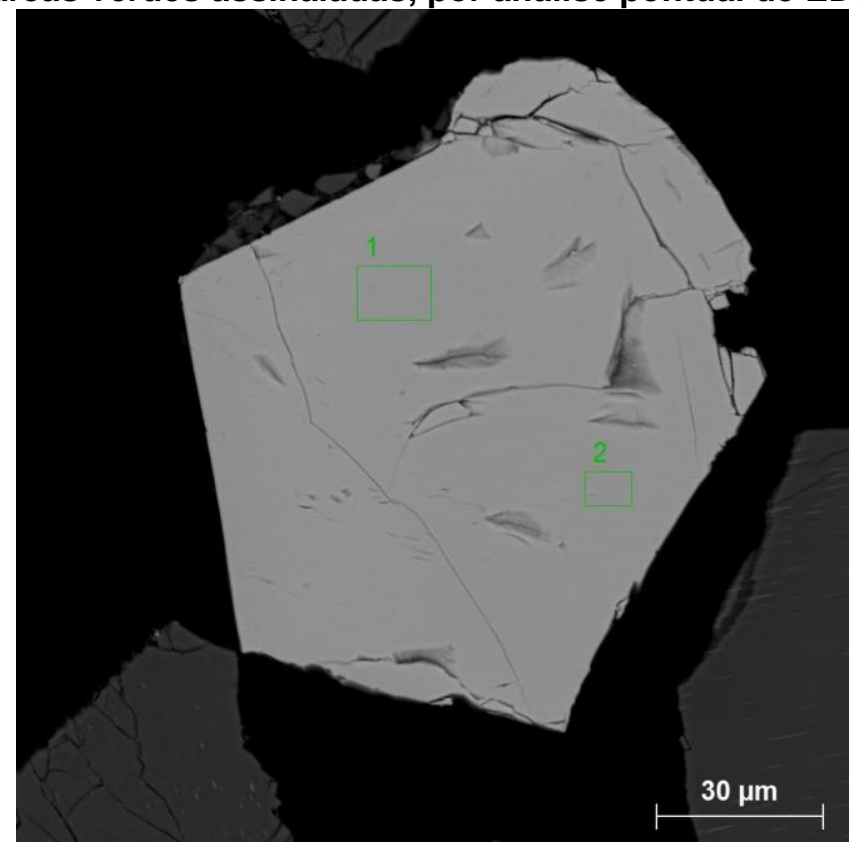

Fonte: amostra $\mathrm{P}$

\begin{tabular}{c|ccc}
\hline $\begin{array}{c}\text { Ponto/ } \\
\text { Área }\end{array}$ & $\mathbf{N i}$ & $\begin{array}{c}\text { Teores (\%) } \\
\mathbf{S}\end{array}$ & $\mathbf{F e}$ \\
\hline 1 & 37,6 & 31,0 & 31,3 \\
2 & 37,4 & 31,3 & 31,3 \\
\hline
\end{tabular}

Tanto a feição de alteração da pentlandita acima citada, como o conteúdo de finos presente nas amostras estudadas estão relacionados à mineralogia do minério ou domínios anteriormente definidos. Amostras relativas a rochas de composição mais peridotítica (OPS) e com maior presença de carbonatos (Gangas A, B e C) são aquelas que apresentam maiores intensidades de alteração da pentlandita, conteúdo de finos e de níquel associado a silicatos; nas amostras de composição mais piroxeníticas (PO e P), a pentlandita apresenta baixo nível de alteração para violarita e pouca ou nenhuma associação com óxidos de ferro.

Desta forma, buscou-se individualizar as proporções de pentlandita e pentlandita oxidada (violarita + óxidos de ferro) utilizando-se do MEV-MLA. Mesmo tendo-se que as fases envolvidas na alteração da pentlandita são a violarita e óxidos de ferro, optou-se por classificá-las ao MLA somente como pentlandita oxidada. Isto deve-se ao fato de que a magnificação utilizada na análise implicava em tamanho de pixel que resultava em espectros de EDS mistos sem possibilidade de discriminação.

A avaliação do conteúdo da pentlandita oxidada nas amostras estudadas (Tabela 20) mostra que há um aumento relativo dessa fase nas amostras OPS e nas 
Gangas A, B e C. Para uma visualização desta textura, imagens de MEV-MLA em BSE e classificadas por falsa cor são apresentadas no Apêndice 8. A Figura 35 ilustra outros exemplos de mapeamento elementar por MEV-EDS da textura de alteração da pentlandita. Já as Figura 33 e Figura 34 mostram exemplos de textura da pentlandita e outros sulfetos ao microscópio óptico de luz refletida .

No processo de beneficiamento da mina Santa Rita utiliza-se a flotação de sulfetos como a operação unitária de concentração. Uma vez alterada a superfície da pentlandita, pode deixar de atuar adequadamente como sulfeto na flotação mesmo com emprego de bissulfeto para a sulfetação da superfície de minerais de interesse. Como o coletor utilizado associa-se a sulfetos, partículas com alto grau de oxidação não serão adequadamente recuperadas na flotação, ocasionando perda na recuperação de Ni. Assim, o conteúdo de pentlandita oxidada é a característica mais relevante da amostra em termos de processo, analisando somente a mineralogia modal. Cabe destacar, então, que a amostra OPS possui uma quantidade expressiva, em relação as demais amostras $(1,71 \%)$, de pentlandita oxidada, representando $40 \%$ do total de sulfetos desta amostra. 
Figura 35 - Outros exemplos de mapeamento elementar por MEV-EDS da textura de alteração da pentlandita

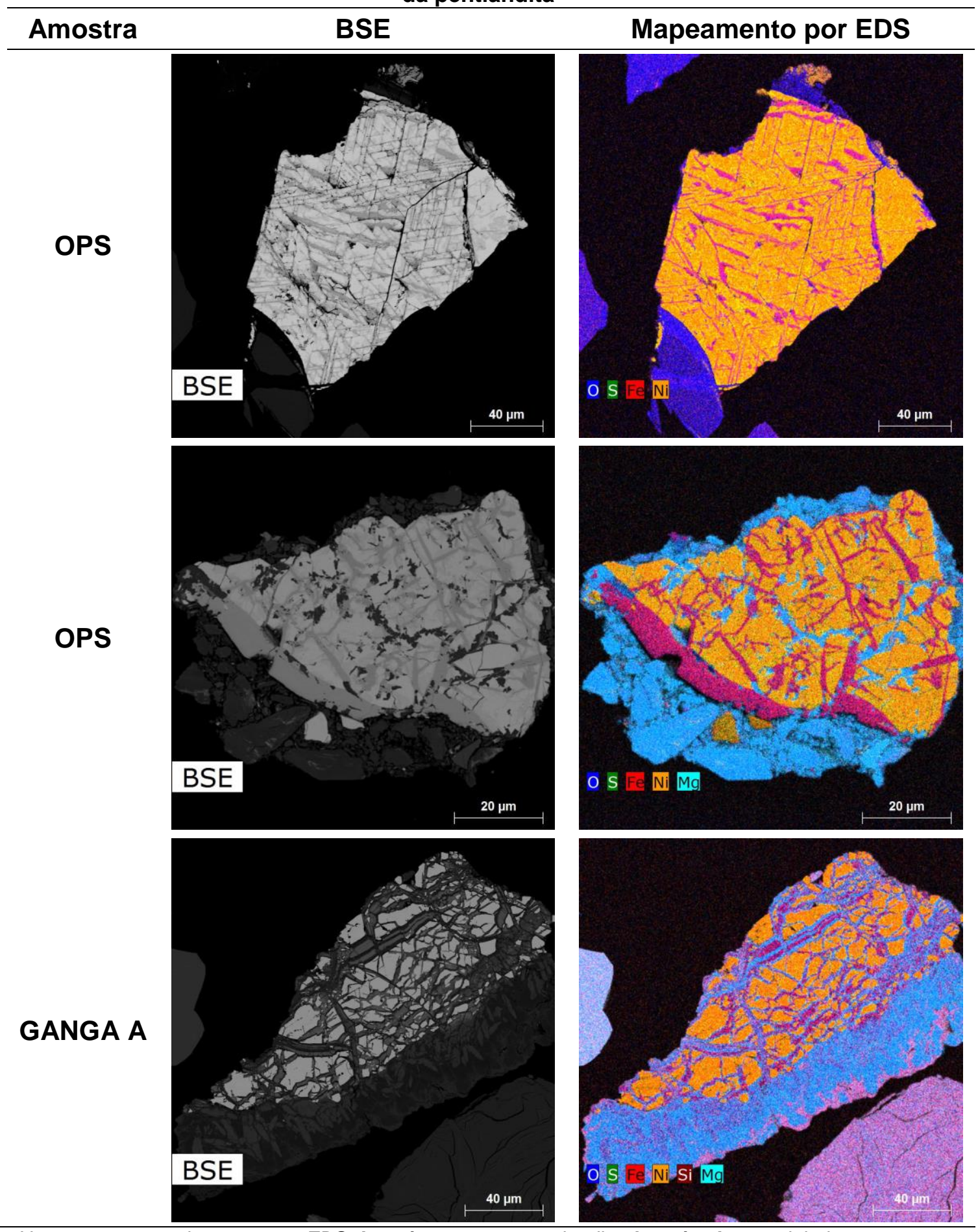

Obs: No mapeamento elementar por EDS, laranja escuro = pentlandita, laranja claro = violarita, rosa escuro = óxido de ferro, rosa claro = anquerita e azul ciano = serpentina. $O P S=$ Olivina/piroxênio/ com serpentina $>10 \%$; CS = Minério carbonático com serpentina $>5 \%$ (separado em Ganga $A, B$ e C); 
Figura 36 - Exemplos de textura da pentlandita e outros sulfetos ao microscópio óptico de luz refletida - amostras OPS, Ganga A, B e C

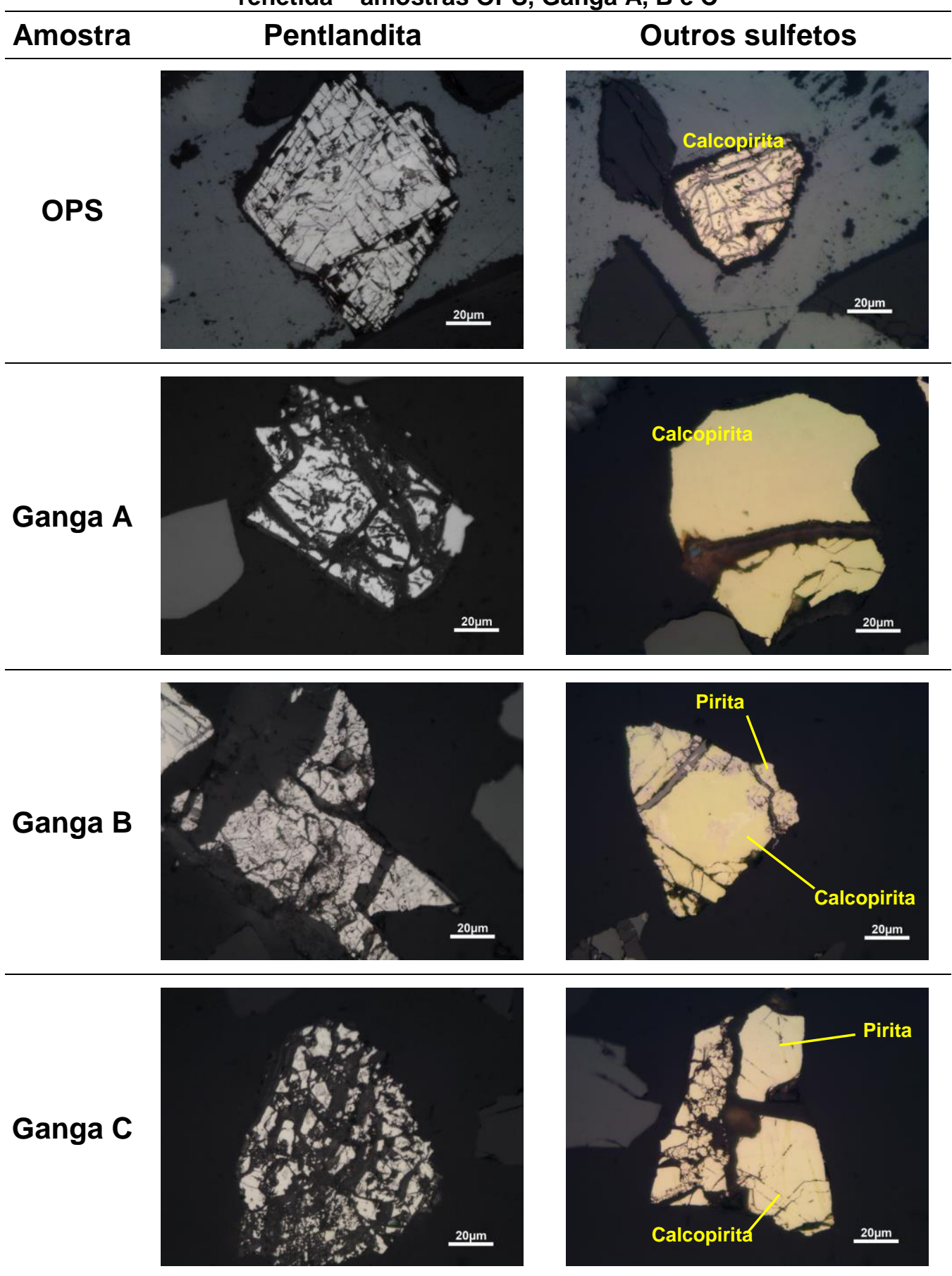

Obs: OPS = Olivina/piroxênio/ com serpentina $>10 \%$; CS = Minério carbonático com serpentina $>5 \%$ (separado em Ganga A, B e C); imagens com nícois paralelos. 
Figura 37 - Exemplos de textura da pentlandita e outros sulfetos ao microscópio óptico de luz refletida - amostras POS, PO, P e Out

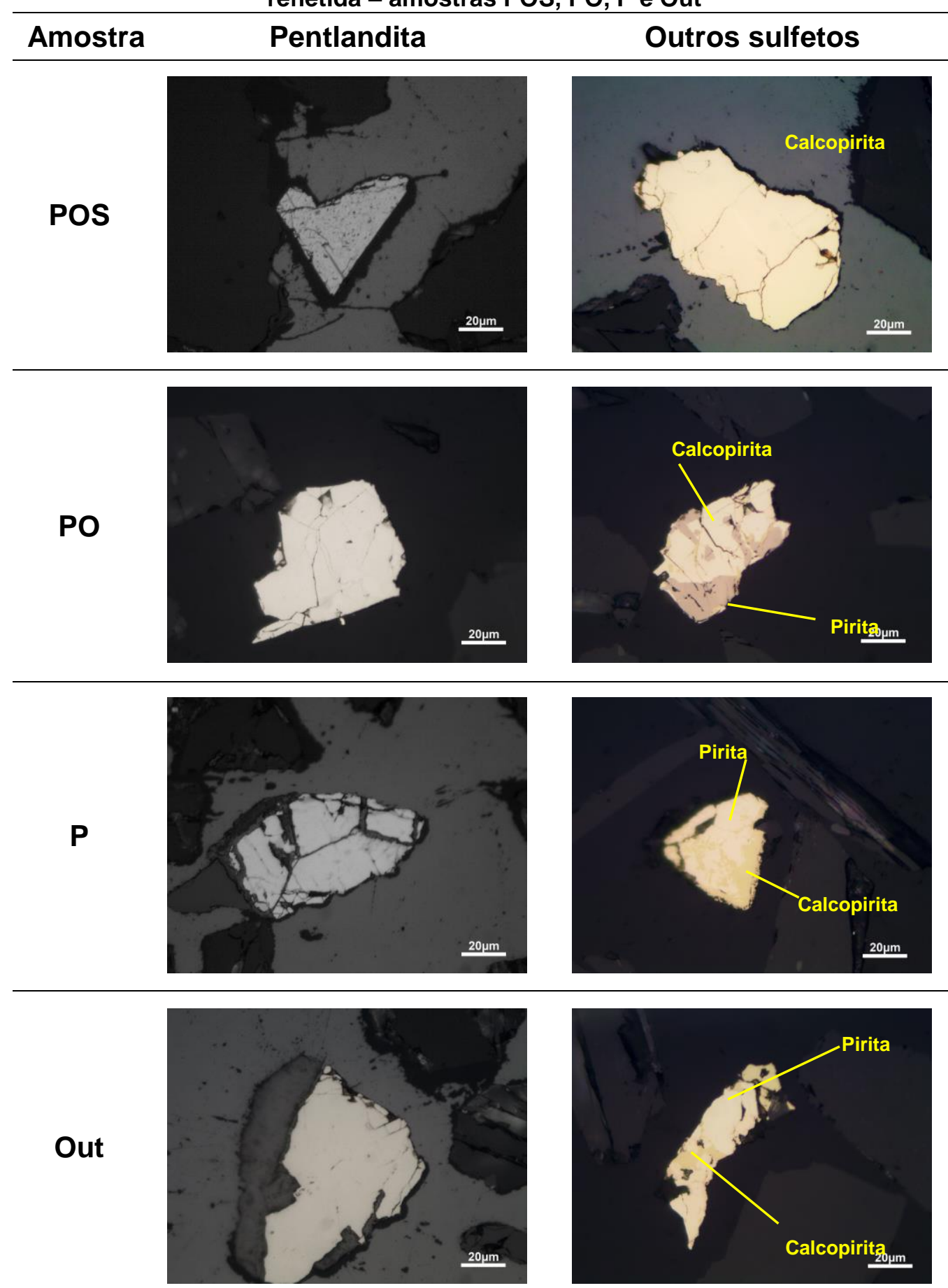

Obs: $\boldsymbol{P O S}=$ Piroxênio/olivina/ com serpentina $=10 \% ; \boldsymbol{P O}=$ Piroxênio/ com olivina $=10 \% ; \boldsymbol{P}=$ Piroxênio/ com olivina $=5 \%$; Out $=$ Outlier 


\subsubsection{Associações minerais}

A Tabela 22 e a Figura 38 apresentam um sumário da distribuição das formas de associação da pentlandita + pentlandita oxidada (\% em massa), entre livre e mista em partículas binárias (2 fases) ou misto em partículas com três ou mais fases ( $\geq 3$ ), para o total $+0,020 \mathrm{~mm}$ em se considerando as condições de cominuição empregadas.

Em todas amostras a porcentagem em massa de partículas livres de pentlandita + pentlandita oxidada não ultrapassa $50 \%$ e pode-se segmentar as amostras em:

a) OPS, Ganga A, B e C com a percentagem em massa de partículas livres variando de $19-28 \%$ e o restante associado predominantemente com serpentina.

b) POS, PO, $\mathrm{P}$ e Out com a percentagem em massa de partículas livres variando de $43-48 \%$ e o restante associado predominantemente com ortopiroxênio.

Destaca-se que as amostras $\mathrm{PO}$ e Out possuem uma significativa associação de pentlandita + pentlandita oxidada com pirita e as OPS e Ganga B com óxido de ferro.

Não se considerou avaliar a liberação da pentlandita separadamente da pentlandita oxidada, por serem fases intrinsicamente relacionadas em uma textura que seria inviável uma separação física por cominuição. 
Tabela 22 - Porcentagem de partículas livres e associadas de pentlandita + pentlandita oxidada para o total $+0,020 \mathrm{~mm}$

\begin{tabular}{|c|c|c|c|c|c|c|c|c|}
\hline Associação & OPS & POS & PO & $\mathbf{P}$ & Ganga A & Ganga B & Ganga C & Out \\
\hline Livre (\%) & 22 & 46 & 43 & 48 & 19 & 16 & 28 & 46 \\
\hline Mistas em binárias (\%) & 40 & 30 & 41 & 30 & 28 & 38 & 36 & 42 \\
\hline Mistas $\geq 3$ fases $(\%)$ & 38 & 24 & 16 & 22 & 53 & 46 & 36 & 12 \\
\hline \multicolumn{9}{|c|}{ Distribuição em binárias (\%) } \\
\hline calcopirita & 0,5 & 0,5 & 0,4 & 0,1 & 0,2 & 0,6 & 2,3 & 0,6 \\
\hline pirita & 2,0 & 4,0 & 12 & 4,1 & 0,3 & 0,7 & 1,1 & 10 \\
\hline pirrotita & 0,1 & 0,4 & 4,8 & 0,1 & & & $<0,1$ & 0,3 \\
\hline sulfetos_FeCoNi & 1,6 & 0,2 & & 0,1 & & 1,7 & 0,6 & \\
\hline ortopiroxênio & 0,5 & 8,8 & 14 & 18 & 3,8 & 2,0 & 2,2 & 25 \\
\hline clinopiroxênio & 0,1 & 0,2 & 0,8 & 1,4 & $<0,1$ & $<0,1$ & 1,4 & 3,4 \\
\hline anfibólio & 0,6 & 0,5 & 0,2 & 1,0 & 0,8 & $<0,1$ & 0,1 & 0,1 \\
\hline olivina & 3,0 & 2,6 & 1,7 & 2,7 & $<0,1$ & $<0,1$ & $<0,1$ & $<0,1$ \\
\hline serpentina & 16 & 8,1 & 3,2 & 1,5 & 20 & 11 & 18 & $<0,1$ \\
\hline outros silicatos & $<0,1$ & $<0,1$ & 0,7 & 0,1 & $<0,1$ & 1,5 & 1,6 & 0,6 \\
\hline espinélio-Cr & 0,2 & 0,7 & 0,1 & $<0,1$ & 0,5 & 0,1 & $<0,1$ & 0,2 \\
\hline óxido-Fe & 12 & 2,4 & 1,1 & 0,1 & 1,1 & 10 & $<0,1$ & 1,2 \\
\hline mica & $<0,1$ & $<0,1$ & $<0,1$ & $<0,1$ & $<0,1$ & & 1,1 & $<0,1$ \\
\hline calcita & 2,8 & 1,1 & 2,3 & 0,9 & 1,9 & 10 & 7,2 & \\
\hline outros & $<0,1$ & $<0,1$ & & & $<0,1$ & $<0,1$ & & \\
\hline \multicolumn{9}{|c|}{ Distribuição $\geq 3$ fases (\%) } \\
\hline calcopirita & 0,8 & 1,0 & 0,2 & 0,2 & 1,9 & 1,5 & 0,7 & 0,4 \\
\hline pirita & 1,4 & 3,2 & 2,4 & 2,7 & 7,4 & 2,4 & 3,4 & 2,0 \\
\hline pirrotita & 0,4 & 1,4 & 1,6 & 0,7 & 0,3 & & 0,7 & 0,3 \\
\hline sulfetos_FeCoNi & 1,1 & 0,2 & & & 1,5 & 2,1 & 0,6 & 0,1 \\
\hline ortopiroxênio & 0,9 & 4,8 & 5,2 & 7,6 & 5,9 & 2,2 & 4,7 & 6,1 \\
\hline clinopiroxênio & 0,2 & 0,4 & 0,6 & 2,0 & $<0,1$ & 0,2 & 0,2 & 0,7 \\
\hline anfibólio & 1,3 & 2,0 & 0,4 & 0,3 & 2,2 & 0,9 & 1,6 & 1,3 \\
\hline olivina & 3,8 & 2,2 & 1,4 & 1,9 & 0,1 & 0,7 & 0,9 & $<0,1$ \\
\hline serpentina & 13 & 6,7 & 1,5 & 1,8 & 19 & 13 & 9,4 & 0,2 \\
\hline outros silicatos & $<0,1$ & 0,1 & 0,5 & 0,8 & 0,4 & 0,7 & 0,6 & 0,6 \\
\hline espinélio-Cr & 1,3 & $<0,1$ & 0,1 & 0,4 & 1,0 & 1,3 & 2,7 & 0,1 \\
\hline óxido-Fe & 11 & 1,0 & 0,4 & 1,5 & 1,3 & 8,8 & 4,0 & 0,7 \\
\hline mica & $<0,1$ & 0,1 & 0,3 & $<0,1$ & 1,5 & $<0,1$ & 0,4 & $<0,1$ \\
\hline calcita & 2,7 & 1,0 & 1,1 & 1,8 & 11 & 11,9 & 5,8 & $<0,1$ \\
\hline outros & 0,1 & $<0,1$ & $<0,1$ & $<0,1$ & $<0,1$ & 0,1 & 0,4 & \\
\hline
\end{tabular}

Obs: outros silicatos = quartzo, feldspato potássico e plagioclásio; carbonatos = calcita, dolomita, magnesita e anquerita; outros = clorita, espinélio-Cr, óxido-Fe, ilmenita, apatita, coríndon. OPS = Olivina/piroxênio/ com serpentina $>10 \% ; \boldsymbol{P O S}=$ Piroxênio/olivinal com serpentina $=10 \% ; \boldsymbol{P O}=$ Piroxênio/ com olivina $=10 \% ; \boldsymbol{P}=$ Piroxênio/ com olivina = 5\%; CS = Minério carbonático com serpentina >5\% (separado em Ganga $A, B$ e C); Out $=$ Outlier. 
Figura 38 - Porcentagem de partículas associadas da pentlandita + pentlandita oxidada para 0 total $+0,020 \mathrm{~mm}$

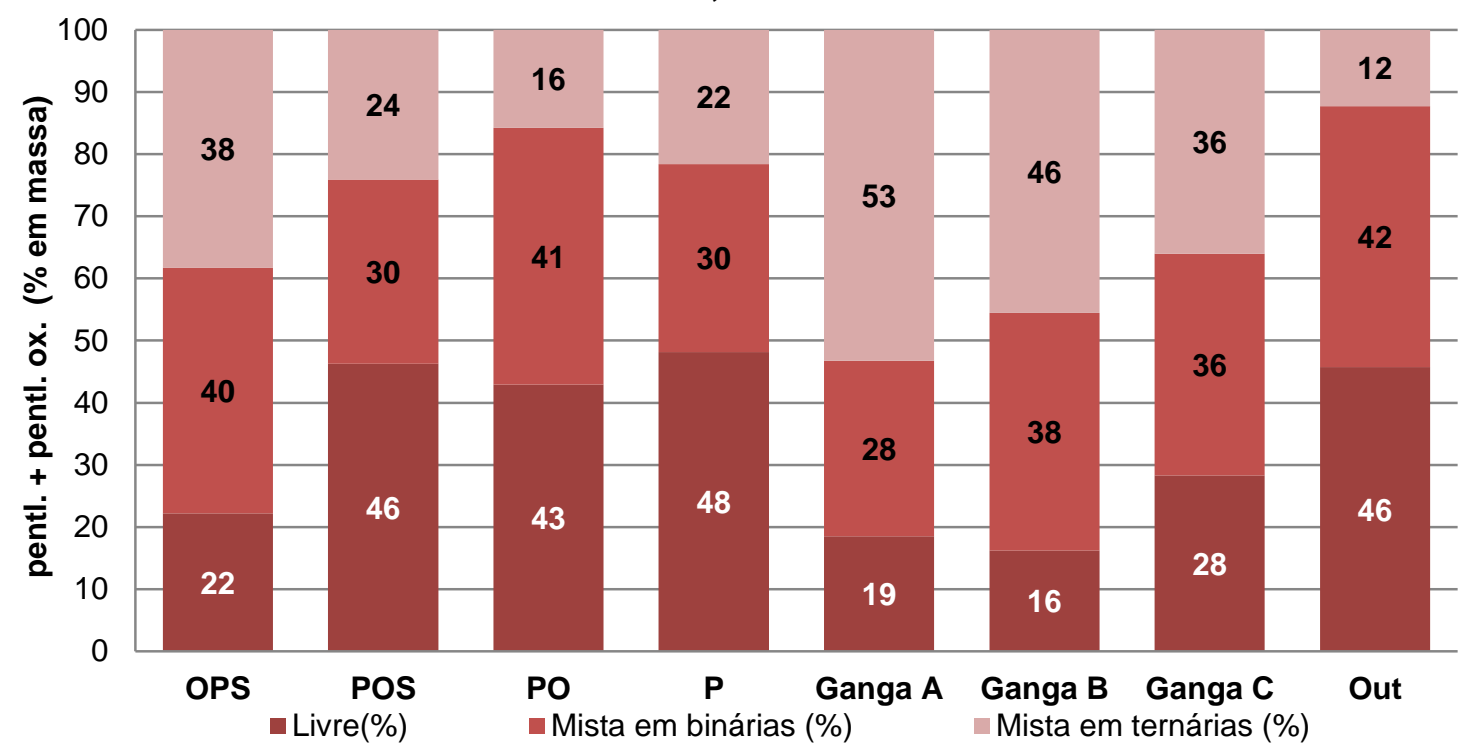

A Tabela 23 e a Figura 39 apresentam um sumário da distribuição das formas de associação da calcopirita (\% em massa), entre livre e misto em partículas binárias (2 fases) ou misto em partículas com três ou mais fases ( $\geq 3$ ) para o total $+0,020 \mathrm{~mm}$.

Para as condições de cominuição empregadas se verifica que as partículas livres de calcopirita representam menos de $40 \%$, com exceção para as amostras P e Out com valores de $57 \%$ e $60 \%$, respectivamente. 
Tabela 23 - Porcentagem de partículas livres e associadas de calcopirita para o total $+0,020 \mathrm{~mm}$

\begin{tabular}{|c|c|c|c|c|c|c|c|c|}
\hline Associação & OPS & POS & PO & $\mathbf{P}$ & Ganga & anga & Ganga C & Out \\
\hline Livres (\%) & 18 & 34 & 40 & 57 & 26 & 18 & 27 & 60 \\
\hline Mista em binárias (\%) & 18 & 36 & 31 & 26 & 52 & 24 & 50 & 29 \\
\hline Mista $\geq 3$ fases $(\%)$ & 64 & 30 & 29 & 17 & 23 & 58 & 23 & 11 \\
\hline Distribuição em binárias (\%) & & & & & & & & \\
\hline pentl. + pentl. ox. & 3,0 & 1,9 & 3,6 & $<0,1$ & 10 & 1,1 & 2,8 & 0,7 \\
\hline pirita & 3,7 & 6,2 & 1,6 & 1,4 & & 0,7 & $<0,1$ & 1,2 \\
\hline pirrotita & 0,6 & 1,2 & $<0,1$ & 1,0 & & & & \\
\hline ortopiroxênio & 0,3 & 14 & 21 & 16 & 10 & 1,9 & 31 & 31 \\
\hline clinopiroxênio & 0,7 & 1,4 & 3,7 & 0,3 & & 0,1 & & 1,0 \\
\hline anfibólio & $<0,1$ & 1,1 & 0,5 & $<0,1$ & $<0,1$ & $<0,1$ & 0,1 & $<0,1$ \\
\hline olivina & 0,2 & 0,1 & $<0,1$ & 7,1 & 0,1 & 0,3 & & $<0,1$ \\
\hline serpentina & 4,0 & 8,6 & 0,1 & & 28 & 9,8 & 1,4 & $<0,1$ \\
\hline outros silicatos & $<0,1$ & 0,2 & 0,1 & 0,1 & 0,1 & 0,7 & $<0,1$ & $<0,1$ \\
\hline espinélio-Cr & 0,6 & 0,1 & 0,2 & & & 1,5 & 0,1 & \\
\hline óxido-Fe & 4,4 & 0,9 & & & 2,1 & 0,3 & & $<0,1$ \\
\hline mica & & $<0,1$ & $<0,1$ & 0,1 & $<0,1$ & & 6,7 & \\
\hline calcita & 0,1 & 0,5 & 0,3 & 0,3 & 0,1 & 7,4 & 7,5 & \\
\hline outros & & & & & $<0,1$ & $<0,1$ & & \\
\hline Distribuição $\geq 3$ fases (\%) & & & & & & & & \\
\hline pentl. + pentl. ox. & 11,1 & 5,1 & 1,0 & 2,6 & 6,0 & 11,6 & 4,6 & 2,2 \\
\hline esfalerita & & & & & & & $<0,1$ & \\
\hline pirita & 1,1 & 1,3 & 1,9 & 1,8 & 1,8 & 1,0 & 0,3 & 4,2 \\
\hline pirrotita & 0,8 & 1,3 & 1,8 & 3,1 & $<0,1$ & & $<0,1$ & 1,5 \\
\hline sulfetos_FeCoNi & 0,2 & $<0,1$ & & & 0,5 & 0,2 & $<0,1$ & $<0,1$ \\
\hline ortopiroxênio & 4,1 & 6,5 & 9,4 & 4,0 & 4,9 & 4,0 & 1,6 & 8,6 \\
\hline clinopiroxênio & 1,6 & 2,6 & 1,2 & 1,6 & $<0,1$ & 0,6 & $<0,1$ & 1,7 \\
\hline anfibólio & 3,6 & 0,5 & 1,3 & 1,2 & 1,6 & 1,8 & 0,2 & 1,9 \\
\hline olivina & 2,9 & 1,1 & 3,4 & 0,1 & $<0,1$ & 0,1 & 0,3 & \\
\hline serpentina & 22 & 8,2 & 5,5 & 1,7 & 4,6 & 16 & 1,6 & $<0,1$ \\
\hline outros silicatos & $<0,1$ & 0,2 & 0,9 & 0,3 & $<0,1$ & 0,3 & 0,2 & 0,1 \\
\hline espinélio-Cr & 1,9 & $<0,1$ & 0,3 & 0,1 & 0,2 & 2,2 & & 0,1 \\
\hline óxido-Fe & 13 & 2,2 & 0,4 & 0,3 & 0,6 & 5,4 & 1,5 & 1,9 \\
\hline mica & $<0,1$ & 0,2 & $<0,1$ & 0,1 & 0,2 & $<0,1$ & 4,5 & 0,1 \\
\hline calcita & 2,5 & 0,2 & 1,9 & 0,1 & 2,0 & 15 & 8,3 & $<0,1$ \\
\hline outros & $<0,1$ & 0,3 & 0,3 & 0,1 & $<0,1$ & 0,3 & $<0,1$ & \\
\hline
\end{tabular}

Obs: outros silicatos = quartzo, feldspato potássico e plagioclásio; carbonatos = calcita, dolomita, magnesita e anquerita; outros = clorita, espinélio-Cr, óxido-Fe, ilmenita, apatita, coríndon. OPS = Olivina/piroxênio/ com serpentina $>10 \% ;$ POS $=$ Piroxênio/olivina/ com serpentina $=10 \% ; P O=$ Piroxênio/ com olivina $=10 \% ; \boldsymbol{P}=$ Piroxênio/ com olivina = 5\%; CS = Minério carbonático com serpentina $>5 \%$ (separado em Ganga $A, B$ e C); Out $=$ Outlier. 
Figura 39 - Porcentagem de partículas associadas da calcopirita para o total $+0,020 \mathrm{~mm}$

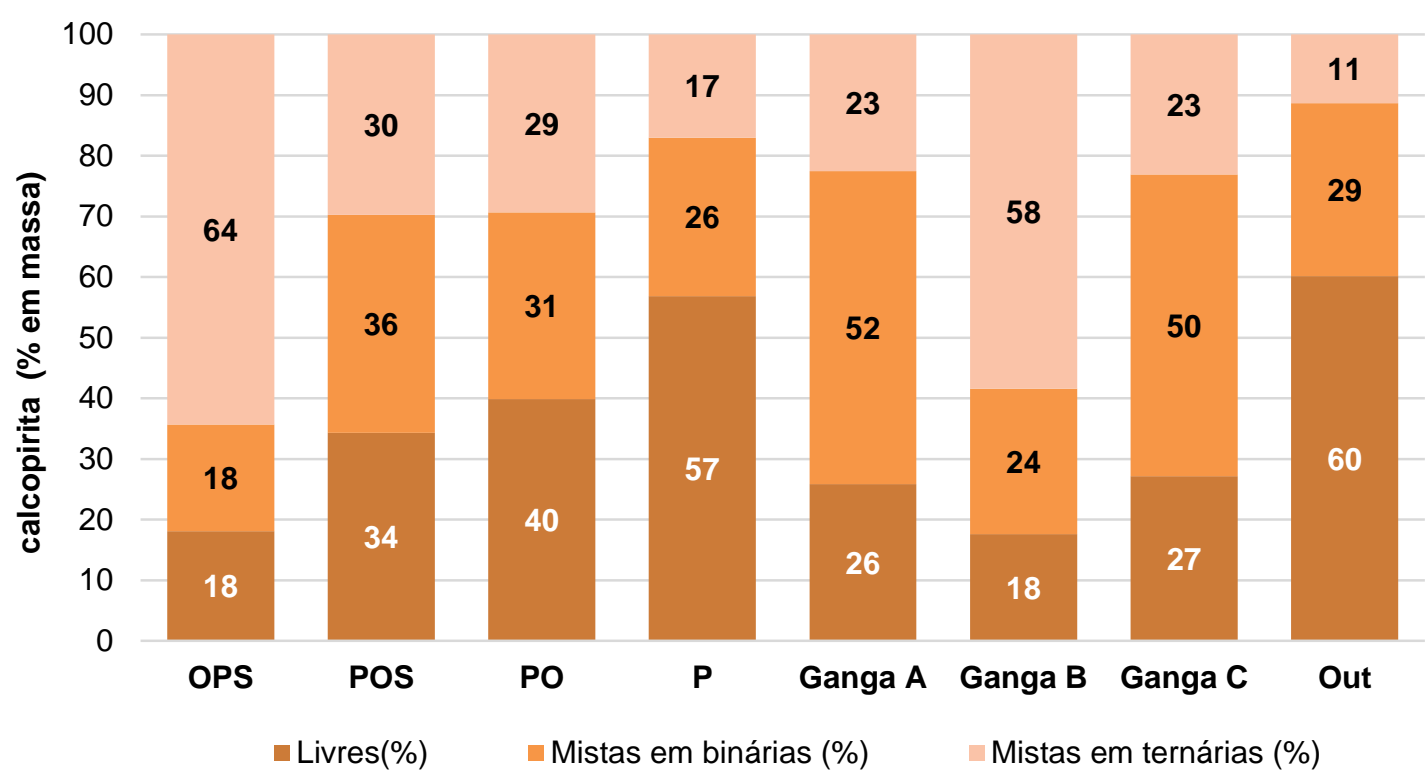

A Tabela 24 e a Figura 41 apresentam um sumário da distribuição das formas de associação do total de sulfetos (\% em massa), entre livre e misto em partículas binárias ( 2 fases) ou misto em partículas com três ou mais fases $(\geq 3)$ para o total $+0,020 \mathrm{~mm}$. Para as condições de cominuição empregadas se verifica que as partículas livres de sulfetos representam cerca de 24 a 37\% para as amostras OPS e Ganga A, B e C, com valores de $54 \%$ a $61 \%$ para as demais.

Figura 40 - Porcentagem de partículas associadas aos sulfetos para o total $+0,020 \mathrm{~mm}$

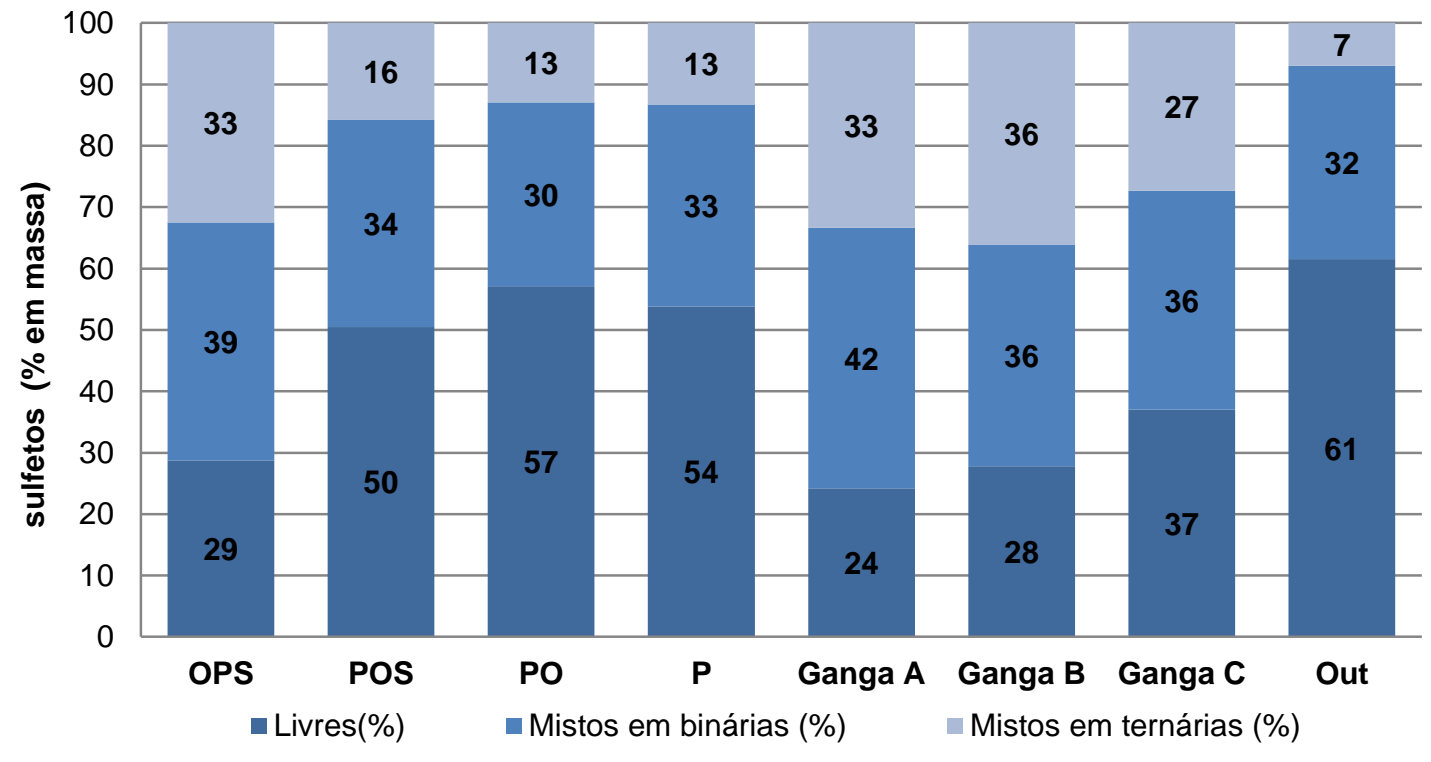


Tabela 24 - Porcentagem de partículas livres e associadas dos sulfetos para o total $+0,020 \mathrm{~mm}$

\begin{tabular}{|c|c|c|c|c|c|c|c|c|}
\hline Associação & OPS & POS & PO & $\mathbf{P}$ & Ganga A & Ganga B & Ganga C & Out \\
\hline Livres (\%) & 29 & 50 & 57 & 54 & 24 & 28 & 37 & 61 \\
\hline Mistos em binárias (\%) & 39 & 34 & 30 & 33 & 42 & 36 & 36 & 32 \\
\hline Mistos $\geq 3$ fases $(\%)$ & 33 & 16 & 13 & 13 & 33 & 36 & 27 & 7 \\
\hline \multicolumn{9}{|c|}{ Distribuição em binárias (\%) } \\
\hline ortopiroxênio & 0,6 & 9,8 & 15 & 22 & 9,2 & 2,6 & 5,8 & 24 \\
\hline clinopiroxênio & 0,1 & 0,6 & 1,7 & 2,1 & $<0,1$ & 0,1 & 1,0 & 2,7 \\
\hline anfibólio & 0,5 & 0,8 & 0,6 & 0,8 & 0,4 & $<0,1$ & 0,1 & 1,3 \\
\hline olivina & 3,0 & 2,0 & 1,6 & 2,9 & $<0,1$ & 0,1 & 0,3 & $<0,1$ \\
\hline serpentina & 17 & 15 & 4,7 & 2,0 & 26 & 12 & 17 & 0,1 \\
\hline espinélio-Cr & 0,2 & 0,4 & 0,1 & $<0,1$ & 0,2 & 0,4 & $<0,1$ & 0,1 \\
\hline óxido-Fe & 15 & 2,8 & 2,0 & 0,8 & 2,3 & 8,1 & 2,8 & 1,3 \\
\hline mica & $<0,1$ & 0,4 & $<0,1$ & 1,2 & $<0,1$ & & 1,4 & $<0,1$ \\
\hline carbonatos & 2,6 & 1,3 & 4,1 & 0,5 & 4,3 & 12 & 6,6 & 0,1 \\
\hline outros silicatos & $<0,1$ & 0,5 & 0,4 & 0,3 & $<0,1$ & 1,4 & 1,0 & 1,1 \\
\hline outros & $<0,1$ & $<0,1$ & & & $<0,1$ & $<0,1$ & & \\
\hline \multicolumn{9}{|l|}{ Distribuição $\geq 3$ fases (\%) } \\
\hline ortopiroxênio & 11 & 5,1 & 1,0 & 2,6 & 6,0 & 12 & 4,6 & 2,2 \\
\hline clinopiroxênio & & & & & & & $<0,1$ & \\
\hline anfibólio & 1,1 & 1,3 & 1,9 & 1,8 & 1,8 & 1,0 & 0,3 & 4,2 \\
\hline olivina & 0,8 & 1,3 & 1,8 & 3,1 & $<0,1$ & & $<0,1$ & 1,5 \\
\hline serpentina & 0,2 & $<0,1$ & & & 0,5 & 0,2 & $<0,1$ & $<0,1$ \\
\hline espinélio-Cr & 4,1 & 6,5 & 9,4 & 4,0 & 4,9 & 4,0 & 1,6 & 8,6 \\
\hline óxido-Fe & 1,6 & 2,6 & 1,2 & 1,6 & $<0,1$ & 0,6 & $<0,1$ & 1,7 \\
\hline mica & 3,6 & 0,5 & 1,3 & 1,2 & 1,6 & 1,8 & 0,2 & 1,9 \\
\hline carbonatos & 2,9 & 1,1 & 3,4 & 0,1 & $<0,1$ & 0,1 & 0,3 & \\
\hline outros silicatos & 22 & 8,2 & 5,5 & 1,7 & 4,6 & 16 & 1,6 & $<0,1$ \\
\hline outros & $<0,1$ & 0,2 & 0,9 & 0,3 & $<0,1$ & 0,3 & 0,2 & 0,1 \\
\hline
\end{tabular}

Obs: outros silicatos = quartzo, feldspato potássico e plagioclásio; carbonatos = calcita, dolomita, magnesita e anquerita; outros = clorita, espinélio-Cr, óxido-Fe, ilmenita, apatita, coríndon. OPS = Olivina/piroxênio/ com serpentina $>10 \% ; \boldsymbol{P O S}=$ Piroxênio/olivina/ com serpentina $=10 \% ; \boldsymbol{P O}=$ Piroxênio/ com olivina $=10 \% ; \boldsymbol{P}=$ Piroxênio/ com olivina = 5\%; CS = Minério carbonático com serpentina $>5 \%$ (separado em Ganga A, B e C); Out $=$ Outlier.

\subsubsection{Distribuição granulométrica dos minerais de interesse}

A distribuição granulométrica da pentlandita + pentlandita oxidada é apresenta na forma de curvas de distribuição acumulada no passante (Figura 41), considerando o diâmetro de elipse equivalente (EED) de cada grão (grão mineral independentemente de este ocorrer na forma livre ou mista) e a Tabela 25 traz os valores dos diâmetros d10, d50 e d90 das curvas de distribuição granulométrica. 
Figura 41 - Distribuição granulométrica acumulada no passante da pentlandita e pentlandita + pentlandita oxidada (\% em massa) para o total $+0,020 \mathrm{~mm}$
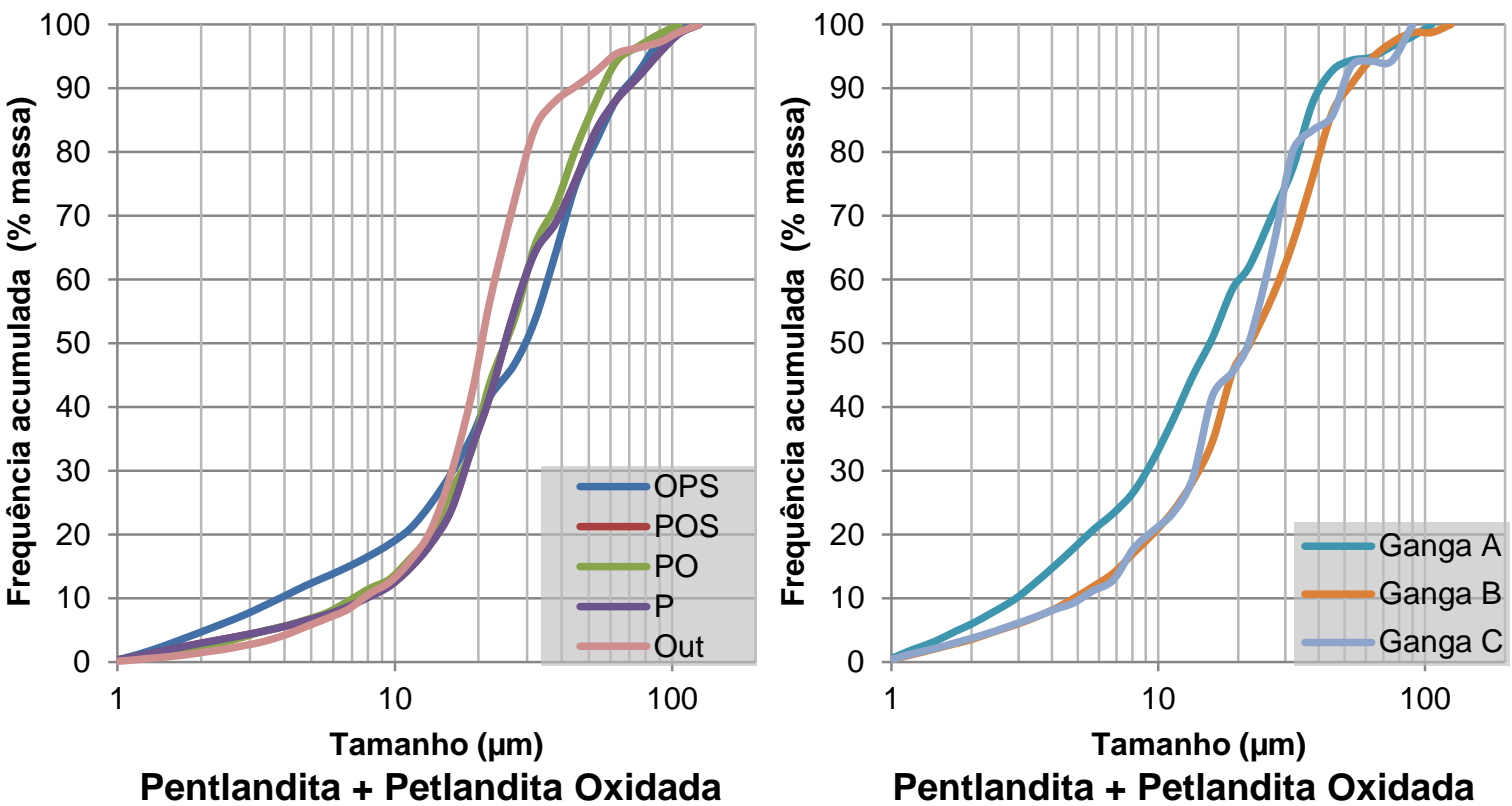

Obs: OPS = Olivina/piroxênio/ com serpentina $>10 \% ;$ POS = Piroxênio/olivina/ com serpentina $=10 \% ; P O=$ Piroxênio/ com olivina $=10 \% ; \boldsymbol{P}=$ Piroxênio/ com olivina $=5 \%$; $\boldsymbol{C S}=$ Minério carbonático com serpentina $>5 \%$ (separado em Ganga A, B e C); Out = Outlier.

Tabela 25 - Diâmetros $d_{10}, d_{50}$ e $d_{90}$ da curva de distribuição granulométrica da pentlandita, pentlandita + pentlandita oxidada para o total $+0,020 \mathrm{~mm}$

\begin{tabular}{l|ccc}
\hline Amostras & \multicolumn{3}{|c}{$\begin{array}{c}\text { Diâmetros }(\mu \mathrm{m}-\text { EED) } \\
\mathbf{d} 50\end{array}$} \\
\hline OPS & $\mathbf{d 1 0}$ & $\mathbf{d 9 0}$ \\
POS & 4 & 25 & 70 \\
PO & 7 & 25 & 70 \\
P & 7 & 28 & 58 \\
Ganga A & 9 & 15 & 75 \\
Ganga B & 3 & 23 & 40 \\
Ganga C & 4 & 22 & 52 \\
Out & 4 & 20 & 49 \\
\hline
\end{tabular}

Obs: OPS = Olivina/piroxênio/ com serpentina $>10 \% ;$ POS = Piroxênio/olivina/ com serpentina $=10 \% ; P O=$ Piroxênio/ com olivina = 10\%; $\boldsymbol{P}=$ Piroxênio/ com olivina $=5 \% ; \boldsymbol{C S}=$ Minério carbonático com serpentina $>5 \%$ (separado em Ganga A, B e C); Out = Outlier.

As curvas de distribuição granulométrica da pentlandita+pentlandita oxidada são similares para as amostras OPS, POS, PO, P e Out. Abaixo de aproximadamente $20 \mu \mathrm{m}$, a amostra OPS apresenta-se mais fina em relação as demais, enquanto acima desse valor, a amostra Out torna-se mais fina. Comparando as Gangas, tem-se a Ganga B e C com curvas semelhantes e a Ganga A mais fina entre as amostras de gangas. 
A distribuição granulométrica da calcopirita é apresenta na forma de curvas de distribuição acumulada no passante (Figura 42), considerando o diâmetro de elipse equivalente (EED) de cada grão e a Tabela 26 traz os valores dos diâmetros d10, d50 e d90 das curvas de distribuição granulométrica.

Figura 42 - Distribuição granulométrica acumulada no passante da calcopirita (\% em massa) para o total $+0,020 \mathrm{~mm}$
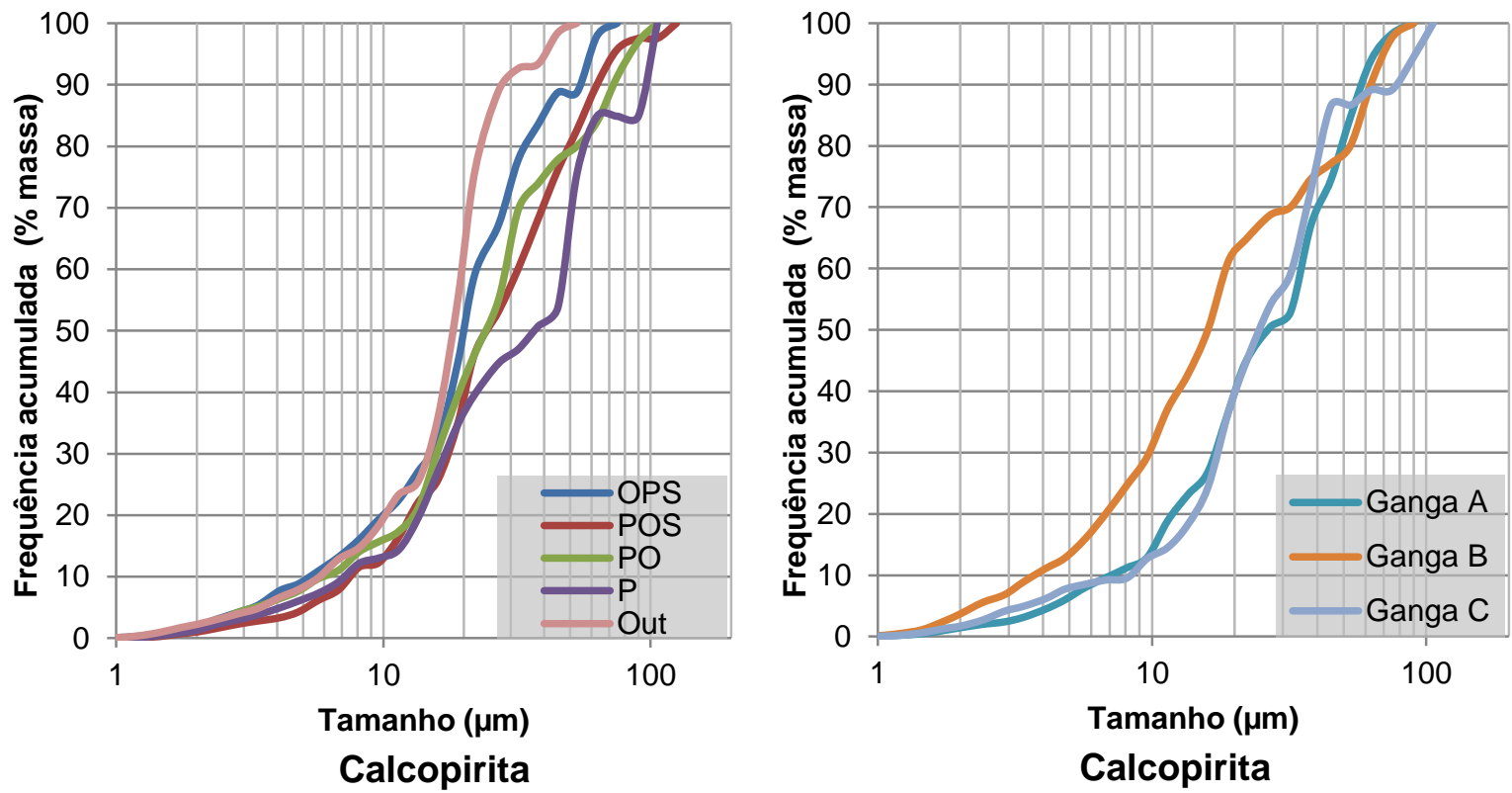

Obs: OPS = Olivina/piroxênio/ com serpentina $>10 \% ;$ POS = Piroxênio/olivina/ com serpentina $=10 \% ; P O=$ Piroxênio/ com olivina $=10 \% ; \boldsymbol{P}=$ Piroxênio/ com olivina $=5 \%$; $\boldsymbol{C S}=$ Minério carbonático com serpentina $>5 \%$ (separado em Ganga A, B e C); Out = Outlier.

Tabela 26 - Diâmetros $d_{10}, d_{50}$ e $d_{90}$ da curva de distribuição granulométrica da calcopirita para o total $+0,020 \mathrm{~mm}$

\begin{tabular}{l|ccc}
\hline \multicolumn{1}{c|}{ Amostras } & \multicolumn{3}{|c}{ Diâmetros $(\boldsymbol{\mu m}$ - EED) } \\
\hline OPS & $\mathbf{d} 10$ & $\mathbf{d} 50$ & d90 \\
POS & 4 & 20 & 55 \\
PO & 7 & 25 & 63 \\
P & 5 & 25 & 72 \\
Ganga A & 7 & 38 & 100 \\
Ganga B & 7 & 28 & 58 \\
Ganga C & 4 & 17 & 60 \\
Out & 7 & 25 & 80 \\
\end{tabular}

Obs: OPS = Olivina/piroxênio/ com serpentina $>10 \% ;$ POS = Piroxênio/olivina/ com serpentina $=10 \% ; P O=$ Piroxênio/ com olivina =10\%; $\boldsymbol{P}=$ Piroxênio/ com olivina $=5 \%$; $\boldsymbol{C S}=$ Minério carbonático com serpentina $>5 \%$ (separado em Ganga A, B e C); Out = Outlier.

Entre as amostras OPS, POS, PO, P e Out, as amostras possuem curvas semelhantes até cerca de $20 \mu \mathrm{m}$. Acima desse valor, as amostras OPS e Out apresentam a calcopirita em granulação mais fina, enquanto a amostra $P$ mais grossa. 
As amostras de Ganga A e C possuem curvas similares, enquanto a Ganga B possui a granulação da calcopirita mais fina em relação as demais.

A distribuição granulométrica dos sulfetos é apresenta na forma de curvas de distribuição acumulada (Figura 43), considerando o diâmetro de elipse equivalente (EED) de cada grão (grão mineral independentemente de este ocorrer na forma livre ou mista) e a Tabela 26 traz o d10, d50 e d90 das curvas de distribuição granulométrica.

Figura 43 - Distribuição granulométrica acumulada no passante dos sulfetos (\% em massa), para o total $+0,020 \mathrm{~mm}$
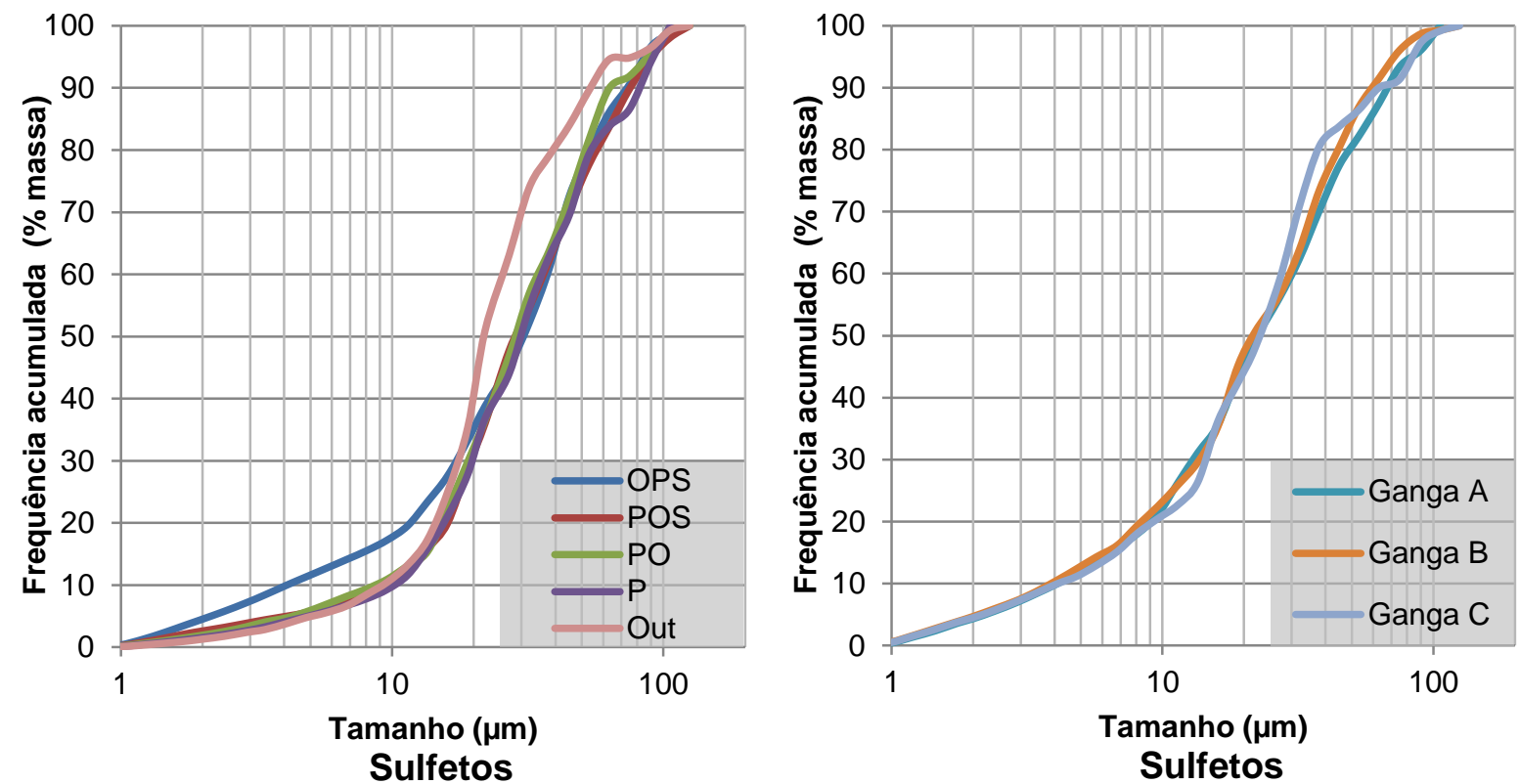

Obs: OPS = Olivina/piroxênio/ com serpentina $>10 \% ;$ POS = Piroxênio/olivina/ com serpentina $=10 \% ; P O=$ Piroxênio/ com olivina = 10\%; $\boldsymbol{P}=$ Piroxênio/ com olivina $=5 \% ; \boldsymbol{C S}=$ Minério carbonático com serpentina $>5 \%$ (separado em Ganga A, B e C); Out = Outlier.

Tabela 27 - Diâmetros $d_{10}, d_{50}$ e $d_{90}$ da curva de distribuição granulométrica dos sulfetos para 0 total $+0,020 \mathrm{~mm}$

\begin{tabular}{l|ccc}
\hline Amostras & \multicolumn{3}{|c}{ Diâmetros $(\mu \mathrm{m}-$ EED) } \\
& $\mathbf{d} 10$ & $\mathbf{d} 50$ & $\mathbf{d 9 0}$ \\
\hline OPS & 4 & 31 & 70 \\
POS & 10 & 30 & 75 \\
PO & 9 & 29 & 60 \\
P & 10 & 30 & 80 \\
Ganga A & 4 & 22 & 70 \\
Ganga B & 4 & 21 & 60 \\
Ganga C & 4 & 23 & 70 \\
Out & 9 & 22 & 52
\end{tabular}

Obs: OPS = Olivina/piroxênio/ com serpentina >10\%; POS = Piroxênio/olivina/ com serpentina $=10 \% ; \boldsymbol{P O}=$ Piroxênio/ com olivina $=10 \% ; \boldsymbol{P}=$ Piroxênio/ com olivina $=5 \%$; $\boldsymbol{C S}=$ Minério carbonático com serpentina $>5 \%$ (separado em Ganga $A, B$ e $C$ ); Out = Outlier. 
As curvas de distribuição granulométrica dos sulfetos são similares para as

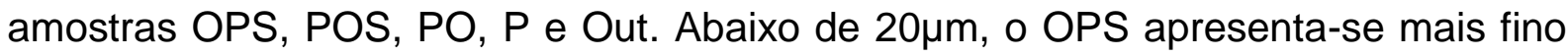
em relação as demais amostras. Acima desse valor, o Out possui uma granulação mais fina para os sulfetos. A Ganga A, B e C possuem curvas semelhantes. Nota-se que a curva de distribuição granulométrica dos sulfetos é muito similar a curva da pentlandita+pentlandita-oxidada.

\subsubsection{Distribuição de $\mathrm{Ni}, \mathrm{Cu}, \mathrm{S}$}

A Tabela 28 e a Figura 44 apresentam a distribuição de Ni dentre as fases portadoras desse elemento para as amostras estudadas. A partição do níquel nos minerais acompanha a tendência citada por Mirabela (2007), Fróes (1993) e Purvis (2005).

Tabela 28 - Estimativa da distribuição de Ni $(\%)$ - total $+0,020 \mathrm{~mm}$

\begin{tabular}{l|cccccccc}
\hline \multicolumn{1}{c}{ Mineral } & OPS & POS & PO & P & Ganga A & Ganga B & Ganga C & Out \\
\hline pentlandita & 43 & 72 & 76 & 78 & 53 & 41 & 43 & 89 \\
pentl_oxid & 30 & 9 & 9 & 5 & 13 & 23 & 16 & 7 \\
pirita & $<1$ & $<1$ & $<1$ & $<1$ & $<1$ & $<1$ & $<1$ & $<1$ \\
sulfetos_FeCoNi & 3 & 1 & 1 & $<1$ & 2 & 9 & 2 & $<1$ \\
ortopiroxênio & $<1$ & 2 & 4 & 4 & 2 & 1 & 2 & 4 \\
olivina & 12 & 9 & 7 & 9 & 2 & 2 & 12 & $<1$ \\
serpentina & 11 & 7 & 4 & 3 & 27 & 25 & 24 & $<1$ \\
espinelio-Cr & $<1$ & $<1$ & $<1$ & $<1$ & $<1$ & $<1$ & $<1$ & $<1$ \\
Pentl + Pentl. Ox. & $\mathbf{7 4}$ & $\mathbf{8 1}$ & $\mathbf{8 5}$ & $\mathbf{8 3}$ & $\mathbf{6 6}$ & $\mathbf{6 4}$ & $\mathbf{5 9}$ & $\mathbf{9 5}$ \\
Silicatos & $\mathbf{2 3}$ & $\mathbf{1 8}$ & $\mathbf{1 4}$ & $\mathbf{1 6}$ & $\mathbf{3 1}$ & $\mathbf{2 7}$ & $\mathbf{3 8}$ & $\mathbf{4}$
\end{tabular}

Obs: OPS = Olivina/piroxênio/ com serpentina $>10 \% ;$ POS = Piroxênio/olivina/ com serpentina $=10 \% ; \mathbf{P O}=$ Piroxênio/ com olivina = 10\%; $\boldsymbol{P}=$ Piroxênio/ com olivina $=5 \%$; $\boldsymbol{C S}=$ Minério carbonático com serpentina $>5 \%$ (separado em Ganga A, B e C); Out = Outlier. FeCoNiS = Sulfeto de níquel cobalto e ferro

As amostras possuem cerca de $60-80 \%$ do total de Ni contido na forma de pentlandita+pentlandita oxidada. A amostra OPS possui a maior parcela do $\mathrm{Ni}$ presente na forma de pentlandita oxidada e a amostra Out a menor. O conteúdo de Ni na forma de pentlandita oxidada é uma parcela do Ni que não necessariamente é passível de ser recuperado. É necessária uma avaliação do potencial de recuperação das partículas quando estas apresentam variados conteúdos de pentlandita oxidada. 
Figura 44 - Estimativa da distribuição de Ni (\%) - total $+0,020 \mathrm{~mm}$

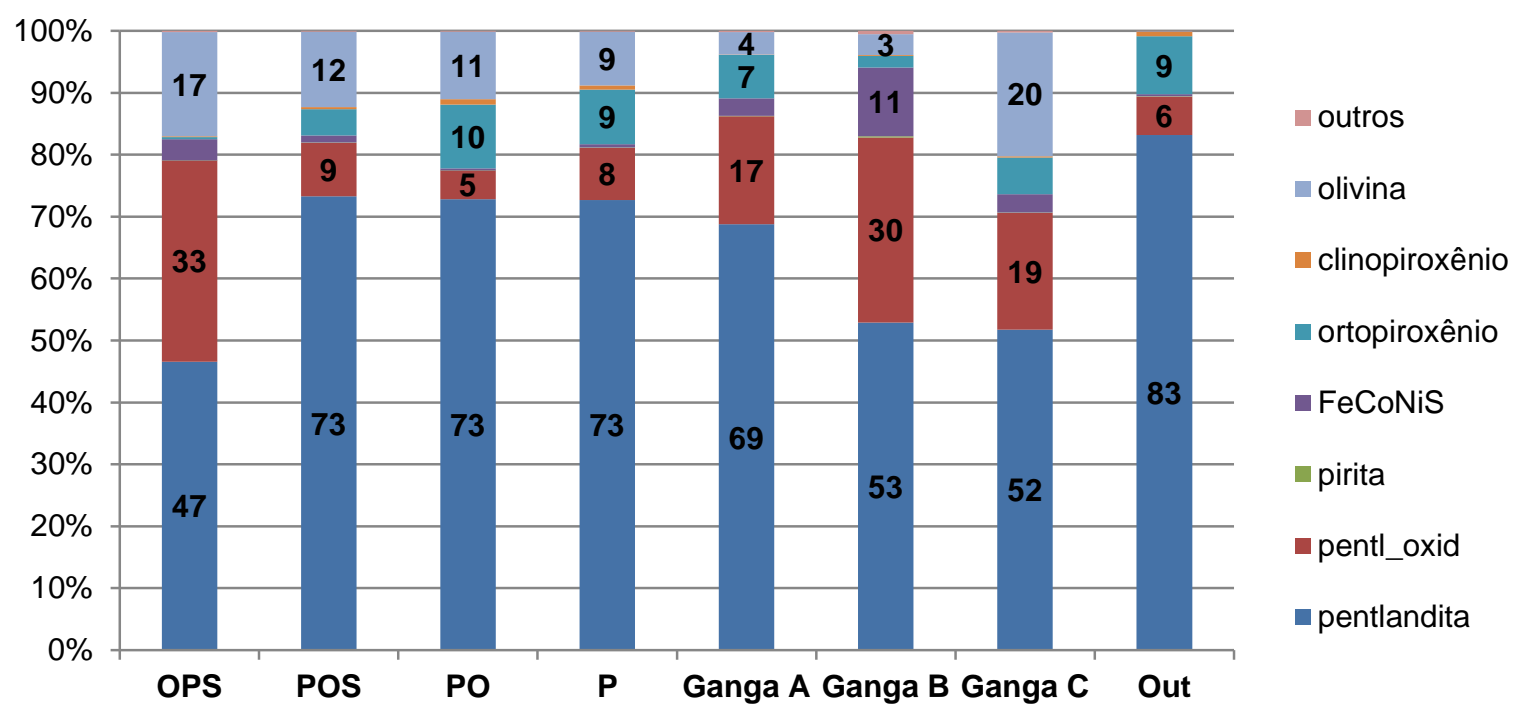

Obs: OPS = Olivina/piroxênio/ com serpentina $>10 \% ;$ POS = Piroxênio/olivina/ com serpentina $=10 \% ; \boldsymbol{P O}=$ Piroxênio/ com olivina = 10\%; $\boldsymbol{P}=$ Piroxênio/ com olivina $=5 \% ; \boldsymbol{C S}=$ Minério carbonático com serpentina $>5 \%$ (separado em Ganga A, B e C); Out = Outlier. FeCoNiS = Sulfeto de níquel cobalto e ferro

Já grande parte do conteúdo de Ni associado aos silicatos (olivina e piroxênios) não é passível de ser recuperado. As amostras Ganga A, B e C, destacam-se das demais por possuir aproximadamente $25 \%$ do conteúdo de Ni associado à serpentina.

A Tabela 29 e a Figura 45 apresentam a distribuição de Cu dentre as fases portadoras desse elemento por amostra; praticamente todo Cu está presente na forma de calcopirita.

Tabela 29 - Estimativa da distribuição de $\mathrm{Cu}(\%)$

\begin{tabular}{l|cccccccc}
\hline \multicolumn{1}{c|}{ Mineral } & OPS & POS & PO & P & Ganga A & Ganga B & Ganga C & Out \\
\hline calcopirita & \multirow{2}{*}{100} & 99 & 99 & 96 & 100 & 100 & 96 & 98 \\
calcossita-covellita & & 1 & 1 & 4 & & & 4 & 2 \\
\hline
\end{tabular}


Figura 45 - Estimativa da distribuição de $\mathrm{Cu}(\%)$

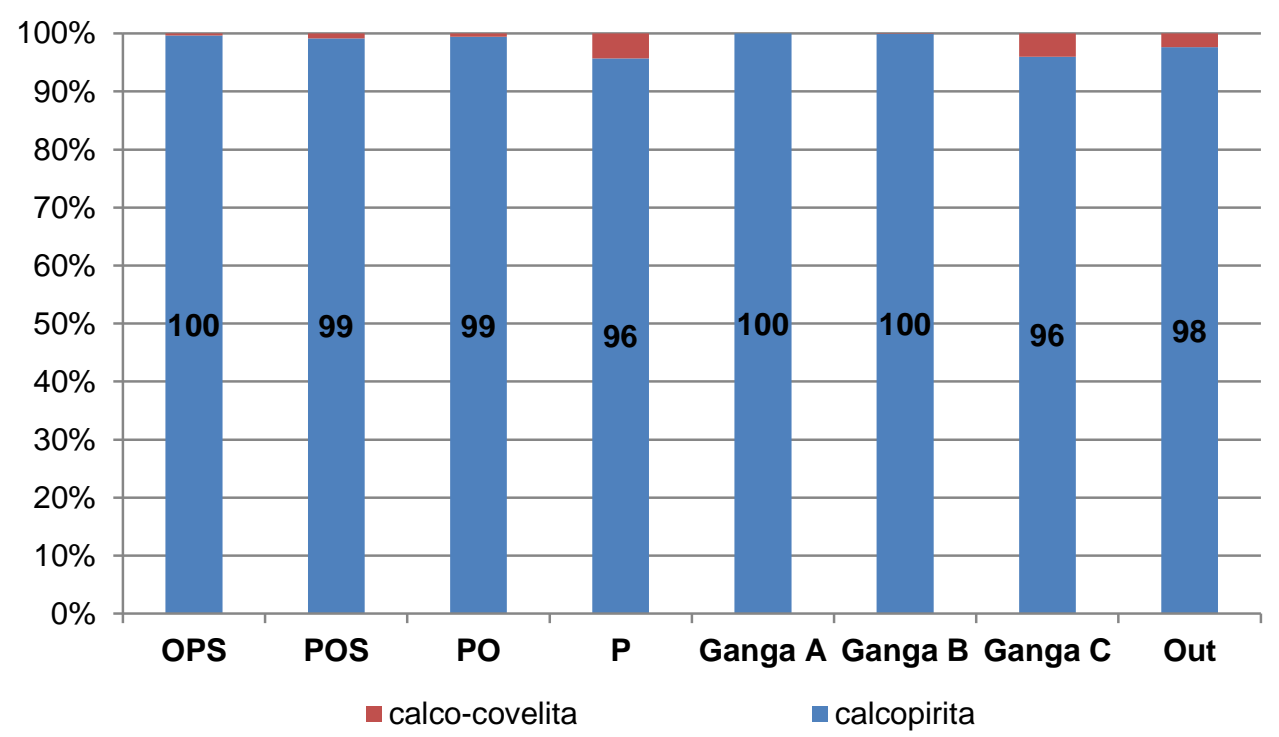

Obs: OPS = Olivina/piroxênio/ com serpentina $>10 \% ;$ POS = Piroxênio/olivina/ com serpentina $=10 \% ; P O=$ Piroxênio/ com olivina $=10 \% ; \boldsymbol{P}=$ Piroxênio/ com olivina $=5 \% ; \boldsymbol{C S}=$ Minério carbonático com serpentina $>5 \%$ (separado em Ganga A, B e C); Out = Outlier.

\subsubsection{Sumário dos resultados}

A Tabela 30 traz o sumário dos resultados relativo as amostras estudadas. 
Tabela 30 - Sumários dos resultados de caracterização mineralógica de detalhe

\begin{tabular}{|c|c|c|c|c|c|c|c|c|}
\hline & OPS & POS & PO & $\mathbf{P}$ & Out & Ganga A & Ganga B & Ganga C \\
\hline $\begin{array}{l}\text { Teores (\%) } \\
\mathrm{Ni} \\
\mathrm{Ni}_{\text {Sulf }}^{*} \\
\mathrm{Cu} \\
\mathrm{Fe} \\
\mathrm{S} \\
\mathrm{SiO}_{2} \\
\mathrm{MgO}\end{array}$ & $\begin{array}{l}0,88 \\
0,67 \\
0,19 \\
9,86 \\
1,20 \\
34,6 \\
34,0\end{array}$ & $\begin{array}{l}0,57 \\
0,47 \\
0,11 \\
9,18 \\
0,93 \\
43,8 \\
29,3\end{array}$ & $\begin{array}{l}0,47 \\
0,40 \\
0,11 \\
9,25 \\
0,86 \\
47,6 \\
27,2\end{array}$ & $\begin{array}{l}0,44 \\
0,37 \\
0,09 \\
9,37 \\
0,67 \\
49,1 \\
27,2\end{array}$ & $\begin{array}{l}0,49 \\
0,47 \\
0,12 \\
8,25 \\
1,06 \\
51,3 \\
26,4\end{array}$ & $\begin{array}{l}0,42 \\
0,29 \\
0,06 \\
7,21 \\
0,52 \\
38,5 \\
28,5\end{array}$ & $\begin{array}{l}0,51 \\
0,37 \\
0,10 \\
7,22 \\
0,67 \\
31,2 \\
27,9\end{array}$ & $\begin{array}{l}0,35 \\
0,21 \\
0,04 \\
8,17 \\
0,38 \\
46,8 \\
22,9\end{array}$ \\
\hline $\begin{array}{l}\text { Granulometria (\% massa) } \\
\text { Fração (mm) } \\
+0,105 \\
-0,105+0,053 \\
-0,053+0,020 \\
-0,020 \\
\end{array}$ & $\begin{array}{l}20,0 \\
29,3 \\
21,6 \\
29,1\end{array}$ & $\begin{array}{l}20,1 \\
31,9 \\
24,8 \\
23,2\end{array}$ & $\begin{array}{l}21,6 \\
32,3 \\
22,0 \\
24,1 \\
\end{array}$ & $\begin{array}{l}25,6 \\
33,3 \\
23,4 \\
17,7\end{array}$ & $\begin{array}{l}26,8 \\
31,9 \\
23,7 \\
17,6 \\
\end{array}$ & $\begin{array}{l}13,8 \\
24,1 \\
21,9 \\
40,2 \\
\end{array}$ & $\begin{array}{l}16,0 \\
23,0 \\
22,0 \\
39,0 \\
\end{array}$ & $\begin{array}{l}16,2 \\
33,2 \\
25,4 \\
25,2 \\
\end{array}$ \\
\hline $\begin{array}{l}\text { Tempo de moagem }(\mathrm{mim}) \\
\text { para } P_{95}=0,15 \mathrm{~mm}\end{array}$ & 4 & 12 & 12 & 16 & 16 & 4 & 4 & 8 \\
\hline $\begin{array}{l}\text { Comp. mineralógica } \\
\text { olivina } \\
\text { serpentina } \\
\text { ortopiroxênio } \\
\text { clinopiroxênio } \\
\text { outros silicatos } \\
\text { espinélio-Cr } \\
\text { óxido-Fe } \\
\text { mica } \\
\text { carbonatos } \\
\text { Total de sulfetos }\end{array}$ & $\begin{array}{r}37,8 \\
37,8 \\
6,49 \\
1,77 \\
0,78 \\
3,38 \\
2,14 \\
0,25 \\
3,11 \\
\mathbf{4 , 2}\end{array}$ & $\begin{array}{r}18,5 \\
16,1 \\
49,5 \\
3,86 \\
1,78 \\
1,47 \\
0,39 \\
1,24 \\
1,72 \\
\mathbf{2 , 8}\end{array}$ & $\begin{array}{r}9,99 \\
3,88 \\
72,6 \\
6,11 \\
2,20 \\
0,78 \\
0,34 \\
0,30 \\
0,37 \\
\mathbf{1 , 5}\end{array}$ & $\begin{array}{r}8,78 \\
5,03 \\
69,7 \\
5,45 \\
1,76 \\
1,34 \\
0,47 \\
0,35 \\
0,54 \\
\mathbf{1 , 9}\end{array}$ & $\begin{array}{r}0,14 \\
0,30 \\
85,7 \\
7,18 \\
2,56 \\
0,27 \\
0,56 \\
0,23 \\
0,08 \\
\mathbf{2 , 3}\end{array}$ & $\begin{array}{r}2,58 \\
36,8 \\
38,7 \\
0,67 \\
3,44 \\
1,30 \\
0,24 \\
6,88 \\
4,87 \\
\mathbf{1 , 8}\end{array}$ & $\begin{array}{r}3,11 \\
42,2 \\
13,2 \\
1,00 \\
8,16 \\
3,92 \\
1,45 \\
0,11 \\
22,2 \\
2,7\end{array}$ & $\begin{array}{r}11,8 \\
24,2 \\
27,2 \\
1,06 \\
19,8 \\
1,09 \\
0,71 \\
8,33 \\
1,55 \\
\mathbf{1 , 2}\end{array}$ \\
\hline $\begin{array}{l}\text { Sulfetos de } \mathbf{N i} \\
\text { Pentlandita (ptl) } \\
\text { pentl_oxid } \\
\text { pentl+pentl oxid. } \\
\text { relação ptl/ptl ox. }\end{array}$ & $\begin{array}{l}1,67 \\
1,71 \\
3,38 \\
0,98\end{array}$ & $\begin{array}{l}1,37 \\
0,31 \\
1,67 \\
\mathbf{4 , 4 2}\end{array}$ & $\begin{array}{l}0,80 \\
0,10 \\
0,90 \\
\mathbf{8 , 0 0}\end{array}$ & $\begin{array}{l}0,90 \\
0,20 \\
1,10 \\
4,50\end{array}$ & $\begin{array}{l}1,18 \\
0,18 \\
1,36 \\
6,56\end{array}$ & $\begin{array}{l}0,68 \\
0,30 \\
0,97 \\
2,27\end{array}$ & $\begin{array}{l}0,69 \\
0,64 \\
1,33 \\
1,08\end{array}$ & $\begin{array}{l}0,48 \\
0,26 \\
0,74 \\
1,85\end{array}$ \\
\hline $\begin{array}{l}\text { Distribuição. } \mathbf{N i}(\%) \\
\text { pentlandita } \\
\text { pentlandita oxidada } \\
\text { sulfetos_FeCoNi } \\
\text { olivina } \\
\text { serpentina } \\
\text { ortopiroxênio } \\
\text { outros }\end{array}$ & $\begin{array}{c}43 \\
30 \\
3 \\
12 \\
11 \\
<1 \\
<1\end{array}$ & $\begin{array}{c}72 \\
9 \\
1 \\
9 \\
7 \\
2 \\
<1\end{array}$ & $\begin{array}{c}76 \\
9 \\
1 \\
7 \\
4 \\
4 \\
<1\end{array}$ & $\begin{array}{c}78 \\
5 \\
<1 \\
9 \\
3 \\
4 \\
<1\end{array}$ & $\begin{array}{c}89 \\
7 \\
<1 \\
<1 \\
<1 \\
4 \\
<1\end{array}$ & $\begin{array}{c}53 \\
13 \\
2 \\
2 \\
27 \\
2 \\
<1\end{array}$ & $\begin{array}{c}41 \\
23 \\
9 \\
2 \\
25 \\
1 \\
<1\end{array}$ & $\begin{array}{c}43 \\
16 \\
2 \\
12 \\
24 \\
2 \\
<1\end{array}$ \\
\hline $\begin{array}{l}\text { pentl + pentl. oxidada } \\
\text { Sulfetos } \\
\text { Silicatos }\end{array}$ & $\begin{array}{l}74 \\
76 \\
23\end{array}$ & $\begin{array}{l}81 \\
82 \\
18\end{array}$ & $\begin{array}{l}85 \\
86 \\
14\end{array}$ & $\begin{array}{l}83 \\
83 \\
16\end{array}$ & $\begin{array}{c}95 \\
96 \\
4\end{array}$ & $\begin{array}{l}66 \\
68 \\
31\end{array}$ & $\begin{array}{l}64 \\
73 \\
27\end{array}$ & $\begin{array}{l}59 \\
61 \\
38\end{array}$ \\
\hline $\begin{array}{l}\text { Assoc. minerais } \\
\text { Pentl+Pentl oxidada } \\
\text { Livre (\%) } \\
\text { Mista em binárias (\%) } \\
\text { Mista } \geq 3(\%)\end{array}$ & $\begin{array}{l}22 \\
40 \\
38\end{array}$ & $\begin{array}{l}46 \\
30 \\
24\end{array}$ & $\begin{array}{l}43 \\
41 \\
16\end{array}$ & $\begin{array}{l}48 \\
30 \\
22\end{array}$ & $\begin{array}{l}46 \\
42 \\
12\end{array}$ & $\begin{array}{l}19 \\
28 \\
53\end{array}$ & $\begin{array}{l}16 \\
38 \\
46\end{array}$ & $\begin{array}{l}28 \\
36 \\
36\end{array}$ \\
\hline $\begin{array}{l}\text { Sulfetos } \\
\text { Livre (\%) } \\
\quad \text { Mistos em binárias (\%) } \\
\text { Mistos } \geq 3(\%)\end{array}$ & $\begin{array}{l}29 \\
39 \\
33\end{array}$ & $\begin{array}{l}50 \\
34 \\
16\end{array}$ & $\begin{array}{l}57 \\
30 \\
13\end{array}$ & $\begin{array}{l}54 \\
33 \\
13\end{array}$ & $\begin{array}{c}61 \\
32 \\
7\end{array}$ & $\begin{array}{l}24 \\
42 \\
33\end{array}$ & $\begin{array}{l}28 \\
36 \\
36\end{array}$ & $\begin{array}{l}37 \\
36 \\
27\end{array}$ \\
\hline $\begin{array}{l}\text { Diâmetro grãos (EED) } \\
\text { Pentl+Pentl oxid. } \\
\text { d10 } \\
\text { d50 } \\
\text { d90 }\end{array}$ & $\begin{array}{c}4 \\
30 \\
70\end{array}$ & $\begin{array}{l}7 \\
25 \\
70\end{array}$ & $\begin{array}{c}7 \\
25 \\
58\end{array}$ & $\begin{array}{c}9 \\
28 \\
75\end{array}$ & $\begin{array}{l}7 \\
20 \\
50\end{array}$ & $\begin{array}{c}3 \\
15 \\
40\end{array}$ & $\begin{array}{c}4 \\
23 \\
52\end{array}$ & $\begin{array}{c}4 \\
22 \\
49\end{array}$ \\
\hline $\begin{array}{r}\text { Sulfetos } \\
\mathrm{d} 10 \\
\mathrm{~d} 50 \\
\mathrm{~d} 90 \\
\end{array}$ & $\begin{array}{r}4 \\
31 \\
70\end{array}$ & $\begin{array}{l}10 \\
30 \\
75\end{array}$ & $\begin{array}{c}9 \\
29 \\
60 \\
\end{array}$ & $\begin{array}{l}10 \\
30 \\
80\end{array}$ & $\begin{array}{c}9 \\
22 \\
52\end{array}$ & $\begin{array}{c}4 \\
22 \\
70\end{array}$ & $\begin{array}{c}4 \\
21 \\
60\end{array}$ & $\begin{array}{c}4 \\
23 \\
70\end{array}$ \\
\hline$\%$ sulfetos $<10 \mu m$ & 17 & 10 & 10 & 10 & 10 & 20 & 20 & 19 \\
\hline
\end{tabular}

Obs: OPS = Olivina/piroxênio/ com serpentina $>10 \% ; P O S=$ Piroxênio/olivina/com serpentina $=10 \% ; P O=$ Piroxênio/ com olivina $=10 \% ; \boldsymbol{P}=$ Piroxênio/ com olivina = 5\%; $\boldsymbol{C S}=$ Minério carbonático com serpentina $>5 \%$ (separado em Ganga $A, B$ e $C) ;$ Out $=$ Outlier. * \% Ni presente na forma de sulfetos calculado a partir da distribuição do níquel por MEV-MLA. 


\section{DISCUSSÃO INTEGRADA DOS RESULTADOS}

\subsection{Em relação aos resultados obtidos nesse estudo}

No caso da mina Santa Rita, a difratometria de raios $X(D R X)$, associada à análise estatística multivariada (AEM) dos difratogramas DRX-AEM, permitiu segmentar mineralogicamente a área relativa ao plano de lavra de 2013-2017 inicialmente em 17 domínios mineralógicos com diferenças no conteúdo dos principais minerais: serpentina, olivina e piroxênio, além das regiões de minério ricas em gangas micáceas, feldspáticas e carbonáticas.

Com base em semelhanças mineralógicas, critérios químicos, e disponibilidade, oito amostras foram objeto de estudos detalhados de caracterização, sendo:

- OPS: como representante dos domínios onde há uma composição harzburgítica (peridotito/serpentinito) com elevado teor de serpentina;

- POS: como representante dos grupos de composição harzburgítica (peridotito/serpentinito), porém em uma transição para uma composição mais piroxenítica, com conteúdo expressivo de serpentina;

- PO: como representante somente do grupo 3 (DRX-AEM), com composição piroxenítica, presença de olivina e com pouca serpentina; destaca-se que um número expressivo de amostras foi agrupado nesse conjunto (137 amostras das 319 totais - 43\%) de forma que se optou por distingui-lo como uma amostra separada para estudo;

- P: como representante dos domínios com composição piroxenítica, com a baixa presença de olivina e com pouca serpentina;

- Ganga A: como representante das amostras de minério associados a uma ganga carbonática (grupo 12) e alto conteúdo de serpentina e mica;

- Ganga B: como representante das amostras de minério associados a uma ganga carbonática;

- Ganga C: como representante das amostras de minério associados a uma ganga com alto teor de feldspato e mica; 
- Out: como representante das amostras que não foram agrupadas em nenhum grupo. Porém, o Grupo 17 dos outiliers, possui membros com composições mineralógicas muito heterogêneas. A amostra Out refere-se somente à uma amostra (RC_100_0073 PCT 1016204), que basicamente configura-se mineralogicamente como representante do litotipo ortopiroxenito.

Os resultados gerados na segunda etapa do estudo (caracterização mineralógica de detalhe) propiciaram um melhor entendimento das características de cada amostra estudada. Assim, considerando-se novamente os domínios geometalúrgicos da Mina Santa Rita (Mirabela, op. cit.), pode-se relacionar os domínios geometalúrgicos pré-definidos com as amostras estudas como: peridotitos (Harzburgito - H) $\rightarrow$ amostras OPS e POS; olivina ortopiroxenito $(\mathrm{O}) \rightarrow$ com as amostras $\mathrm{PO}$ e $\mathrm{P}$; ortopiroxenito $(\mathrm{P}) \rightarrow$ amostra Out. $\mathrm{O}$ minério com a presença de gangas micáceas, carbonáticas e feldspáticas (Gangas A, B e C, respectivamente) não possuem domínios geometalúrgicos definidos por Mirabela (op. cit.).

Em relação a química das amostras, pode-se separar as amostras em dois grupos mais a amostra Out:

A. OPS, POS, PO e P, com os teores de $\mathrm{Ni}, \mathrm{Cu}, \mathrm{S}, \mathrm{MgO}$ decrescendo do OPS para o $\mathrm{P}$ com o aumento do teor de $\mathrm{SiO}_{2}$ no sentido inverso - do $\mathrm{P}$ para OPS;

B. Ganga A, B e C não possuem nenhuma tendência de aumento ou diminuição de teores entre si, mas quando comparadas ao primeiro grupo, pode-se dizer que elas possuem teores menores de Fe e S.

A amostra Out possui teores similares ao primeiro grupo acima citado, porém com maior conteúdo de $\mathrm{SiO}_{2}$.

Em relação ao tempo de moagem para obtenção de produtos com topsizes com $\mathrm{P}_{95}$ abaixo de $0,15 \mathrm{~mm}$ verificou-se marcantes diferenças em relação ao comportamento das amostras no procedimento de moagem empregado por meio de moinho planetário. As amostras OPS, Ganga A e B necessitaram apenas de um ciclo de 4 minutos; a Ganga $C$ necessitaram de 2 ciclos em um total de 8 minutos; já as amostras POS e PO empregou-se três ciclos de moagem, totalizando 12 minutos e as 
amostras Out e $\mathrm{P}$ possuem a maior resistência a moagem, necessitando de 16 minutos (4 ciclos).

Em relação à distribuição em massa e de níquel, destaca-se que aproximadamente de 40-50\% do níquel contido nas amostras está contido no intervalo $-0,105+0,020 \mathrm{~mm}$. A distribuição do níquel entre as amostras varia no intervalo acima de $0,105 \mathrm{~mm}$ e abaixo de $0,020 \mathrm{~mm}$. As amostras PO e OPS possuem, respectivamente, $23 \%$ e $19 \%$ do níquel acima de 0,105 mm, enquanto as Gangas $\mathrm{A}$ e B contém $46 \%$ e $41 \%$ do níquel abaixo de $0,020 \mathrm{~mm}$.

Mineralogicamente, no grupo "A" a amostra OPS possui o maior conteúdo de pentlandita, pentlandita oxidada e sulfetos, corroborando com seus maiores teores de $\mathrm{Ni}$, Cu e S, quando comparada com as demais; há uma diminuição nos teores de olivina, serpentina e sulfetos da amostra OPS para as amostras POS, PO e P;. No grupo "B" a amostra Ganga B destaca-se pelo alto conteúdo de carbonatos (22\%), enquanto a amostra Ganga A e B pela alta nos teores de mica e outros silicatos (predominantemente feldspatos). A amostra Out possui o maior conteúdo de piroxênios, aliada a traços de olivina e serpentina $(<0,5 \%)$.

A avaliação do conteúdo da pentlandita oxidada nas amostras estudadas mostra que há um aumento relativo dessa fase nas amostras OPS e nas Gangas A, B e $\mathrm{C}$, em relação as demais amostras.

Os estudos das associações minerais mostraram que em todas amostras a porcentagem em massa de partículas livres de pentlandita + pentlandita oxidada não ultrapassa $50 \%$ para as condições de moagem empregadas. As amostras OPS, Ganga A, B e C apresentam a percentagem de partículas livres variando de $19-28 \%$ estando as partículas mistas associadas predominantemente à serpentina. As amostras POS, PO, P e Out possuem a percentagem de partículas livres variando de 43-48\% estando as mistas associadas predominantemente a ortopiroxênio.

Em relação à distribuição (partição) do níquel, se verifica que as amostras possuem cerca de 60-95\% do total de Ni contido na forma de pentlandita+pentlandita oxidada e havendo um aumento da parcela de níquel em silicatos para as amostras OPS, Gangas A, B e C em relação as demais amostras (de 25 a 40\% do Ni contido).

As curvas de distribuição granulométrica dos sulfetos são similares para as amostras OPS, POS, PO, P e Out. Abaixo de 20um, o OPS apresenta-se mais fino em relação as demais amostras. Acima desse valor, o Out possui uma granulação mais grossa para os sulfetos. A Ganga A, B e C possuem curvas semelhantes. 
Em relação ao processamento mineral, pode-se pontuar algumas características avaliadas nas amostras estudadas na $2^{\underline{a}}$ etapa que podem ter influência na etapa de processamento mineral:

- alteração da pentlandita: pode diminuir significativamente a flotabilidade da pentlandida, pela presença de violarita e óxidos de ferro (pentlandita oxidada) intercrescidos, mais marcadamentente nos litotipos de composição mais peridotítica e quando da presença de carbonatos.

- distribuição granulométrica de sulfetos: particularmente de partículas com dimensões inferiores a $10 \mu \mathrm{m}$, acarretando também em perdas de recuperação dada a menor seletividade de flotação da pentlandita para partículas nesta faixa de tamanho.

- distribuição do níquel nos silicatos: uma vez que o beneficiamento da mina Santa Rita concentra unicamente sulfetos; a parcela de Ni em silicatos não é passível de ser recuperada.

- liberação e associações da pentlandita e dos sulfetos: partículas mistas possuem menor potencial de recuperação na flotação e se flotadas podem deduzir o teor de sulfetos no concentrado final e carrear elementos indesejáveis ao concentrado, a depender de suas associações minerais.

Assim, observa-se que amostras OPS, Ganga A, B e C apresentaram maior grau de alteração da pentlandita; maior quantidade de sulfetos abaixo de $10 \mu \mathrm{m}$ (cerca de $50 \%$ superior as outras amostras); maior conteúdo de níquel associado a silicatos; e menor porcentagem de partículas livres de sulfetos e de pentlandita em relação às demais.

Com os dados sumarizados (Tabela 30), observou-se

- uma relação entre a porcentagem de partículas livres de pentlandita + pentlandita oxidada e o conteúdo de serpentina nos domínios mineralógicos estudados, como mostra o gráfico da Figura 46;

- uma relação entre o tempo de moagem para $P_{95}=0,15 \mathrm{~mm}$ pela porcentagem de pentlandita + pentlandita oxidada livres (Figura 48). 
Figura 46 - Gráfico mostrando a relação entre a porcentagem de serpentina vs. liberação da pentlandita + pentlandita oxidada

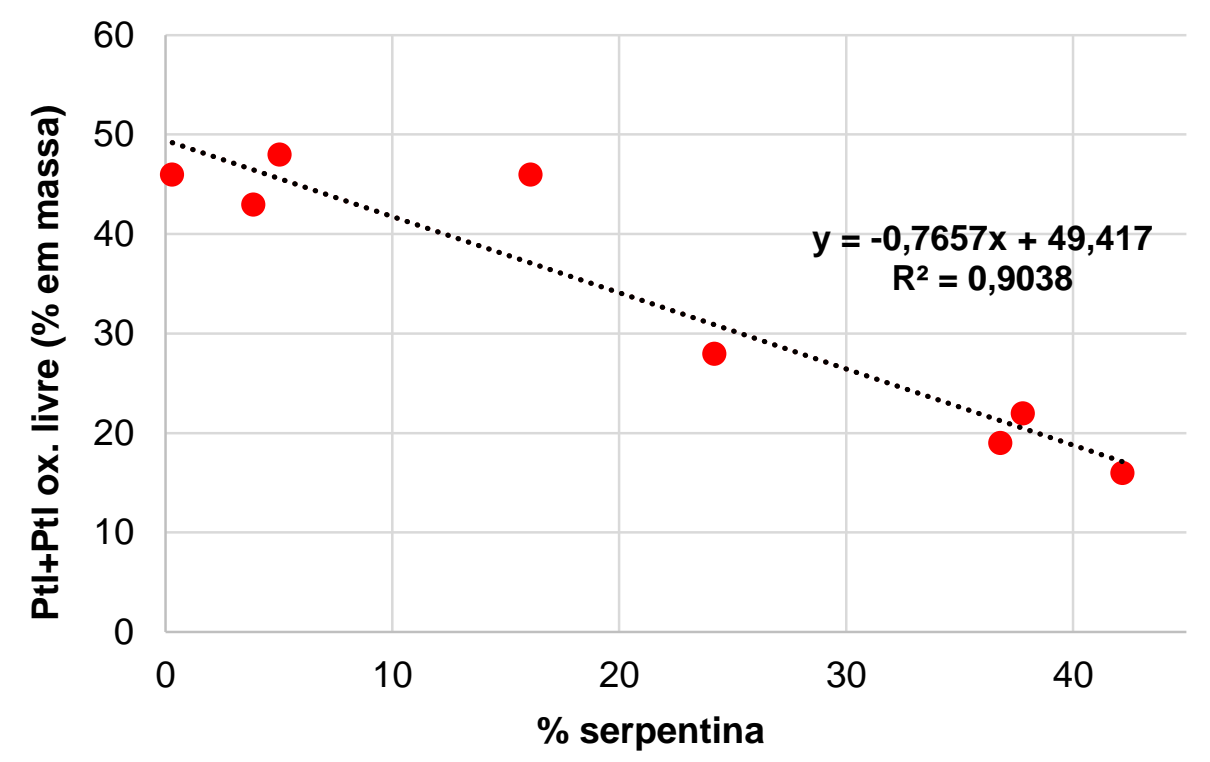

Figura 47 - Gráfico mostrando a relação entre o tempo de moagem para $P_{95}=0,15 \mathrm{~mm}$ vs. liberação da pentlandita + pentlandita oxidada

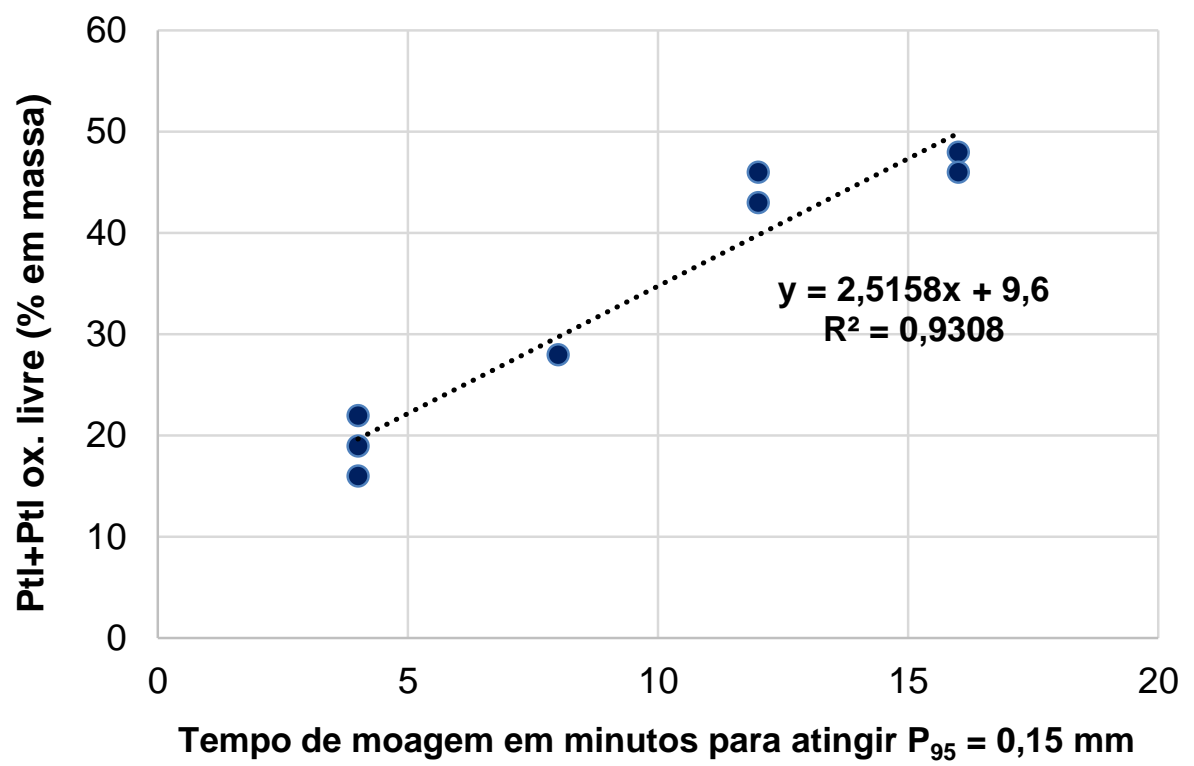

A relação observada na Figura 46 pode indicar que eventos geológicos posteriores ao magmatismo alteraram as feições texturais da pentlandita. Porém é preciso buscar o melhor entendimento ou causa da relação observada entre conteúdo de serpentina e o grau de liberação de pentlandita + pentlandita oxidada.

Já a relação entre o tempo de moagem para atingir $P_{95}=0,15 \mathrm{~mm}$ e a porcentagem de partículas livres de pentlandita+pentlandita oxidada indica que as amostras OPS, Ganga A, B e C possuem maior facilidade de moagem, porém menor grau de liberação. Assim, é preciso estudar melhor as relações entre as características 
do material que influenciarão na etapa de moagem e, principalmente, quais serão as características da pentlandita após esta etapa: é possível atingir uma maior liberação da pentlandita sem a geração excessiva de finos?

Não foi possível estabelecer nenhuma outra relação linear entre as características mineralógicas analisadas e os teores dosados de forma satisfatória $\left(R^{2}\right.$ $>0,85$ e significado físico), muito embora algumas tendências tenham sido observadas.

\subsection{Em relação aos métodos empregados nesse estudo}

Uma das grandes vantagens da difratometria de raios $X(D R X)$, associada à análise estatística multivariada (AEM) dos difratogramas, é que um número elevado de amostras pode ser analisado sem a necessidade de interpretação de todos os difratogramas. Das 319 amostras (264 amostras da exploração e 55 amostras de pó de perfuratriz) foram interpretadas somente aquelas classificadas como mais representativas da composição média de cada grupo (um total de 17 difratogramas). Isto, aliado à visualização dos dados no gráfico 3D por análise de componente principal (PCA) e do dendrograma, permite uma avaliação da similaridade entre as amostras e do agrupamento definido.

Considerando-se os domínios geometalúrgicos da Mina Santa Rita, definidos por Mirabela (2007), com base na classificação de rochas ultramáficas da IUGS (International Union of Geological Sciences), pode-se observar que não são contempladas rochas de composição intermediária entre os membros compostos por olivina, ortopiroxênio e clinopiroxênio. Por exemplo, uma rocha classificada como um harzburgito, pode possuir de 41 a 89 \% de olivina em sua composição.

Outro problema encontrado na classificação de Mirabela (op. cit.) refere-se à não observância de possíveis alterações (serpentinização) das rochas. Apesar deste estudo caracterizar petrograficamente cada litotipo, observando a serpentinização nos dunitos e harzburgitos, este parâmetro não foi considerado de forma relativa (não foram estabelecidos critérios para mensurar o grau de serpentinização).

Somado ao referido acima, a classificação dos domínios mineralógicos da Mina de Santa Rita foi inicialmente baseada na classificação visual das rochas em testemunhos de sondagem e no mapeamento da mina. Obviamente, esta classificação depende da área exposta para análise e é suscetível a vieses 
interpretativos. Adiciona-se que a dificuldade de se determinar visualmente a proporção de minerais não apresenta a sensibilidade necessária quanto a avaliação dos conteúdos relativos de olivina, serpentina, ortopiroxênio e clinopiroxênio para a classificação litológica das rochas do depósito e que a presença de minerais acessórios, particularmente carbonatos, pode ser relevante frente ao comportamento na etapa de concentração.

A difratometria de raios $X(D R X)$, associada à análise estatística multivariada (AEM) dos difratogramas, pode ser utilizada como uma fonte de informação da variabilidade mineralógica do depósito, segmentando este em porções ou grupos onde a composição mineralógica das amostras é semelhante. Esta abordagem pode ser utilizada como fonte de dados mineralógicos para o modelo geometalúrgico da mina e possui a sensibilidade necessária para detectar variações mineralógicas de um depósito composto por rochas ultramáficas peridotíticas e piroxeníticas. 


\section{CONCLUSÕES}

Com base nos resultados desse estudo é possível concluir que a região do depósito relativa ao planejamento de lavra do período 2013-2017 pode ser inicialmente classificada em 17 domínios mineralógicos com base no conteúdo dos principais minerais de ganga (serpentina, olivina, piroxênio), além da presença de gangas micáceas, feldspáticas e carbonáticas.

Estudos mineralógicos de detalhe dos principais domínios mineralógicos indicam que os grupos com composições mais peridotíticas e/ou carbonáticas, com maiores conteúdos de serpentina, apresentam menor tempo de moagem para atingir $P_{95}$ igual a $0,15 \mathrm{~mm}$, maior alteração dos grãos de pentlandita, maior parcela de total de níquel associado a silicatos, menor grau de liberação dos sulfetos e maior quantidade de sulfetos abaixo de $10 \mu \mathrm{m}$, em relação aos grupos de composição mais piroxenítica. 


\section{TRABALHOS FUTUROS}

Com base nos resultados desse estudo pode se elencar como sugestões de trabalhos futuros:

1) complementar os estudos de caracterização de detalhe de amostras representativas dos 17 domínios mineralógicos inicialmente definidos, e reavaliar a classificação de DRX-AEM;

2) dentre os domínios mais importantes, realizar teste de variabilidade das características químicas e mineralógicas (mineralogia modal, associações, texturas de alteração e partição dos elementos de interesse) nas amostras pertencentes a um mesmo grupo definido por DRX-AEM;

3) realizar testes em escala de bancada ou em planta piloto de cada domínio mineralógico para se avaliar comportamentos diferenciais frente ao processamento mineral e, posteriormente, reclassificá-los como tipos de minério / domínios geometalúrgicos.

4) avaliar as relações entre desempenho de processo com as características dos tipos de minério / domínios geometalúrgicos (item 3 acima).

5) avaliar a existência de possíveis controles geológicos relacionados às feições texturais da pentlandita (alteração e tamanho de grãos) e buscar o entendimento ou causa da relação observada entre conteúdo de serpentina e o grau de liberação de pentlandita + pentlandita oxidada.

6) avaliar eventual controle geológico de materiais com presença de carbonatos (controle tectônico/estrutural relacionado ao metamorfismo?)

7) definir outros parâmetros físicos do minério, como índice de moabilidade e quantidade de finos gerados e procurar associar estes parâmetros, somados às características mineralógicas e de associações minerais, com o desempenho em ensaios de flotação. 


\section{REFERÊNCIAS BIBLIOGRÁFICAS}

ANTONIASSI, J. L. A Difração de Raios $\mathrm{x}$ com o Método de Rietveld aplicada a bauxitas de Porto Trombetas. 2010. 111 p. Dissertação (mestrado) - Escola Politécnica, Universidade de São Paulo, São Paulo, 2010.

ANTONIASSI, J. L.; KAHN, H.; ULSEN, C.; TASSINARI, M. M. M. L. Prediction of mineral processing behavior of bauxite ores by XRD cluster analysis. In: 10th ICAM International Congress for Applied Mineralogy, Trondheim: 10th ICAM Proceedings, 2011. p. 9-16.

BARBOSA, J.S.F.; SABATÉ, P.; MARINHO, M.M. O Cráton de São Francisco na Bahia: uma síntese. Rev. Bras. Geoc., n. 33 (1). p. 3-6, 2003.

BARBOSA, J.S.F.; SABATÉ, P. Archean and Paleoproterozoic crust of the São Francisco Craton, Bahia, Brazil: geodynamic features. Precambrian Research, Holanda, n. 133, p. 1-47, 2004.

BARNES, S. J.; OSBORNE, G. A.; COOK, D.; BARNES, L.; MAIER, W. D.; GODEL, B. The Santa Rita Nickel Sulfide Deposit in the Fazenda Mirabela Intrusion, Bahia, Brazil: Geology, Sulfide Geochemistry, and Genesis. Economic Geology, v. 106, p. 1083-1110. 2011.

BITTENCOURT, H. R.; VIALI, L. Contribuições para o ensino da distribuição normal ou curva de Gauss em cursos de graduação. In: III Seminário Internacional de Pesquisa em Educação Matemática, Brasil, São Paulo, Águas de Lindóia, 11-14 de outubro, 2006. p.1-16.

BATTERHAM, R.J.; GRANT, R.M.; MOODIE, J.P. 1992. A perspective on Process mineralogy and Mineral processing. In: First International Conference on Modern Process Mineralogy and Mineral Processing, Beijing: Proceedings, 1992. p. 3-12.

COOLEY, W. W.; LOHNES, P. R. Multivariate data analysis. New York : J. Wiley and Sons Inc., 1971. 364 p.

CORNWALL, H. R. Nickel deposit of north america. Washington: U.S. Geological Survey bulletin 1223, 1966. $62 \mathrm{p}$.

COWARD, S.; VANN, J.; DUNHAM, S.; STEWART, M. The primary-response framework for geometallurgical variables. In: Seventh International Mining Geology Conference, Perth, 2009. p. 109-113.

CULLITY, B. D. Elemets of X-ray diffraction. New York: Addison-Wesley publishing company Inc, 1978. $514 \mathrm{p}$.

CUNHA, J. C. \& FERREIRA, R. J.B. Complexo máfico-ultramáfico da Fazenda Mirabela (CFM): Geologia e mineralização. In: CONGR. BRAS. GEOL., 37, São Paulo, Bol. Res. Exp., SBG/SP, v. 2, 1992. p.158-159. 
DOBBY, G.; BENNETT, C.; BULLED, D.; KOSICK, X. Geometallurgical modelling The new approach to plant design and production forecasting/planning, and Mine/Mill Optimization. In: 36th Annual Meeting of the Canadian Mineral Processors, Ottawa, 2004, paper No.15.

DUNHAM, S.; VANN, J. Geometallurgy, geostatistics and project value - Does your block model tell you what you need to know?, In: Project Evaluation 2007, Melbourn, 2007. p 189-196.

EVERITT, B. S.; LANDAU, S.; LEESE, M.; STAHL, D. Cluster analysis. New York: John Wiley, Probability and Statistics, 2010. 346 p.

FANDRICH R., GU Y., BURROWS D., MOELLER K. 2007. Modern SEM-based mineral liberation analysis. Int. J. Miner. Process, n. 84, p. 310-320, 2007.

FRÓES, R.J.B. Petrology, geochemistry and Cu-Ni-PGE Mineralisation of the

Fazenda Mirabela Complex, State of Bahia, Brazil.1993. Dissertação (mestrado não publicado), Universidade de Toronto, Toronto, 1993.

FULTZ, B., HOWE, J. Transmission electron microscopy and diffractometry of materials. Berlim: Springer, 2007. 758 p.

GOONAN, T.G. Nickel recycling in the United States in 2004, In: SIBLEY, S.F.(ed.), Flow studies for recycling metal commodities in the United States: U.S. Geological Survey Circular 1195, 2009. 100 p.

GOTTLIEB, P.; WILKIE, G.; SUTHERLAND, D.; HO-TUN, E.; SUTHERS, S.; PERERA, K.; JENKINS, B.; SPENCER, S.; BUTCHER, A.; RAYNER, J. Using Quantitative Electron Microscopy for Process Mineral Applications. JoM, v. 52(4), p. 24-25. 2000.

GU, Y. Automated scanning electron microscope based liberation analysis. Journal of Minerals and Materials Characterization and Engineering, v. 2, p. 33-41, 2003.

JENKINS, R. SNYDER, R.L. Introduction to x-ray powder diffractometry. New York: John Wiley, Chemical Analysis, v. 138, 1969. 403 p.

JONES M. Applied Mineralogy, a quantitative approach. London: Graham and Trotman, 1987. 259p.

KAHN H., D'AGOSTINO L.Z., BRUMATTI M., TASSINARI M.M.M.L., ULIANA, D., ULSEN, C. Mineralogia quantitativa através de análise de imagens automatizada conjugada a MEV/EDS: Estudos de caso aplicados a minérios de fosfato e ouro. In: 44ํㅡㄹ Congresso Brasileiro de Geologia, Curitiba, PR. Anais, 2008. p. 669-675.

KAHN H., MANO E.S., TASSINARI M.M.M.L. Image analysis coupled with a SEMEDS applied to the characterization of a partially weathered $\mathrm{Zn}-\mathrm{Pb}$ ore. Journal of Minerals \& Materials Characterization \& Engineering, v. 1, n.1, p 1-9, 2002. 
KÖNIG, U.; GOBBO, L. Modern X-Ray Diffraction Techniques as a Fast Industrial Analysis Method for Iron Ores - From Exploration to Process Control. In: Iron Ore Conference, Perth, Austrália, 27-29 Julho, 2009. p. 121-128.

LAMBERG, P. Particles - the bridge between geology and metallurgy. In: Conference in Mineral Engineering, Proceedings, Luleå, Suécia, 8-9 Fevereiro, 2011. p. 1-16.

LAZARIN, F. A. Geologia, petrologia e estudos isotópicos dos depósitos de níquel-cobre sulfetados santa rita e peri-peri. 2011. 191 p. Dissertação (mestrado) - Instituto de Geociências, Universidade de Brasília, Brasília, 2011.

LONDON METAL EXCHANGE, 2013. Disponível em: http://www.Ime.com/metals/non-ferrous/nickel/\#tab2>. Acesso em: 22 de novembro de 2016.

LUND, L; LAMBERG, P. Geometallurgy - A tool for better resource efficiency. European geologist magazine, v. 37, p 39-43. 2014.

MACCHIAROLA K., KOENIG U., GOBBO L., CAMPBELL I., Mc'DONALD A.M., CIRELLI J. 2007. Modern X-ray Diffraction Techniques for Exploration and Analysis of Ore Bodies. In : $7^{\text {th }}$ Int. Conference on Mineral Exploration, Otawa. Unpublished.

MANLY, B. F. J. Multivariate statistical methods: a primer. New York: CRC Press, 1994. $224 \mathrm{p}$.

MIRABELA. Bank Feasibility Study. Austrália: Mirabela Nickel Ltda., 2007 (não publicado).

MIRABELA. http://www.mirabela.com.au. Visitado em 17/01/2015.

MOITA NETO J. M., MOITA G.C. Uma Introdução à Análise Exploratória de Dados Multivariados. São Paulo: Química Nova, 1998. 469 p.

NEUMAN R., SCHNEIDER C.L., NETO A.A. Caracterização tecnológica de minérios. In: Luz A.B., Sampaio J.A., Almeida S.L.M. Tratamento de Minérios, Rio de Janeiro -CETEM, 2004. p. 55-109.

NIIRANEN, K.; BÖHM, A. A systematic characterization of the ore body for mineral processing at Kiirunavaara iron ore mine operated by LKAB, Northern Sweden. In: XXVI International Mineral Processing Congress (IMPC), New Delhi, India. 2012, p. 3855-3864.

PANALYTICAL. User Manual X'Pert Highscore Plus. Netherlands: Panalytical Inc., 2008 (não publicado).

PETRUK, W. Short course on image analysis applied to mineral and earth sciences. Otawa: Mineralogical Association of Canada, 1989. 268 p.

PETRUK, W. Applied mineralogy in the mining industry. Otawa: Elsevier, 2000. $268 \mathrm{p}$. 
PURVIS, A.C. Mineralogical Report No. $\mathbf{8 8 1 5}$ for Mirabela Nickel Limited. Pontifex and Associates, 2005 (não publicado).

PURVIS, A.C. Mineralogical Report No. 8907 for Mirabela Nickel Limited. Pontifex and Associates, 2006 (não publicado).

REYNOLDS JR., R.C. Principles of powder diffraction. In: BISH, D.L; POST, J.E. (Ed.). Modern powder diffraction. Washington: Mineralogy Society of America, Reviews in Mineralogy, v. 20, 1989. p. 19-43.

ROBB, L. Introduction to ore-forming processes. Oxford: Blackwell publishing, 2005. 373p.

SANT'AGOSTINO L.M., KAHN H. Metodologia para a caracterização tecnológica de matérias primas minerais. Boletim Técnico da Escola Politécnica da USP. BT/PMI/069, 1997. p. 29.

SANTOS JÚNIOR, L. T., DELBONI JÚNIOR, H. Modelling and simulation of the Santa Rita mine milling circuit. Rem: Rev. Esc. Minas, v. 69, n. 2, p. 207-201, 2016.

SHIMIZU, V. K.; KAHN, H.; ANTONIASSI, J. L.; ULSEN, C. Copper ore type definition from Sossego mine using $\mathrm{x}$-ray diffraction and cluster analysis technique. REM. Revista Escola de Minas, v. 65, p. 561-566, 2012.

SUTHERLAND D.N., GOTTLIEB P. Application of automated quantitative mineralogy in mineral processing. Minerals Engineering, v. 4, n.7-11, p.753-762, 1991.

USGS - United States Geological Survey, 2016. Disponível em: http://minerals.usgs.gov/minerals/pubs/commodity/nickel/ Acesso em: 22 de novembro de 2016. 


\section{APÊNDICES}

APÊNDICE 1 - Comparativo entre os difratogramas dispostos em cada grupo

APÊNDICE 2 - Relação de amostras por grupo e parâmetros PC

APÊNDICE 3 - Difratogramas médios dos domínios mineralógicos

APÊNDICE 4 - Análises químicas semi-quantitativas das amostras de contraparte dos pós de perfuratriz

APÊNDICE 5 - Composição químicas dos minerais (base para banco de dados MLA)

APÊNDICE 6 - Resultados MLA

APÊNDICE 7 - Composição química calculada por fração a partir do MLA (\% em massa)

APÊNDICE 8 - Imagens das fases discriminadas ao MLA com destaque para pentlandita 


\section{APÊNDICE 1}

Comparativo entre os difratogramas dispostos em cada grupo

Figura 48 - Comparativo entre os difratogramas das amostras do grupo 1 (total de 8 amostras)
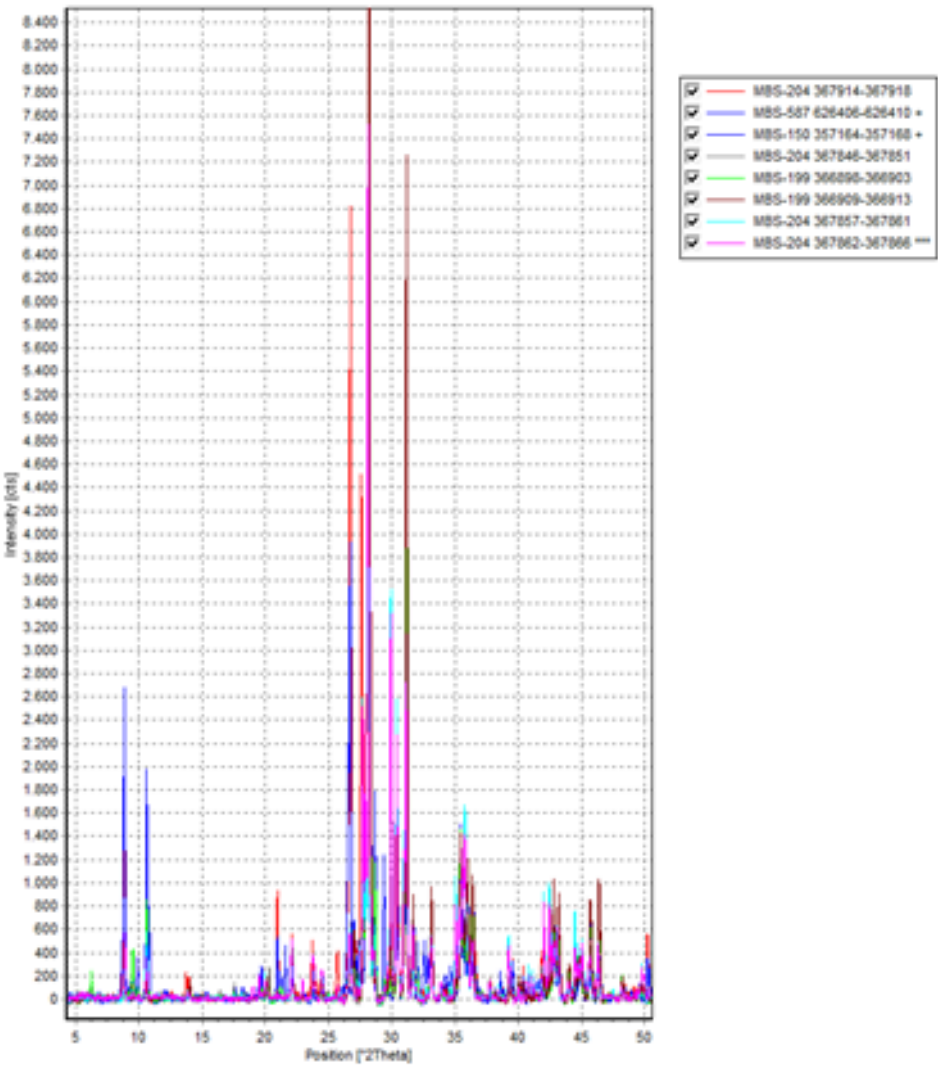

Figura 49 - Comparativo entre os difratogramas das amostras do grupo 2 (total de 10 amostras)

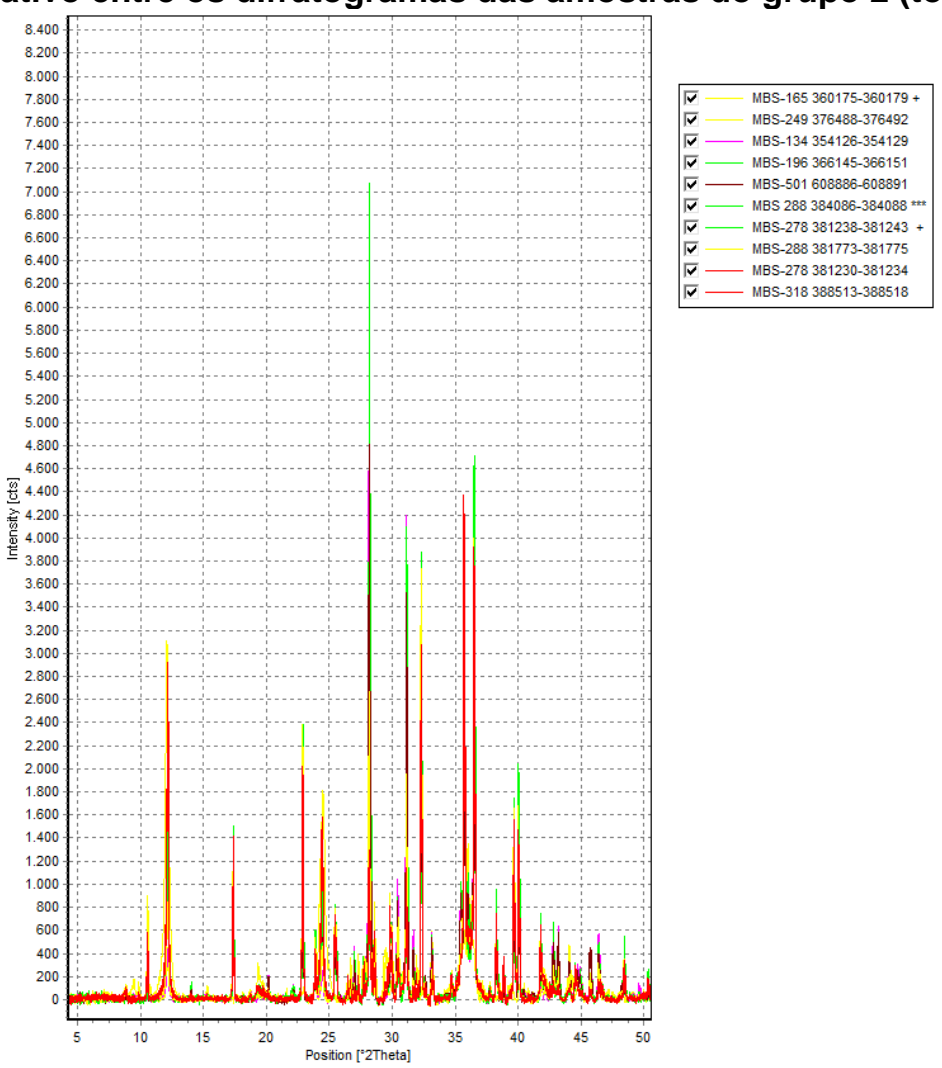




\section{APÊNDICE 1}

Comparativo entre os difratogramas dispostos em cada grupo

Figura 50 - Comparativo entre os difratogramas das amostras do grupo 3 (total de 122

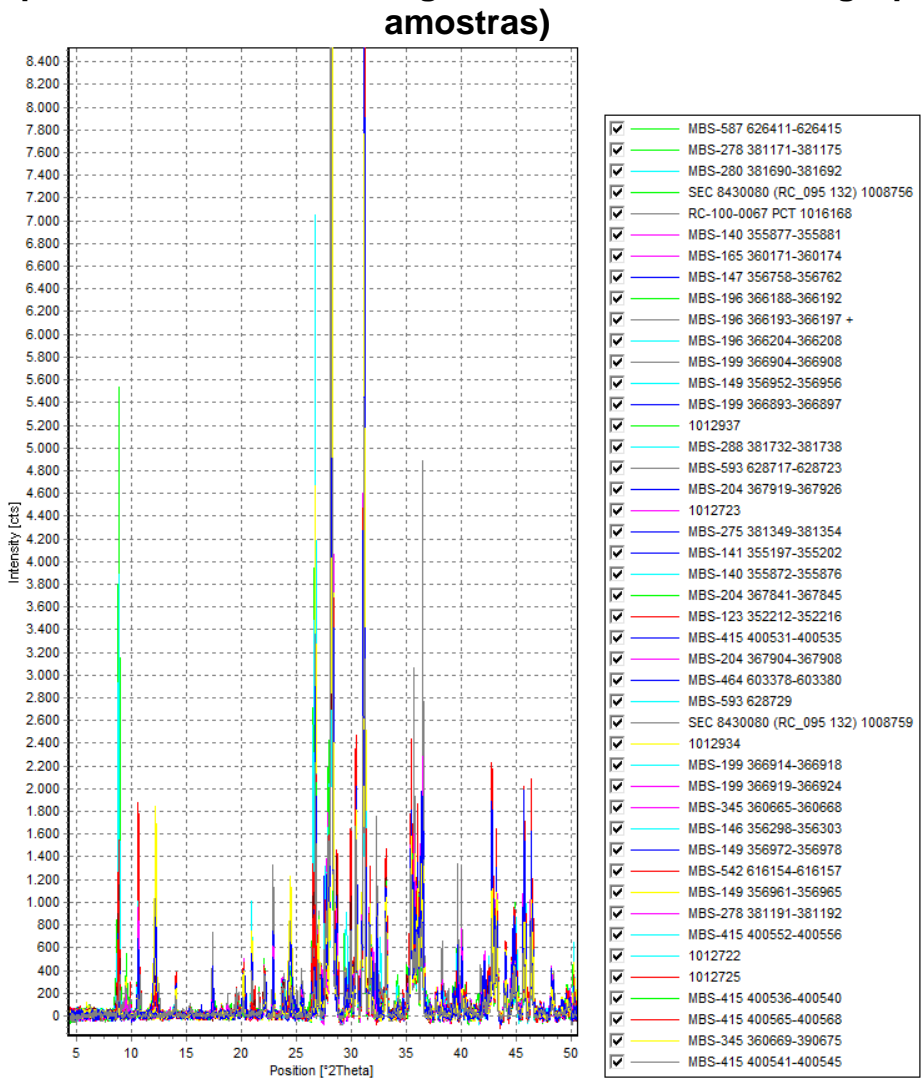

Figura 51 - Comparativo entre os difratogramas das amostras do grupo 4 (total de 2 amostras)

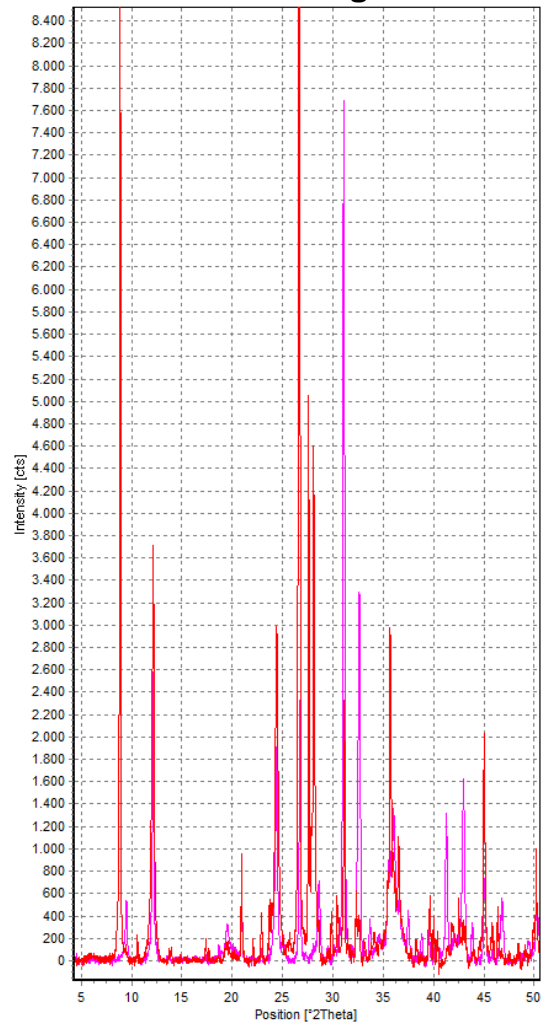

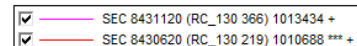




\section{APÊNDICE 1}

Comparativo entre os difratogramas dispostos em cada grupo

Figura 52 - Comparativo entre os difratogramas das amostras do grupo 5 (total de 20 amostras)
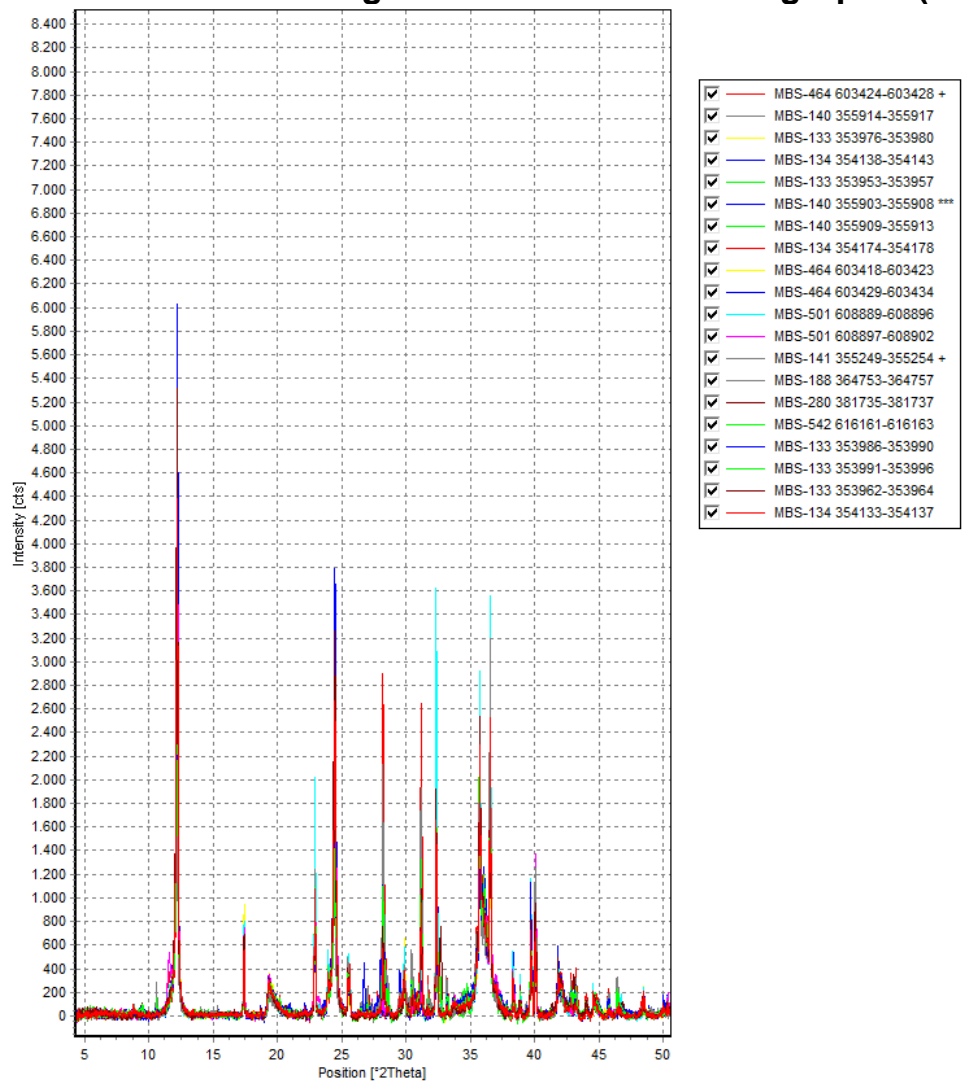

Figura 53 - Comparativo entre os difratogramas das amostras do grupo 6 (total de 33 amostras)
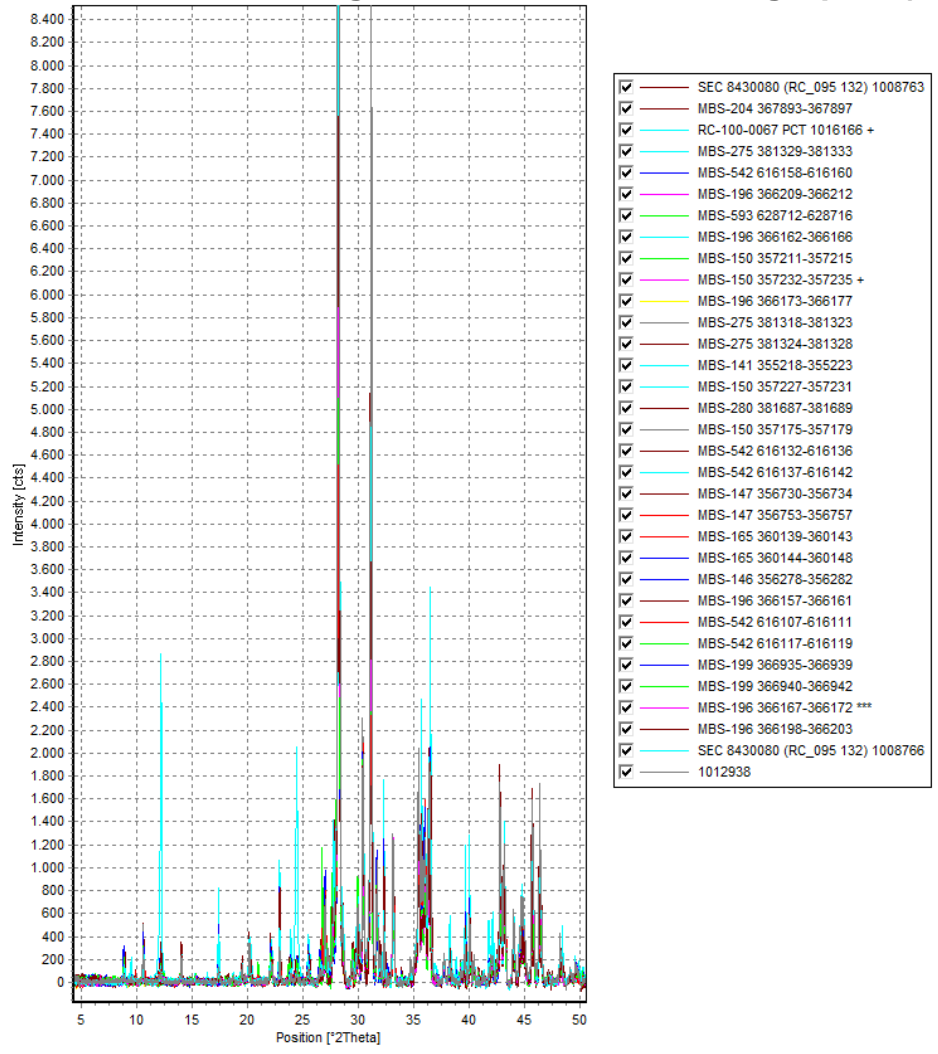


\section{APÊNDICE 1}

Comparativo entre os difratogramas dispostos em cada grupo

Figura 54 - Comparativo entre os difratogramas das amostras do grupo 7 (total de 3 amostras)
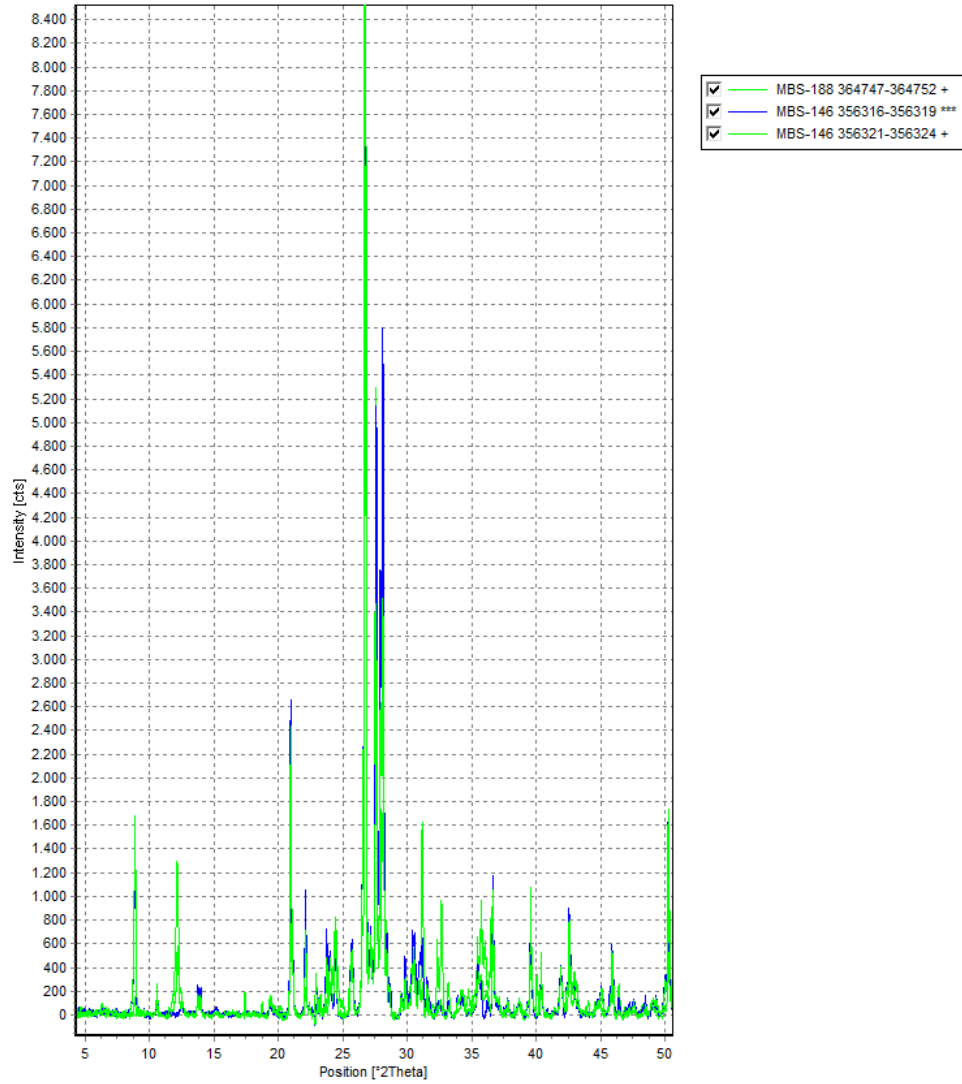

— WBS-146 356316-356319 *

Figura 55 - Comparativo entre os difratogramas das amostras do grupo 8 (total de 40 amostras)

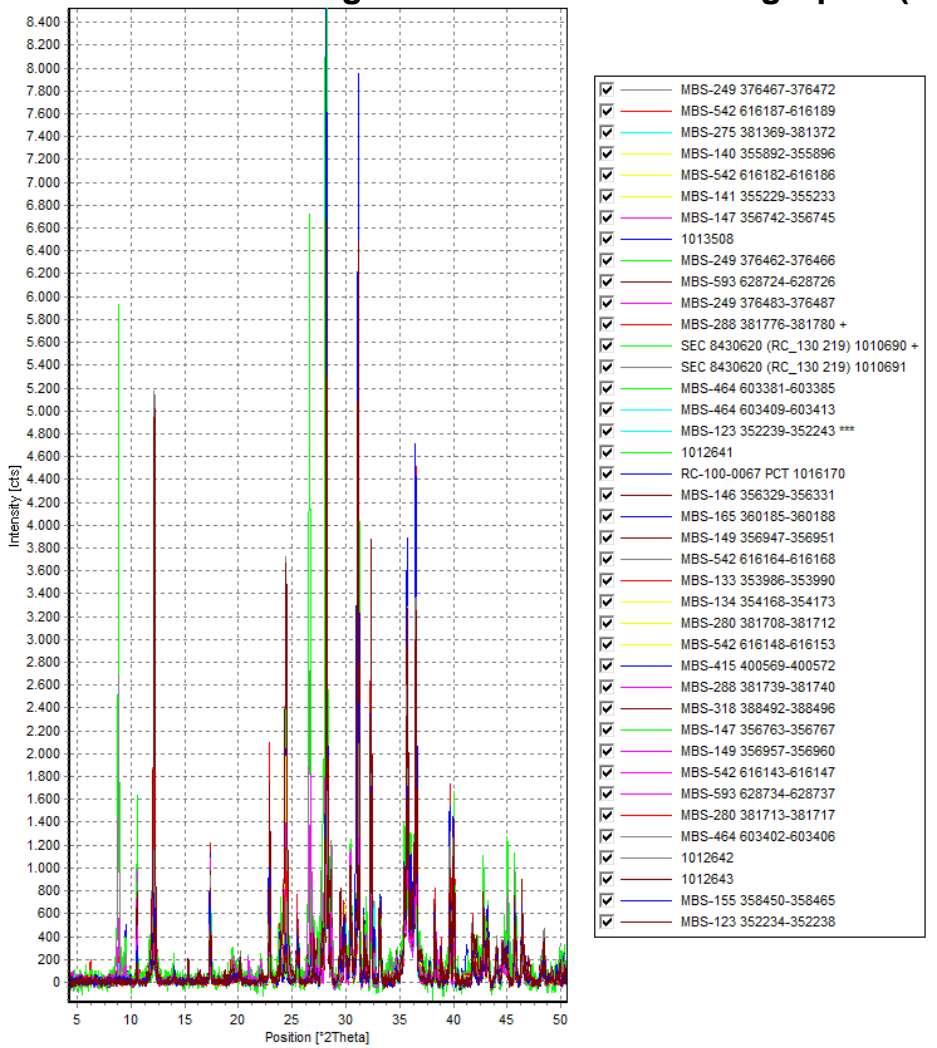




\section{APÊNDICE 1}

Comparativo entre os difratogramas dispostos em cada grupo

Figura 56 - Comparativo entre os difratogramas das amostras do grupo 9 (total de 6 amostras)
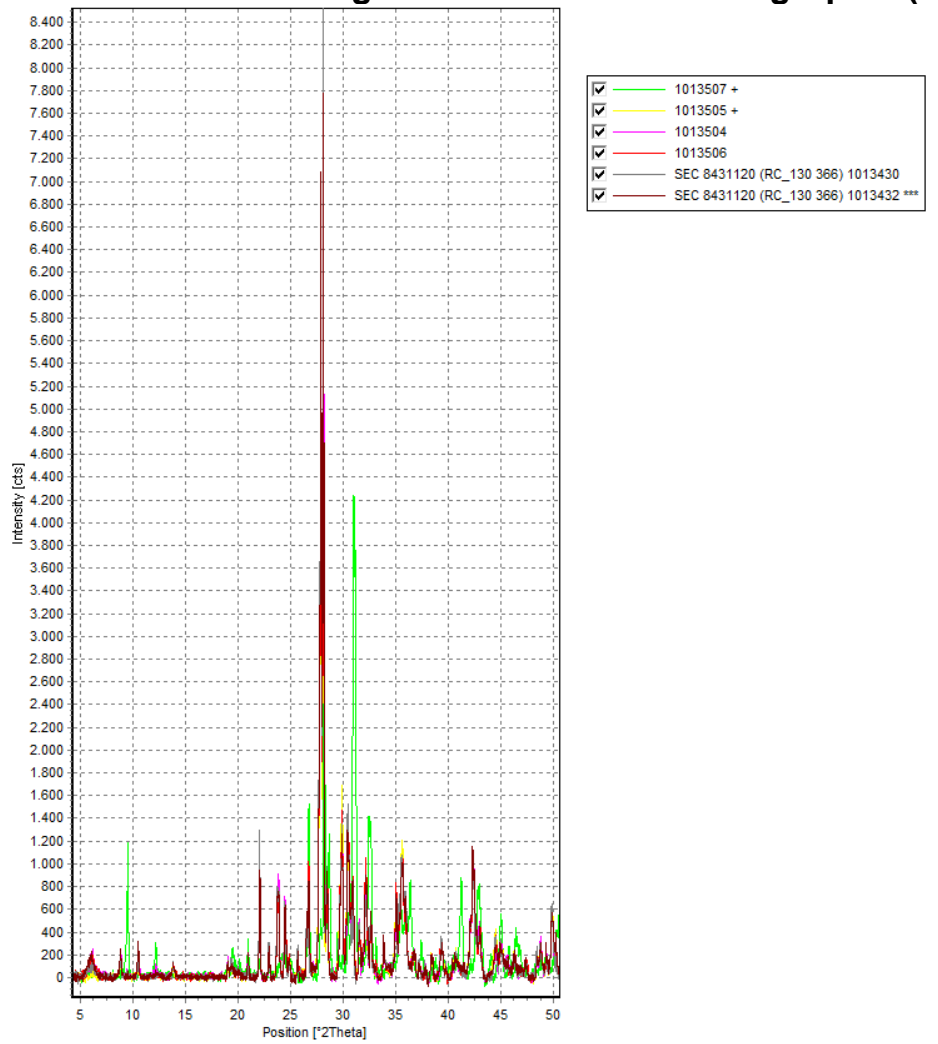

Figura 57 - Comparativo entre os difratogramas das amostras do grupo 10 (total de 10 amostras)

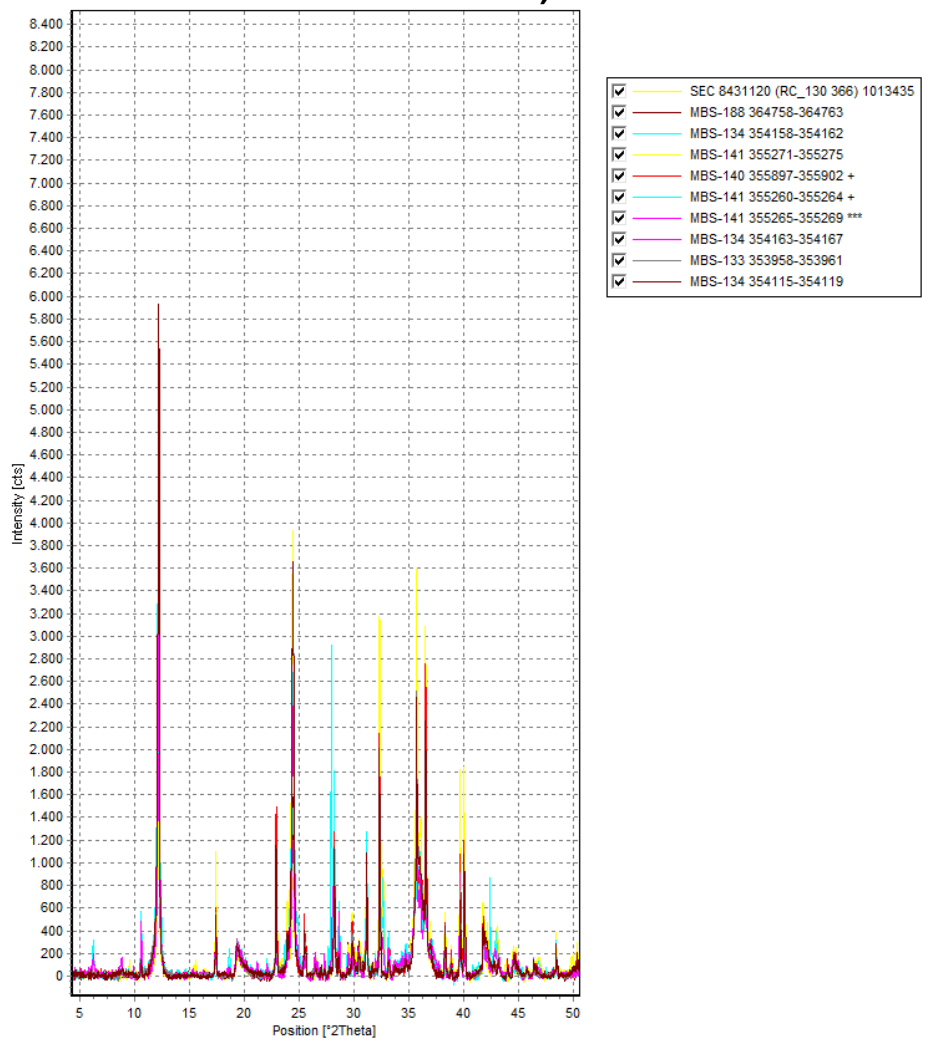




\section{APÊNDICE 1}

Comparativo entre os difratogramas dispostos em cada grupo

Figura 58 - Comparativo entre os difratogramas das amostras do grupo 11 (total de 32 amostras)

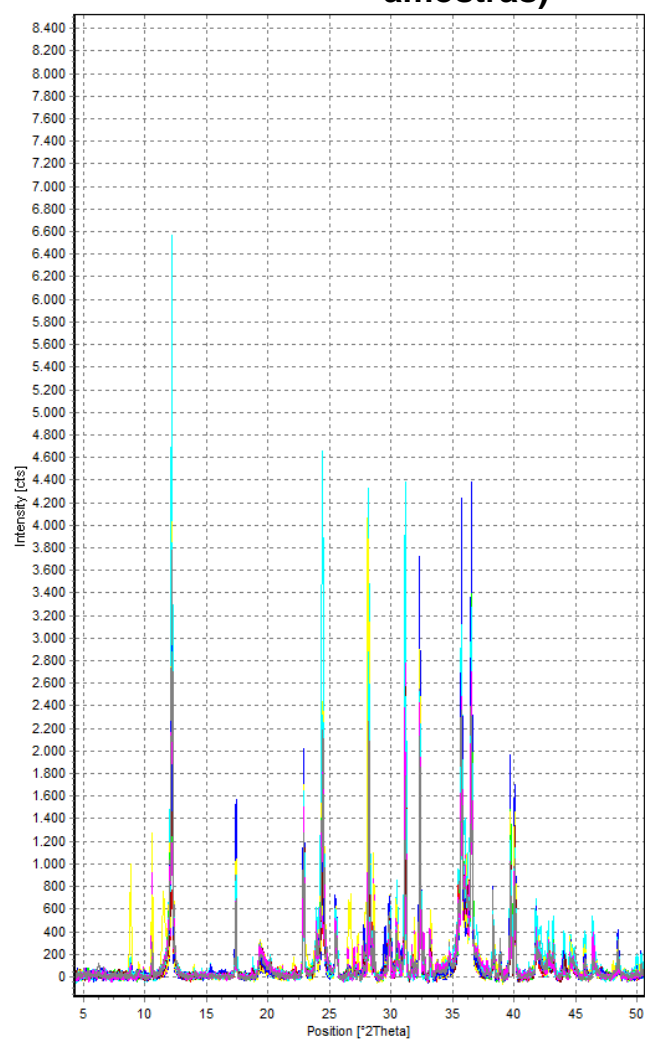

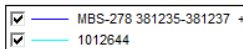

$$
\begin{aligned}
& \text { BS-123 352249-3522 } \\
& \text { MBS-318 388497-388502 } \\
& \text { MBS-501 } 608903-608906 \\
& \text { MBS-278 381226-381229 } \\
& \text { MBS } 288 \text { 384081-384085 } \\
& \text { MBS-146 356325-356328 } \\
& \text { MBS-146 356332-356333 } \\
& \text { MBS-141 355244-355248 } \\
& \text { MBS-280 381725-381729 } \\
& \text { MBS-280 381730-381734 + } \\
& \text { MBS-501 608875-608879 } \\
& \text { MBS- } 134 \text { 354130-354132 } \\
& \sqrt{V} \text { — MBS-141 355234-355238 } \\
& \text { MBS-318 388508-388512 }
\end{aligned}
$$

Figura 59 - Comparativo entre os difratogramas das amostras do grupo 12 (total de 2 amostras)

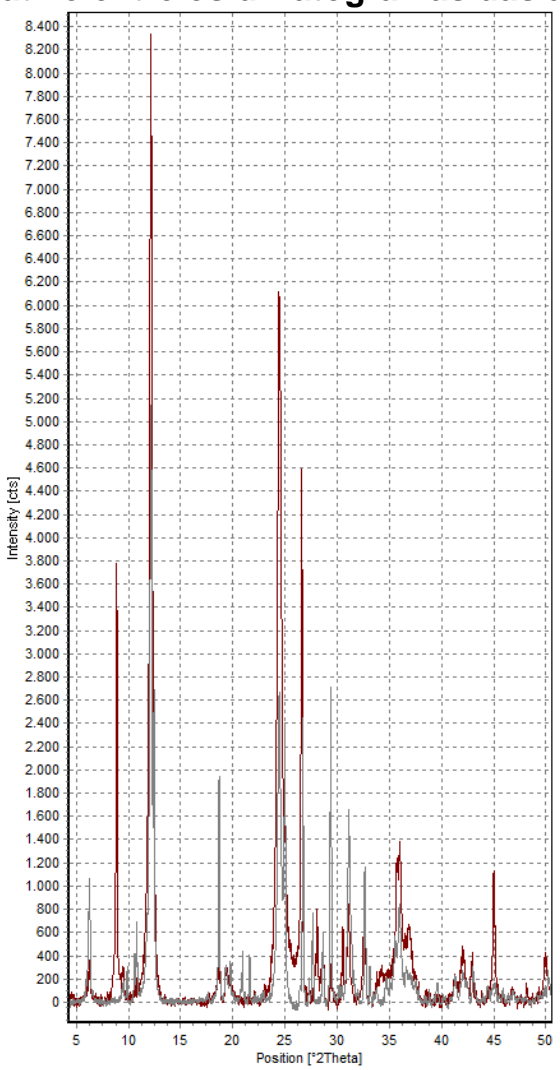




\section{APÊNDICE 1}

Comparativo entre os difratogramas dispostos em cada grupo

Figura 60 - Comparativo entre os difratogramas das amostras do grupo 13 (total de 6 amostras)

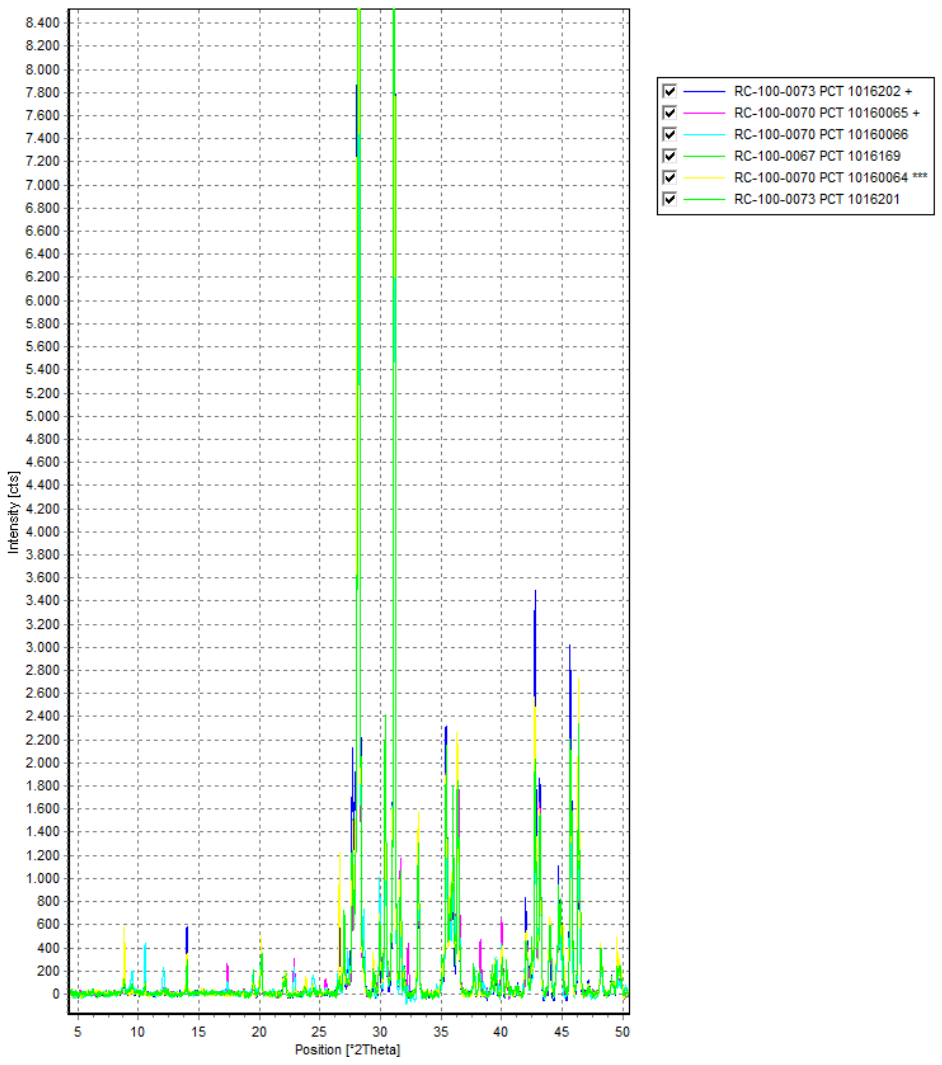

Figura 61 - Comparativo entre os difratogramas das amostras do grupo 14 (total de 5 amostras)
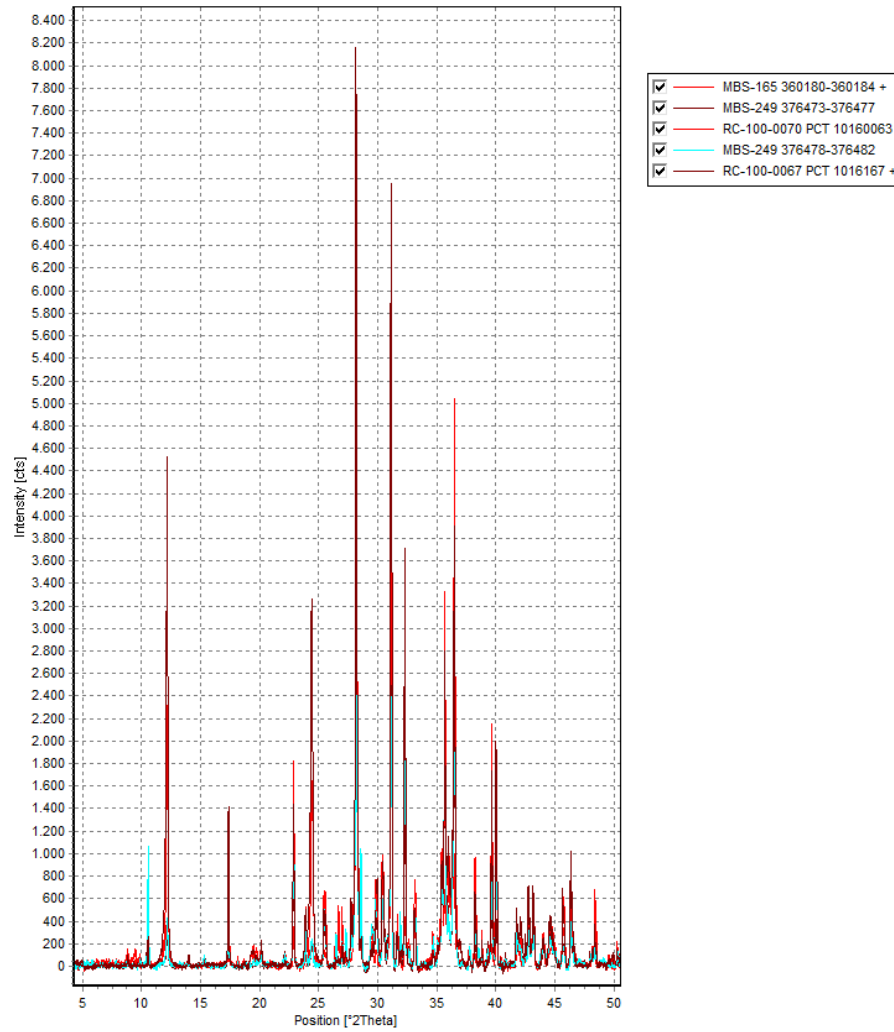


\section{APÊNDICE 1}

Comparativo entre os difratogramas dispostos em cada grupo

Figura 62 - Comparativo entre os difratogramas das amostras do grupo 15 (total de 4 amostras)

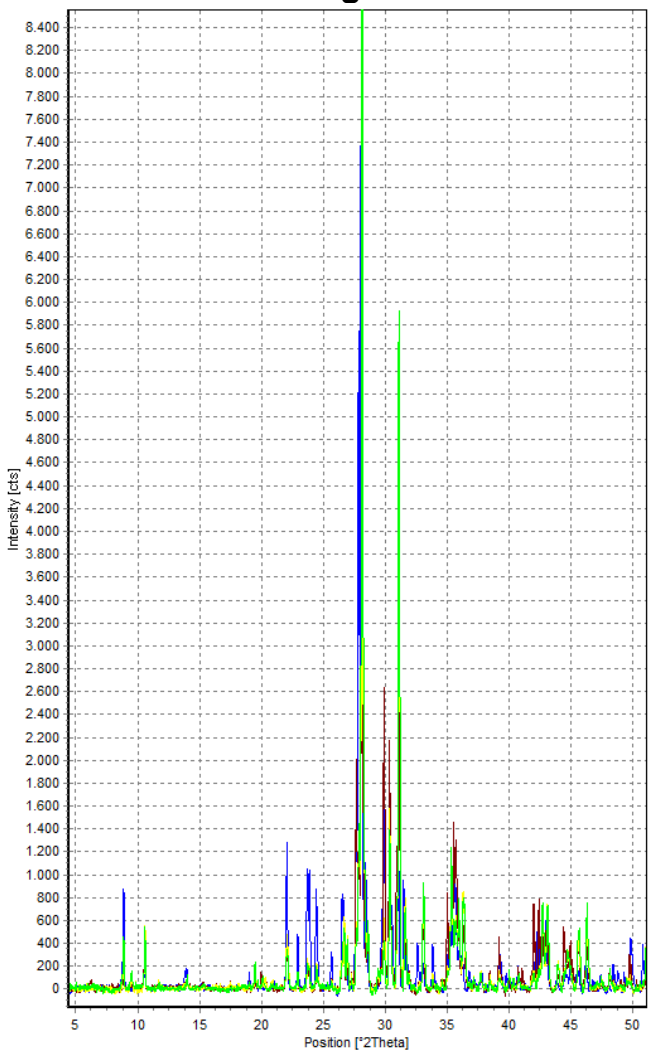

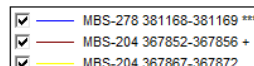

\begin{tabular}{|lr}
$\sqrt{V}$ & MBS-204 $367967-367872$ \\
$\nabla$ & MBS-204 $367883-367887$
\end{tabular}

Figura 63 - Comparativo entre os difratogramas das amostras do grupo 16 (total de 11 amostras).
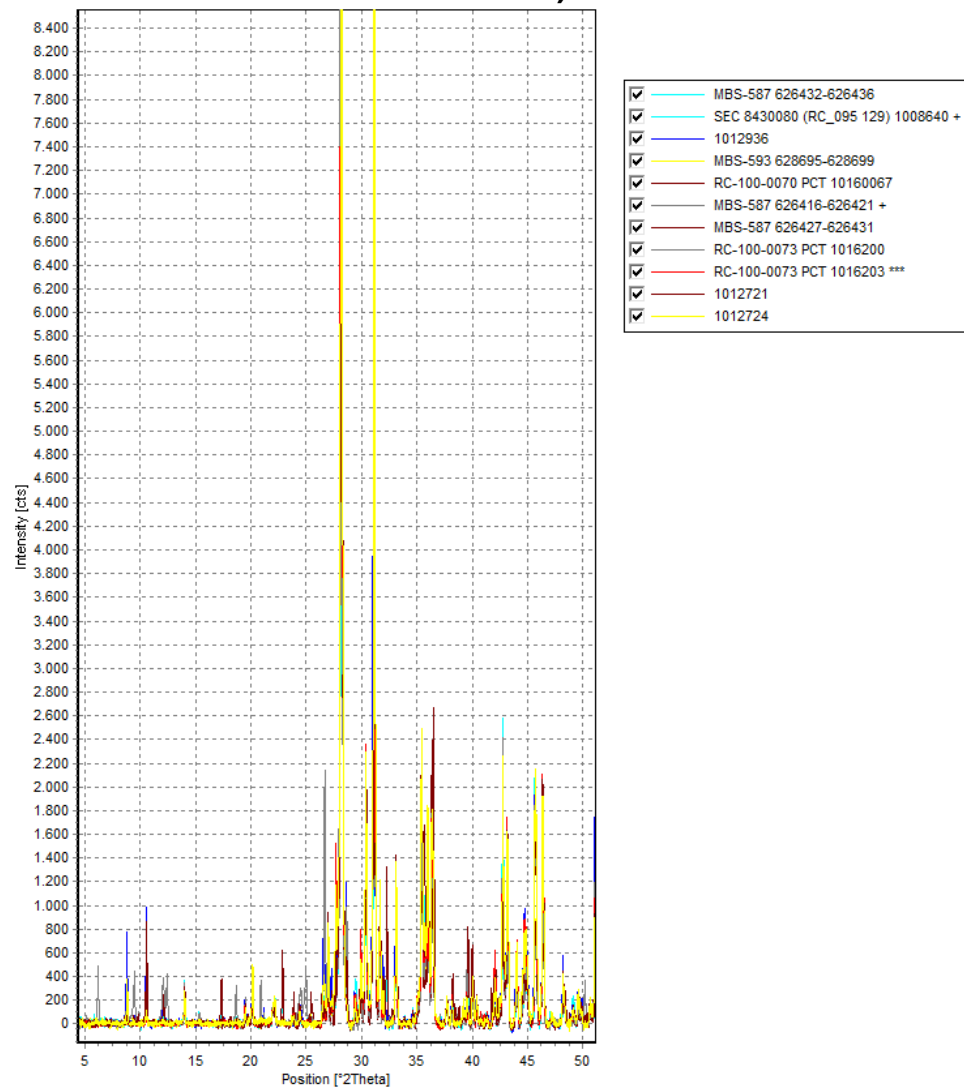


\section{APÊNDICE 1}

Comparativo entre os difratogramas dispostos em cada grupo

Figura 64 - Comparativo entre os difratogramas das amostras do grupo 17 (total de 5 amostras diferentes entre si)
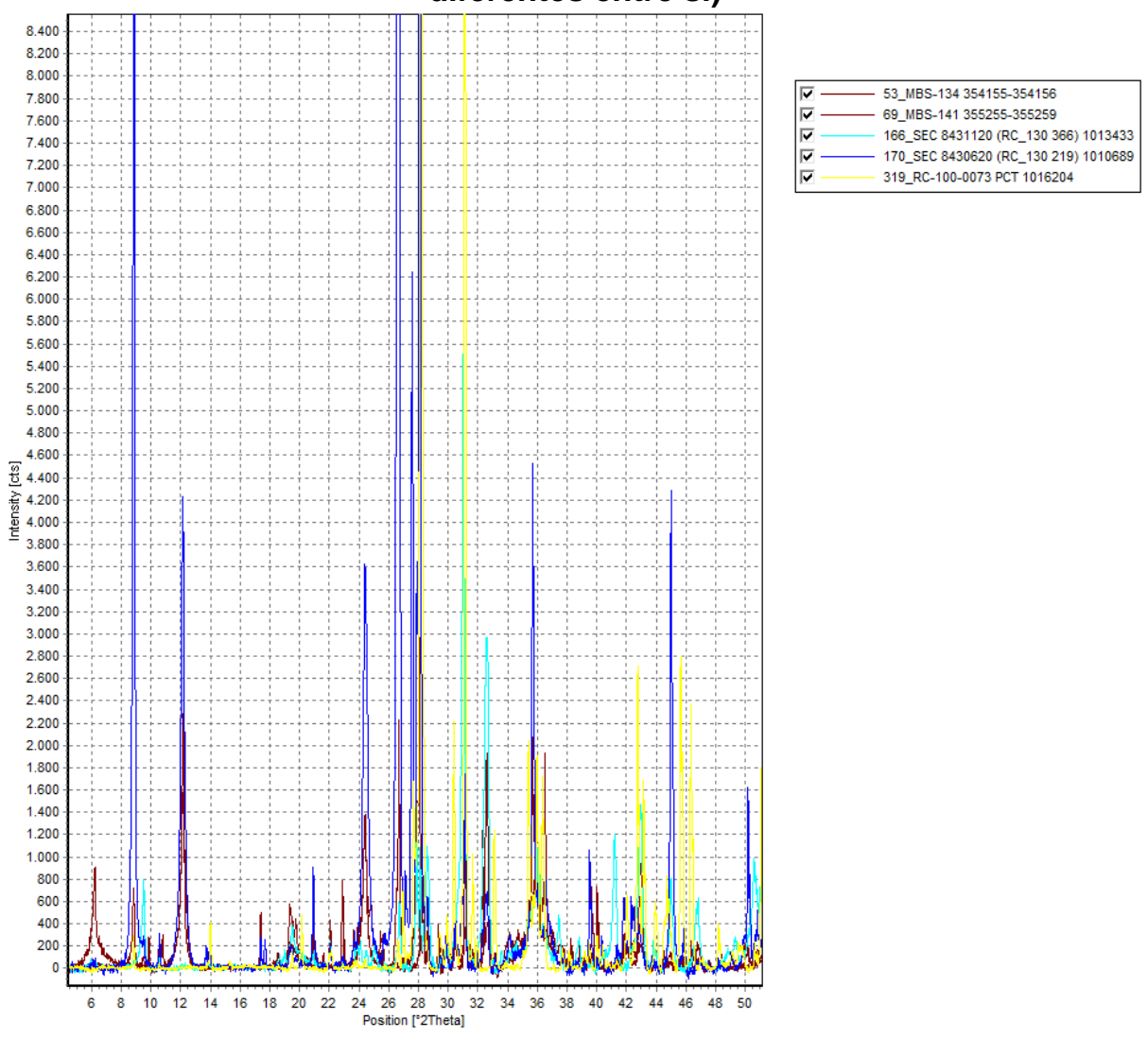
APÊNDICE 2

Relação de amostras por grupo e parâmetros PC

Tabela 31 - Relação de amostras por grupo e parâmetros PCA

\begin{tabular}{|c|c|c|c|c|c|c|c|c|c|c|c|}
\hline ID & GRUPO & PC 1 & PC 2 & PC 3 & PC 4 & PC 5 & PC 6 & PC 7 & PC 8 & PC 9 & PC 10 \\
\hline MBS-150 357164-357168 & 1 & $-9,88$ & 25,60 & 0,73 & 4,33 & 1,25 & 1,03 & $-3,44$ & 0,26 & $-0,14$ & 0,46 \\
\hline MBS-199 366898-366903 & 1 & $-5,43$ & 20,70 & 1,61 & $-0,22$ & 0,86 & 0,77 & $-1,63$ & 2,44 & $-0,50$ & $-0,06$ \\
\hline MBS-199 366909-366913 & 1 & $-8,03$ & 24,64 & 0,13 & $-0,51$ & $-0,12$ & $-0,44$ & $-2,61$ & 1,72 & $-0,01$ & $-0,83$ \\
\hline MBS-204 367846-367851 & 1 & $-5,49$ & 2,56 & 14,67 & 1,08 & 1,04 & $-0,19$ & $-2,72$ & $-2,25$ & 1,28 & 2,64 \\
\hline MBS-204 367857-367861 & 1 & $-10,70$ & $-0,92$ & 10,34 & 3,34 & $-1,42$ & $-1,09$ & 0,09 & $-2,80$ & 0,64 & $-1,82$ \\
\hline MBS-204 367862-367866 & 1 & $-16,67$ & $-11,53$ & 4,14 & 2,26 & $-1,16$ & $-2,69$ & $-1,50$ & $-2,95$ & 0,86 & 0,10 \\
\hline MBS-204 367914-367918 & 1 & 14,40 & $-2,45$ & $-2,80$ & $-4,20$ & $-1,62$ & $-0,10$ & 1,81 & 0,27 & 2,50 & 2,36 \\
\hline MBS-587 626406-626410 & 1 & $-13,44$ & $-6,53$ & $-4,02$ & $-4,23$ & $-2,14$ & 0,40 & $-3,60$ & $-0,51$ & 0,11 & 0,83 \\
\hline MBS-134 354126-354129 & 2 & $-10,92$ & 5,99 & $-1,35$ & 2,28 & $-3,71$ & 4,55 & $-4,75$ & $-0,52$ & 1,84 & 0,46 \\
\hline MBS-165 360175-360179 & 2 & $-15,45$ & 9,76 & 2,82 & 5,60 & $-0,78$ & 1,20 & 1,86 & 0,04 & $-1,21$ & $-1,27$ \\
\hline MBS-196 366145-366151 & 2 & $-9,59$ & 6,76 & $-4,63$ & 1,31 & 0,79 & 1,78 & $-2,19$ & $-2,05$ & 2,15 & $-2,22$ \\
\hline MBS-249 376488-376492 & 2 & 14,87 & 0,40 & $-2,72$ & $-5,08$ & $-2,59$ & $-1,59$ & 1,33 & 1,83 & 1,85 & 1,16 \\
\hline MBS-278 381230-381234 & 2 & 13,54 & $-3,40$ & $-4,12$ & $-4,59$ & $-1,21$ & $-0,54$ & 1,69 & $-0,02$ & 3,51 & 1,47 \\
\hline MBS-278 381238-381243 & 2 & 0,09 & $-13,50$ & $-1,98$ & $-2,89$ & 0,89 & $-0,05$ & 2,00 & $-2,25$ & 1,88 & 2,11 \\
\hline MBS-288 384073-384075 & 2 & 0,48 & 10,47 & 2,76 & $-2,15$ & 1,09 & 1,49 & $-2,58$ & 2,85 & $-3,38$ & 0,74 \\
\hline MBS-288 384086-384088 & 2 & 3,92 & 8,01 & 2,59 & $-3,23$ & $-1,03$ & 1,64 & $-2,51$ & 3,08 & $-2,31$ & 0,39 \\
\hline MBS-318 388513-388518 & 2 & $-15,32$ & 27,36 & 4,99 & $-3,03$ & 1,70 & 3,89 & $-0,74$ & 0,64 & $-1,39$ & $-1,32$ \\
\hline MBS-501 608886-608891 & 2 & 10,56 & 0,92 & $-1,05$ & 0,39 & $-0,34$ & 0,13 & $-0,20$ & $-0,47$ & $-2,09$ & $-1,61$ \\
\hline MBS-155 358454-358459 & 3 & 7,32 & $-0,88$ & $-2,28$ & 2,20 & 0,64 & $-0,76$ & $-0,23$ & $-0,04$ & 0,97 & 0,71 \\
\hline MBS-275 381313-381317 & 3 & 14,01 & $-4,35$ & 2,19 & 0,06 & $-2,85$ & $-1,67$ & 0,18 & 1,28 & $-0,83$ & 1,30 \\
\hline MBS-275 381334-381338 & 3 & 15,65 & $-6,30$ & 1,49 & 0,66 & $-1,99$ & $-1,68$ & 1,94 & 0,82 & $-0,77$ & 0,04 \\
\hline MBS-275 381339-381343 & 3 & 15,18 & $-6,73$ & 2,11 & $-0,22$ & $-2,57$ & $-1,41$ & 1,51 & 0,81 & $-0,74$ & 0,49 \\
\hline MBS-275 381344-381348 & 3 & 14,28 & $-9,86$ & 4,54 & $-0,82$ & $-1,75$ & 0,88 & 2,88 & 0,48 & $-0,95$ & $-0,27$ \\
\hline MBS-275 381349-381354 & 3 & 11,87 & $-4,23$ & 4,17 & $-0,19$ & $-1,36$ & 1,07 & 2,48 & 0,46 & $-0,90$ & $-0,05$ \\
\hline MBS-275 381355-381359 & 3 & 7,27 & 5,08 & 0,90 & 0,27 & 2,34 & $-1,56$ & 2,88 & 1,53 & $-1,33$ & 0,79 \\
\hline MBS-275 381360-381364 & 3 & 10,61 & $-2,15$ & 1,46 & 0,05 & $-1,15$ & $-1,00$ & 1,54 & 1,09 & $-0,54$ & 0,77 \\
\hline MBS-275 381365-381368 & 3 & 13,56 & $-10,43$ & 1,11 & 0,62 & $-2,15$ & $-0,40$ & 1,20 & 0,40 & 0,30 & 0,47 \\
\hline MBS-345 360665-390668 & 3 & 11,42 & $-1,08$ & 0,93 & 0,84 & 0,37 & $-2,05$ & 1,86 & 0,92 & $-1,50$ & 0,06 \\
\hline MBS-345 360669-390675 & 3 & 4,54 & $-4,63$ & 8,22 & 1,47 & 0,85 & 4,30 & 2,13 & 0,85 & $-1,35$ & $-0,03$ \\
\hline MBS-123 352212-352216 & 3 & 9,54 & 2,33 & 1,17 & 2,61 & $-1,18$ & $-1,93$ & $-0,80$ & $-0,02$ & 0,12 & $-0,17$ \\
\hline MBS-123 352217-352222 & 3 & 11,28 & $-2,39$ & 2,49 & 1,88 & 3,22 & 0,59 & 2,54 & 0,35 & $-1,24$ & $-0,36$ \\
\hline MBS-123 352223-352228 & 3 & 14,52 & $-13,38$ & 3,46 & 0,61 & $-1,59$ & 0,03 & 2,17 & $-0,29$ & $-0,45$ & $-1,23$ \\
\hline MBS-123 352229-352233 & 3 & 9,34 & $-1,40$ & 2,16 & 2,09 & 1,63 & 0,20 & 2,46 & $-0,14$ & $-0,75$ & $-1,15$ \\
\hline MBS-415 $400526-400530$ & 3 & 9,22 & 5,34 & 0,49 & 2,02 & 2,35 & $-1,39$ & 0,98 & 0,69 & $-0,73$ & 0,43 \\
\hline MBS-415 400531-400535 & 3 & 6,89 & 3,88 & 1,19 & 2,54 & $-3,37$ & $-0,37$ & $-2,61$ & 0,79 & 0,20 & 0,34 \\
\hline MBS-415 400536-400540 & 3 & 11,31 & $-3,03$ & 2,53 & 1,52 & $-4,37$ & $-0,51$ & $-0,93$ & 0,29 & 0,16 & $-0,20$ \\
\hline MBS-415 400541-400545 & 3 & 5,77 & $-3,28$ & 5,12 & 1,20 & 0,78 & 2,88 & 2,98 & 0,09 & $-1,25$ & $-1,30$ \\
\hline MBS-415 400546-400551 & 3 & 8,88 & $-0,92$ & 2,49 & 1,28 & 1,15 & 0,59 & 1,78 & 0,50 & $-0,88$ & $-1,03$ \\
\hline MBS-415 $400552-400556$ & 3 & 9,10 & $-3,76$ & 4,63 & $-0,86$ & 2,14 & 1,44 & 3,02 & $-0,08$ & $-1,20$ & $-1,11$ \\
\hline MBS-415 400557-400560 & 3 & 13,00 & $-1,56$ & 0,63 & 0,74 & 0,16 & $-2,76$ & 0,91 & 0,82 & $-0,42$ & 1,24 \\
\hline MBS-415 400561-400564 & 3 & 6,32 & $-0,80$ & $-2,55$ & 2,81 & 0,95 & $-0,06$ & 0,07 & $-0,64$ & 1,28 & $-0,13$ \\
\hline MBS-415 400565-400568 & 3 & 13,73 & $-4,15$ & 0,58 & 2,23 & $-1,36$ & $-1,28$ & $-0,75$ & 0,03 & 0,87 & 0,94 \\
\hline MBS-141 $355197-355202$ & 3 & 11,49 & $-6,44$ & 3,15 & 2,80 & 1,43 & 1,43 & 1,37 & $-0,18$ & $-0,03$ & 0,26 \\
\hline MBS-141 355103-355207 & 3 & 17,76 & $-6,85$ & 1,71 & 1,92 & $-1,09$ & $-1,33$ & $-0,65$ & 0,10 & 0,44 & 0,14 \\
\hline MBS-141 $355108-355212$ & 3 & 7,06 & 6,17 & 0,08 & 3,88 & 3,26 & $-1,59$ & 0,86 & $-1,03$ & 0,14 & $-0,54$ \\
\hline MBS-141 355113-355217 & 3 & 15,51 & $-5,69$ & 2,31 & 0,96 & $-2,84$ & $-1,47$ & $-1,43$ & $-0,28$ & 0,73 & $-0,48$ \\
\hline MBS-141 355224-355228 & 3 & 9,09 & $-2,36$ & 1,46 & 3,30 & $-2,17$ & 0,69 & $-2,38$ & $-0,08$ & 0,67 & 0,47 \\
\hline MBS-146 356273-356277 & 3 & 18,34 & $-5,67$ & 1,95 & 0,22 & $-0,68$ & $-1,82$ & $-0,43$ & $-0,26$ & 0,97 & $-0,36$ \\
\hline MBS-146 356283-356287 & 3 & 8,21 & 7,35 & $-0,44$ & 1,66 & 0,84 & $-2,26$ & $-0,19$ & $-1,29$ & 1,51 & $-1,26$ \\
\hline MBS-146 356288-356292 & 3 & 9,58 & 6,70 & $-1,00$ & 3,03 & 2,60 & $-2,58$ & $-0,91$ & $-0,36$ & 0,81 & $-1,00$ \\
\hline MBS-146 356293-356297 & 3 & 11,43 & 1,51 & 1,64 & 2,98 & $-0,12$ & $-1,04$ & $-2,13$ & 0,69 & $-0,28$ & $-0,24$ \\
\hline MBS-146 356298-356303 & 3 & 11,86 & 4,97 & $-1,97$ & 1,16 & 2,71 & $-2,85$ & 0,76 & $-0,81$ & 1,37 & $-1,87$ \\
\hline MBS-146 356304-356308 & 3 & 14,53 & $-5,18$ & 2,87 & 1,81 & $-2,20$ & $-0,31$ & $-1,91$ & $-0,14$ & 0,51 & $-0,46$ \\
\hline MBS-146 356309-356312 & 3 & 14,03 & $-1,10$ & 0,87 & 2,44 & 0,50 & $-1,10$ & $-1,96$ & 0,66 & 0,52 & $-0,35$ \\
\hline MBS-146 356313-356315 & 3 & 14,84 & $-2,58$ & 2,14 & 2,48 & $-0,03$ & $-1,48$ & $-0,88$ & 0,28 & $-0,04$ & 0,03 \\
\hline MBS-150 357148-357153 & 3 & 8,84 & 4,99 & 0,79 & 1,72 & 4,23 & $-1,88$ & $-0,17$ & 0,84 & $-0,50$ & 1,00 \\
\hline MBS-150 357154-357158 & 3 & 17,82 & $-8,45$ & 3,60 & 0,87 & 0,06 & $-0,63$ & $-1,43$ & 0,78 & $-0,26$ & 0,69 \\
\hline MBS-150 357159-357163 & 3 & 7,29 & 6,93 & 1,17 & 2,84 & 2,94 & $-1,42$ & $-0,88$ & 0,43 & $-1,07$ & 0,43 \\
\hline MBS-150 357169-357174 & 3 & 8,29 & 5,16 & 2,04 & 1,58 & 0,58 & $-1,63$ & $-1,32$ & 0,54 & $-0,49$ & 0,29 \\
\hline MBS-150 357180-357184 & 3 & 10,95 & 1,52 & 1,77 & 1,89 & 1,80 & $-0,55$ & $-0,61$ & 0,96 & $-0,75$ & 0,49 \\
\hline MBS-150 357185-357189 & 3 & 6,89 & 6,10 & 2,32 & 1,99 & $-1,32$ & 0,31 & $-4,10$ & 1,28 & $-0,22$ & 0,66 \\
\hline MBS-150 357190-357194 & 3 & 13,01 & 0,21 & 3,09 & 0,87 & $-0,57$ & $-0,57$ & $-1,64$ & 1,41 & $-0,42$ & 0,19 \\
\hline MBS-150 357195-357199 & 3 & 13,29 & $-1,51$ & 2,42 & 2,71 & 0,84 & $-0,38$ & $-1,64$ & 1,23 & $-0,98$ & 0,72 \\
\hline MBS-150 357201-357205 & 3 & 13,30 & 1,12 & 0,11 & 2,74 & 3,10 & $-2,20$ & $-0,64$ & 0,13 & 0,03 & 0,01 \\
\hline MBS-150 357206-357210 & 3 & 5,77 & 8,29 & 1,17 & 3,25 & $-1,09$ & $-0,58$ & $-4,05$ & 0,19 & 0,92 & 0,31 \\
\hline MBS-150 357216-357221 & 3 & 9,55 & 6,36 & $-0,75$ & 3,24 & 3,53 & $-1,91$ & $-0,43$ & $-0,17$ & 0,02 & 0,02 \\
\hline MBS-150 357222-357226 & 3 & 6,35 & 4,20 & 1,98 & 2,25 & 4,32 & $-0,43$ & $-0,91$ & 1,01 & $-0,82$ & 1,16 \\
\hline MBS-165 360134-360138 & 3 & 8,13 & 6,68 & $-0,42$ & 3,50 & 1,57 & $-1,99$ & $-1,20$ & $-0,69$ & 0,84 & $-0,65$ \\
\hline MBS-165 360150-360154 & 3 & 10,45 & 3,03 & 0,05 & 2,61 & $-0,17$ & $-2,04$ & $-2,10$ & $-0,42$ & 1,28 & $-0,69$ \\
\hline MBS-165 360155-360159 & 3 & 8,12 & 4,60 & 1,24 & 1,79 & $-1,59$ & $-1,13$ & $-1,58$ & $-0,46$ & 0,82 & $-0,81$ \\
\hline MBS-165 360160-360164 & 3 & 10,72 & $-3,72$ & 1,56 & 3,41 & $-0,07$ & 0,62 & $-1,37$ & $-0,62$ & 0,80 & 0,65 \\
\hline MBS-165 360165-360169 & 3 & 12,73 & $-7,08$ & 1,42 & 1,95 & $-2,33$ & 0,99 & $-1,69$ & $-0,69$ & 1,72 & $-0,36$ \\
\hline MBS-165 360171-360174 & 3 & 2,75 & $-0,47$ & $-3,37$ & 3,30 & 3,21 & 1,34 & $-0,67$ & $-1,29$ & 1,94 & $-0,34$ \\
\hline MBS-140 355872-355876 & 3 & 13,50 & $-10,84$ & 4,61 & 1,14 & 0,06 & 2,34 & 0,74 & $-0,85$ & 0,39 & $-1,36$ \\
\hline
\end{tabular}


APÊNDICE 2

Relação de amostras por grupo e parâmetros PC

Tabela 30 - Relação de amostras por grupo e parâmetros PCA (continuação)

\begin{tabular}{|c|c|c|c|c|c|c|c|c|c|c|c|}
\hline ID & GRUPO & PC 1 & PC 2 & PC 3 & PC 4 & PC 5 & PC 6 & PC 7 & PC 8 & PC 9 & PC 10 \\
\hline MBS-140 355877-355881 & 3 & 9,51 & $-0,39$ & 1,08 & $-2,30$ & 4,10 & 0,74 & 1,40 & $-0,14$ & 1,24 & $-2,20$ \\
\hline MBS-147 356735-356741 & 3 & 8,57 & 4,05 & $-0,05$ & 4,33 & 3,93 & $-0,25$ & 0,53 & $-0,54$ & 0,14 & $-0,73$ \\
\hline MBS-147 356746-356752 & 3 & 10,83 & 1,65 & 0,64 & 2,28 & 0,59 & $-0,58$ & $-0,70$ & $-0,70$ & 0,90 & $-0,38$ \\
\hline MBS-147 356758-356762 & 3 & 7,56 & $-0,32$ & 2,25 & 3,63 & 3,64 & 2,15 & 0,49 & $-0,67$ & $-0,57$ & $-0,54$ \\
\hline MBS-149 356943-356946 & 3 & 14,94 & $-10,37$ & 1,40 & $-2,02$ & $-1,11$ & 0,82 & 0,01 & 0,70 & 1,89 & $-0,85$ \\
\hline MBS-149 356952-356956 & 3 & 11,09 & $-3,20$ & 2,73 & $-1,12$ & $-2,60$ & 1,14 & $-1,08$ & 0,99 & 0,41 & $-1,28$ \\
\hline MBS-149 356961-356965 & 3 & 13,15 & $-8,32$ & $-1,00$ & 1,33 & 1,78 & 1,09 & 0,36 & $-0,46$ & 1,09 & $-0,80$ \\
\hline MBS-149 356966-356971 & 3 & 17,96 & $-11,52$ & 2,49 & 0,06 & $-0,89$ & 0,95 & $-0,01$ & 0,32 & 0,66 & $-0,41$ \\
\hline MBS-149 356972-356978 & 3 & 9,62 & 4,34 & $-0,69$ & $-1,08$ & $-0,28$ & $-1,74$ & 0,50 & $-0,06$ & 2,39 & $-1,28$ \\
\hline MBS-196 366152-366156 & 3 & 16,51 & $-4,96$ & $-0,29$ & $-0,34$ & $-0,48$ & $-1,96$ & 0,04 & $-0,22$ & 2,70 & $-1,54$ \\
\hline MBS-196 366178-366182 & 3 & 18,20 & $-4,65$ & 0,99 & $-0,70$ & $-1,85$ & $-2,09$ & $-1,02$ & 0,25 & 1,88 & $-0,86$ \\
\hline MBS-196 366183-366187 & 3 & 16,00 & $-5,05$ & 1,20 & $-1,41$ & $-3,04$ & $-1,55$ & $-0,94$ & 0,09 & 2,64 & $-1,12$ \\
\hline MBS-196 366188-366192 & 3 & 10,23 & 2,66 & 1,12 & $-1,71$ & $-4,53$ & $-1,57$ & $-1,74$ & 0,00 & 2,94 & $-1,71$ \\
\hline MBS-196 366193-366197 & 3 & 5,22 & 7,62 & 1,23 & $-1,87$ & $-5,22$ & $-1,63$ & $-2,59$ & $-0,04$ & 3,71 & $-1,62$ \\
\hline MBS-196 366204-366208 & 3 & 12,63 & 1,40 & 2,10 & $-3,63$ & 0,66 & $-1,48$ & 2,29 & 0,57 & 1,49 & $-2,44$ \\
\hline MBS-196 366213-366215 & 3 & 17,06 & $-4,20$ & 1,34 & $-1,85$ & $-3,18$ & $-1,85$ & $-0,77$ & 0,50 & 2,51 & $-1,26$ \\
\hline MBS-199 366887-366892 & 3 & 5,81 & 4,51 & 3,68 & $-3,27$ & 0,41 & $-0,39$ & $-1,84$ & 2,80 & $-0,67$ & 0,71 \\
\hline MBS-199 366893-366897 & 3 & 14,54 & $-3,16$ & 4,08 & $-3,97$ & 0,04 & $-0,79$ & $-0,59$ & 2,72 & $-0,09$ & $-0,14$ \\
\hline MBS-199 366904-366908 & 3 & 11,02 & 4,60 & 0,62 & $-6,63$ & 0,05 & $-3,05$ & 1,02 & 2,68 & 2,92 & $-1,41$ \\
\hline MBS-199 366914-366918 & 3 & 10,65 & 5,55 & 0,20 & $-2,99$ & 0,36 & $-2,62$ & $-0,36$ & 2,15 & 1,05 & $-1,00$ \\
\hline MBS-199 366919-366924 & 3 & 14,41 & 2,79 & 0,78 & $-1,16$ & 0,93 & $-2,95$ & $-0,42$ & 1,51 & 1,01 & 0,05 \\
\hline MBS-199 366925-366929 & 3 & 16,63 & $-4,24$ & 2,63 & $-1,59$ & $-2,82$ & $-1,50$ & $-1,56$ & 0,95 & 1,22 & $-0,44$ \\
\hline MBS-199 366930-366934 & 3 & 9,87 & 7,34 & $-0,93$ & 1,24 & 2,66 & $-2,40$ & 0,24 & 0,23 & 0,34 & $-0,37$ \\
\hline MBS-204 367841-367845 & 3 & $-5,71$ & 3,54 & 13,94 & $-0,11$ & 1,45 & $-0,87$ & $-3,01$ & $-1,67$ & 1,59 & 1,92 \\
\hline MBS-204 367867-367872 & 3 & $-7,51$ & $-4,65$ & 8,38 & $-5,97$ & 1,63 & 0,33 & 1,75 & $-1,58$ & 2,21 & $-3,52$ \\
\hline MBS-204 367873-367877 & 3 & $-12,26$ & 7,04 & 5,73 & $-13,43$ & 2,14 & 1,99 & 1,55 & 2,73 & 4,40 & $-5,21$ \\
\hline MBS-204 367878-367882 & 3 & $-2,36$ & $-10,94$ & 8,62 & 0,93 & 1,61 & 1,23 & 1,07 & $-2,54$ & $-0,49$ & $-0,21$ \\
\hline MBS-204 367888-367892 & 3 & $-25,15$ & 5,01 & 9,15 & $-0,57$ & $-3,08$ & $-1,57$ & 1,92 & $-3,58$ & $-0,04$ & $-1,63$ \\
\hline MBS-204 367898-367903 & 3 & 15,63 & $-1,74$ & $-3,50$ & $-5,73$ & $-2,51$ & $-0,58$ & 1,58 & 1,61 & 2,56 & 1,58 \\
\hline MBS-204 367904-367908 & 3 & 9,64 & 0,80 & $-2,91$ & $-0,35$ & 1,56 & 0,17 & 2,34 & $-1,47$ & 1,30 & 1,87 \\
\hline MBS-204 367909-367913 & 3 & 9,24 & 1,77 & $-2,46$ & 0,61 & 1,77 & 0,92 & 1,75 & $-1,21$ & 1,09 & 2,35 \\
\hline MBS-278 381164-381167 & 3 & 6,57 & 11,22 & $-3,63$ & $-3,43$ & 1,04 & $-1,13$ & 2,63 & 2,18 & 1,22 & 1,43 \\
\hline MBS-278 381171-381175 & 3 & 4,52 & 10,18 & $-3,92$ & 0,33 & 2,87 & 0,21 & 1,58 & $-0,39$ & 1,33 & 2,39 \\
\hline MBS-278 381176-381181 & 3 & 10,21 & 7,50 & $-3,72$ & $-1,72$ & 0,07 & $-2,34$ & 1,16 & 0,67 & 1,20 & 1,36 \\
\hline MBS-278 381182-381185 & 3 & 17,38 & $-6,17$ & 0,51 & $-2,97$ & $-2,13$ & 0,08 & 1,51 & $-0,03$ & 1,08 & 1,01 \\
\hline MBS-278 381186-381190 & 3 & 13,87 & 1,69 & $-2,16$ & $-1,99$ & 0,10 & $-1,27$ & 2,07 & 0,44 & 0,70 & 0,83 \\
\hline MBS-278 381191-381192 & 3 & 8,05 & 9,43 & $-2,28$ & $-1,20$ & $-0,65$ & $-1,52$ & 0,20 & 0,89 & 0,69 & 1,92 \\
\hline MBS-280 381682-381686 & 3 & 1,30 & $-16,14$ & $-2,46$ & $-2,59$ & 0,00 & $-0,44$ & 0,63 & $-2,19$ & 1,75 & 1,77 \\
\hline MBS-280 381690-381692 & 3 & $-2,67$ & 2,56 & 11,77 & $-2,59$ & 0,96 & $-0,72$ & $-0,87$ & $-3,76$ & 1,89 & 5,45 \\
\hline MBS-280 381693-381695 & 3 & $-5,39$ & 2,47 & 12,57 & $-0,73$ & 0,27 & $-1,53$ & $-0,63$ & $-5,85$ & 1,53 & 6,77 \\
\hline MBS-288 384032-384038 & 3 & $-7,93$ & 16,47 & 4,14 & $-1,15$ & 5,71 & $-1,56$ & $-2,36$ & 0,95 & $-1,14$ & 2,91 \\
\hline MBS-464 603378-603380 & 3 & 11,79 & 4,31 & $-1,18$ & $-1,30$ & 1,66 & $-0,73$ & 0,73 & 1,62 & $-3,05$ & $-0,25$ \\
\hline MBS-542 616112-616116 & 3 & $-10,41$ & $-1,94$ & $-6,25$ & $-2,86$ & 0,52 & 2,09 & $-3,17$ & 0,86 & $-0,03$ & 0,43 \\
\hline MBS-542 616129-616131 & 3 & 11,72 & 4,24 & $-1,92$ & 1,58 & $-1,79$ & $-0,42$ & $-0,39$ & $-0,51$ & $-1,45$ & $-2,57$ \\
\hline MBS-542 616154-616157 & 3 & $-1,41$ & $-18,07$ & $-2,03$ & $-2,18$ & $-1,05$ & $-0,26$ & $-0,76$ & $-1,06$ & $-1,25$ & $-0,52$ \\
\hline MBS-587 626411-626415 & 3 & $-20,10$ & 2,37 & $-6,71$ & $-3,09$ & 1,37 & 0,19 & $-3,12$ & $-0,82$ & 0,71 & 0,46 \\
\hline MBS-587 626437-626440 & 3 & $-9,21$ & $-6,71$ & $-2,17$ & $-2,51$ & 1,93 & 1,81 & $-1,67$ & 0,27 & $-1,24$ & 0,33 \\
\hline MBS-593 628701-628705 & 3 & $-24,99$ & 8,16 & $-4,56$ & $-2,40$ & 0,71 & 0,37 & $-2,25$ & $-0,86$ & $-0,11$ & 0,35 \\
\hline MBS-593 628706-628711 & 3 & 10,69 & $-5,77$ & $-4,21$ & 1,20 & $-0,09$ & 1,79 & $-0,97$ & $-2,26$ & $-0,26$ & $-1,44$ \\
\hline MBS-593 628717-628723 & 3 & $-3,17$ & $-16,56$ & $-1,45$ & $-1,68$ & 0,77 & $-0,77$ & $-1,68$ & $-1,34$ & $-1,93$ & 0,00 \\
\hline MBS-593 628729 & 3 & $-0,31$ & $-11,61$ & $-2,68$ & $-0,80$ & 0,63 & 1,05 & $-1,90$ & $-1,31$ & $-1,04$ & $-0,77$ \\
\hline SEC 8430080 (RC_095 129) 1008649 & 3 & 4,70 & 14,89 & $-4,59$ & 2,37 & $-1,85$ & 0,78 & 0,49 & $-1,73$ & $-0,82$ & $-1,41$ \\
\hline SEC 8430080 (RC_095 129) 1008653 & 3 & 14,55 & $-0,44$ & $-0,30$ & 1,36 & $-2,15$ & 1,36 & $-0,54$ & $-0,34$ & $-2,61$ & $-0,84$ \\
\hline SEC 8430080 (RC_095 129) 1008646 & 3 & $-1,81$ & 11,54 & $-5,20$ & 3,03 & 0,65 & 2,98 & $-0,13$ & $-2,36$ & 0,54 & $-1,28$ \\
\hline SEC 8430080 (RC_095 129) 1008643 & 3 & $-0,29$ & 13,63 & $-5,08$ & 3,15 & 1,36 & 2,29 & 0,39 & $-1,95$ & $-0,07$ & $-1,26$ \\
\hline SEC 8430080 (RC_095 132) 1008756 & 3 & $-1,02$ & $-17,48$ & $-1,78$ & $-1,22$ & 2,78 & $-1,33$ & 0,57 & $-0,66$ & $-2,37$ & $-0,82$ \\
\hline SEC 8430080 (RC_095 132) 1008759 & 3 & $-2,77$ & $-13,82$ & $-4,10$ & $-1,15$ & 2,90 & $-0,72$ & 0,73 & $-1,27$ & $-1,64$ & $-1,08$ \\
\hline SEC 8430080 (RC_095 132) 1008769 & 3 & $-22,30$ & 1,36 & $-1,47$ & $-0,44$ & 2,15 & $-3,11$ & 0,51 & $-1,63$ & $-1,72$ & $-1,60$ \\
\hline 1012934 & 3 & $-5,10$ & $-15,28$ & $-2,62$ & $-1,84$ & $-0,10$ & $-0,39$ & $-1,29$ & $-0,40$ & $-1,31$ & $-0,67$ \\
\hline 1012935 & 3 & $-8,68$ & $-8,96$ & $-4,81$ & $-1,58$ & 3,09 & $-1,05$ & $-0,51$ & $-0,63$ & $-1,28$ & $-0,60$ \\
\hline 1012937 & 3 & $-16,16$ & $-10,92$ & 0,09 & $-2,50$ & $-1,97$ & $-2,78$ & $-1,30$ & $-1,91$ & $-1,77$ & $-0,48$ \\
\hline 1012722 & 3 & $-7,99$ & 17,31 & 3,44 & $-1,39$ & 2,66 & 3,70 & 3,14 & 0,01 & $-1,63$ & $-1,70$ \\
\hline 1012723 & 3 & 5,97 & 2,08 & 5,91 & $-3,93$ & $-1,90$ & 3,71 & 2,68 & $-0,91$ & $-1,27$ & $-1,58$ \\
\hline 1012725 & 3 & 9,71 & 11,12 & $-2,92$ & 1,07 & $-1,95$ & 0,99 & 2,49 & $-0,97$ & $-1,91$ & $-0,85$ \\
\hline 1012640 & 3 & 11,54 & 7,62 & $-2,59$ & 3,04 & $-1,95$ & 0,67 & $-0,10$ & $-1,42$ & $-1,58$ & $-0,22$ \\
\hline RC_100_0067 PCT 1016168 & 3 & 6,80 & $-7,69$ & $-4,62$ & $-2,83$ & 1,28 & 2,69 & 1,60 & $-0,95$ & 0,14 & 1,75 \\
\hline SEC 8431120 (RC_130 366) 1013434 & 4 & $-14,22$ & $-12,21$ & $-0,38$ & $-2,90$ & $-2,78$ & $-3,49$ & $-0,98$ & $-2,23$ & $-2,17$ & $-0,21$ \\
\hline SEC 8430620 (RC_130 219) 1010688 & 4 & $-14,55$ & 8,21 & $-6,22$ & 1,07 & 1,87 & 2,95 & $-2,68$ & $-1,63$ & 0,70 & $-1,15$ \\
\hline MBS-133 353953-353957 & 5 & $-22,11$ & $-1,96$ & $-2,74$ & 1,77 & 1,68 & $-0,87$ & 0,45 & 2,02 & 0,36 & $-0,06$ \\
\hline MBS-133 353962-353964 & 5 & $-29,02$ & 4,54 & $-1,41$ & 1,12 & $-1,04$ & $-0,81$ & 0,86 & 1,24 & 0,69 & $-0,50$ \\
\hline MBS-133 353976-353980 & 5 & $-29,45$ & 0,78 & 2,60 & 1,84 & $-5,12$ & 0,80 & 1,21 & 2,36 & 0,53 & 0,04 \\
\hline MBS-133 353986-353990 & 5 & $-26,42$ & 2,16 & 0,40 & 3,63 & $-1,28$ & 0,98 & 1,49 & 2,25 & $-0,37$ & $-0,52$ \\
\hline MBS-133 353991-353996 & 5 & $-26,56$ & 3,97 & $-0,69$ & 2,64 & $-1,68$ & 0,15 & 1,34 & 1,57 & 0,03 & $-0,19$ \\
\hline MBS-134 354133-354137 & 5 & $-29,45$ & 3,64 & $-1,24$ & 1,54 & $-0,83$ & $-0,67$ & 1,34 & 1,52 & 1,03 & 0,05 \\
\hline
\end{tabular}


APÊNDICE 2

Relação de amostras por grupo e parâmetros PC

Tabela 30 - Relação de amostras por grupo e parâmetros PCA (continuação)

\begin{tabular}{|c|c|c|c|c|c|c|c|c|c|c|c|}
\hline ID & GRUPO & PC 1 & PC 2 & PC 3 & PC 4 & PC 5 & PC 6 & PC 7 & PC 8 & PC 9 & PC 10 \\
\hline MBS-134 354138-354143 & 5 & $-29,73$ & $-3,43$ & 0,94 & $-0,08$ & $-1,98$ & 0,76 & 0,38 & 2,08 & 2,05 & 0,07 \\
\hline MBS-134 354174-354178 & 5 & $-20,18$ & 1,09 & $-2,26$ & 4,30 & $-2,47$ & 1,10 & $-1,39$ & 1,21 & 0,36 & $-0,22$ \\
\hline MBS-141 355249-355254 & 5 & $-17,48$ & $-1,39$ & $-3,80$ & 2,93 & 1,41 & 0,66 & $-0,02$ & 1,57 & 1,16 & 0,93 \\
\hline MBS-188 364753-364757 & 5 & $-18,74$ & $-0,58$ & $-3,91$ & 3,00 & 4,41 & 0,11 & 0,92 & $-0,03$ & 0,86 & $-0,49$ \\
\hline MBS-140 355903-355908 & 5 & $-26,83$ & $-0,44$ & 0,81 & 1,20 & $-0,18$ & $-1,10$ & 0,55 & 0,40 & 0,82 & $-0,96$ \\
\hline MBS-140 355909-355913 & 5 & $-27,60$ & $-3,41$ & 2,94 & 2,38 & $-3,61$ & 0,01 & $-0,32$ & 0,46 & 0,74 & 0,27 \\
\hline MBS-140 355914-355917 & 5 & $-31,93$ & 7,93 & $-0,32$ & 1,30 & 0,84 & $-0,96$ & 1,72 & $-0,24$ & 0,73 & $-0,48$ \\
\hline MBS-280 381735-381737 & 5 & 2,33 & 7,20 & 3,14 & $-1,83$ & 5,89 & $-1,04$ & $-0,65$ & 1,53 & $-2,44$ & 2,32 \\
\hline MBS-464 603418-603423 & 5 & $-14,76$ & 5,33 & $-3,95$ & $-1,71$ & 3,42 & 3,14 & $-2,38$ & 0,32 & 0,30 & 2,13 \\
\hline MBS-464 603424-603428 & 5 & 10,75 & 2,17 & 0,32 & $-0,25$ & $-1,42$ & $-0,25$ & $-0,34$ & 0,01 & $-2,46$ & $-1,45$ \\
\hline MBS-464 603429-603434 & 5 & 0,69 & 6,31 & 6,84 & $-7,12$ & 1,69 & $-1,31$ & $-2,26$ & 1,13 & $-0,61$ & 0,69 \\
\hline MBS-501 608889-608896 & 5 & 13,41 & $-1,78$ & $-3,24$ & $-0,37$ & $-1,12$ & 0,46 & 0,84 & $-0,21$ & $-1,60$ & $-2,23$ \\
\hline MBS-501 608897-608902 & 5 & 11,83 & $-7,72$ & $-0,23$ & $-1,35$ & 1,47 & 1,76 & $-0,94$ & 0,49 & $-1,76$ & $-0,02$ \\
\hline MBS-542 616161-616163 & 5 & $-15,54$ & $-8,92$ & $-1,28$ & $-1,95$ & 1,43 & $-4,47$ & 0,41 & $-2,05$ & $-2,18$ & 0,00 \\
\hline RC $100 \quad 0067$ PCT 1016166 & 6 & $-4,60$ & 10,81 & $-7,53$ & $-0,75$ & 3,44 & 3,23 & 3,10 & $-1,36$ & 1,10 & 1,65 \\
\hline MBS-275 381318-381323 & 6 & 0,51 & 11,41 & $-1,26$ & $-0,23$ & 1,18 & $-2,78$ & 3,94 & 0,50 & $-0,35$ & 0,24 \\
\hline MBS-275 381324-381328 & 6 & 3,17 & 11,93 & $-2,05$ & 2,02 & 2,18 & $-3,15$ & 1,76 & 0,55 & $-0,36$ & 0,03 \\
\hline MBS-275 381329-381333 & 6 & 2,61 & 8,76 & 0,51 & 1,43 & $-2,21$ & $-1,41$ & $-0,93$ & 0,74 & $-0,26$ & 0,30 \\
\hline MBS-141 355218-355223 & 6 & 3,35 & 8,58 & 0,30 & 4,15 & 1,74 & $-0,84$ & $-0,18$ & $-1,06$ & 0,41 & 0,42 \\
\hline MBS-146 356278-356282 & 6 & $-1,75$ & 18,41 & 0,09 & 3,04 & $-0,15$ & $-0,73$ & $-3,11$ & $-0,07$ & 0,56 & $-0,85$ \\
\hline MBS-150 357175-357179 & 6 & 5,86 & 8,76 & 0,40 & 3,30 & 3,44 & $-0,98$ & $-1,06$ & 0,87 & $-0,54$ & 0,30 \\
\hline MBS-150 357211-357215 & 6 & 2,22 & 13,25 & 0,49 & 3,42 & 1,31 & $-0,78$ & $-2,94$ & 0,61 & $-0,16$ & 0,36 \\
\hline MBS-150 357227-357231 & 6 & 3,99 & 8,76 & 1,25 & 4,21 & 0,38 & $-0,41$ & $-2,70$ & $-0,11$ & 0,65 & 0,33 \\
\hline MBS-150 357232-357235 & 6 & 0,09 & 10,82 & 2,48 & 3,80 & $-2,33$ & 1,44 & $-4,85$ & 0,11 & 0,37 & 0,13 \\
\hline MBS-165 360139-360143 & 6 & 4,36 & 10,30 & $-0,28$ & 1,91 & $-0,35$ & $-1,43$ & $-1,39$ & $-0,78$ & 1,32 & $-0,89$ \\
\hline MBS-165 360144-360148 & 6 & 6,02 & 9,04 & $-0,37$ & 2,07 & 1,14 & $-2,08$ & 0,23 & $-0,98$ & 1,58 & $-0,27$ \\
\hline MBS-147 356730-356734 & 6 & 4,72 & 10,55 & $-0,39$ & 4,08 & 2,55 & $-0,29$ & $-0,13$ & $-0,03$ & 0,14 & $-0,12$ \\
\hline MBS-147 356753-356757 & 6 & 4,04 & 7,68 & $-2,07$ & 3,51 & 3,74 & 0,46 & $-0,50$ & $-0,75$ & 1,21 & $-0,07$ \\
\hline MBS-196 366157-366161 & 6 & $-0,68$ & 17,41 & $-1,24$ & 1,33 & $-1,29$ & $-1,18$ & $-2,73$ & $-0,09$ & 2,59 & $-0,87$ \\
\hline MBS-196 366162-366166 & 6 & 4,68 & 12,36 & $-1,30$ & 1,21 & 0,25 & $-2,20$ & $-1,34$ & 0,26 & 1,90 & $-0,57$ \\
\hline MBS-196 366167-366172 & 6 & 8,76 & 9,22 & $-2,43$ & $-0,26$ & 1,02 & $-3,81$ & 0,69 & $-0,15$ & 2,74 & $-1,45$ \\
\hline MBS-196 366173-366177 & 6 & $-2,43$ & 18,62 & $-0,77$ & $-0,03$ & $-0,98$ & $-1,73$ & $-1,13$ & $-0,73$ & 2,30 & $-1,39$ \\
\hline MBS-196 366198-366203 & 6 & 8,58 & 8,99 & $-1,58$ & $-0,74$ & $-0,39$ & $-3,28$ & $-0,91$ & 0,74 & 2,42 & $-1,66$ \\
\hline MBS-196 366209-366212 & 6 & 2,30 & 16,74 & $-1,68$ & $-0,61$ & 0,70 & $-2,45$ & 0,09 & 0,93 & 1,74 & $-1,26$ \\
\hline MBS-199 366935-366939 & 6 & 7,54 & 10,20 & $-0,24$ & 0,17 & 1,66 & $-1,97$ & $-1,14$ & 1,67 & 0,14 & $-0,62$ \\
\hline MBS-199 366940-366942 & 6 & 8,30 & 9,84 & $-1,02$ & $-1,18$ & 2,88 & $-2,73$ & 0,24 & 1,82 & 0,96 & $-0,43$ \\
\hline MBS-204 367893-367897 & 6 & 6,56 & 8,68 & $-4,33$ & $-6,53$ & $-1,14$ & $-0,54$ & 0,86 & 2,56 & 2,88 & 1,66 \\
\hline MBS-280 381687-381689 & 6 & $-9,83$ & $-4,89$ & $-3,68$ & $-1,00$ & 3,48 & $-1,85$ & 2,75 & $-3,04$ & 1,39 & 1,24 \\
\hline MBS-542 616107-616111 & 6 & $-23,11$ & 6,20 & $-6,14$ & $-3,32$ & $-0,20$ & 1,11 & $-2,57$ & $-0,37$ & 0,61 & $-0,28$ \\
\hline MBS-542 616117-616119 & 6 & $-17,80$ & 0,50 & $-5,14$ & $-4,07$ & $-2,62$ & 0,97 & $-3,26$ & $-0,63$ & 0,78 & 0,38 \\
\hline MBS-542 616132-616136 & 6 & 4,27 & 13,48 & $-4,57$ & 2,49 & $-0,89$ & $-1,16$ & 0,64 & $-1,56$ & $-0,56$ & $-2,21$ \\
\hline MBS-542 616137-616142 & 6 & 8,99 & 2,71 & $-1,21$ & 0,27 & $-7,38$ & 1,16 & $-2,03$ & $-0,69$ & $-0,43$ & $-2,36$ \\
\hline MBS-542 616158-616160 & 6 & $-11,40$ & $-13,26$ & $-0,30$ & $-2,43$ & $-0,28$ & $-2,38$ & $-1,23$ & $-1,34$ & $-2,56$ & 0,54 \\
\hline MBS-593 $628712-628716$ & 6 & $-2,84$ & $-8,97$ & $-2,76$ & $-0,50$ & $-1,31$ & 1,88 & $-3,88$ & $-0,89$ & $-0,35$ & $-0,10$ \\
\hline SEC 8430080 (RC_095 132) 1008763 & 6 & 14,37 & $-1,74$ & $-1,24$ & 1,23 & $-5,59$ & 1,96 & $-0,18$ & $-2,54$ & $-1,04$ & $-1,17$ \\
\hline SEC 8430080 (RC 095 132) 1008766 & 6 & 2,12 & 7,05 & $-6,12$ & 2,56 & 3,26 & 2,58 & 0,43 & $-1,58$ & $-0,25$ & $-0,91$ \\
\hline 1012938 & 6 & $-4,59$ & $-12,25$ & $-0,23$ & $-0,76$ & 3,50 & $-0,94$ & 0,37 & $-0,75$ & $-2,51$ & $-1,02$ \\
\hline MBS-146 356316-356319 & 7 & $-9,02$ & 7,89 & 12,47 & $-6,64$ & 4,63 & 5,01 & 0,30 & $-0,11$ & 3,31 & $-4,62$ \\
\hline MBS-146 356321-356324 & 7 & $-14,42$ & 8,00 & 13,19 & $-6,76$ & 4,82 & 4,34 & 0,85 & 0,32 & 3,67 & $-5,37$ \\
\hline MBS-188 364747-364752 & 7 & $-11,35$ & 4,29 & 3,55 & $-4,16$ & 5,93 & 1,97 & 2,59 & $-1,25$ & 3,50 & $-4,89$ \\
\hline MBS-155 358450-358465 & 8 & 8,56 & $-14,93$ & $-2,59$ & 1,00 & $-0,34$ & 0,85 & $-0,50$ & 0,49 & 0,58 & 0,68 \\
\hline MBS-275 381369-381372 & 8 & 9,57 & $-10,21$ & 1,14 & 0,89 & $-0,22$ & 0,10 & 0,62 & 0,95 & $-0,90$ & 0,17 \\
\hline MBS-123 352234-352238 & 8 & 9,21 & $-13,55$ & $-2,16$ & 2,00 & 0,09 & 1,10 & $-1,02$ & 0,34 & 0,96 & 1,11 \\
\hline MBS-123 352239-352243 & 8 & 0,43 & $-19,16$ & $-2,21$ & 2,13 & $-0,42$ & 0,08 & 0,42 & 1,32 & 0,78 & 0,40 \\
\hline MBS-415 400569-400572 & 8 & 6,91 & $-16,77$ & $-2,82$ & 2,15 & 0,15 & 1,19 & $-0,11$ & 0,33 & 1,32 & 0,18 \\
\hline MBS-133 $353981-353985$ & 8 & $-4,66$ & $-18,05$ & $-2,55$ & 2,64 & 0,01 & $-0,67$ & 0,54 & 2,53 & 0,49 & 0,35 \\
\hline MBS-134 354168-354173 & 8 & $-3,04$ & $-15,77$ & $-3,34$ & 1,42 & 0,24 & $-0,21$ & $-0,31$ & 0,86 & 1,60 & $-0,21$ \\
\hline MBS-141 355229-355233 & 8 & 0,16 & $-14,01$ & 0,46 & 4,24 & $-1,01$ & 2,88 & $-0,98$ & 0,84 & 1,43 & 0,73 \\
\hline MBS-146 356329-356331 & 8 & 5,37 & $-10,84$ & $-1,47$ & 1,39 & $-0,28$ & 2,46 & $-1,73$ & $-0,84$ & 1,77 & $-1,16$ \\
\hline MBS-165 360185-360188 & 8 & 5,26 & $-12,10$ & 0,29 & 3,72 & 0,93 & 2,75 & $-0,85$ & 0,19 & 0,49 & 0,33 \\
\hline MBS-140 355892-355896 & 8 & $-4,55$ & $-12,88$ & $-4,50$ & 1,83 & 3,14 & $-0,87$ & 0,67 & $-0,68$ & 1,17 & $-1,08$ \\
\hline MBS-147 356742-356745 & 8 & $-1,55$ & $-11,29$ & 0,23 & 4,85 & 2,90 & 2,27 & $-0,36$ & $-0,75$ & 0,53 & $-0,31$ \\
\hline MBS-147 356763-356767 & 8 & 7,69 & $-9,38$ & 2,95 & 2,57 & 1,06 & 3,48 & $-0,29$ & $-0,98$ & 0,38 & $-0,70$ \\
\hline MBS-149 356947-356951 & 8 & 9,06 & $-11,07$ & 1,02 & 0,35 & $-0,10$ & 2,74 & $-0,28$ & $-0,28$ & 0,69 & $-0,79$ \\
\hline MBS-149 356957-356960 & 8 & 6,90 & $-11,36$ & 1,62 & 1,58 & 3,30 & 3,34 & $-0,04$ & $-0,42$ & $-0,24$ & $-0,99$ \\
\hline MBS-249 376462-376466 & 8 & 11,40 & $-8,99$ & $-2,76$ & $-2,42$ & 0,93 & 1,58 & 1,32 & $-0,94$ & 2,23 & 2,16 \\
\hline MBS-249 376467-376472 & 8 & $-3,12$ & 14,80 & $-1,55$ & $-5,13$ & $-4,63$ & 2,27 & $-2,20$ & 1,31 & 2,85 & 1,91 \\
\hline MBS-249 376483-376487 & 8 & 12,34 & $-5,36$ & $-3,60$ & $-3,14$ & $-0,44$ & $-0,41$ & 0,91 & $-0,07$ & 2,19 & 0,44 \\
\hline MBS-280 381708-381712 & 8 & $-2,81$ & 0,84 & 12,33 & $-1,60$ & 0,50 & $-0,70$ & $-0,81$ & $-4,60$ & 1,68 & 6,00 \\
\hline MBS-280 381713-381717 & 8 & $-3,23$ & $-2,33$ & 9,74 & 2,74 & $-0,58$ & 1,59 & 2,08 & $-5,40$ & 0,38 & 2,88 \\
\hline MBS-288 384039-384040 & 8 & $-6,50$ & 16,35 & 3,71 & $-2,16$ & 5,94 & $-0,87$ & $-1,96$ & 1,65 & $-1,47$ & 2,57 \\
\hline MBS-288 384076-384080 & 8 & 12,01 & $-0,72$ & 2,33 & $-3,83$ & 1,12 & $-0,01$ & $-0,89$ & 2,29 & $-3,19$ & 0,67 \\
\hline MBS-318 388492-388496 & 8 & 2,53 & 13,56 & $-1,27$ & $-2,84$ & 1,95 & $-1,01$ & $-0,34$ & 2,66 & $-2,69$ & $-0,62$ \\
\hline MBS-464 603381-603385 & 8 & 1,36 & $-15,04$ & $-0,08$ & $-2,32$ & 1,47 & 2,37 & $-1,84$ & 0,05 & $-1,08$ & 2,05 \\
\hline MBS-464 603402-603406 & 8 & 3,55 & $-8,60$ & 0,11 & $-0,31$ & 4,90 & 2,71 & $-1,10$ & $-0,34$ & $-0,80$ & 1,59 \\
\hline
\end{tabular}


APÊNDICE 2

Relação de amostras por grupo e parâmetros PC

Tabela 30 - Relação de amostras por grupo e parâmetros PCA (continuação)

\begin{tabular}{|c|c|c|c|c|c|c|c|c|c|c|c|}
\hline ID & GRUPO & PC 1 & PC 2 & PC 3 & PC 4 & PC 5 & PC 6 & PC 7 & PC 8 & PC 9 & PC 10 \\
\hline MBS-464 603409-603413 & 8 & $-7,53$ & 3,18 & $-4,87$ & $-0,60$ & 5,55 & 2,76 & $-0,55$ & 0,20 & 0,04 & 1,56 \\
\hline MBS-542 616143-616147 & 8 & 14,57 & $-3,35$ & $-3,04$ & $-0,89$ & $-1,68$ & $-0,07$ & $-0,05$ & $-0,47$ & $-0,94$ & $-1,75$ \\
\hline MBS-542 616148-616153 & 8 & $-0,58$ & $-15,07$ & $-4,18$ & $-1,80$ & $-0,16$ & $-1,30$ & 0,21 & $-1,36$ & $-1,13$ & $-1,58$ \\
\hline MBS-542 616164-616168 & 8 & $-16,83$ & $-4,63$ & $-0,60$ & $-0,84$ & 1,82 & $-4,42$ & 1,50 & $-2,19$ & $-2,54$ & $-0,73$ \\
\hline MBS-542 616182-616186 & 8 & $-15,13$ & 1,87 & $-6,57$ & $-3,49$ & $-0,26$ & 2,03 & $-3,55$ & 0,51 & 0,71 & 0,29 \\
\hline MBS-542 616187-616189 & 8 & $-3,74$ & $-10,96$ & $-5,36$ & $-4,00$ & $-0,88$ & 1,30 & $-2,61$ & 0,09 & $-0,18$ & 0,89 \\
\hline MBS-593 628724-628726 & 8 & $-12,83$ & $-11,33$ & 0,10 & $-1,84$ & 0,35 & $-3,45$ & $-0,65$ & $-1,92$ & $-2,08$ & 0,05 \\
\hline MBS-593 628734-628737 & 8 & $-15,75$ & $-5,92$ & $-3,83$ & $-2,06$ & 0,29 & $-1,50$ & $-0,15$ & $-0,74$ & $-1,28$ & $-1,24$ \\
\hline SEC 8430620 (RC_130 219) 1010690 & 8 & $-27,02$ & 0,78 & 0,06 & $-2,41$ & $-2,29$ & $-2,55$ & 0,37 & $-3,25$ & $-1,17$ & $-0,53$ \\
\hline SEC 8430620 (RC 130 219) 1010691 & 8 & $-20,70$ & $-7,74$ & 1,66 & $-2,67$ & $-2,35$ & $-3,68$ & $-0,67$ & $-3,07$ & $-2,32$ & 0,24 \\
\hline 1012641 & 8 & 18,35 & $-0,90$ & $-1,28$ & 1,05 & $-3,97$ & 1,03 & $-0,45$ & $-1,42$ & $-2,10$ & $-0,09$ \\
\hline 1012642 & 8 & 10,15 & 9,56 & $-1,97$ & 0,39 & $-5,31$ & 1,15 & 1,43 & $-1,53$ & $-2,10$ & $-1,05$ \\
\hline 1012643 & 8 & 12,72 & 2,16 & $-1,70$ & 1,71 & $-2,89$ & 1,67 & 1,22 & $-1,50$ & $-1,97$ & $-1,31$ \\
\hline 1013508 & 8 & $-1,06$ & $-16,25$ & $-1,79$ & $-1,85$ & 1,10 & 0,43 & $-0,52$ & $-0,03$ & $-1,87$ & $-1,10$ \\
\hline RC_100_0067 PCT 1016170 & 8 & 1,05 & $-10,42$ & $-4,39$ & $-3,81$ & 0,63 & 2,11 & 0,88 & $-0,95$ & 0,76 & 1,60 \\
\hline SEC 8431120 (RC_130 366) 1013430 & 9 & $-28,66$ & 5,58 & $-3,34$ & $-1,94$ & 0,68 & $-2,78$ & 0,73 & $-2,83$ & $-0,67$ & $-1,03$ \\
\hline SEC 8431120 (RC_130 366) 1013432 & 9 & $-31,96$ & 5,97 & 1,85 & $-2,87$ & $-4,87$ & $-1,28$ & $-0,15$ & $-3,19$ & $-1,34$ & $-0,71$ \\
\hline 1013504 & 9 & 7,15 & 9,77 & $-2,70$ & 2,11 & 0,77 & 1,64 & 0,78 & $-1,49$ & $-1,19$ & $-0,33$ \\
\hline 1013505 & 9 & 10,35 & $-1,88$ & $-3,64$ & 0,20 & $-2,11$ & 3,38 & 0,29 & $-2,23$ & $-1,04$ & $-0,78$ \\
\hline 1013506 & 9 & 4,57 & $-17,29$ & $-0,04$ & $-0,90$ & 0,57 & 2,43 & $-0,34$ & $-1,02$ & $-1,20$ & $-1,00$ \\
\hline 1013507 & 9 & 9,88 & $-6,04$ & $-2,00$ & 2,01 & 2,32 & 2,44 & $-1,20$ & $-1,20$ & $-1,47$ & $-0,62$ \\
\hline MBS-133 353958-353961 & 10 & $-24,93$ & $-7,60$ & 0,83 & 0,97 & $-0,70$ & $-0,96$ & 1,28 & 2,41 & 1,75 & 0,57 \\
\hline MBS-134 354115-354119 & 10 & $-22,83$ & $-6,94$ & 0,82 & 0,93 & $-3,06$ & $-0,20$ & 0,58 & 2,30 & 1,34 & 0,08 \\
\hline MBS-134 354158-354162 & 10 & $-16,44$ & $-6,98$ & 2,09 & 1,85 & $-1,68$ & $-0,70$ & 2,57 & 2,72 & 0,03 & $-0,24$ \\
\hline MBS-134 354163-354167 & 10 & $-21,74$ & $-5,99$ & 2,09 & 1,92 & $-2,84$ & $-0,10$ & 2,81 & 3,14 & $-0,05$ & 0,30 \\
\hline MBS-141 355260-355264 & 10 & $-23,29$ & $-5,02$ & 5,67 & 3,43 & $-2,79$ & 0,39 & 3,79 & 3,95 & 0,27 & 1,83 \\
\hline MBS-141 355265-355269 & 10 & $-22,40$ & $-10,07$ & 2,87 & 2,39 & $-1,96$ & 0,75 & 2,50 & 4,96 & 0,33 & 2,16 \\
\hline MBS-141 355271-355275 & 10 & $-25,34$ & $-5,16$ & 1,42 & 3,27 & $-2,61$ & 0,86 & 1,69 & 4,32 & 0,58 & 1,08 \\
\hline MBS-188 364758-364763 & 10 & $-20,19$ & $-11,54$ & 1,97 & 3,48 & $-0,25$ & $-0,38$ & 0,30 & 1,43 & 0,11 & 0,43 \\
\hline MBS-140 355897-355902 & 10 & $-22,93$ & $-4,68$ & 0,04 & 0,49 & $-1,87$ & $-0,60$ & $-0,10$ & 0,46 & 0,43 & $-0,67$ \\
\hline SEC 8431120 (RC_130 366) 1013435 & 10 & $-11,32$ & $-8,56$ & $-4,02$ & $-2,64$ & 1,97 & $-1,36$ & $-0,20$ & $-1,10$ & $-1,06$ & $-0,10$ \\
\hline MBS-123 352244-352248 & 11 & $-9,94$ & $-13,92$ & $-3,26$ & 3,07 & 1,27 & $-0,83$ & 0,92 & 2,43 & 0,39 & 0,22 \\
\hline MBS-123 $352249-352255$ & 11 & $-11,64$ & $-13,57$ & 2,35 & 0,04 & 0,31 & $-0,78$ & 1,33 & 2,78 & $-0,84$ & $-0,23$ \\
\hline MBS-133 353965-353969 & 11 & $-11,29$ & $-13,98$ & $-1,04$ & 3,07 & $-0,85$ & $-1,79$ & 0,80 & 1,47 & 1,01 & $-0,40$ \\
\hline MBS-133 353971-353975 & 11 & $-13,64$ & $-11,72$ & $-0,89$ & 3,29 & $-1,37$ & $-0,71$ & 1,37 & 2,57 & $-0,29$ & 0,07 \\
\hline MBS-134 354110-354114 & 11 & $-15,40$ & $-11,70$ & $-1,11$ & 2,66 & $-1,48$ & $-1,10$ & 1,32 & 2,30 & 0,21 & $-0,30$ \\
\hline MBS-134 354121-354125 & 11 & $-7,98$ & $-15,77$ & $-2,59$ & 2,19 & $-0,24$ & $-1,27$ & 0,73 & 1,65 & 0,70 & $-0,25$ \\
\hline MBS-134 354130-354132 & 11 & $-13,56$ & $-9,46$ & $-2,14$ & 2,20 & $-1,03$ & 1,00 & $-0,48$ & 1,69 & 0,90 & 0,26 \\
\hline MBS-134 354144-354148 & 11 & $-15,01$ & $-10,10$ & $-2,74$ & 3,14 & 0,57 & $-1,80$ & 1,13 & 1,92 & 0,80 & $-0,28$ \\
\hline MBS-134 354149-354154 & 11 & $-16,99$ & $-14,50$ & $-0,20$ & 2,29 & $-1,46$ & $-1,02$ & 1,66 & 3,55 & 0,74 & 0,45 \\
\hline MBS-141 355234-355238 & 11 & $-14,12$ & $-10,34$ & $-0,63$ & 3,76 & $-2,03$ & 1,72 & $-0,47$ & 2,38 & 0,88 & 0,65 \\
\hline MBS-141 355239-355243 & 11 & $-14,83$ & $-14,23$ & $-1,39$ & 2,48 & $-1,37$ & 0,10 & 1,04 & 2,96 & 0,82 & 0,67 \\
\hline MBS-141 355244-355248 & 11 & $-13,07$ & $-8,42$ & $-4,04$ & 3,64 & 1,83 & $-0,23$ & 0,89 & 1,84 & 1,14 & 0,44 \\
\hline MBS-146 356325-356328 & 11 & $-7,40$ & $-16,27$ & $-1,19$ & 2,78 & 1,01 & $-0,04$ & 1,45 & 1,25 & 0,23 & $-0,36$ \\
\hline MBS-146 356332-356333 & 11 & $-10,58$ & $-13,91$ & $-1,08$ & 1,94 & $-0,87$ & 1,93 & $-0,95$ & 1,32 & 0,98 & 0,28 \\
\hline MBS-278 381226-381229 & 11 & 14,47 & $-3,23$ & 0,24 & $-0,90$ & $-1,42$ & $-1,09$ & 0,46 & $-0,53$ & 0,71 & 2,13 \\
\hline MBS-278 381235-381237 & 11 & 2,80 & $-10,42$ & $-5,36$ & $-2,62$ & 2,05 & $-0,25$ & 2,08 & $-2,05$ & 2,59 & 0,88 \\
\hline MBS-280 381718-381724 & 11 & 7,37 & $-12,18$ & 1,04 & $-1,52$ & 0,47 & 2,62 & 1,01 & $-1,93$ & 0,60 & 1,22 \\
\hline MBS-280 381725-381729 & 11 & 6,47 & 5,70 & 1,84 & $-2,47$ & 2,98 & $-0,75$ & $-1,16$ & 2,61 & $-3,23$ & 1,03 \\
\hline MBS-280 381730-381734 & 11 & $-5,02$ & 17,45 & 1,82 & $-3,37$ & 2,46 & 0,52 & $-1,47$ & 3,23 & $-2,91$ & 0,06 \\
\hline MBS-288 384081-384085 & 11 & 11,30 & 2,79 & 0,75 & $-3,93$ & 2,29 & $-0,81$ & $-0,95$ & 3,41 & $-3,45$ & 0,00 \\
\hline MBS-318 388497-388502 & 11 & 6,12 & 3,71 & 3,73 & $-4,87$ & $-1,51$ & 0,76 & $-2,02$ & 2,79 & $-3,01$ & 0,16 \\
\hline MBS-318 388503-388507 & 11 & 9,36 & 1,57 & 3,90 & $-3,33$ & $-0,74$ & 1,43 & $-1,51$ & 2,37 & $-2,89$ & 0,74 \\
\hline MBS-318 388508-388512 & 11 & 14,11 & $-0,30$ & 0,75 & $-2,92$ & 0,30 & $-0,28$ & 0,15 & 2,55 & $-3,60$ & $-0,84$ \\
\hline MBS-464 603407-603408 & 11 & $-3,14$ & $-3,18$ & $-0,58$ & $-1,20$ & 1,64 & 4,02 & $-2,68$ & 0,49 & $-0,81$ & 1,87 \\
\hline MBS-464 603414-603417 & 11 & $-4,79$ & $-8,74$ & $-1,27$ & $-2,55$ & 1,16 & 3,06 & $-2,85$ & 0,36 & $-0,72$ & 2,47 \\
\hline MBS-501 608875-608879 & 11 & 3,85 & 5,09 & 2,32 & $-1,04$ & $-4,42$ & 2,19 & $-1,74$ & 0,12 & $-2,14$ & $-2,14$ \\
\hline MBS-501 608880-608885 & 11 & 13,76 & 3,14 & $-2,33$ & 0,92 & 0,74 & $-0,89$ & 0,71 & 0,41 & $-2,44$ & $-1,78$ \\
\hline MBS-501 608903-608906 & 11 & $-13,18$ & $-5,42$ & $-1,26$ & $-3,50$ & $-2,33$ & 2,69 & $-2,77$ & 0,43 & $-0,85$ & 0,11 \\
\hline MBS-542 616169-616173 & 11 & $-21,76$ & 1,85 & $-0,12$ & $-0,66$ & 2,64 & $-4,00$ & 1,41 & $-2,43$ & $-1,70$ & 0,12 \\
\hline MBS-542 616174-616178 & 11 & 7,79 & 1,46 & $-5,02$ & $-0,64$ & $-0,44$ & 1,27 & 0,74 & $-0,99$ & $-0,55$ & $-1,48$ \\
\hline MBS-542 616179-616181 & 11 & $-3,18$ & $-16,23$ & $-3,58$ & $-3,68$ & 1,30 & $-0,09$ & $-1,37$ & $-0,26$ & $-0,87$ & 0,83 \\
\hline 1012644 & 11 & 16,25 & 1,20 & $-1,65$ & 0,29 & $-4,92$ & 2,12 & 0,97 & $-1,21$ & $-2,13$ & $-0,90$ \\
\hline MBS-318 388492-3884981 & 12 & 11,59 & 2,67 & 1,22 & $-4,60$ & 1,42 & $-0,79$ & $-0,94$ & 2,89 & $-3,26$ & $-0,17$ \\
\hline SEC 8430620 (RC_130 219) 1010692 & 12 & 6,42 & 12,54 & $-4,58$ & 3,19 & $-2,18$ & 0,51 & 1,13 & $-2,50$ & $-0,74$ & $-1,95$ \\
\hline RC_100_0067 PCT 1016169 & 13 & 4,31 & 19,79 & $-4,95$ & 0,80 & $-1,69$ & 0,06 & 3,26 & $-1,19$ & $-0,94$ & 1,51 \\
\hline RC_100_0070 PCT 10160064 & 13 & 2,75 & 21,53 & $-2,85$ & $-1,73$ & $-2,71$ & 0,31 & 4,32 & $-0,23$ & $-1,55$ & 1,74 \\
\hline RC $100 \quad 0070$ PCT 10160065 & 13 & $-1,84$ & 23,39 & $-4,01$ & $-0,02$ & $-0,94$ & 1,51 & 1,94 & $-0,70$ & $-0,45$ & 2,24 \\
\hline RC_100_0070 PCT 10160066 & 13 & 2,63 & 20,79 & $-3,48$ & $-0,76$ & $-0,69$ & 0,77 & 3,44 & $-0,05$ & $-1,00$ & 2,04 \\
\hline RC_100_0073 PCT 1016201 & 13 & 1,61 & 20,16 & $-3,47$ & $-0,03$ & $-3,14$ & 0,63 & 3,05 & $-0,79$ & $-0,81$ & 1,45 \\
\hline RC $100 \quad 0073$ PCT 1016202 & 13 & $-2,47$ & 25,67 & $-0,63$ & $-2,80$ & $-8,46$ & 2,20 & 2,22 & $-0,85$ & $-0,99$ & 1,79 \\
\hline
\end{tabular}




\section{APÊNDICE 2}

Relação de amostras por grupo e parâmetros PC

Tabela 30 - Relação de amostras por grupo e parâmetros PCA (continuação)

\begin{tabular}{|c|c|c|c|c|c|c|c|c|c|c|c|}
\hline ID & GRUPO & PCA 1 & PCA 2 & PCA 3 & PCA 4 & PCA 5 & PCA 6 & PCA 7 & PCA 8 & PCA 9 & PCA 10 \\
\hline MBS-165 360180-360184 & 14 & $-5,95$ & 1,58 & 1,03 & 4,66 & 3,78 & 3,66 & 1,09 & $-0,03$ & $-0,55$ & 0,02 \\
\hline MBS-249 376473-376477 & 14 & 5,02 & 9,49 & $-3,46$ & 0,09 & 2,31 & 0,56 & 1,61 & $-0,33$ & 0,95 & 2,46 \\
\hline MBS-249 376478-376482 & 14 & 9,73 & 1,25 & $-4,14$ & $-2,08$ & 2,44 & 0,39 & 2,21 & $-0,25$ & 1,62 & 2,39 \\
\hline RC_100_0070 PCT 10160063 & 14 & $-5,39$ & $-0,79$ & $-6,85$ & $-2,76$ & 1,14 & 2,79 & 0,77 & $-1,47$ & 1,20 & 1,04 \\
\hline RC_100_0067 PCT 1016167 & 14 & $-9,00$ & 4,66 & $-7,00$ & $-1,95$ & 2,84 & 2,24 & 1,58 & $-1,45$ & 1,79 & 1,44 \\
\hline MBS-204 367852-367856 & 15 & $-14,63$ & 13,24 & 10,33 & 5,48 & 0,91 & $-0,26$ & $-1,24$ & $-2,36$ & 0,26 & 0,69 \\
\hline MBS-204 367883-367887 & 15 & 1,53 & $-13,31$ & 6,10 & 1,45 & 0,43 & 0,70 & 2,75 & $-2,87$ & $-1,06$ & $-0,97$ \\
\hline MBS-204 367919-367926 & 15 & 7,53 & $-3,61$ & $-0,20$ & $-2,61$ & $-3,58$ & 2,69 & $-0,73$ & $-0,47$ & 1,89 & 1,31 \\
\hline MBS-278 381168-381169 & 15 & 13,25 & $-7,03$ & 4,42 & $-2,21$ & 0,42 & 2,38 & 2,03 & $-0,94$ & $-0,27$ & 1,06 \\
\hline MBS-587 626416-626421 & 16 & $-17,67$ & 2,15 & 6,11 & $-2,79$ & $-2,96$ & $-2,72$ & 1,28 & $-3,54$ & $-2,72$ & $-1,43$ \\
\hline MBS-587 626427-626431 & 16 & $-5,48$ & $-15,95$ & $-1,51$ & $-4,15$ & 0,69 & $-0,43$ & $-1,86$ & $-0,28$ & $-1,83$ & 1,14 \\
\hline MBS-587 626432-626436 & 16 & $-11,41$ & $-10,45$ & 0,42 & $-3,75$ & $-0,67$ & $-1,31$ & $-2,37$ & $-1,00$ & $-2,07$ & 1,48 \\
\hline MBS-593 628695-628699 & 16 & $-9,28$ & $-6,60$ & $-5,86$ & $-2,33$ & 2,50 & 0,96 & $-1,39$ & $-0,03$ & $-1,08$ & $-0,36$ \\
\hline SEC 8430080 (RC_095 129) 1008640 & 16 & 13,37 & 3,62 & $-2,32$ & 2,09 & $-1,17$ & 0,77 & $-0,25$ & $-0,50$ & $-2,14$ & $-0,75$ \\
\hline 1012936 & 16 & $-18,26$ & $-8,11$ & 0,38 & $-2,35$ & $-2,78$ & $-2,52$ & $-1,32$ & $-1,74$ & $-2,14$ & $-0,73$ \\
\hline 1012721 & 16 & $-1,15$ & $-17,76$ & 2,54 & $-1,32$ & 1,69 & $-0,16$ & 0,19 & $-0,63$ & $-2,00$ & $-1,00$ \\
\hline 1012724 & 16 & 7,33 & 10,15 & $-1,29$ & 1,36 & $-2,26$ & 1,51 & 0,87 & $-0,69$ & $-1,74$ & $-0,57$ \\
\hline RC_100_0070 PCT 10160067 & 16 & 7,74 & 10,61 & $-3,58$ & $-1,65$ & $-3,58$ & 1,46 & 3,49 & $-1,89$ & $-0,17$ & 2,23 \\
\hline RC_100_0073 PCT 1016200 & 16 & 8,49 & 13,34 & $-2,63$ & $-1,76$ & $-4,35$ & 1,23 & 3,66 & $-0,51$ & $-1,70$ & 1,34 \\
\hline RC_100 0073 PCT 1016203 & 16 & 10,11 & 12,10 & $-2,88$ & $-1,47$ & $-5,92$ & 0,69 & 3,00 & $-1,38$ & $-1,12$ & 2,05 \\
\hline MBS-141 355255-355259 & 17 & $-36,85$ & 16,89 & $-0,58$ & 3,23 & $-2,77$ & 1,81 & 0,06 & 1,52 & $-0,29$ & $-0,64$ \\
\hline MBS-134 354155-354156 & 17 & $-24,32$ & 6,73 & 11,57 & 2,29 & $-1,84$ & 2,16 & 5,21 & 2,63 & $-0,35$ & 1,07 \\
\hline SEC 8431120 (RC_130 366) 1013433 & 17 & $-32,60$ & 9,41 & $-1,75$ & $-2,09$ & $-0,79$ & $-2,31$ & 0,39 & $-2,93$ & $-0,74$ & $-1,32$ \\
\hline SEC 8430620 (RC_130 219) 1010689 & 17 & $-25,53$ & $-0,37$ & $-3,74$ & $-2,25$ & $-0,05$ & $-2,20$ & $-0,99$ & $-2,62$ & $-0,88$ & $-0,59$ \\
\hline RC_100_0073 PCT 1016204 & 17 & $-9,50$ & 32,90 & $-2,40$ & $-0,48$ & $-2,73$ & 1,44 & 2,28 & $-0,02$ & $-0,77$ & 1,83 \\
\hline
\end{tabular}

\begin{tabular}{|l|l|l|}
\hline Amostra representativa do cluster & Amostras mais distantes & Amostras de pó de perfuratriz \\
\hline
\end{tabular} 


\section{APÊNDICE 3}

OPS

Difratogramas médios dos domínios mineralógicos

Figura 65 - Comparação dos difratogramas médios de cada grupo agrupados como OPS
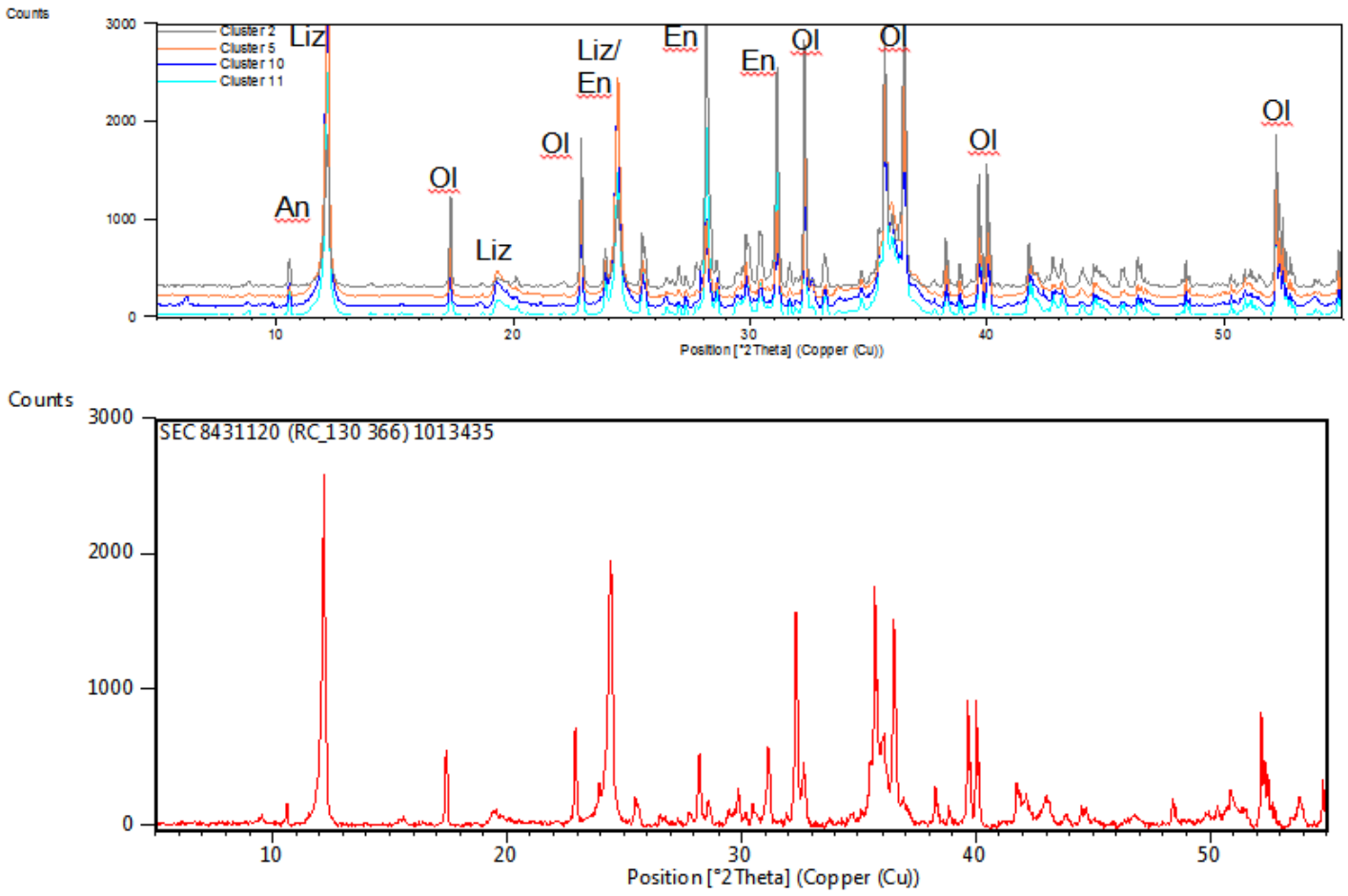

POS

Figura 66 - Comparação dos difratogramas médios de cada cluster agrupados como POS

counts

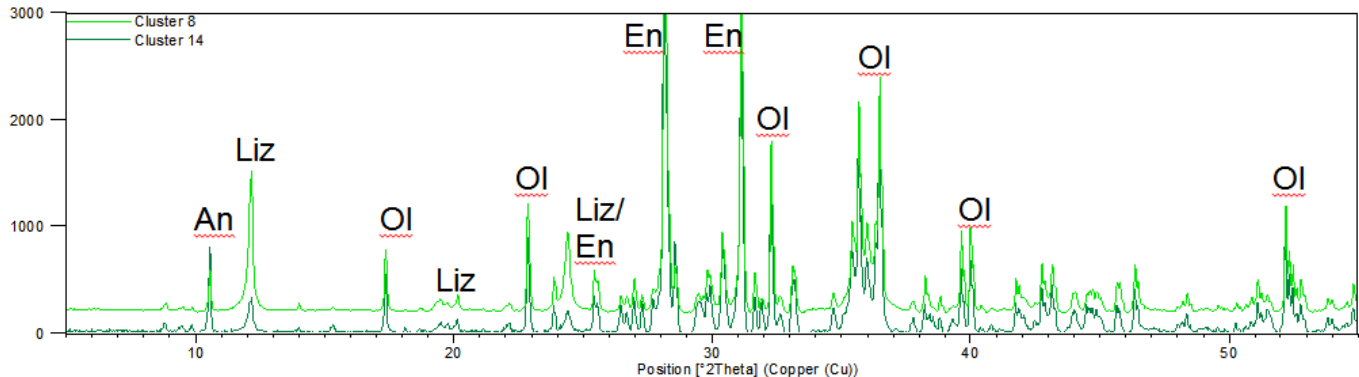

Obs: OPS = Olivina/piroxênio/ com serpentina $>10 \% ; P O S=$ Piroxênio/olivina/ com serpentina $=10 \% ; P O=$ Piroxênio/ com olivina $=10 \% ; \boldsymbol{P}=$ Piroxênio/ com olivina $=5 \% ; \boldsymbol{C S}=$ Minério carbonático com serpentina $>5 \%$ (separado em Ganga A, B e C); Out = Outlier.

Liz = lizardita; $O I=$ olivina; $E n=$ enstatita; $A n=$ anfibólio; $Q z=$ quartzo; $T=$ talco; $M=$ mica; $K$-feld = feldspato potássico; $A b=$ plagioclasio;albita?; $D=$ dolomita; $M a g=$ Magnesita; $V=$ vermiculita; $\mathrm{Cl}=\mathrm{clorita}$ 


\section{APÊNDICE 3}

Difratogramas médios dos domínios mineralógicos

PO

Figura 67 - Comparação dos difratogramas médios de cada cluster agrupados como PO Counts

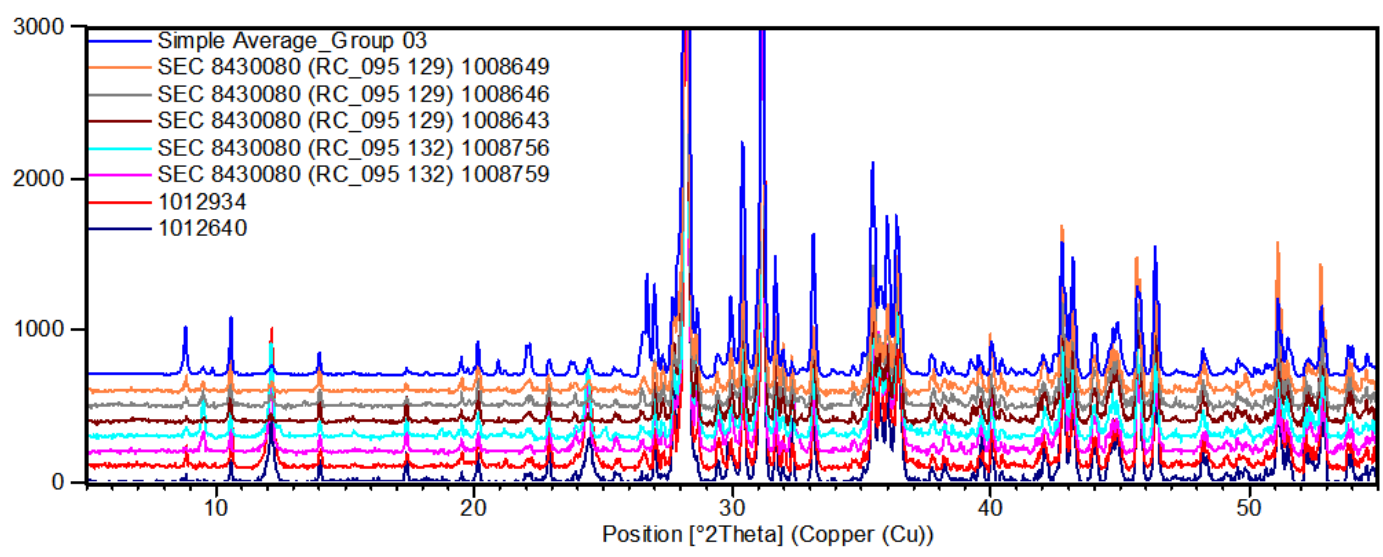

$\mathbf{P}$

Figura 68 - Comparação dos difratogramas médios de cada cluster agrupados como P

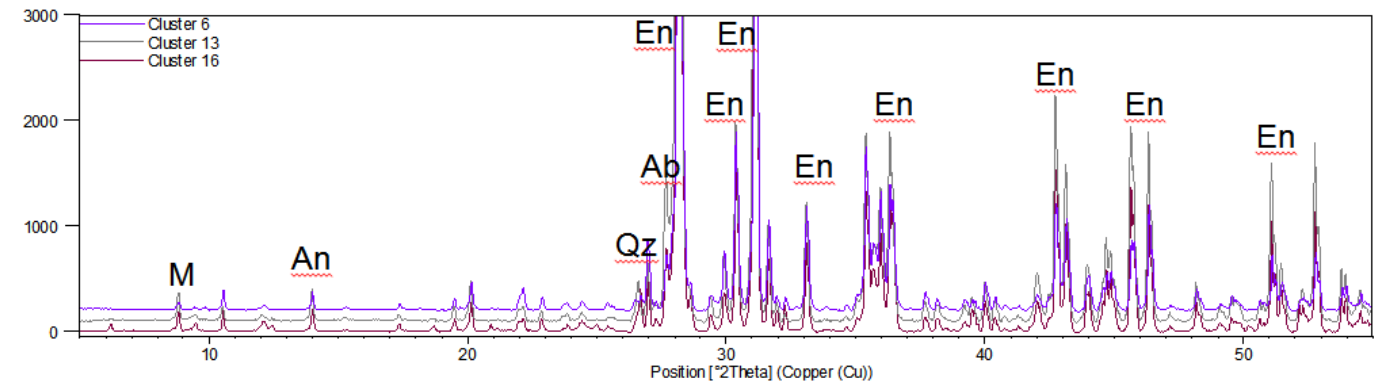

PAF

Figura 69 - Comparação dos difratogramas médios de cada cluster agrupados como PAF

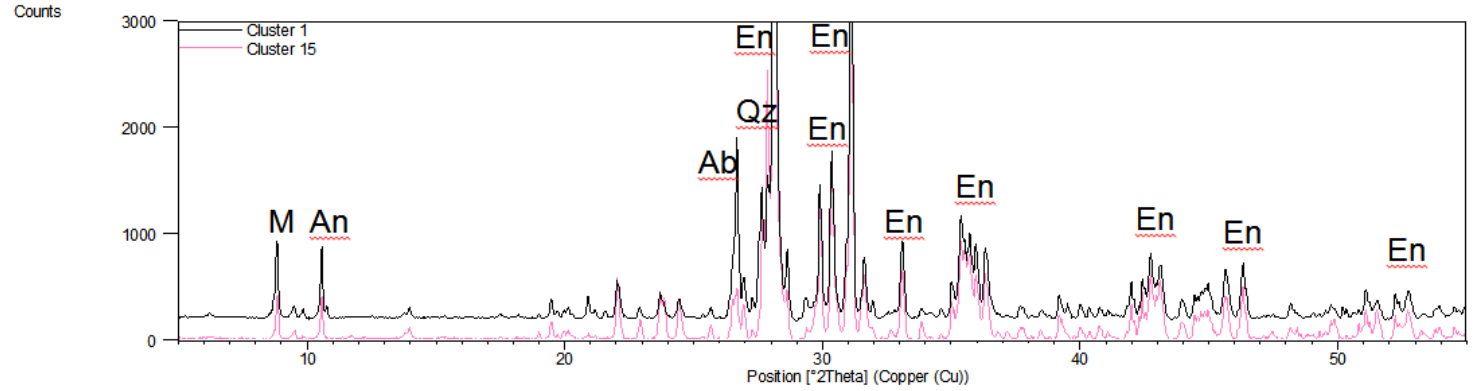

Obs: OPS = Olivina/piroxênio/ com serpentina $>10 \% ; P O S=$ Piroxênio/olivina/ com serpentina $=10 \% ; \mathbf{P O}=$ Piroxênio/ com olivina $=10 \% ; \boldsymbol{P}=$ Piroxênio/ com olivina $=5 \% ; \boldsymbol{C S}=$ Minério carbonático com serpentina $>5 \%$ (separado em Ganga A, B e C); Out = Outlier.

Liz = lizardita; $\mathrm{Ol}=$ olivina; $E n=$ enstatita; $A n=$ anfibólio; $Q z=$ quartzo; $T$ = talco; $M=$ mica; $K$-feld = feldspato potássico; $A b=$ plagioclasio;albita?; $D=$ dolomita; $M a g=$ Magnesita; $V=$ vermiculita; $\mathrm{Cl}=$ clorita. 


\section{APÊNDICE 4}

Análises químicas semi-quantitativas das amostras de contraparte dos pós de perfuratriz

Tabela 32 - Análises químicas semi-quantitativas das amostras de contraparte dos pós de perfuratriz. Em verde as amostras selecionadas para composição (amostras não seriam consideradas se \% Ni $<0,35$ e/ou $\% \mathrm{~S}<0,10$ )

\begin{tabular}{|c|c|c|c|c|c|c|c|c|c|c|c|c|c|}
\hline \multirow{2}{*}{ Grupo Caracterização } & \multirow{2}{*}{ Grupo Cluster } & \multirow{2}{*}{ ID } & \multicolumn{9}{|c|}{ Elementos (\%) } & \multirow[b]{2}{*}{$\mathrm{Ni} / \mathrm{S}$} & \multirow[b]{2}{*}{$\mathrm{SiO}_{2} / \mathrm{MgO}$} \\
\hline & & & $\mathrm{Ni}$ & $\mathrm{Cu}$ & $\mathbf{S}$ & $\mathrm{Fe}_{2} \mathrm{O}_{3}$ & $\mathrm{SiO}_{2}$ & MgO & $\mathrm{Al}_{2} \mathrm{O}_{3}$ & $\mathrm{CaO}$ & PF & & \\
\hline \multirow{2}{*}{ OPS } & 10 & $\begin{array}{l}\text { SEC 8431120 (RC_130 366) } \\
1013435\end{array}$ & 1,18 & 0,259 & 1,04 & 17,2 & 29,7 & 36,4 & 0,815 & 1,38 & 10,1 & 1,13 & 0,81 \\
\hline & 11 & 1012644 & 0,466 & 0,030 & 0,093 & 16,7 & 35,0 & 36,9 & 1,22 & 1,49 & 6,57 & 3,79 & 0,95 \\
\hline \multirow{8}{*}{ POS } & 8 & $\begin{array}{l}\text { SEC } 8430620 \text { (RC_130 219) } \\
1010691\end{array}$ & 0,627 & 0,140 & 0,421 & 15,6 & 39,8 & 30,3 & 2,65 & 1,96 & 6,09 & 1,49 & 1,32 \\
\hline & 8 & 1012641 & 0,663 & 0,128 & 0,561 & 16,8 & 37,0 & 35,7 & 1,58 & 1,94 & 3,86 & 1,18 & 1,04 \\
\hline & 8 & 1012642 & 1,67 & 0,344 & 1,63 & 18,9 & 33,8 & 35,0 & 1,11 & 1,39 & 4,62 & 1,02 & 0,97 \\
\hline & 8 & 1012643 & 1,48 & 0,295 & 1,48 & 18,7 & 34,1 & 35,2 & 1,10 & 1,37 & 4,68 & 1,00 & 0,97 \\
\hline & 8 & 1013508 & 1,25 & 0,348 & 1,38 & 15,9 & 35,9 & 29,0 & 1,92 & 4,44 & 8,19 & 0,91 & 1,24 \\
\hline & 8 & RC_100_0067 PCT 1016170 & 0,777 & 0,174 & 0,521 & 18,4 & 34,7 & 35,9 & 1,24 & 1,67 & 4,88 & 1,49 & 0,97 \\
\hline & 8 & $\begin{array}{l}\text { SEC } 8430620 \text { (RC_130 219) } \\
1010690\end{array}$ & 0,327 & 0,027 & 0,095 & 14,3 & 40,3 & 28,0 & 4,72 & 2,17 & 6,48 & 3,44 & 1,44 \\
\hline & $\begin{array}{l}14 \\
14\end{array}$ & $\begin{array}{l}\text { RC_100_0070 PCT } 10160063 \\
\text { RC_100_0067 PCT } 1016167\end{array}$ & $\begin{array}{l}0,800 \\
0,487\end{array}$ & $\begin{array}{l}0,126 \\
0,035 \\
\end{array}$ & $\begin{array}{l}0,541 \\
0,237\end{array}$ & $\begin{array}{l}18,4 \\
18,0\end{array}$ & $\begin{array}{l}36,2 \\
36,6\end{array}$ & $\begin{array}{l}36,0 \\
35,9\end{array}$ & $\begin{array}{l}1,43 \\
1,31 \\
\end{array}$ & $\begin{array}{l}1,75 \\
1,91 \\
\end{array}$ & $\begin{array}{l}3,10 \\
3,89 \\
\end{array}$ & $\begin{array}{l}1,48 \\
2,05 \\
\end{array}$ & $\begin{array}{l}1,01 \\
1,02\end{array}$ \\
\hline \multirow{14}{*}{ PO } & 3 & $\begin{array}{l}\text { SEC } 8430080 \text { (RC_095 129) } \\
1008649\end{array}$ & 0,417 & 0,076 & 0,279 & 16,0 & 43,6 & 29,2 & 3,22 & 3,19 & 1,89 & 1,49 & 1,50 \\
\hline & 3 & $\begin{array}{l}\text { SEC } 8430080 \text { (RC_095 129) } \\
1008646\end{array}$ & 0,367 & 0,065 & 0,220 & 15,3 & 44,3 & 29,8 & 3,21 & 3,13 & 1,43 & 1,67 & 1,49 \\
\hline & 3 & $\begin{array}{l}\text { SEC } 8430080 \text { (RC_095 129) } \\
1008643\end{array}$ & 0,696 & 0,200 & 0,723 & 16,6 & 43,6 & 29,9 & 2,90 & 2,99 & 0,36 & 0,96 & 1,46 \\
\hline & 3 & $\begin{array}{l}\text { SEC } 8430080 \text { (RC_095 132) } \\
1008756\end{array}$ & 0,845 & 0,220 & 0,978 & 16,7 & 40,8 & 29,7 & 2,74 & 2,89 & 3,04 & 0,86 & 1,37 \\
\hline & 3 & $\begin{array}{l}\text { SEC } 8430080 \text { (RC_095 132) } \\
1008759\end{array}$ & 0,732 & 0,229 & 0,727 & 17,3 & 39,7 & 31,2 & 2,33 & 2,61 & 3,12 & 1,01 & 1,27 \\
\hline & $\begin{array}{l}3 \\
3\end{array}$ & $\begin{array}{l}1012640 \\
1012934\end{array}$ & $\begin{array}{l}0,499 \\
0,638\end{array}$ & $\begin{array}{l}0,098 \\
0,225\end{array}$ & $\begin{array}{l}0,381 \\
0,676\end{array}$ & $\begin{array}{l}15,2 \\
16,0\end{array}$ & $\begin{array}{l}43,9 \\
42,4\end{array}$ & $\begin{array}{l}32,1 \\
31,3\end{array}$ & $\begin{array}{l}2,36 \\
2,09\end{array}$ & $\begin{array}{l}2,65 \\
2,17\end{array}$ & $\begin{array}{l}1,00 \\
2,47\end{array}$ & $\begin{array}{l}1,31 \\
0,94\end{array}$ & $\begin{array}{l}1,37 \\
1,35\end{array}$ \\
\hline & 3 & $\begin{array}{l}\text { SEC } 8430080 \text { (RC_095 132) } \\
1008769\end{array}$ & 0,345 & 0,060 & 0,217 & 16,3 & 43,7 & 30,4 & 2,97 & 3,23 & 0,62 & 1,59 & 1,44 \\
\hline & 3 & 1012935 & 0,322 & 0,054 & 0,231 & 14,8 & 47,5 & 29,3 & 2,86 & 2,63 & 0,19 & 1,39 & 1,62 \\
\hline & 3 & 1012937 & 0,261 & 0,035 & 0,129 & 12,2 & 49,8 & 24,4 & 5,55 & 2,78 & 1,43 & 2,02 & 2,04 \\
\hline & 3 & 1012722 & 0,283 & 0,062 & 0,231 & 13,8 & 47,6 & 27,2 & 3,73 & 2,93 & 1,68 & 1,23 & 1,75 \\
\hline & 3 & $\begin{array}{l}\text { SEC } 8430080 \text { (RC_095 129) } \\
1008653\end{array}$ & 0,341 & 0,044 & 0,161 & 15,6 & 44,4 & 30,3 & 3,22 & 3,19 & 0,52 & 2,12 & 1,47 \\
\hline & 3 & 1012723 & 0,218 & 0,025 & 0,093 & 13,8 & 48,6 & 28,2 & 3,44 & 2,82 & 0,54 & 2,34 & 1,72 \\
\hline & 3 & 1012725 & 0,255 & 0,039 & 0,146 & 14,2 & 47,6 & 30,0 & 2,74 & 2,90 & 0,28 & 1,75 & 1,59 \\
\hline & 3 & RC_100_0067 PCT 1016168 & 0,459 & 0,021 & 0,100 & 17,8 & 39,0 & 34,1 & 1,84 & 2,28 & 2,55 & 4,37 & 1,14 \\
\hline
\end{tabular}

= Minério carbonático com serpentina $>5 \%$ (separado em Ganga $A, B$ e C):C = Minério carbonático Out = Outlier. 


\section{APÊNDICE 4}

Análises químicas semi-quantitativas das amostras de contraparte dos pós de perfuratriz

Tabela 32 (Continuação) - Análises químicas semi-quantitativas das amostras de contraparte dos pós de perfuratriz. Em verde as amostras selecionadas para composição (amostras não seriam consideradas se $\% \mathrm{Ni}<0,35 \mathrm{e} / \mathrm{ou} \% \mathrm{~S}<0,10$ )

\begin{tabular}{|c|c|c|c|c|c|c|c|c|c|c|c|c|c|}
\hline \multirow{2}{*}{ Grupo Caracterização } & \multirow{2}{*}{$\begin{array}{l}\text { Grupo } \\
\text { Cluster }\end{array}$} & \multirow{2}{*}{ ID } & \multicolumn{9}{|c|}{ Elementos (\%) } & \multirow[b]{2}{*}{$\mathrm{Ni} / \mathrm{S}$} & \multirow[b]{2}{*}{$\mathrm{SiO} / \mathrm{MgC}$} \\
\hline & & & $\mathbf{N i}$ & $\mathrm{Cu}$ & $\mathbf{S}$ & $\mathrm{Fe}_{2} \mathrm{O}_{3}$ & $\mathrm{SiO}_{2}$ & MgO & $\mathrm{Al}_{2} \mathrm{O}_{3}$ & $\mathrm{CaO}$ & PF & & \\
\hline \multirow{17}{*}{$\mathbf{P}$} & 16 & SEC 8430080 (RC_095 129) 1008640 & 0,849 & 0,226 & 1,02 & 17,7 & 42,9 & 28,4 & 2,87 & 3,14 & 0,79 & 0,83 & 1,51 \\
\hline & 16 & 1012936 & 0,427 & 0,092 & 0,362 & 15,1 & 46,8 & 29,6 & 2,61 & 2,64 & 0,49 & 1,18 & 1,58 \\
\hline & 16 & RC_100_0073 PCT 1016200 & 0,347 & 0,083 & 0,301 & 15,0 & 47,1 & 27,2 & 3,48 & 2,99 & 1,53 & 1,15 & 1,73 \\
\hline & 16 & RC_100_0073 PCT 1016203 & 0,430 & 0,101 & 0,516 & 15,8 & 46,1 & 27,9 & 3,27 & 3,28 & 0,62 & 0,83 & 1,65 \\
\hline & 16 & 1012721 & 0,297 & 0,043 & 0,169 & 14,7 & 47,1 & 29,8 & 2,85 & 2,94 & 0,19 & 1,76 & 1,58 \\
\hline & 16 & 1012724 & 0,293 & 0,052 & 0,185 & 14,6 & 47,4 & 29,8 & 2,86 & 2,78 & 0,12 & 1,58 & 1,59 \\
\hline & 16 & RC_100_0070 PCT 10160067 & 0,335 & 0,023 & 0,126 & 17,5 & 43,3 & 31,2 & 2,48 & 2,86 & GF & 2,66 & 1,39 \\
\hline & 13 & RC_100_0067 PCT 1016169 & 0,522 & 0,110 & 0,526 & 15,7 & 46,0 & 28,7 & 3,03 & 3,15 & 0,21 & 0,99 & 1,60 \\
\hline & 13 & RC_100_0070 PCT 10160064 & 0,506 & 0,120 & 0,502 & 16,3 & 45,7 & 28,2 & 3,06 & 3,31 & 0,17 & 1,01 & 1,62 \\
\hline & 13 & RC_100_0070 PCT 10160065 & 0,577 & 0,112 & 0,543 & 16,8 & 44,3 & 29,8 & 2,75 & 3,07 & GF & 1,06 & 1,49 \\
\hline & 13 & RC_100_0070 PCT 10160066 & 0,313 & 0,035 & 0,121 & 15,9 & 45,3 & 29,4 & 2,69 & 3,10 & 1,04 & 2,59 & 1,54 \\
\hline & 13 & RC_100_0073 PCT 1016201 & 0,311 & 0,053 & 0,234 & 16,0 & 46,4 & 28,6 & 2,82 & 3,10 & 0,64 & 1,33 & 1,62 \\
\hline & 13 & RC_100_0073 PCT 1016202 & 0,358 & 0,061 & 0,269 & 15,819 & 46,46 & 28,37 & 3,08 & 3,27 & 0,47 & 1,14 & 1,63 \\
\hline & 6 & SEC 8430080 (RC_095 132) 1008763 & 0,776 & 0,168 & 0,755 & 16,9 & 42,8 & 29,7 & 2,94 & 2,96 & 0,90 & 1,03 & 1,44 \\
\hline & 6 & SEC 8430080 (RC_095 132) 1008766 & 0,356 & 0,052 & 0,192 & 15,6 & 44,8 & 29,5 & 3,14 & 3,50 & 0,66 & 1,70 & 1,52 \\
\hline & 6 & RC_100_0067 PCT 1016166 & 0,426 & 0,018 & 0,093 & 17,7 & 38,6 & 34,6 & 1,60 & 2,02 & 3,05 & 4,58 & 1,11 \\
\hline & 6 & 1012938 & 0,261 & 0,015 & 0,091 & 14,9 & 45,3 & 31,8 & 2,41 & 2,80 & 0,70 & 2,87 & 1,42 \\
\hline \multirow{3}{*}{ CS } & 12 & SEC 8430620 (RC_130 219) 1010692 & 0,595 & 0,083 & 0,384 & 12,6 & 33,6 & 30,9 & 3,01 & 1,47 & 14,8 & 1,5 & 1,09 \\
\hline & 4 & SEC 8431120 (RC_130 366) 1013434 & 0,727 & 0,159 & 0,464 & 13,2 & 24,6 & 28,1 & 0,585 & 6,95 & 23,3 & 1,6 & 0,88 \\
\hline & 4 & SEC 8430620 (RC_130 219) 1010688 & 0,406 & 0,041 & 0,239 & 13,5 & 42,7 & 25,0 & 5,30 & 1,42 & 7,09 & 1,70 & 1,70 \\
\hline \multirow{6}{*}{ C } & 9 & SEC 8431120 (RC_130 366) 1013430 & 0,020 & 0,043 & 0,061 & 19,4 & 40,4 & 8,01 & 12,4 & 8,63 & 4,61 & 0,33 & 5,05 \\
\hline & 9 & SEC 8431120 (RC_130 366) 1013432 & 0,013 & 0,042 & 0,055 & 20,0 & 40,0 & 7,28 & 12,2 & 9,16 & 4,52 & 0,24 & 5,50 \\
\hline & 9 & 1013504 & 0,026 & 0,051 & 0,063 & 19,3 & 39,8 & 7,87 & 12,1 & 8,81 & 3,39 & 0,41 & 5,06 \\
\hline & 9 & 1013505 & 0,030 & 0,050 & 0,104 & 19,8 & 40,2 & 6,57 & 12,5 & 10,3 & 3,40 & 0,29 & 6,12 \\
\hline & 9 & 1013506 & 0,040 & 0,043 & 0,231 & 19,6 & 40,0 & 7,42 & 12,1 & 9,15 & 4,81 & 0,17 & 5,40 \\
\hline & 9 & 1013507 & 0,050 & 0,312 & 0,847 & 14,8 & 30,6 & 23,5 & 2,12 & 7,92 & 17,1 & 1,3 & 1,30 \\
\hline \multirow{3}{*}{ Out } & 17 & SEC 8431120 (RC_130 366) 1013433 & 0,553 & 0,132 & 0,092 & 14,0 & 23,4 & 22,9 & 2,59 & 9,57 & 23,9 & 2,5 & 1,02 \\
\hline & 17 & SEC 8431120 (RC_130 219) 1010689 & 0,492 & 0,073 & 0,093 & 13,7 & 43,8 & 21,1 & 5,84 & 1,35 & 7,79 & 1,45 & 2,08 \\
\hline & 17 & RC_100_0073 PCT 1016204 & 0,795 & 0,220 & 0,993 & 17,0 & 44,8 & 27,7 & 3,11 & 3,39 & GF & 0,80 & 1,62 \\
\hline
\end{tabular}

Obs: OPS = Olivina/piroxênio/ com serpentina $>10 \% ; \boldsymbol{P O S}=$ Piroxênio/olivina $/$ com serpentina $=10 \% ; \boldsymbol{P O}=$ Piroxênio/ com olivina $=10 \% ; \boldsymbol{P}=$ Piroxênio/ com olivina $=5 \% ;$ CS = Minério carbonático com serpentina $>5 \%$ (separado em Ganga A, B e C);C = Minério carbonático Out = Outlier. 


\section{APÊNDICE 5}

Composição químicas dos minerais (base para banco de dados MLA)

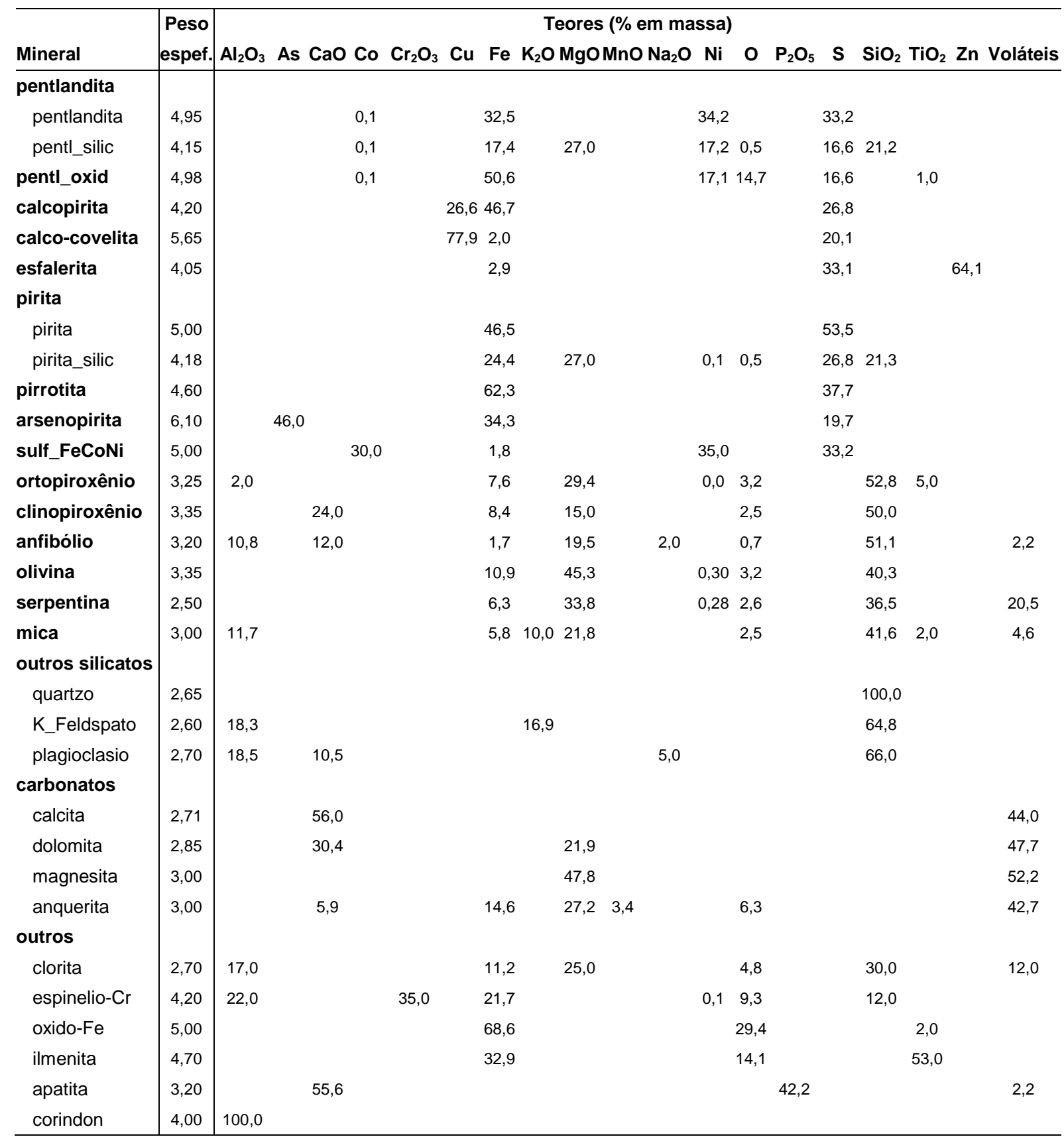




\section{APÊNDICE 6}

Resultados MLA

\section{Amostras}

As seguintes amostras foram objeto de análises mineralógicas e associações minerais através do sistema MLA - Mineral Liberation Analyser:

- OPS = Olivina/piroxênio/ com serpentina $>10 \%$

- $\quad$ POS $=$ Piroxênio/olivina/ com serpentina $=10 \%$

- $\mathrm{PO}=$ Piroxênio/ com olivina $=10 \%$

- $\quad P=$ Piroxênio/ com olivina $=5 \%$

- Minério com ganga tipo A - micáceo

- Minério com ganga tipo B - carbonático Minério carbonático com

- Minério com ganga tipo C - feldspático/micáceo

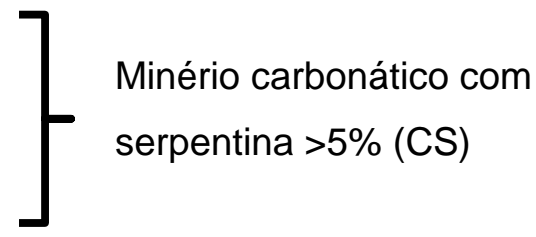

- Outlier

\section{Classificação granulométrica}

As distribuições de teores por frações granulométricas estão expostas da Tabela 33 a Tabela 40, para as amostras OPS, POS, PO, P, Ganga A, Ganga B, Ganga C e Out, respectivamente.

\begin{tabular}{c|c|ccccccccc|ccc}
\multicolumn{8}{c}{ Tabela 33 - Distribuição de teores por fração granulométrica - OPS } \\
\hline & & \multicolumn{8}{c}{ Teores (\%) } & \multicolumn{3}{c}{ Distribuição (\%) } \\
Fração & \% massa & Ni & Cu & Co & Fe & S & SiO $_{2}$ & MgO & Ni/S & Ni & Cu & S \\
\hline+0.105 & 20,0 & 0,83 & 0,13 & 0,05 & 10,15 & 1,27 & 35,2 & 35,8 & 0,65 & 18,9 & 13,8 & 21,2 \\
$-0.105+0.053$ & 29,3 & 0,82 & 0,14 & 0,04 & 10,23 & 1,18 & 35,5 & 34,9 & 0,69 & 27,4 & 21,9 & 28,9 \\
$-0.053+0.020$ & 21,6 & 0,92 & 0,19 & 0,04 & 10,18 & 1,29 & 34,5 & 33,4 & 0,72 & 22,6 & 22,2 & 23,2 \\
-0.020 & 29,1 & 0,94 & 0,27 & 0,04 & 9,04 & 1,10 & 33,3 & 32,2 & 0,85 & 31,1 & 42,2 & 26,7 \\
Total calculado & 100,0 & 0,88 & 0,19 & 0,04 & 9,86 & 1,20 & 34,6 & 34,0 & 0,73 & 100,0 & 100,0 & 100,0 \\
Total dosado & & 0,88 & 0,19 & 0,03 & 9,80 & 1,41 & 35,9 & 34,5 & & & &
\end{tabular}


APÊNDICE 6

Resultados MLA

Tabela 34 - Distribuição de teores por fração granulométrica - POS

\begin{tabular}{c|c|cccccccc|cccc}
\hline & & \multicolumn{1}{|c|}{ Teores (\%) } & \multicolumn{4}{|c}{ Distribuição (\%) } \\
Fração & \% massa & $\mathbf{N i}$ & $\mathbf{C u}$ & $\mathbf{C o}$ & $\mathbf{F e}$ & $\mathbf{S}$ & $\mathbf{S i O}_{2}$ & $\mathbf{M g O}$ & $\mathbf{N i} / \mathbf{S}$ & $\mathbf{N i}$ & $\mathbf{C u}$ & $\mathbf{S}$ \\
\hline+0.105 & 20,1 & 0,40 & 0,06 & $<0,001$ & 9,38 & 0,64 & 46,6 & 30,2 & 0,63 & 16,0 & 12,6 & 18,4 \\
$-0.105+0.053$ & 31,9 & 0,38 & 0,06 & 0,05 & 9,83 & 0,52 & 45,3 & 29,9 & 0,72 & 23,9 & 18,7 & 24,0 \\
$-0.053+0.020$ & 24,8 & 0,54 & 0,10 & 0,02 & 9,16 & 0,79 & 44,1 & 29,9 & 0,69 & 26,9 & 24,7 & 28,1 \\
-0.020 & 23,2 & 0,72 & 0,19 & 0,05 & 9,39 & 0,89 & 41,4 & 27,2 & 0,81 & 33,2 & 44,0 & 29,6 \\
Total calculado & 100,0 & 0,50 & 0,10 & 0,03 & 9,47 & 0,70 & 44,4 & 29,3 & 0,72 & 100,0 & 100,0 & 100,0 \\
Total dosado & & 0,57 & 0,11 & 0,03 & 9,18 & 0,93 & 43,8 & 29,3 & 0,61 & & & \\
\hline
\end{tabular}

Tabela 35 - Distribuição de teores por fração granulométrica - PO

\begin{tabular}{c|c|cccccccc|cccc}
\hline & \multicolumn{10}{|c|}{ Teores (\%) } & \multicolumn{4}{c}{ Distribuição (\%) } \\
Fração & \% massa & $\mathbf{N i}$ & $\mathbf{C u}$ & $\mathbf{C o}$ & $\mathbf{F e}$ & $\mathbf{S}$ & $\mathbf{S i O}_{2}$ & $\mathbf{M g O}$ & $\mathbf{N i} / \mathbf{S}$ & $\mathbf{N i}$ & $\mathbf{C u}$ & $\mathbf{S}$ \\
\hline+0.105 & 21,6 & 0,43 & 0,08 & 0,02 & 12,02 & 0,54 & 47,4 & 25,4 & 0,79 & 22,6 & 19,3 & 22,4 \\
$-0.105+0.053$ & 32,3 & 0,27 & 0,04 & 0,04 & 10,83 & 0,28 & 48,9 & 26,4 & 0,94 & 21,1 & 14,4 & 17,5 \\
$-0.053+0.020$ & 22,0 & 0,38 & 0,08 & 0,01 & 8,73 & 0,56 & 48,9 & 28,4 & 0,69 & 20,6 & 18,8 & 23,5 \\
-0.020 & 24,1 & 0,60 & 0,17 & 0,04 & 9,14 & 0,79 & 46,1 & 26,9 & 0,76 & 35,6 & 47,4 & 36,6 \\
Total calculado & 100,0 & 0,41 & 0,09 & 0,03 & 10,22 & 0,52 & 47,9 & 26,8 & 0,78 & 100,0 & 100,0 & 100,0 \\
Total dosado & & 0,47 & 0,11 & 0,03 & 9,25 & 0,86 & 47,6 & 27,2 & 0,55 & & & \\
\hline
\end{tabular}

Tabela 36 - Distribuição de teores por fração granulométrica - P

\begin{tabular}{c|c|cccccccc|ccc}
\hline & & \multicolumn{1}{|c|}{ Teores (\%) } & \multicolumn{3}{|c}{ Distribuição (\%) } \\
Fração & \% massa & $\mathbf{N i}$ & $\mathbf{C u}$ & $\mathbf{C o}$ & $\mathbf{F e}$ & $\mathbf{S}$ & $\mathbf{S i O}_{2}$ & $\mathbf{M g O}$ & $\mathbf{N i} / \mathbf{S}$ & $\mathbf{N i}$ & $\mathbf{C u}$ & $\mathbf{S}$ \\
\hline+0.105 & 25,6 & 0,21 & 0,02 & 0,03 & 8,45 & 0,25 & 51,5 & 29,3 & 0,85 & 14,0 & 8,1 & 11,6 \\
$-0.105+0.053$ & 33,3 & 0,28 & 0,04 & 0,02 & 8,33 & 0,39 & 50,7 & 29,2 & 0,71 & 23,7 & 17,7 & 23,6 \\
$-0.053+0.020$ & 23,4 & 0,49 & 0,08 & $<0,001$ & 8,74 & 0,77 & 48,6 & 27,8 & 0,63 & 29,4 & 24,9 & 32,8 \\
-0.020 & 17,7 & 0,72 & 0,22 & 0,04 & 9,63 & 1,00 & 45,7 & 25,5 & 0,72 & 33,0 & 49,2 & 32,0 \\
& & & & & & & & & \\
Total calculado & 100,0 & 0,39 & 0,08 & 0,02 & 8,69 & 0,55 & 49,5 & 28,2 & 0,70 & 100,0 & 100,0 & 100,0 \\
Total dosado & & 0,44 & 0,09 & 0,03 & 9,37 & 0,67 & 49,1 & 27,2 & 0,66 & & & \\
\hline
\end{tabular}

Tabela 37 - Distribuição de teores por fração granulométrica - Ganga A

\begin{tabular}{c|c|cccccccc|ccc}
\hline & & \multicolumn{1}{|c|}{ Teores (\%) } & \multicolumn{3}{|c}{ Distribuição (\%) } \\
Fração & \% massa & $\mathbf{N i}$ & $\mathbf{C u}$ & $\mathbf{C o}$ & $\mathbf{F e}$ & $\mathbf{S}$ & $\mathbf{S i O}_{2}$ & $\mathbf{M g O}$ & $\mathbf{N i} / \mathbf{S}$ & $\mathbf{N i}$ & $\mathbf{C u}$ & $\mathbf{S}$ \\
\hline+0.105 & 13,8 & 0,36 & 0,06 & $<0,001$ & 8,02 & 0,27 & 39,6 & 27,4 & 1,33 & 12,6 & 13,2 & 13,3 \\
$-0.105+0.053$ & 24,1 & 0,32 & 0,06 & 0,03 & 6,87 & 0,28 & 40,0 & 30,1 & 1,15 & 19,6 & 20,1 & 23,9 \\
$-0.053+0.020$ & 21,9 & 0,39 & 0,08 & $<0,001$ & 7,33 & 0,27 & 39,8 & 29,4 & 1,45 & 21,7 & 25,7 & 21,0 \\
-0.020 & 40,2 & 0,45 & 0,07 & 0,02 & 7,12 & 0,29 & 39,4 & 29,3 & 1,55 & 46,1 & 40,9 & 41,8 \\
Total calculado & 100,0 & 0,39 & 0,07 & 0,02 & 7,23 & 0,28 & 39,7 & 29,3 & 1,40 & 100,0 & 100,0 & 100,0 \\
Total dosado & & 0,42 & 0,06 & 0,03 & 7,21 & 0,52 & 38,5 & 28,5 & 0,82 & & & \\
\hline
\end{tabular}


APÊNDICE 6

Resultados MLA

Tabela 38 - Distribuição de teores por fração granulométrica - Ganga B

\begin{tabular}{c|c|cccccccc|cccc}
\hline & & \multicolumn{8}{|c|}{ Teores (\%) } & \multicolumn{4}{|c}{ Distribuição (\%) } \\
Fração & \% massa & $\mathbf{N i}$ & $\mathbf{C u}$ & $\mathbf{C o}$ & $\mathbf{F e}$ & $\mathbf{S}$ & $\mathbf{S i O}_{2}$ & $\mathbf{M g O}$ & $\mathbf{N i} / \mathbf{S}$ & $\mathbf{N i}$ & $\mathbf{C u}$ & $\mathbf{S}$ \\
\hline+0.105 & 16,0 & 0,52 & 0,11 & 0,01 & 7,58 & 0,51 & 32,8 & 28,6 & 1,02 & 15,2 & 15,1 & 19,3 \\
$-0.105+0.053$ & 23,0 & 0,55 & 0,11 & 0,02 & 8,09 & 0,42 & 32,5 & 27,8 & 1,31 & 23,2 & 23,2 & 22,8 \\
$-0.053+0.020$ & 22,0 & 0,50 & 0,11 & 0,02 & 7,10 & 0,43 & 32,2 & 27,8 & 1,16 & 20,2 & 20,8 & 22,6 \\
-0.020 & 39,0 & 0,58 & 0,12 & $<0,001$ & 7,51 & 0,38 & 29,7 & 27,0 & 1,52 & 41,4 & 40,8 & 35,3 \\
Total calculado & 100,0 & 0,55 & 0,11 & 0,01 & 7,56 & 0,42 & 31,4 & 27,6 & 1,29 & 100,0 & 100,0 & 100,0 \\
Total dosado & & 0,51 & 0,10 & 0,03 & 7,22 & 0,67 & 31,2 & 27,9 & 0,77 & & & \\
\hline
\end{tabular}

Tabela 39 - Distribuição de teores por fração granulométrica - Ganga C

\begin{tabular}{c|c|ccccccccc|ccc}
\hline & & \multicolumn{8}{|c|}{ Teores (\%) } & \multicolumn{4}{c}{ Distribuição (\%) } \\
Fração & \% massa & $\mathbf{N i}$ & $\mathbf{C u}$ & $\mathbf{C o}$ & $\mathbf{F e}$ & $\mathbf{S}$ & $\mathbf{S i O}_{\mathbf{2}}$ & $\mathbf{M g O}$ & $\mathbf{N i} / \mathbf{S}$ & $\mathbf{N i}$ & $\mathbf{C u}$ & $\mathbf{S}$ \\
\hline+0.105 & 16,2 & 0,26 & 0,03 & 0,05 & 7,83 & 0,29 & 49,4 & 21,8 & 0,90 & 13,4 & 13,6 & 15,1 \\
$-0.105+0.053$ & 33,2 & 0,26 & 0,03 & 0,03 & 7,46 & 0,27 & 48,9 & 23,7 & 0,98 & 27,5 & 29,3 & 28,3 \\
$-0.053+0.020$ & 25,4 & 0,29 & 0,04 & 0,03 & 7,67 & 0,32 & 47,4 & 24,5 & 0,93 & 23,3 & 26,8 & 25,4 \\
-0.020 & 25,2 & 0,45 & 0,04 & 0,03 & 8,02 & 0,39 & 44,6 & 24,0 & 1,17 & 35,8 & 30,4 & 31,1 \\
Total calculado & 100,0 & 0,32 & 0,04 & 0,03 & 7,71 & 0,32 & 47,5 & 23,7 & 1,01 & 100,0 & 100,0 & 100,0 \\
Total dosado & & 0,35 & 0,04 & 0,06 & 8,17 & 0,38 & 46,8 & 22,9 & 0,92 & & &
\end{tabular}

Tabela 40 - Distribuição de teores por fração granulométrica - Outlier

\begin{tabular}{c|c|cccccccccccc}
\hline & & \multicolumn{10}{|c|}{ Teores (\%) } & \multicolumn{4}{c}{ Distribuição (\%) } \\
Fração & \% massa & $\mathbf{N i}$ & $\mathbf{C u}$ & $\mathbf{C o}$ & $\mathbf{F e}$ & $\mathbf{S}$ & $\mathbf{S i O}_{2}$ & $\mathbf{M g O}$ & $\mathbf{N i} / \mathbf{S}$ & $\mathbf{N i}$ & $\mathbf{C u}$ & $\mathbf{S}$ \\
\hline+0.105 & 26,8 & 0,23 & 0,04 & $<0,001$ & 9,70 & 0,26 & 52,5 & 26,2 & 0,88 & 14,2 & 8,5 & 9,4 \\
$-0.105+0.053$ & 31,9 & 0,21 & 0,03 & 0,03 & 9,19 & 0,35 & 52,3 & 26,4 & 0,62 & 16,0 & 9,9 & 14,9 \\
$-0.053+0.020$ & 23,7 & 0,50 & 0,12 & 0,04 & 8,53 & 0,89 & 50,2 & 26,1 & 0,56 & 27,7 & 24,9 & 28,7 \\
-0.020 & 17,6 & 1,02 & 0,36 & 0,02 & 8,70 & 1,98 & 47,4 & 23,9 & 0,52 & 42,1 & 56,7 & 47,1 \\
Total calculado & 100,0 & 0,43 & 0,11 & 0,02 & 9,09 & 0,74 & 51,0 & 25,8 & 0,58 & 100,0 & 100,0 & 100,0 \\
Total dosado & & 0,49 & 0,12 & 0,01 & 8,25 & 1,06 & 51,3 & 26,4 & 0,46 & & & \\
\hline
\end{tabular}


APÊNDICE 6

Resultados MLA

\section{Composicão mineralógica}

Os resultados de composição mineralógica são apresentados da Tabela 41 a Tabela 48, para as amostras OPS, POS, PO, P, Ganga A, Ganga B, Ganga C e Outlier, respectivamente.

Tabela 41 - Composição mineralógica por fração (\% em massa) - OPS

\begin{tabular}{l|c|cccc}
\hline Fração (mm) & Total & $\mathbf{+ 0 , 1 0 5}$ & $\mathbf{+ 0 , 1 0 5 - 0 , 0 5 3}$ & $\mathbf{- 0 , 0 5 3 + 0 , 0 2 0}$ & $\mathbf{- 0 , 0 2 0}$ \\
\hline \% massa & 100 & 20,0 & 29,3 & 21,6 & 29,1 \\
\hline pentlandita & 1,7 & 1,6 & 1,4 & 1,8 & 1,8 \\
pentl_oxid & 1,7 & 1,5 & 1,8 & 1,8 & 1,7 \\
calcopirita & 0,2 & 0,2 & 0,2 & 0,2 & 0,4 \\
calco-covelita & $<0,1$ & $<0,1$ & $<0,1$ & $<0,1$ & - \\
esfalerita & $<0,1$ & $<0,1$ & - & - & - \\
pirita & 0,5 & 0,3 & 0,4 & 0,4 & 0,7 \\
pirrotita & $<0,1$ & $<0,1$ & $<0,1$ & $<0,1$ & $<0,1$ \\
arsenopirita & - & - & - & - & - \\
Sulf_FeCoNi & 0,1 & $<0,1$ & $<0,1$ & 0,1 & $<0,1$ \\
ortopiroxênio & 6,5 & 5,8 & 5,8 & 6,5 & 7,7 \\
clinopiroxênio & 1,8 & 1,9 & 1,8 & 2,0 & 1,5 \\
anfibólio & 2,0 & 1,2 & 1,6 & 2,7 & 2,4 \\
olivina & 37,8 & 49,5 & 46,5 & 34,1 & 23,7 \\
serpentina & 37,8 & 29,5 & 31,8 & 40,8 & 47,3 \\
outros silicatos & 0,8 & 0,3 & 0,8 & 0,9 & 1,0 \\
espinelio-Cr & 3,4 & 4,0 & 4,4 & 3,3 & 2,0 \\
oxido-Fe & 2,1 & 1,8 & 1,3 & 2,3 & 3,0 \\
mica & 0,3 & 0,2 & 0,2 & 0,2 & 0,4 \\
carbonatos & 3,1 & 1,9 & 1,7 & 2,5 & 5,7 \\
outros & 0,3 & 0,2 & 0,2 & 0,3 & 0,4 \\
\hline Obs:ouros sica & & & & \\
\hline
\end{tabular}

Obs: outros silicatos = quartzo, feldspato potássico e plagioclásio; carbonatos = calcita, dolomita, magnesita e anquerita; outros = clorita, espinélio-Cr, óxido-Fe, ilmenita, apatita, coríndon. 
APÊNDICE 6

Resultados MLA

Tabela 42 - Composição mineralógica por fração (\% em massa) - POS

\begin{tabular}{l|c|cccc}
\hline Fração (mm) & Total & $\mathbf{+ 0 , 1 0 5}$ & $\mathbf{+ 0 , 1 0 5 - 0 , 0 5 3}$ & $\mathbf{- 0 , 0 5 3 + 0 , 0 2 0}$ & $\mathbf{- 0 , 0 2 0}$ \\
\hline \% massa & 100 & 20,1 & 31,9 & 24,8 & 23,2 \\
\hline pentlandita & 1,4 & 0,7 & 0,9 & 1,6 & 2,3 \\
pentl_oxid & 0,3 & 0,2 & $<0,1$ & 0,4 & 0,6 \\
calcopirita & 0,3 & $<0,1$ & 0,3 & 0,3 & 0,6 \\
calco-covelita & $<0,1$ & $<0,1$ & $<0,1$ & $<0,1$ & - \\
esfalerita & $<0,1$ & $<0,1$ & $<0,1$ & - & $<0,1$ \\
pirita & 0,6 & 0,3 & 0,3 & 0,7 & 1,1 \\
pirrotita & $<0,1$ & 0,2 & 0,2 & 0,1 & 0,1 \\
arsenopirita & $<0,1$ & $<0,1$ & - & - & $<0,1$ \\
sulf_FeCoNi & $<0,1$ & $<0,1$ & 0,0 & 0,0 & $<0,1$ \\
ortopiroxênio & 49,5 & 57,4 & 49,8 & 46,5 & 45,5 \\
clinopiroxênio & 3,9 & 3,8 & 3,5 & 4,2 & 4,0 \\
anfibólio & 2,4 & 1,2 & 1,7 & 3,1 & 3,8 \\
olivina & 18,5 & 21,2 & 23,1 & 17,2 & 11,1 \\
serpentina & 16,1 & 10,4 & 14,4 & 18,4 & 20,9 \\
outros silicatos & 1,8 & 1,2 & 1,4 & 2,0 & 2,5 \\
espinelio-Cr & 1,5 & 1,0 & 1,5 & 2,0 & 1,3 \\
oxido-Fe & 0,4 & 0,1 & 0,2 & 0,4 & 0,8 \\
mica & 1,2 & 0,8 & 0,9 & 1,3 & 2,1 \\
carbonatos & 1,7 & 1,1 & 1,5 & 1,5 & 2,8 \\
outros & 0,2 & 0,2 & 0,2 & 0,2 & 0,3 \\
\hline Obs:outros sicatos & & & & & \\
\hline
\end{tabular}

Obs: outros silicatos = quartzo, feldspato potássico e plagioclásio; carbonatos = calcita, dolomita, magnesita e anquerita; outros = clorita, espinélio-Cr, óxido-Fe, ilmenita, apatita, coríndon. 
APÊNDICE 6

Resultados MLA

Tabela 43 - Composição mineralógica por fração (\% em massa) - PO

\begin{tabular}{l|c|cccc}
\hline Fração (mm) & Total & $\mathbf{+ 0 , 1 0 5}$ & $\mathbf{+ 0 , 1 0 5 - 0 , 0 5 3}$ & $\mathbf{- 0 , 0 5 3 + 0 , 0 2 0}$ & $\mathbf{- 0 , 0 2 0}$ \\
\hline \% massa & 100 & 25,6 & 33,3 & 23,4 & 17,7 \\
\hline pentlandita & 0,8 & 0,3 & 0,4 & 1,3 & 1,5 \\
pentl_oxid & $<0,1$ & $<0,1$ & $<0,1$ & 0,1 & 0,3 \\
calcopirita & 0,2 & $<0,1$ & 0,1 & 0,2 & 0,5 \\
calco-covelita & $<0,1$ & $<0,1$ & $<0,1$ & $<0,1$ & - \\
esfalerita & $<0,1$ & $<0,1$ & $<0,1$ & - & 0,0 \\
pirita & 0,3 & 0,1 & 0,3 & 0,4 & 0,7 \\
pirrotita & 0,1 & $<0,1$ & 0,1 & 0,1 & 0,2 \\
arsenopirita & $<0,1$ & $<0,1$ & - & - & $<0,1$ \\
sulf_FeCoNi & $<0,1$ & $<0,1$ & $<0,1$ & $<0,1$ & $<0,1$ \\
ortopiroxênio & 72,6 & 80,9 & 73,5 & 68,1 & 64,6 \\
clinopiroxênio & 6,1 & 5,0 & 5,8 & 7,2 & 7,0 \\
anfibólio & 1,8 & 0,5 & 1,2 & 2,5 & 3,7 \\
olivina & 10,0 & 8,9 & 11,6 & 10,9 & 7,5 \\
serpentina & 3,9 & 1,9 & 3,2 & 4,6 & 7,1 \\
outros silicatos & 2,2 & 1,4 & 2,1 & 2,4 & 3,1 \\
espinelio-Cr & 0,8 & 0,5 & 0,8 & 0,8 & 1,2 \\
oxido-Fe & 0,3 & 0,2 & 0,2 & 0,3 & 0,8 \\
mica & 0,3 & 0,1 & 0,1 & 0,5 & 0,7 \\
carbonatos & 0,4 & 0,2 & 0,3 & 0,4 & 0,8 \\
outros & $<0,1$ & $<0,1$ & $<0,1$ & 0,2 & 0,2 \\
\hline Obs:outros silcatos & $9 v a t z 0,4$ & & \\
\hline
\end{tabular}

Obs: outros silicatos = quartzo, feldspato potássico e plagioclásio; carbonatos = calcita, dolomita, magnesita e anquerita; outros = clorita, espinélio-Cr, óxido-Fe, ilmenita, apatita, coríndon. 
APÊNDICE 6

Resultados MLA

Tabela 44 - Composição mineralógica por fração (\% em massa) - P

\begin{tabular}{l|c|cccc}
\hline Fração (mm) & Total & $\mathbf{+ 0 , 1 0 5}$ & $\mathbf{+ 0 , 1 0 5 - 0 , 0 5 3}$ & $\mathbf{- 0 , 0 5 3 + 0 , 0 2 0}$ & $\mathbf{- 0 , 0 2 0}$ \\
\hline \% massa & 100 & 21,6 & 32,3 & 22,0 & 24,1 \\
\hline pentlandita & 0,9 & 0,3 & 0,5 & 0,8 & 2,0 \\
pentl_oxid & 0,2 & $<0,1$ & 0,2 & 0,2 & 0,4 \\
calcopirita & 0,2 & 0,1 & 0,1 & 0,2 & 0,5 \\
calco-covelita & $<0,1$ & $<0,1$ & $<0,1$ & $<0,1$ & $<0,1$ \\
esfalerita & $<0,1$ & - & - & - & $<0,1$ \\
pirita & 0,3 & 0,1 & 0,1 & 0,4 & 0,5 \\
pirrotita & 0,3 & $<0,1$ & 0,3 & 0,2 & 0,4 \\
arsenopirita & $<0,1$ & $<0,1$ & - & $<0,1$ & $<0,1$ \\
Sulf_FeCoNi & $<0,1$ & $<0,1$ & $<0,1$ & $<0,1$ & $<0,1$ \\
ortopiroxênio & 69,7 & 77,9 & 72,6 & 65,2 & 62,7 \\
clinopiroxênio & 5,4 & 4,3 & 5,3 & 6,8 & 5,5 \\
anfibólio & 4,5 & 2,2 & 3,4 & 5,8 & 6,9 \\
olivina & 8,8 & 7,8 & 9,5 & 10,2 & 7,3 \\
serpentina & 5,0 & 3,7 & 4,2 & 5,5 & 6,8 \\
outros silicatos & 1,8 & 1,3 & 1,5 & 1,7 & 2,6 \\
espinelio-Cr & 1,3 & 1,0 & 1,2 & 1,3 & 1,8 \\
oxido-Fe & 0,5 & 0,3 & 0,3 & 0,6 & 0,8 \\
mica & 0,4 & 0,2 & 0,2 & 0,5 & 0,6 \\
carbonatos & 0,5 & 0,3 & 0,3 & 0,5 & 1,1 \\
outros & 0,1 & 0,1 & 0,1 & 0,1 & 0,2 \\
\hline Obs:outros sicatos & & & & & \\
\hline
\end{tabular}

Obs: outros silicatos = quartzo, feldspato potássico e plagioclásio; carbonatos = calcita, dolomita, magnesita e anquerita; outros = clorita, espinélio-Cr, óxido-Fe, ilmenita, apatita, coríndon 
APÊNDICE 6

Resultados MLA

Tabela 45 - Composição mineralógica por fração (\% em massa) - Ganga A

\begin{tabular}{l|c|cccc}
\hline Fração (mm) & Total & $\mathbf{+ 0 , 1 0 5}$ & $\mathbf{+ 0 , 1 0 5 - 0 , 0 5 3}$ & $\mathbf{- 0 , 0 5 3 + 0 , 0 2 0}$ & $\mathbf{- 0 , 0 2 0}$ \\
\hline \% massa & 100 & 13,8 & 24,1 & 21,9 & 40,2 \\
\hline pentlandita & 0,7 & 0,4 & 0,5 & 0,7 & 0,9 \\
pentl_oxid & 0,3 & 0,4 & 0,2 & 0,2 & 0,4 \\
calcopirita & 0,2 & 0,2 & 0,2 & 0,3 & 0,2 \\
calco-covelita & - & - & - & - & - \\
esfalerita & $<0,1$ & $<0,1$ & - & - & - \\
pirita & 0,6 & 0,5 & 0,3 & 0,5 & 0,9 \\
pirrotita & $<0,1$ & $<0,1$ & $<0,1$ & - & $<0,1$ \\
arsenopirita & $<0,1$ & - & - & - & $<0,1$ \\
sulf_FeCoNi & $<0,1$ & $<0,1$ & $<0,1$ & $<0,1$ & $<0,1$ \\
ortopiroxênio & 38,7 & 32,3 & 35,3 & 37,2 & 43,8 \\
clinopiroxênio & 0,7 & 0,4 & 0,8 & 1,0 & 0,6 \\
anfibólio & 1,8 & 1,2 & 1,5 & 2,3 & 2,0 \\
olivina & 2,6 & 2,2 & 2,4 & 2,1 & 3,1 \\
serpentina & 36,8 & 41,6 & 39,7 & 39,2 & 32,2 \\
outros silicatos & 3,4 & 4,0 & 4,0 & 3,2 & 3,0 \\
espinelio-Cr & 1,3 & 1,3 & 1,6 & 1,5 & 1,1 \\
oxido-Fe & 0,2 & $<0,1$ & 0,1 & 0,1 & 0,4 \\
mica & 6,9 & 10,7 & 8,0 & 6,5 & 5,1 \\
carbonatos & 4,9 & 3,9 & 4,4 & 4,2 & 5,9 \\
outros & 0,8 & 1,0 & 1,1 & 1,0 & 0,6 \\
\hline Obs:outros slicato & & & & & \\
\hline
\end{tabular}

Obs: outros silicatos = quartzo, feldspato potássico e plagioclásio; carbonatos = calcita, dolomita, magnesita e anquerita; outros = clorita, espinélio-Cr, óxido-Fe, ilmenita, apatita, coríndon. 
APÊNDICE 6

Resultados MLA

Tabela 46 - Composição mineralógica por fração (\% em massa) - Ganga B

\begin{tabular}{l|c|cccc}
\hline Fração $\mathbf{m m})$ & Total & $\mathbf{+ 0 , 1 0 5}$ & $\mathbf{+ 0 , 1 0 5 - 0 , 0 5 3}$ & $\mathbf{- 0 , 0 5 3 + 0 , 0 2 0}$ & $\mathbf{- 0 , 0 2 0}$ \\
\hline \% massa & 100 & 13,8 & 24,1 & 21,9 & 40,2 \\
\hline pentlandita & 0,7 & 0,6 & 0,7 & 0,9 & 0,7 \\
pentl_oxid & 0,6 & 0,7 & 0,5 & 0,7 & 0,7 \\
calcopirita & 0,2 & 0,2 & 0,2 & 0,2 & 0,3 \\
calco-covelita & $<0,1$ & $<0,1$ & $<0,1$ & - & - \\
esfalerita & $<0,1$ & $<0,1$ & $<0,1$ & - & - \\
pirita & 1,0 & 0,6 & 0,6 & 0,8 & 1,6 \\
pirrotita & $<0,1$ & $<0,1$ & $<0,1$ & $<0,1$ & $<0,1$ \\
arsenopirita & $<0,1$ & - & - & - & $<0,1$ \\
Sulf_FeCoNi & 0,1 & $<0,1$ & $<0,1$ & $<0,1$ & 0,2 \\
ortopiroxênio & 13,2 & 11,3 & 11,9 & 12,4 & 15,2 \\
clinopiroxênio & 1,0 & 1,1 & 1,1 & 1,0 & 0,9 \\
anfibólio & 1,6 & 0,9 & 1,1 & 2,0 & 2,0 \\
olivina & 3,1 & 3,8 & 4,4 & 2,9 & 2,2 \\
serpentina & 42,2 & 44,7 & 43,4 & 45,0 & 38,8 \\
outros silicatos & 8,2 & 12,1 & 10,4 & 8,1 & 5,3 \\
espinelio-Cr & 3,9 & 4,6 & 5,9 & 4,5 & 2,2 \\
oxido-Fe & 1,4 & 1,2 & 1,2 & 1,3 & 1,8 \\
mica & 0,1 & $<0,1$ & $<0,1$ & $<0,1$ & 0,1 \\
carbonatos & 22,2 & 17,8 & 18,2 & 19,7 & 27,7 \\
outros & 0,3 & 0,2 & 0,2 & 0,4 & 0,3 \\
\hline
\end{tabular}

Obs: outros silicatos = quartzo, feldspato potássico e plagioclásio; carbonatos = calcita, dolomita, magnesita e anquerita; outros = clorita, espinélio-Cr, óxido-Fe, ilmenita, apatita, coríndon 
APÊNDICE 6

Resultados MLA

Tabela 47 - Composição mineralógica por fração (\% em massa) - Ganga C

\begin{tabular}{l|ccccc}
\hline Fração $\mathbf{( m m})$ & Total & $\mathbf{+ 0 , 1 0 5}$ & $\mathbf{+ 0 , 1 0 5 - 0 , 0 5 3}$ & $\mathbf{- 0 , 0 5 3 + 0 , 0 2 0}$ & $\mathbf{- 0 , 0 2 0}$ \\
\hline \% massa & 100 & 16,2 & 33,2 & 25,4 & 25,2 \\
\hline pentlandita & 0,5 & 0,2 & 0,2 & 0,3 & 1,1 \\
pentI_oxid & 0,3 & 0,1 & 0,2 & 0,4 & 0,3 \\
calcopirita & 0,1 & $<0,1$ & $<0,1$ & 0,1 & 0,2 \\
calco-covelita & $<0,1$ & $<0,1$ & $<0,1$ & $<0,1$ & $<0,1$ \\
esfalerita & $<0,1$ & $<0,1$ & $<0,1$ & $<0,1$ & - \\
pirita & 0,3 & 0,3 & 0,1 & 0,3 & 0,4 \\
pirrotita & $<0,1$ & $<0,1$ & $<0,1$ & 0,0 & $<0,1$ \\
arsenopirita & $<0,1$ & $<0,1$ & - & - & - \\
Sulf_FeCoNi & $<0,1$ & $<0,1$ & $<0,1$ & $<0,1$ & $<0,1$ \\
ortopiroxênio & 27,2 & 25,1 & 25,4 & 27,1 & 31,3 \\
clinopiroxênio & 1,1 & 0,9 & 0,9 & 1,2 & 1,2 \\
anfibólio & 2,9 & 1,3 & 2,0 & 3,1 & 5,0 \\
olivina & 11,8 & 15,2 & 14,6 & 10,7 & 7,1 \\
serpentina & 24,2 & 19,6 & 22,8 & 26,7 & 26,4 \\
feldspatos & 19,8 & 23,8 & 22,8 & 19,1 & 14,1 \\
espinelio-Cr & 1,1 & 1,0 & 1,1 & 1,5 & 0,8 \\
oxido-Fe & 0,7 & 0,5 & 0,7 & 0,7 & 0,8 \\
mica & 8,3 & 10,6 & 7,7 & 7,2 & 8,8 \\
carbonatos & 1,5 & 1,2 & 1,2 & 1,4 & 2,3 \\
outros & 0,1 & $<0,1$ & 0,1 & 0,2 & $<0,1$ \\
\hline
\end{tabular}

Obs: carbonatos = calcita, dolomita, magnesita e anquerita; outros = clorita, espinélio-Cr, óxido-Fe, ilmenita, apatita, coríndon, quartzo. 
APÊNDICE 6

Resultados MLA

Tabela 48 - Composição mineralógica por fração (\% em massa) - Outlier

\begin{tabular}{l|c|cccc}
\hline Fração $(\mathbf{m m})$ & Total & $\mathbf{+ 0 , 1 0 5}$ & $\mathbf{+ 0 , 1 0 5 - 0 , 0 5 3}$ & $\mathbf{- 0 , 0 5 3 + 0 , 0 2 0}$ & $\mathbf{- 0 , 0 2 0}$ \\
\hline \% massa & 100 & 26,8 & 31,9 & 23,7 & 17,6 \\
\hline pentlandita & 1,2 & 0,2 & 0,3 & 1,8 & 3,5 \\
pentl_oxid & 0,2 & $<0,1$ & $<0,1$ & 0,4 & 0,4 \\
calcopirita & 0,3 & $<0,1$ & 0,1 & 0,3 & 1,1 \\
calco-covelita & $<0,1$ & $<0,1$ & $<0,1$ & - & 0,0 \\
esfalerita & - & - & - & - & - \\
pirita & 0,5 & 0,1 & 0,2 & 0,8 & 1,6 \\
pirrotita & 0,1 & $<0,1$ & $<0,1$ & 0,2 & 0,3 \\
arsenopirita & $<0,1$ & $<0,1$ & - & $<0,1$ & $<0,1$ \\
Sulf_FeCoNi & $<0,1$ & $<0,1$ & $<0,1$ & $<0,1$ & $<0,1$ \\
ortopiroxênio & 85,7 & 92,7 & 89,4 & 80,8 & 74,7 \\
clinopiroxênio & 7,2 & 4,8 & 6,5 & 9,4 & 9,0 \\
anfibólio & 0,6 & 0,2 & 0,3 & 0,7 & 1,9 \\
olivina & 0,1 & 0,2 & $<0,1$ & 0,1 & 0,1 \\
serpentina & 0,3 & 0,3 & 0,3 & 0,4 & 0,3 \\
outros silicatos & 2,6 & 0,9 & 2,1 & 3,6 & 4,5 \\
espinelio-Cr & 0,3 & 0,1 & 0,2 & 0,3 & 0,6 \\
oxido-Fe & 0,6 & 0,2 & 0,4 & 0,8 & 1,2 \\
mica & 0,2 & $<0,1$ & 0,1 & 0,3 & 0,7 \\
carbonatos & $<0,1$ & $<0,1$ & 0,1 & 0,1 & 0,2 \\
outros & $<0,1$ & $<0,1$ & $<0,1$ & 0,1 & 0,1 \\
\hline
\end{tabular}

Obs: outros silicatos = quartzo, feldspato potássico e plagioclásio; carbonatos = calcita, dolomita, magnesita e anquerita; outros = clorita, espinélio-Cr, óxido-Fe, ilmenita, apatita, coríndon.

\section{Características das associacões minerais}

\section{Pentlandita + Pentlandita Oxidada}

\section{OPS}

A Tabela 49 e a Figura 70 apresentam um sumário da distribuição das formas de associação da pentlandita + pentlandita oxidada (\% em massa), entre livre e misto em partículas binárias (2 fases) ou misto em partículas ternárias ( 3 ou mais fases minerais), para as frações granulométricas acima de $0,020 \mathrm{~mm}$ para a amostra OPS. 
APÊNDICE 6

Resultados MLA

Tabela 49 - Formas de associação da pentlandita + pentlandita oxidada - OPS

\begin{tabular}{|c|c|c|c|c|}
\hline Fração (mm) & Total $+0,020$ & $-0,15+0,105$ & $-0,105+0,053$ & $-0,053+0,020$ \\
\hline$\%$ massa & 70 & 20 & 29 & 22 \\
\hline Livres(\%) & 22 & 11 & 21 & 32 \\
\hline Mista em binárias (\%) & 40 & 34 & 45 & 37 \\
\hline Mista em ternárias (\%) & 38 & 54 & 34 & 31 \\
\hline \multicolumn{5}{|c|}{ Distribuição - binárias (\%) } \\
\hline calcopirita & 0,5 & 0,9 & 0,6 & 0,2 \\
\hline calco-covelita & $<0,1$ & $<0,1$ & $<0,1$ & $<0,1$ \\
\hline esfalerita & $<0,1$ & $<0,1$ & $<0,1$ & $<0,1$ \\
\hline pirita & 2,0 & 0,9 & 3,7 & 0,8 \\
\hline pirrotita & 0,1 & $<0,1$ & $<0,1$ & 0,3 \\
\hline arsenopirita & $<0,1$ & $<0,1$ & $<0,1$ & $<0,1$ \\
\hline FeNiCoS & 1,6 & 0,4 & 3,0 & 0,8 \\
\hline ortopiroxênio & 0,5 & 0,6 & 0,4 & 0,7 \\
\hline clinopiroxênio & 0,1 & $<0,1$ & $<0,1$ & 0,2 \\
\hline anfibólio & 0,6 & 0,4 & 0,6 & 0,6 \\
\hline olivina & 3,0 & 1,2 & 2,3 & 5,2 \\
\hline serpentina & 16 & 7,1 & 17 & 22 \\
\hline outros silicatos & $<0,1$ & $<0,1$ & $<0,1$ & $<0,1$ \\
\hline espinelio-Cr & 0,2 & 0,5 & 0,1 & $<0,1$ \\
\hline oxido-Fe & 12 & 21 & 13 & 4,5 \\
\hline mica & $<0,1$ & $<0,1$ & $<0,1$ & $<0,1$ \\
\hline calcita & 2,8 & 1,5 & 3,9 & 2,5 \\
\hline outros & $<0,1$ & $<0,1$ & $<0,1$ & $<0,1$ \\
\hline \multicolumn{5}{|c|}{ Distribuição - ternárias (\%) } \\
\hline calcopirita & 0,8 & 1,7 & 0,6 & 0,4 \\
\hline calco-covelita & $<0,1$ & $<0,1$ & $<0,1$ & $<0,1$ \\
\hline esfalerita & $<0,1$ & $<0,1$ & $<0,1$ & $<0,1$ \\
\hline pirita & 1,4 & 1,3 & 1,6 & 1,2 \\
\hline pirrotita & 0,4 & 0,8 & 0,6 & $<0,1$ \\
\hline arsenopirita & $<0,1$ & $<0,1$ & $<0,1$ & $<0,1$ \\
\hline FeNiCos & 1,1 & 0,4 & 1,3 & 1,5 \\
\hline ortopiroxênio & 0,9 & 1,3 & 0,3 & 1,2 \\
\hline clinopiroxênio & 0,2 & 0,3 & 0,2 & 0,3 \\
\hline anfibólio & 1,3 & 1,3 & 0,8 & 1,8 \\
\hline olivina & 3,8 & 3,3 & 3,2 & 5,0 \\
\hline serpentina & 13 & 18 & 12,1 & 11,1 \\
\hline outros silicatos & $<0,1$ & $<0,1$ & $<0,1$ & 0,1 \\
\hline espinelio-Cr & 1,3 & 3,0 & 1,0 & 0,4 \\
\hline oxido-Fe & 11 & 18 & 9,3 & 6,3 \\
\hline mica & $<0,1$ & 0,1 & $<0,1$ & $<0,1$ \\
\hline calcita & 2,7 & 4,0 & 3,0 & 1,4 \\
\hline outros & 0,1 & $<0,1$ & 0,1 & 0,1 \\
\hline
\end{tabular}

Obs: outros silicatos = quartzo, feldspato potássico e plagioclásio; carbonatos = calcita, dolomita, magnesita e anquerita; outros = clorita, espinélio-Cr, óxido-Fe, ilmenita, apatita, coríndon. 


\section{APÊNDICE 6}

Resultados MLA

Figura 70 - Distribuição das formas de associação da pentlandita + pentlandita oxidada na amostra OPS

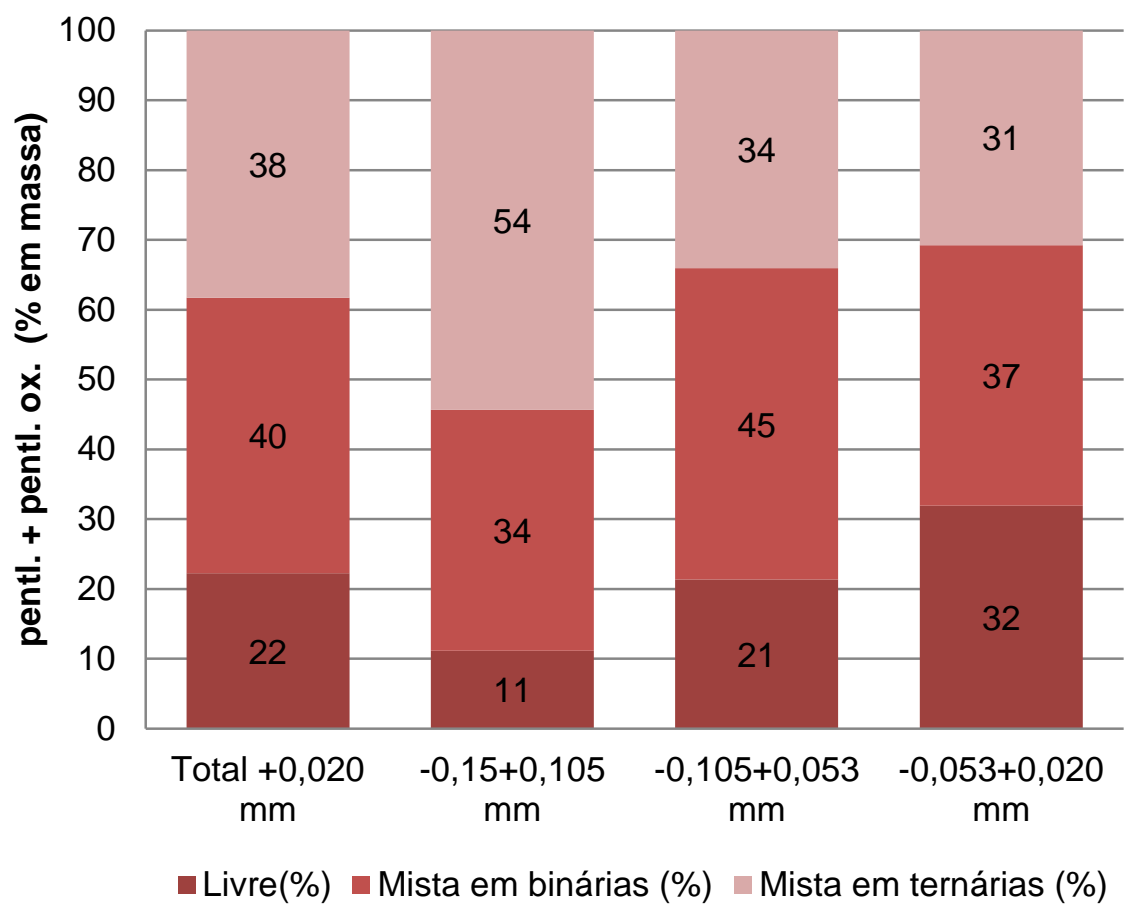

$\underline{\text { POS }}$

A Tabela 50 e a Figura 71 apresentam um sumário da distribuição das formas de associação da pentlandita + pentlandita oxidada (\% em massa), entre livre e misto em partículas binárias (2 fases) ou misto em partículas ternárias ( 3 ou mais fases minerais), para as frações granulométricas acima de $0,020 \mathrm{~mm}$ para a amostra de POS. 
APÊNDICE 6

Resultados MLA

Tabela 50 - Formas de associação da pentlandita + pentlandita oxidada - POS

\begin{tabular}{|c|c|c|c|c|}
\hline Fração (mm) & Total $+\mathbf{0 , 0 2 0}$ & $-0,15+0,105$ & $-0,105+0,053$ & $-0,053+0,020$ \\
\hline$\%$ massa & 77 & 20 & 32 & 25 \\
\hline Livres (\%) & 46 & 37 & 45 & 50 \\
\hline Mistas em binárias (\%) & 30 & 39 & 31 & 26 \\
\hline Mistas em ternárias (\%) & 24 & 25 & 24 & 24 \\
\hline \multicolumn{5}{|l|}{ Distribuição - binárias (\%) } \\
\hline calcopirita & 0,5 & 1,1 & $<0,1$ & 0,7 \\
\hline calco-covelita & $<0,1$ & $<0,1$ & $<0,1$ & $<0,1$ \\
\hline esfalerita & $<0,1$ & $<0,1$ & $<0,1$ & $<0,1$ \\
\hline pirita & 4,0 & 9,6 & 4,5 & 1,7 \\
\hline pirrotita & 0,4 & 1,2 & 0,3 & 0,3 \\
\hline arsenopirita & $<0,1$ & $<0,1$ & $<0,1$ & $<0,1$ \\
\hline FeNiCoS & 0,2 & $<0,1$ & $<0,1$ & 0,4 \\
\hline ortopiroxênio & 8,8 & 7,7 & 6,7 & 11 \\
\hline clinopiroxênio & 0,2 & 0,4 & 0,3 & 0,1 \\
\hline anfibólio & 0,5 & 0,5 & $<0,1$ & 0,8 \\
\hline olivina & 2,6 & 2,0 & 3,1 & 2,5 \\
\hline serpentina & 8,1 & 8,8 & 9,4 & 7,0 \\
\hline outros silicatos & $<0,1$ & $<0,1$ & $<0,1$ & $<0,1$ \\
\hline espinelio-Cr & 0,7 & 0,1 & 2,1 & $<0,1$ \\
\hline oxido-Fe & 2,4 & 2,3 & 4,3 & 1,3 \\
\hline mica & $<0,1$ & $<0,1$ & $<0,1$ & $<0,1$ \\
\hline calcita & 1,1 & 4,6 & $<0,1$ & 0,6 \\
\hline outros & $<0,1$ & $<0,1$ & $<0,1$ & $<0,1$ \\
\hline \multicolumn{5}{|l|}{ Distribuição - ternárias (\%) } \\
\hline calcopirita & 1,0 & 0,6 & 1,1 & 1,0 \\
\hline calco-covelita & $<0,1$ & $<0,1$ & $<0,1$ & $<0,1$ \\
\hline esfalerita & $<0,1$ & $<0,1$ & $<0,1$ & $<0,1$ \\
\hline pirita & 3,2 & 3,2 & 3,0 & 3,4 \\
\hline pirrotita & 1,4 & 2,0 & 2,7 & 0,3 \\
\hline arsenopirita & $<0,1$ & $<0,1$ & $<0,1$ & $<0,1$ \\
\hline FeNiCoS & 0,2 & 0,1 & 0,5 & 0,1 \\
\hline ortopiroxênio & 4,8 & 4,2 & 5,8 & 4,4 \\
\hline clinopiroxênio & 0,4 & 1,0 & 0,5 & 0,2 \\
\hline anfibólio & 2,0 & 1,6 & 1,2 & 2,6 \\
\hline olivina & 2,2 & 2,2 & 2,1 & 2,3 \\
\hline serpentina & 6,7 & 6,1 & 4,7 & 8,1 \\
\hline outros silicatos & 0,1 & 0,2 & $<0,1$ & $<0,1$ \\
\hline espinelio-Cr & $<0,1$ & 0,1 & $<0,1$ & $<0,1$ \\
\hline oxido-Fe & 1,0 & 1,1 & 0,6 & 1,1 \\
\hline mica & 0,1 & 0,2 & 0,1 & 0,1 \\
\hline calcita & 1,0 & 1,6 & 1,8 & 0,2 \\
\hline Outros & $<0,1$ & 0,2 & $<0,1$ & $<0,1$ \\
\hline
\end{tabular}

Obs: outros silicatos = quartzo, feldspato potássico e plagioclásio; carbonatos = calcita, dolomita, magnesita e anquerita; outros = clorita, espinélio-Cr, óxido-Fe, ilmenita, apatita, coríndon. 
APÊNDICE 6

Resultados MLA

Figura 71 - Distribuição das formas de associação da pentlandita + pentlandita oxidada na amostra POS

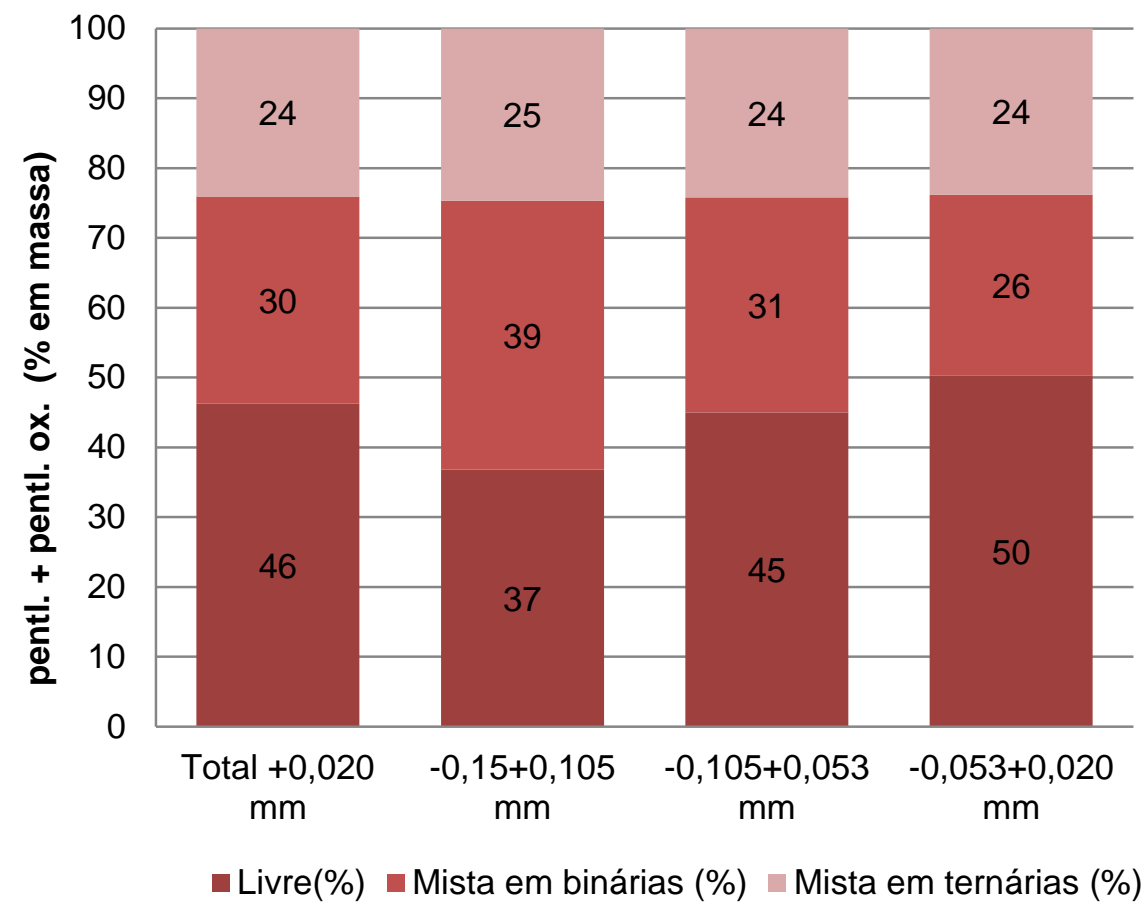

$\underline{\mathrm{PO}}$

A Tabela 51 e Figura 72 apresentam um sumário da distribuição das formas de associação da pentlandita + pentlandita oxidada (\% em massa), entre livre e misto em partículas binárias (2 fases) ou misto em partículas ternárias (3 ou mais fases minerais), para as frações granulométricas acima de $0,020 \mathrm{~mm}$ para a amostra de PO. 
APÊNDICE 6

Resultados MLA

Tabela 51 - Formas de associação da pentlandita + pentlandita oxidada - PO

\begin{tabular}{|c|c|c|c|c|}
\hline Fração (mm) & Total $+0,020$ & $-0,15+0,105$ & $-0,105+0,053$ & $-0,053+0,020$ \\
\hline$\%$ massa & 76 & 22 & 32 & 22 \\
\hline Livres (\%) & 43 & 23 & 35 & 58 \\
\hline Mistas em binárias (\%) & 41 & 49 & 50 & 30 \\
\hline Mistas em ternárias (\%) & 16 & 28 & 15 & 12 \\
\hline \multicolumn{5}{|l|}{ Distribuição - binárias (\%) } \\
\hline calcopirita & 0,4 & 2,6 & $<0,1$ & $<0,1$ \\
\hline calco-covelita & $<0,1$ & $<0,1$ & $<0,1$ & $<0,1$ \\
\hline esfalerita & $<0,1$ & $<0,1$ & $<0,1$ & $<0,1$ \\
\hline pirita & 12 & 11 & 18 & 6,0 \\
\hline pirrotita & 4,8 & 3,1 & 10,0 & 0,6 \\
\hline arsenopirita & $<0,1$ & $<0,1$ & $<0,1$ & $<0,1$ \\
\hline FeNiCoS & $<0,1$ & $<0,1$ & $<0,1$ & $<0,1$ \\
\hline ortopiroxênio & 14,3 & 18,2 & 15,2 & 12,0 \\
\hline clinopiroxênio & 0,8 & 0,3 & 0,1 & 1,8 \\
\hline anfibólio & 0,2 & 0,8 & 0,2 & 0,1 \\
\hline olivina & 1,7 & 0,2 & 0,4 & 3,4 \\
\hline serpentina & 3,2 & 6,0 & 2,5 & 2,7 \\
\hline outros silicatos & 0,7 & 0,4 & 1,5 & $<0,1$ \\
\hline espinelio-Cr & 0,1 & 0,3 & 0,1 & $<0,1$ \\
\hline oxido-Fe & 1,1 & 3,5 & $<0,1$ & 1,2 \\
\hline mica & $<0,1$ & $<0,1$ & $<0,1$ & $<0,1$ \\
\hline calcita & 2,3 & 2,6 & 2,2 & 2,3 \\
\hline outros & $<0,1$ & $<0,1$ & $<0,1$ & $<0,1$ \\
\hline \multicolumn{5}{|l|}{ Distribuição - ternárias (\%) } \\
\hline calcopirita & 0,2 & 0,3 & 0,3 & 0,1 \\
\hline calco-covelita & $<0,1$ & $<0,1$ & $<0,1$ & $<0,1$ \\
\hline esfalerita & $<0,1$ & $<0,1$ & $<0,1$ & $<0,1$ \\
\hline pirita & 2,4 & 7,7 & 1,4 & 1,4 \\
\hline pirrotita & 1,6 & 3,6 & 2,1 & 0,2 \\
\hline arsenopirita & $<0,1$ & $<0,1$ & $<0,1$ & $<0,1$ \\
\hline FeNiCoS & $<0,1$ & $<0,1$ & $<0,1$ & $<0,1$ \\
\hline ortopiroxênio & 5,2 & 9,8 & 4,2 & 4,4 \\
\hline clinopiroxênio & 0,6 & 1,5 & 0,6 & 0,3 \\
\hline anfibólio & 0,4 & 0,6 & 0,2 & 0,6 \\
\hline olivina & 1,4 & 0,8 & 1,4 & 1,7 \\
\hline serpentina & 1,5 & 2,4 & 1,5 & 1,3 \\
\hline outros silicatos & 0,5 & 0,6 & 0,6 & 0,3 \\
\hline espinelio-Cr & 0,1 & 0,2 & $<0,1$ & 0,1 \\
\hline oxido-Fe & 0,4 & 0,2 & 0,7 & 0,3 \\
\hline mica & 0,3 & 0,1 & $<0,1$ & 0,6 \\
\hline calcita & 1,1 & 0,3 & 2,3 & 0,2 \\
\hline outros & $<0,1$ & 0,2 & $<0,1$ & $<0,1$ \\
\hline
\end{tabular}

Obs: outros silicatos = quartzo, feldspato potássico e plagioclásio; carbonatos = calcita, dolomita, magnesita e anquerita; outros = clorita, espinélio-Cr, óxido-Fe, ilmenita, apatita, coríndon. 


\section{APÊNDICE 6}

Resultados MLA

Figura 72 - Distribuição das formas de associação da pentlandita + pentlandita oxidada na amostra PO

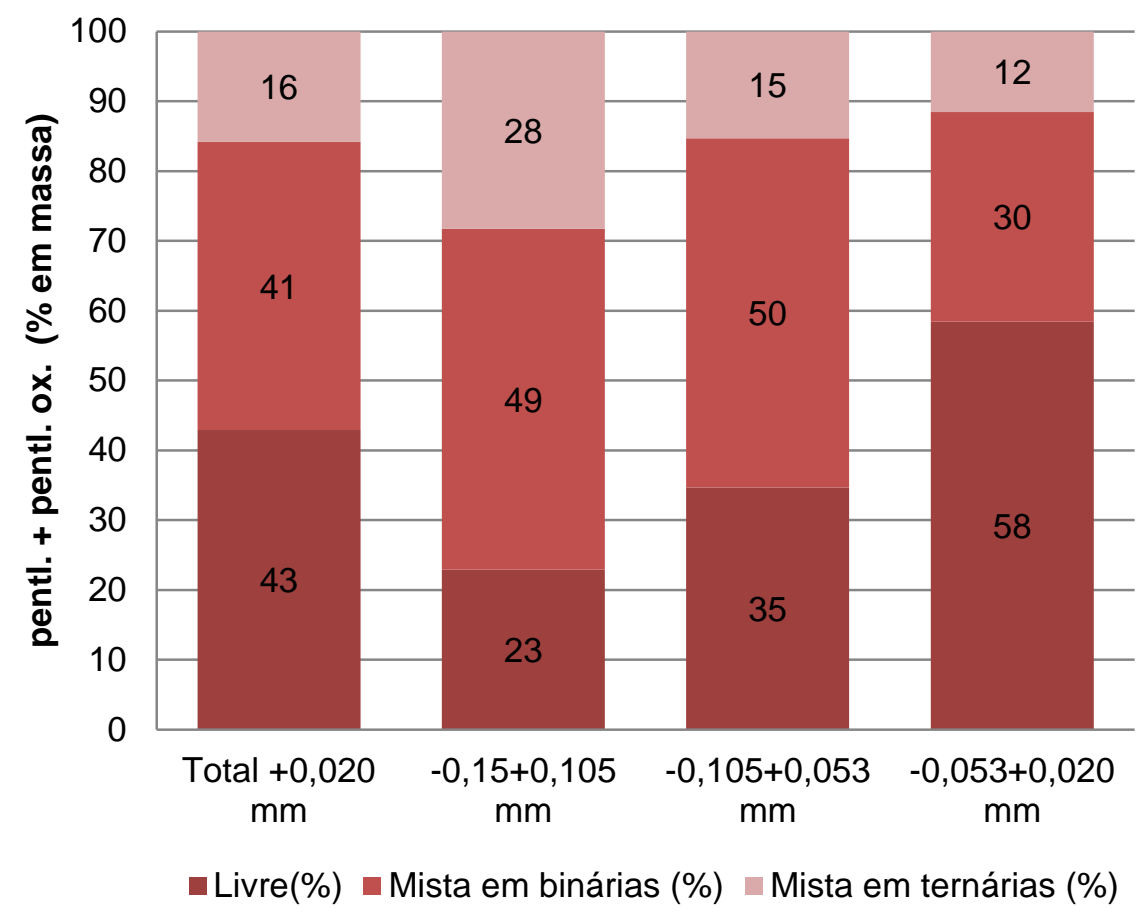

$\underline{P}$

A Tabela 52 e a Figura 73 apresentam um sumário da distribuição das formas de associação da pentlandita + pentlandita oxidada (\% em massa), entre livre e misto em partículas binárias (2 fases) ou misto em partículas ternárias ( 3 ou mais fases minerais), para as frações granulométricas acima de 0,020 $\mathrm{mm}$ para a amostra $\mathrm{P}$. 
APÊNDICE 6

Resultados MLA

Tabela 52 - Formas de associação da pentlandita + pentlandita oxidada - P

\begin{tabular}{|c|c|c|c|c|}
\hline Fração (mm) & Total $+\mathbf{0 , 0 2 0}$ & $-0,15+0,105$ & $-0,105+0,053$ & $-0,053+0,020$ \\
\hline$\%$ massa & 82 & 26 & 33 & 23 \\
\hline Livres(\%) & 48 & 37 & 63 & 44 \\
\hline Mistas em binárias (\%) & 30 & 32 & 19 & 35 \\
\hline Mistas em ternárias (\%) & 22 & 31 & 18 & 21 \\
\hline \multicolumn{5}{|l|}{ Distribuição - binárias (\%) } \\
\hline calcopirita & 0,1 & $<0,1$ & 0,4 & $<0,1$ \\
\hline calco-covelita & $<0,1$ & $<0,1$ & $<0,1$ & $<0,1$ \\
\hline esfalerita & $<0,1$ & $<0,1$ & $<0,1$ & $<0,1$ \\
\hline pirita & 4,1 & 8,2 & 3,4 & 3,4 \\
\hline pirrotita & 0,1 & $<0,1$ & $<0,1$ & 0,1 \\
\hline arsenopirita & $<0,1$ & $<0,1$ & $<0,1$ & $<0,1$ \\
\hline FeNiCoS & 0,1 & $<0,1$ & $<0,1$ & 0,1 \\
\hline ortopiroxênio & 18,1 & 13,2 & 7,2 & 23,9 \\
\hline clinopiroxênio & 1,4 & 0,9 & 3,6 & 0,5 \\
\hline anfibólio & 1,0 & 2,3 & 0,2 & 1,1 \\
\hline olivina & 2,7 & 0,1 & 0,2 & 4,4 \\
\hline serpentina & 1,5 & 6,9 & 0,6 & 0,7 \\
\hline outros silicatos & 0,1 & 0,6 & $<0,1$ & 0,1 \\
\hline espinelio-Cr & $<0,1$ & $<0,1$ & 0,1 & $<0,1$ \\
\hline oxido-Fe & 0,1 & $<0,1$ & $<0,1$ & 0,2 \\
\hline mica & $<0,1$ & $<0,1$ & $<0,1$ & $<0,1$ \\
\hline calcita & 0,9 & $<0,1$ & 3,3 & $<0,1$ \\
\hline outros & $<0,1$ & $<0,1$ & $<0,1$ & $<0,1$ \\
\hline \multicolumn{5}{|l|}{ Distribuição - ternárias (\%) } \\
\hline calcopirita & 0,2 & 0,3 & 0,2 & 0,2 \\
\hline calco-covelita & $<0,1$ & $<0,1$ & $<0,1$ & $<0,1$ \\
\hline esfalerita & $<0,1$ & $<0,1$ & $<0,1$ & $<0,1$ \\
\hline pirita & 2,7 & 7,1 & 3,3 & 1,4 \\
\hline pirrotita & 0,7 & 0,3 & 0,5 & 0,8 \\
\hline arsenopirita & $<0,1$ & $<0,1$ & $<0,1$ & $<0,1$ \\
\hline FeNiCoS & $<0,1$ & $<0,1$ & $<0,1$ & $<0,1$ \\
\hline ortopiroxênio & 7,6 & 6,3 & 6,0 & 8,6 \\
\hline clinopiroxênio & 2,0 & 1,3 & 3,1 & 1,7 \\
\hline anfibólio & 0,3 & 0,9 & 0,3 & 0,2 \\
\hline olivina & 1,9 & 1,3 & 0,4 & 2,6 \\
\hline serpentina & 1,8 & 7,0 & 1,2 & 0,9 \\
\hline outros silicatos & 0,8 & $<0,1$ & $<0,1$ & 1,3 \\
\hline espinelio-Cr & 0,4 & 2,6 & 0,1 & 0,1 \\
\hline oxido-Fe & 1,5 & 2,8 & 0,1 & 1,7 \\
\hline mica & $<0,1$ & 0,1 & $<0,1$ & $<0,1$ \\
\hline calcita & 1,8 & 0,9 & 2,3 & 1,8 \\
\hline outros & $<0,1$ & $<0,1$ & $<0,1$ & $<0,1$ \\
\hline
\end{tabular}

Obs: outros silicatos = quartzo, feldspato potássico e plagioclásio; carbonatos = calcita, dolomita, magnesita e anquerita; outros = clorita, espinélio-Cr, óxido-Fe, ilmenita, apatita, coríndon. 


\section{APÊNDICE 6}

Resultados MLA

Figura 73 - Distribuição das formas de associação da pentlandita + pentlandita oxidada na amostra $\mathbf{P}$

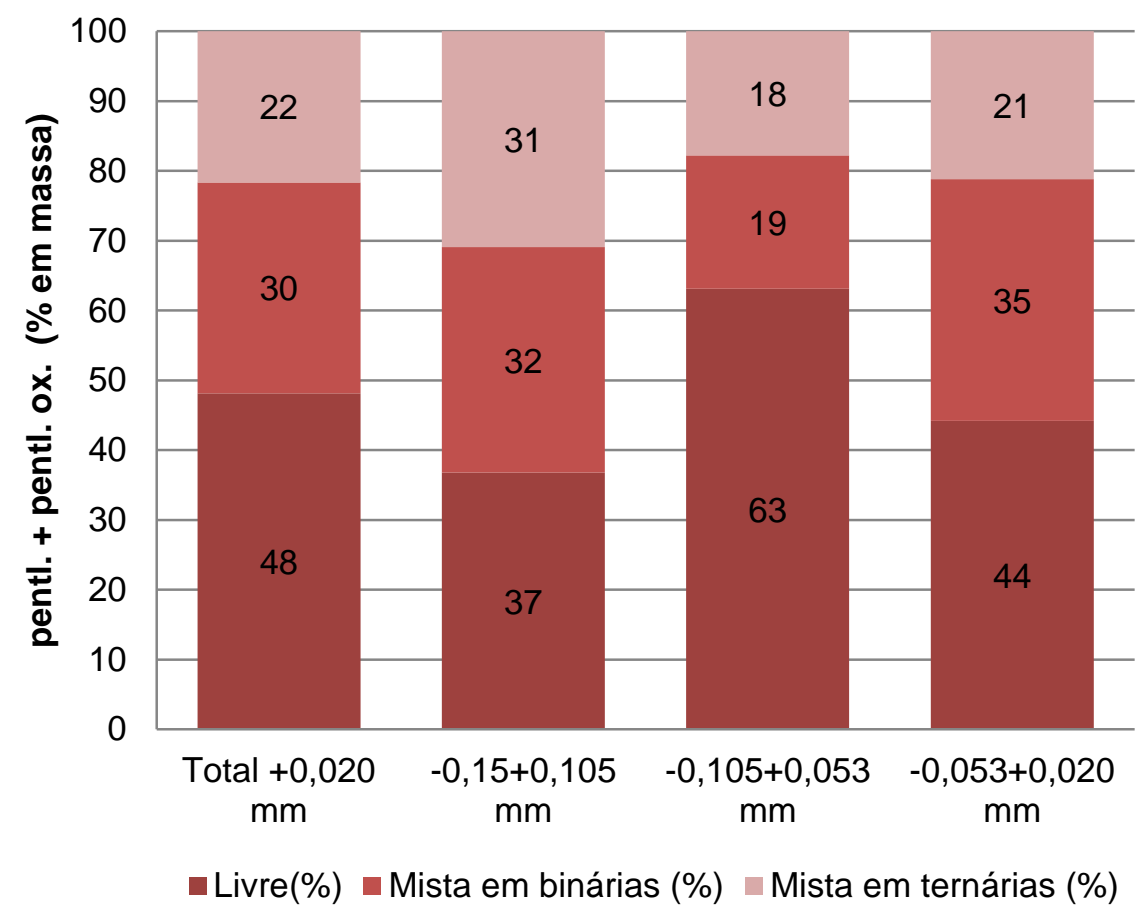

\section{Ganga A}

A Tabela 53 e a Figura 74 apresentam um sumário da distribuição das formas de associação da pentlandita + pentlandita oxidada (\% em massa), entre livre e misto em partículas binárias ( 2 fases) ou misto em partículas ternárias ( 3 ou mais fases minerais), para as frações granulométricas acima de $0,020 \mathrm{~mm}$ para a amostra de Ganga A. 
APÊNDICE 6

Resultados MLA

Tabela 53 - Formas de associação da pentlandita + pentlandita oxidada - Ganga A

\begin{tabular}{|c|c|c|c|c|}
\hline Fração (mm) & Total $+\mathbf{0 , 0 2 0}$ & $-0,15+0,105$ & $-0,105+0,053$ & $-0,053+0,020$ \\
\hline$\%$ massa & 60 & 14 & 24 & 22 \\
\hline Livres(\%) & 19 & 15 & 13 & 24 \\
\hline Mistas em binárias (\%) & 28 & 24 & 26 & 32 \\
\hline Mistas em ternárias (\%) & 53 & 61 & 61 & 43 \\
\hline \multicolumn{5}{|l|}{ Distribuição - binárias (\%) } \\
\hline calcopirita & 0,2 & $<0,1$ & 0,3 & 0,2 \\
\hline calco-covelita & $<0,1$ & $<0,1$ & $<0,1$ & $<0,1$ \\
\hline esfalerita & $<0,1$ & $<0,1$ & $<0,1$ & $<0,1$ \\
\hline pirita & 0,3 & 0,3 & $<0,1$ & 0,6 \\
\hline pirrotita & $<0,1$ & $<0,1$ & $<0,1$ & $<0,1$ \\
\hline arsenopirita & $<0,1$ & $<0,1$ & $<0,1$ & $<0,1$ \\
\hline FeNiCoS & $<0,1$ & $<0,1$ & $<0,1$ & $<0,1$ \\
\hline ortopiroxênio & 3,8 & 5,5 & 4,2 & 2,5 \\
\hline clinopiroxênio & $<0,1$ & $<0,1$ & $<0,1$ & 0,1 \\
\hline anfibólio & 0,8 & 3,3 & $<0,1$ & $<0,1$ \\
\hline olivina & $<0,1$ & $<0,1$ & $<0,1$ & $<0,1$ \\
\hline serpentina & 19,7 & 11,2 & 16,2 & 26,8 \\
\hline outros silicatos & $<0,1$ & $<0,1$ & $<0,1$ & $<0,1$ \\
\hline espinelio-Cr & 0,5 & $<0,1$ & $<0,1$ & 1,0 \\
\hline oxido-Fe & 1,1 & $<0,1$ & 3,1 & $<0,1$ \\
\hline mica & $<0,1$ & $<0,1$ & $<0,1$ & $<0,1$ \\
\hline calcita & 1,9 & 3,3 & 1,9 & 1,1 \\
\hline outros & $<0,1$ & $<0,1$ & $<0,1$ & $<0,1$ \\
\hline \multicolumn{5}{|l|}{ Distribuição - ternárias (\%) } \\
\hline calcopirita & 1,9 & 5,0 & 1,4 & 0,6 \\
\hline calco-covelita & $<0,1$ & $<0,1$ & $<0,1$ & $<0,1$ \\
\hline esfalerita & $<0,1$ & $<0,1$ & $<0,1$ & $<0,1$ \\
\hline pirita & 7,4 & 6,0 & 13,0 & 3,9 \\
\hline pirrotita & 0,3 & 1,4 & $<0,1$ & $<0,1$ \\
\hline arsenopirita & $<0,1$ & $<0,1$ & $<0,1$ & $<0,1$ \\
\hline FeNiCoS & 1,5 & 0,5 & 3,4 & 0,5 \\
\hline ortopiroxênio & 5,9 & 11,0 & 5,4 & 3,8 \\
\hline clinopiroxênio & $<0,1$ & 0,2 & $<0,1$ & $<0,1$ \\
\hline anfibólio & 2,2 & 0,5 & 0,8 & 4,3 \\
\hline olivina & 0,1 & 0,2 & 0,1 & 0,1 \\
\hline serpentina & 19,2 & 20,2 & 20,8 & 17,4 \\
\hline outros silicatos & 0,4 & $<0,1$ & $<0,1$ & 0,8 \\
\hline espinelio-Cr & 1,0 & 0,1 & 0,9 & 1,5 \\
\hline oxido-Fe & 1,3 & 2,6 & 0,6 & 1,1 \\
\hline mica & 1,5 & 0,2 & 2,3 & 1,6 \\
\hline calcita & 10,5 & 13,4 & 12,6 & 7,5 \\
\hline outros & $<0,1$ & $<0,1$ & $<0,1$ & 0,1 \\
\hline
\end{tabular}

Obs: outros silicatos = quartzo, feldspato potássico e plagioclásio; carbonatos = calcita, dolomita, magnesita e anquerita; outros = clorita, espinélio-Cr, óxido-Fe, ilmenita, apatita, coríndon. 
APÊNDICE 6

Resultados MLA

Figura 74 - Distribuição das formas de associação da pentlandita + pentlandita oxidada na amostra Ganga $A$

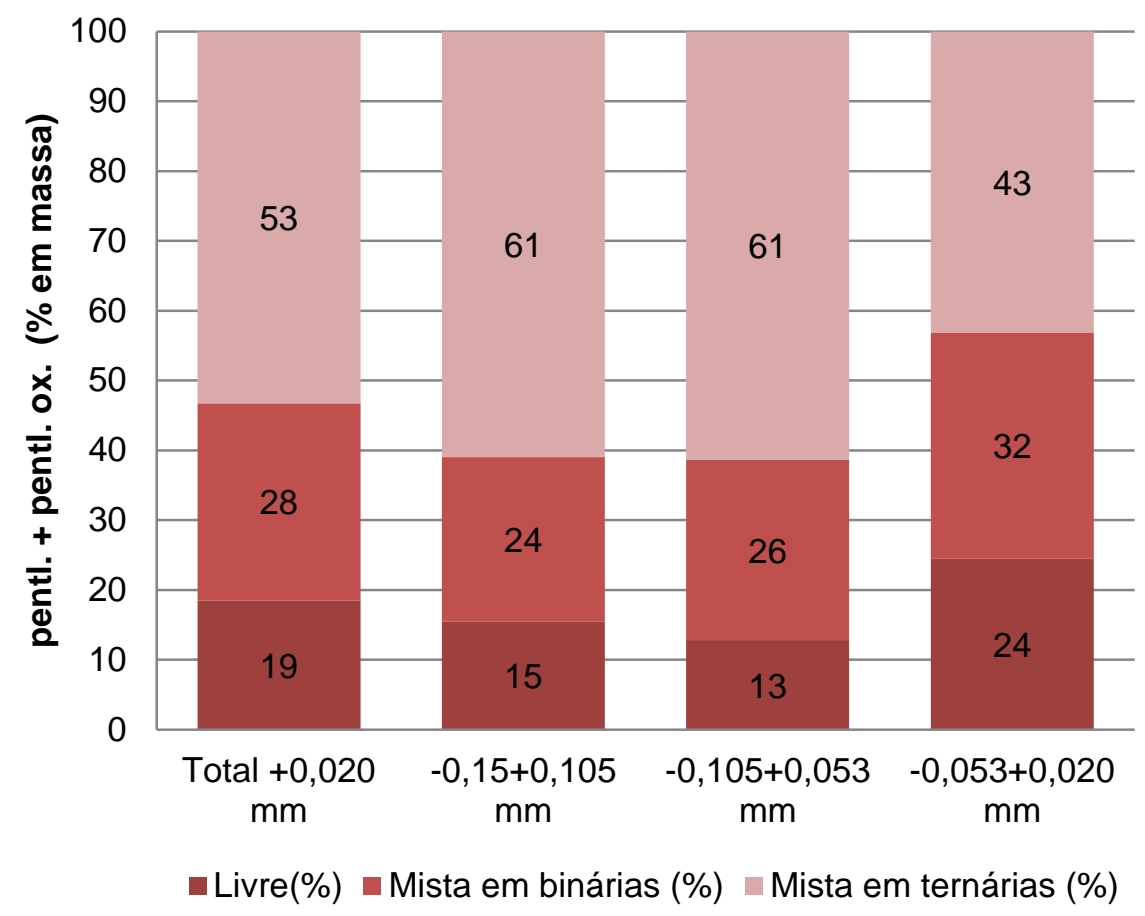

\section{Ganga B}

A Tabela 54 e a Figura 75 apresentam um sumário da distribuição das formas de associação da pentlandita + pentlandita oxidada (\% em massa), entre livre e misto em partículas binárias ( 2 fases) ou misto em partículas ternárias ( 3 ou mais fases minerais), para as frações granulométricas acima de $0,020 \mathrm{~mm}$ para a amostra de Ganga B. 
APÊNDICE 6

Resultados MLA

Tabela 54 - Formas de associação da pentlandita + pentlandita oxidada - Ganga B

\begin{tabular}{|c|c|c|c|c|}
\hline Fração (mm) & Total $+\mathbf{0 , 0 2 0}$ & $-0,15+0,105$ & $-0,105+0,053$ & $-0,053+0,020$ \\
\hline$\%$ massa & 61 & 16 & 23 & 22 \\
\hline Livres(\%) & 16 & 12 & 6 & 27 \\
\hline Mistas em binárias (\%) & 38 & 27 & 48 & 38 \\
\hline Mistas em ternárias (\%) & 46 & 61 & 46 & 36 \\
\hline \multicolumn{5}{|l|}{ Distribuição - binárias (\%) } \\
\hline calcopirita & 0,6 & 1,2 & 0,9 & $<0,1$ \\
\hline calco-covelita & $<0,1$ & $<0,1$ & $<0,1$ & $<0,1$ \\
\hline esfalerita & $<0,1$ & $<0,1$ & $<0,1$ & $<0,1$ \\
\hline pirita & 0,7 & 1,4 & 1,2 & 0,1 \\
\hline pirrotita & $<0,1$ & $<0,1$ & $<0,1$ & $<0,1$ \\
\hline arsenopirita & $<0,1$ & $<0,1$ & $<0,1$ & $<0,1$ \\
\hline FeNiCos & 1,7 & 0,7 & 1,3 & 2,5 \\
\hline ortopiroxênio & 2,0 & 0,5 & 1,8 & 3,0 \\
\hline clinopiroxênio & $<0,1$ & $<0,1$ & 0,1 & $<0,1$ \\
\hline anfibólio & $<0,1$ & $<0,1$ & $<0,1$ & $<0,1$ \\
\hline olivina & $<0,1$ & 0,1 & $<0,1$ & $<0,1$ \\
\hline serpentina & 11,0 & 6,8 & 9,5 & 14,6 \\
\hline outros silicatos & 1,5 & 2,7 & 1,6 & 0,8 \\
\hline espinelio-Cr & 0,1 & 0,1 & 0,1 & $<0,1$ \\
\hline oxido-Fe & 10,2 & 2,2 & 21,5 & 6,0 \\
\hline mica & $<0,1$ & $<0,1$ & $<0,1$ & $<0,1$ \\
\hline calcita & 10,4 & 11,0 & 9,8 & 10,5 \\
\hline outros & $<0,1$ & $<0,1$ & $<0,1$ & $<0,1$ \\
\hline \multicolumn{5}{|l|}{ Distribuição - ternárias (\%) } \\
\hline calcopirita & 1,5 & 2,1 & 1,3 & 1,2 \\
\hline calco-covelita & $<0,1$ & $<0,1$ & $<0,1$ & $<0,1$ \\
\hline esfalerita & $<0,1$ & $<0,1$ & $<0,1$ & $<0,1$ \\
\hline pirita & 2,4 & 2,3 & 1,7 & 3,0 \\
\hline pirrotita & $<0,1$ & $<0,1$ & $<0,1$ & $<0,1$ \\
\hline arsenopirita & $<0,1$ & $<0,1$ & $<0,1$ & $<0,1$ \\
\hline FeNiCoS & 2,1 & 2,5 & 2,8 & 1,3 \\
\hline ortopiroxênio & 2,2 & 2,5 & 3,2 & 1,3 \\
\hline clinopiroxênio & 0,2 & 0,2 & 0,1 & 0,3 \\
\hline anfibólio & 0,9 & 0,8 & 1,3 & 0,7 \\
\hline olivina & 0,7 & 1,1 & 0,9 & 0,2 \\
\hline serpentina & 12,7 & 16,1 & 11,6 & 11,6 \\
\hline outros silicatos & 0,7 & 0,2 & 0,6 & 1,1 \\
\hline espinelio-Cr & 1,3 & 2,1 & 2,0 & 0,2 \\
\hline oxido-Fe & 8,8 & 15,1 & 10,2 & 4,1 \\
\hline mica & $<0,1$ & $<0,1$ & $<0,1$ & $<0,1$ \\
\hline calcita & 11,9 & 16,3 & 10,4 & 10,5 \\
\hline outros & 0,1 & $<0,1$ & $<0,1$ & 0,2 \\
\hline
\end{tabular}

Obs: outros silicatos = quartzo, feldspato potássico e plagioclásio; carbonatos = calcita, dolomita, magnesita e anquerita; outros = clorita, espinélio-Cr, óxido-Fe, ilmenita, apatita, coríndon. 
APÊNDICE 6

Resultados MLA

Figura 75 - Distribuição das formas de associação da pentlandita + pentlandita oxidada na amostra Ganga B

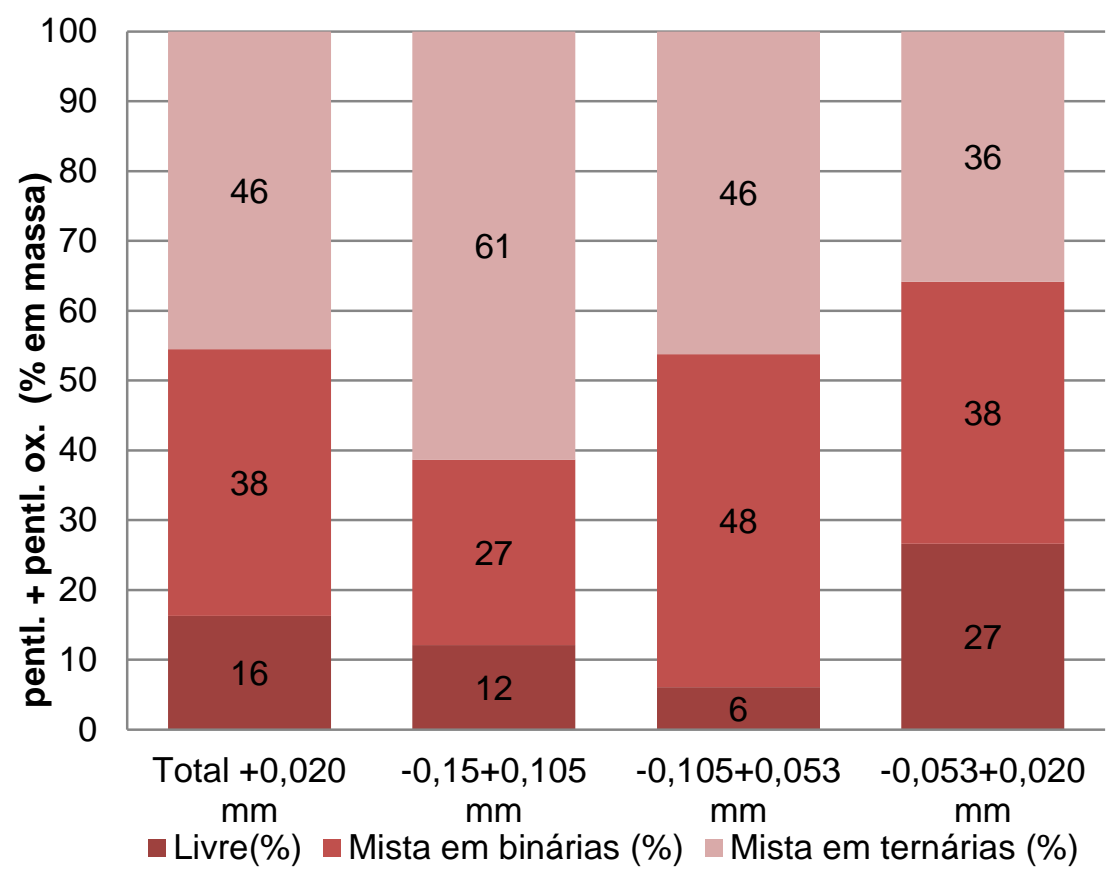

\section{Ganga C}

A Tabela 55 e a Figura 76 apresentam um sumário da distribuição das formas de associação da pentlandita + pentlandita oxidada (\% em massa), entre livre e misto em partículas binárias (2 fases) ou misto em partículas ternárias ( 3 ou mais fases minerais), para as frações granulométricas acima de $0,020 \mathrm{~mm}$ para a amostra de Ganga C. 
APÊNDICE 6

Resultados MLA

Tabela 55 - Formas de associação da pentlandita + pentlandita oxidada - Ganga C

\begin{tabular}{|c|c|c|c|c|}
\hline Fração (mm) & Total $+\mathbf{0 , 0 2 0}$ & $-0,15+0,105$ & $-0,105+0,053$ & $-0,053+0,020$ \\
\hline$\%$ massa & 75 & 16 & 33 & 25 \\
\hline Livres(\%) & 28 & 0 & 22 & 42 \\
\hline Mistas em binárias (\%) & 36 & 36 & 36 & 36 \\
\hline Mistas em ternárias (\%) & 36 & 64 & 43 & 23 \\
\hline \multicolumn{5}{|l|}{ Distribuição - binárias (\%) } \\
\hline calcopirita & 2,3 & $<0,1$ & $<0,1$ & 4,7 \\
\hline calco-covelita & $<0,1$ & $<0,1$ & $<0,1$ & $<0,1$ \\
\hline esfalerita & $<0,1$ & $<0,1$ & $<0,1$ & $<0,1$ \\
\hline pirita & 1,1 & 0,3 & 2,8 & $<0,1$ \\
\hline pirrotita & $<0,1$ & 0,1 & $<0,1$ & $<0,1$ \\
\hline arsenopirita & $<0,1$ & $<0,1$ & $<0,1$ & $<0,1$ \\
\hline FeNiCos & 0,6 & $<0,1$ & $<0,1$ & 1,3 \\
\hline ortopiroxênio & 2,2 & 3,3 & 3,1 & 1,2 \\
\hline clinopiroxênio & 1,4 & $<0,1$ & $<0,1$ & 2,8 \\
\hline anfibólio & 0,1 & $<0,1$ & $<0,1$ & 0,3 \\
\hline olivina & $<0,1$ & $<0,1$ & $<0,1$ & $<0,1$ \\
\hline serpentina & 17,9 & 15,4 & 21,5 & 15,9 \\
\hline outros silicatos & 1,6 & 1,1 & 0,4 & 2,7 \\
\hline espinelio-Cr & $<0,1$ & $<0,1$ & $<0,1$ & $<0,1$ \\
\hline oxido-Fe & $<0,1$ & $<0,1$ & $<0,1$ & $<0,1$ \\
\hline mica & 1,1 & $<0,1$ & $<0,1$ & 2,3 \\
\hline calcita & 7,2 & 15,6 & 7,9 & 4,2 \\
\hline outros & $<0,1$ & $<0,1$ & $<0,1$ & $<0,1$ \\
\hline \multicolumn{5}{|c|}{ Distribuição - ternárias (\%) } \\
\hline calcopirita & 0,7 & 2,5 & 0,8 & $<0,1$ \\
\hline calco-covelita & $<0,1$ & $<0,1$ & $<0,1$ & $<0,1$ \\
\hline esfalerita & $<0,1$ & $<0,1$ & $<0,1$ & $<0,1$ \\
\hline pirita & 3,4 & 2,5 & 2,3 & 4,5 \\
\hline pirrotita & 0,7 & 0,1 & 1,8 & $<0,1$ \\
\hline arsenopirita & $<0,1$ & $<0,1$ & $<0,1$ & $<0,1$ \\
\hline FeNiCoS & 0,6 & 0,4 & $<0,1$ & 1,2 \\
\hline ortopiroxênio & 4,7 & 8,3 & 6,9 & 1,9 \\
\hline clinopiroxênio & 0,2 & 1,3 & 0,1 & $<0,1$ \\
\hline anfibólio & 1,6 & 1,0 & 2,9 & 0,7 \\
\hline olivina & 0,9 & 0,9 & 0,4 & 1,3 \\
\hline serpentina & 9,4 & 23,0 & 12,1 & 3,3 \\
\hline outros silicatos & 0,6 & 0,3 & 1,1 & 0,4 \\
\hline espinelio-Cr & 2,7 & 0,2 & 1,6 & 4,3 \\
\hline oxido-Fe & 4,0 & 4,1 & 4,5 & 3,6 \\
\hline mica & 0,4 & 1,2 & 0,5 & 0,1 \\
\hline calcita & 5,8 & 18,3 & 6,5 & 1,6 \\
\hline outros & 0,4 & $<0,1$ & 1,0 & $<0,1$ \\
\hline
\end{tabular}

Obs: outros silicatos = quartzo, feldspato potássico e plagioclásio; carbonatos = calcita, dolomita, magnesita e anquerita; outros = clorita, espinélio-Cr, óxido-Fe, ilmenita, apatita, coríndon. 
APÊNDICE 6

Resultados MLA

Figura 76 - Distribuição das formas de associação da pentlandita + pentlandita oxidada na amostra Ganga C

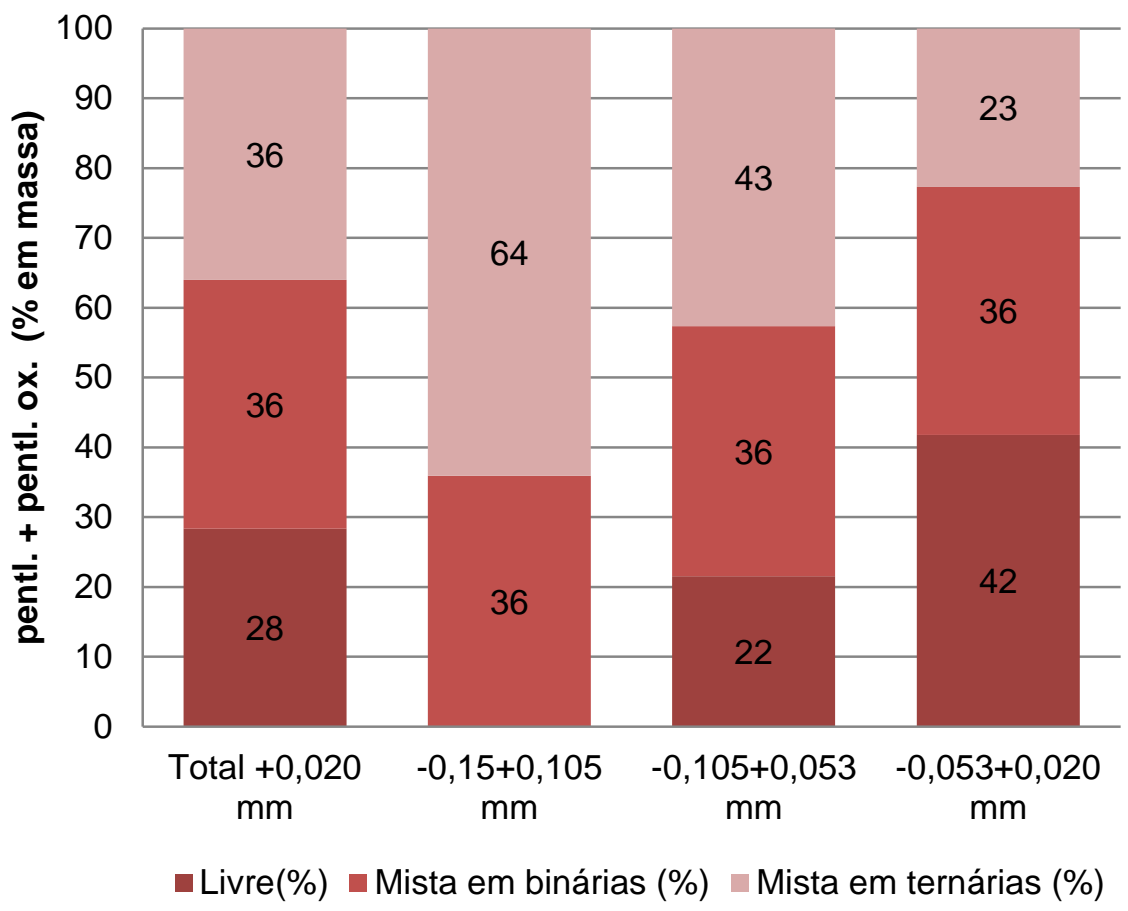

Outlier

A Tabela 56 e a Figura 77 apresentam um sumário da distribuição das formas de associação da pentlandita + pentlandita oxidada (\% em massa), entre livre e misto em partículas binárias ( 2 fases) ou misto em partículas ternárias ( 3 ou mais fases minerais), para as frações granulométricas acima de $0,020 \mathrm{~mm}$ para a amostra de Outlier. 
APÊNDICE 6

Resultados MLA

Tabela 56 - Formas de associação da pentlandita + pentlandita oxidada - Outlier

\begin{tabular}{|c|c|c|c|c|}
\hline Fração (mm) & Total $+\mathbf{0 , 0 2 0}$ & $-0,15+0,105$ & $-0,105+0,053$ & $-0,053+0,020$ \\
\hline$\%$ massa & 82 & 27 & 32 & 24 \\
\hline Livres(\%) & 46 & 35 & 32 & 50 \\
\hline Mistas em binárias (\%) & 42 & 54 & 50 & 39 \\
\hline Mistas em ternárias (\%) & 12 & 11 & 18 & 11 \\
\hline \multicolumn{5}{|l|}{ Distribuição - binárias (\%) } \\
\hline calcopirita & 0,6 & 0,0 & 0,0 & 0,8 \\
\hline calco-covelita & 0,0 & 0,0 & 0,0 & 0,0 \\
\hline esfalerita & 0,0 & 0,0 & 0,0 & 0,0 \\
\hline pirita & 10,4 & 32,1 & 22,5 & 5,3 \\
\hline pirrotita & 0,3 & 0,0 & 0,9 & 0,2 \\
\hline arsenopirita & 0,0 & 0,0 & 0,0 & 0,0 \\
\hline FeNiCoS & 0,0 & 0,0 & 0,0 & 0,0 \\
\hline ortopiroxênio & 25,2 & 19,8 & 18,0 & 27,2 \\
\hline clinopiroxênio & 3,4 & 1,4 & 1,0 & 4,1 \\
\hline anfibólio & 0,1 & 0,0 & 0,1 & 0,1 \\
\hline olivina & 0,0 & 0,0 & 0,0 & 0,0 \\
\hline serpentina & 0,0 & 0,1 & 0,2 & 0,0 \\
\hline outros silicatos & 0,6 & 0,0 & 0,0 & 0,8 \\
\hline espinelio-Cr & 0,2 & 0,5 & 0,0 & 0,1 \\
\hline oxido-Fe & 1,2 & 0,0 & 7,8 & 0,2 \\
\hline mica & 0,0 & 0,0 & 0,0 & 0,0 \\
\hline calcita & 0,0 & 0,0 & 0,0 & 0,0 \\
\hline outros & 0,0 & 0,0 & 0,0 & 0,0 \\
\hline \multicolumn{5}{|l|}{ Distribuição - ternárias (\%) } \\
\hline calcopirita & 0,4 & 0,4 & 0,1 & 0,4 \\
\hline calco-covelita & 0,0 & 0,0 & 0,0 & 0,0 \\
\hline esfalerita & 0,0 & 0,0 & 0,0 & 0,0 \\
\hline pirita & 2,0 & 0,3 & 2,3 & 2,2 \\
\hline pirrotita & 0,3 & 0,6 & 0,5 & 0,2 \\
\hline arsenopirita & 0,0 & 0,0 & 0,0 & 0,0 \\
\hline FeNiCoS & 0,1 & 0,5 & 0,0 & 0,0 \\
\hline ortopiroxênio & 6,1 & 6,7 & 11,3 & 5,1 \\
\hline clinopiroxênio & 0,7 & 1,1 & 1,6 & 0,5 \\
\hline anfibólio & 1,3 & 0,0 & 0,2 & 1,7 \\
\hline olivina & 0,0 & 0,0 & 0,0 & 0,0 \\
\hline serpentina & 0,2 & 1,1 & 0,2 & 0,0 \\
\hline outros silicatos & 0,6 & 0,1 & 0,6 & 0,7 \\
\hline espinelio-Cr & 0,1 & 0,0 & 0,0 & 0,1 \\
\hline oxido-Fe & 0,7 & 0,4 & 0,9 & 0,7 \\
\hline mica & 0,0 & 0,0 & 0,1 & 0,0 \\
\hline calcita & 0,0 & 0,0 & 0,0 & 0,0 \\
\hline outros & 0,0 & 0,0 & 0,0 & 0,0 \\
\hline
\end{tabular}

Obs: outros silicatos = quartzo, feldspato potássico e plagioclásio; carbonatos = calcita, dolomita, magnesita e anquerita; outros = clorita, espinélio-Cr, óxido-Fe, ilmenita, apatita, coríndon. 
APÊNDICE 6

Resultados MLA

Figura 77 - Distribuição das formas de associação da pentlandita + pentlandita oxidada na amostra Outlier

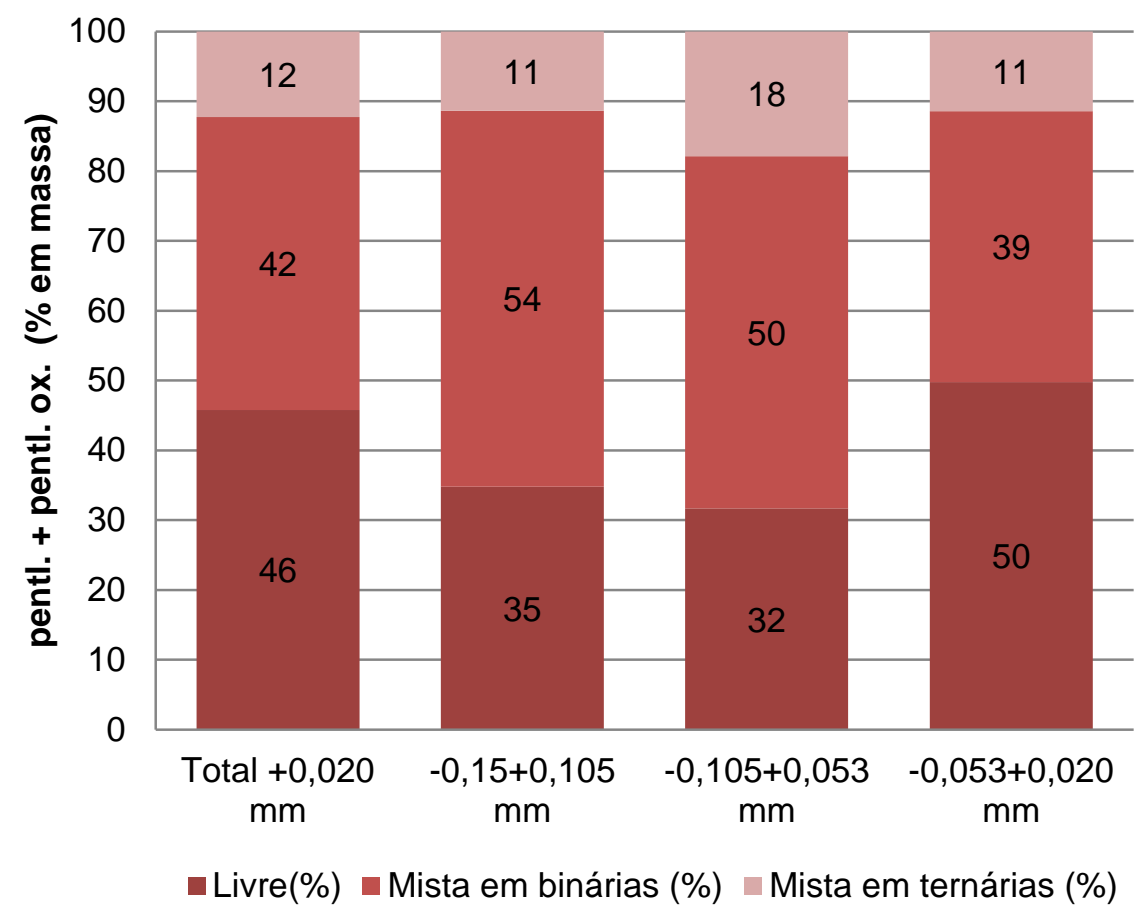

Através do processamento das imagens digitais (MLA) é possível determinar a distribuição do mineral de interesse segundo a sua fração em área (em relação à área total das partículas) ou em perímetro exposto (parcela do mineral exposta no perímetro das partículas). As curvas de espectro de liberação da pentlandita + pentlandita oxidada são apresentadas da Figura 78 a Figura 85, para frações em área e em perímetro exposto, de acordo com suas respectivas faixas granulométricas 
APÊNDICE 6

Resultados MLA

Figura 78 - Espectro de liberação da pentlandita + pentlandita oxidada - OPS
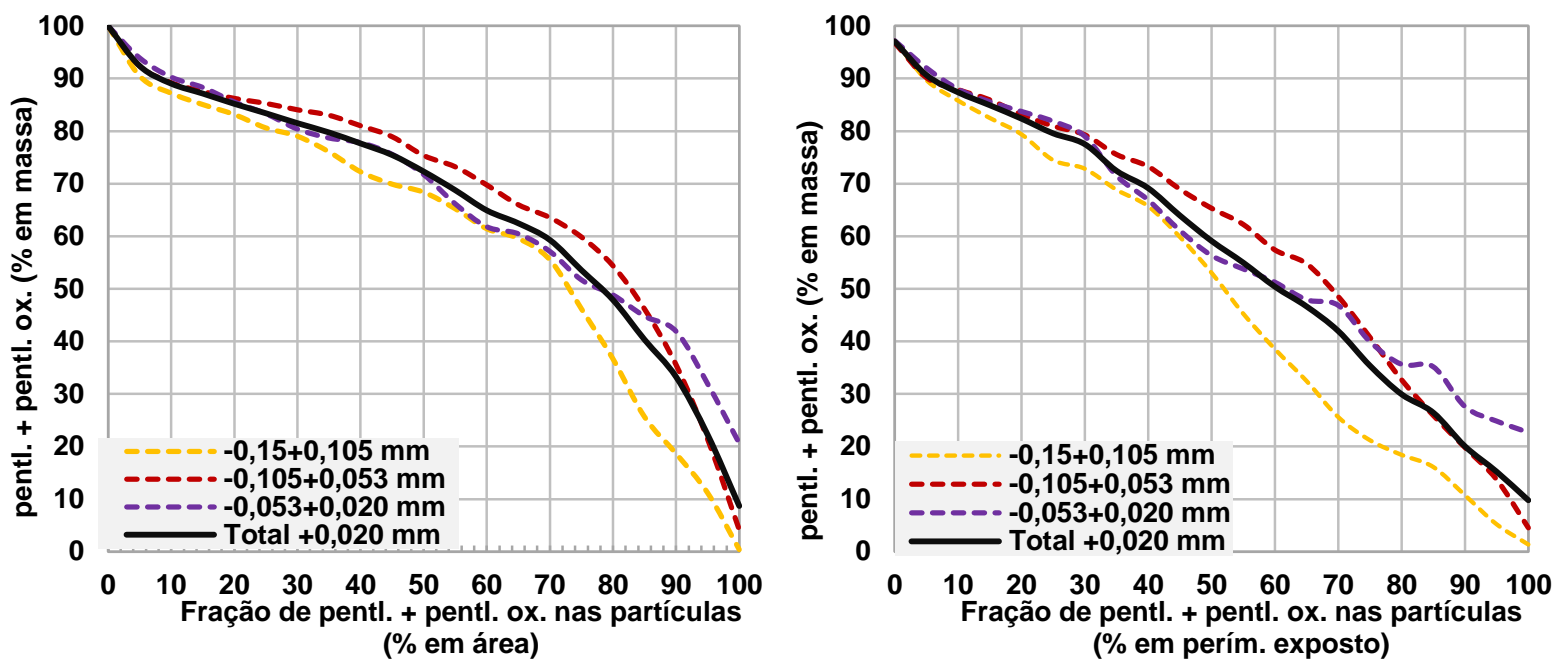

Figura 79 - Espectro de liberação da pentlandita + pentlandita oxidada - POS
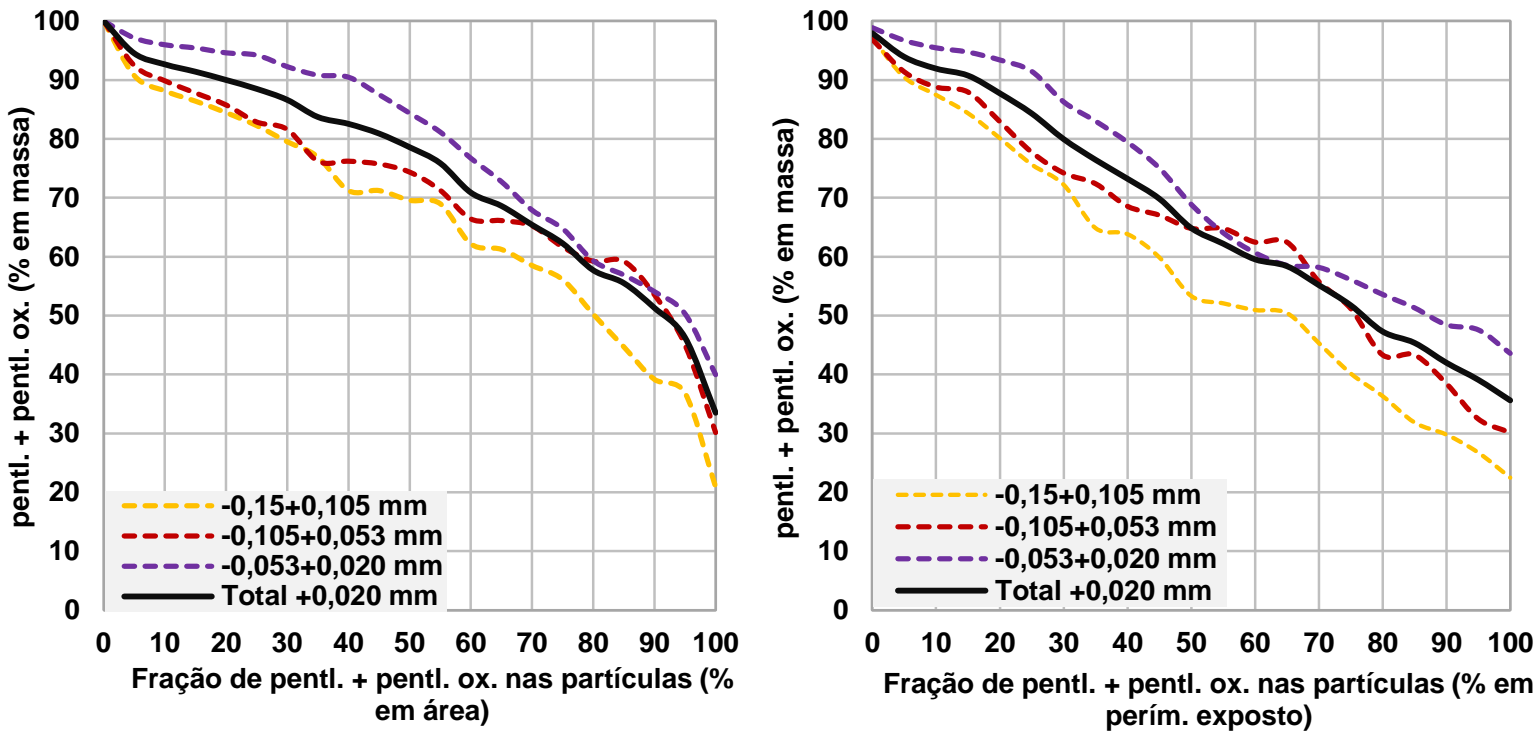
APÊNDICE 6

Resultados MLA

Figura 80 - Espectro de liberação da pentlandita + pentlandita oxidada - PO
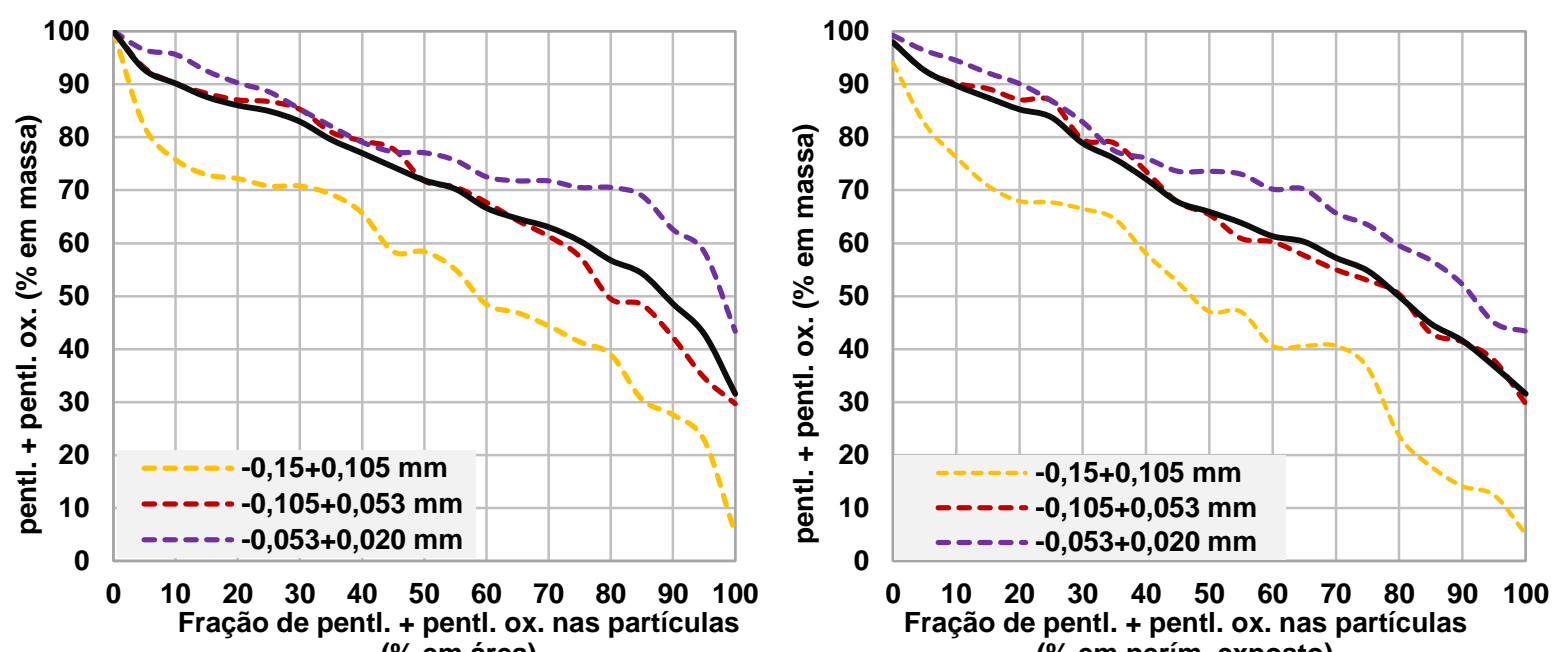

(\% em área)

(\% em perím. exposto)

Figura 81 - Espectro de liberação da pentlandita + pentlandita oxidada - P
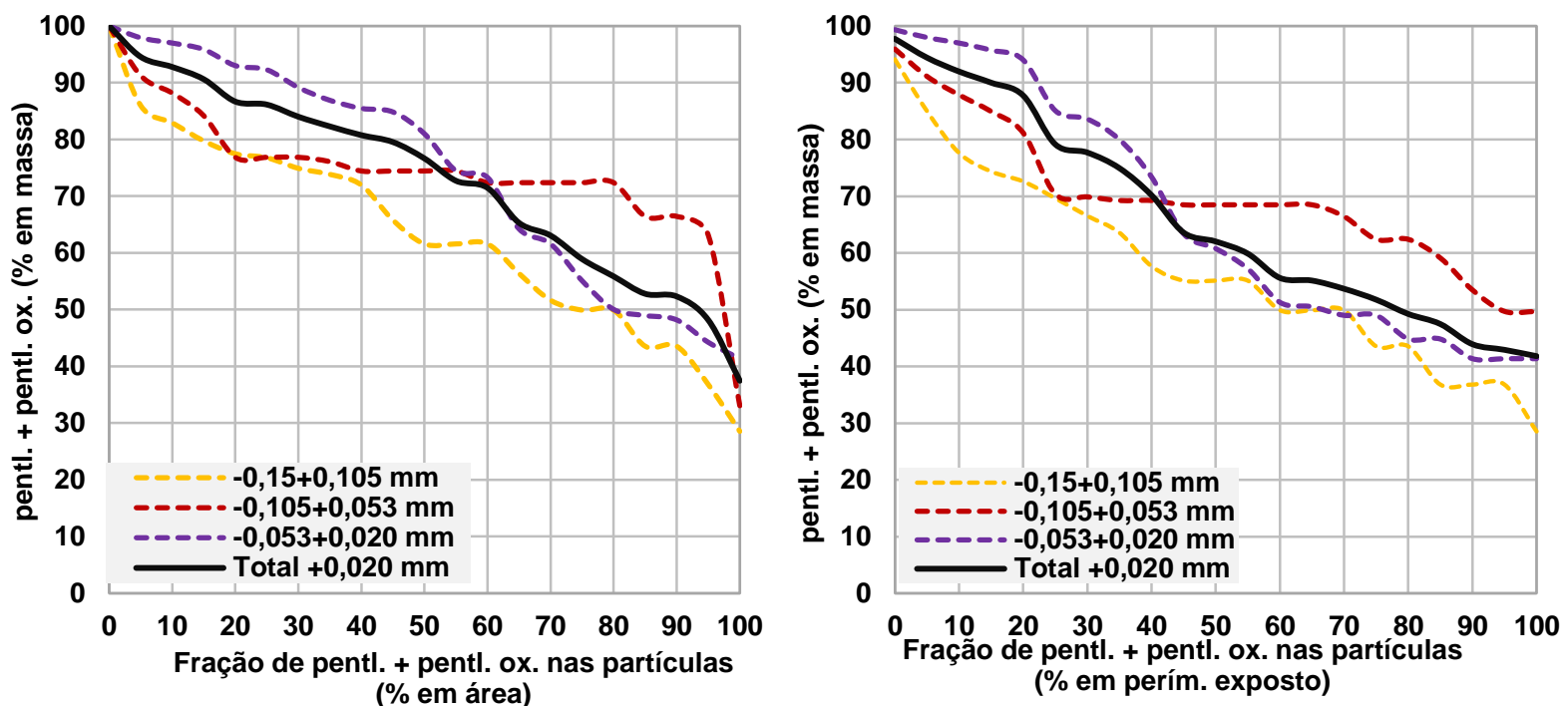

( $\%$ em área) 


\section{APÊNDICE 6}

Resultados MLA

Figura 82 - Espectro de liberação da pentlandita + pentlandita oxidada - Ganga A
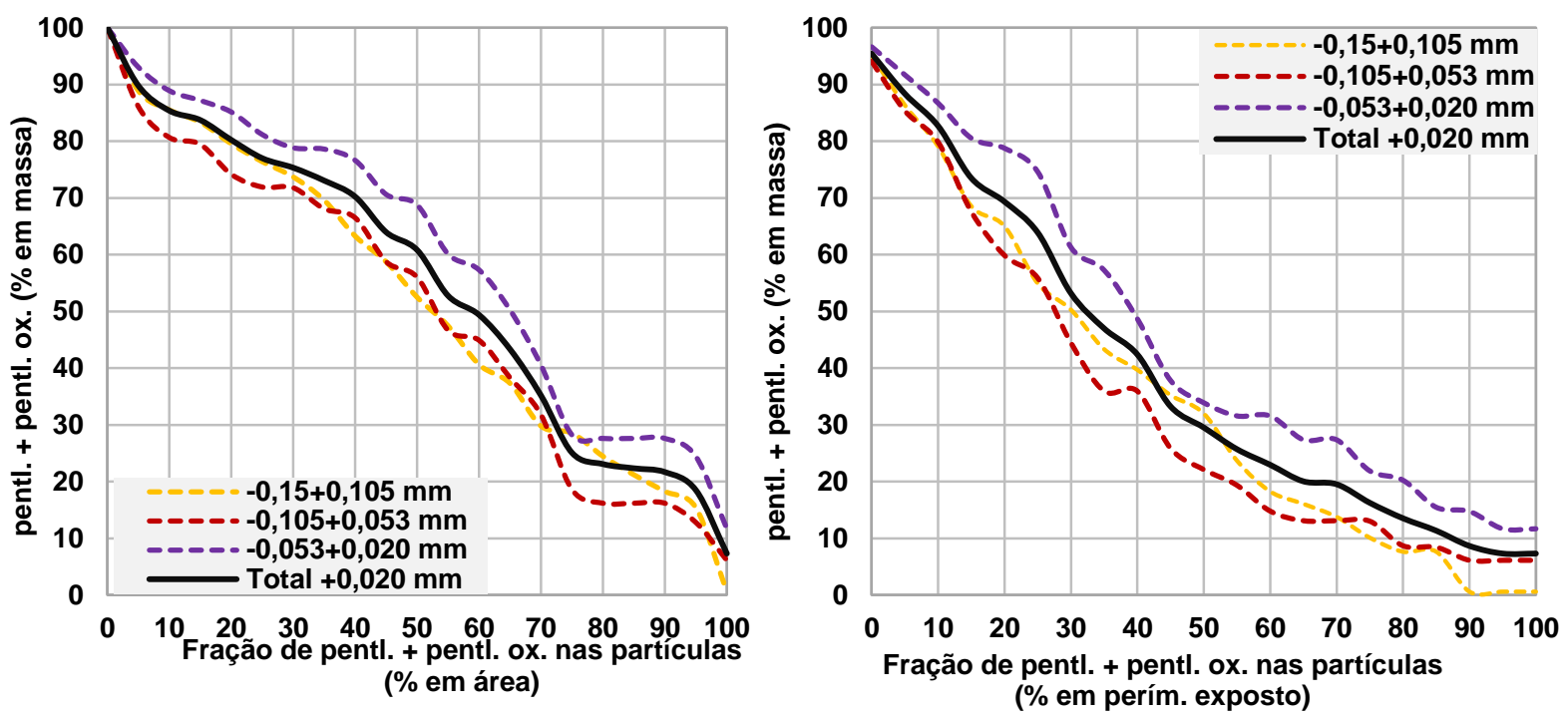

Figura 83 - Espectro de liberação da pentlandita + pentlandita oxidada - Ganga B
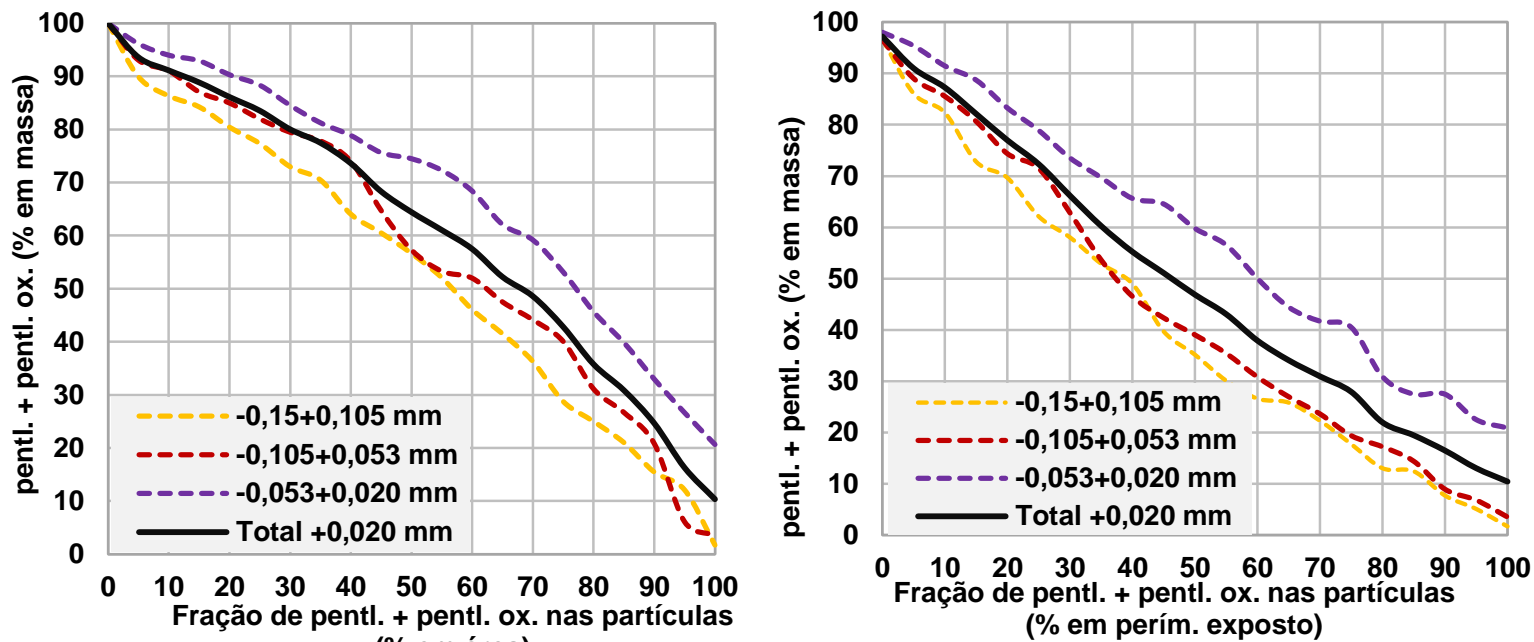
(\% em área) 
APÊNDICE 6

Resultados MLA

Figura 84 - Espectro de liberação da pentlandita + pentlandita oxidada - Ganga C
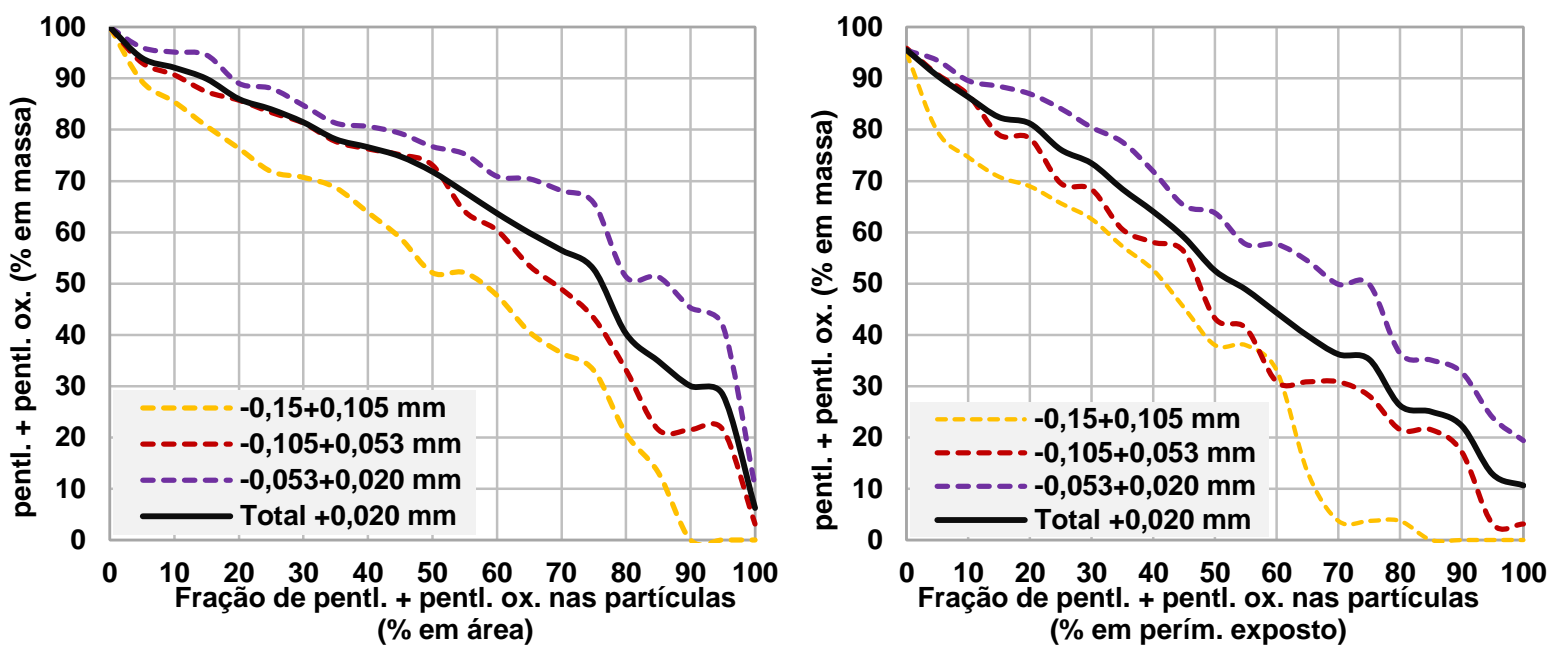

Figura 85 - Espectro de liberação da pentlandita + pentlandita oxidada - Outlier
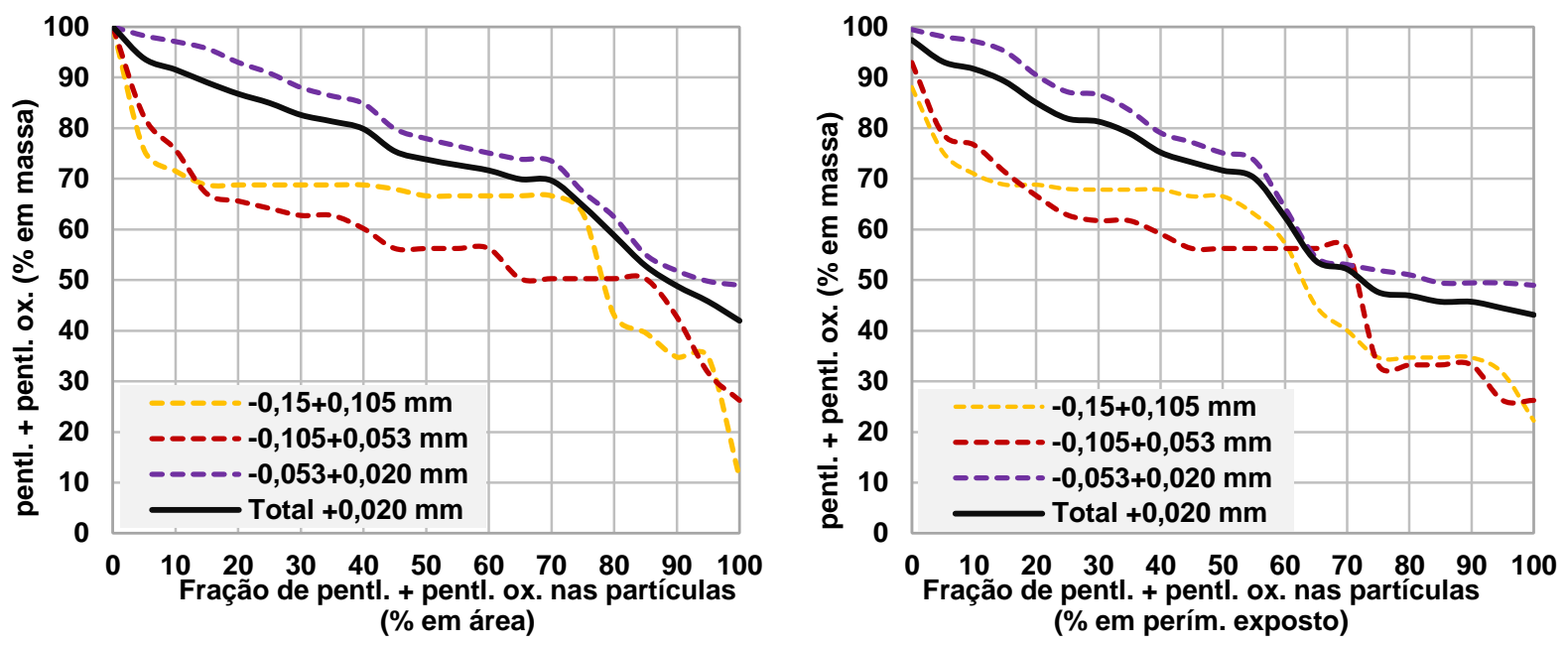

\section{Calcopirita}

\section{$\underline{\text { OPS }}$}

A Tabela 57 e a Figura 86 apresentam um sumário da distribuição das formas de associação de calcopirita (\% em massa), entre livre e misto em partículas binárias (2 fases) ou misto em partículas ternárias (3 ou mais fases minerais), para as frações granulométricas acima de $0,020 \mathrm{~mm}$ para a amostra de OPS. 
APÊNDICE 6

Resultados MLA

Tabela 57 - Formas de associação de calcopirita - OPS

\begin{tabular}{|c|c|c|c|c|}
\hline Fração (mm) & Total $+0,020$ & $-0,15+0,105$ & $-0,105+0,053$ & $-0,053+0,020$ \\
\hline$\%$ massa & 70 & 20 & 29 & 22 \\
\hline Livre (\%) & 18 & - & 24 & 33 \\
\hline Mista em binárias (\%) & 18 & 10 & 12 & 33 \\
\hline Mista em ternárias (\%) & 64 & 90 & 64 & 35 \\
\hline \multicolumn{5}{|c|}{ Distribuição - binárias (\%) } \\
\hline pentl. + pentl. ox. & 3,0 & 1,6 & 0,9 & 7,0 \\
\hline calco-covelita & 0,0 & 0,0 & 0,0 & 0,0 \\
\hline esfalerita & 0,0 & 0,0 & 0,0 & 0,0 \\
\hline pirita & 3,7 & 0,7 & 0,0 & 11,5 \\
\hline pirrotita & 0,6 & 0,0 & 1,8 & 0,0 \\
\hline arsenopirita & 0,0 & 0,0 & 0,0 & 0,0 \\
\hline FeNiCoS & 0,0 & 0,0 & 0,0 & 0,0 \\
\hline ortopiroxênio & 0,3 & 0,7 & 0,0 & 0,1 \\
\hline clinopiroxênio & 0,7 & 0,1 & 0,4 & 1,6 \\
\hline anfibólio & 0,0 & 0,0 & 0,0 & 0,0 \\
\hline olivina & 0,2 & 0,1 & 0,0 & 0,6 \\
\hline serpentina & 4,0 & 0,8 & 0,7 & 11,3 \\
\hline outros silicatos & 0,0 & 0,0 & 0,0 & 0,0 \\
\hline espinelio-Cr & 0,6 & 0,3 & 1,5 & 0,0 \\
\hline oxido-Fe & 4,4 & 6,0 & 6,3 & 0,4 \\
\hline mica & 0,0 & 0,0 & 0,0 & 0,0 \\
\hline calcita & 0,1 & 0,1 & 0,1 & 0,2 \\
\hline outros & 0,0 & 0,0 & 0,0 & 0,0 \\
\hline \multicolumn{5}{|c|}{ Distribuição - ternárias (\%) } \\
\hline pentl. + pentl. ox. & 11,1 & 15,5 & 10,6 & 6,6 \\
\hline calco-covelita & 0,0 & 0,0 & 0,0 & 0,0 \\
\hline esfalerita & 0,0 & 0,0 & 0,0 & 0,0 \\
\hline pirita & 1,1 & 0,0 & 0,0 & 3,4 \\
\hline pirrotita & 0,8 & 1,7 & 0,7 & 0,0 \\
\hline arsenopirita & 0,0 & 0,0 & 0,0 & 0,0 \\
\hline FeNiCoS & 0,2 & 0,1 & 0,1 & 0,3 \\
\hline ortopiroxênio & 4,1 & 5,4 & 3,7 & 3,2 \\
\hline clinopiroxênio & 1,6 & 1,3 & 3,2 & 0,2 \\
\hline anfibólio & 3,6 & 4,6 & 5,5 & 0,1 \\
\hline olivina & 2,9 & 2,4 & 5,2 & 0,7 \\
\hline serpentina & 21,9 & 32,3 & 27,2 & 3,8 \\
\hline outros silicatos & 0,0 & 0,0 & 0,0 & 0,0 \\
\hline espinelio-Cr & 1,9 & 1,8 & 3,6 & 0,2 \\
\hline oxido-Fe & 12,6 & 22,0 & 3,7 & 11,6 \\
\hline mica & 0,0 & 0,0 & 0,0 & 0,0 \\
\hline calcita & 2,5 & 2,3 & 0,8 & 4,8 \\
\hline outros & 0,0 & 0,0 & 0,0 & 0,0 \\
\hline
\end{tabular}

Obs: outros silicatos = quartzo, feldspato potássico e plagioclásio; carbonatos = calcita, dolomita, magnesita e anquerita; outros = clorita, espinélio-Cr, óxido-Fe, ilmenita, apatita, coríndon. 
APÊNDICE 6

Resultados MLA

Figura 86 - Distribuição das formas de associação de calcopirita na amostra de OPS

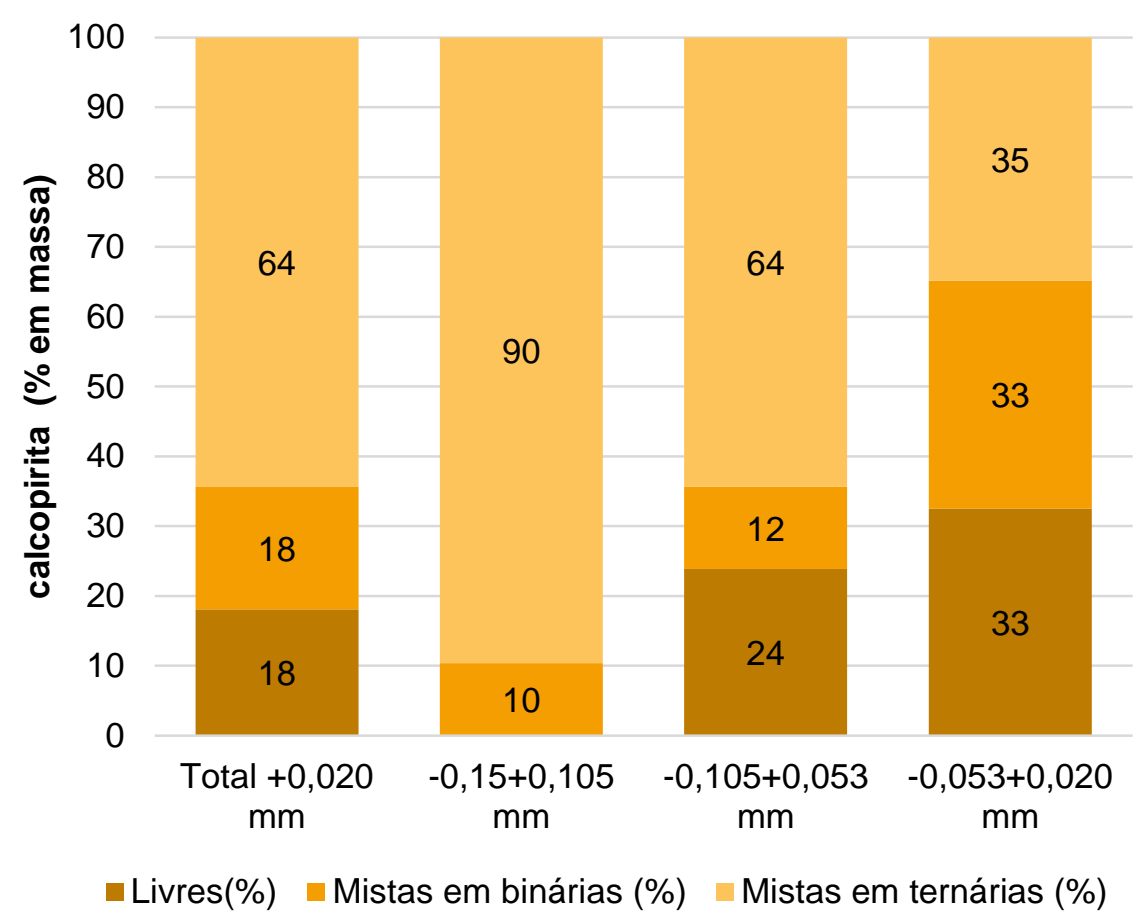

POS

A Tabela 58 e a Figura 87 apresentam um sumário da distribuição das formas de associação de calcopirita (\% em massa), entre livre e misto em partículas binárias (2 fases) ou misto em partículas ternárias (3 ou mais fases minerais), para as frações granulométricas acima de $0,020 \mathrm{~mm}$ para a amostra de POS. 
APÊNDICE 6

Resultados MLA

Tabela 58 - Formas de associação de calcopirita - POS

\begin{tabular}{|c|c|c|c|c|}
\hline Fração (mm) & Total $+0,020$ & $-0,15+0,105$ & $-0,105+0,053$ & $-0,053+0,020$ \\
\hline$\%$ massa & 77 & 20 & 32 & 25 \\
\hline Livre(\%) & 34 & 18 & 46 & 26 \\
\hline Mista em binárias (\%) & 36 & 37 & 24 & 50 \\
\hline Mista em ternárias (\%) & 30 & 45 & 29 & 24 \\
\hline \multicolumn{5}{|c|}{ Distribuição - binárias (\%) } \\
\hline pentl. + pentl. ox. & 1,9 & 12,8 & 0,0 & 0,4 \\
\hline calco-covelita & 0,0 & 0,0 & 0,0 & 0,0 \\
\hline esfalerita & 0,0 & 0,0 & 0,0 & 0,0 \\
\hline pirita & 6,2 & 10,2 & 10,2 & 0,2 \\
\hline pirrotita & 1,2 & 0,1 & 0,0 & 2,9 \\
\hline arsenopirita & 0,0 & 0,0 & 0,0 & 0,0 \\
\hline FeNiCos & 0,0 & 0,0 & 0,0 & 0,0 \\
\hline ortopiroxênio & 13,7 & 6,7 & 8,6 & 22,1 \\
\hline clinopiroxênio & 1,4 & 0,7 & 1,7 & 1,3 \\
\hline anfibólio & 1,1 & 4,0 & 1,2 & 0,0 \\
\hline olivina & 0,1 & 0,1 & 0,1 & 0,0 \\
\hline serpentina & 8,6 & 1,4 & 1,0 & 20,0 \\
\hline outros silicatos & 0,2 & 0,0 & 0,0 & 0,4 \\
\hline espinelio-Cr & 0,1 & 0,5 & 0,2 & 0,0 \\
\hline oxido-Fe & 0,9 & 0,0 & 0,0 & 2,4 \\
\hline mica & 0,0 & 0,0 & 0,0 & 0,0 \\
\hline calcita & 0,5 & 0,3 & 1,0 & 0,0 \\
\hline outros & 0,0 & 0,0 & 0,0 & 0,0 \\
\hline \multicolumn{5}{|c|}{ Distribuição - ternárias (\%) } \\
\hline pentl. + pentl. ox. & 5,1 & 6,9 & 5,8 & 3,6 \\
\hline calco-covelita & 0,0 & 0,0 & 0,0 & 0,0 \\
\hline esfalerita & 0,0 & 0,0 & 0,0 & 0,0 \\
\hline pirita & 1,3 & 2,5 & 2,0 & 0,1 \\
\hline pirrotita & 1,3 & 0,7 & 1,0 & 1,8 \\
\hline arsenopirita & 0,0 & 0,0 & 0,0 & 0,0 \\
\hline FeNiCos & 0,0 & 0,0 & 0,0 & 0,0 \\
\hline ortopiroxênio & 6,5 & 10,4 & 8,5 & 2,8 \\
\hline clinopiroxênio & 2,6 & 2,6 & 0,3 & 5,4 \\
\hline anfibólio & 0,5 & 2,8 & 0,1 & 0,2 \\
\hline olivina & 1,1 & 0,2 & 0,6 & 2,0 \\
\hline serpentina & 8,2 & 17,8 & 5,5 & 8,0 \\
\hline outros silicatos & 0,2 & 0,5 & 0,3 & 0,0 \\
\hline espinelio-Cr & 0,0 & 0,2 & 0,0 & 0,0 \\
\hline oxido-Fe & 2,2 & 0,0 & 4,6 & 0,0 \\
\hline mica & 0,2 & 0,5 & 0,1 & 0,2 \\
\hline calcita & 0,2 & 0,3 & 0,0 & 0,3 \\
\hline outros & 0,3 & 0,1 & 0,5 & 0,0 \\
\hline
\end{tabular}

Obs: outros silicatos = quartzo, feldspato potássico e plagioclásio; carbonatos = calcita, dolomita, magnesita e anquerita; outros = clorita, espinélio-Cr, óxido-Fe, ilmenita, apatita, coríndon. 
APÊNDICE 6

Resultados MLA

Figura 87 - Distribuição das formas de associação de calcopirita na amostra de POS

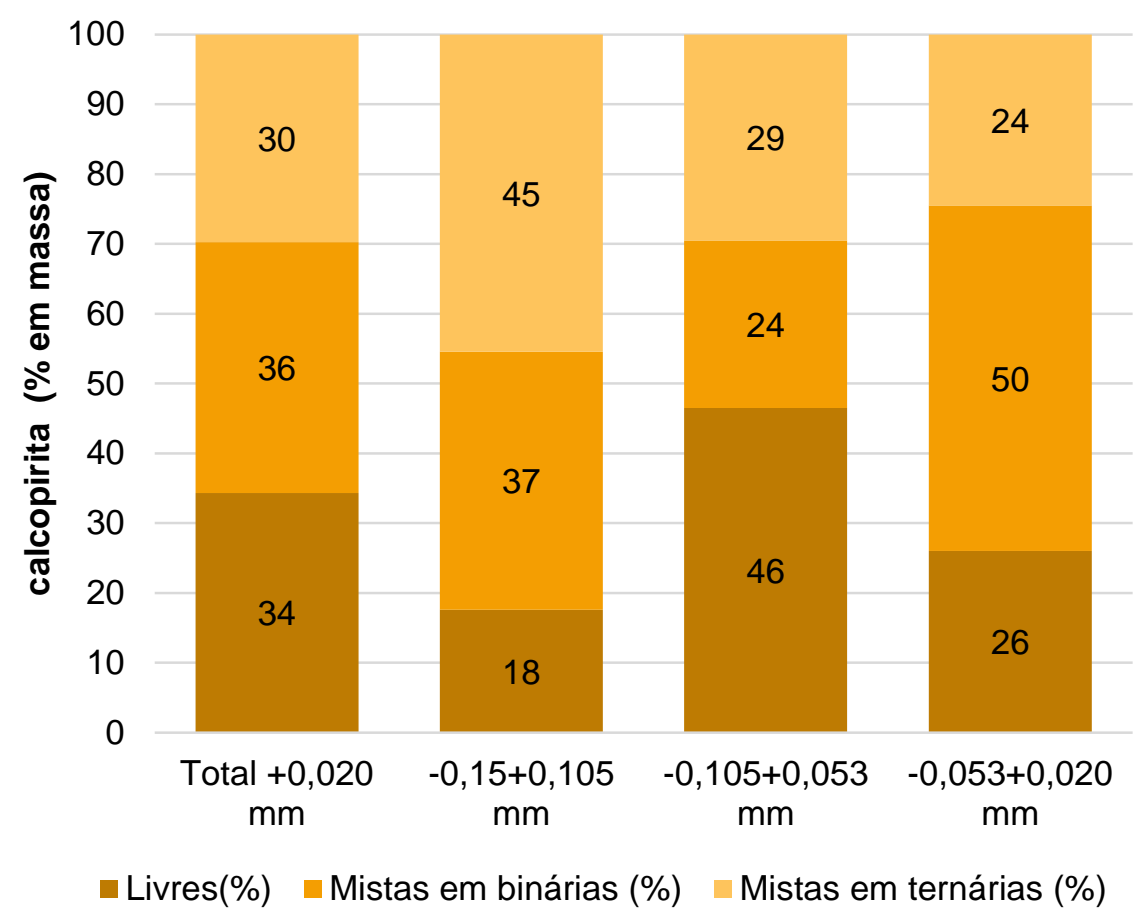

$\underline{\mathrm{PO}}$

A Tabela 59 e Figura 88 apresentam um sumário da distribuição das formas de associação de calcopirita (\% em massa), entre livre e misto em partículas binárias (2 fases) ou misto em partículas ternárias ( 3 ou mais fases minerais), para as frações granulométricas acima de $0,020 \mathrm{~mm}$ para a amostra de $\mathrm{PO}$. 
APÊNDICE 6

Resultados MLA

Tabela 59 - Formas de associação de calcopirita - PO

\begin{tabular}{|c|c|c|c|c|}
\hline Fração (mm) & Total $+0,020$ & $-0,15+0,105$ & $-0,105+0,053$ & $-0,053+0,020$ \\
\hline$\%$ massa & 76 & 22 & 32 & 22 \\
\hline Livre(\%) & 40 & 23 & 34 & 54 \\
\hline Mista em binárias (\%) & 31 & 46 & 34 & 19 \\
\hline Mista em ternárias (\%) & 29 & 31 & 31 & 27 \\
\hline \multicolumn{5}{|c|}{ Distribuição - binárias (\%) } \\
\hline pentl. + pentl. ox. & 3,6 & 13,2 & 0,2 & 0,0 \\
\hline calco-covelita & 0,0 & 0,0 & 0,0 & 0,0 \\
\hline esfalerita & 0,0 & 0,0 & 0,0 & 0,0 \\
\hline pirita & 1,6 & 1,0 & 4,2 & 0,1 \\
\hline pirrotita & 0,0 & 0,0 & 0,0 & 0,0 \\
\hline arsenopirita & 0,0 & 0,0 & 0,0 & 0,0 \\
\hline FeNiCoS & 0,0 & 0,0 & 0,0 & 0,0 \\
\hline ortopiroxênio & 20,6 & 22,5 & 23,4 & 17,5 \\
\hline clinopiroxênio & 3,7 & 7,1 & 5,1 & 0,6 \\
\hline anfibólio & 0,5 & 0,6 & 0,9 & 0,2 \\
\hline olivina & 0,0 & 0,1 & 0,0 & 0,0 \\
\hline serpentina & 0,1 & 0,1 & 0,1 & 0,1 \\
\hline outros silicatos & 0,1 & 0,1 & 0,2 & 0,0 \\
\hline espinelio-Cr & 0,2 & 0,2 & 0,4 & 0,0 \\
\hline oxido-Fe & 0,0 & 0,0 & 0,0 & 0,0 \\
\hline mica & 0,0 & 0,0 & 0,0 & 0,1 \\
\hline calcita & 0,3 & 1,0 & 0,0 & 0,0 \\
\hline outros & 0,0 & 0,0 & 0,0 & 0,0 \\
\hline \multicolumn{5}{|c|}{ Distribuição - ternárias (\%) } \\
\hline pentl. + pentl. ox. & 1,0 & 1,5 & 1,4 & 0,4 \\
\hline calco-covelita & 0,0 & 0,0 & 0,0 & 0,0 \\
\hline esfalerita & 0,0 & 0,0 & 0,0 & 0,0 \\
\hline pirita & 1,9 & 0,9 & 1,9 & 2,5 \\
\hline pirrotita & 1,8 & 1,0 & 5,1 & 0,1 \\
\hline arsenopirita & 0,0 & 0,0 & 0,0 & 0,0 \\
\hline FeNiCoS & 0,0 & 0,0 & 0,0 & 0,0 \\
\hline ortopiroxênio & 9,4 & 9,5 & 14,4 & 5,8 \\
\hline clinopiroxênio & 1,2 & 2,5 & 1,3 & 0,2 \\
\hline anfibólio & 1,3 & 1,2 & 1,9 & 0,9 \\
\hline olivina & 3,4 & 3,8 & 0,1 & 5,4 \\
\hline serpentina & 5,5 & 8,3 & 3,9 & 5,0 \\
\hline outros silicatos & 0,9 & 0,2 & 0,3 & 1,7 \\
\hline espinelio-Cr & 0,3 & 0,1 & 0,9 & 0,0 \\
\hline oxido-Fe & 0,4 & 0,8 & 0,0 & 0,5 \\
\hline mica & 0,0 & 0,0 & 0,0 & 0,1 \\
\hline calcita & 1,9 & 0,2 & 0,1 & 4,3 \\
\hline outros & 0,3 & 1,1 & 0,0 & 0,0 \\
\hline
\end{tabular}

Obs: outros silicatos = quartzo, feldspato potássico e plagioclásio; carbonatos = calcita, dolomita, magnesita e anquerita; outros = clorita, espinélio-Cr, óxido-Fe, ilmenita, apatita, coríndon. 
APÊNDICE 6

Resultados MLA

Figura 88 - Distribuição das formas de associação de calcopirita na amostra de PO

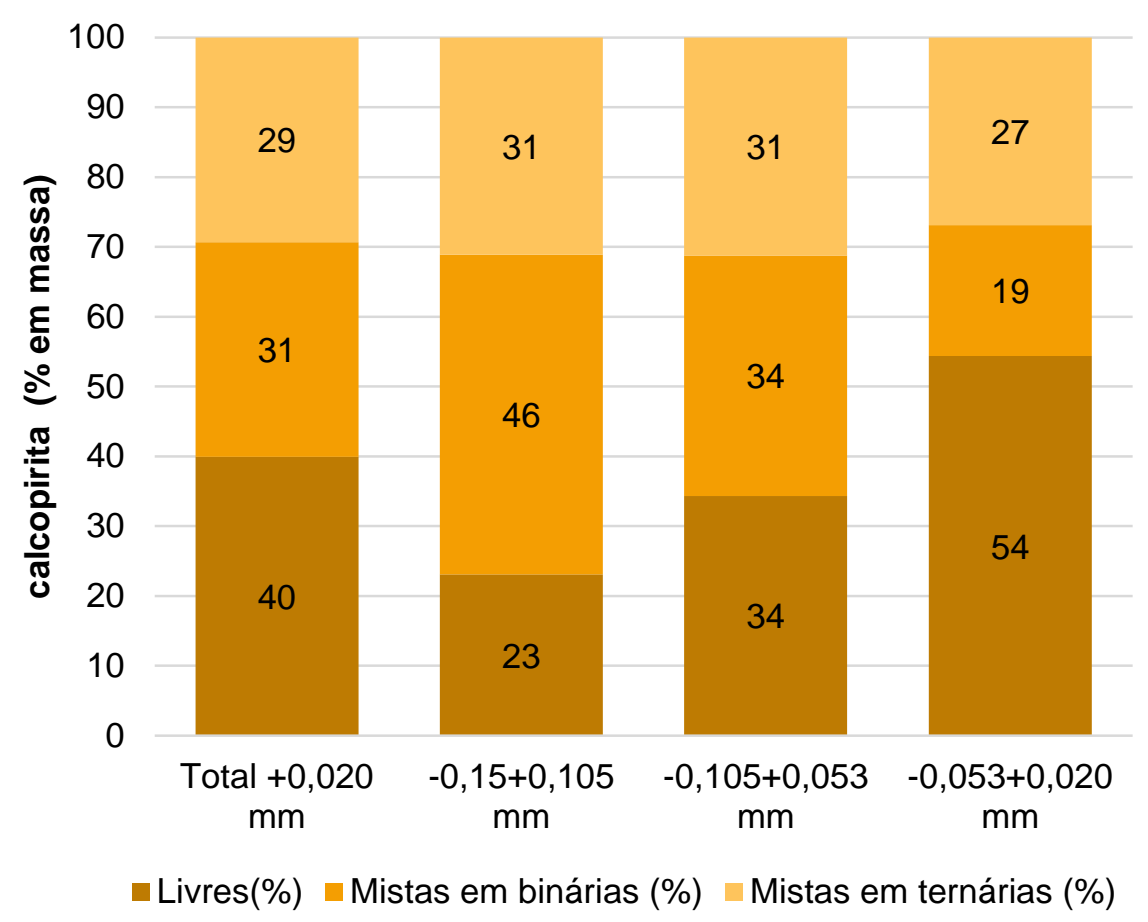

$\underline{P}$

A Tabela 34 e a Figura 20 apresentam um sumário da distribuição das formas de associação de calcopirita (\% em massa), entre livre e misto em partículas binárias (2 fases) ou misto em partículas ternárias (3 ou mais fases minerais), para as frações granulométricas acima de $0,020 \mathrm{~mm}$ para a amostra de $P$. 
APÊNDICE 6

Resultados MLA

Tabela 60 - Formas de associação de calcopirita - $\mathbf{P}$

\begin{tabular}{|c|c|c|c|c|}
\hline Fração (mm) & Total $+\mathbf{0 , 0 2 0}$ & $-0,15+0,105$ & $-0,105+0,053$ & $-0,053+0,020$ \\
\hline$\%$ massa & 82 & 26 & 33 & 23 \\
\hline Livre(\%) & 57 & 30 & 40 & 79 \\
\hline Mista em binária (\%) & 26 & 37 & 45 & 5 \\
\hline Mista em ternária (\%) & 17 & 33 & 15 & 16 \\
\hline \multicolumn{5}{|c|}{ Distribuição - binárias (\%) } \\
\hline pentl. + pentl. ox. & 0,0 & 0,1 & 0,0 & 0,0 \\
\hline calco-covelita & 0,0 & 0,0 & 0,0 & 0,0 \\
\hline esfalerita & 0,0 & 0,0 & 0,0 & 0,0 \\
\hline pirita & 1,4 & 0,0 & 0,0 & 3,1 \\
\hline pirrotita & 1,0 & 0,0 & 2,1 & 0,0 \\
\hline arsenopirita & 0,0 & 0,0 & 0,0 & 0,0 \\
\hline FeNiCoS & 0,0 & 0,0 & 0,0 & 0,0 \\
\hline ortopiroxênio & 15,8 & 31,3 & 27,3 & 1,6 \\
\hline clinopiroxênio & 0,3 & 1,7 & 0,1 & 0,2 \\
\hline anfibólio & 0,0 & 0,1 & 0,0 & 0,0 \\
\hline olivina & 7,1 & 0,0 & 15,5 & 0,0 \\
\hline serpentina & 0,0 & 0,0 & 0,0 & 0,0 \\
\hline outros silicatos & 0,1 & 0,7 & 0,0 & 0,0 \\
\hline espinelio-Cr & 0,0 & 0,0 & 0,0 & 0,0 \\
\hline oxido-Fe & 0,0 & 0,0 & 0,0 & 0,0 \\
\hline mica & 0,1 & 0,1 & 0,1 & 0,1 \\
\hline calcita & 0,3 & 3,4 & 0,0 & 0,0 \\
\hline outros & 0,0 & 0,0 & 0,0 & 0,0 \\
\hline \multicolumn{5}{|c|}{ Distribuição - ternárias (\%) } \\
\hline pentl. + pentl. ox. & 2,6 & 3,5 & 3,3 & 1,7 \\
\hline calco-covelita & 0,0 & 0,0 & 0,0 & 0,0 \\
\hline esfalerita & 0,0 & 0,0 & 0,0 & 0,0 \\
\hline pirita & 1,8 & 1,6 & 3,0 & 0,6 \\
\hline pirrotita & 3,1 & 0,0 & 0,2 & 6,6 \\
\hline arsenopirita & 0,0 & 0,0 & 0,0 & 0,0 \\
\hline FeNiCos & 0,0 & 0,0 & 0,0 & 0,0 \\
\hline ortopiroxênio & 4,0 & 15,1 & 1,6 & 4,4 \\
\hline clinopiroxênio & 1,6 & 4,3 & 2,1 & 0,5 \\
\hline anfibólio & 1,2 & 1,9 & 1,6 & 0,7 \\
\hline olivina & 0,1 & 0,5 & 0,0 & 0,1 \\
\hline serpentina & 1,7 & 2,2 & 2,4 & 0,9 \\
\hline outros silicatos & 0,3 & 2,1 & 0,0 & 0,3 \\
\hline espinelio-Cr & 0,1 & 0,8 & 0,0 & 0,2 \\
\hline oxido-Fe & 0,3 & 0,0 & 0,6 & 0,1 \\
\hline mica & 0,1 & 0,0 & 0,1 & 0,0 \\
\hline calcita & 0,1 & 1,0 & 0,0 & 0,0 \\
\hline outros & 0,1 & 0,0 & 0,2 & 0,1 \\
\hline
\end{tabular}

Obs: outros silicatos = quartzo, feldspato potássico e plagioclásio; carbonatos = calcita, dolomita, magnesita e anquerita; outros = clorita, espinélio-Cr, óxido-Fe, ilmenita, apatita, coríndon. 


\section{APÊNDICE 6}

Resultados MLA

Figura 89 - Distribuição das formas de associação de calcopirita na amostra de $P$

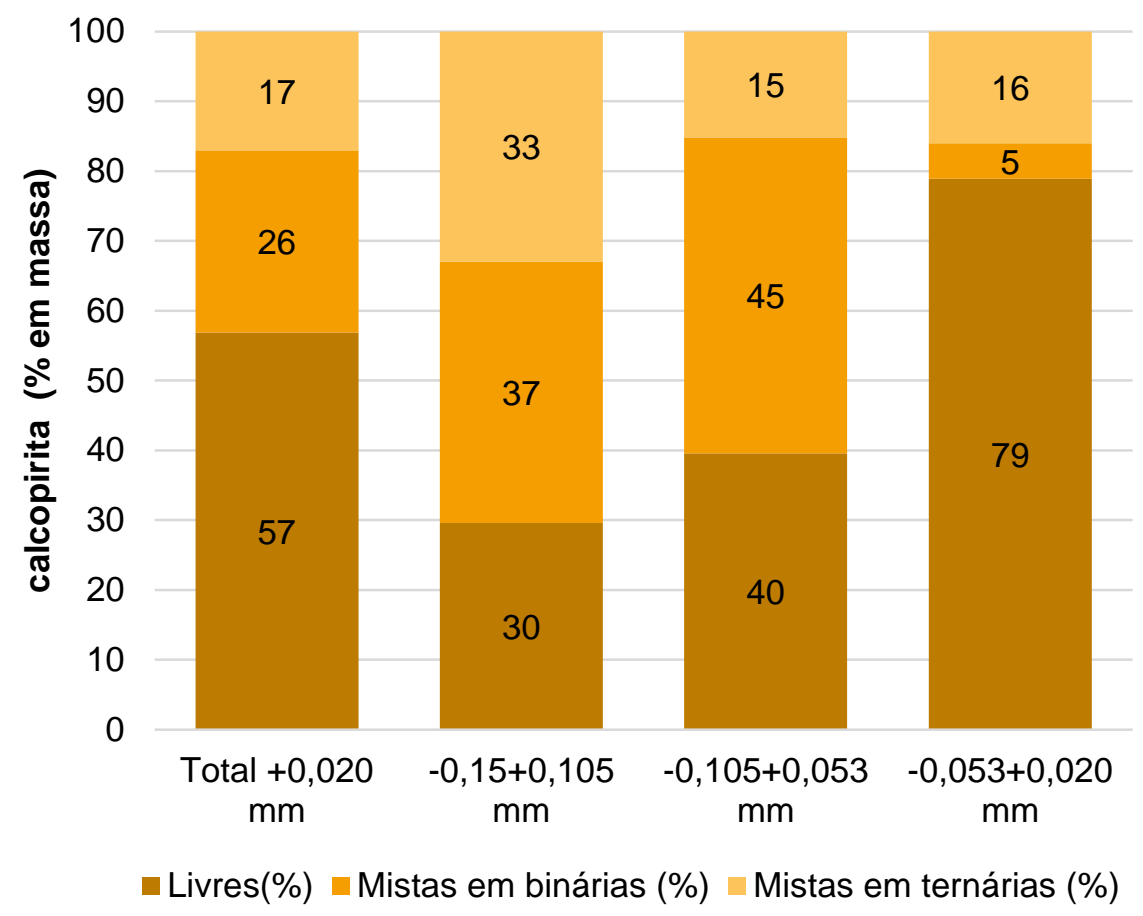

\section{Ganga A}

A Tabela 61 e a Figura 90 apresentam um sumário da distribuição das formas de associação de calcopirita (\% em massa), entre livre e misto em partículas binárias (2 fases) ou misto em partículas ternárias (3 ou mais fases minerais), para as frações granulométricas acima de 0,020 $\mathrm{mm}$ para a amostra de Ganga A. 
APÊNDICE 6

Resultados MLA

Tabela 61 - Formas de associação de Calcopirita - Ganga A

\begin{tabular}{|c|c|c|c|c|}
\hline Fração (mm) & Total $+0,020$ & $-0,15+0,105$ & $-0,105+0,053$ & $-0,053+0,020$ \\
\hline$\%$ massa & 60 & 14 & 24 & 22 \\
\hline Livre(\%) & 26 & 11 & 15 & 39 \\
\hline Mista em binárias (\%) & 52 & 37 & 61 & 51 \\
\hline Mista em ternárias (\%) & 23 & 51 & 24 & 10 \\
\hline \multicolumn{5}{|c|}{ Distribuição - binárias (\%) } \\
\hline pentl. + pentl. ox. & 10,4 & 0,0 & 20,7 & 7,2 \\
\hline calco-covelita & 0,0 & 0,0 & 0,0 & 0,0 \\
\hline esfalerita & 0,0 & 0,0 & 0,0 & 0,0 \\
\hline pirita & 0,0 & 0,0 & 0,0 & 0,0 \\
\hline pirrotita & 0,0 & 0,0 & 0,0 & 0,0 \\
\hline arsenopirita & 0,0 & 0,0 & 0,0 & 0,0 \\
\hline FeNiCoS & 0,0 & 0,0 & 0,0 & 0,0 \\
\hline ortopiroxênio & 10,4 & 13,5 & 9,0 & 10,1 \\
\hline clinopiroxênio & 0,0 & 0,0 & 0,0 & 0,0 \\
\hline anfibólio & 0,0 & 0,0 & 0,0 & 0,0 \\
\hline olivina & 0,1 & 0,0 & 0,3 & 0,0 \\
\hline serpentina & 28,4 & 12,1 & 30,6 & 33,4 \\
\hline outros silicatos & 0,1 & 0,5 & 0,0 & 0,0 \\
\hline espinelio-Cr & 0,0 & 0,0 & 0,0 & 0,0 \\
\hline oxido-Fe & 2,1 & 11,1 & 0,0 & 0,0 \\
\hline mica & 0,0 & 0,0 & 0,0 & 0,0 \\
\hline calcita & 0,1 & 0,1 & 0,2 & 0,0 \\
\hline outros & 0,0 & 0,1 & 0,0 & 0,0 \\
\hline \multicolumn{5}{|c|}{ Distribuição - ternárias (\%) } \\
\hline pentl. + pentl. ox. & 6,0 & 18,8 & 4,2 & 2,2 \\
\hline calco-covelita & 0,0 & 0,0 & 0,0 & 0,0 \\
\hline esfalerita & 0,0 & 0,0 & 0,0 & 0,0 \\
\hline pirita & 1,8 & 8,2 & 0,5 & 0,2 \\
\hline pirrotita & 0,0 & 0,2 & 0,0 & 0,0 \\
\hline arsenopirita & 0,0 & 0,0 & 0,0 & 0,0 \\
\hline FeNiCos & 0,5 & 0,0 & 1,4 & 0,0 \\
\hline ortopiroxênio & 4,9 & 10,4 & 7,0 & 1,2 \\
\hline clinopiroxênio & 0,0 & 0,0 & 0,1 & 0,0 \\
\hline anfibólio & 1,6 & 0,2 & 0,9 & 2,6 \\
\hline olivina & 0,0 & 0,0 & 0,0 & 0,0 \\
\hline serpentina & 4,6 & 7,6 & 6,2 & 2,4 \\
\hline outros silicatos & 0,0 & 0,0 & 0,0 & 0,0 \\
\hline espinelio-Cr & 0,2 & 0,8 & 0,1 & 0,0 \\
\hline oxido-Fe & 0,6 & 2,9 & 0,1 & 0,1 \\
\hline mica & 0,2 & 0,0 & 0,3 & 0,3 \\
\hline calcita & 2,0 & 2,1 & 3,0 & 1,3 \\
\hline outros & 0,0 & 0,0 & 0,1 & 0,0 \\
\hline
\end{tabular}

Obs: outros silicatos = quartzo, feldspato potássico e plagioclásio; carbonatos = calcita, dolomita, magnesita e anquerita; outros = clorita, espinélio-Cr, óxido-Fe, ilmenita, apatita, coríndon. 
APÊNDICE 6

Resultados MLA

Figura 90 - Distribuição das formas de associação de calcopirita na amostra Ganga A

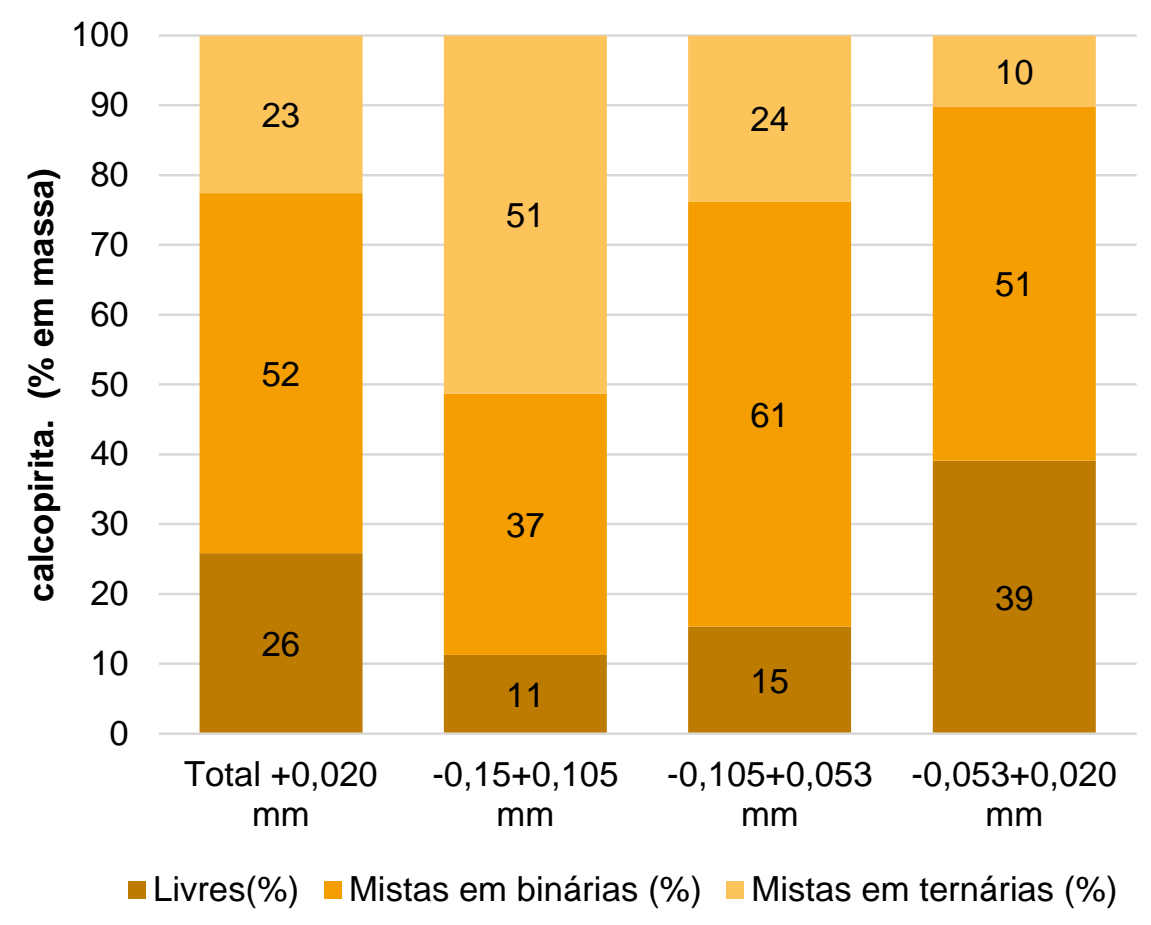

\section{Ganga B}

A Tabela 62 e a Figura 91 apresentam um sumário da distribuição das formas de associação de calcopirita (\% em massa), entre livre e misto em partículas binárias (2 fases) ou misto em partículas ternárias (3 ou mais fases minerais), para as frações granulométricas acima de $0,020 \mathrm{~mm}$ para a amostra de Ganga B. 
APÊNDICE 6

Resultados MLA

Tabela 62 - Formas de associação de calcopirita - Ganga B

\begin{tabular}{|c|c|c|c|c|}
\hline Fração (mm) & Total $+0,020$ & $-0,15+0,105$ & $-0,105+0,053$ & $-0,053+0,020$ \\
\hline$\%$ massa & 61 & 16 & 23 & 22 \\
\hline Livre(\%) & 18 & - & 31 & 18 \\
\hline Mista em binárias (\%) & 24 & 27 & 11 & 37 \\
\hline Mista em ternárias (\%) & 58 & 73 & 58 & 45 \\
\hline \multicolumn{5}{|c|}{ Distribuição - binárias (\%) } \\
\hline pentl. + pentl. ox. & 1,1 & 1,4 & 1,1 & 0,9 \\
\hline calco-covelita & 0,0 & 0,0 & 0,0 & 0,0 \\
\hline esfalerita & 0,0 & 0,0 & 0,0 & 0,0 \\
\hline pirita & 0,7 & 2,4 & 0,0 & 0,0 \\
\hline pirrotita & 0,0 & 0,0 & 0,0 & 0,0 \\
\hline arsenopirita & 0,0 & 0,0 & 0,0 & 0,0 \\
\hline FeNiCoS & 0,0 & 0,0 & 0,0 & 0,0 \\
\hline ortopiroxênio & 1,9 & 4,3 & 1,2 & 0,6 \\
\hline clinopiroxênio & 0,1 & 0,3 & 0,0 & 0,0 \\
\hline anfibólio & 0,0 & 0,0 & 0,0 & 0,1 \\
\hline olivina & 0,3 & 0,9 & 0,0 & 0,0 \\
\hline serpentina & 9,8 & 13,9 & 1,9 & 15,4 \\
\hline outros silicatos & 0,7 & 1,4 & 0,6 & 0,2 \\
\hline espinelio-Cr & 1,5 & 1,1 & 0,5 & 3,3 \\
\hline oxido-Fe & 0,3 & 0,0 & 0,0 & 0,9 \\
\hline mica & 0,0 & 0,0 & 0,0 & 0,0 \\
\hline calcita & 7,4 & 1,2 & 5,2 & 16,2 \\
\hline outros & 0,0 & 0,0 & 0,0 & 0,0 \\
\hline \multicolumn{5}{|c|}{ Distribuição - ternárias (\%) } \\
\hline pentl. + pentl. ox. & 11,6 & 11,3 & 13,0 & 10,3 \\
\hline calco-covelita & 0,0 & 0,0 & 0,0 & 0,0 \\
\hline esfalerita & 0,0 & 0,0 & 0,0 & 0,0 \\
\hline pirita & 1,0 & 1,4 & 1,0 & 0,4 \\
\hline pirrotita & 0,0 & 0,0 & 0,0 & 0,0 \\
\hline arsenopirita & 0,0 & 0,0 & 0,0 & 0,0 \\
\hline FeNiCos & 0,2 & 0,0 & 0,5 & 0,0 \\
\hline ortopiroxênio & 4,0 & 9,0 & 2,8 & 0,6 \\
\hline clinopiroxênio & 0,6 & 0,7 & 0,3 & 0,9 \\
\hline anfibólio & 1,8 & 1,6 & 1,3 & 2,7 \\
\hline olivina & 0,1 & 0,3 & 0,1 & 0,0 \\
\hline serpentina & 15,9 & 17,2 & 17,3 & 13,1 \\
\hline outros silicatos & 0,3 & 0,7 & 0,1 & 0,2 \\
\hline espinelio-Cr & 2,2 & 3,7 & 1,3 & 1,7 \\
\hline oxido-Fe & 5,4 & 7,5 & 3,2 & 6,0 \\
\hline mica & 0,0 & 0,1 & 0,0 & 0,0 \\
\hline calcita & 14,8 & 19,6 & 16,1 & 8,8 \\
\hline outros & 0,3 & 0,0 & 0,8 & 0,1 \\
\hline
\end{tabular}

Obs: outros silicatos = quartzo, feldspato potássico e plagioclásio; carbonatos = calcita, dolomita, magnesita e anquerita; outros = clorita, espinélio-Cr, óxido-Fe, ilmenita, apatita, coríndon. 
APÊNDICE 6

Resultados MLA

Figura 91 - Distribuição das formas de associação de calcopirita na amostra Ganga B

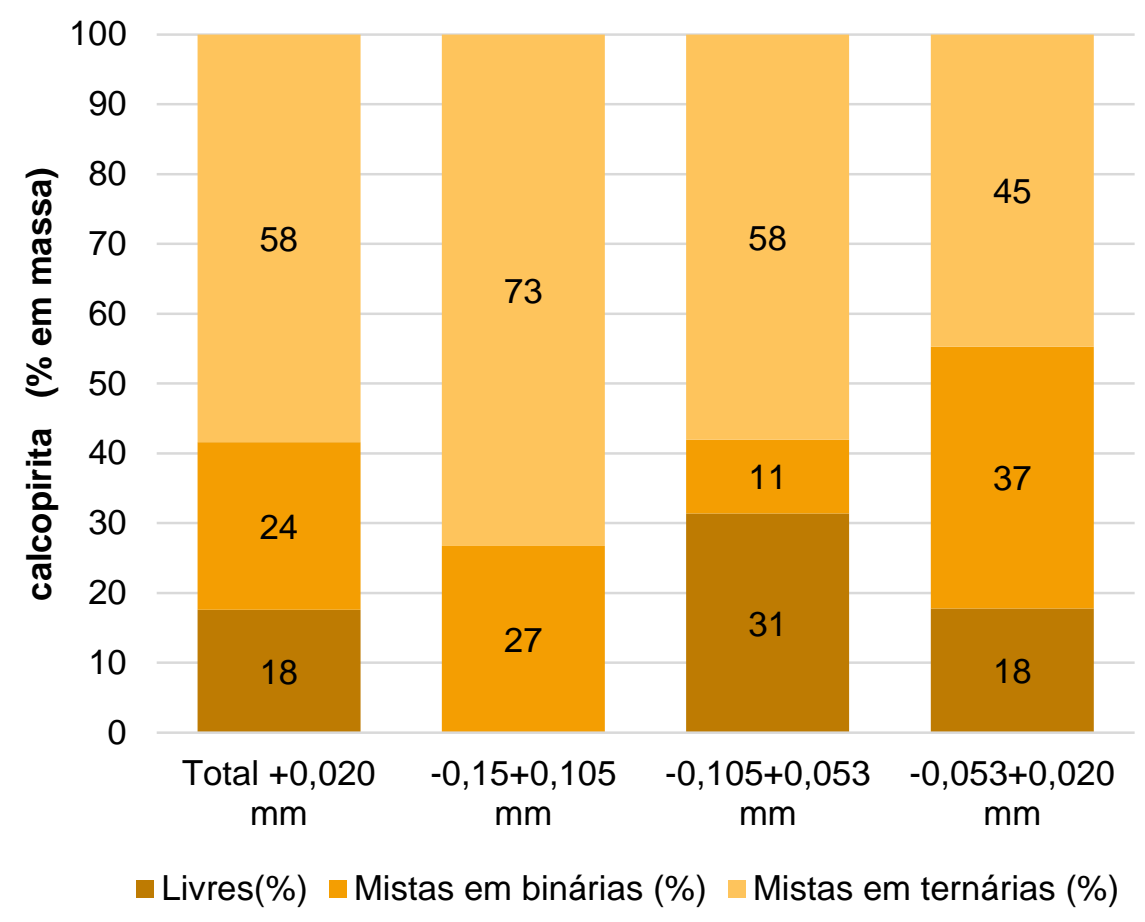

\section{Ganga C}

A Tabela 63 e a Figura 92 apresentam um sumário da distribuição das formas de associação de calcopirita (\% em massa), entre livre e misto em partículas binárias (2 fases) ou misto em partículas ternárias (3 ou mais fases minerais), para as frações granulométricas acima de 0,020 $\mathrm{mm}$ para a amostra de Ganga C. 
APÊNDICE 6

Resultados MLA

Tabela 63 - Formas de associação de calcopirita - Ganga C

\begin{tabular}{|c|c|c|c|c|}
\hline Fração (mm) & Total $+\mathbf{0 , 0 2 0}$ & $-0,15+0,105$ & $-0,105+0,053$ & $-0,053+0,020$ \\
\hline$\%$ massa & 75 & 16 & 33 & 25 \\
\hline Livre(\%) & 27 & 63 & 17 & 22 \\
\hline Mista em binária (\%) & 50 & 8 & 41 & 74 \\
\hline Mista em ternária (\%) & 23 & 29 & 41 & 4 \\
\hline \multicolumn{5}{|c|}{ Distribuição - binárias (\%) } \\
\hline pentl. + pentl. ox. & 2,8 & 0,0 & 0,0 & 6,7 \\
\hline calco-covelita & 0,0 & 0,0 & 0,0 & 0,0 \\
\hline esfalerita & 0,0 & 0,0 & 0,0 & 0,0 \\
\hline pirita & 0,0 & 0,2 & 0,0 & 0,0 \\
\hline pirrotita & 0,0 & 0,0 & 0,0 & 0,0 \\
\hline arsenopirita & 0,0 & 0,0 & 0,0 & 0,0 \\
\hline FeNiCoS & 0,0 & 0,0 & 0,0 & 0,0 \\
\hline ortopiroxênio & 31,0 & 3,2 & 39,5 & 34,4 \\
\hline clinopiroxênio & 0,0 & 0,0 & 0,0 & 0,0 \\
\hline anfibólio & 0,1 & 0,5 & 0,0 & 0,0 \\
\hline olivina & 0,0 & 0,0 & 0,0 & 0,0 \\
\hline serpentina & 1,4 & 4,2 & 1,6 & 0,0 \\
\hline outros silicatos & 0,0 & 0,0 & 0,0 & 0,0 \\
\hline espinelio-Cr & 0,1 & 0,0 & 0,3 & 0,0 \\
\hline oxido-Fe & 0,0 & 0,0 & 0,0 & 0,0 \\
\hline mica & 6,7 & 0,1 & 0,0 & 15,6 \\
\hline calcita & 7,5 & 0,1 & 0,0 & 17,6 \\
\hline outros & 0,0 & 0,0 & 0,0 & 0,0 \\
\hline \multicolumn{5}{|c|}{ Distribuição - ternárias (\%) } \\
\hline pentl. + pentl. ox. & 4,6 & 5,3 & 7,9 & 1,2 \\
\hline calco-covelita & 0,0 & 0,0 & 0,0 & 0,0 \\
\hline esfalerita & 0,0 & 0,0 & 0,0 & 0,0 \\
\hline pirita & 0,3 & 0,1 & 0,3 & 0,4 \\
\hline pirrotita & 0,0 & 0,0 & 0,1 & 0,0 \\
\hline arsenopirita & 0,0 & 0,0 & 0,0 & 0,0 \\
\hline FeNiCoS & 0,0 & 0,0 & 0,0 & 0,0 \\
\hline ortopiroxênio & 1,6 & 3,0 & 1,7 & 0,9 \\
\hline clinopiroxênio & 0,0 & 0,1 & 0,0 & 0,0 \\
\hline anfibólio & 0,2 & 0,4 & 0,3 & 0,0 \\
\hline olivina & 0,3 & 0,3 & 0,6 & 0,0 \\
\hline serpentina & 1,6 & 3,2 & 2,5 & 0,1 \\
\hline outros silicatos & 0,2 & 0,3 & 0,4 & 0,0 \\
\hline espinelio-Cr & 0,0 & 0,0 & 0,0 & 0,0 \\
\hline oxido-Fe & 1,5 & 1,1 & 2,5 & 0,7 \\
\hline mica & 4,5 & 2,4 & 10,0 & 0,1 \\
\hline calcita & 8,3 & 12,8 & 14,9 & 0,3 \\
\hline outros & 0,0 & 0,0 & 0,0 & 0,0 \\
\hline
\end{tabular}

Obs: outros silicatos = quartzo, feldspato potássico e plagioclásio; carbonatos = calcita, dolomita, magnesita e anquerita; outros = clorita, espinélio-Cr, óxido-Fe, ilmenita, apatita, coríndon. 
APÊNDICE 6

Resultados MLA

Figura 92 - Distribuição das formas de associação de calcopirita na amostra Ganga C

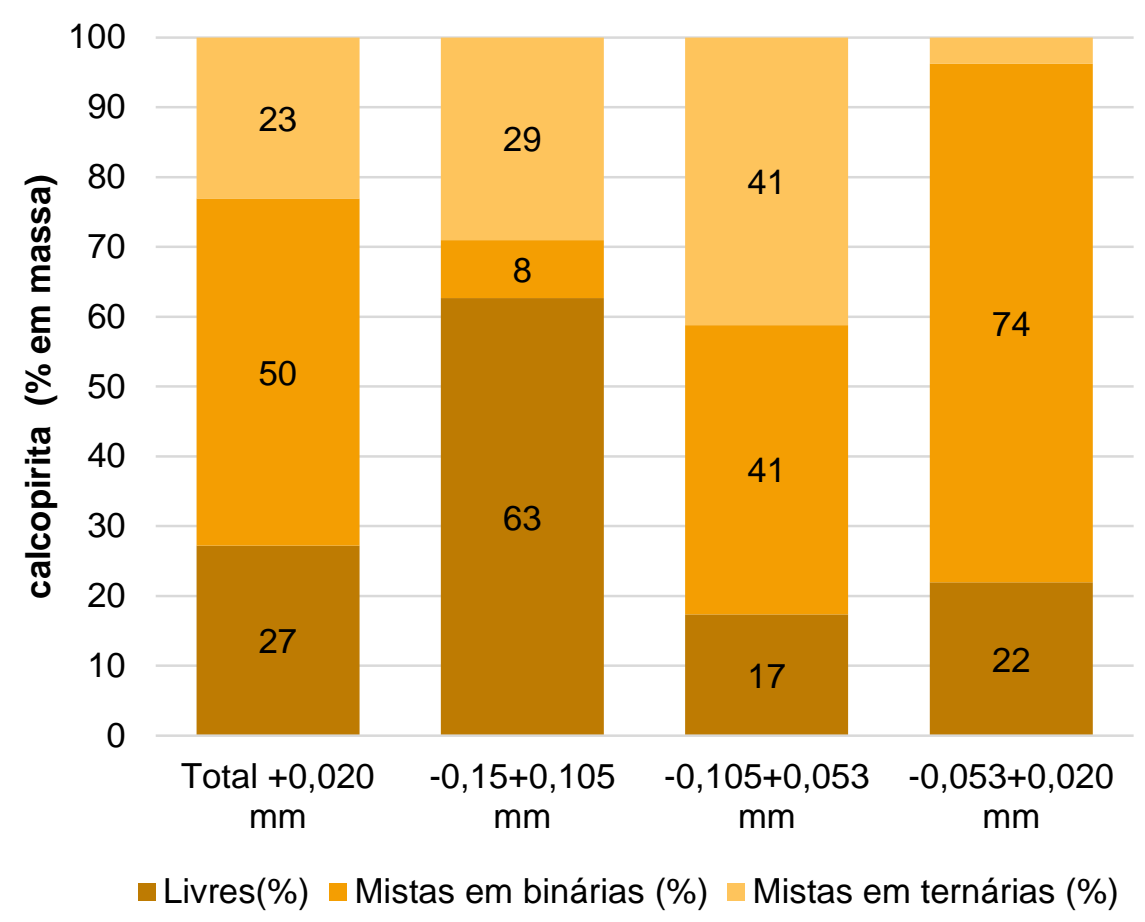

$\underline{\text { Out }}$

A Tabela 64 e a Figura 93 apresentam um sumário da distribuição das formas de associação de calcopirita (\% em massa), entre livre e misto em partículas binárias (2 fases) ou misto em partículas ternárias (3 ou mais fases minerais), para as frações granulométricas acima de 0,020 mm para a amostra de Out. 
APÊNDICE 6

Resultados MLA

Tabela 64 - Formas de associação de calcopirita - Outlier

\begin{tabular}{|c|c|c|c|c|}
\hline Fração (mm) & Total $+\mathbf{0 , 0 2 0}$ & $-0,15+0,105$ & $-0,105+0,053$ & $-0,053+0,020$ \\
\hline$\%$ massa & 82 & 27 & 32 & 24 \\
\hline Livre(\%) & 43 & - & - & 60 \\
\hline Mista em binárias (\%) & 34 & 59 & 44 & 29 \\
\hline Mista em ternárias (\%) & 22 & 41 & 56 & 11 \\
\hline \multicolumn{5}{|c|}{ Distribuição - binárias (\%) } \\
\hline pentl. + pentl. ox. & 0,7 & 0,0 & 0,0 & 1,0 \\
\hline calco-covelita & 0,0 & 0,0 & 0,0 & 0,0 \\
\hline esfalerita & 0,0 & 0,0 & 0,0 & 0,0 \\
\hline pirita & 1,2 & 0,7 & 0,4 & 1,4 \\
\hline pirrotita & 0,0 & 0,0 & 0,0 & 0,0 \\
\hline arsenopirita & 0,0 & 0,0 & 0,0 & 0,0 \\
\hline FeNiCoS & 0,0 & 0,0 & 0,0 & 0,0 \\
\hline ortopiroxênio & 31,2 & 55,4 & 42,0 & 25,2 \\
\hline clinopiroxênio & 1,0 & 2,6 & 1,2 & 0,8 \\
\hline anfibólio & 0,0 & 0,0 & 0,0 & 0,0 \\
\hline olivina & 0,0 & 0,0 & 0,0 & 0,0 \\
\hline serpentina & 0,0 & 0,0 & 0,0 & 0,0 \\
\hline outros silicatos & 0,0 & 0,1 & 0,2 & 0,0 \\
\hline espinelio-Cr & 0,0 & 0,0 & 0,0 & 0,0 \\
\hline oxido-Fe & 0,0 & 0,0 & 0,0 & 0,0 \\
\hline mica & 0,0 & 0,0 & 0,0 & 0,0 \\
\hline calcita & 0,0 & 0,0 & 0,0 & 0,0 \\
\hline outros & 0,0 & 0,0 & 0,0 & 0,0 \\
\hline \multicolumn{5}{|c|}{ Distribuição - ternárias (\%) } \\
\hline pentl. + pentl. ox. & 2,2 & 4,9 & 1,5 & 2,1 \\
\hline calco-covelita & 0,0 & 0,0 & 0,0 & 0,0 \\
\hline esfalerita & 0,0 & 0,0 & 0,0 & 0,0 \\
\hline pirita & 4,2 & 1,9 & 13,4 & 2,2 \\
\hline pirrotita & 1,5 & 15,7 & 0,0 & 0,0 \\
\hline arsenopirita & 0,0 & 0,0 & 0,0 & 0,0 \\
\hline FeNiCos & 0,0 & 0,0 & 0,0 & 0,0 \\
\hline ortopiroxênio & 8,6 & 14,4 & 30,6 & 2,3 \\
\hline clinopiroxênio & 1,7 & 2,8 & 3,0 & 1,2 \\
\hline anfibólio & 1,9 & 0,3 & 7,3 & 0,7 \\
\hline olivina & 0,0 & 0,0 & 0,0 & 0,0 \\
\hline serpentina & 0,0 & 0,0 & 0,0 & 0,0 \\
\hline outros silicatos & 0,1 & 0,3 & 0,1 & 0,1 \\
\hline espinelio-Cr & 0,1 & 0,0 & 0,0 & 0,1 \\
\hline oxido-Fe & 1,9 & 0,7 & 0,1 & 2,6 \\
\hline mica & 0,1 & 0,0 & 0,0 & 0,1 \\
\hline calcita & 0,0 & 0,2 & 0,0 & 0,0 \\
\hline outros & 0,0 & 0,0 & 0,0 & 0,0 \\
\hline
\end{tabular}

Obs: outros silicatos = quartzo, feldspato potássico e plagioclásio; carbonatos = calcita, dolomita, magnesita e anquerita; outros = clorita, espinélio-Cr, óxido-Fe, ilmenita, apatita, coríndon. 
APÊNDICE 6

Resultados MLA

Figura 93 - Distribuição das formas de associação de calcopirita na amostra Outlier

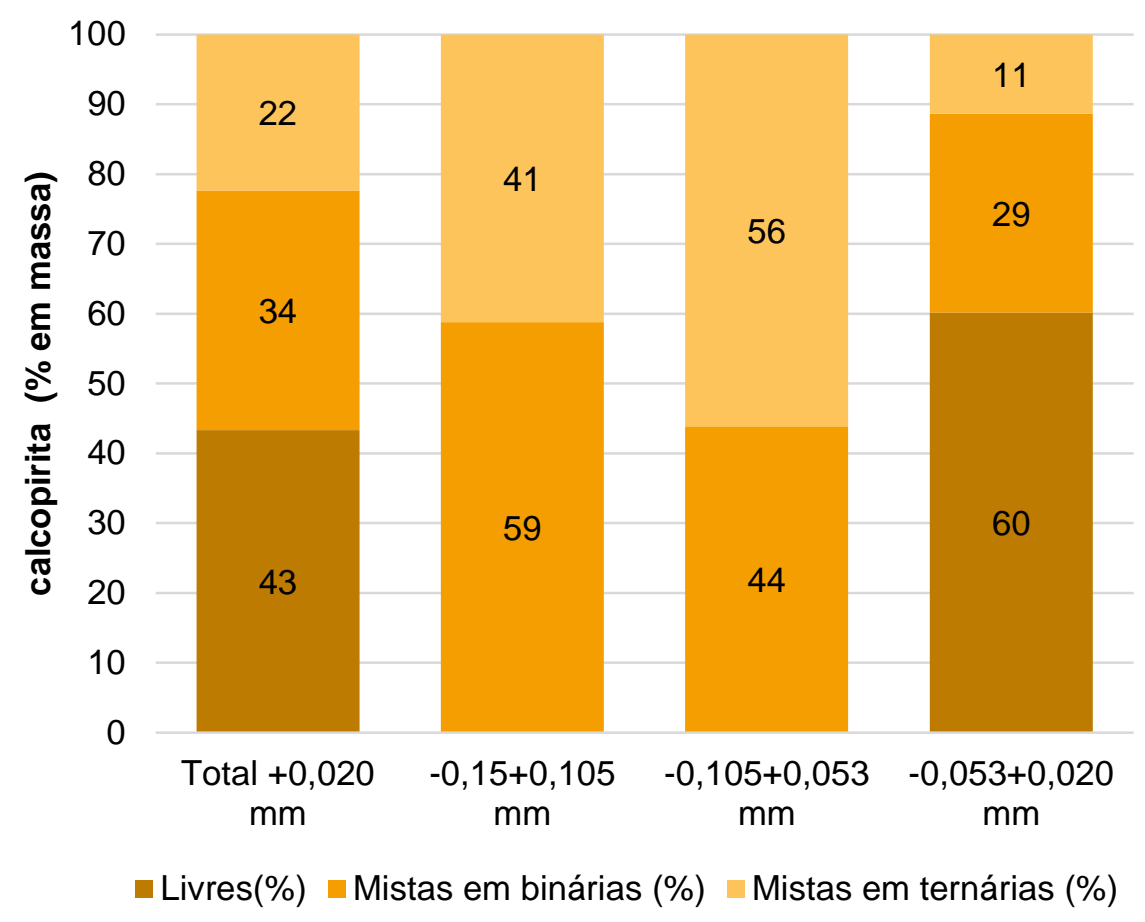

As curvas de espectro de liberação da pentlandita + pentlandita oxidada são apresentadas da Figura 94 a Figura 101, para frações em área e em perímetro exposto, de acordo com suas respectivas faixas granulométricas

Figura 94 - Espectro de liberação de calcopirita na amostra OPS
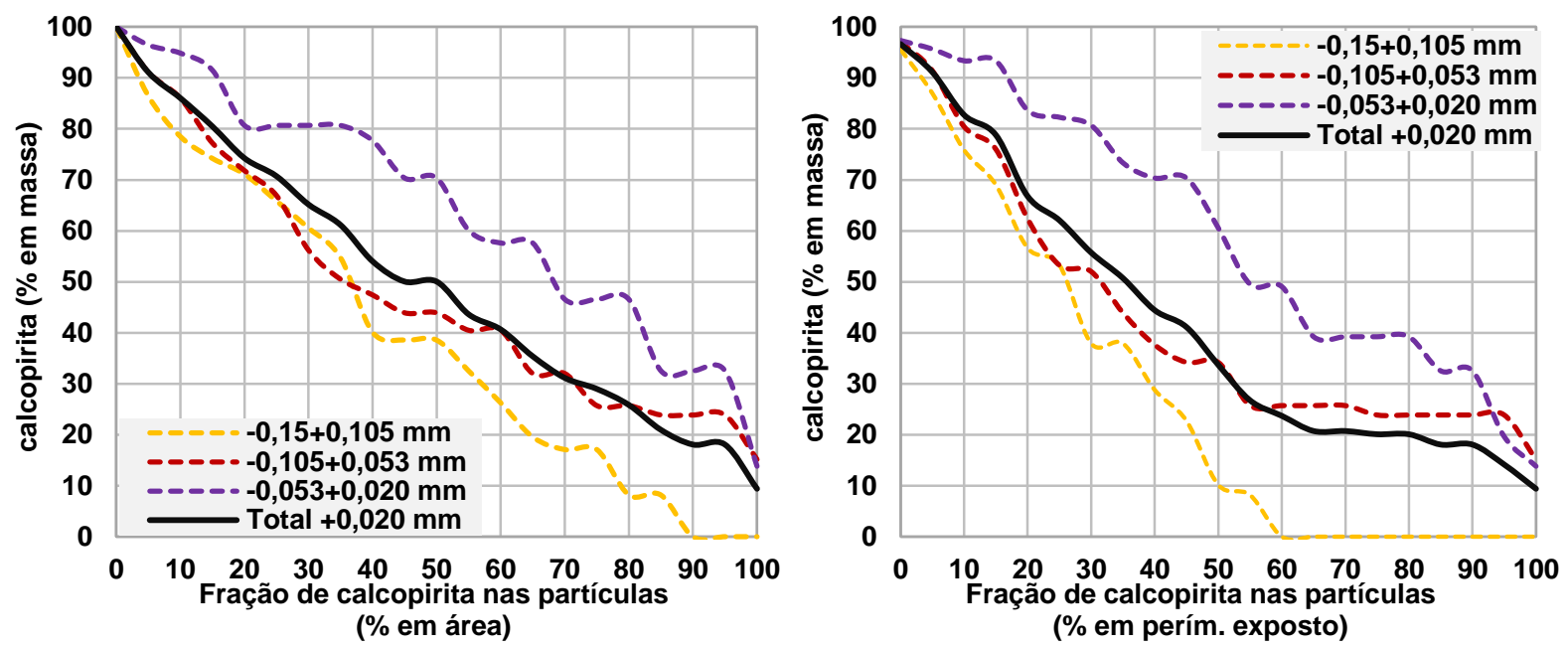
APÊNDICE 6

Resultados MLA

Figura 95 - Espectro de liberação de calcopirita na amostra POS
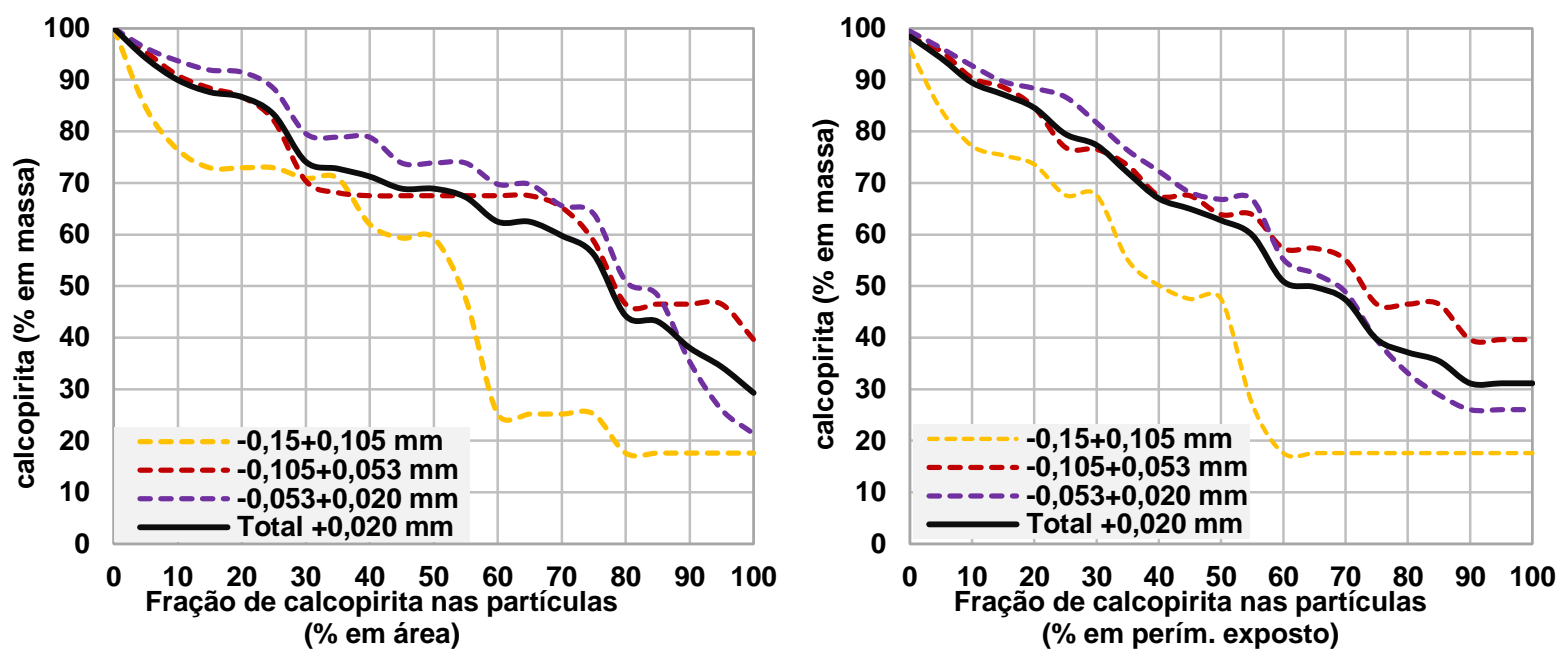

Figura 96 - Espectro de liberação de calcopirita na amostra PO
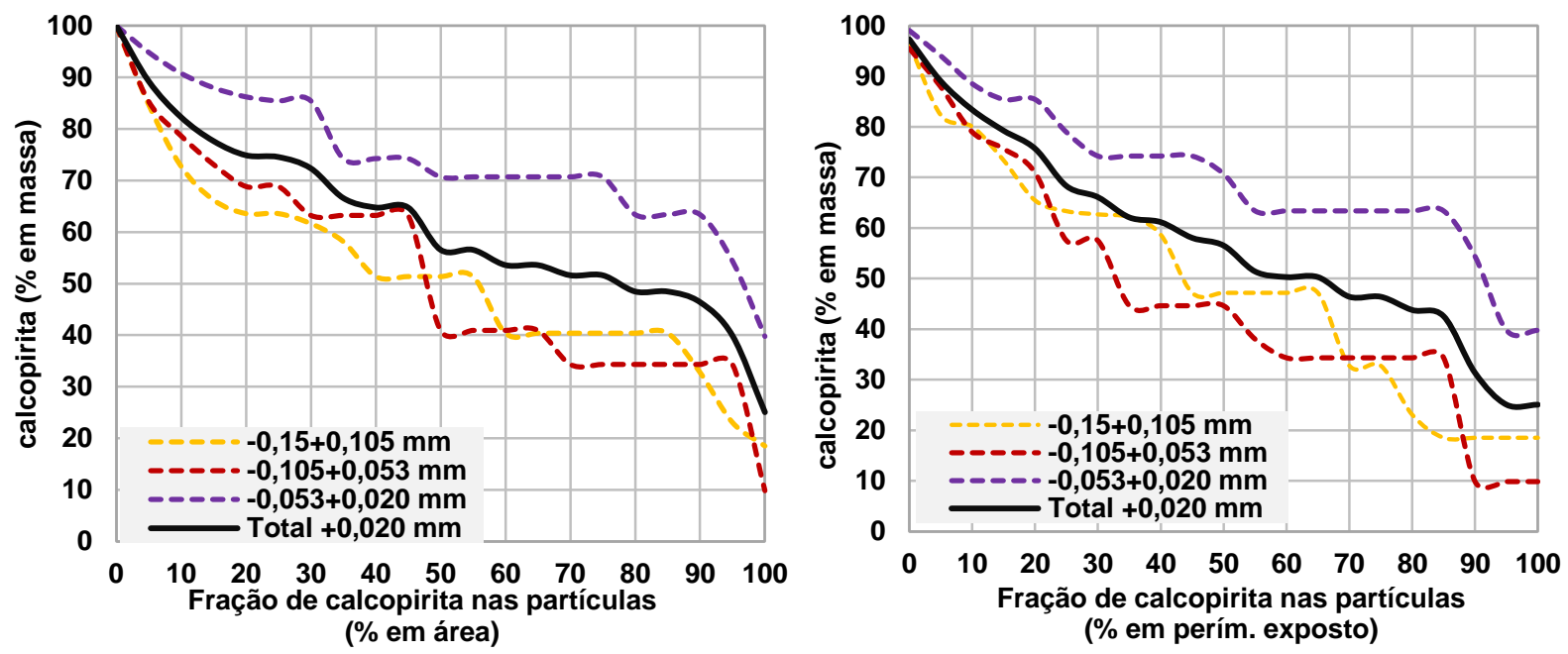
APÊNDICE 6

Resultados MLA

Figura 97 - Espectro de liberação de calcopirita na amostra P
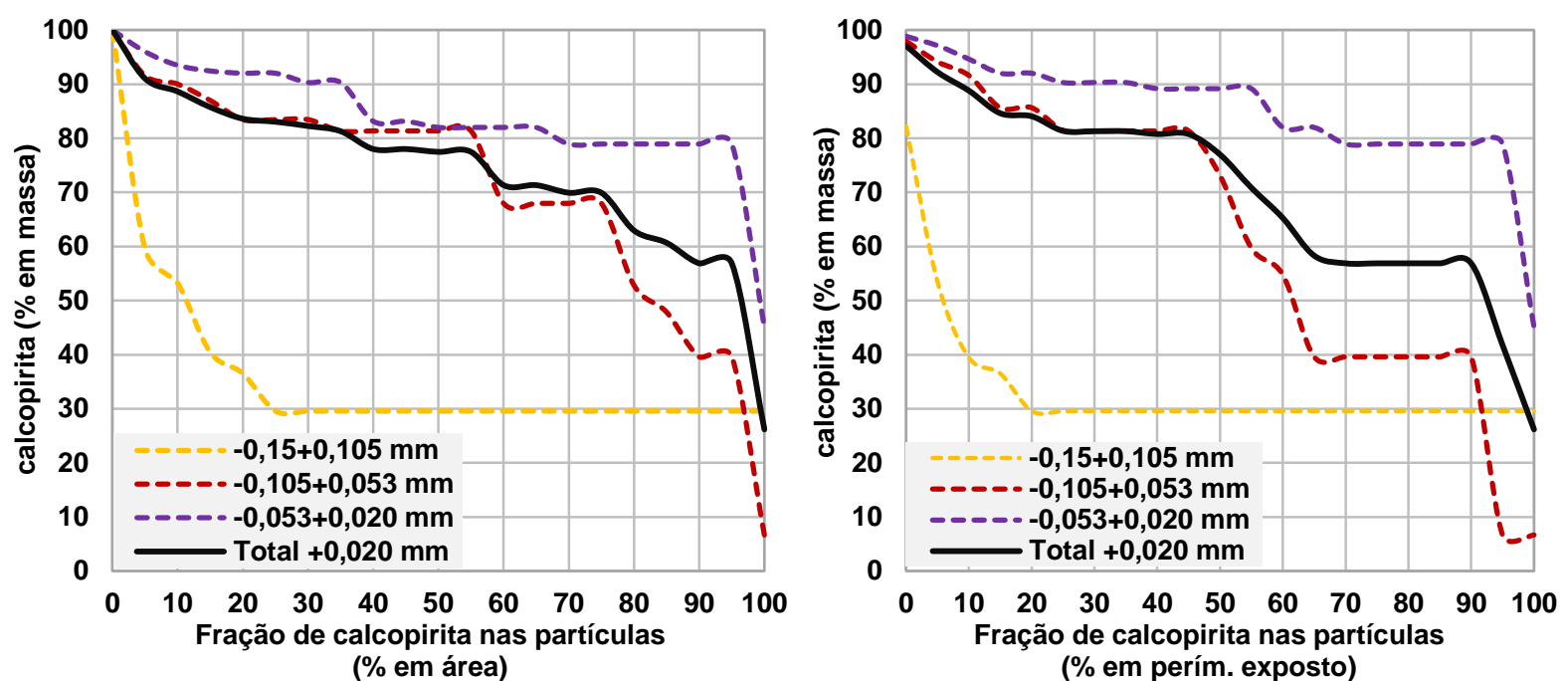

Figura 98 - Espectro de liberação de calcopirita na amostra Ganga A
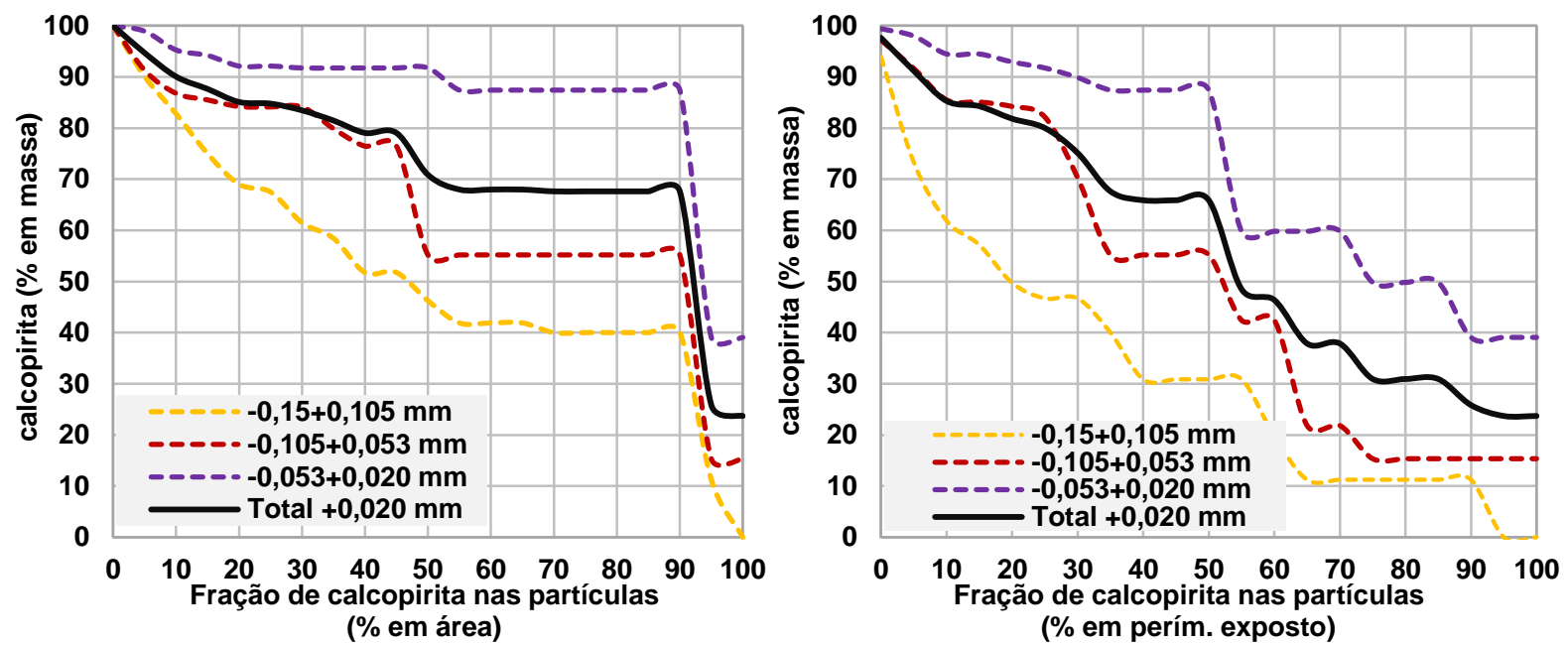
APÊNDICE 6

Resultados MLA

Figura 99 - Espectro de liberação de calcopirita na amostra Ganga B
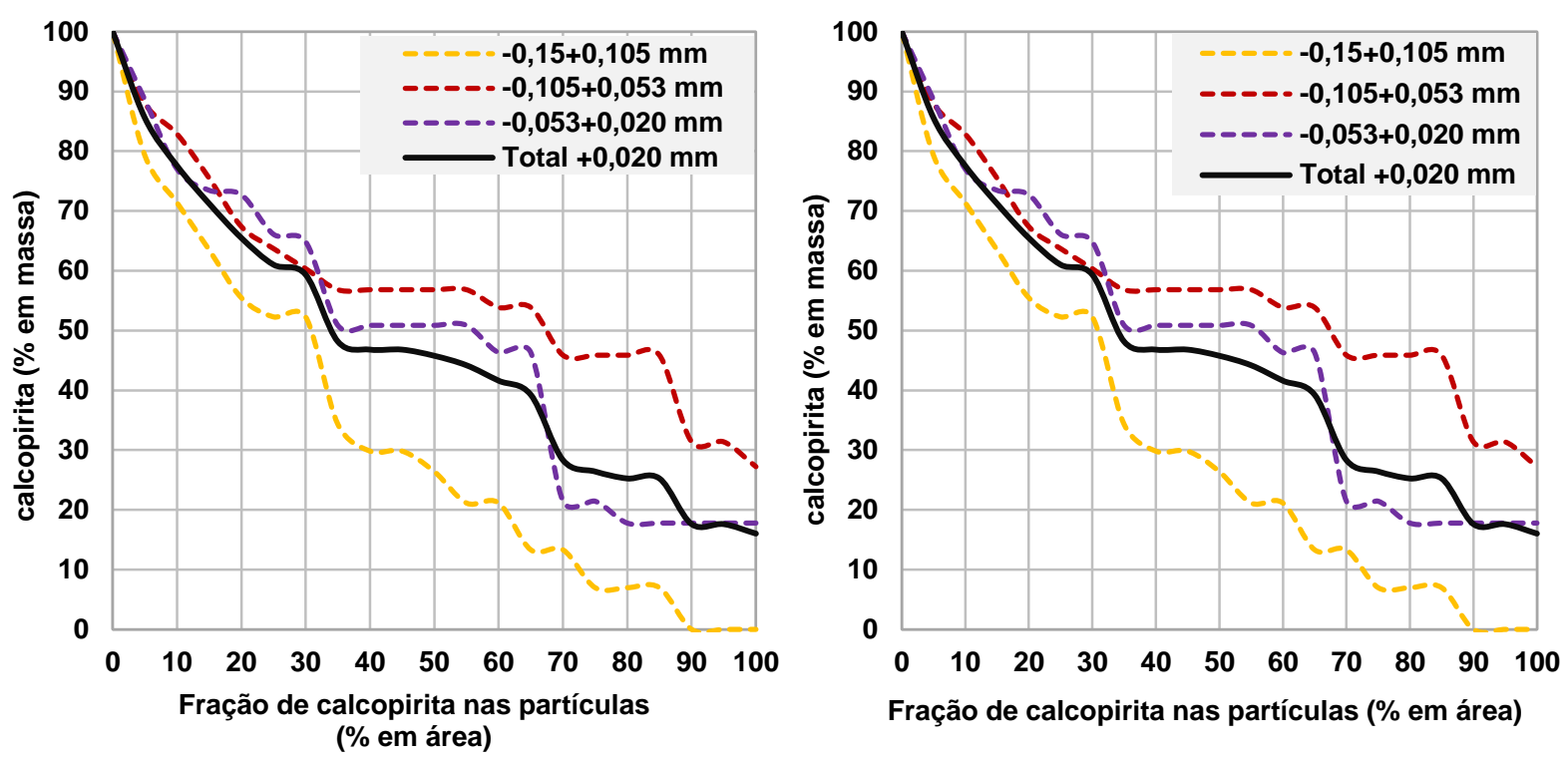

Figura 100 - Espectro de liberação de calcopirita na amostra Ganga C
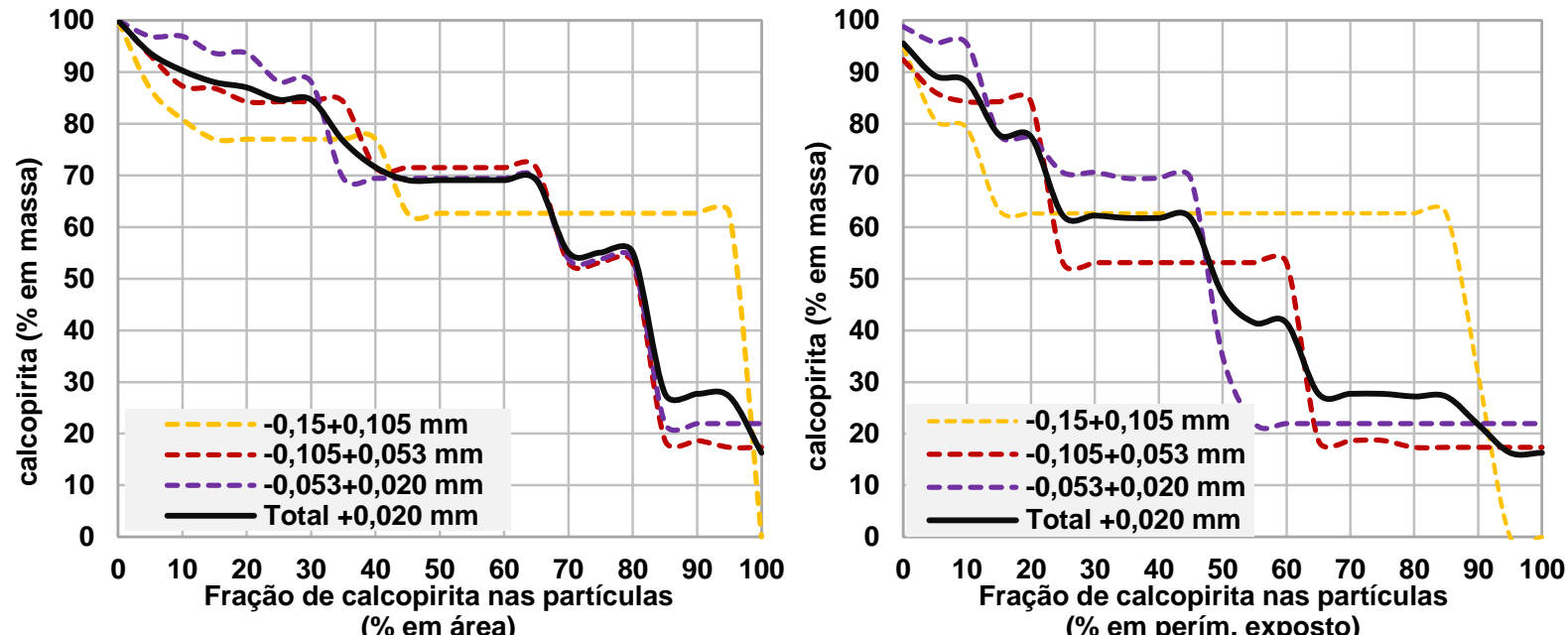

(\% em área) 
APÊNDICE 6

Resultados MLA

Figura 101 - Espectro de liberação de calcopirita na amostra Outlier
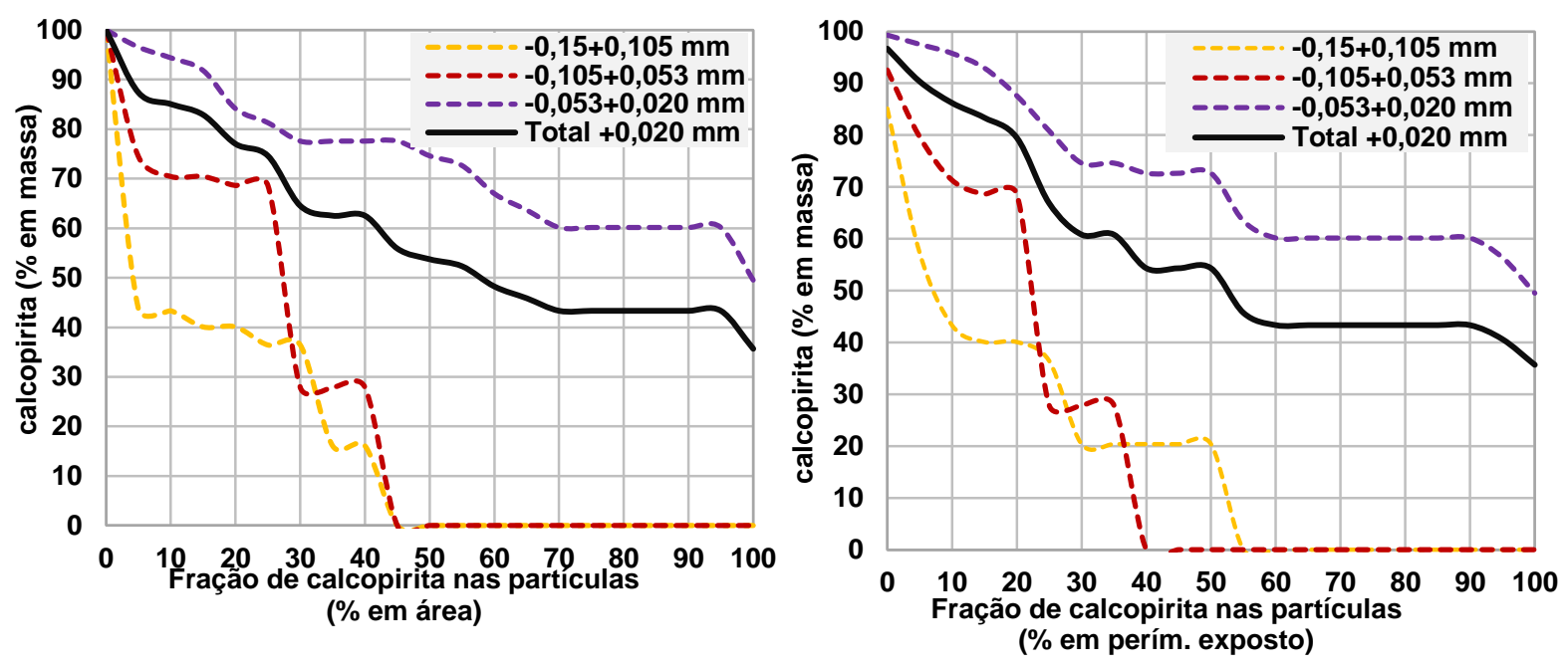

\section{Sulfetos}

\section{OPS}

A Tabela 39 e Figura 33 apresentam um sumário da distribuição das formas de associação de sulfetos (\% em massa), entre livre e misto em partículas binárias (2 fases) ou misto em partículas ternárias (3 ou mais fases minerais), para as frações granulométricas acima de $0,020 \mathrm{~mm}$ para a amostra de OPS. 
APÊNDICE 6

Resultados MLA

Tabela 65 - Formas de associação de sulfetos - OPS

\begin{tabular}{l|cccc}
\hline Fração (mm) & Total +0,020 & $\mathbf{- 0 , 1 5 + 0 , 1 0 5}$ & $\mathbf{- 0 , 1 0 5 + 0 , 0 5 3}$ & $\mathbf{- 0 , 0 5 3 + 0 , 0 2 0}$ \\
\hline \% massa & 70 & 20 & 29 & 22 \\
\hline Livres(\%) & 29 & 16 & 30 & 37 \\
Mistos em binárias (\%) & 39 & 37 & 41 & 36 \\
Mistos em ternárias (\%) & 33 & 46 & 28 & 27 \\
\hline Distribuição - binárias (\%) & & & & \\
ortopiroxênio & 0,6 & 0,6 & 0,3 & 0,9 \\
clinopiroxênio & 0,1 & 0,0 & 0,1 & 0,2 \\
anfibólio & 0,5 & 0,3 & 0,6 & 0,5 \\
olivina & 3,0 & 1,1 & 3,0 & 4,5 \\
serpentina & 17,0 & 9,4 & 17,7 & 22,4 \\
espinelio-Cr & 0,2 & 0,5 & 0,2 & 0,0 \\
oxido-Fe & 14,7 & 24,4 & 15,9 & 5,5 \\
mica & 0,0 & 0,0 & 0,0 & 0,0 \\
carbonatos & 2,6 & 1,2 & 3,7 & 2,3 \\
outros silicatos & 0,0 & 0,0 & 0,0 & 0,0 \\
outros & 0,0 & 0,0 & 0,0 & 0,0 \\
\hline Distribuição - ternárias (\%) & & & & \\
ortopiroxênio & 1,1 & 1,8 & 0,5 & 1,2 \\
clinopiroxênio & 0,4 & 0,3 & 0,3 & 0,7 \\
anfibólio & 1,3 & 1,5 & 1,0 & 1,5 \\
olivina & 3,9 & 3,4 & 3,5 & 4,8 \\
serpentina & 12,5 & 18,0 & 11,1 & 9,8 \\
espinelio-Cr & 1,4 & 3,0 & 1,1 & 0,6 \\
oxido-Fe & 9,1 & 14,3 & 8,0 & 6,1 \\
mica & 0,1 & 0,1 & 0,0 & 0,0 \\
carbonatos & 2,6 & 3,7 & 2,6 & 1,6 \\
outros silicatos & 0,0 & 0,1 & 0,0 & 0,1 \\
outros & 0,1 & 0,0 & 0,1 & 0,1 \\
\hline abs:ouros & & 0,0 & \\
\hline
\end{tabular}

Obs: outros silicatos = quartzo, feldspato potássico e plagioclásio; carbonatos = calcita, dolomita, magnesita e anquerita; outros = clorita, espinélio-Cr, óxido-Fe, ilmenita, apatita, coríndon. 
APÊNDICE 6

Resultados MLA

Figura 102 - Distribuição das formas de associação de sulfetos na amostra OPS

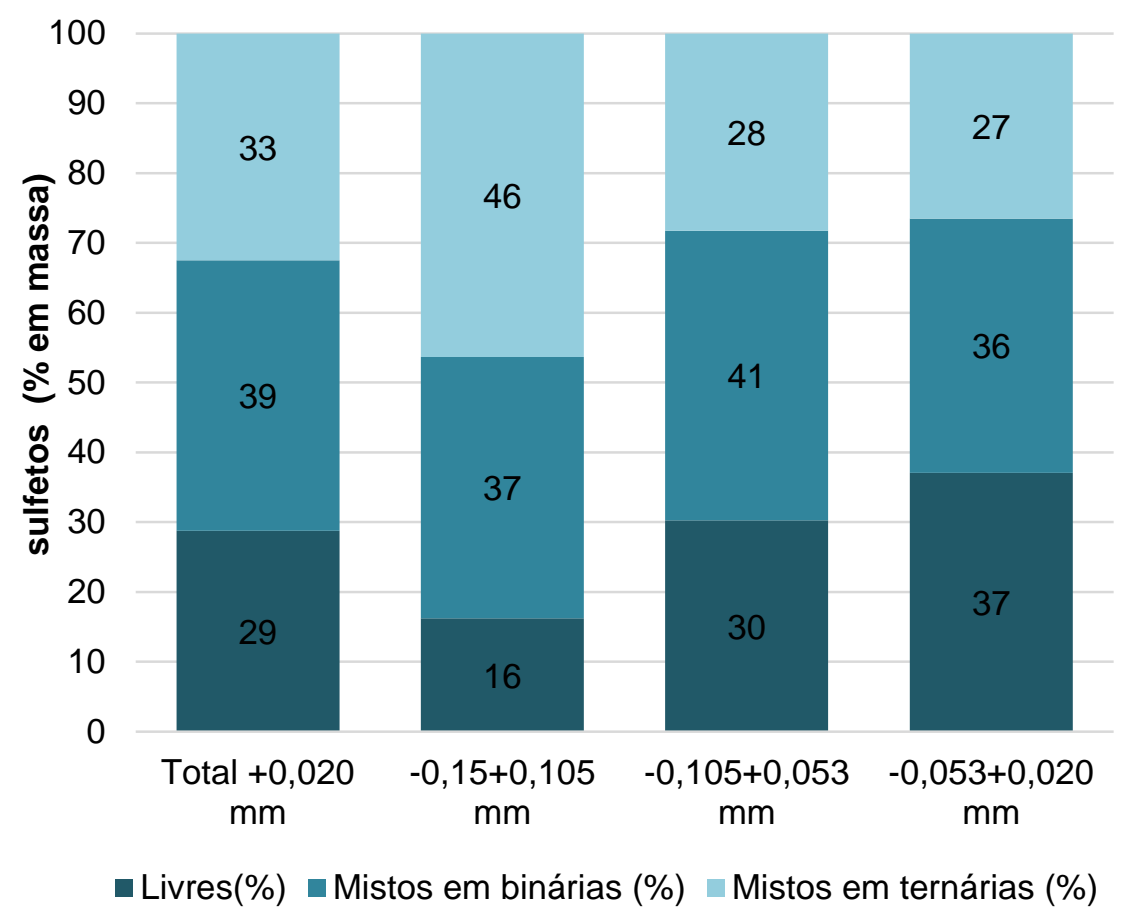

POS

A Tabela 66 e Figura 103 apresentam um sumário da distribuição das formas de associação de sulfetos (\% em massa), entre livre e misto em partículas binárias (2 fases) ou misto em partículas ternárias (3 ou mais fases minerais), para as frações granulométricas acima de $0,020 \mathrm{~mm}$ para a amostra POS. 
APÊNDICE 6

Resultados MLA

Tabela 66 - Formas de associação de sulfetos - POS

\begin{tabular}{|c|c|c|c|c|}
\hline Fração (mm) & Total $+0,020$ & $-0,15+0,105$ & $-0,105+0,053$ & $-0,053+0,020$ \\
\hline$\%$ massa & 77 & 20 & 32 & 25 \\
\hline Livres(\%) & 50 & 52 & 51 & 50 \\
\hline Mistos em binárias (\%) & 34 & 32 & 34 & 34 \\
\hline Mistos em ternárias (\%) & 16 & 16 & 14 & 17 \\
\hline \multicolumn{5}{|l|}{ Distribuição - binárias (\%) } \\
\hline ortopiroxênio & 9,8 & 7,0 & 8,8 & 11,6 \\
\hline clinopiroxênio & 0,6 & 0,3 & 0,6 & 0,7 \\
\hline anfibólio & 0,8 & 0,7 & 0,9 & 0,8 \\
\hline olivina & 2,0 & 2,4 & 1,8 & 2,0 \\
\hline serpentina & 15,1 & 15,3 & 14,9 & 15,1 \\
\hline espinelio-Cr & 0,4 & 0,2 & 1,2 & 0,0 \\
\hline oxido-Fe & 2,8 & 2,5 & 3,7 & 2,2 \\
\hline mica & 0,4 & 0,0 & 0,0 & 0,8 \\
\hline carbonatos & 1,3 & 3,8 & 1,4 & 0,4 \\
\hline outros silicatos & 0,5 & 0,0 & 1,2 & 0,0 \\
\hline outros & 0,0 & 0,0 & 0,0 & 0,0 \\
\hline \multicolumn{5}{|l|}{ Distribuição - ternárias (\%) } \\
\hline ortopiroxênio & 4,7 & 4,9 & 5,2 & 4,2 \\
\hline clinopiroxênio & 0,5 & 0,9 & 0,6 & 0,3 \\
\hline anfibólio & 1,3 & 1,5 & 0,5 & 1,8 \\
\hline olivina & 1,8 & 1,1 & 1,6 & 2,2 \\
\hline serpentina & 5,3 & 4,9 & 3,5 & 6,7 \\
\hline espinelio- $\mathrm{Cr}$ & 0,1 & 0,1 & 0,1 & 0,0 \\
\hline oxido-Fe & 1,1 & 0,9 & 1,4 & 0,9 \\
\hline mica & 0,2 & 0,6 & 0,1 & 0,1 \\
\hline carbonatos & 0,7 & 0,7 & 1,1 & 0,5 \\
\hline outros silicatos & 0,2 & 0,6 & 0,1 & 0,1 \\
\hline outros & 0,1 & 0,1 & 0,1 & 0,0 \\
\hline
\end{tabular}

Obs: outros silicatos = quartzo, feldspato potássico e plagioclásio; carbonatos = calcita, dolomita, magnesita e anquerita; outros = clorita, espinélio-Cr, óxido-Fe, ilmenita, apatita, coríndon. 
APÊNDICE 6

Resultados MLA

Figura 103 - Distribuição das formas de associação de sulfetos na amostra POS

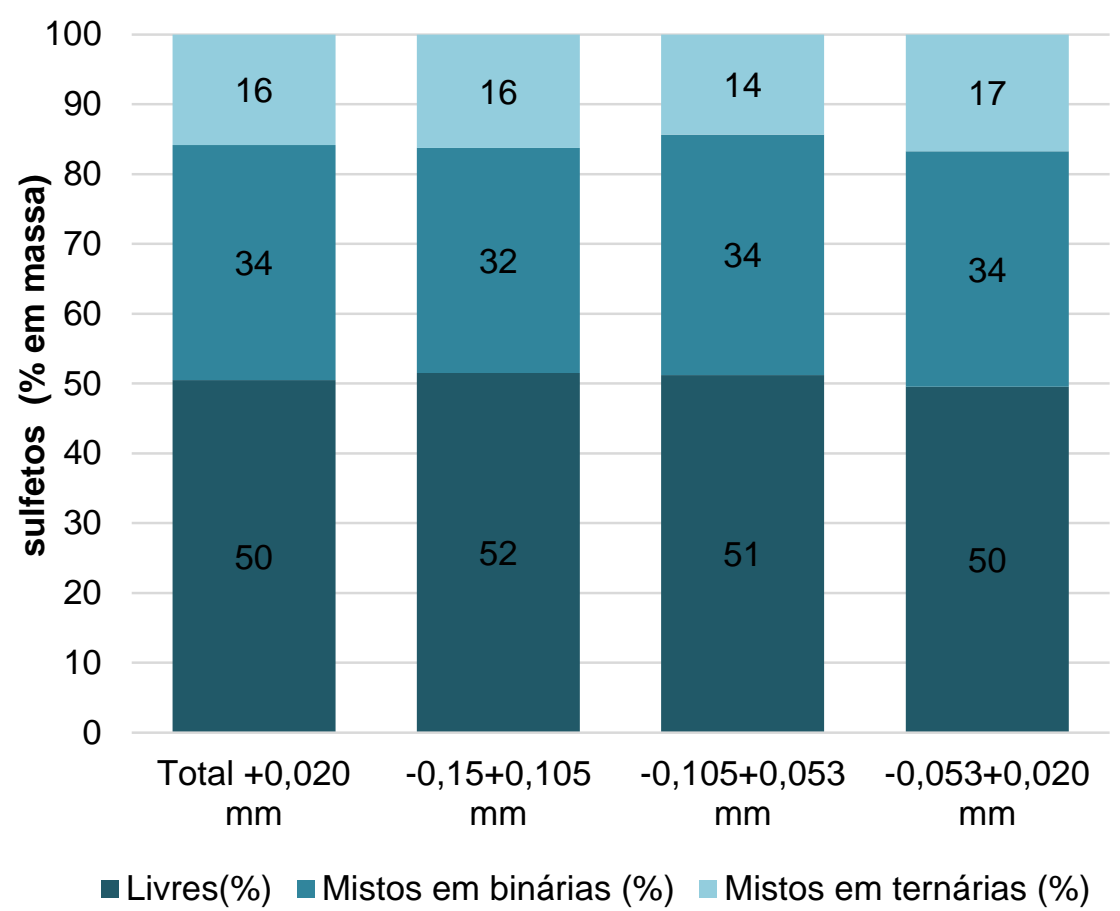

$\underline{\mathrm{PO}}$

A Tabela 67 e Figura 104 apresentam um sumário da distribuição das formas de associação de sulfetos (\% em massa), entre livre e misto em partículas binárias (2 fases) ou misto em partículas ternárias (3 ou mais fases minerais), para as frações granulométricas acima de $0,020 \mathrm{~mm}$, para a amostra PO. 
APÊNDICE 6

Resultados MLA

Tabela 67 - Formas de associação de sulfetos - PO

\begin{tabular}{l|cccc}
\hline Fração (mm) & Total +0,020 & $\mathbf{- 0 , 1 5 + 0 , 1 0 5}$ & $\mathbf{- 0 , 1 0 5 + 0 , 0 5 3}$ & $\mathbf{- 0 , 0 5 3 + 0 , 0 2 0}$ \\
\hline \% massa & 76 & 22 & 32 & 22 \\
\hline Livres(\%) & 57 & 47 & 58 & 61 \\
Mistos em binárias (\%) & 30 & 37 & 30 & 27 \\
Mistos em ternárias (\%) & 13 & 16 & 13 & 12 \\
\hline Distribuição - binárias (\%) & & & & \\
ortopiroxênio & 14,8 & 24,9 & 12,4 & 13,3 \\
clinopiroxênio & 1,7 & 3,7 & 1,1 & 1,5 \\
anfibólio & 0,6 & 0,6 & 0,3 & 0,9 \\
olivina & 1,6 & 0,1 & 1,0 & 2,7 \\
serpentina & 4,7 & 3,8 & 4,4 & 5,4 \\
espinelio-Cr & 0,1 & 0,2 & 0,1 & 0,1 \\
oxido-Fe & 2,0 & 1,9 & 3,1 & 1,0 \\
mica & 0,0 & 0,0 & 0,0 & 0,0 \\
carbonatos & 4,1 & 1,6 & 6,5 & 2,6 \\
outros silicatos & 0,4 & 0,2 & 0,9 & 0,0 \\
outros & 0,0 & 0,0 & 0,0 & 0,0 \\
\hline Distribuição - ternárias (\%) & & & & \\
ortopiroxênio & 5,7 & 6,4 & 6,0 & 5,1 \\
clinopiroxênio & 0,6 & 1,4 & 0,7 & 0,3 \\
anfibólio & 0,4 & 0,7 & 0,4 & 0,4 \\
olivina & 1,1 & 1,5 & 0,9 & 1,2 \\
serpentina & 2,3 & 4,0 & 1,9 & 2,2 \\
espinelio-Cr & 0,2 & 0,2 & 0,1 & 0,2 \\
oxido-Fe & 0,9 & 0,6 & 0,6 & 1,2 \\
mica & 0,2 & 0,0 & 0,2 & 0,4 \\
carbonatos & 0,8 & 0,6 & 1,2 & 0,5 \\
outros silicatos & 0,5 & 0,5 & 0,4 & 0,6 \\
outros & 0,1 & 0,4 & 0,1 & 0,0 \\
\hline Obsiouros & & & 0,4 & \\
\hline
\end{tabular}

Obs: outros silicatos = quartzo, feldspato potássico e plagioclásio; carbonatos = calcita, dolomita, magnesita e anquerita; outros = clorita, espinélio-Cr, óxido-Fe, ilmenita, apatita, coríndon. 
APÊNDICE 6

Resultados MLA

Figura 104 - Distribuição das formas de associação de sulfetos na amostra PO

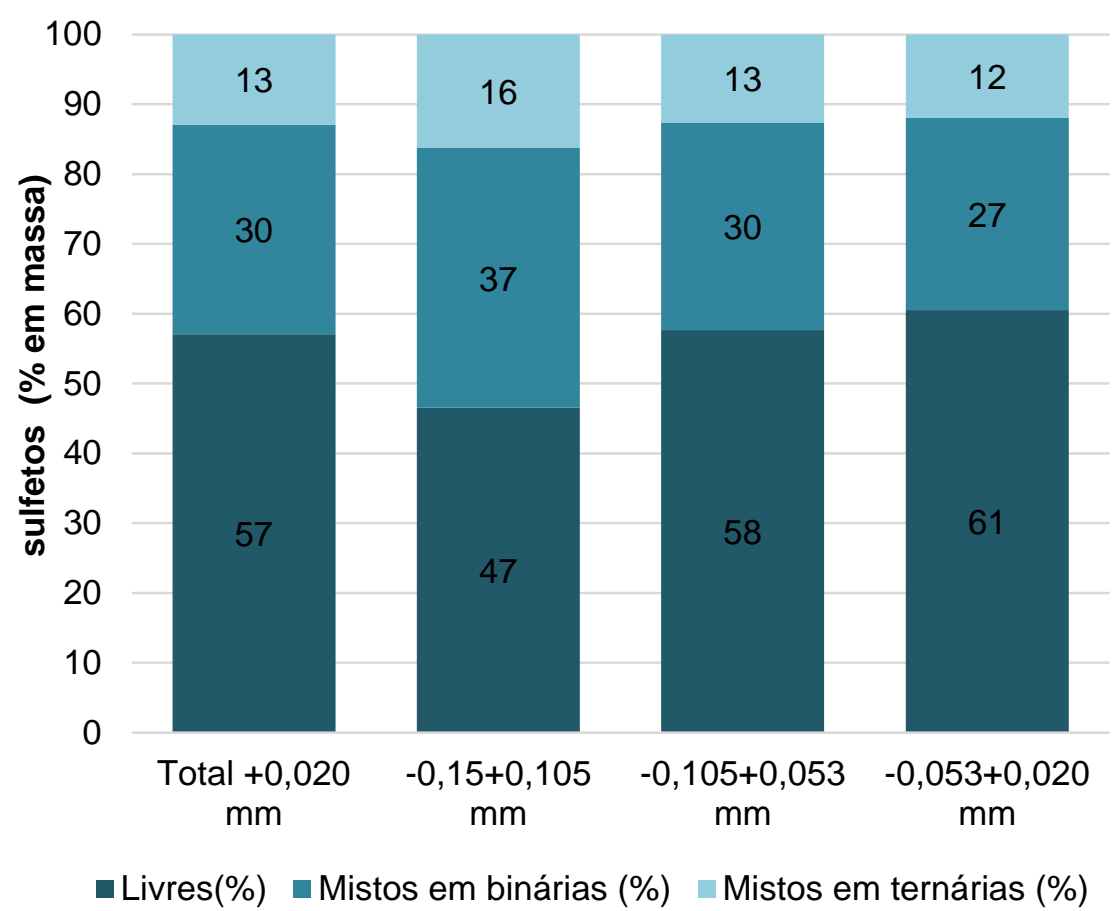

$\underline{P}$

A Tabela 68 e Figura 105 apresentam um sumário da distribuição das formas de associação de sulfetos (\% em massa), entre livre e misto em partículas binárias (2 fases) ou misto em partículas ternárias (3 ou mais fases minerais), para as frações granulométricas acima de $0,020 \mathrm{~mm}$ para a amostra $\mathrm{P}$. 
APÊNDICE 6

Resultados MLA

Tabela 68 - Formas de associação de sulfetos - $P$

\begin{tabular}{|c|c|c|c|c|}
\hline Fração (mm) & Total $+\mathbf{0 , 0 2 0}$ & $-0,15+0,105$ & $-0,105+0,053$ & $-0,053+0,020$ \\
\hline$\%$ massa & 82 & 26 & 33 & 23 \\
\hline Livres(\%) & 54 & 51 & 60 & 50 \\
\hline Mistos em binárias (\%) & 33 & 28 & 29 & 36 \\
\hline Mistos em ternárias (\%) & 13 & 21 & 10 & 13 \\
\hline \multicolumn{5}{|l|}{ Distribuição - binárias (\%) } \\
\hline ortopiroxênio & 22,2 & 19,0 & 17,6 & 25,9 \\
\hline clinopiroxênio & 2,1 & 1,0 & 5,2 & 0,4 \\
\hline anfibólio & 0,8 & 1,5 & 0,1 & 1,1 \\
\hline olivina & 2,9 & 0,1 & 2,4 & 3,9 \\
\hline serpentina & 2,0 & 1,3 & 2,3 & 1,9 \\
\hline espinelio-Cr & 0,0 & 0,0 & 0,1 & 0,0 \\
\hline oxido-Fe & 0,8 & 4,5 & 0,1 & 0,3 \\
\hline mica & 1,2 & 0,0 & 0,1 & 2,2 \\
\hline carbonatos & 0,5 & 0,2 & 1,5 & 0,0 \\
\hline outros silicatos & 0,3 & 0,5 & 0,0 & 0,5 \\
\hline outros & 0,0 & 0,0 & 0,0 & 0,0 \\
\hline \multicolumn{5}{|l|}{ Distribuição - ternárias (\%) } \\
\hline ortopiroxênio & 5,3 & 5,6 & 4,7 & 5,7 \\
\hline clinopiroxênio & 1,1 & 1,3 & 0,6 & 1,3 \\
\hline anfibólio & 0,4 & 1,4 & 0,4 & 0,2 \\
\hline olivina & 1,1 & 1,5 & 0,3 & 1,5 \\
\hline serpentina & 1,9 & 6,5 & 2,0 & 0,8 \\
\hline espinelio-Cr & 0,3 & 1,7 & 0,1 & 0,1 \\
\hline oxido-Fe & 1,1 & 0,9 & 0,7 & 1,5 \\
\hline mica & 0,2 & 0,1 & 0,3 & 0,1 \\
\hline carbonatos & 1,3 & 1,7 & 1,2 & 1,3 \\
\hline outros silicatos & 0,5 & 0,2 & 0,0 & 0,8 \\
\hline outros & 0,1 & 0,0 & 0,0 & 0,1 \\
\hline
\end{tabular}

Obs: outros silicatos = quartzo, feldspato potássico e plagioclásio; carbonatos = calcita, dolomita, magnesita e anquerita; outros = clorita, espinélio-Cr, óxido-Fe, ilmenita, apatita, coríndon. 


\section{APÊNDICE 6}

Resultados MLA

Figura 105 - Distribuição das formas de associação de sulfetos na amostra $P$

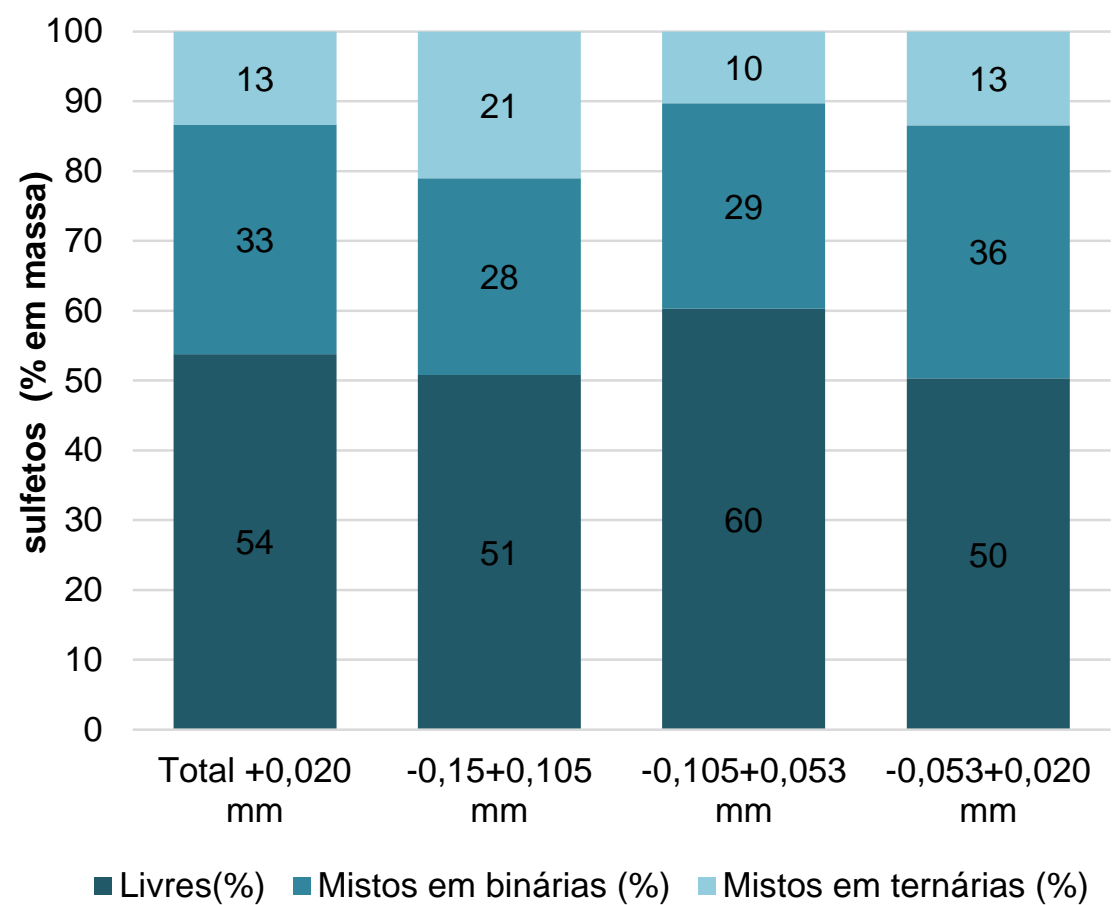

\section{Ganga A}

A Tabela 69 e Figura 106 apresentam um sumário da distribuição das formas de associação de sulfetos (\% em massa), entre livre e misto em partículas binárias (2 fases) ou misto em partículas ternárias (3 ou mais fases minerais), para as frações granulométricas acima de 0,020 $\mathrm{mm}$ para a amostra de Ganga A. 
APÊNDICE 6

Resultados MLA

Tabela 69 - Formas de associação de Sulfetos - Ganga A

\begin{tabular}{|c|c|c|c|c|}
\hline Fração (mm) & Total $+\mathbf{0 , 0 2 0}$ & $-0,15+0,105$ & $-0,105+0,053$ & $-0,053+0,020$ \\
\hline$\%$ massa & 60 & 14 & 24 & 22 \\
\hline Livres(\%) & 24 & 22 & 16 & 32 \\
\hline Mistos em binárias (\%) & 42 & 44 & 46 & 39 \\
\hline Mistos em ternárias (\%) & 33 & 34 & 39 & 29 \\
\hline \multicolumn{5}{|l|}{ Distribuição - binárias (\%) } \\
\hline ortopiroxênio & 9,2 & 15,0 & 11,3 & 4,3 \\
\hline clinopiroxênio & 0,0 & 0,0 & 0,0 & 0,0 \\
\hline anfibólio & 0,4 & 1,8 & 0,0 & 0,0 \\
\hline olivina & 0,0 & 0,0 & 0,1 & 0,0 \\
\hline serpentina & 26,0 & 19,3 & 23,9 & 31,2 \\
\hline espinelio-Cr & 0,2 & 0,0 & 0,0 & 0,6 \\
\hline oxido-Fe & 2,3 & 4,7 & 3,5 & 0,0 \\
\hline mica & 0,0 & 0,0 & 0,0 & 0,0 \\
\hline carbonatos & 4,3 & 3,2 & 6,9 & 2,9 \\
\hline outros silicatos & 0,0 & 0,1 & 0,0 & 0,0 \\
\hline outros & 0,0 & 0,0 & 0,0 & 0,0 \\
\hline \multicolumn{5}{|l|}{ Distribuição - ternárias (\%) } \\
\hline ortopiroxênio & 6,4 & 7,1 & 8,9 & 4,2 \\
\hline clinopiroxênio & 0,1 & 0,1 & 0,1 & 0,2 \\
\hline anfibólio & 1,6 & 0,3 & 0,7 & 2,9 \\
\hline olivina & 0,1 & 0,1 & 0,1 & 0,1 \\
\hline serpentina & 14,4 & 14,6 & 16,6 & 12,6 \\
\hline espinelio- $\mathrm{Cr}$ & 0,8 & 0,3 & 0,8 & 1,1 \\
\hline oxido-Fe & 1,5 & 2,0 & 1,0 & 1,7 \\
\hline mica & 1,9 & 0,1 & 4,3 & 1,0 \\
\hline carbonatos & 6,3 & 9,5 & 6,3 & 4,5 \\
\hline outros silicatos & 0,2 & 0,0 & 0,0 & 0,5 \\
\hline outros & 0,0 & 0,0 & 0,0 & 0,0 \\
\hline
\end{tabular}

Obs: outros silicatos = quartzo, feldspato potássico e plagioclásio; carbonatos = calcita, dolomita, magnesita e anquerita; outros = clorita, espinélio-Cr, óxido-Fe, ilmenita, apatita, coríndon. 
APÊNDICE 6

Resultados MLA

Figura 106 - Distribuição das formas de associação de sulfetos na amostra Ganga A

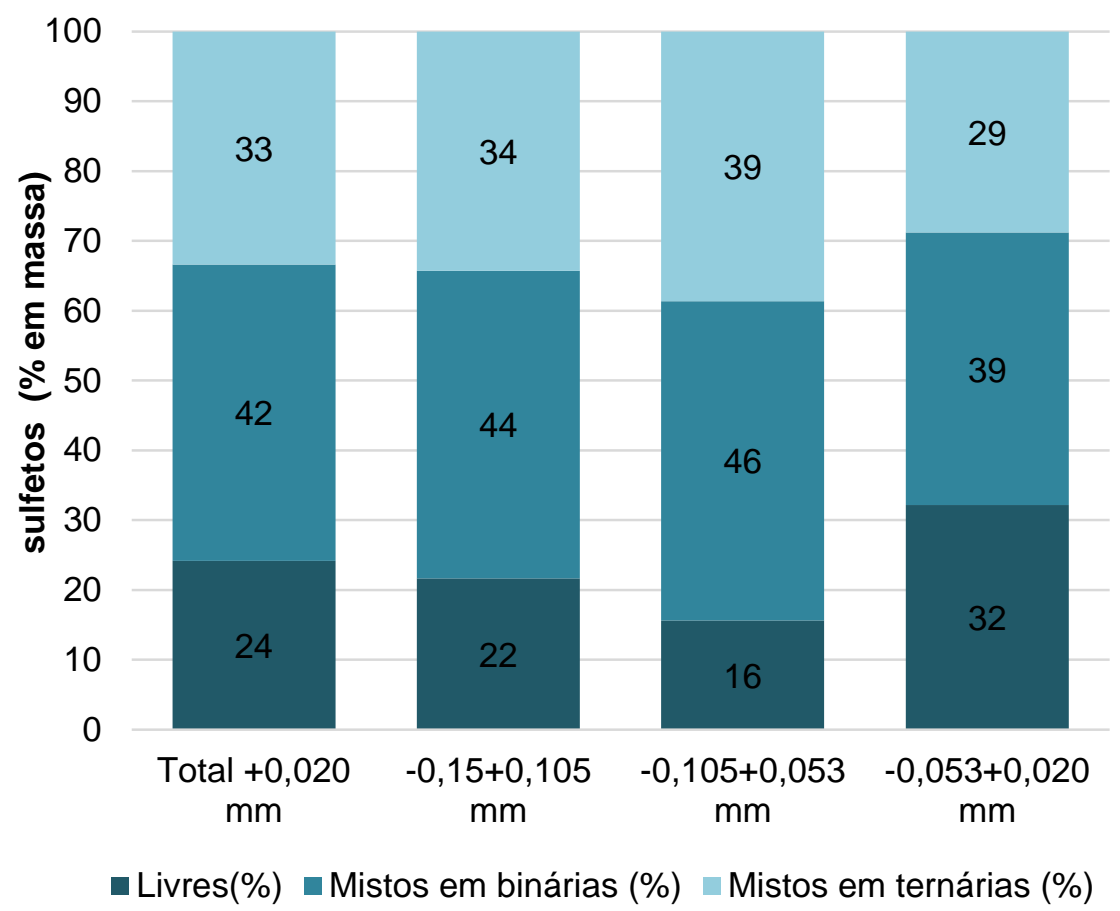

\section{Ganga B}

A Tabela 70 e Figura 107 apresentam um sumário da distribuição das formas de associação de sulfetos (\% em massa), entre livre e misto em partículas binárias (2 fases) ou misto em partículas ternárias (3 ou mais fases minerais), para as frações granulométricas acima de 0,020 mm, na amostra de Ganga B. 
APÊNDICE 6

Resultados MLA

Tabela 70 - Formas de associação de Sulfetos - Ganga B

\begin{tabular}{l|cccc}
\hline Fração (mm) & Total +0,020 & $\mathbf{- 0 , 1 5 + 0 , 1 0 5}$ & $\mathbf{- 0 , 1 0 5 + 0 , 0 5 3}$ & $\mathbf{- 0 , 0 5 3 + 0 , 0 2 0}$ \\
\hline \% massa & 61 & 16 & 23 & 22 \\
\hline Livres(\%) & 28 & 18 & 25 & 36 \\
Mistos em binárias (\%) & 36 & 33 & 40 & 34 \\
Mistos em ternárias (\%) & 36 & 48 & 35 & 30 \\
\hline Distribuição - binárias (\%) & & & & \\
ortopiroxênio & 2,6 & 1,9 & 2,6 & 2,9 \\
clinopiroxênio & 0,1 & 0,1 & 0,1 & 0,1 \\
anfibólio & 0,0 & 0,0 & 0,0 & 0,0 \\
olivina & 0,1 & 0,2 & 0,1 & 0,0 \\
serpentina & 11,9 & 9,5 & 12,5 & 12,8 \\
espinelio-Cr & 0,4 & 0,3 & 0,4 & 0,5 \\
oxido-Fe & 8,1 & 6,2 & 12,4 & 5,7 \\
mica & 0,0 & 0,0 & 0,0 & 0,0 \\
carbonatos & 11,5 & 12,6 & 10,7 & 11,6 \\
outros silicatos & 1,4 & 2,6 & 1,3 & 0,9 \\
outros & 0,0 & 0,0 & 0,0 & 0,0 \\
\hline Distribuição - ternárias (\%) & & & & \\
ortopiroxênio & 3,0 & 3,9 & 3,4 & 2,2 \\
clinopiroxênio & 0,3 & 0,4 & 0,2 & 0,3 \\
anfibólio & 1,0 & 1,4 & 1,1 & 0,8 \\
olivina & 0,6 & 0,8 & 0,9 & 0,2 \\
serpentina & 12,7 & 16,3 & 11,3 & 11,7 \\
espinelio-Cr & 1,3 & 2,1 & 1,8 & 0,4 \\
oxido-Fe & 5,8 & 8,9 & 7,1 & 2,9 \\
mica & 0,1 & 0,1 & 0,0 & 0,1 \\
carbonatos & 10,0 & 13,7 & 8,7 & 8,8 \\
outros silicatos & 1,3 & 0,6 & 0,8 & 2,1 \\
outros & 0,1 & 0,0 & 0,1 & 0,2 \\
\hline absiolos slo, & & 0,0 & \\
\hline
\end{tabular}

Obs: outros silicatos = quartzo, feldspato potássico e plagioclásio; carbonatos = calcita, dolomita, magnesita e anquerita; outros = clorita, espinélio-Cr, óxido-Fe, ilmenita, apatita, coríndon. 
APÊNDICE 6

Resultados MLA

Figura 107 - Distribuição das formas de associação de sulfetos na amostra Ganga B

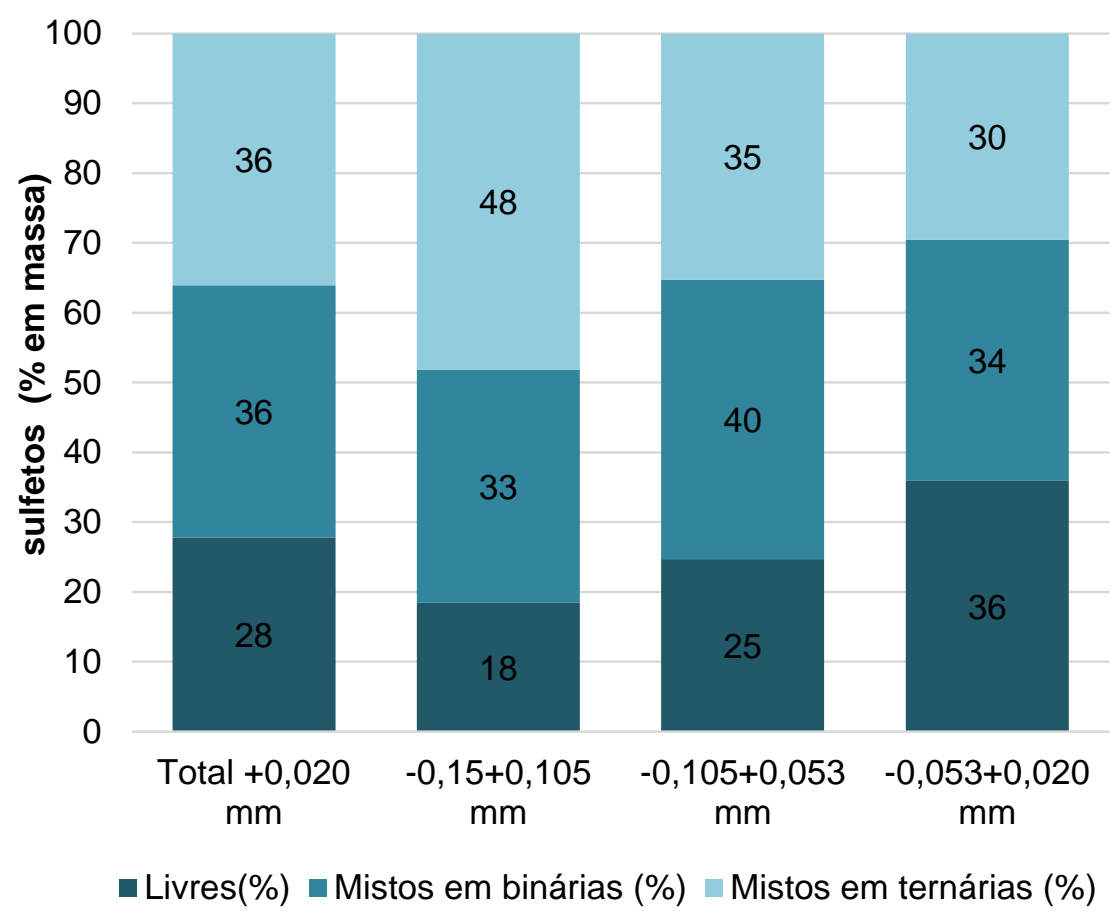

\section{Ganga C}

A Tabela 71 e Figura 108 apresentam um sumário da distribuição das formas de associação de sulfetos (\% em massa), entre livre e misto em partículas binárias (2 fases) ou misto em partículas ternárias (3 ou mais fases minerais), para as frações granulométricas acima de 0,020 mm, na amostra de Ganga C. 
APÊNDICE 6

Resultados MLA

Tabela 71 - Formas de associação de sulfetos - Ganga C

\begin{tabular}{l|cccc}
\hline Fração (mm) & Total +0,020 & $\mathbf{- 0 , 1 5 + 0 , 1 0 5}$ & $\mathbf{- 0 , 1 0 5 + 0 , 0 5 3}$ & $\mathbf{- 0 , 0 5 3 + 0 , 0 2 0}$ \\
\hline \% massa & 75 & 16 & 33 & 25 \\
\hline Livres(\%) & 37 & 38 & 24 & 45 \\
Mistos em binárias (\%) & 36 & 28 & 38 & 37 \\
Mistos em ternárias (\%) & 27 & 33 & 38 & 18 \\
\hline Distribuição - binárias (\%) & & & & \\
ortopiroxênio & 5,8 & 3,0 & 9,2 & 4,6 \\
clinopiroxênio & 1,0 & 1,0 & 0,0 & 1,7 \\
anfibólio & 0,1 & 0,1 & 0,0 & 0,2 \\
olivina & 0,3 & 0,1 & 0,8 & 0,0 \\
serpentina & 16,7 & 13,9 & 17,9 & 17,0 \\
espinelio-Cr & 0,0 & 0,0 & 0,1 & 0,0 \\
oxido-Fe & 2,8 & 0,5 & 1,7 & 4,4 \\
mica & 1,4 & 0,0 & 0,0 & 2,8 \\
carbonatos & 6,6 & 9,3 & 7,9 & 4,6 \\
outros silicatos & 1,0 & 0,6 & 0,3 & 1,6 \\
outros & 0,0 & 0,0 & 0,0 & 0,0 \\
\hline Distribuição - ternárias (\%) & & & & \\
ortopiroxênio & 4,2 & 5,5 & 6,7 & 2,0 \\
clinopiroxênio & 0,1 & 0,3 & 0,1 & 0,0 \\
anfibólio & 1,9 & 0,7 & 2,2 & 2,1 \\
olivina & 0,8 & 1,1 & 0,5 & 0,9 \\
serpentina & 8,4 & 11,8 & 13,0 & 3,9 \\
espinelio-Cr & 2,1 & 0,1 & 1,9 & 2,9 \\
oxido-Fe & 2,5 & 3,4 & 3,7 & 1,4 \\
mica & 0,9 & 0,9 & 2,0 & 0,2 \\
carbonatos & 5,6 & 9,2 & 6,7 & 3,6 \\
outros silicatos & 0,5 & 0,3 & 0,8 & 0,3 \\
outros & 0,3 & 0,0 & 0,7 & 0,2 \\
\hline Obsoutos slo & & 0,0 & \\
\hline
\end{tabular}

Obs: outros silicatos = quartzo, feldspato potássico e plagioclásio; carbonatos = calcita, dolomita, magnesita e anquerita; outros = clorita, espinélio-Cr, óxido-Fe, ilmenita, apatita, coríndon. 
APÊNDICE 6

Resultados MLA

Figura 108 - Distribuição das formas de associação de sulfetos na amostra Ganga C

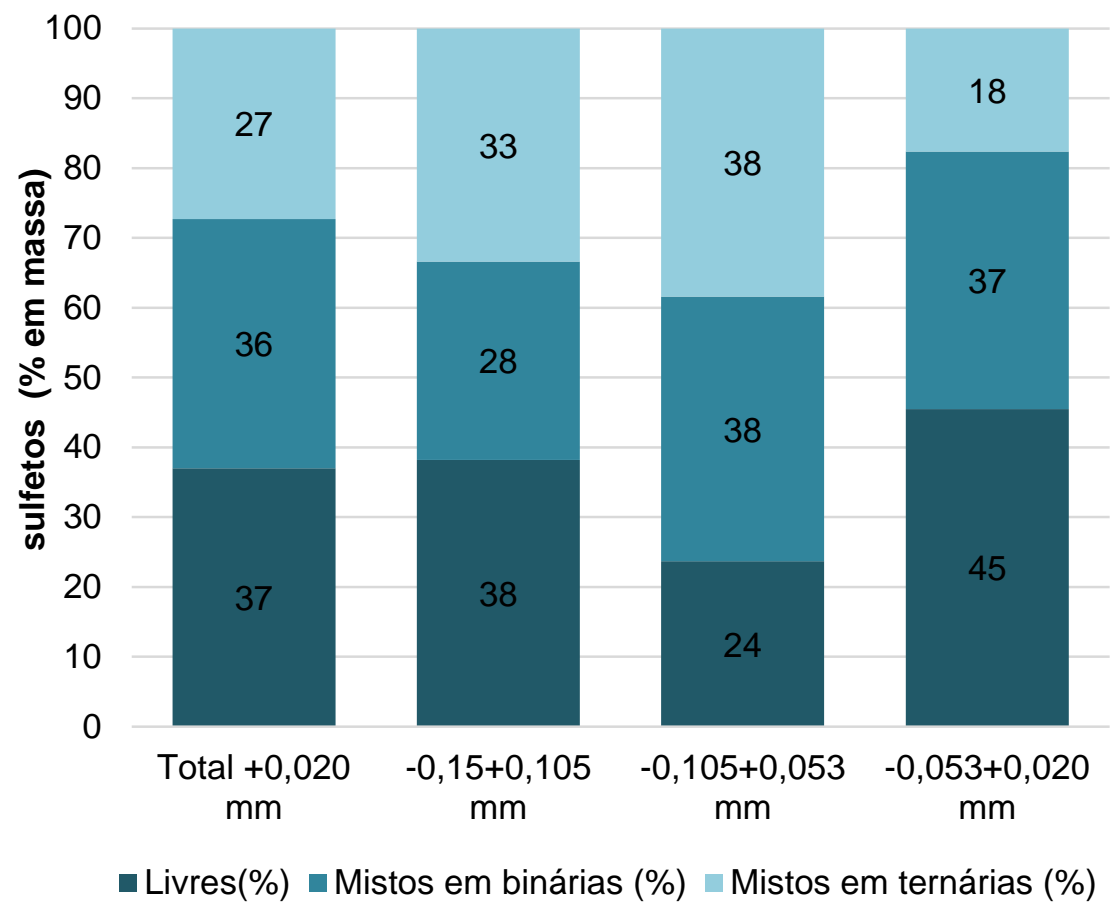

$\underline{\text { Out }}$

A Tabela 72 e Figura 109 apresentam um sumário da distribuição das formas de associação de sulfetos (\% em massa), entre livre e misto em partículas binárias (2 fases) ou misto em partículas ternárias (3 ou mais fases minerais), para as frações granulométricas acima de 0,020 mm, na amostra de Out. 
APÊNDICE 6

Resultados MLA

Tabela 72 - Formas de associação de sulfetos - Outlier

\begin{tabular}{|c|c|c|c|c|}
\hline Fração (mm) & Total $+0,020$ & $-0,15+0,105$ & $-0,105+0,053$ & $-0,053+0,020$ \\
\hline$\%$ massa & 82 & 27 & 32 & 24 \\
\hline Livres(\%) & 60 & 65 & 48 & 61 \\
\hline Mistos em binárias (\%) & 31 & 26 & 33 & 32 \\
\hline Mistos em ternárias (\%) & 9 & 9 & 19 & 7 \\
\hline \multicolumn{5}{|l|}{ Distribuição - binárias (\%) } \\
\hline ortopiroxênio & 24,4 & 23,2 & 26,2 & 24,1 \\
\hline clinopiroxênio & 2,7 & 1,2 & 0,9 & 3,4 \\
\hline anfibólio & 1,3 & 0,0 & 0,1 & 1,8 \\
\hline olivina & 0,0 & 0,0 & 0,0 & 0,0 \\
\hline serpentina & 0,1 & 1,1 & 0,1 & 0,0 \\
\hline espinelio-Cr & 0,1 & 0,4 & 0,0 & 0,1 \\
\hline oxido-Fe & 1,3 & 0,1 & 5,0 & 0,6 \\
\hline mica & 0,0 & 0,0 & 0,0 & 0,0 \\
\hline carbonatos & 0,1 & 0,0 & 0,8 & 0,0 \\
\hline outros silicatos & 1,1 & 0,2 & 0,1 & 1,5 \\
\hline outros & 0,0 & 0,0 & 0,0 & 0,0 \\
\hline \multicolumn{5}{|l|}{ Distribuição - ternárias (\%) } \\
\hline ortopiroxênio & 5,5 & 6,6 & 13,5 & 3,5 \\
\hline clinopiroxênio & 0,7 & 1,2 & 1,5 & 0,5 \\
\hline anfibólio & 1,2 & 0,1 & 2,2 & 1,1 \\
\hline olivina & 0,0 & 0,0 & 0,0 & 0,0 \\
\hline serpentina & 0,1 & 0,1 & 0,4 & 0,0 \\
\hline espinelio-Cr & 0,1 & 0,0 & 0,0 & 0,1 \\
\hline oxido-Fe & 1,1 & 0,9 & 0,9 & 1,2 \\
\hline mica & 0,0 & 0,0 & 0,0 & 0,0 \\
\hline carbonatos & 0,0 & 0,0 & 0,0 & 0,0 \\
\hline outros silicatos & 0,4 & 0,1 & 0,4 & 0,4 \\
\hline outros & 0,0 & 0,0 & 0,0 & 0,0 \\
\hline
\end{tabular}

Obs: outros silicatos = quartzo, feldspato potássico e plagioclásio; carbonatos = calcita, dolomita, magnesita e anquerita; outros = clorita, espinélio-Cr, óxido-Fe, ilmenita, apatita, coríndon. 
APÊNDICE 6

Resultados MLA

Figura 109 - Distribuição das formas de associação de sulfetos na amostra Outlier

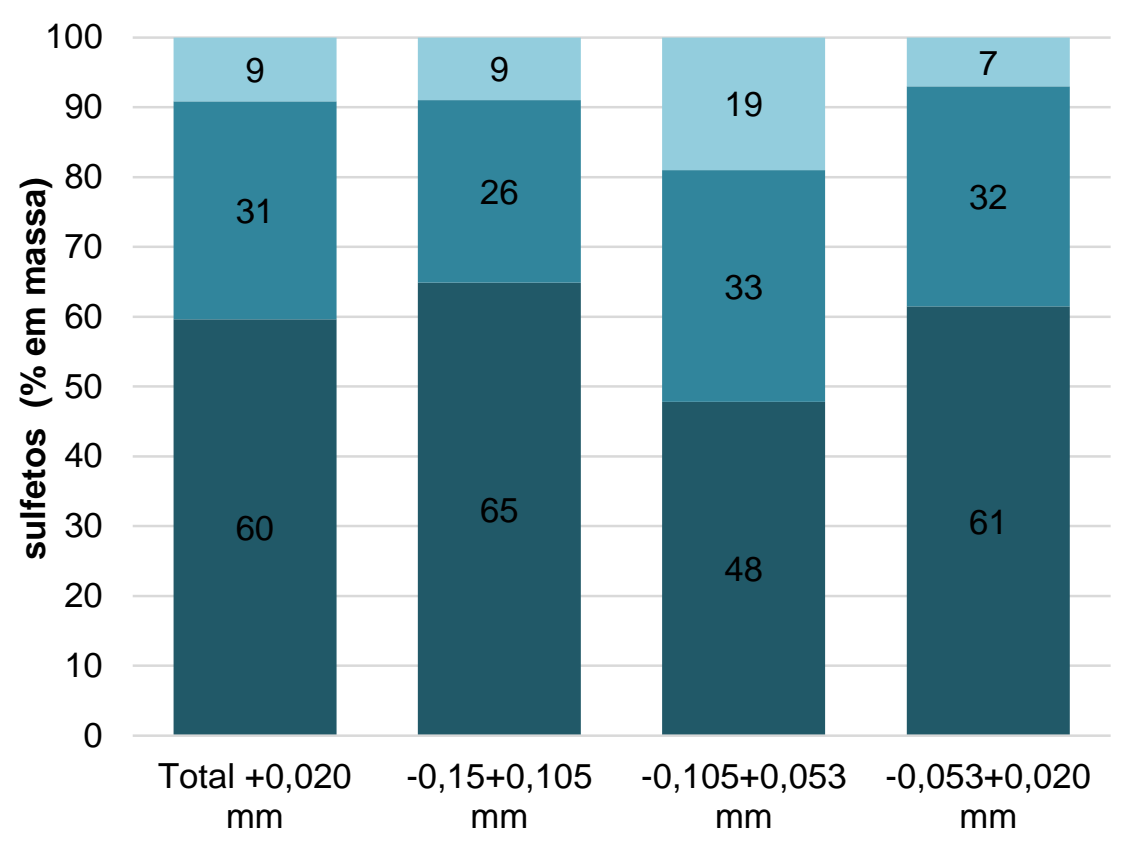

- Livres(\%) घ Mistos em binárias (\%) $\llbracket$ Mistos em ternárias (\%)

As curvas de espectro de sulfetos são apresentadas da Figura 110 a Figura 117, para frações em área e em perímetro exposto, de acordo com suas respectivas faixas granulométricas

Figura 110 - Espectro de liberação de sulfetos na amostra OPS
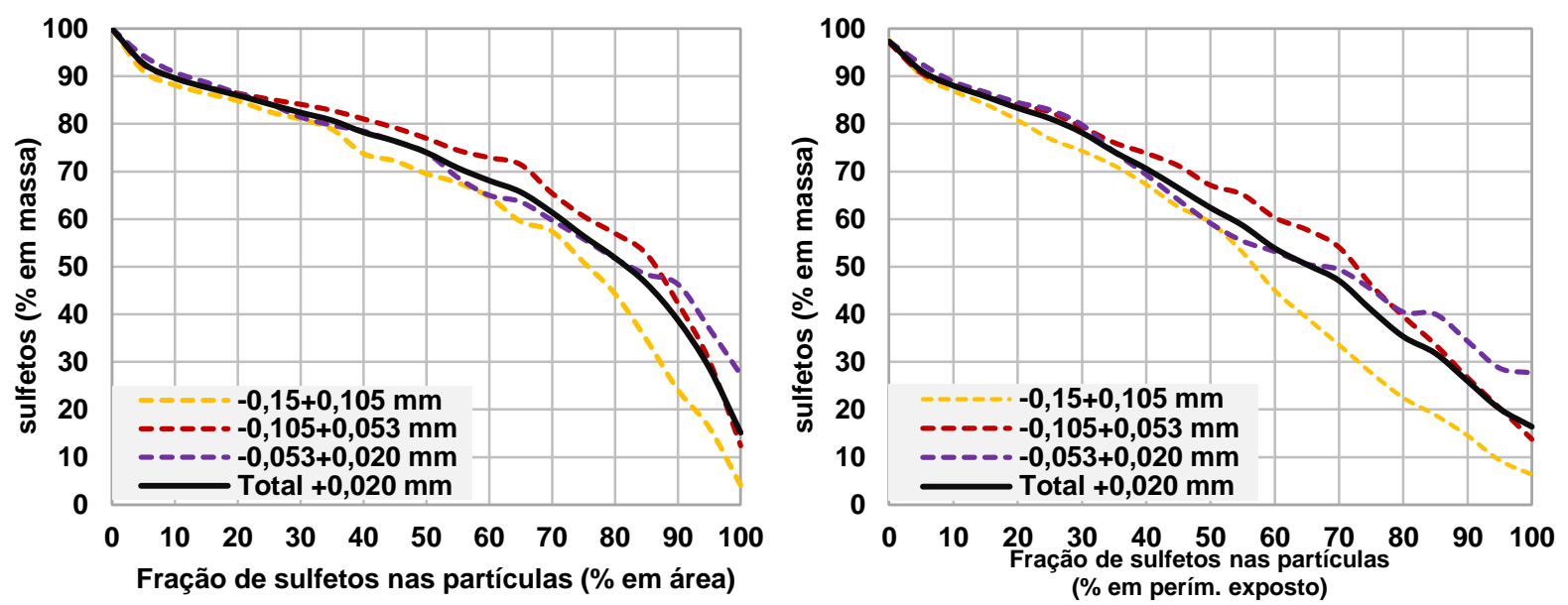
APÊNDICE 6

Resultados MLA

Figura 111 - Espectro de liberação de sulfetos na amostra POS
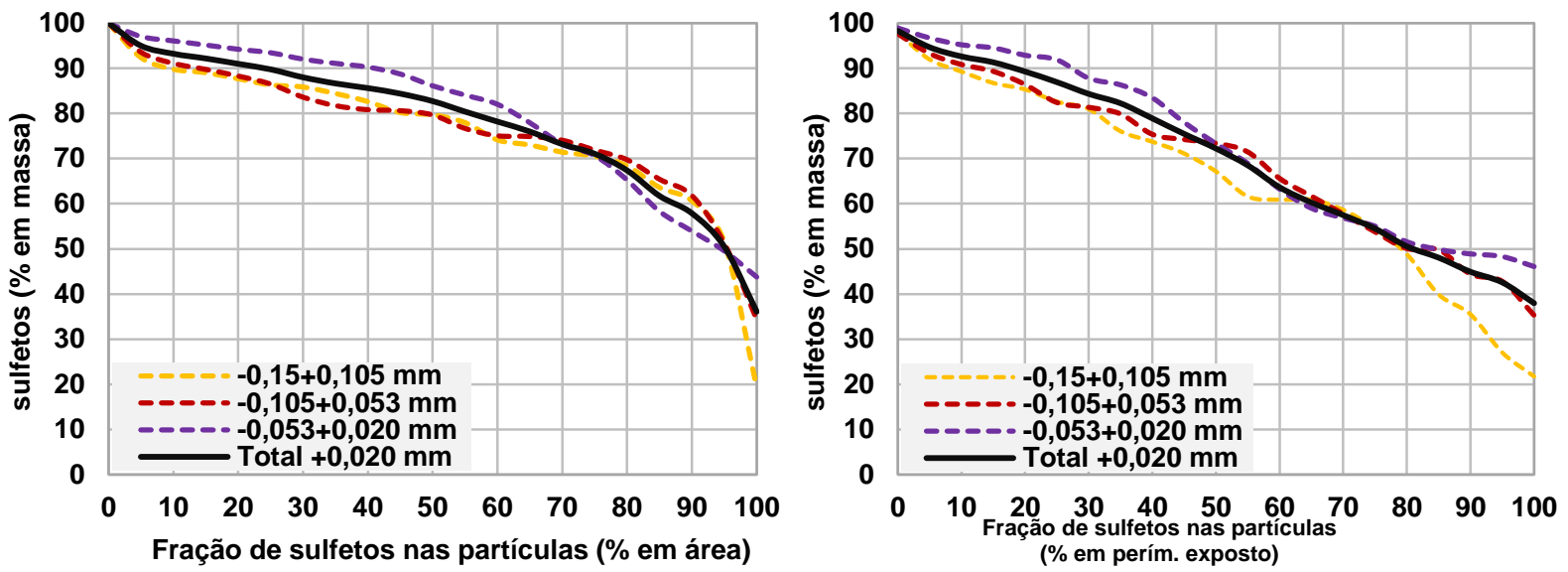

Figura 112 - Espectro de liberação de sulfetos na amostra PO
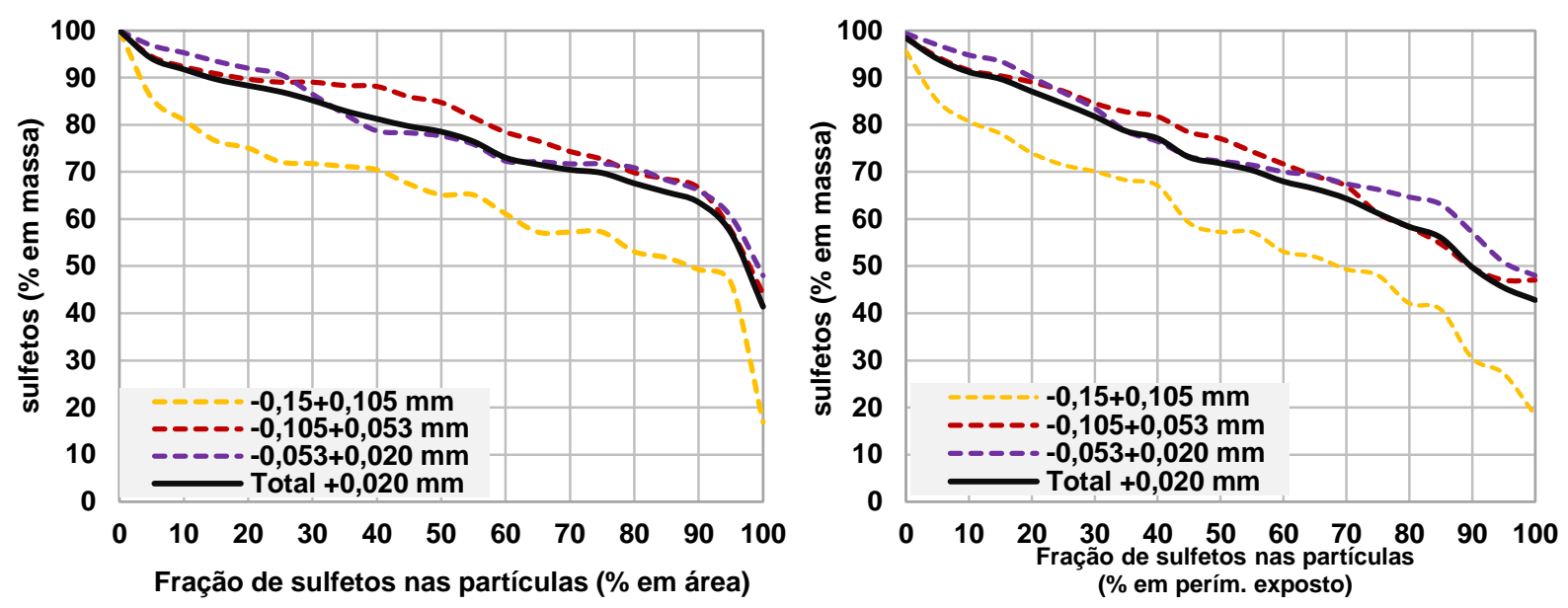

Figura 113 - Espectro de liberação de sulfetos na amostra $P$

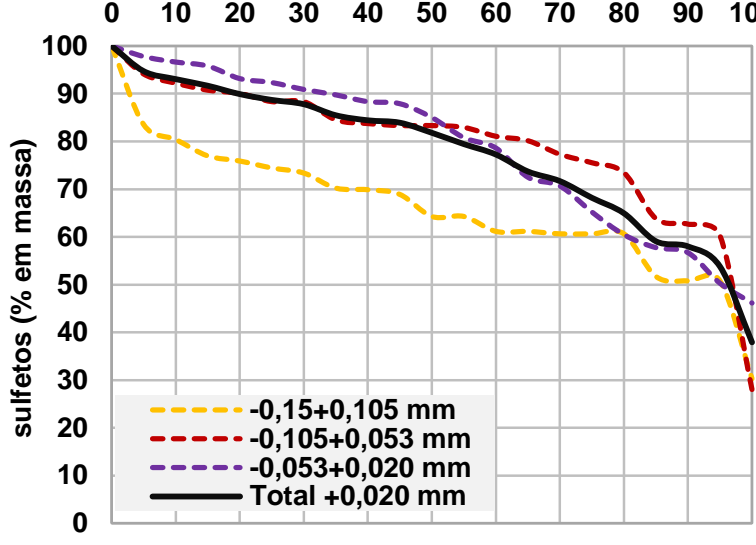

Fração de sulfetos nas partículas (\% em área)

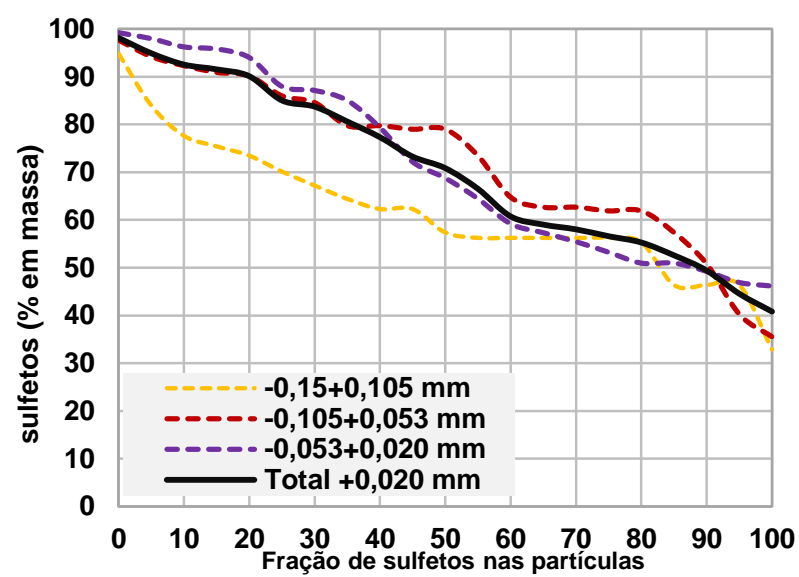

(\% em perím. exposto) 
APÊNDICE 6

Resultados MLA

Figura 114 - Espectro de liberação de sulfetos na amostra Ganga A
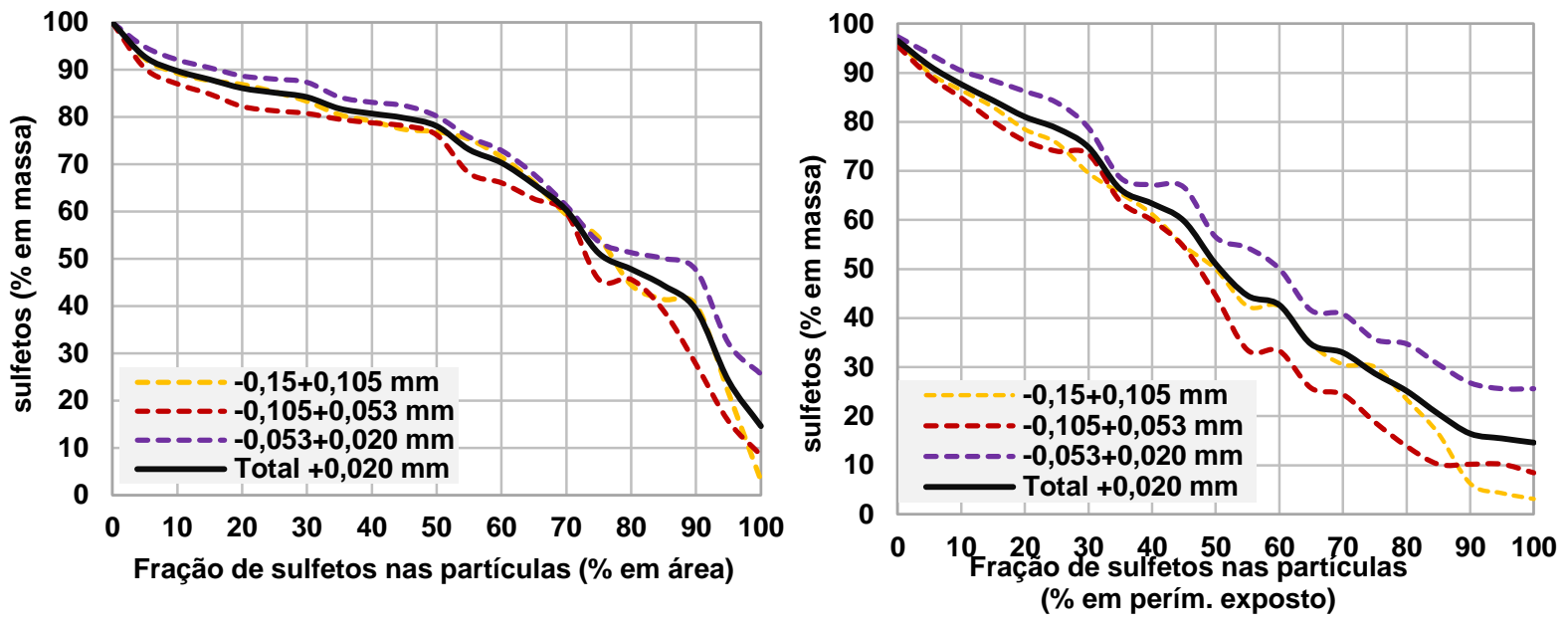

Figura 115 - Espectro de liberação de sulfetos na amostra Ganga B
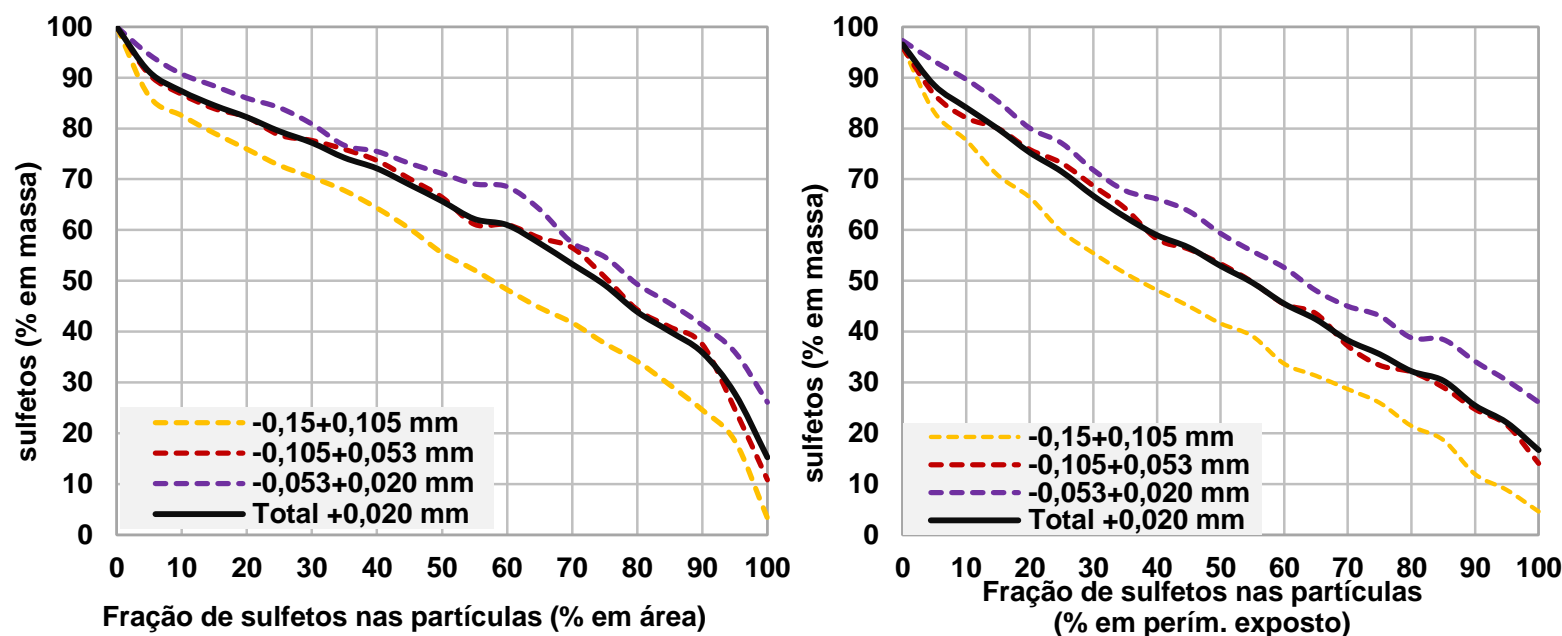

Fração de sulfetos nas partículas (\% em área) (\% em perím. exposto)

Figura 116 - Espectro de liberação de sulfetos na amostra Ganga C

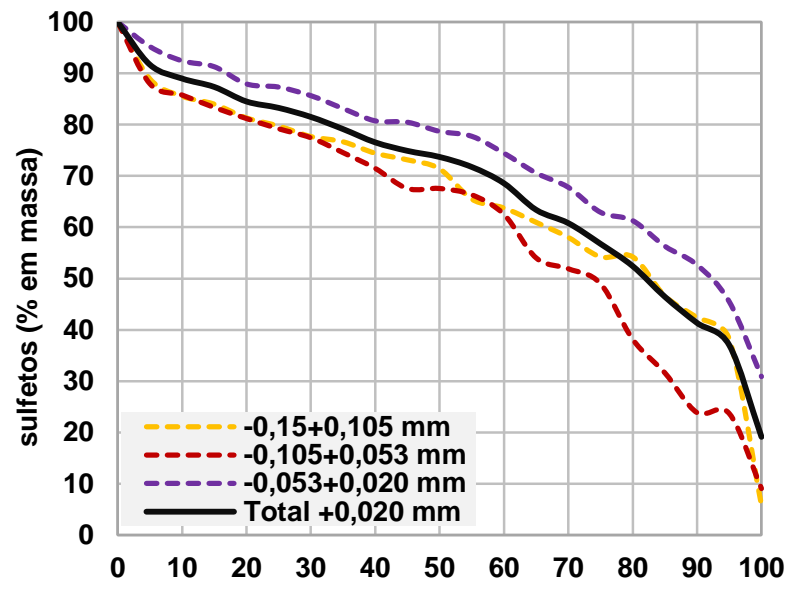

Fração de sulfetos nas partículas (\% em área)

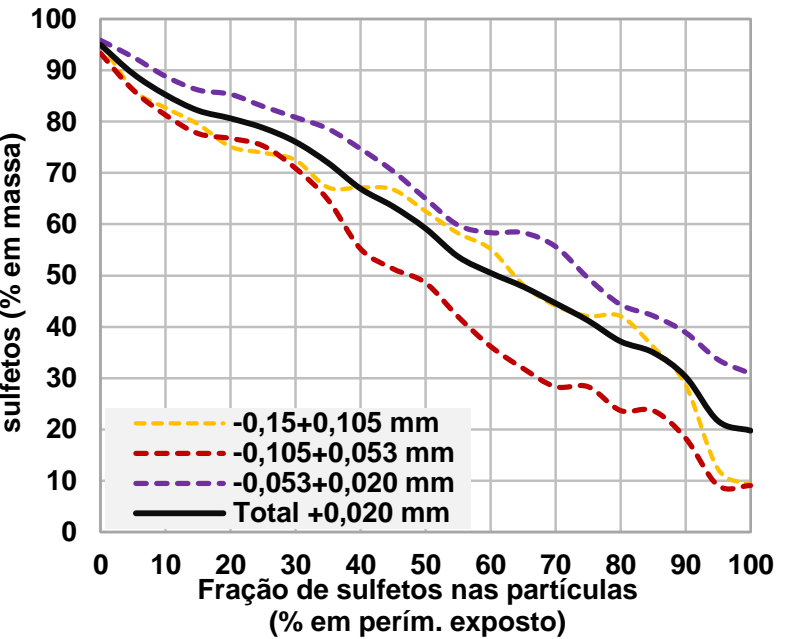

(\% em perím. exposto) 


\section{APÊNDICE 6}

Resultados MLA

Figura 117 - Espectro de liberação de sulfetos na amostra Outlier
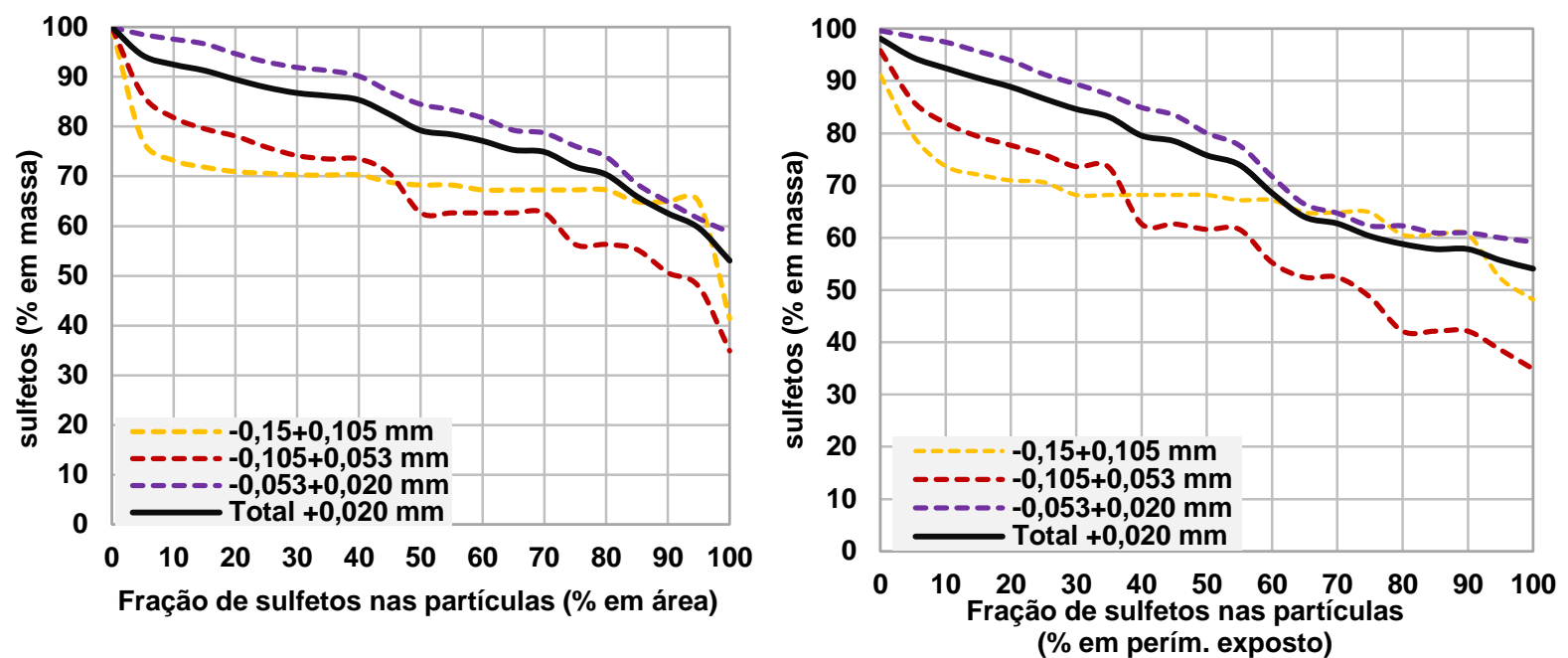
APÊNDICE 7

OPS

Composição química calculada por fração a partir do MLA (\% em massa)

\begin{tabular}{c|c|ccccccc}
\hline & & & \multicolumn{7}{c}{ Teores (\%) } & \multirow{2}{*}{ Fração } & \% massa & $\mathbf{N i}$ & $\mathbf{C u}$ & Co & Fe & S & SiO2 & MgO \\
\hline & & & & & & & & \\
+0.105 & 20,0 & 0,94 & 0,06 & 0,03 & 11,4 & 0,91 & 36,3 & 35,5 \\
$-0.105+0.053$ & 29,3 & 0,95 & 0,04 & 0,03 & 11,1 & 0,91 & 36,6 & 34,9 \\
$-0.053+0.020$ & 21,6 & 1,03 & 0,05 & 0,03 & 10,9 & 0,98 & 36,0 & 33,1 \\
-0.020 & 29,1 & 0,96 & 0,11 & 0,03 & 10,6 & 1,07 & 34,5 & 32,3 \\
& & & & & & & & \\
Total calculado & 100,0 & 0,97 & 0,07 & 0,03 & 11,0 & 0,97 & 35,8 & 33,9 \\
Total dosado & & 0,88 & 0,19 & 0,03 & 9,80 & 1,41 & 35,9 & 34,5 \\
& & & & & & & & \\
\hline
\end{tabular}

POS

\begin{tabular}{c|c|ccccccc}
\hline & & & & \multicolumn{7}{c}{ Teores (\%) } & & \\
Fração & $\%$ massa & Ni & Cu & Co & Fe & S & SiO2 & MgO \\
\hline & & & & & & & & \\
+0.105 & 20,1 & 0,37 & 0,04 & 0,01 & 8,63 & 0,5 & 46,6 & 31,3 \\
$-0.105+0.053$ & 31,9 & 0,44 & 0,08 & 0,00 & 8,74 & 0,61 & 45,3 & 31,5 \\
$-0.053+0.020$ & 24,8 & 0,71 & 0,09 & 0,01 & 9,01 & 1,04 & 44,3 & 29,7 \\
-0.020 & 23,2 & 0,98 & 0,17 & 0,01 & 9,29 & 1,59 & 43,2 & 28,2 \\
& & & & & & & & \\
Total calculado & 100,0 & 0,62 & 0,09 & 0,01 & 8,92 & 0,92 & 44,8 & 30,2 \\
Total dosado & & 0,57 & 0,11 & 0,03 & 9,18 & 0,93 & 43,8 & 29,3 \\
\hline
\end{tabular}

PO

\begin{tabular}{c|c|ccccccc}
\hline & & & \multicolumn{7}{c}{ Teores (\%) } & \\
Fração & \% massa & Ni & Cu & Co & Fe & S & SiO2 & MgO \\
\hline & & & & & & & & \\
+0.105 & 21,6 & 0,17 & 0,04 & 0,00 & 8,10 & 0,24 & 50,1 & 29,0 \\
$-0.105+0.053$ & 32,3 & 0,25 & 0,03 & 0,00 & 8,32 & 0,4 & 49,4 & 28,8 \\
$-0.053+0.020$ & 22,0 & 0,36 & 0,06 & 0,00 & 8,55 & 0,63 & 48,5 & 28,1 \\
-0.020 & 24,1 & 0,80 & 0,15 & 0,01 & 9,06 & 1,26 & 47,1 & 26,7 \\
& & & & & & & & \\
Total calculado & 100,0 & 0,39 & 0,06 & 0,00 & 8,51 & 0,62 & 48,8 & 28,2 \\
Total dosado & & 0,47 & 0,11 & 0,03 & 9,25 & 0,86 & 47,6 & 27,2 \\
& & & & & & & & \\
\hline
\end{tabular}

$\mathbf{P}$

\begin{tabular}{c|c|ccccccc}
$\mathbf{P}$ & \multicolumn{10}{c}{ Teores (\%) } & SiO2 & MgO \\
\hline Fração & \% massa & Ni & Cu & Co & Fe & S & Se \\
+0.105 & 25,6 & 0,15 & 0,01 & 0,00 & 8,01 & 0,16 & 50,9 & 29,4 \\
$-0.105+0.053$ & 33,3 & 0,21 & 0,04 & 0,00 & 8,29 & 0,37 & 50,0 & 29,2 \\
$-0.053+0.020$ & 23,4 & 0,54 & 0,05 & 0,00 & 8,52 & 0,75 & 49,0 & 28,3 \\
-0.020 & 17,7 & 0,61 & 0,13 & 0,00 & 8,95 & 1,06 & 47,9 & 27,0 \\
& & & & & & & & \\
Total calculado & 100,0 & 0,34 & 0,05 & 0,00 & 8,39 & 0,53 & 49,6 & 28,7 \\
Total dosado & & 0,44 & 0,09 & 0,03 & 9,37 & 0,67 & 49,1 & 27,2 \\
& & & & & & & & \\
\hline
\end{tabular}




\section{APÊNDICE 7}

Composição química calculada por fração a partir do MLA (\% em massa)

Ganga A

\begin{tabular}{c|c|ccccccc}
\hline & & & \multicolumn{7}{c}{ Teores (\%) } & \\
Fração & \% massa & Ni & Cu & Co & Fe & S & SiO2 & MgO \\
\hline & & & & & & & & \\
$-0.21+0.105$ & 13,8 & 0,31 & 0,04 & 0,01 & 6,99 & 0,43 & 41,6 & 28,6 \\
$-0.105+0.053$ & 24,1 & 0,31 & 0,04 & 0,01 & 6,95 & 0,35 & 41,9 & 28,6 \\
$-0.053+0.020$ & 21,9 & 0,39 & 0,07 & 0,01 & 7,16 & 0,5 & 41,9 & 28,6 \\
-0.020 & 40,2 & 0,43 & 0,05 & 0,00 & 7,53 & 0,74 & 42,0 & 28,6 \\
& & & & & & & & \\
Total calculado & 100,0 & 0,38 & 0,05 & 0,01 & 7,24 & 0,55 & 41,9 & 28,6 \\
Total dosado & & 0,42 & 0,06 & 0,03 & 7,21 & 0,52 & 38,5 & 28,5 \\
& & & & & & & & \\
\hline
\end{tabular}

Ganga B

\begin{tabular}{c|c|ccccccc}
\hline \multirow{2}{*}{ Fração } & \% massa & Ni & Cu & Co & Fe & S & SiO2 & MgO \\
\hline & & & & & & & & \\
+0.105 & 16,0 & 0,44 & 0,06 & 0,02 & 6,97 & 0,57 & 37,6 & 25,2 \\
$-0.105+0.053$ & 23,0 & 0,45 & 0,05 & 0,03 & 7,24 & 0,56 & 36,2 & 25,4 \\
$-0.053+0.020$ & 22,0 & 0,53 & 0,04 & 0,02 & 7,20 & 0,69 & 34,5 & 25,9 \\
-0.020 & 39,0 & 0,48 & 0,08 & 0,06 & 7,13 & 0,92 & 30,4 & 26,6 \\
& & & & & & & & \\
Total calculado & 100,0 & 0,48 & 0,06 & 0,04 & 7,15 & 0,73 & 33,8 & 25,9 \\
Total dosado & & 0,51 & 0,10 & 0,03 & 7,22 & 0,67 & 31,2 & 27,9 \\
& & & & & & & & \\
\hline
\end{tabular}

Ganga C

\begin{tabular}{c|c|ccccccc}
\hline Fração & \% massa & Ni & Cu & Co & Fe & S & SiO2 & MgO \\
\hline & & & & & & & & \\
+0.105 & 16,2 & 0,19 & 0,02 & 0,00 & 6,40 & 0,25 & 51,1 & 24,1 \\
$-0.105+0.053$ & 33,2 & 0,22 & 0,02 & 0,00 & 6,49 & 0,17 & 50,5 & 24,5 \\
$-0.053+0.020$ & 25,4 & 0,28 & 0,03 & 0,00 & 6,80 & 0,36 & 48,8 & 24,7 \\
-0.020 & 25,2 & 0,43 & 0,05 & 0,02 & 6,89 & 0,53 & 47,3 & 25,5 \\
& & & & & & & & \\
Total calculado & 100,0 & 0,28 & 0,03 & 0,01 & 6,66 & 0,32 & 49,4 & 24,7 \\
Total dosado & & 0,35 & 0,04 & 0,06 & 8,17 & 0,38 & 46,8 & 22,9 \\
& & & & & & & & \\
\hline
\end{tabular}

Outlier

\begin{tabular}{c|c|ccccccc}
\hline & & & \multicolumn{7}{c}{ Teores (\%) } & \\
Fração & \% massa & Ni & Cu & Co & Fe & S & SiO2 & MgO \\
\hline & & & & & & & & \\
+0.105 & 26,8 & 0,11 & 0,01 & 0,00 & 7,76 & 0,15 & 52,3 & 28,3 \\
$-0.105+0.053$ & 31,9 & 0,11 & 0,02 & 0,00 & 7,88 & 0,21 & 52,3 & 27,5 \\
$-0.053+0.020$ & 23,7 & 0,69 & 0,09 & 0,00 & 8,96 & 1,21 & 50,5 & 25,6 \\
-0.020 & 17,6 & 1,25 & 0,28 & 0,01 & 10,1 & 2,36 & 48,5 & 24,1 \\
& & & & & & & & \\
Total calculado & 100,0 & 0,45 & 0,08 & 0,00 & 8,49 & 0,81 & 51,2 & 26,7 \\
Total dosado & & 0,49 & 0,12 & 0,01 & 8,25 & 1,06 & 51,3 & 26,4 \\
& & & & & & & & \\
\hline
\end{tabular}




\section{APÊNDICE 8}

Imagens das fases discriminadas ao MLA com destaque para pentlandita
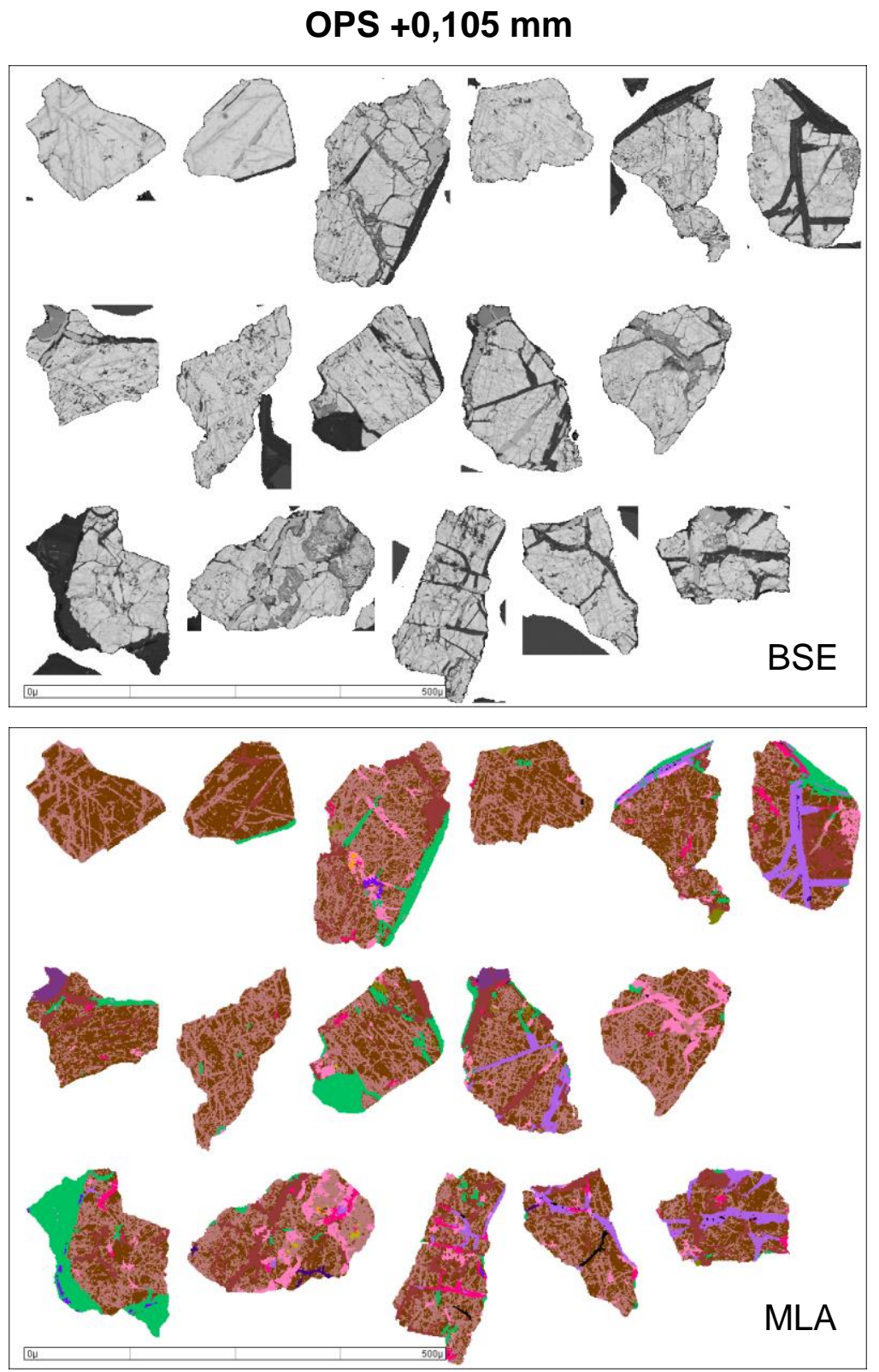

$\square$ pentlandita
$\square$ calco-covelita
$\square$ pirrotita
$\square$ ortopirox
$\square$ olivina
$\square$ carbonatos

\begin{tabular}{ll}
$\square$ pentl_oxid & $\square$ calcopirita \\
\hline esfalerita & $\square$ pirita \\
arsenopirita & $\square$ FeCoNis \\
clinopirox & $\square$ anfibolio \\
$\square$ serpentina & $\square$ mica \\
outros silicatos & $\square$ outros
\end{tabular}




\section{APÊNDICE 8}

Imagens das fases discriminadas ao MLA com destaque para pentlandita

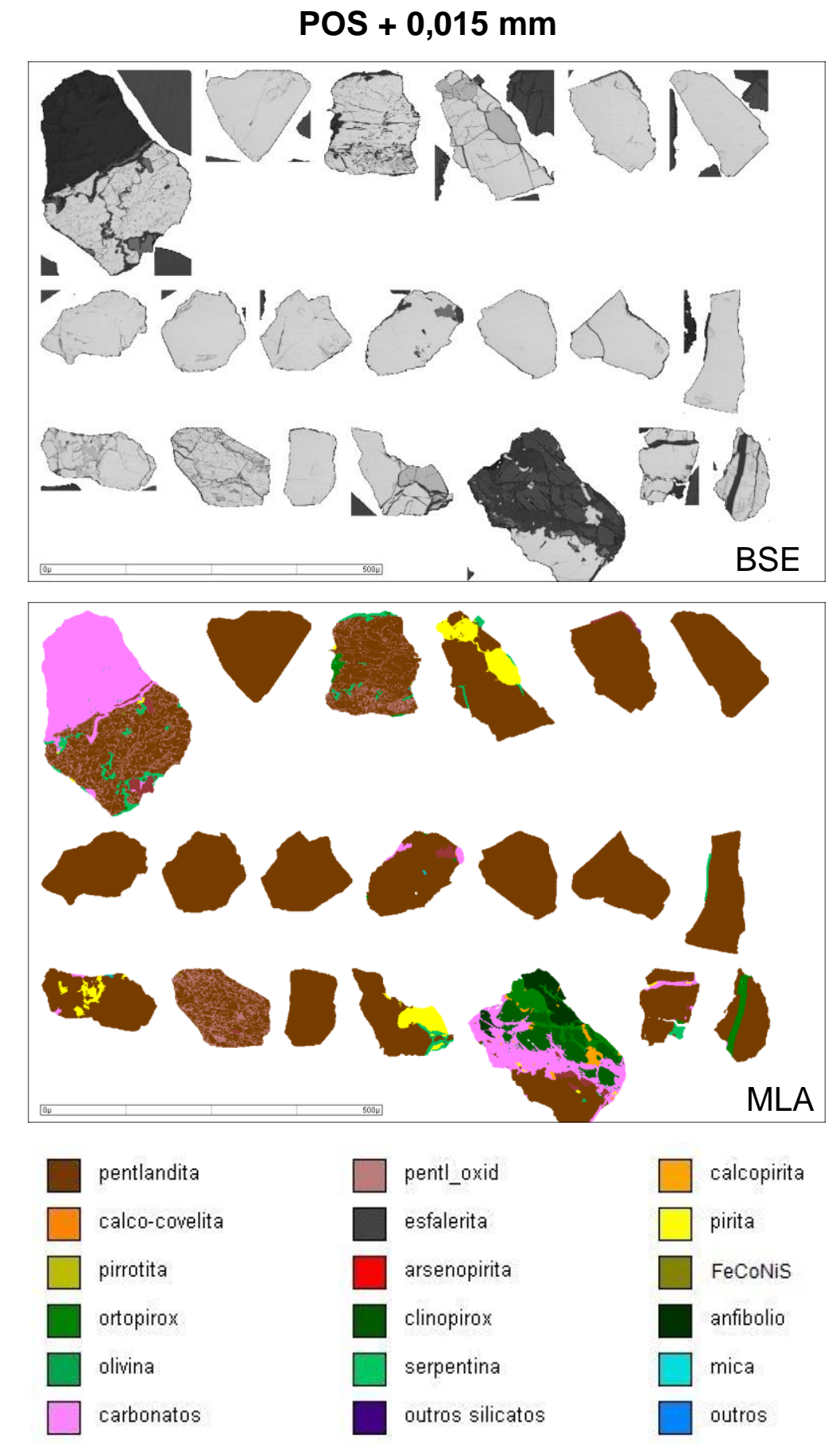




\section{APÊNDICE 8}

Imagens das fases discriminadas ao MLA com destaque para pentlandita

\section{$\mathrm{PO}+\mathbf{0 , 1 0 5} \mathrm{mm}$}
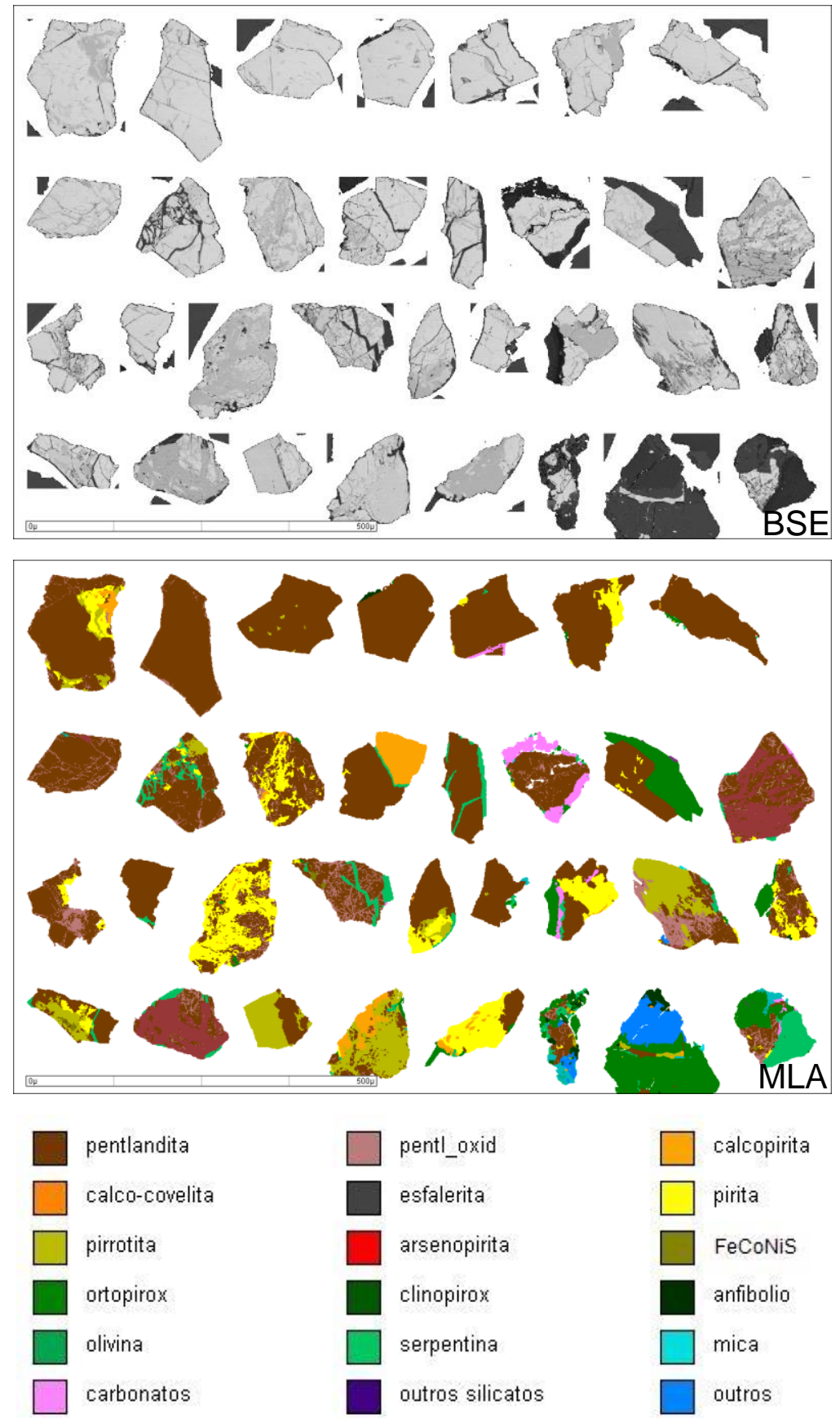


\section{APÊNDICE 8}

Imagens das fases discriminadas ao MLA com destaque para pentlandita
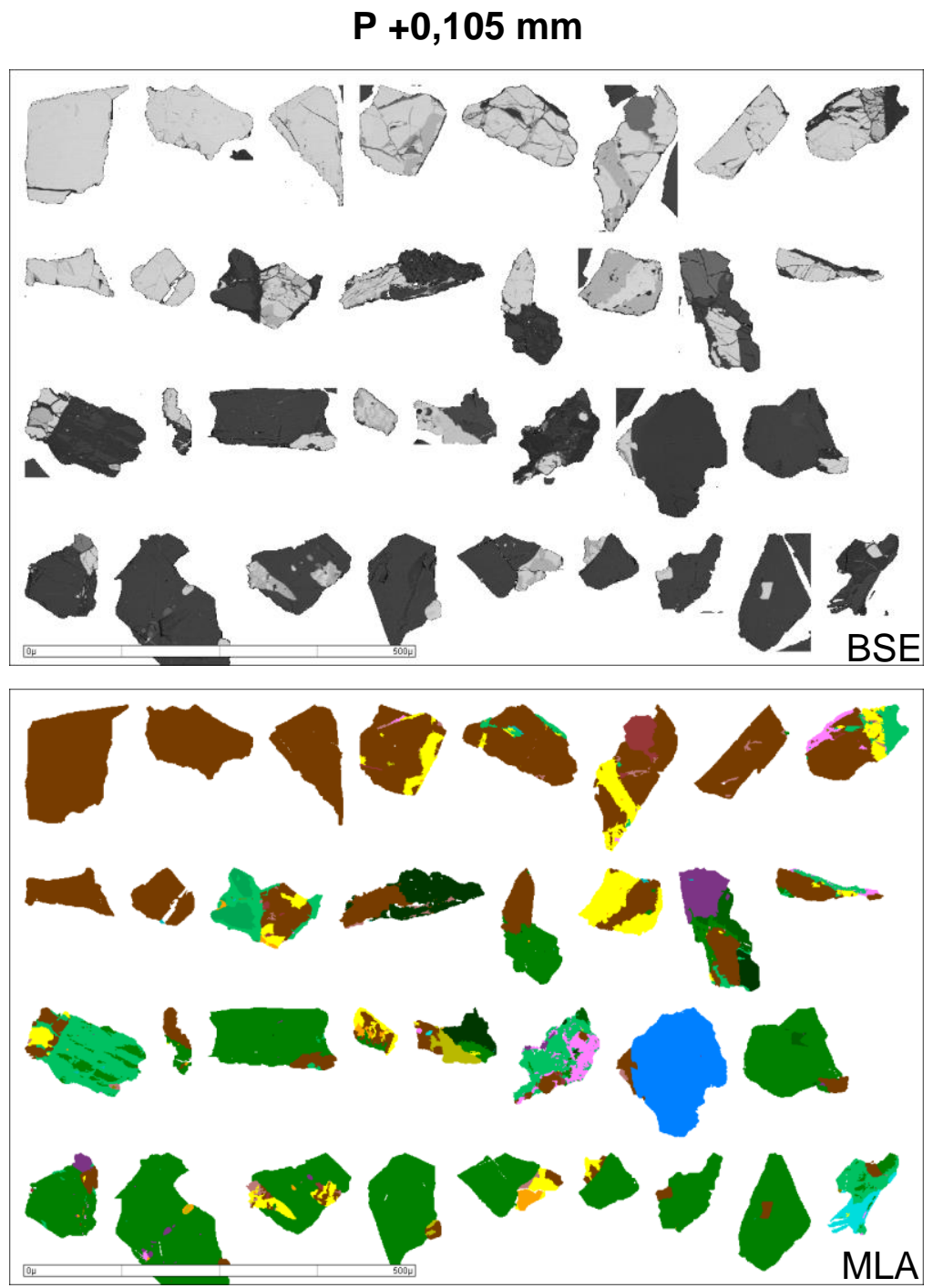

$\square$ pentlandita
$\square$ calco-covelita
$\square$ pirrotita
$\square$ ortopirox
$\square$ olivina
$\square$ carbonatos

$\square$ pentl_oxid
$\square$ esfalerita
$\square$ arsenopirita
$\square$ clinopirox
$\square$ serpentina
$\square$ outros silicatos

$\square$ calcopirita
pirita
$\square$ FeCoNis
anfibolio
$\square$ mica
outros




\section{APÊNDICE 8}

Imagens das fases discriminadas ao MLA com destaque para pentlandita
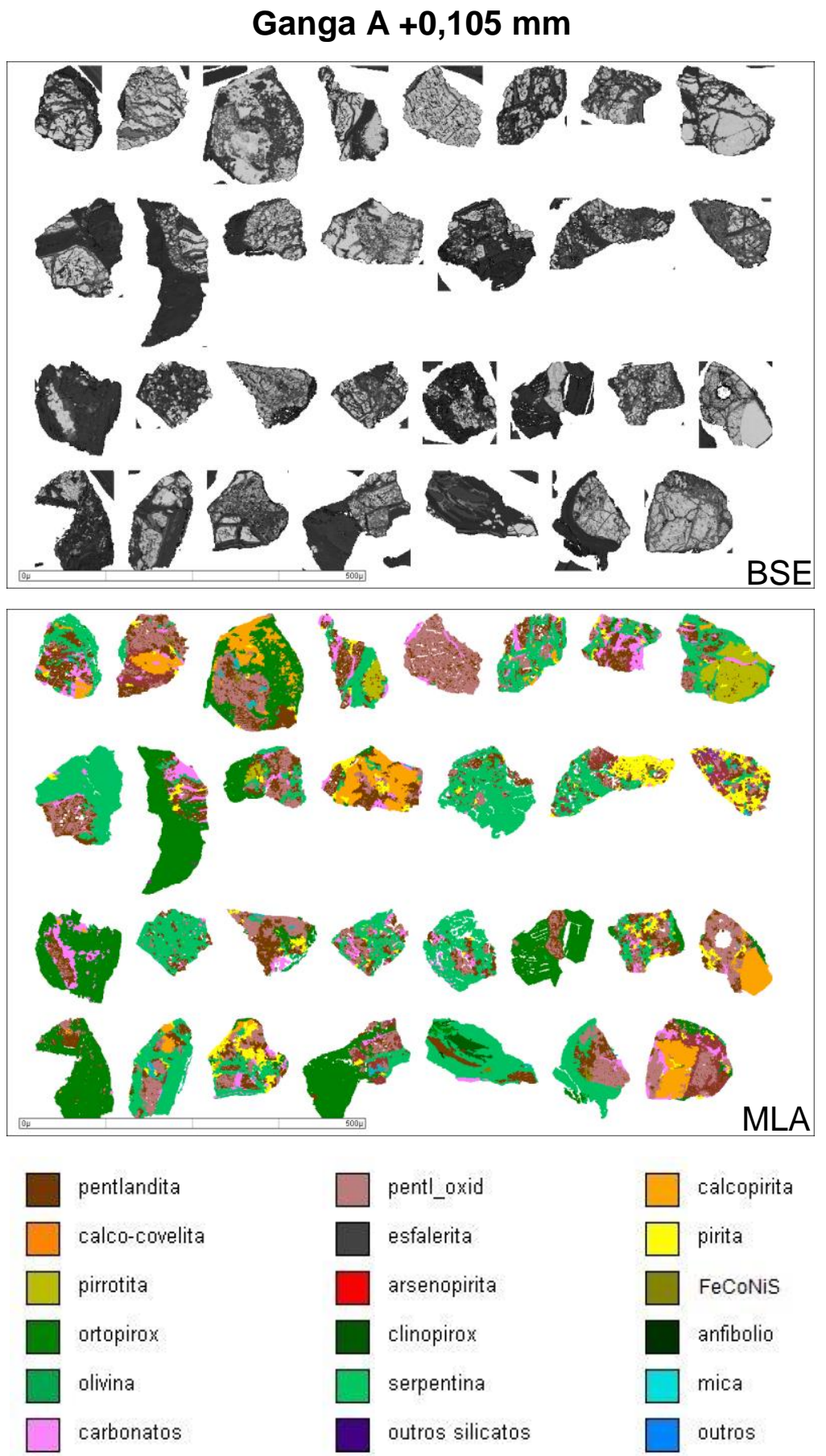

$\square$ pentl_oxid
$\square$ esfalerita
$\square$ arsenopirita
$\square$ clinopirox
$\square$ serpentina
$\square$ outros silicatos

calcopirita

$\square$ calco-covelita

$\square$ calcopirit

$\square$ pirita

$\square$ FeCoNiS

$\square$ anfibolio

$\square$ mica

$\square$ outros 


\section{APÊNDICE 8}

Imagens das fases discriminadas ao MLA com destaque para pentlandita

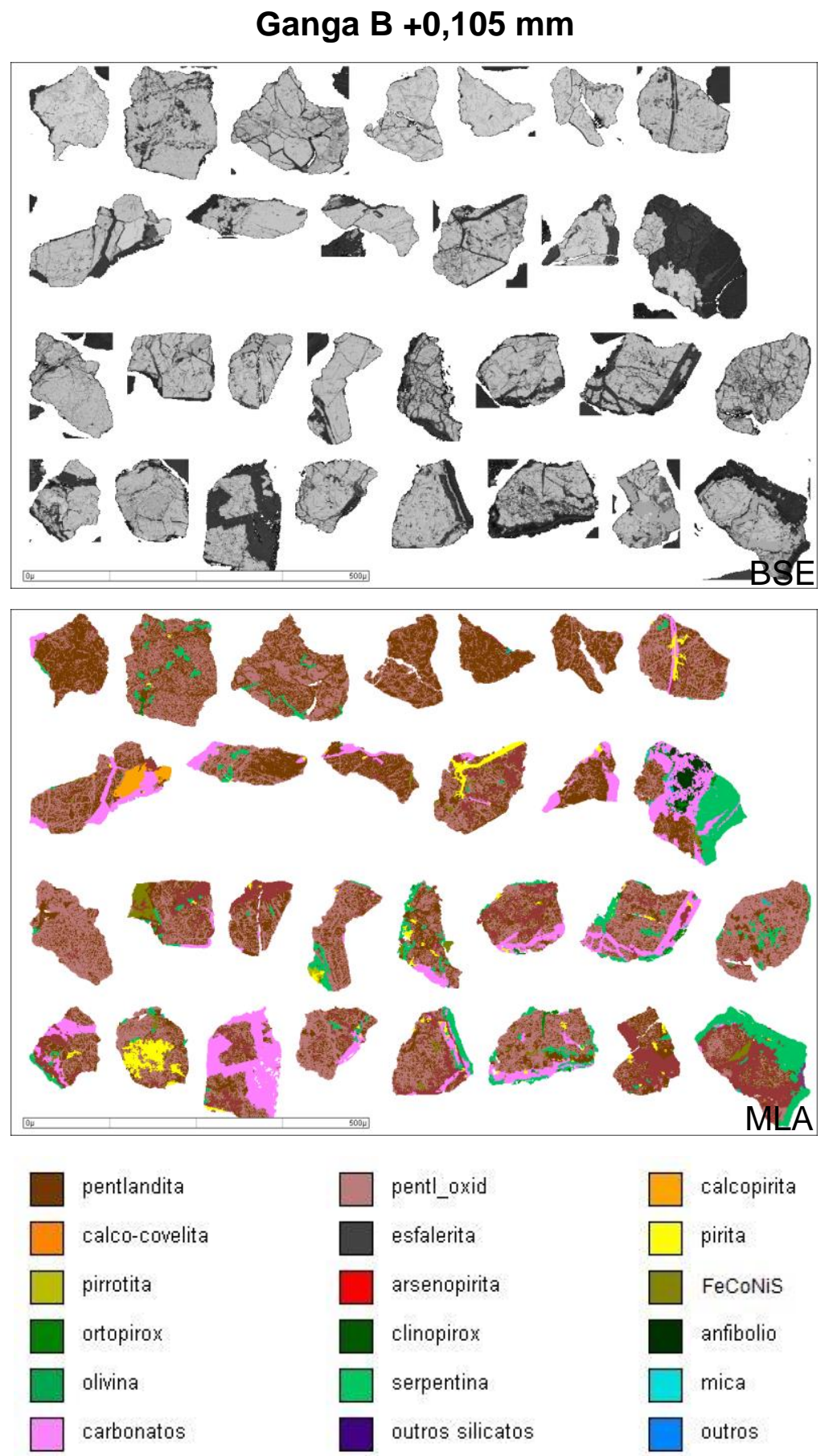




\section{APÊNDICE 8}

Imagens das fases discriminadas ao MLA com destaque para pentlandita

\section{Ganga $C+0,105 \mathrm{~mm}$}
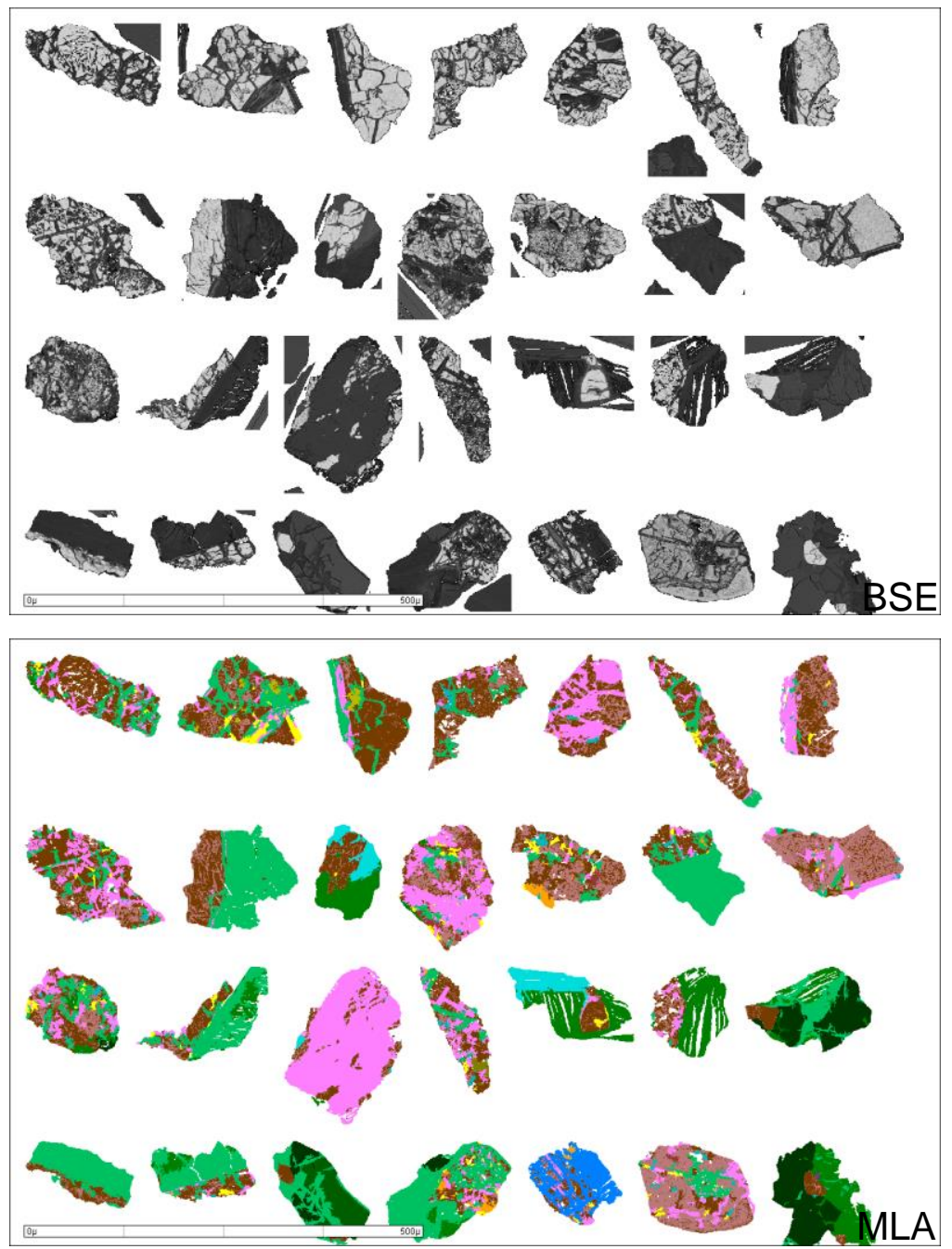

\begin{tabular}{lll}
$\square$ pentlandita & $\square$ pentloxid & $\square$ calcopirita \\
$\square$ calco-covelita & $\square$ esfalerita & $\square$ pirita \\
\hline pirrotita & $\square$ arsenopirita & FecoNis \\
\hline ortopirox & clinopirox & $\square$ anfibolio \\
$\square$ olivina & $\square$ serpentina & $\square$ outros
\end{tabular}




\section{APÊNDICE 8}

Imagens das fases discriminadas ao MLA com destaque para pentlandita

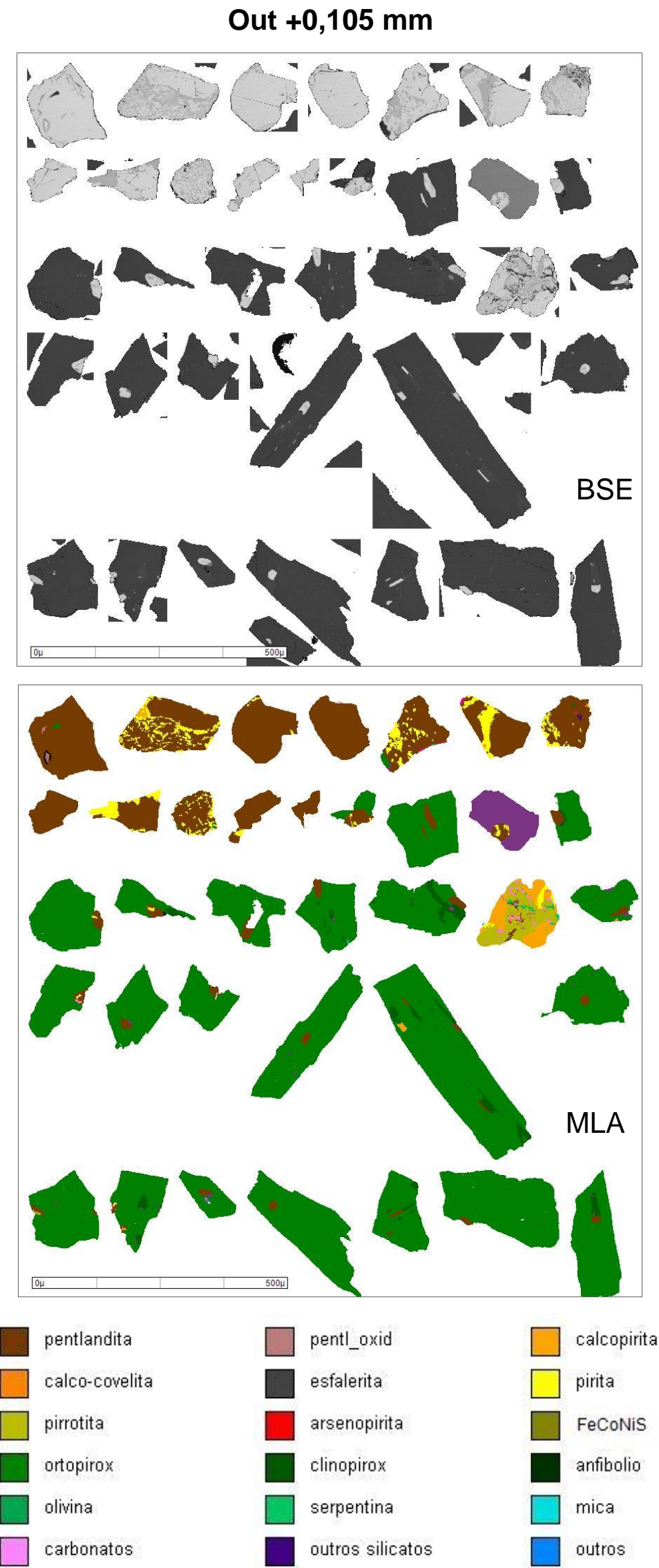

